\title{
A Cost-Benefit Assessment of Gasification-Based Biorefining in the Kraft Pulp and Paper Industry
}

\author{
Volume 1 \\ Main Report
}

FINAL REPORT

Under contract DE-FG26-04NT42260 with the U.S. Department of Energy and with cost-sharing by the American Forest and Paper Association

21 December 2006

Eric D. Larson

Princeton Environmental Institute

Princeton University

Princeton, NJ

elarson@princeton.edu

Stefano Consonni

Department of Energy Engineering

Politecnico di Milano

Milan, Italy

stefano.consonni@polimi.it

Ryan E. Katofsky

Navigant Consulting, Inc.

Burlington, MA

rkatofsky@navigantconsulting.com

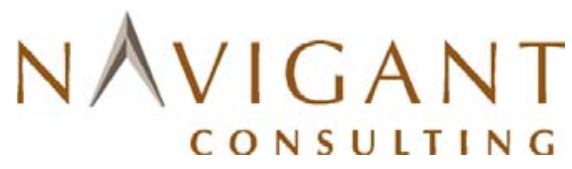

Kristiina Iisa and W. James Frederick, Jr.

Institute of Paper Science and Technology

School of Chemical and Biomolecular Engineering

Georgia Institute of Technology

Atlanta, GA

Kristiina.Iisa@ipst.gatech.edu

Jim.Frederick@ipst.gatech.edu 
This report consists of four volumes:

Volume 1: Main Report.

Volume 2: Detailed Biorefinery Design and Performance Simulation.

Volume 3: Fuel Chain and National Cost-Benefit Analysis.

Volume 4: Preliminary Biorefinery Analysis with Low-Temperature Black Liquor Gasification.

Note: "Navigant is a service mark of Navigant International, Inc. Navigant Consulting, Inc.

(NCI) is not affiliated, associated, or in any way connected with Navigant International, Inc., and NCI's use of "Navigant” is made under license from Navigant International, Inc. 


\section{Abstract}

Production of liquid fuels and chemicals via gasification of kraft black liquor and woody residues ("biorefining") has the potential to provide significant economic returns for kraft pulp and paper mills replacing Tomlinson boilers beginning in the 2010-2015 timeframe.

Commercialization of gasification technologies is anticipated in this period, and synthesis gas from gasifiers can be converted into liquid fuels using catalytic synthesis technologies that are in most cases already commercially established today in the "gas-to-liquids” industry.

These conclusions are supported by detailed analysis carried out in a two-year project co-funded by the American Forest and Paper Association and the Biomass Program of the U.S. Department of Energy. This work assessed the energy, environment, and economic costs and benefits of biorefineries at kraft pulp and paper mills in the United States. Seven detailed biorefinery process designs were developed for a reference freesheet pulp/paper mill in the Southeastern U.S., together with the associated mass/energy balances, air emissions estimates, and capital investment requirements. Commercial ("Nth") plant levels of technology performance and cost were assumed. The biorefineries provide chemical recovery services and co-produce process steam for the mill, some electricity, and one of three liquid fuels: a Fischer-Tropsch synthetic crude oil (which would be refined to vehicle fuels at existing petroleum refineries), dimethyl ether (a diesel engine fuel or LPG substitute), or an ethanol-rich mixed-alcohol product.

Compared to installing a new Tomlinson power/recovery system, a biorefinery would require larger capital investment. However, because the biorefinery would have higher energy efficiencies, lower air emissions, and a more diverse product slate (including transportation fuel), the internal rates of return (IRR) on the incremental capital investments would be attractive under many circumstances. For nearly all of the cases examined in the study, the IRR lies between $14 \%$ and $18 \%$, assuming a 25 -year levelized world oil price of $\$ 50 / \mathrm{bbl}$ - the US Department of Energy's 2006 reference oil price projection. The IRRs would rise to as high as $35 \%$ if positive incremental environmental benefits associated with biorefinery products are monetized (e.g., if an excise tax credit for the liquid fuel is available comparable to the one that exists for ethanol in the United States today). Moreover, if future crude oil prices are higher (\$78/bbl levelized price, the US Department of Energy’s 2006 high oil price scenario projection, representing an extrapolation of mid-2006 price levels), the calculated IRR exceeds $45 \%$ in some cases when environmental attributes are also monetized.

In addition to the economic benefits to kraft pulp/paper producers, biorefineries widely implemented at pulp mills in the U.S. would result in nationally-significant liquid fuel production levels, petroleum savings, greenhouse gas emissions reductions, and criteria-pollutant reductions. These are quantified in this study. A fully-developed pulpmill biorefinery industry could be double or more the size of the current corn-ethanol industry in the United States in terms of annual liquid fuel production. Forest biomass resources are sufficient in the United States to sustainably support such a scale of forest biorefining in addition to the projected growth in pulp and paper production. 


\section{TABLE OF CONTENTS FOR VOLUME 1}

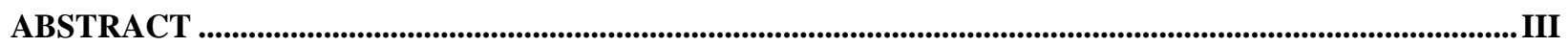

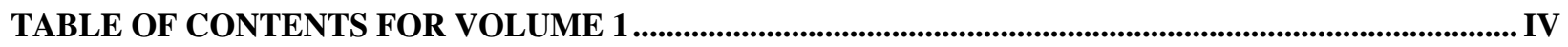

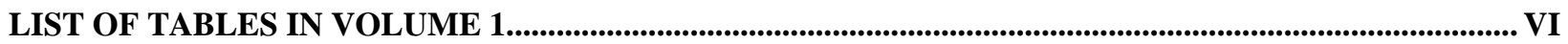

LIST OF FIGURES IN VOLUME 1........................................................................................................................ VIII

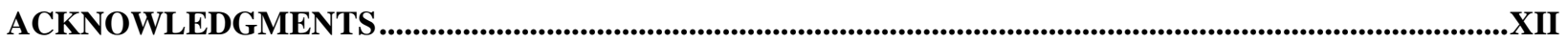

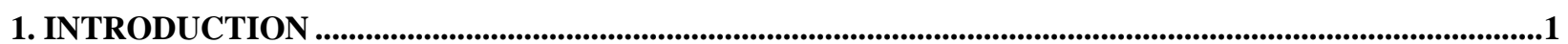

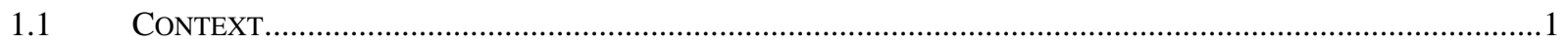

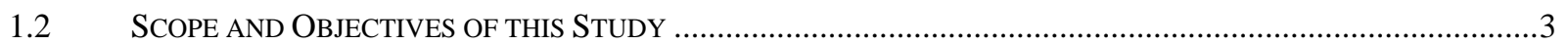

2 SYNTHETIC FUELS CHOSEN FOR DETAILED ANALYSIS .................................................................6

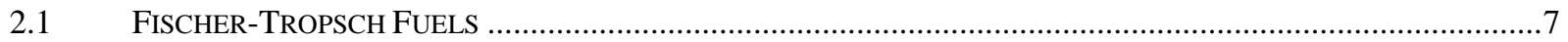

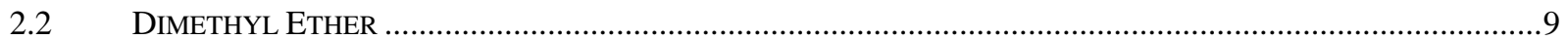

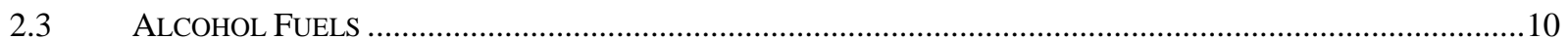

3 CHEMICAL RECOVERY AND POWER/STEAM COGENERATION AT PULP AND PAPER

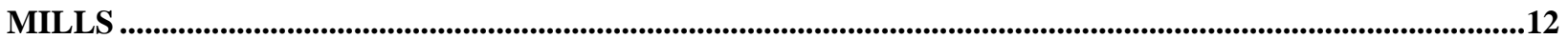

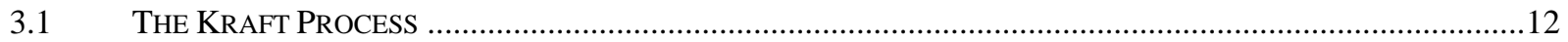

3.2 REFERENCE KRAft Pulp/PAPER Mill For CASE StUdy CoMPARISONS ..................................................13

3.3 PREVIOUS RESULTS FOR PUlP MILL POWER GENERATION ................................................................14

3.3.1 Tomlinson Power/Recovery at the Reference Mill ....................................................................14

3.3.2 BLGCC Power/Recovery at the Reference Mill..................................................................................16

4 OVERVIEW OF BIOREFINERY DESIGNS ..............................................................................................

5 BIOREFINERY DESIGN AND PERFORMANCE SIMULATION ........................................................26

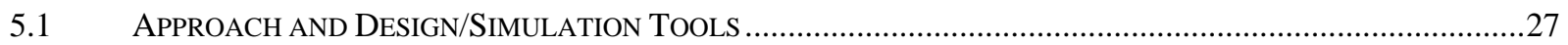

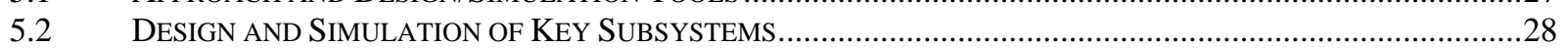

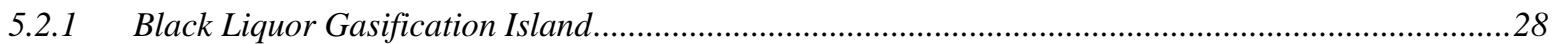

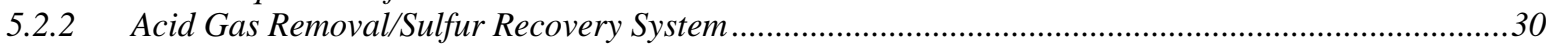

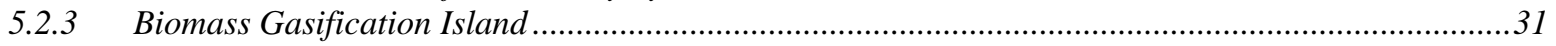

5.2.4 Gas Turbine Combined Cycle Island ...............................................................................................35

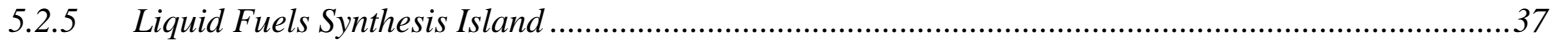

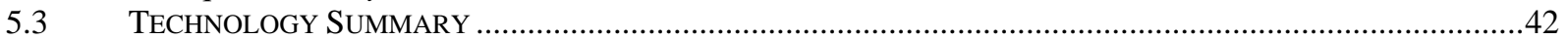

5.4 DETAILED BIOREFINERY MASS/ENERgY BALANCE RESULTS ...................................................................42

5.4.1 Process Flow Sheets and Performance Analysis ...........................................................................42

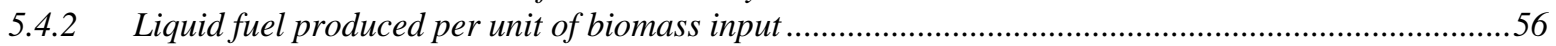

6 “WELL-TO-WHEELS” ENVIRONMENTAL ANALYSIS........................................................................59

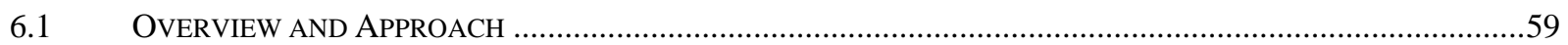

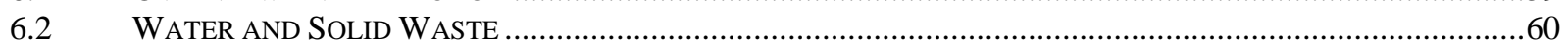

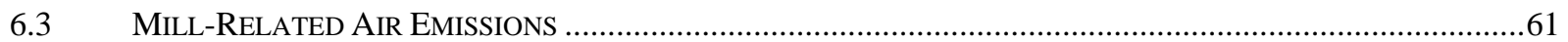

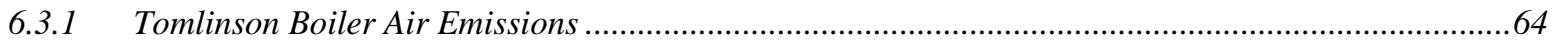

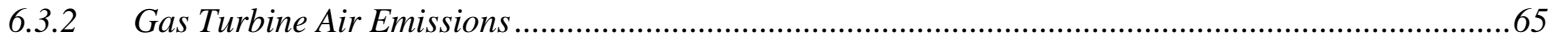

$6.4 \quad$ GRID POWER AIR EMISSIONS AND OFFSETS ...............................................................................67

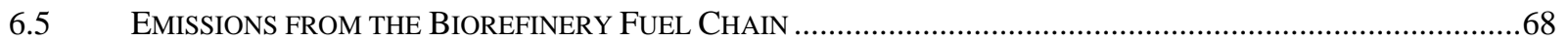

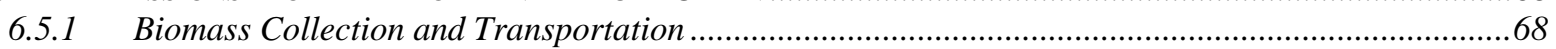

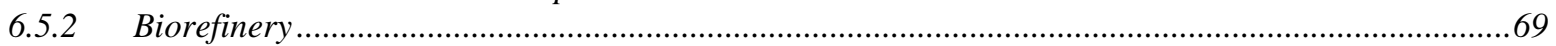

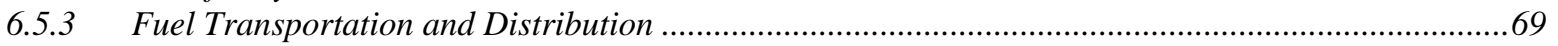

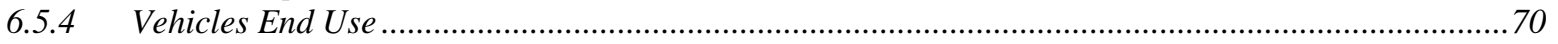

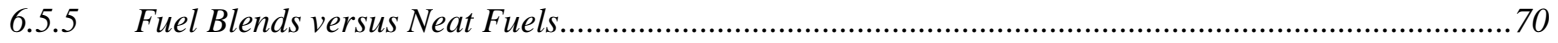

6.6 ENERGY USE AND EMISSIONS FROM CONVENTIONAL FUEL CHAINS .....................................................71

6.7 NET EMISSIONS ESTIMATES FOR THE CASE STUDY BIOREFINERY SYSTEMS …...........................................71 


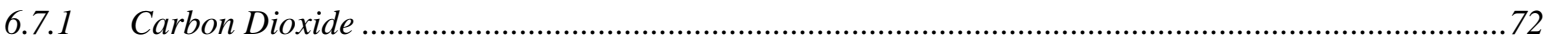

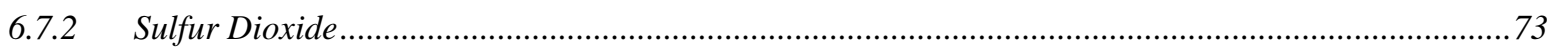

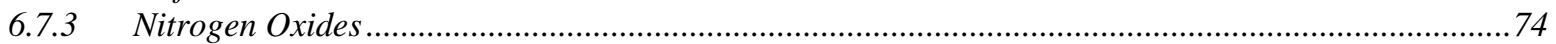

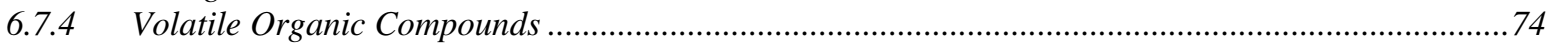

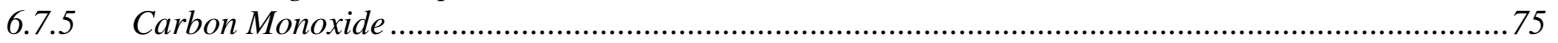

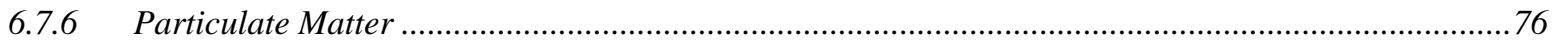

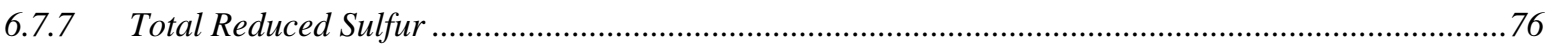

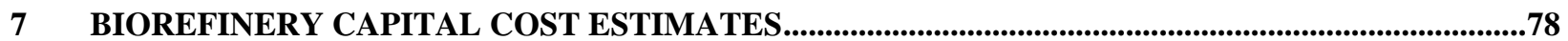

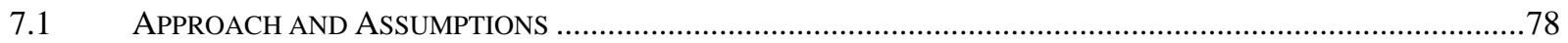

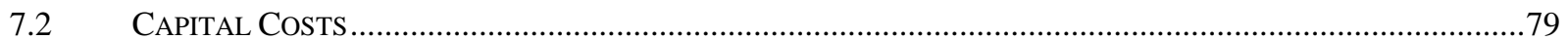

7.2.1 Specific Capital Investments per Unit of Biofuel Production ............................................................82

7.3 EFFECTIVE LEVELIZED COST OF LIQUID FUEL PRODUCTION …….............................................................84

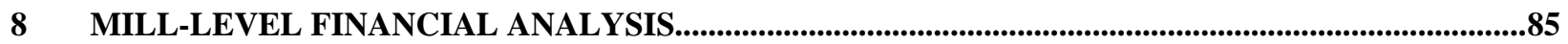

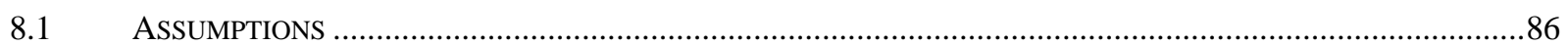

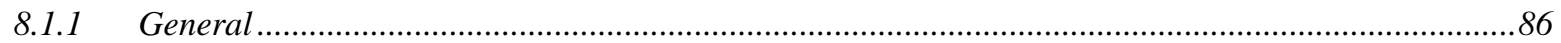

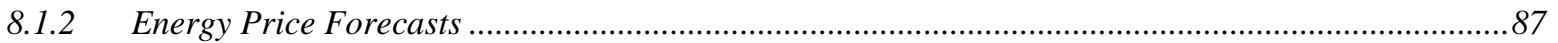

8.1.3 Incentives and the Monetary Value of Environmental Attributes ......................................................92

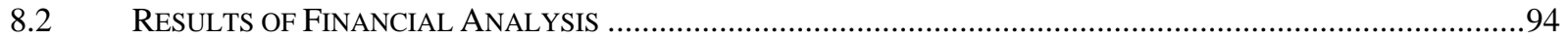

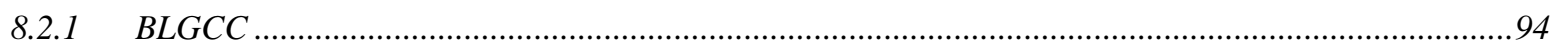

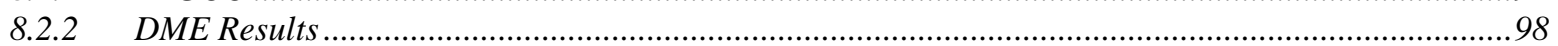

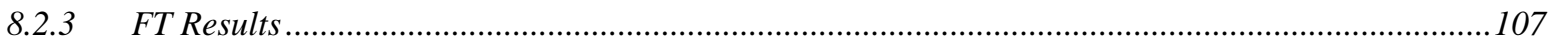

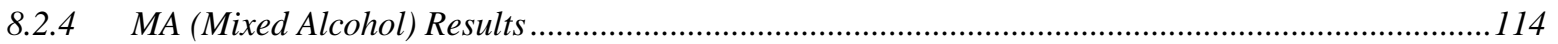

8.3 SUMMARY DISCUSSION OF FINANCIAL RESULTS ...........................................................................

$9 \quad$ NATIONAL IMPACTS OF A PULP MILL BIOREFINERY INDUSTRY .............................................121

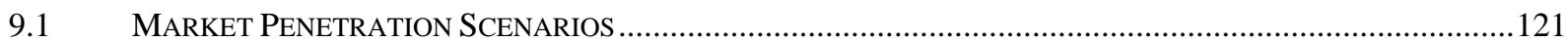

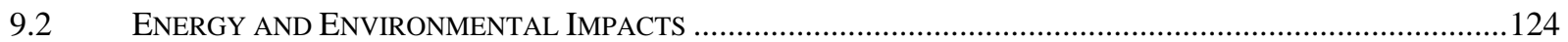

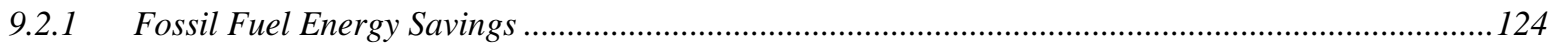

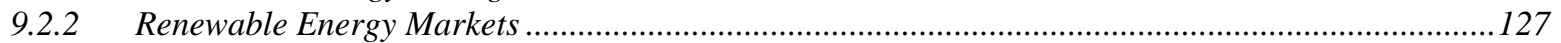

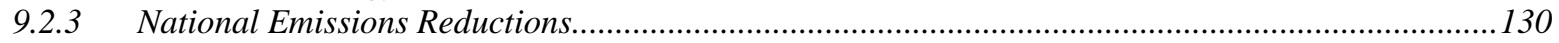

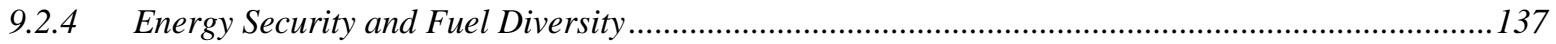

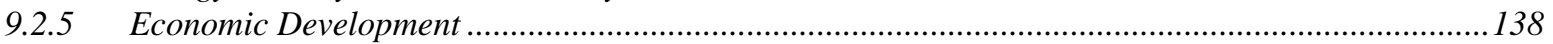

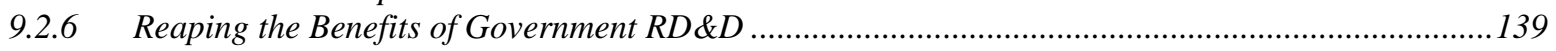

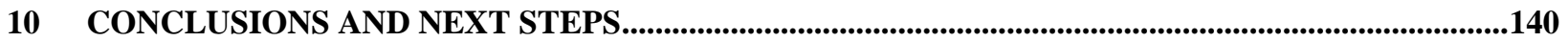

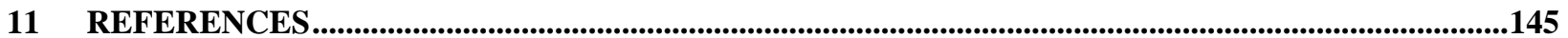




\section{List of Tables in Volume 1}

Table 1. Markets and values for potential biorefinery products.

Table 2. Properties of DME, petroleum diesel, propane, and butane []. The latter two are the main constituents of

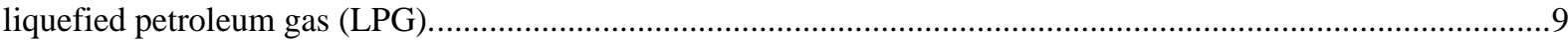

Table 3. LPG consumption in the United States in 2004 [] ...........................................................................10

Table 4. Authors' estimates of the number of centrally refueled urban fleet vehicles in the United States and

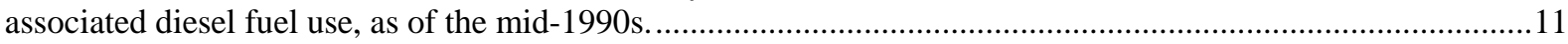

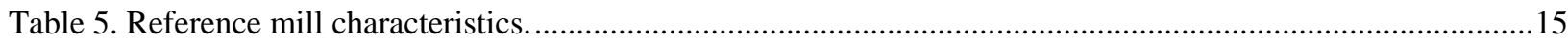

Table 6. Summary of key design parameter values for biorefinery simulations and, for comparison, BLGCC and

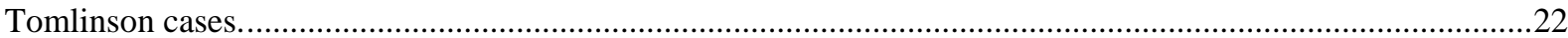

Table 7. Assumed operating parameters for black liquor gasifier simulations ....................................................29

Table 8. Predicted raw syngas composition leaving the black liquor gasifier quench vessel. ..................................30

Table 9. Composition and heating value of hog fuel and wood waste...............................................................33

Table 10. Key simulation assumptions for biomass gasifier/tar cracker unit. ....................................................34

Table 11. Summary of technologies included in our biorefinery designs including commercial status of each technology. . .42

Table 12. Biorefinery performance estimates, with comparisons to Tomlinson and BLGCC. Units are megawatts unless otherwise indicated. Fuel values are given on a lower heating value basis.

Table 13. Energy efficiencies (LHV basis) for biorefineries and Tomlinson. See text for definitions......................55

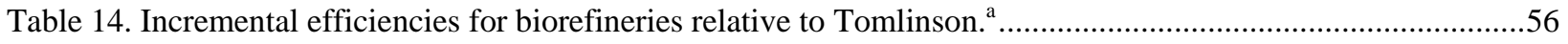

Table 15: Qualitative indication of relative environmental impact of different mill-level emissions, together with relative emission rates for controlled and uncontrolled Tomlinson furnaces and with Biorefinery technology (VL

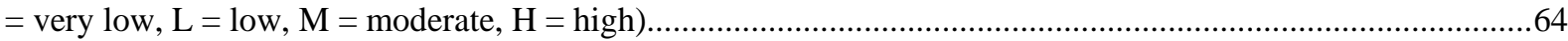

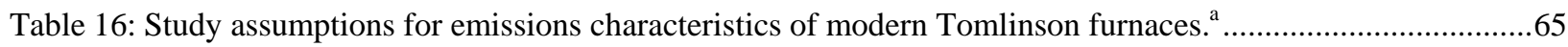

Table 17: Study assumptions for emissions characteristics of gas turbines burning syngas at biorefineries...............66

Table 18: Total average U.S. grid emissions (including non-fossil fuel sources) assumed in estimating grid offsets. ${ }^{\text {a }}$

Table 19: Correspondence between the biorefinery fuel and the fuel chain available in GREET - fuel transportation and distribution

Table 20: Correspondence between the biorefinery fuel and the fuel chain available in GREET - vehicle end use ..70

Table 21: Biorefinery fuel and the corresponding conventional fuel chain used to estimate net emissions impacts...71

Table 22. Estimated overnight installed capital costs (thousand 2005\$) and non-fuel operating and maintenance costs (thousand 2005\$ per year). Installed capital costs include engineering, equipment, installation, owner's costs (including initial catalyst), contingencies, and spare parts.

Table 23. Effective capital investment required per barrel of annual production capacity.....................................84

Table 24. Effective levelized cost of liquid fuels production at pulp mill biorefineries.........................................85

Table 25: Summary of key input assumptions for the financial analysis.............................................................87

Table 26: Levelized costs (in constant 2005\$) for energy commodities (plant gate, no incentives). Fuel prices are on

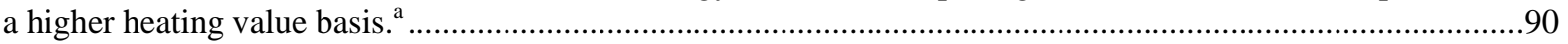

Table 27. Values assumed for financial incentives and monetized environmental benefits. ...................................93

Table 28. Renewable energy programs and incentives not included in the financial analysis. ................................94

Table 29. Annual material and energy flows for the alternative power/recovery/biorefinery systems......................96

Table 30. Composition of mixed alcohol product. ...............................................................................114

Table 31: Summary of IRR and NPV results for all cases, assuming no incentives...........................................120

Table 32: Summary of IRR and NPV results for all cases, assuming bundled incentives, including ETC, ITC, PTC,

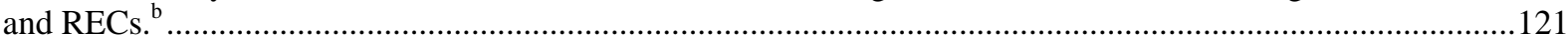

Table 33: Summary of biorefinery market penetration scenarios developed in this study.................................123 
Table 34. Biofuel production potential (billion gal/year) for different biorefinery configurations. ${ }^{\text {a }}$ These are actual volumes, not corrected for energy content, and are for the total industry. The estimates are total technical potential and do not consider any market penetration scenario. The current RFS target is 7.5 billion gallons by 2012.

Table 35. Power production potential (MW) for different biorefinery configurations - incremental power production relative to continued use of Tomlinson technology. ${ }^{a}$

Table 36. Cumulative market value (25 year) of certain emissions reductions relative to Tomlinson systems under the three market penetration scenarios in this study 


\section{List of Figures in Volume 1}

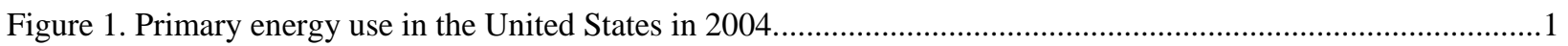

Figure 2. Future "biorefinery" concept based at a pulp and paper manufacturing facility. ...........................................2

Figure 3. Age distribution of Tomlinson recovery boilers in the United States. ...........................................................

Figure 4. Organizational structure and principal participants in this project. ............................................................

Figure 5. Simplified representation of kraft pulping and the associated chemical recovery cycle. Indicated mass

flows are on a dry-matter basis and intended only to be illustrative..................................................................13

Figure 6. Energy/mass balance for a new Tomlinson power/recovery system.......................................................16

Figure 7. Pressurized, oxygen-blown, high-temperature black liquor gasifier technology under development by

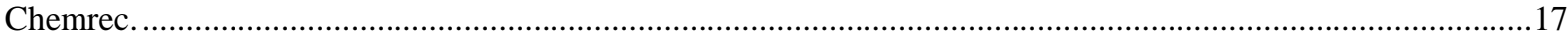

Figure 8. Simplified schematic representation of "mill-scale” BLGCC system.....................................................19

Figure 9. Energy/mass balance for BLGCC with high-temperature gasifier and mill-scale gas turbine....................20

Figure 10. Schematic of biorefinery DMEa. Key features include recycling of unconverted syngas to increase DME

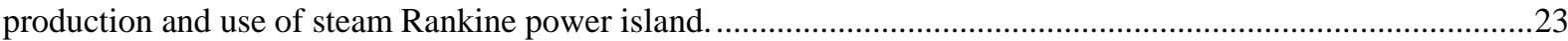

Figure 11. Schematic of biorefinery DMEb. Key differences from DMEa (Figure 10), represented by darker shading, include biomass gasifier and gas turbine combined cycle power island. .............................................................24

Figure 12. Schematic of biorefinery DMEc. Key difference from DMEb (Figure 11), represented by darker shading, include synthesis reactor operating in single-pass (rather than recycle) mode. .....................................................24

Figure 13. Schematic of biorefinery FTa. Key features of all FT designs are single-pass synthesis and gasification of woody biomass. In FTa, the gasified biomass and unconverted syngas fuel the gas turbine combined cycle

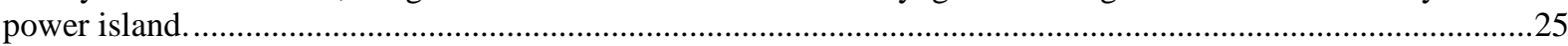

Figure 14. Schematic of biorefinery FTb. The key difference compared to FTa is highlighted by the darker shading: a larger gas turbine, requiring greater woody biomass consumption.....................................................................25

Figure 15. Schematic of biorefinery FTc. Similar to FTa, except that gasified woody biomass supplements gasified black liquor flowing to the synthesis island. ......................................................................................................26

Figure 16. Schematic of biorefinery MA. The design is similar to FTc in that syngas from both the black liquor gasifier and the biomass gasifier are processed through the synthesis reactor. MA differs from FTc in that a significant fraction of the unconverted synthesis gas is recycled for further conversion, as indicated by the more darkly-shaded blocks.

Figure 17. Interactions between GS and Aspen Plus during process simulations. The black liquor gasification island is calculated first with GS. Aspen is then run twice to simulate the acid gas recovery (Rectisol) system and the fuel synthesis island. Finally, GS is re-run, taking into account the results generated by the Aspen runs. See Volume 2 for additional details.

Figure 18. Equipment configuration for black liquor gasification......................................................................29

Figure 19. Biomass gasification island for biorefinery designs utilizing the biomass-derived syngas as gas turbine fuel.

Figure 20. Biomass gasification island for biorefinery designs utilizing the biomass-derived syngas for liquid fuels

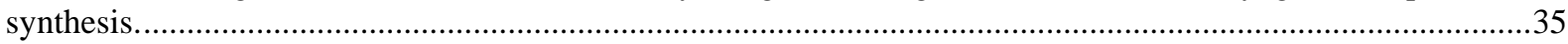

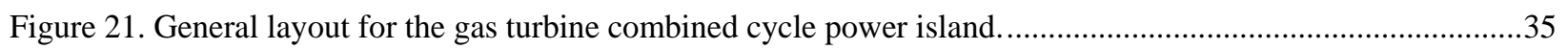

Figure 22. Simplified schematic of liquid phase synthesis reactor.....................................................................38

Figure 23. Mass and energy balance for DMEa. Key distinguishing features are the recycle synthesis loop and the hog fuel/purchased residues boiler/steam cycle power island.............................................................................45

Figure 24. Mass and energy balance for DMEb. Key distinguishing features are the recycle synthesis loop and the hog fuel/residues gasifier gas turbine combined cycle power island. ..................................................................46

Figure 25. Mass and energy balance for DMEc. Key distinguishing features are the once-through synthesis reactor and the hog fuel/residues gasifier gas turbine combined cycle power island..........................................................47

Figure 26. Mass and energy balance for FTa. Key distinguishing features are the once-through synthesis reactor and the hog fuel/residues gasifier gas turbine combined cycle power island. ...............................................................48 
Figure 27. Mass and energy balance for FTb. Key distinguishing features are the once-through synthesis reactor and the hog fuel/residues gasifier gas turbine combined cycle power island with larger (7FA) gas turbine................49

Figure 28. Mass and energy balance for FTc. Key distinguishing features are the once-through synthesis reactor fed with syngas from both black liquor and hog fuel/residues gasifiers. Unconverted syngas fuels the gas turbine combined cycle power island.

Figure 29. Mass and energy balance for MA. Key distinguishing features are the recycle synthesis island fed with syngas from both black liquor and hog fuel/residues gasifiers. Unconverted syngas fuels the gas turbine combined cycle power island.

Figure 30. Energy efficiencies and contribution of each output (steam, electricity, and liquid fuel) to $\eta_{\text {first }}$ and to $\eta_{\mathrm{el}}$

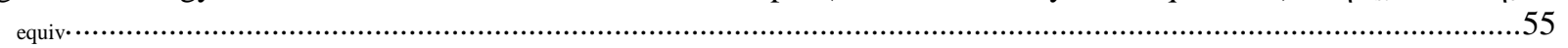

Figure 31. Incremental biorefinery energy inputs and outputs relative to the Tomlinson case. .................................56

Figure 32. Comparison of adjusted liquid fuel yields (gallon of gasoline equivalent or gallon of ethanol equivalent) per metric tonne of dry biomass input. See text for discussion............................................................................58

Figure 33. Accounting used to calculate the adjusted liquid fuel yields per unit of biomass input.............................58

Figure 34: Well-to-Wheels Analysis Framework for Pulp and Paper Biorefineries..................................................60

Figure 35: Change in annual full fuel chain net $\mathrm{CO}_{2}$ emissions at the reference mill in 2010 ................................73

Figure 36: Changes in annual full fuel-chain $\mathrm{CO}_{2}$ emissions and offsets at the reference mill in 2010 (million tons

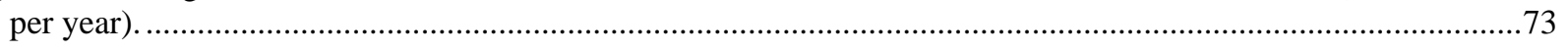

Figure 37: Change in annual full fuel-chain net $\mathrm{SO}_{2}$ emissions at reference mill in 2010 ........................................74

Figure 38: Change in annual full fuel-chain net $\mathrm{NO}_{\mathrm{x}}$ emissions at the reference mill in 2010...................................75

Figure 39: Change in annual full fuel-chain net VOC emissions at the reference mill in 2010.................................75

Figure 40: Change in annual full fuel-chain net CO emissions at the reference mill in 2010 ...................................76

Figure 41: Change in annual full fuel-chain net $\mathrm{PM}_{10}$ emissions at the reference mill in 2010.................................77

Figure 42: Change in annual full fuel-chain net TRS emissions at the reference mill in 2010...................................77

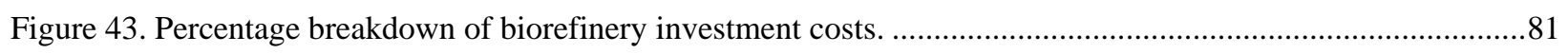

Figure 44. Effective capital investment intensity (2005\$ per barrel diesel-equivalent per day) for liquid fuels production as a function of liquids production capacity. See text for assumptions. ...............................................82

Figure 45. Accounting used to calculate the capital intensity of liquid biofuel production.........................................83

Figure 46: Basic logic for the ethanol/mixed alcohol price forecast.........................................................................89

Figure 47: Basic logic for the DME and FT crude price forecasts ........................................................................89

Figure 48: Study assumptions for electricity prices............................................................................................91

Figure 49: Study assumptions for purchased wood, \#6 oil and natural gas prices (\$/MMBtu, HHV). .......................91

Figure 50: Biorefinery product prices forecasts - no incentives (\$MMBtu, HHV). …...........................................92

Figure 51: Allowable incremental capital cost for BLGCC relative to new Tomlinson to achieve different target IRR

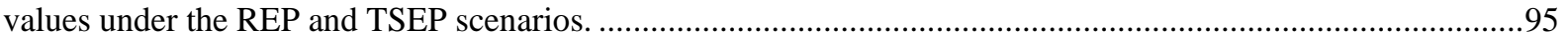

Figure 52: Allowable incremental capital cost for BLGCC relative to new Tomlinson to achieve different target IRR values with indicated biomass and power prices under our Reference Energy Price scenario and for baseline

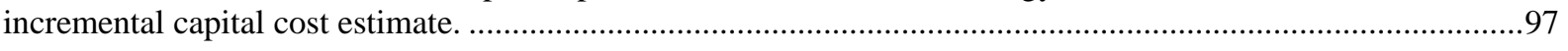

Figure 53: IRR of incremental capital invested for BLGCC relative to new Tomlinson, with different environmental benefits monetized and for our Reference Energy Price (REP) scenario............................................................98

Figure 54: Allowable incremental capital cost for DMEa biorefinery (with DME sold as vehicle fuel) relative to new Tomlinson investment for different target IRR values under our two energy price scenarios..............................99

Figure 55: IRR on incremental capital cost for DMEa biorefinery (with DME sold as vehicle fuel) relative to new Tomlinson system with indicated biomass and power prices and other energy prices as in the REP scenario......99

Figure 56: IRR on incremental capital investment in DMEa biorefinery (with DME sold as vehicle fuel) relative to a new Tomlinson system with different environmental benefits monetized under REP scenario. ..........................100

Figure 57: IRR on incremental capital investment in DMEa biorefinery (with DME sold as vehicle fuel) relative to a new Tomlinson system with different environmental benefits monetized and for our TSEP scenario.................100

Figure 58: Allowable incremental capital cost for DMEa biorefinery (with DME sold as LPG substitute) relative to new Tomlinson investment for different target IRR values under our two energy price scenarios......................101 
Figure 59: IRR on incremental capital cost for DMEa biorefinery (with DME sold as LPG substitute) relative to new Tomlinson system with indicated biomass and power prices and other energy prices as in the REP scenario....101

Figure 60: IRR on incremental capital invested in DMEa biorefinery (with DME sold as LPG substitute) relative to new Tomlinson with environmental benefits monetized under REP scenario.

Figure 61: IRR on incremental capital invested in DMEa biorefinery (with DME sold as LPG substitute) relative to new Tomlinson, with environmental benefits monetized in TSEP scenario. 102

Figure 62: Allowable incremental capital cost for DMEb biorefinery (with DME sold as vehicle fuel) relative to new Tomlinson investment for different target IRR values under our two energy price scenarios.. .103

Figure 63: IRR on incremental capital cost for DMEb biorefinery (with DME sold as vehicle fuel) relative to new Tomlinson system with indicated biomass and power prices and other energy prices as in the REP scenario....104

Figure 64: IRR on incremental capital investment in DMEb biorefinery (with DME sold as vehicle fuel) relative to a new Tomlinson system with different environmental benefits monetized under REP scenario. 104

Figure 65: IRR on incremental capital investment in DMEb biorefinery (with DME sold as vehicle fuel) relative to a new Tomlinson system with different environmental benefits monetized and for our TSEP scenario.....

Figure 66: Allowable incremental capital cost for DMEc biorefinery (with DME sold as vehicle fuel) relative to new Tomlinson investment for different target IRR values under our two energy price scenarios. .105

Figure 67: IRR on incremental capital cost for DMEc biorefinery (with DME sold as vehicle fuel) relative to new Tomlinson system with indicated biomass and power prices and other energy prices as in the REP scenario....106

Figure 68: IRR on incremental capital in DMEc biorefinery (with DME sold as vehicle fuel) relative to a new Tomlinson with different environmental benefits monetized under REP scenario. 106

Figure 69: IRR on incremental capital investment in DMEc biorefinery (with DME sold as vehicle fuel) relative to a new Tomlinson system with different environmental benefits monetized and for our TSEP scenario...

Figure 70: Allowable incremental capital cost for FTa biorefinery relative to new Tomlinson investment for different target IRR values under our two energy price scenarios... 108

Figure 71: IRR on incremental capital cost for FTa biorefinery relative to new Tomlinson system with indicated biomass and power prices and other energy prices as in the REP scenario. 108

Figure 72: IRR on incremental capital investment in FTa biorefinery relative to a new Tomlinson system with different environmental benefits monetized under our REP scenario.

Figure 73: IRR on incremental capital investment in FTa biorefinery relative to a new Tomlinson system with different environmental benefits monetized under our TSEP scenario.

Figure 74: Allowable incremental capital cost for FTb biorefinery relative to new Tomlinson investment for different target IRR values under our two energy price scenarios.

Figure 75: IRR on incremental capital cost for FTb biorefinery relative to new Tomlinson system with indicated biomass and power prices and other energy prices as in the REP scenario.

Figure 76: IRR on incremental capital investment in FTb biorefinery relative to a new Tomlinson system with different environmental benefits monetized under our REP scenario...

Figure 77: IRR on incremental capital investment in FTb biorefinery relative to a new Tomlinson system with different environmental benefits monetized under our TSEP scenario.

Figure 78: Allowable incremental capital cost for FTc biorefinery relative to new Tomlinson investment for different target IRR values under our two energy price scenarios.

Figure 79: IRR on incremental capital cost for FTc biorefinery relative to new Tomlinson system with indicated biomass and power prices and other energy prices as in the REP scenario.

Figure 80: IRR on incremental capital investment in FTc biorefinery relative to a new Tomlinson system with different environmental benefits monetized under our REP scenario.

Figure 81: IRR on incremental capital investment in FTc biorefinery relative to a new Tomlinson system with different environmental benefits monetized under our TSEP scenario.

Figure 82: Allowable incremental capital cost for MA biorefinery (with MA sold as a fuel) relative to new Tomlinson investment for different target IRR values under our two energy price scenarios..

Figure 83: IRR on incremental capital cost for MA biorefinery (with MA sold as fuel) with indicated biomass and power prices and other energy prices as in the REP scenario. 
Figure 84: IRR on incremental capital investment in MA biorefinery (with MA sold as a fuel mixture) relative to a new Tomlinson system with different environmental benefits monetized under our REP scenario.

Figure 85: IRR on incremental capital investment in MA biorefinery (with MA sold as a fuel mixture) relative to a new Tomlinson system with different environmental benefits monetized under our TSEP scenario.

Figure 86: Allowable incremental capital cost for MA biorefinery (with MA sold as components) relative to new Tomlinson investment for different target IRR values under our two energy price scenarios. ${ }^{52}$

Figure 87: IRR on incremental capital cost for MA biorefinery (with MA sold as components) relative to new Tomlinson system with indicated biomass and power prices and other energy prices as in the REP scenario....118

Figure 88: IRR on incremental capital investment in MA biorefinery (with MA sold as components) relative to a new Tomlinson system with different environmental benefits monetized under our REP scenario.

Figure 89: IRR on incremental capital investment in MA biorefinery (with MA sold as components) relative to a new Tomlinson system with different environmental benefits monetized under our TSEP scenario.

Figure 90: Market penetration estimates used to assess energy and environmental impacts of biorefinery implementation in the United States.

Figure 91: Net national fossil fuel savings relative to continued use of Tomlinson systems for the Aggressive biorefinery market penetration scenario

Figure 92: Cumulative (25-year) national net fossil fuel savings relative to continued use of Tomlinson systems under different biorefinery market penetration scenarios.

Figure 93. Net annual national $\mathrm{CO}_{2}$ emissions reductions relative to continued use of Tomlinson systems under the Aggressive biorefinery market penetration scenario.

Figure 94. Net annual national $\mathrm{SO}_{2}$ emissions reductions relative to continued use of Tomlinson systems under the Aggressive biorefinery market penetration scenario.

Figure 95. Net annual national $\mathrm{NO}_{\mathrm{x}}$ emissions reductions relative to continued use of Tomlinson technology under the Aggressive biorefinery market penetration scenario. .....

Figure 96. Net annual national VOC emissions reductions relative to continued use of Tomlinson technology under the Aggressive biorefinery market penetration scenario.

Figure 97. Net annual national CO emissions reductions relative to continued use of Tomlinson technology under the Aggressive biorefinery market penetration scenario.

Figure 98. Net annual national $\mathrm{PM}_{10}$ emissions reductions relative to continued use of Tomlinson technology under the Aggressive biorefinery market penetration scenario. 136

Figure 99: Cumulative (25-year) national net fossil fuel and petroleum savings relative to continued use of Tomlinson systems under the Aggressive biorefinery market penetration scenario. 


\section{Acknowledgments}

The authors thank Matthew Campbell and Etienne Parent (Navigant Consulting), Charles E. Courchene (Institute of Paper Science and Technology, Georgia Institute of Technology), Farminder Anand and Matthew Realff (School of Chemical and Biomolecular Engineering, Georgia Institute of Technology), Silvia Napoletano and Wang Xun (Department of Energy Engineering, School of Industrial Engineering, Politecnico di Milano), and Sheldon Kramer (Nexant Engineering) for their contributions to the analysis reported here. We also thank the Steering Committee and Resource Persons (see Figure 4 in this volume) for their suggestions and guidance throughout the project. We also thank the many other individuals who provided inputs to us in the course of this work.

For primary financial support, we thank the U.S. Department of Energy Biomass Program and the American Forest and Paper Association. Additionally, support is gratefully acknowledged from the Princeton University Carbon Mitigation Initiative, the William and Flora Hewlett Foundation, and the member companies of the Institute of Paper Science and Technology (at the Georgia Institute of Technology) who have sponsored IPST's research project "Gasification and Biorefinery Development." 


\section{Introduction}

\subsection{Context}

The U.S. pulp and paper industry is the largest producer and user of biomass energy in the United States today, nearly all derived from sustainably-grown trees. Renewable resources used at pulp mills include bark, wood wastes, and black liquor, the lignin-rich by-product of cellulosefiber extraction. The total of these biomass energy sources consumed at pulp mills in 2004 in the United States was an estimated 1.3 quads (one quad is $10^{15} \mathrm{BTU}$ ). ${ }^{1}$ Additionally, there are substantial residues that remain behind after harvesting of trees for pulpwood. A recent major study of U.S. biomass resources [1] estimates there are some 2 quads of unused wood resources (logging residues, fire-prevention thinnings, mill residues, and urban wood waste) that are recoverable on a sustainable basis at present, increasing to nearly 3 quads in the future. Additionally, the sustainable agricultural biomass resource potential (crop residues, crop processing residues, and future perennial energy crops) is estimated to be 10 to 17 quads by 2025. The sum of existing and potential biomass energy resources in the United States comes to 14 to 21 quads. For comparison, 100 quads of primary energy (all forms) were consumed in 2004 in the United States (Figure 1), about 3\% of which was biomass in various forms.

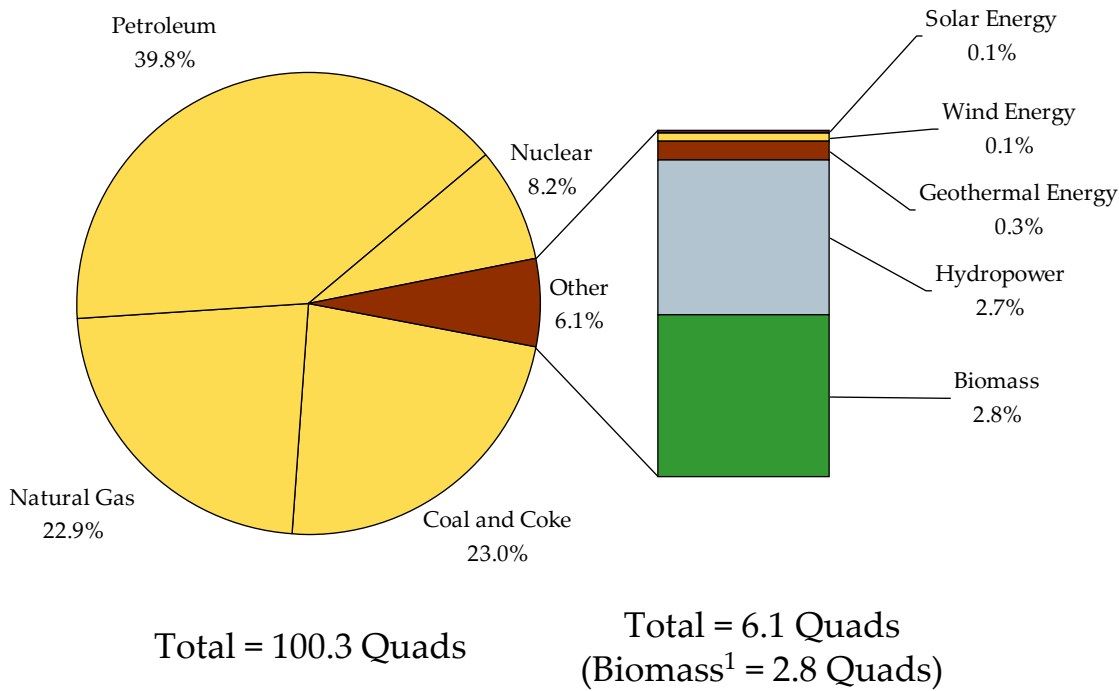

1. Included in biomass are the following: black liquor, wood/wood waste liquids, wood/wood waste solids, municipal solid waste (MSW), landfill gas, agriculture byproducts/crops, sludge waste, tires, alcohol fuels (primarily ethanol derived from corn and blended into motor gasoline) and other biomass solids, liquids and gases.

Source: DOE/EIA Renewable Energy Trends 2004, August 2005

Note: 1 Quad $=10^{15} \mathrm{Btu}$ (1 quadrillion Btu) or about 1.055 Exajoules (10 ${ }^{18}$ Joules), the amount of energy contained in about 172 million barrels of oil.

Figure 1. Primary energy use in the United States in 2004.

With substantial renewable energy resources at its immediate disposal and with potentially much more extensive resources available in the long-term, the U.S. pulp and paper industry has the potential to contribute significantly to addressing climate change and U.S. energy security concerns, while also improving its global competitiveness. A key requirement for achieving these goals is the commercialization of breakthrough technologies, especially gasification, to

\footnotetext{
${ }^{1}$ Approximately 1.0 quad of black liquor and 0.3 quads of woody residues (hog fuel) were generated and consumed in the U.S. paper industry in 2004 (based on estimates from the American Forest and Paper Association).
} 
enable the clean and efficient conversion of biomass to useful energy forms, including electricity and transportation fuels.

Gasification technology enables low-quality solid fuels like biomass to be converted with low pollution into a fuel gas (synthesis gas or "syngas") consisting largely of hydrogen $\left(\mathrm{H}_{2}\right)$ and carbon monoxide (CO). Syngas can be burned cleanly and efficiently in a gas turbine to generate electricity. It can be passed over appropriate catalysts to synthesize clean liquid transportation fuels or chemicals. It can also be converted efficiently into pure $\mathrm{H}_{2}$ fuel.

While most pulp and paper manufacturing facilities in the United States today do not export electricity and none export transportation fuels, their established infrastructure for collecting and processing biomass resources provides a strong foundation for future gasification-based "biorefineries" that might produce a variety of renewable fuels, electricity, and chemicals in conjunction with pulp and paper products (Figure 2).

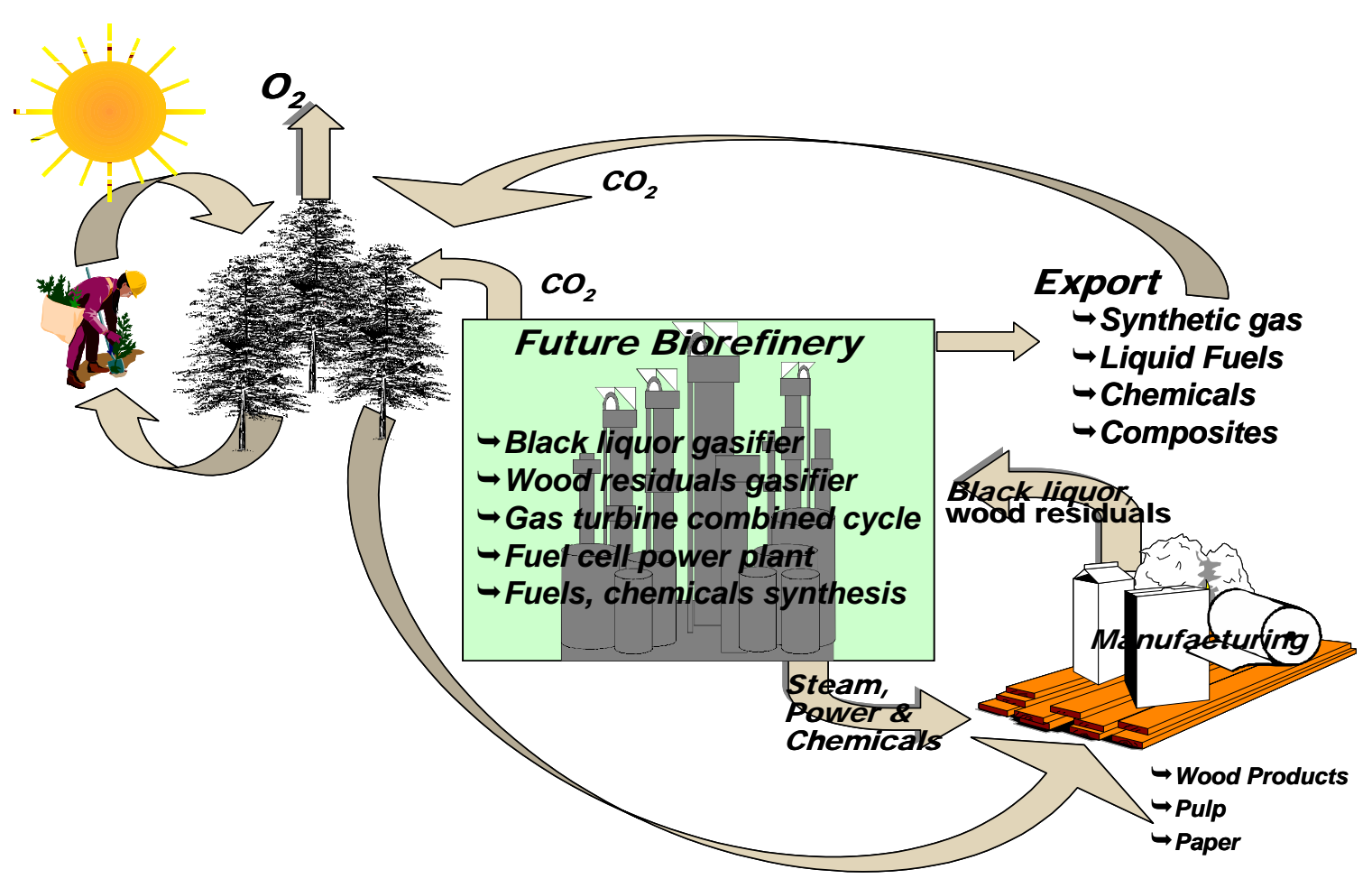

Figure 2. Future "biorefinery" concept based at a pulp and paper manufacturing facility.

If the biomass resources from which energy carriers are produced at such biorefineries are sustainably grown and harvested, there would be few net lifecycle emissions of $\mathrm{CO}_{2}$ associated with biorefineries and their products. To the extent that the biorefinery products replace fuels or chemicals that would otherwise have come from fossil fuels, there would be net reductions in $\mathrm{CO}_{2}$ emissions from the energy system as a whole. The reductions would be even more significant if by-product $\mathrm{CO}_{2}$ generated at biorefineries were to be captured and sent for longterm underground storage [2]. Carbon capture and storage with fossil fuels is of wide interest today [3]. Several large-scale $\mathrm{CO}_{2}$ storage projects (storing $\geq 1$ million tonnes/year of $\mathrm{CO}_{2}$ ) are operating and more are under development worldwide to demonstrate feasibility. 
Coupled with the potential to address national energy security and global warming concerns is the looming need in the U.S. pulp and paper industry for major capital investments to replace the aging fleet of Tomlinson recovery boilers used today to recover energy and pulping chemicals from black liquor. The majority of Tomlinson boilers operating in the United States were built beginning in the late 1960s through the 1970s (Figure 3). With serviceable lifetimes of 30 to 40 years, the Tomlinson fleet began undergoing a wave of life-extension rebuilds in the mid-1980s (Figure 3). Within the next 10 to 20 years, rebuilt boilers will be approaching the age at which they will need to be replaced, the capital investment for which at a typical mill is between $\$ 100$ and \$200 million. A similar situation exists in the European pulp industry [4]. This situation provides an unusual window of economic opportunity for introducing black liquor gasifiers as replacements for Tomlinson boilers. Concerted efforts are ongoing in the United States and Sweden to develop commercial black liquor gasification technologies.

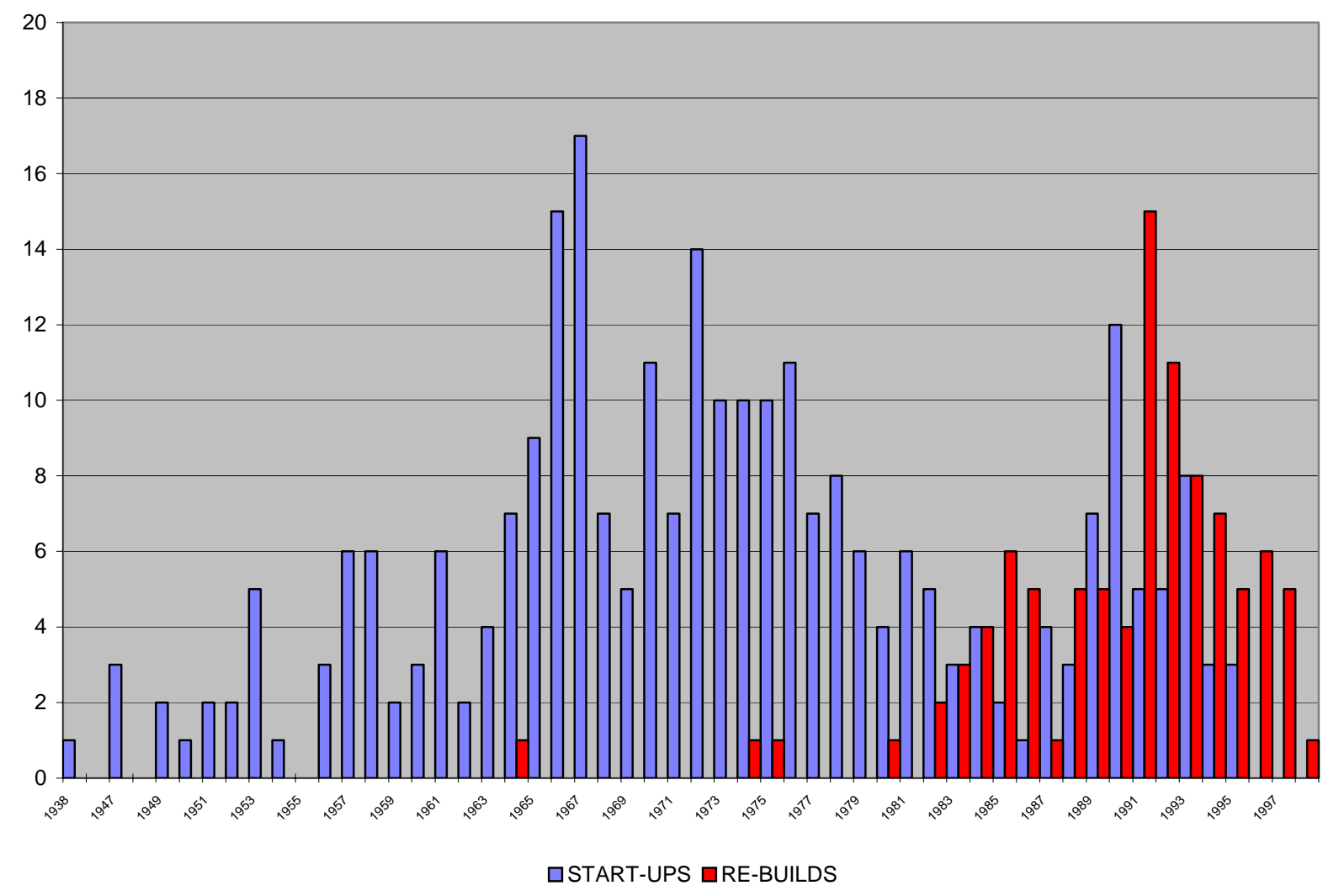

\section{Year Built / Rebuilt}

Figure 3. Age distribution of Tomlinson recovery boilers in the United States.

\subsection{Scope and Objectives of this Study}

This report describes the results of a two-year effort to examine the prospective technical viability, commercial viability, and environmental and energy impacts locally and nationally of gasification-based biorefineries for liquid fuels production at kraft pulp and paper mills.

One key objective of this study is to assess the prospective commercial viability of gasification technology in the long term. For this reason, the analysis in this study assumes that black liquor 
gasification systems are at a comparable level of technological maturity as Tomlinson black liquor boiler systems. In particular, the commercial risk of installing a black liquor gasification system is assumed to be comparable to that of installing a Tomlinson system in the post-2010 time frame. The implicit assumption is that in the years between the present and the post-2010 time period, research, development, and demonstration work with black liquor gasification technology will bring it to the point where its commercial reliability approaches that of Tomlinson technology.

Our biorefinery analysis began by identifying three biorefinery liquid products for detailed analysis. Detailed process design and simulation were then pursued for alternative configurations for the manufacture of these products assuming projected commercial ( $\mathrm{N}^{\text {th }}$ plant) performance. Detailed mass and energy balances for each configuration were then reviewed with engineers at Nexant, the A\&E firm that subsequently developed " $\mathrm{N}^{\text {th }}$ plant" capital cost estimates for each process design. A detailed internal rate of return analysis was carried out for each process design, both without and with the assumption that some renewable-energy financial incentives are available.

The mill-level energy and environmental performance results were used as a basis for estimating potential national energy/environment impacts under alternative assumptions about the rate at which existing Tomlinson systems would be retired and replaced with biorefineries.

The study described in this report has been built on the foundation of an earlier major study examining the potential for black liquor gasification combined cycle (BLGCC) electricity generation at U.S. kraft pulp and paper mills [5]. To facilitate comparisons with the BLGCC results, we have taken care to maintain as much consistency as possible between the two studies:

- The reference pulp and paper mill used as the basis for the BLGCC analysis has been adopted directly for this biorefinery study. The reference pulp and paper mill represents the expected state-of-the-art mill in the 2010 time frame in the Southeastern United States, where 2/3 of kraft pulp mill capacity is located. The reference mill produces uncoated freesheet paper, generating a nominal 6 million lbs/day of black liquor solids (BLS). Pulp mills at this scale or larger account for about $1 / 3$ of all U.S. capacity today, and this fraction is expected to grow over time as mill consolidations continue.

- The core process design/simulation tool and, where appropriate, the equipment performance assumptions used for the biorefinery analysis are the same as used for the BLGCC analysis.

- The same engineering firm that was engaged to develop capital cost estimates for the BLGCC analysis was engaged to provide biorefinery capital cost estimates.

- The biorefinery cost-benefit analysis adopts, to the extent possible, the same financial and emissions model and parameter values as for the BLGCC analysis. However, in making comparisons of energy and environmental costs/benefits between the Tomlinson, BLGCC and biorefinery cases, we use the most recently available DOE forecasts for energy prices, fuel mix assumptions for power generation, and emissions factors for power generation, as detailed later in this report and in Volume 3. The forecast prices, fuel mixes, and emissions factors are different from those used in the BLGCC study [5], but the results from the BLGCC study shown later in this report are updated results using the same forecasts as used for the biorefinery cases. 
- Finally, The biorefinery analysis has been carried out with guidance from an industrygovernment Steering Group (Figure 4), several members of which were also part of the BLGCC Steering Committee.

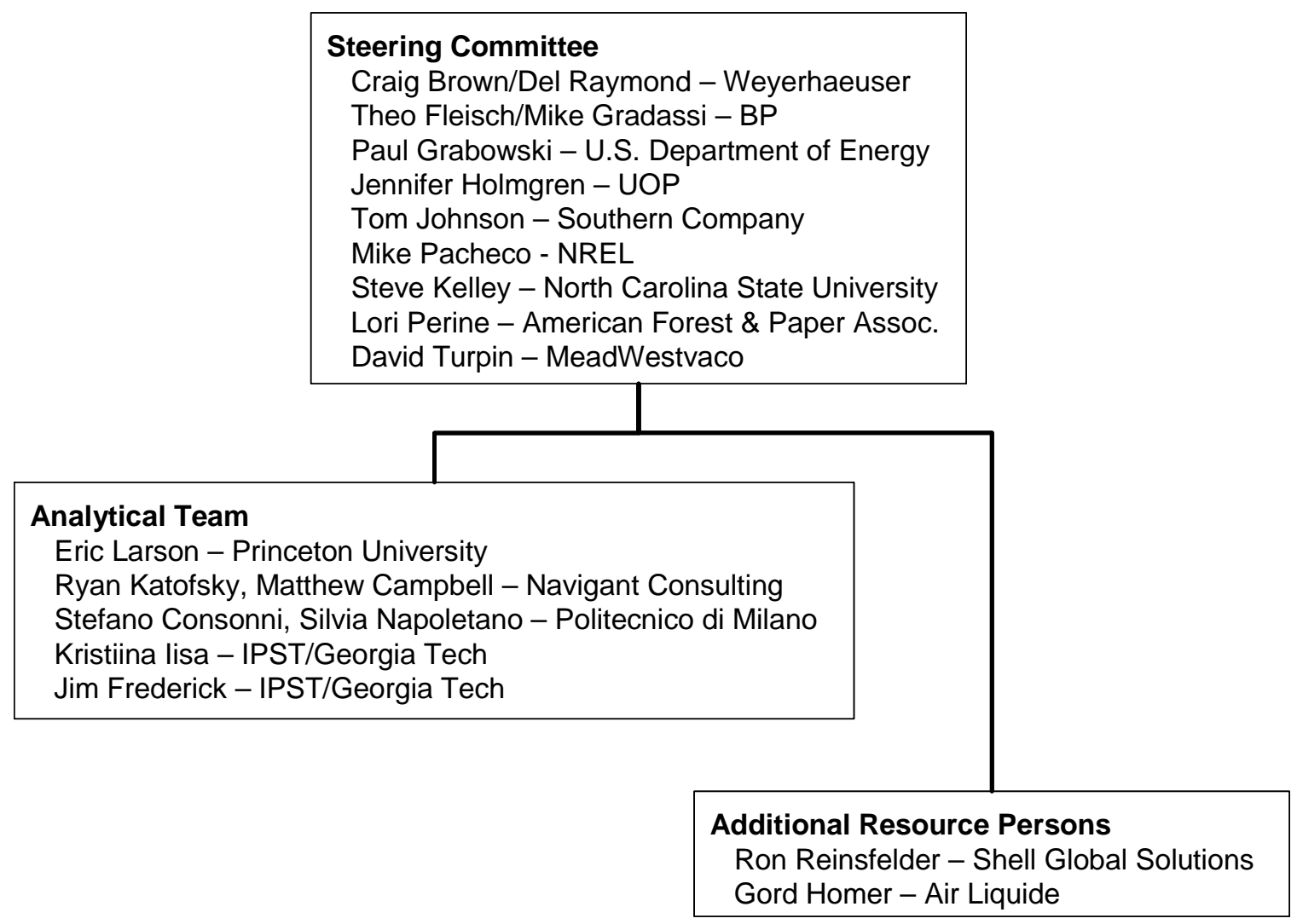

Figure 4. Organizational structure and principal participants in this project.

While consistency has been maintained to the extent possible between the BLGCC and biorefinery analyses, there are also key differences in the fundamental design approaches:

- In the BLGCC analysis a key design criterion for the energy/chemical recovery area was maximizing electricity production while providing all of the mill's process steam needs. The biorefinery study recognizes the broader "breakthrough" nature of the gasification technology platform insofar as it can enable the production of high-value chemicals and/or transportation fuels in addition to or instead of electricity. The biorefinery designs maintain the constraint that pulp mill process steam demands are met, but focus on maximizing liquid fuels production or optimizing fuels and electricity co-production. In some cases, this results in the need for imports of electricity to satisfy mill process needs.

- The BLGCC analysis considered some use of natural gas (a non-renewable resource) as a supplemental fuel. The biorefinery analysis considers that only renewable biomass fuels (black liquor and woody residues) are used as feedstock, making the biorefinery products essentially fully renewable.

- The BLGCC analysis assumed that only a relatively modest level of woody residue is available as energy feedstock at the mill - a level much lower than potentially available at 
many existing mills, as suggested by the recent "billion ton study" [1]. The biorefinery analysis assumes that larger quantities of forest-based residues are available in some cases. In the longer term, non-forest biomass (e.g., short rotation woody crops or perennial grasses) might augment forest-based biomass as feedstock for still larger-scale pulpmill biorefineries.

- The BLGCC analysis assumed that woody biomass residues would be burned in boilers to augment steam generation. The biorefinery analysis aims to maximize the capability to produce liquid fuels. Toward this end, the biomass residues used in all of the biorefinery designs except one are gasified to produce additional syngas rather than being burned to make steam. The potential exists in these cases to convert this syngas into liquid fuel.

- Finally, the BLGCC designs included ones using a high-temperature black liquor gasifier and one using a low-temperature black liquor gasifier in order to help assess the relative costs and benefits between the two gasifier designs. Because the high-temperature design showed more favorable performance and cost results in the BLGCC application, this gasifier design was selected for use in all of the detailed biorefinery analysis here. (A scoping study for lowtemperature black liquor gasification, as reported in Volume 4 of this study, suggests that the low-temperature technology might be best suited for applications other than the biorefinery concepts examined in detail in this volume.) The focus on high-temperature black liquor gasification for detailed analysis enabled a broader set of process configurations and biorefinery products to be examined using the limited resources available for the project.

\section{Synthetic Fuels Chosen for Detailed Analysis}

A wide variety of liquid fuels or chemicals can be made from synthesis gas [6,7]. A screening analysis was undertaken to help identify the products to be included for detailed analysis in this study. Potential domestic market size in the near-to-medium term and potential for enhancing domestic energy security were key screening criteria. Table 1 lists consumption and price levels of various fuels and bulk chemicals in the United States today. Among those listed, only ethanol and natural gas are not derived primarily from petroleum today in the United States. While the natural gas market today is large, with relatively high gas prices, a decision was made early in the project to limit the analysis to products with the potential for displacing petroleum directly. Among the other products in the table, fuels markets are substantially larger than chemicals markets, both in physical and monetary terms. Given the large potential size of a pulp mill-based biorefining industry, a further decision was made to focus the biorefinery analysis on liquid fuel products rather than on chemicals. In future actual biorefinery implementations where markets for higher-value products (e.g., chemicals) are accessible to a particular biorefiner, financial performance may be better than the results found in this work focusing on fuel products. The focus here on petroleum and transportation is also consistent with the DOE's strategic objective of reducing dependence on imported oil. We chose not to examine hydrogen as a fuel product, because in the near-to-medium term, hydrogen is unlikely to play any significant commercial role as a transportation fuel.

Three liquid fuel products were chosen for detailed analysis: Fischer-Tropsch liquids (FTL), dimethyl ether (DME), and mixed alcohols (MA). Each of these products and the current status of their production globally are discussed next. 
Table 1. Markets and values for potential biorefinery products.

\begin{tabular}{|c|c|c|c|c|}
\hline & \multicolumn{2}{|c|}{ Physical U.S. market size, 2005} & \multirow{2}{*}{$\begin{array}{l}\text { Average refinery gate } \\
\text { price (excl. taxes), } 2005\end{array}$} & \multirow{2}{*}{$\begin{array}{l}\text { Approximate market } \\
\text { U.S. wholesale, } 2005\end{array}$} \\
\hline & Physical Units & Quads/yr & & \\
\hline \multicolumn{5}{|c|}{ Fuels (from [8], except ethanol price, which is from [9]) } \\
\hline Motor gasoline & 9.13 million bbl/day & 17.2 & $\begin{array}{l}\text { \$1.67/gal } \\
\$ 13.6 / \text { million BTU }\end{array}$ & $\$ 233$ billion/yr \\
\hline Motor diesel & 4.11 million bbl/day & 8.74 & $\begin{array}{l}\$ 1.75 / \mathrm{gal} \\
\$ 12.6 / \text { million BTU }\end{array}$ & $\$ 110$ billion/yr \\
\hline LPG & 2.02 million bbl/day & 3.05 & $\begin{array}{l}\$ 0.92 / \mathrm{gal} \\
\$ 9.36 / \text { million BTU }\end{array}$ & $\$ 29$ billion/yr \\
\hline Ethanol & 0.26 million bbl/day & 0.34 & $\begin{array}{l}\$ 1.89 / \mathrm{gal} \\
\$ 22.4 / \mathrm{million} \text { BTU }\end{array}$ & $\$ 8$ billion/yr \\
\hline Natural Gas & 21.98 trillion SCF & 22.6 & $\begin{array}{l}\$ 7.51 / \text { scf (well head) } \\
\$ 7.31 / \text { million BTU }\end{array}$ & $\$ 165$ billion/yr \\
\hline \multicolumn{5}{|l|}{ Chemicals } \\
\hline Methanol & 0.185 million bbl/day (2001) & NA & $\begin{array}{l}\text { \$1.33/gallon } \\
\text { (Q3 2006) }\end{array}$ & $\$ 3-\$ 4$ billion/yr \\
\hline Hydrogen & $\begin{array}{l}10 \text { million tonnes ( } 85 \% \\
\text { captive, } 15 \% \text { merchant) }\end{array}$ & 1.3 & $\$ 10-50 /$ tonne & $\begin{array}{l}\$ 15-\$ 75 \text { million/yr } \\
\text { (merchant market) }\end{array}$ \\
\hline Ammonia & 21 Million tons (2001) & NA & $\begin{array}{l}\$ 94-325 / \text { ton f.o.b. Gulf } \\
\text { Coast (1996-01) }\end{array}$ & $\$ 2-\$ 7$ billion/yr \\
\hline Mixed Alcohols & 3.7 billion pounds & NA & $\begin{array}{l}\$ 0.80-1.05 / \mathrm{lb} \\
(2006)\end{array}$ & $\$ 3-\$ 4$ billion/yr \\
\hline
\end{tabular}

\subsection{Fischer-Tropsch Fuels}

The product of Fischer-Tropsch synthesis is a mixture of primarily straight-chain hydrocarbons (olefins and paraffins) that resembles a semi-refined crude oil. The mixture can either be shipped to a conventional petroleum refinery for processing or refined onsite into "clean diesel" and naphtha fractions, the latter of which can be further upgraded to a gasoline blendstock.

FTL fuels were first produced commercially in the 1930s when Germany started production from coal syngas as vehicle fuel [10]. Subsequently a coal-to-fuels program was started in South Africa and has been operating there since the early 1950s. Starting in the 1990s, there has been renewed interest globally in FT synthesis to produce liquids from large reserves of remote "stranded" natural gas that have little or no value because of their distance from markets [11,12]. Of particular interest today is the production of middle distillate fuels (diesel-like fuels) with unusually high cetane numbers and containing little or no sulfur or aromatics. Such fuels (derived by natural gas conversion) are now beginning to be blended with conventional diesel fuels in some countries to meet increasingly strict vehicle fuel specifications designed to reduce tailpipe emissions.

Such environmental factors, together with today's high crude oil prices, are driving major expansion in global capacity for FTL production. In addition to Shell's gas-to-liquids (GTL, used synonymously with gas-to-FT liquids) plant in Malaysia (14,500 barrels per day FTL capacity) and the PetroSA (formerly Mossgas) plant in South Africa (23,000 bpd) that started up in 1993, there are additional large commercial GTL facilities nearing startup or at advanced planning stages, including: 
- 34,000 barrels per day (bpd) project of Qatar Petroleum that will use Sasol FT synthesis technology and is slated to come on line in 2006.

- $\quad 66,000$ bpd expansion of the Qatar Petroleum project to startup in 2009.

- 34,000 bpd Chevron project in Nigeria, also using Sasol FT technology, expected on line in 2009.

- 30,000 bpd BP project in Colombia using BP’s FT synthesis technology to come on line in 2011.

- 36,000 bpd project in Algeria to come on line in 2011.

- 140,000 bpd Shell project in Qatar using Shell's FT technology; to come on line in two phases in 2009 and 2011.

- 154,000 bpd ExxonMobil project in Qatar using ExxonMobil FT technology; to come on line in 2011

There is also a growing resurgence of interest in FT fuels from gasified coal. Coal-based FT fuel production was commercialized beginning with the Sasol I, II, and III plants $(175,000 \mathrm{~b} / \mathrm{d}$ total capacity) built between 1956 and 1982 in South Africa. (Sasol I is now retired). China's first commercial coal-FT project is under construction in Inner Mongolia. The plant is slated to produce 20,000 bpd when it comes on line in 2007. China has also signed a letter of intent with Sasol for two coal-FT plants that will produce together 120,000 bpd. The U.S. Department of Energy is cost-sharing a $\$ 0.6$ billion demonstration project in Gilberton, Pennsylvania, that will make 5,000 bpd of FT liquids and $41 \mathrm{MW}_{\mathrm{e}}$ of electricity from coal wastes. Also, there are proposals for 33,000 bpd and 57,000 bpd facilities for FT fuels production from coal in the state of Wyoming and for a comparable project in Southeastern Montana.

The process for converting biomass into FT liquids is similar in many respects to that for converting coal. Preliminary technical/economic analyses on biomass conversion were published by Larson and Jin [13,14]. More recently, there have been several detailed technical and economic assessments published $[15,16,17,18,19,20]$. A preliminary study of FT fuels from black liquor has also recently been completed [4]. There is considerable current interest in Europe in production of FT fuels from biomass, motivated in part by large financial incentives. For example, in the UK a 20 pence per liter (\$1.40/gal) incentive for biomass-derived diesel fuel has been in place since July 2002. Incentives are also in place in Germany, Spain, and Sweden. Such incentives have been introduced in part as a result of European Union Directive 2003/30/EC, which recommends that all member states have $2 \%$ of all petrol and diesel consumption (on an energy basis) be from biofuels or other renewable fuels by the end of 2005, reaching $5.75 \%$ by the end of 2010 . The Shell Oil Company, which offers one of the leading commercial entrained-flow coal gasifiers and also has long commercial experience with FT synthesis, recently announced a partnership with Choren, a German company with a biomass gasification system, with plans for constructing a commercial biomass to FT liquids facility in Germany [21,22,23]. A "beta” plant, with a production capacity of 15,000 tonnes per year of FT diesel is currently under construction in Freiberg/Saxonia.

The scale of most coal and natural gas FT projects today is far larger than could be supported by syngas from biomass feedstocks potentially available at a typical pulp mill biorefinery. Most prior biomass FTL analyses have used cost estimates scaled from such large-scale systems. However, smaller, modular, FTL reactors have been under development by several companies (Rentech, Syntroleum, BP) and are now commercially available [24]. This development has 
been driven by an interest in monetizing the hundreds of smaller pockets of stranded gas, as well as by an interest in increasing factory production of components over field fabrication to reduce costs of even large installations. Such technology development is of direct interest for pulp mill biorefinery applications.

\subsection{Dimethyl Ether}

Dimethyl ether (DME) is a colorless gas at ambient temperature and pressure, with a slight ethereal odor. It liquefies under slight pressure, much like propane. It is relatively inert, noncorrosive, non-carcinogenic, almost non-toxic, and does not form peroxides by prolonged exposure to air [25]. Today, DME is used primarily as an aerosol propellant in hair sprays and other personal care products, but its physical properties (Table 2) make it a suitable substitute (or blending agent) for liquefied petroleum gas (LPG, a mixture of propane and butane). It is also an excellent diesel engine fuel due to its high cetane number and absence of soot production during combustion.

Table 2. Properties of DME, petroleum diesel, propane, and butane [26]. The latter two are the main constituents of liquefied petroleum gas (LPG).

\begin{tabular}{|l|c|c|c|c|}
\hline Property & DME & Diesel & Propane & Butane \\
\hline Cetane number & $55-60$ & $40-55$ & na & na \\
\hline Vapor Pressure @ 20 deg C [bar] & 5.1 & $<1$ & 8.4 & 2.1 \\
\hline Liquid density @ 20 deg C [kg/m3] & 668 & 840 & 501 & 610 \\
\hline Lower Heating Value [MJ/kg] & 28.4 & 43.0 & 46.4 & 45.7 \\
\hline
\end{tabular}

Until recently, DME was being produced globally at a rate of only about 150,000 tons per year [27]. This level is now increasing dramatically [28,29]. From 2003 through 2006, a total of 265,000 t/yr of DME production capacity (110,000 of which is from natural gas and the rest from coal) came on line in China. An additional 2.6 million t/yr of capacity (from coal) is expected to come on line there by 2009, and plans are being developed for a further one million t/yr of capacity. In Iran, a gas to DME facility producing 800,000 tons per year will come on line in 2008. There is also discussion of a facility to be built in Australia (with Japanese investment) to produce between one and two million tonnes per year of DME from natural gas. Thus by the end of this decade, DME production capacity globally may reach between 3.8 and 6.8 million t/yr, which would represent a 25 to 45 fold increase compared to the beginning of the decade.

Essentially all new DME produced this decade will be used as an LPG substitute for domestic (household) fuel. In China, however, some DME will also be used in buses, initially in Shanghai and subsequently elsewhere. Commercial development of DME buses is underway in China, and volume production is anticipated before the end of this decade [29]. Development of heavyduty vehicles (trucks and buses) fueled with DME is also underway in Sweden by Volvo, who expects to have 30 vehicles in field tests starting no later than 2009 [30] and commercial vehicles available by 2011 [31]. Major efforts in Japan are also ongoing to commercialize heavy duty DME road vehicles [32]. Volvo anticipates that biomass-derived DME will be available in the 2010 time frame from a commercial project to be established in Sweden, building on experiences at the Värnamo [33] and Piteå [34] pilot plant facilities.

Two potential near-term markets for DME in the United States are as a blending agent in LPG and as a dedicated fuel for centrally refueled urban fleet vehicles. DME can be used as a substitute for LPG in stationary combustion applications, e.g., home heating, but the difference in calorific values between LPG and DME would necessitate changes to the burners and related 
equipment if DME were to be used as a complete replacement for LPG. However, mixtures of DME and LPG can be used with combustion equipment designed for LPG without changes to the equipment, if the DME blending level is limited to $15-25 \%$ by volume $[35,36]$. Thus, DME as a blendstock for LPG provides an immediate market opportunity - one recognized by the World LP Gas Association [37]. Considering that the total market for LPG fuel in the United States is approximately one quad today (Table 3), the blending market for DME is about 0.2 quads, which is large enough to absorb the DME that could be produced by tens of pulp mill biorefineries.

Table 3. LPG consumption in the United States in 2004 [38].

\begin{tabular}{|c|c|c|c|c|}
\hline & \multicolumn{4}{|c|}{ Thousand Metric Tonnes [quads] } \\
\hline & Fuel & Feedstock & To & tal \\
\hline Residential & $14,843 \quad[0.705]$ & 0 & 14,843 & [0.705] \\
\hline Agricultural & [0.115] & 0 & 2,425 & [0.115] \\
\hline Industrial & [0.187] & $31,180 \quad[1.482]$ & 35,109 & [1.669] \\
\hline Transport & [0.035] & 0 & 740 & [0.035] \\
\hline Total & $21,937 \quad[1.042]$ & $31,180 \quad[1.482]$ & 53,117 & [2.524] \\
\hline
\end{tabular}

Note: Conversion from tonnes to quads assumes 47.5 MBTU/metric tonne lower heating value (for 60/40 butane/propane mix).]

A second promising market for DME in the United States is as a fuel for compression ignition engine vehicles, an application being pursued in China, Sweden, and Japan, among other countries. It is not feasible to blend DME with conventional diesel fuel in existing engines, because DME must be stored under mild pressure to maintain a liquid state. However, because DME burns extremely cleanly in an appropriately designed compression ignition engine, an attractive application is in compression ignition vehicles operating in urban areas, where vehicle air pollution is most severe. Because vehicle refueling station equipment differs from that at conventional refueling stations dispensing petroleum-derived fuels, and modified on-board fueling systems are required, fleet vehicles that are centrally-maintained and centrally fueled (buses, delivery trucks, etc.) are a logical initial target market. Since many such vehicles operate in urban areas with petroleum diesel fuel today, the dramatically lower exhaust emissions with DME engines compared to diesel engines (especially of health-damaging small particles) [32,39] provides strong public motivation for adopting DME fleets. The estimated number of centrally fueled fleet vehicles in the United States provides a significant potential market for pulp mill biorefiners producing DME (Table 4).

\subsection{Alcohol Fuels}

Two alcohol fuels are drawing attention in the United States at present. One is ethanol, the qualities of which as a vehicle fuel are relatively well known. A second potential fuel is a mixture of alcohols that includes a significant fraction of ethanol plus smaller fractions of several higher alcohols. Mixed-alcohol fuels have the potential to be used much the way ethanol is today for blending with gasoline, or higher alcohols can be separated from the ethanol fraction and sold for chemical use.

The United States ranks as the largest producer of fuel ethanol in the world today (4 billion gallons in 2005 [40]). In the United States ethanol is used primarily for blending in gasoline as an oxygenate and an octane booster (at a blending rate of up to $10 \%$ by volume), and such blends can be used in gasoline engine vehicles without modification. Higher blends (up to about 25\% ethanol, as found in Brazil) are feasible with only minor engine modifications. Flexible-fuel vehicles (FFVs), which are designed to use fuel with anywhere from zero to 85\% ethanol (E85), 
require some additional minor modifications, and are growing in number in the United States. The number of retail service stations in the United States offering E85 fuel tripled between 2004 to 2005 to a total of 650 [40].

Table 4. Authors' estimates of the number of centrally refueled urban fleet vehicles in the United States and associated diesel fuel use, as of the mid-1990s.

\begin{tabular}{|c|c|c|c|c|}
\hline Vehicle type & $\begin{array}{l}\text { Total number } \\
\text { (thousands) }\end{array}$ & $\begin{array}{c}\text { Centrally refueled } \\
\text { (thousands) }\end{array}$ & $\begin{array}{c}\text { Annual diesel use* } \\
\text { million gal/y [quads/yr] }\end{array}$ & $\begin{array}{c}\text { DME } \\
\text { Million t/yr }\end{array}$ \\
\hline Total of below 3 types & 4,718 & 3,845 & $6,329 \quad[0.922]$ & 35 \\
\hline Uurban transit buses & 76 & 74 & [0.096] & 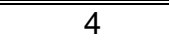 \\
\hline School buses & 458 & 426 & [0.133] & 5 \\
\hline Light/delivery trucks & 4,184 & 3,345 & $4,760 \quad[0.693]$ & 26 \\
\hline
\end{tabular}

* Assuming 3.6 miles per gallon and 31,932 miles/yr for urban transit buses; $7.0 \mathrm{mpg}$ and 15,000 mi/yr for school buses; and $17.6 \mathrm{mpg}$ and 24,960 mi/yr for light/delivery trucks.

Mixtures of alcohols have not been used commercially as a fuel in the United States or other countries. Higher alcohols are characterized by higher volumetric energy densities and lower vapor pressures than ethanol and these features make them more attractive as fuels or blending agents. A major private sector effort was recently announced to commercialize biomass-derived butanol as a gasoline blending agent [41].

All ethanol (and the proposed commercial butanol fuel) in the United States is produced by biological processing of primarily corn and also some sweet sorghum, both relatively expensive feedstocks. Development efforts to enable effective conversion of lower-cost feedstocks are ongoing. Most such efforts are focusing on biological routes for converting lignocellulosic feedstocks such as corn stover, wood residues, and energy crops like switchgrass. Such biological routes typically involve parallel or sequential processes to extract carbohydrate sugars from the cellulose and hemicelluose components of the feedstock and to ferment these sugars to ethanol. The lignin portion of the biomass is not amenable to fermentation. Advances in engineering of biological organisms and processes, and in low-cost production of lignocellulosic feedstocks like switchgrass, are projected to lead to commercial competitiveness of biological fuel ethanol (at crude oil prices well below mid-2006 levels) in the next 10 to 20 years [42].

Meanwhile there are also development efforts ongoing on technologies and processes for converting synthesis gas into ethanol by fermentation [7]. This combined thermo/bio-chemical route to ethanol, if it can be made commercially viable, would enable the lignin in the biomass feedstock, as well as the hemicellulose and cellulose, to be converted to ethanol. At least one private company (BRI Energy, Inc.) is actively seeking to commercialize technology for fermentation of syngas. BRI claims to have a viable process for cost-competitive production of ethanol [43], but little detailed documentation is available to enable an independent evaluation of this claim. BRI recently announced their intention to build two commercial facilities near Oak Ridge, Tennessee. One facility would convert coal-derived syngas to ethanol, and the other would convert municipal solid waste via gasification to ethanol [44]. Other than BRI's commercially oriented activities, most other syngas fermentation technology development efforts are limited to small-scale research efforts [7].

Syngas can also be converted into a mixture of alcohols by catalytic synthesis. The process steps for making mixed alcohols this way from biomass resemble those for making FT liquids.

Gasification is used to produce a synthesis gas that is cleaned and then passed over a catalyst, forming a mixture of alcohol molecules with from one to six carbons each. One company developing a mixed alcohol catalyst indicates an expected composition of 25-30\% methanol (by 
weight); $45-50 \%$ ethanol; $15 \%$ propanol; $5 \%$ butanol; $3 \%$ pentanol; and $2 \%$ hexanol and higher. The methanol fraction may be recycled to the reactor to increase the conversion to ethanol and higher alcohols. A number of different catalysts for mixed alcohol production from syngas were patented in the late 1970s and early 1980s [45], but most development efforts were abandoned after oil prices fell in the mid-1980s. Steep increases in oil prices in recent years have reignited interest.

There are as yet no commercially-demonstrated technologies for synthesis of mixed alcohols, but several startup companies claim to be on the path to developing such technologies [46]. A commercial project is at an early stage of development in Hawaii by Clear Fuels Inc. to convert sugarcane bagasse via gasification and synthesis to ethanol [45]. BCT Inc. is developing a commercial system for gasification of any solid carbonaceous feedstock, followed by conversion of the syngas to a mixed-alcohol product [47]. Power Energy Fuels, Inc. [48], Nova Fuels [49], and Syntec Biofuel [50], are additional companies pursing similar technologies. Aside from patents and patent applications, relatively little published information is available concerning these private-sector activities.

\section{Chemical Recovery and Power/Steam Cogeneration at Pulp and Paper Mills}

\subsection{The Kraft Process}

The pulp and paper industry represents one of the most energy-intensive industries in the United States in terms of energy use per dollar of value-added output. Unlike other energy-intensive industries, however, a majority of the energy consumed by the industry is generated from renewable biomass by-products of pulp production. The kraft pulping process, by which most pulp is produced from wood in the United States, is illustrated generically in Figure 5.

At a typical kraft mill, logs are debarked and chipped, with the clean chips sent to the digester for cellulose separation. The bark and waste wood (called "hog fuel") are used as a boiler fuel. The wood chips undergo cellulose separation in the digester in a solution of sodium sulfide $\left(\mathrm{Na}_{2} \mathrm{~S}\right)$ and sodium hydroxide $(\mathrm{NaOH})$ called "white liquor.” A subsequent washing step separates the cellulose fibers from the remaining solution ("black liquor") containing the spent pulping chemicals and the lignin and hemicellulose fractions of the original wood chips. The cellulose fibers are processed into a final pulp product (at a stand-alone pulp mill) or into paper (at an integrated pulp and paper mill).

The black liquor solids (BLS) contain about half the energy in the original wood chips sent into the digester, and thus represent a considerable energy resource. To make effective use of this energy, the black liquor is concentrated from a dilute solution (15-20\% solids fraction) to one with a solids content of 75 to $80 \%$ in multiple-effect evaporators, with steam providing the heating in the evaporators. The concentrated black liquor is then burned in a Tomlinson recovery boiler. Steam from the Tomlinson boiler, together with steam from the hog fuel boilers (or in some cases from auxiliary fossil fuel boilers), provides the steam needed to run the pulp (or integrated pulp and paper) mill. The steam is raised at an elevated pressure and, before being used in the process, it is expanded to lower pressure through a steam turbine that generates electricity to provide a fraction of the mill's electricity demand. Most U.S. mills must also purchase some electricity, since the amount generated from black liquor and hog fuel is not 
sufficient to meet all of the mill's electricity needs with the power generating technology in use today.

In a Tomlinson boiler, the organic fraction of the black liquor burns to produce heat and the inorganic fraction leaves as a molten smelt containing largely $\mathrm{Na}_{2} \mathrm{~S}$ and $\mathrm{Na}_{2} \mathrm{CO}_{3}$. Unlike in a conventional fuel or solid biomass boiler, boiler tube leaks are a considerable safety concern with Tomlinson systems, since water from the leak contacting molten smelt can result in a steam explosion, which can have deadly consequences.

The smelt is dissolved in water to form "green liquor" that is sent to a causticizer, where lime $(\mathrm{CaO})$ is added to convert the $\mathrm{Na}_{2} \mathrm{CO}_{3}$ in the green liquor back to the desired $\mathrm{NaOH}$ pulping chemical. The lime is converted to calcium carbonate $\left(\mathrm{CaCO}_{3}\right)$ in the causticizer, and must be converted back to $\mathrm{CaO}$ by heating in the lime kiln. Typically, fuel oil or natural gas is burned in the kiln to generate the needed heat.

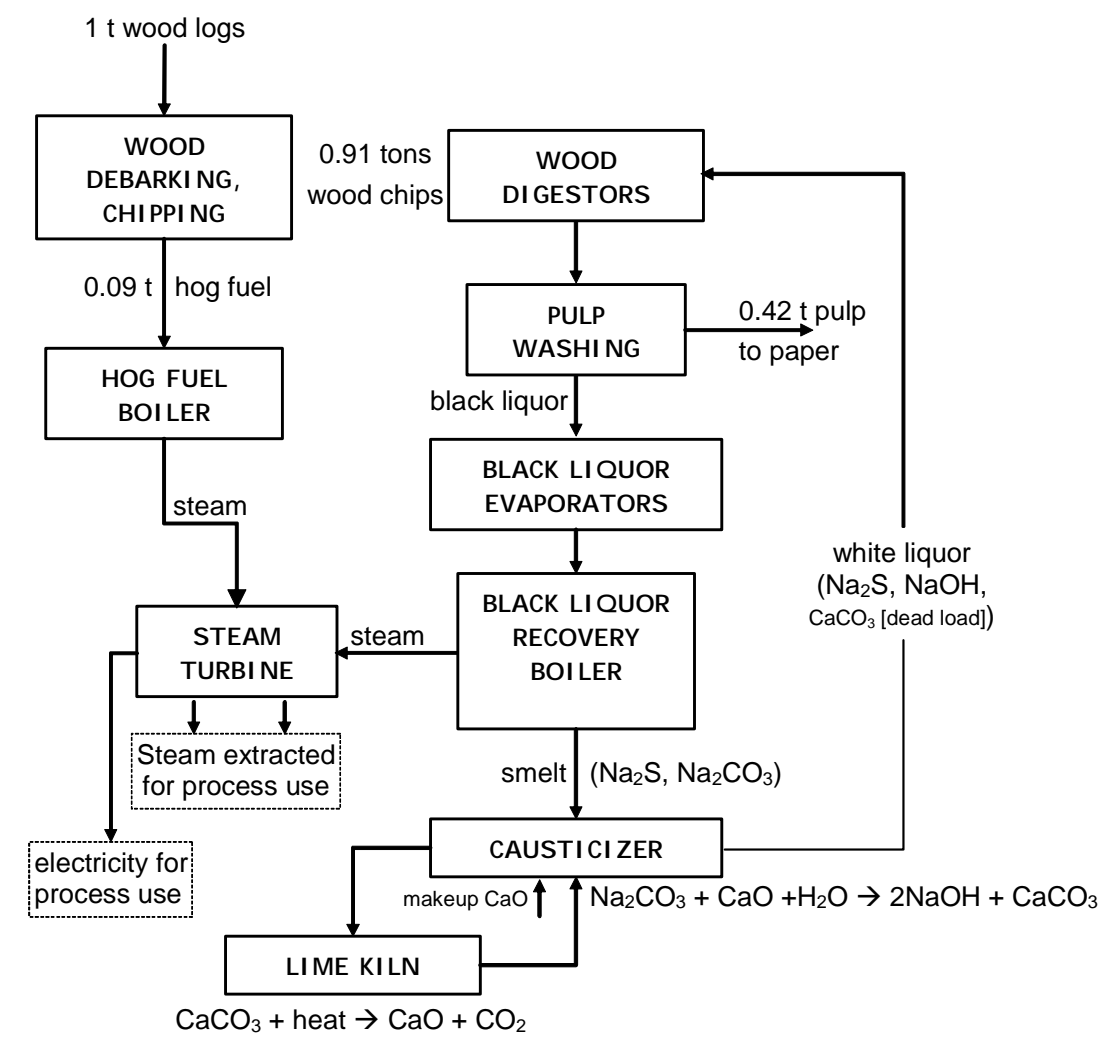

Figure 5. Simplified representation of kraft pulping and the associated chemical recovery cycle. Indicated mass flows are on a dry-matter basis and intended only to be illustrative.

\subsection{Reference Kraft Pulp/Paper Mill for Case Study Comparisons}

To assess the prospective commercial competitiveness of biorefineries relative to existing Tomlinson-based systems, we developed detailed biorefinery process designs assuming these would be built as complete replacements of existing Tomlinson power/recovery systems at the reference mill used in the earlier BLGCC analysis [5].

The reference mill is an integrated pulp and paper mill producing uncoated freesheet paper from a 65/35 mix of hardwood and softwood. Consistent with the forward-looking nature of this study 
and the continual improvements in process energy efficiency historically achieved by U.S. pulp and paper makers, the process steam demands at the mill are taken to be about $10 \%$ below current "best-practice" levels. The nominal scale of the reference mill is 6 million lbs/day of black liquor solids (BLS).

Key reference mill parameter assumptions are shown in Table 5 for both conventional pulping and polysulfide pulping. The latter pulping chemistry is enabled by the use of black liquor gasification in the recovery area, and we assume this chemistry is implemented where biorefineries are installed. ${ }^{2}$ Polysulfide pulping raises the digester yield, enabling a reduction in wood feed to the mill compared to conventional pulping (for the same paper production ${ }^{3}$ ). Pulpwood cost savings amount to over $\$ 4$ million per year for the assumptions of this study, as will be detailed later. The higher digester yield also reduces the amount of black liquor solids sent to the recovery area. Consistent with industry trends toward higher solids concentration in black liquor sent to recovery, we have assumed a solids concentration of $80 \%$.

\subsection{Previous Results for Pulp Mill Power Generation}

For later comparisons against our biorefinery results, we reproduce here results for two options for steam and power generation at the reference mill examined in our earlier study [5]. One of these options is a new conventional Tomlinson power/recovery system - the "Base" Tomlinson design in our previous study. The second is a black liquor gasifier combined cycle (BLGCC) system. Three BLGCC desing were developed in our previous study incorporating different gasification technologies, gas turbines, and design philosophies: two "mill-scale" cases (each with a different gasifier design), wherein the gas turbine is sized to the flow of black liquor syngas available, and one "utility-scale" case employing a larger gas turbine co-fired with natural gas to achieve higher electricity output. As discussed later, we have selected the most appropriate of these three designs to include for comparison purposes here.

Both of the Tomlinson and BLGCC systems used for comparison here provide all process steam needed by the mill. The BLGCC system produces more electricity than is needed by the mill, while the mill with the Tomlinson system must purchase some electricity to augment that generated in the power/recovery area.

\subsubsection{Tomlinson Power/Recovery at the Reference Mill}

The Tomlinson case represents a state-of-the art power/recovery system assumed as the "business-as-usual" choice of technology when considering replacement of the existing power/recovery system at the reference mill. The process configuration for the Tomlinson system (Figure 6) features steam conditions of 1,250 psig (87.2 bar abs.) and temperature of $480^{\circ} \mathrm{C}\left(896^{\circ} \mathrm{F}\right)$, and a common high-pressure (HP) steam header for the Tomlinson and hog fuel

\footnotetext{
${ }^{2}$ Elemental sulfur can be generated from $\mathrm{H}_{2} \mathrm{~S}$ recovered from the product gas of a black liquor gasifier. When the elemental sulfur is mixed with a solution containing $\mathrm{Na}_{2} \mathrm{~S}$ at moderate temperature $\left(<100^{\circ} \mathrm{F}\right)$, polysulfide forms, for example, $3 \mathrm{~S}+\mathrm{Na}_{2} \mathrm{~S} \rightarrow \mathrm{Na}_{2}-\mathrm{S}_{3}-\mathrm{S}$. Polysulfide pulping increases digester yield compared to conventional white liquor pulping [51], which enables a mill to decrease wood input compared to conventional pulping (for a fixed pulp production) or increase pulp production (for a fixed wood input). The cost impacts of integrating polysulfide pulping with black liquor gasification are considered in this study.

${ }^{3}$ The implicit assumption here is that the mill is already operating at capacity (outside of the power/recovery area) when using conventional pulping, so that an increase in digester yield can be accommodated only by decreasing wood input, not by increasing pulp production.
} 
boilers. The hog fuel boilers generate steam from bark and waste wood by-products of pulpwood preparation at the mill. The HP steam expands through the back-pressure steam turbine existing previously at the mill. There is one extraction of steam from the turbine at 175 psig (13 bar abs.) to provide steam for boiler air pre-heating (together with LP steam bled from the deaerator) and medium-pressure (MP) process steam for the mill, and a second extraction at 30 bar providing steam for soot blowing. The balance of steam exhausts at 55 psig or 4.8 bar abs. to provide the mill with its low-pressure (LP) process steam. Because of the process-steam efficiency gains assumed for the reference mill (compared to a typical existing mill today), the amount of exhaust steam is more than is needed for the process. A small condensing steam turbine is added to enable increased electricity generation. Flue gases leave the economizer section of the Tomlinson boiler at $170^{\circ} \mathrm{C}$ with an oxygen content of $2 \%$ by volume (wet basis).

Table 5. Reference mill characteristics.

\begin{tabular}{|c|c|c|c|}
\hline \multicolumn{2}{|l|}{ POWER/RECOVERY SYSTEM $\rightarrow$} & \multirow{2}{*}{$\begin{array}{l}\text { Tomlinson } \\
\text { Conventional }\end{array}$} & \multirow{2}{*}{$\begin{array}{l}\text { Gasification } \\
\text { Polysulfide }\end{array}$} \\
\hline PULPING CHEMISTRY $\rightarrow$ & & & \\
\hline $\begin{array}{l}\text { Product Flow (paper) } \\
\text { Unbleached Pulp Rate } \\
\text { Mill Hardwood/Softwood Mix }\end{array}$ & $\begin{array}{l}\text { Machine-dry metric tons / day } \\
\text { Bone dry short tons / day } \\
\% \mathrm{HW}, \% \mathrm{SW}\end{array}$ & \multicolumn{2}{|c|}{$\begin{array}{c}1,580 \\
65 \% \mathrm{HW}, 35 \% \mathrm{SW}\end{array}$} \\
\hline Digester Yield & $\begin{array}{l}\% \text { for softwood } \\
\% \text { for hardwood }\end{array}$ & $\begin{array}{l}45.50 \% \\
46.50 \%\end{array}$ & $\begin{array}{l}48.75 \% \\
49.75 \%\end{array}$ \\
\hline $\begin{array}{l}\text { Wood To Process ( } 91 \% \text { of total) } \\
\text { Hog Fuel ( } 9 \% \text { of total) } \\
\text { Total pulpwood logs } \\
\end{array}$ & Bone dry short tons / day & $\begin{array}{l}3,434 \\
\underline{340} \\
3,774 \\
\end{array}$ & $\begin{array}{l}3,208 \\
\underline{317} \\
3,525 \\
\end{array}$ \\
\hline Black Liquor Solids Concentration & $\%$ solids & $80 \%$ & $80 \%$ \\
\hline BL Solids Flow Rate & $\begin{array}{l}\mathrm{lb} \text { BLS / day } \\
\mathrm{kg} \mathrm{BLS} / \text { day }\end{array}$ & $\begin{array}{l}6,000,000 \\
2,721,555 \\
\end{array}$ & $\begin{array}{l}5,419,646 \\
2,458,311 \\
\end{array}$ \\
\hline BL Energy Content & $\begin{array}{l}\text { MJ / kg of BLS, LHV (HHV) } \\
\text { Btu / lb of BLS, LHV (HHV) } \\
\text { MW, LHV (HHV) }\end{array}$ & $\begin{array}{l}12.46(13.89) \\
5,359(5,974) \\
392.6(437.6) \\
\end{array}$ & $\begin{array}{l}12.31(13.87) \\
5,295(5,966) \\
350.7(394.7)\end{array}$ \\
\hline BL Solids Composition, mass $\%$ & $\begin{array}{l}\mathrm{C} \\
\mathrm{H} \\
\mathrm{O} \\
\mathrm{S} \\
\mathrm{Na} \\
\mathrm{K} \\
\text { Ash/chlorides }\end{array}$ & $\begin{array}{c}33.46 \% \\
3.75 \% \\
37.35 \% \\
4.10 \% \\
19.27 \% \\
1.86 \% \\
0.21 \% \\
\end{array}$ & $\begin{array}{c}32.97 \% \\
3.70 \% \\
36.88 \% \\
4.27 \% \\
20.03 \% \\
1.93 \% \\
0.22 \% \\
\end{array}$ \\
\hline $\begin{array}{l}\text { Hog Fuel Energy Content } \\
(50 \% \text { moisture content) }\end{array}$ & $\begin{array}{l}\text { MJ / kg of hog fuel, LHV (HHV) } \\
\text { Btu / lb of hog fuel, LHV (HHV) } \\
\text { MWth, LHV (HHV) }\end{array}$ & $\begin{array}{c}8.14(10.0) \\
3,501(4,300) \\
57.8(71.3) \\
\end{array}$ & $\begin{array}{c}8.14(10.0) \\
3,501(4,300) \\
54.1(66.6) \\
\end{array}$ \\
\hline Mill $\mathrm{O}_{2}$ use (for delignification) & $\mathrm{kg} /$ metric t pulp & 23 & 23 \\
\hline $\begin{array}{l}\text { Mill Steam Use, } 55 \text { psig Steam } \\
\text { (including evaporators, but excluding } \\
\text { power/recovery area) }\end{array}$ & $\begin{array}{l}\mathrm{kg} / \mathrm{kg} \text { of paper } \\
\mathrm{MWth} \\
\mathrm{MJ} / \mathrm{mt} \text { of paper }\end{array}$ & $\begin{array}{l}3.384 \\
142.8 \\
7,149 \\
\end{array}$ & $\begin{array}{l}3.207 \\
135.3 \\
6,774 \\
\end{array}$ \\
\hline $\begin{array}{l}\text { Mill Steam Use, } 175 \text { psig Steam } \\
\text { (including evaporators, but excluding } \\
\text { power/recovery area) }\end{array}$ & $\begin{array}{l}\mathrm{kg} / \mathrm{kg} \text { of paper } \\
\text { MWth } \\
\mathrm{MJ} / \mathrm{mt} \text { of paper }\end{array}$ & $\begin{array}{c}1.760 \\
69.3 \\
3,469\end{array}$ & $\begin{array}{c}1.648 \\
64.8 \\
3,247\end{array}$ \\
\hline \begin{tabular}{|l} 
Total Mill Steam Use \\
Mill Electricity Use (excluding \\
power/recovery)
\end{tabular} & \begin{tabular}{|l} 
MWth \\
kWh / mt of paper \\
MWe
\end{tabular} & $\begin{array}{l}212.1 \\
1,407 \\
100.1\end{array}$ & $\begin{array}{l}200.1 \\
1,407 \\
100.1\end{array}$ \\
\hline
\end{tabular}


The Tomlinson power/recovery system shown in Figure 6 has a gross electricity generation of 72 $\mathrm{MW}_{\mathrm{e}}$, with a parasitic load of 7.8 $\mathrm{MW}_{\mathrm{e}}$. Considering both the black liquor and hog fuel inputs (393 and $58 \mathrm{MW}_{\mathrm{LHV}}$, respectively), the net electricity generating efficiency of the system is $13.3 \%$ on a LHV basis). Since the mill requires $100 \mathrm{MW}_{\mathrm{e}}$ of electricity for the process (Table 5), the mill must purchase $36 \mathrm{MW}_{\mathrm{e}}$ to meet its needs.

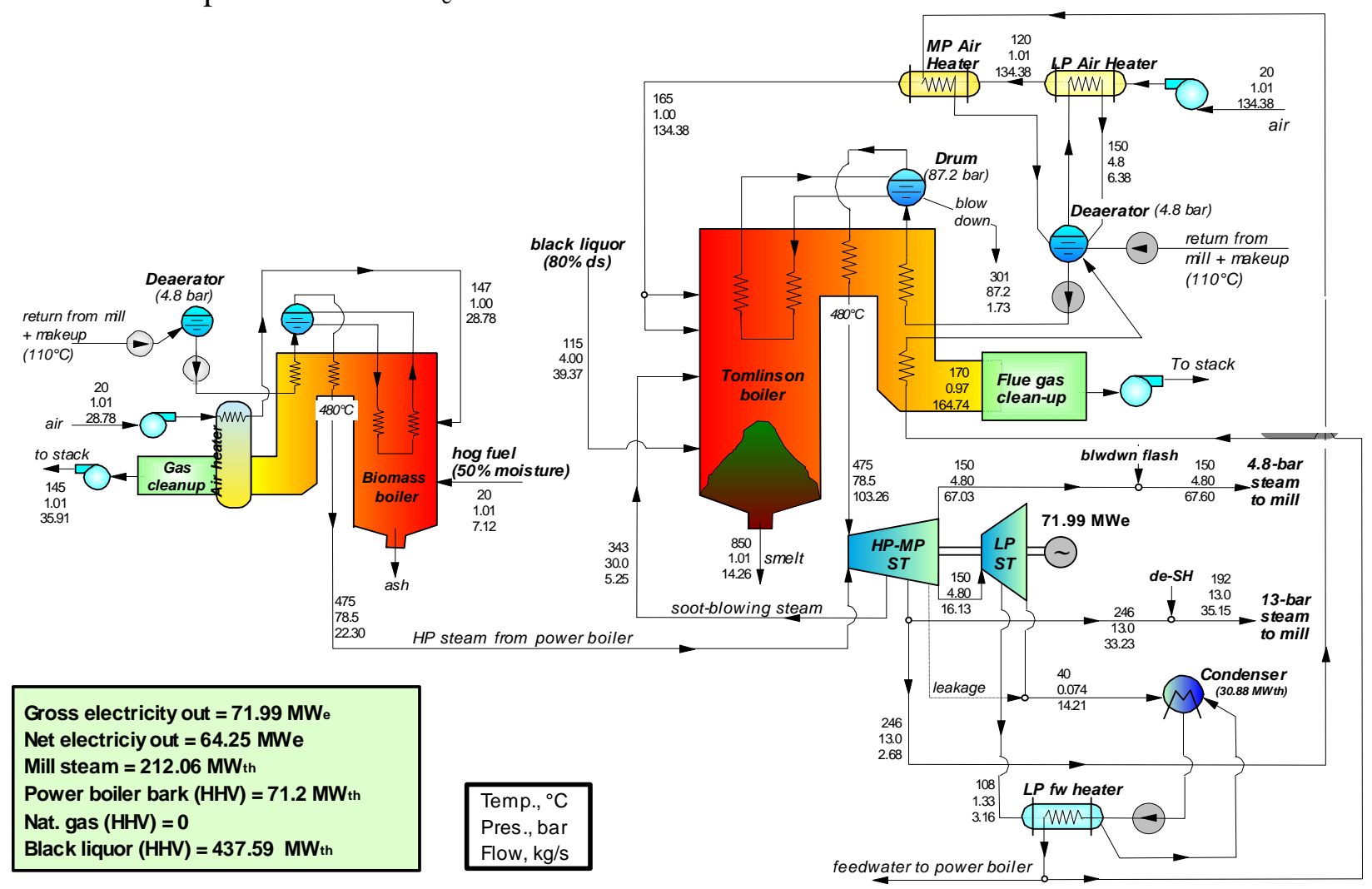

Figure 6. Energy/mass balance for a new Tomlinson power/recovery system.

\subsubsection{BLGCC Power/Recovery at the Reference Mill}

Gasifying black liquor enables it to be used as fuel in a gas turbine combined cycle, a much more efficient electricity generating option than the Tomlinson boiler steam turbine technology.

\subsubsection{Choice of Black Liquor Gasification Technology}

A number of concepts for black liquor gasification have been proposed in the past [52]. Our earlier assessment of black liquor gasification combined cycle (BLGCC) systems included detailed analysis of two black liquor gasifiers that have been the focus of sustained commercialization efforts.

A pressurized, oxygen-blown, high-temperature black liquor gasification technology (Figure 7) is being developed by Chemrec, a Swedish company [53,54]. The Chemrec design is distinguished by the majority of the inorganic material in the black liquor leaving the reactor as a molten liquid (smelt) due to the high reactor temperature $\left(950-1000^{\circ} \mathrm{C}\right)$. The Chemrec process resembles an entrained-flow coal gasifier in this respect. Chemrec tested an initial pilot unit starting in 1994 at a pulp mill near Karlstad, Sweden. This unit was designed to use air as the oxidant and to run at 15 bar pressure and $975^{\circ} \mathrm{C}$ temperature. The pilot plant was modified in 
1997 to use oxygen instead of air, resulting in an increase in capacity to $10 \mathrm{t} /$ day of black liquor solids (BLS). The unit was shut down in 2000, having provided significant data for further development of the technology. Meanwhile, the Weyerhaeuser company installed an atmospheric-pressure, air-blown Chemrec reactor (365 t/d BLS) at a mill in North Carolina in the late 1990s to augment the chemical recovery capacity provided by the existing Tomlinson boiler. The Weyerhaueser unit operated for three years before being shut down for repairs of an unanticipated problem. The unit was restarted in June 2003, after redesign based on the learnings from the original unit. Meanwhile, construction of a new Chemrec pilot plant was completed in the second half of 2005 at a pulp mill in Piteå, Sweden. The unit, which is designed to operate at 30 bar pressure on oxygen and process up to 20 tpd BLS, will provide data for scale-up [34] to full-scale Tomlinson boiler replacement applications.

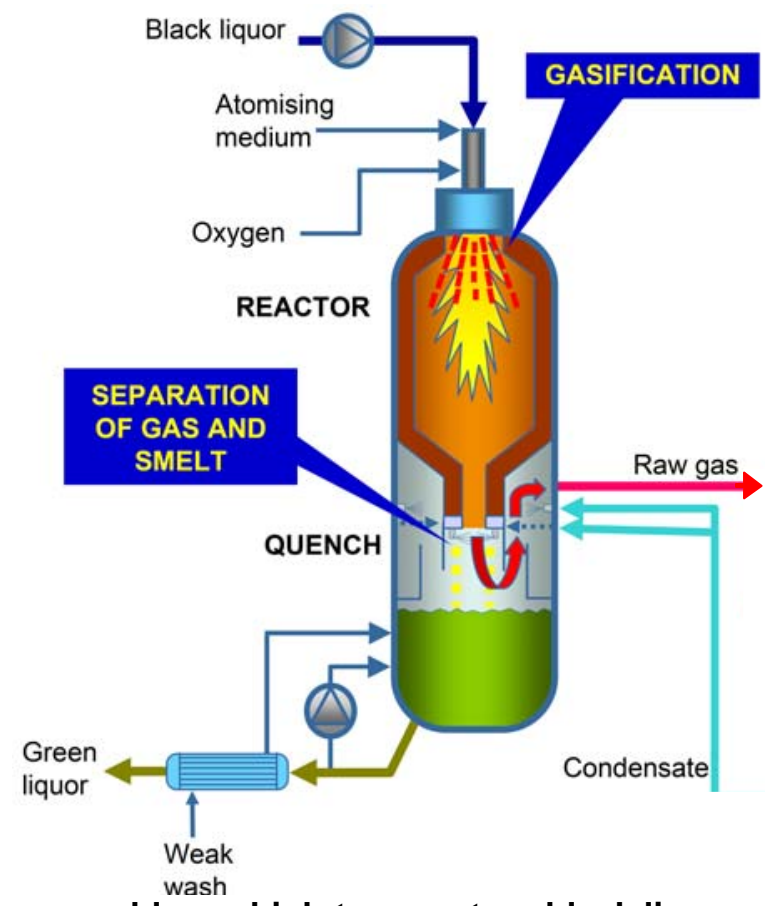

Figure 7. Pressurized, oxygen-blown, high-temperature black liquor gasifier technology under development by Chemrec.

The second black liquor gasification process, being commercialized by Thermochem Recovery International (TRI), an American company, utilizes indirectly-delivered heat via a bank of pulsecombustor heat exchange tubes immersed in a fluidized bed $[55,56]$. Steam is used to fluidize the bed in which the black liquor is gasified. With a moderate temperature maintained in the reactor $\left(\sim 600^{\circ} \mathrm{C}\right)$, the condensed-phase material leaves as a dry solid. TRI carried out gasification studies of spent pulping liquor in a 0.5 tpd BLS pilot unit starting in the early 1990s. A nominal 50-ton per day pilot plant completed a 500-hour continuous test at a Weyerhaeuser kraft pulp mill in North Carolina in 1994/1995. Two commercial-scale ( 200 tpd BLS) units are installed, one at a pulp mill in Trenton, Ontario (Canada) and one at a mill in Big Island, Virginia. Both of these mills use a non-sulfur pulping process. A decision to shut down the Big Island unit was made in mid-2006. The Trenton unit continues to operate, with some 18,000 hours of operation completed to date. 
A key objective in the present biorefinery assessment is to understand the relative costs/benefits of liquid fuels production vis-à-vis electricity, so an early decision was made to focus the biorefinery analysis around a single black liquor gasifier design rather than carrying out parallel designs with two gasifiers as we did in our BLGCC work. The BLGCC work showed more favorable performance and economics for BLGCC systems designed around the hightemperature gasifier, so this gasifier design was selected for the detailed kraft pulp mill biorefinery designs we have developed in this work. This decision is supported by some lessdetailed comparative analysis we have carried out for low-temperature BLG in a kraft pulpmill biorefinery application. Volume 4 describes this analysis.

\subsubsection{Choice of Gas Turbine Technology}

From our prior study [5], we reproduce results here for the BLGCC design incorporating a hightemperature black liquor gasifier and a "mill-scale" gas turbine. Commercial gas turbines are available in only a relatively few specific sizes, unlike steam turbines which can be built to any desired size. Thus, the design of the BLGCC system is largely fixed by the specific choice of gas turbine. In our BLGCC design, we selected a gas turbine based on General Electric's 6FA model, which is in the class of the most advanced machines now widely deployed in the market ("F" technology) and which has fuel requirements very close to the amount of synthesis gas available from the black liquor gasifier at our reference mill. As discussed earlier, another of the BLGCC designs included a "utility-scale" gas turbine, which required a considerable amount of natural gas to supplement the available synthesis gas. Since we do not consider the use of natural gas in our biorefinery analysis, the "mill-scale" BLGCC is the appropriate one for comparisons to be made later in this report.

In our "mill scale" BLGCC (Figure 8), the black liquor is gasified, and the syngas product is cooled, cleaned, stripped of $\mathrm{H}_{2} \mathrm{~S}$ (using a Selexol ${ }^{\circledR}$ unit), and then burned in the gas turbine. The turbine exhaust passes through a "duct burner" to the heat recovery steam generator (HRSG), where steam is raised to drive a steam turbine. A small amount of natural gas is burned in the duct burner ${ }^{4}$ to enable production of the requisite process steam needed to run the mill. Steam is extracted at two different pressures from the steam turbine. The HRSG steam production is augmented by steam delivered from hog fuel boilers assumed to be pre-existing at the reference mill. One design constraint in the BLGCC analysis was the size of the existing hog fuel boilers, which limited the available steam delivered from these boilers. (This limitation is the reason a small quantity of natural gas is used in the duct burner.)

\subsubsection{Sulfur Cycle and Lime Cycle Issues with Kraft Black Liquor Gasification}

Unlike in a Tomlinson boiler, where essentially all of the sodium and sulfur leave in the smelt, there is a natural partitioning of sulfur (mainly as hydrogen sulfide, $\mathrm{H}_{2} \mathrm{~S}$ ) to the gas phase and sodium to the condensed phase during gasification of kraft black liquor. This split represents an important potential benefit to a pulp mill, since it can facilitate alternative pulping chemistries that can lead to increased pulp yields per unit of wood consumed [57]. Based on thermodynamic considerations, the lower the gasification temperature, the more complete will be the partitioning of sulfur and sodium. ${ }^{5}$ With the low-temperature black liquor gasification process described in

\footnotetext{
${ }^{4}$ Because of the high air-fuel ratio that characterizes gas turbine combustion, there is sufficient oxygen in the gas turbine exhaust to burn additional fuel in the duct burner.

${ }^{5}$ Higher pressure also favors greater conversion of sulfur to the gas phase.
} 
Section 3.3.2.1, over $90 \%$ of the sulfur in the black liquor will leave the gasifier as $\mathrm{H}_{2} \mathrm{~S}$ in the product gas. With the high-temperature process, slightly more than half of the sulfur goes to the gas phase.

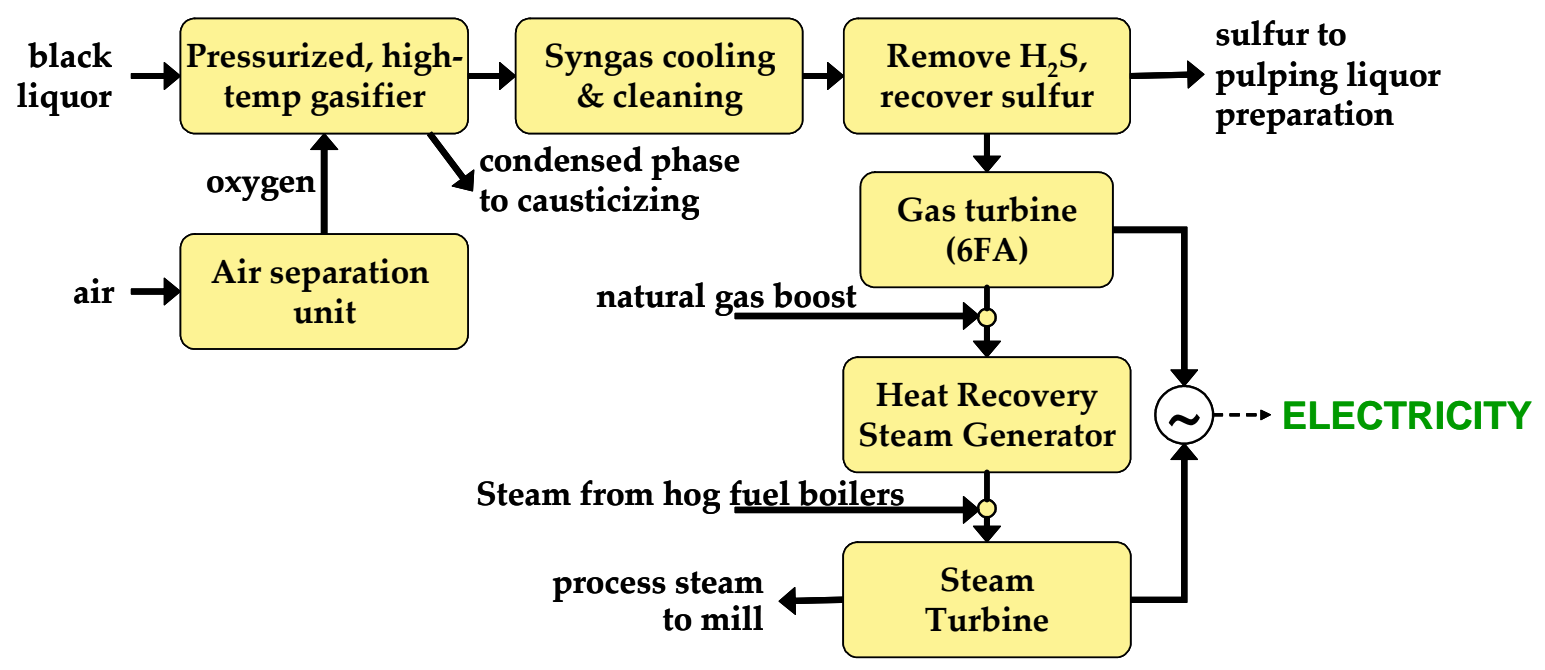

Figure 8. Simplified schematic representation of "mill-scale" BLGCC system.

To take advantage of the natural separation of sulfur and sodium, it is necessary to recover $\mathrm{H}_{2} \mathrm{~S}$ from the gas in a form suitable for preparing modified pulping liquors. Capture of acid gases like $\mathrm{H}_{2} \mathrm{~S}$ is routinely practiced in other industries (e.g., petroleum refining) using patented physical or chemical absorption processes such as Selexol ${ }^{\circledR}$ or Rectisol ${ }^{\circledR}$. It is also possible to capture $\mathrm{H}_{2} \mathrm{~S}$ using green liquor or white liquor as a scrubbing medium, though this has ot been done in any commercial application.

A negative consequence of the natural split of sulfur and sodium during gasification is a higher causticizing load, i.e., larger required lime kiln capacity and lime kiln fuel consumption per unit of black liquor solids processed compared to processing in a Tomlinson boiler. One cause of this increase is that more of the sodium $(\mathrm{Na})$ in the condensed phase forms carbonate $\left(\mathrm{Na}_{2} \mathrm{CO}_{3}\right)$ in the green liquor because less sulfur is available in the condensed phase to form sodium sulfide $\left(\mathrm{Na}_{2} \mathrm{~S}\right)$. In effect, for each unit of sulfur that goes to the gas phase, one additional unit of carbonate forms in the condensed phase. Since the carbonate must be converted to hydroxide $(\mathrm{NaOH})$ through the causticizing cycle (Figure 5), one additional unit of lime must be generated at the lime kiln.

A second source of added causticizing load will appear if green or white liquor scrubbing is used to capture $\mathrm{H}_{2} \mathrm{~S}$, since some $\mathrm{CO}_{2}$ in the gas will be co-absorbed and form $\mathrm{NaHCO}_{3}$ in the liquor, which must eventually be converted back to $\mathrm{NaOH}$. Alternatively, the problem associated with $\mathrm{CO}_{2}$ co-absorption can be eliminated entirely if $\mathrm{H}_{2} \mathrm{~S}$ is captured using a commercial process (e.g., Selexol ${ }^{\circledR}$ ) and then converted to elemental sulfur using a commercially available process (Claus/SCOT technology). This is the approach we have assumed in our BLGCC design.

\subsubsection{Detailed BLGCC Performance Simulation}

Figure 9 gives the detailed mass/energy balance for our BLGCC design. The raw syngas undergoes an integral quench in the lower section of the black liquor gasifier, leaving the reactor 
at $217^{\circ} \mathrm{C}, 35$ bar. The gas is then cooled through a medium pressure boiler and a water heater. Most of the water in the syngas condenses, thereby releasing most of the energy picked-up in the quench. The syngas passes from the water heater at about $120^{\circ} \mathrm{C}$ to a trim cooler, which it leaves at $40^{\circ} \mathrm{C}$ before entering the sulfur recovery unit (SRU).

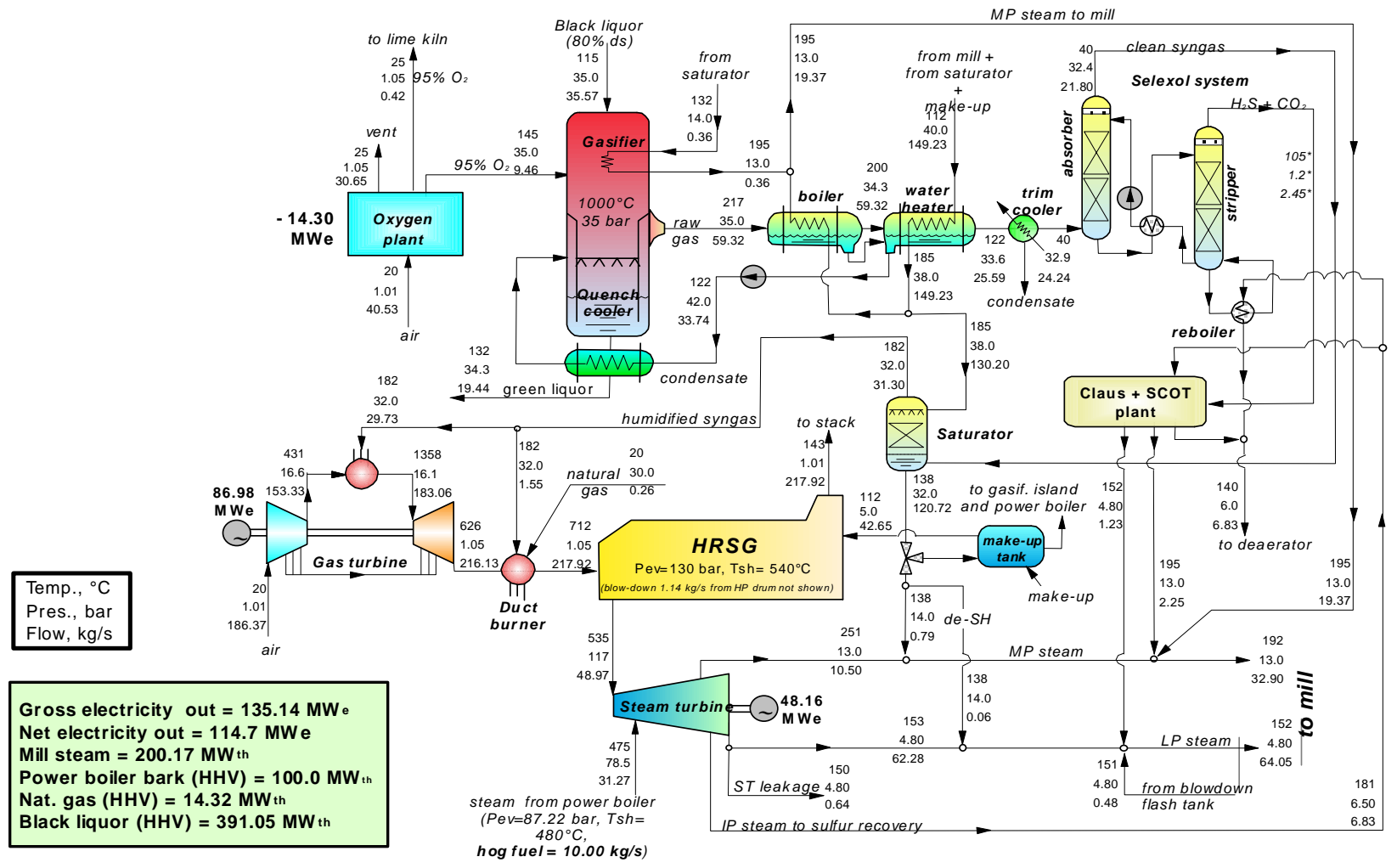

Figure 9. Energy/mass balance for BLGCC with high-temperature gasifier and mill-scale gas turbine.

All of the $\mathrm{H}_{2} \mathrm{~S}$ and some of the $\mathrm{CO}_{2}$ in the syngas are absorbed in the sulfur recovery unit (SRU) based on commercial Selexol ${ }^{\circledR}$ technology. All of the absorbed $\mathrm{H}_{2} \mathrm{~S}$ is converted into elemental sulfur via a standard, commercial Claus/SCOT system. About half of the sulfur in the black liquor is contained in the $\mathrm{H}_{2} \mathrm{~S}$. The rest is contained in the gasifier smelt, where it forms the $\mathrm{Na}_{2} \mathrm{~S}$ that provides the needed base for polysulfide formation when the recovered elemental sulfur is dissolved in it. The estimated additional lime-kiln load for this BLGCC design (relative to the Tomlinson system) is a relatively modest $16 \%$, and is accommodated by using oxygenenriched air to increase the throughput capacity of the existing kiln, with oxygen provided from the air separation unit [5].

The sulfur-free syngas leaves the SRU and travels to a saturator, wherein the gas is humidified by mixing with water pre-heated to $185^{\circ} \mathrm{C}$. By humidifying the syngas, a significant increase in power production from the gas turbine can be achieved (due to increased syngas mass flow). The humidified gas also results in a lower flame temperature in the gas turbine combustor, thereby reducing thermal $\mathrm{NO}_{\mathrm{x}}$ emissions.

The available black liquor enables slightly more syngas to be generated than is required to fuel the gas turbine. Excess syngas is burned in the duct burner. Hog fuel boilers (not shown in Figure 9) consume $54 \mathrm{MW}_{\mathrm{LHV}}$ of hog fuel and $27 \mathrm{MW}_{\mathrm{LHV}}$ of purchased wood residues, for a 
total of $81 \mathrm{MWth}$ LHV. A small amount of natural gas supplements the syngas burned in the duct burner to meet the mill's steam demand, since it was assumed that the existing hog fuel boilers would be fully loaded at $81 \mathrm{MWth}$ (LHV) input, and adding a small amount of natural gas via the duct burner was more economical than adding hog fuel boiler capacity.

This BLGCC power/recovery configuration has a gross electricity generation of $135 \mathrm{MW}_{\mathrm{e}}, 64 \%$ of which is produced by the gas turbine. The parasitic load is $20.5 \mathrm{MW}_{\mathrm{e}}$, mostly due to the cryogenic air separation unit that produces the oxygen needed for the gasifier. Since the mill requires $100 \mathrm{MW}_{\mathrm{e}}$ for the process, 14.5 $\mathrm{MW}_{\mathrm{e}}$ are available for export to the grid.

\section{Overview of Biorefinery Designs}

We developed seven biorefinery designs taking into consideration the objective of being able to make meaningful performance and cost comparisons against our prior results for a conventional Tomlinson system and a BLGCC system. Beyond these comparisons, we wished to explore the potential impacts of supplementing to a substantial degree the relatively modest quantities of woody residues that are used for energy at typical pulp mills today. To maximize the effectiveness of woody residue utilization, all but one of our process designs incorporate gasification of biomass in tandem with gasification of black liquor.

In this section we provide a schematic overview of our biorefinery designs - three variants for DME production, three variants for FTL production, and one design for mixed-alcohols production. (Design and simulation details are provided in Section 5.) The process designs all include five basic equipment "islands": (i) black liquor gasification island, (ii) biomass gasification island (or, in one case, a hog fuel boiler island), (iii) syngas heat recovery and syngas clean-up island, (iv) fuel synthesis island, and (v) power island.

The gasification island includes a cryogenic air separation unit for the production of oxygen. The black liquor and biomass gasification islands are essentially the same for all the cases considered (except for the size of the biomass gasification island). The syngas clean-up island is centered around commercial Rectisol ${ }^{\circledR}$ technology, except for the mixed alcohol case in which commercial Selexol $^{\circledR}$ technology is adopted. For the fuel synthesis island, we consider one of two basic arrangements: single-pass or recycle. In the single-pass arrangement, the syngas passes once through the synthesis reactor and any syngas unconverted to liquid product is sent for use in the power island. In the recycle arrangement, some significant fraction of the unconverted syngas is recycled to the synthesis reactor to increase liquid fuel production. For the power island, in one case a boiler back-pressure steam turbine cycle is adopted. In the other six cases, a combined gas turbine/steam turbine cycle is employed. The gas turbine is modelled in five of the six cases on the medium-scale, heavy-duty 6FA gas turbine offered by General Electric. In the sixth case, we consider a larger GE gas turbine, the 7FA.

Table 6 summarizes key design characteristics for each of the biorefineries, along with corresponding values for the Tomlinson and BLGCC designs developed in our prior work. As indicated in this table, the black liquor flow is the same in all cases, except for the Tomlinson case where more black liquor is available (at a mill with the same level of pulp/paper output) due to lower pulp yield compared to the mills where gasification is used (as discussed in Section 3.2). The woody biomass input as energy (including hog fuel and purchased residues) is also shown. The amount of biomass energy use is set by the constraint that the biorefinery provide all of the pulp/paper mill's process steam demand, subject to other constraints placed on the biorefinery 
design, as discussed later in this section. Table 6 also shows the net increase in total wood (pulpwood and purchased residues) that must be handled in the wood yard at the pulp/paper mill compared to the Tomlinson case. There is some reduction in pulpwood input to the mill (compared with Tomlinson case) with biorefining (due to higher-yield pulping process assumed), but this reduction is more than compensated for by the additional purchased residues needed so that wood handling capacity increases in all cases. For all but two of the biorefinery designs, the net increase in total wood flow that must be handled in the wood yard is $25 \%$ or less. The highest percentage increase in net wood flow is for the FTc design (69\%).

Table 6. Summary of key design parameter values for biorefinery simulations and, for comparison, BLGCC and Tomlinson cases.

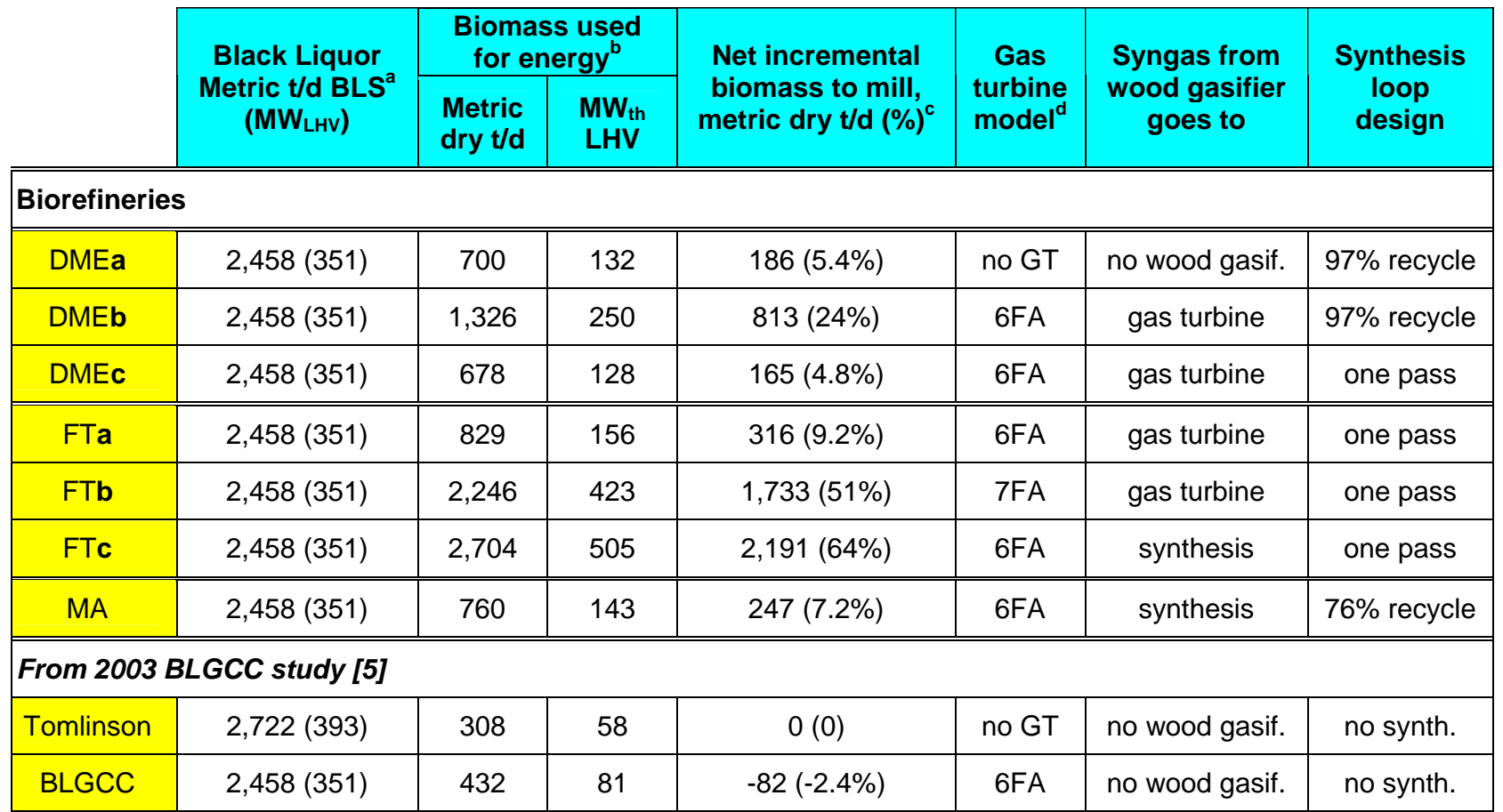

(a) For mills with black liquor gasifiers, less black liquor is generated than with the Tomlinson system (for the same level of pulp output) due to the higher-yield polysulfide pulping process used.

(b) This is biomass used directly for energy. The totals shown are the sum of hog fuel $(9 \%$ of incoming pulpwood logs is converted to hog fuel) and purchased woody residues.

(c) This is the net additional biomass that must be handled in the woodyard at the mill. It is the sum of pulpwood logs and purchased wood residues less the pulpwood-log flow in the reference (Tomlinson) case. The total incoming pulpwood logs is 3,421 metric dry t/day in the Tomlinson case and 3,197 metric dry t/d for gasification-based cases.

(d) The rated output in simple-cycle mode when operating on natural gas is 75MW for the 6FA and $170 \mathrm{MW}$ for the 7FA.

The right three columns in Table 6 show, respectively, the gas turbine selected in each case, whether syngas from a biomass gasifier (if present in the design) is used entirely as a gas turbine fuel or sent first to the liquids synthesis reactor, and whether a recycle or one-pass synthesis reactor design is used. The rationale for the parameter choices shown in Table 6 are described below for each biorefinery design.

In the design identified as DMEa (Figure 10), the black liquor gasifier, supplied with oxygen from an air separation unit, provides all of the synthesis gas to a liquid-phase DME reactor. Unconverted synthesis gas is separated from product DME and $97 \%$ of it is recycled to the synthesis reactor to increase DME production. The 3\% purge stream taken from the recycle loop prevents excessive buildup of inert gases. The purge gas is sent to the hog fuel boiler, where it 
burns with an amount of wood residues selected such that the amount of steam generated is sufficient to meet all of the mill's process steam needs. Heat recovered from the black liquor and syngas processing areas are integrated into the boiler to increase steam production and minimize the amount of woody residues needed. The steam is expanded through a back-pressure turbine to generate some electricity which goes toward meeting the mill's process electricity needs. To fully meet the mill's electricity need, some electricity must be imported from the grid. Because black liquor is being converted primarily into liquid fuel and not electricity, the amount of electricity imported is larger than with a conventional Tomlinson system.

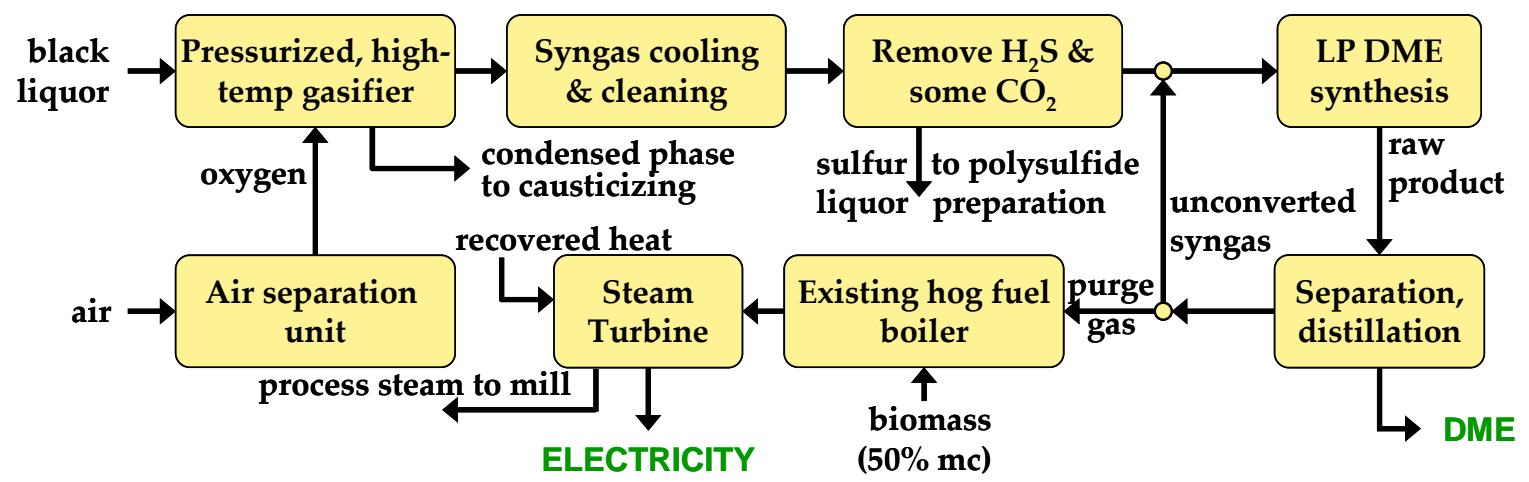

Figure 10. Schematic of biorefinery DMEa. Key features include recycling of unconverted syngas to increase DME production and use of steam Rankine power island.

One approach to increasing net electricity production is to increase the consumption of wood residues and/or increase the efficiency with which electricity is being generated. Biorefinery DMEb adopts both of these approaches. In this design (Figure 11), the black liquor and synthesis gas processing areas are unchanged from DMEa, and DME production is identical to that in DMEa. However, woody biomass is gasified and used to fuel a gas turbine-steam turbine combined cycle (GTCC). In this design, the amount of biomass consumed is again set by the amount of process steam that must be raised to meet the pulp and paper mill demand. Because the GTCC is characterized by a higher electricity to steam production ratio than the boiler/steam turbine system in DMEa, more biomass must be used in the DMEb design than in the DMEa design to deliver the same amount of process steam, but electricity production with DMEb is considerably greater than with DMEa.

Another approach to increasing electricity production compared to DMEa that involves woody biomass consumption not much greater than $\mathrm{DMEa}$, is to use a lower level of syngas recycle to the synthesis reactor, such that more unconverted gas is available for power generation. In DMEc (Figure 12), we eliminate the syngas recycle loop entirely such that the synthesis gas passes only once through the reactor, leading to much lower DME production than in DMEb but requiring relativel little purchased biomass. The design is otherwise very similar to DMEb. Larson and Ren [58] indicate that high single-pass syngas conversion rates that characterize liquid-phase reactors (of the type assumed in our design) can make such "one-pass" synthesis designs especially attractive from an overall cost perspective when co-producing electricity with fuels. DMEc tests whether this might hold true for a pulp mill biorefinery. 


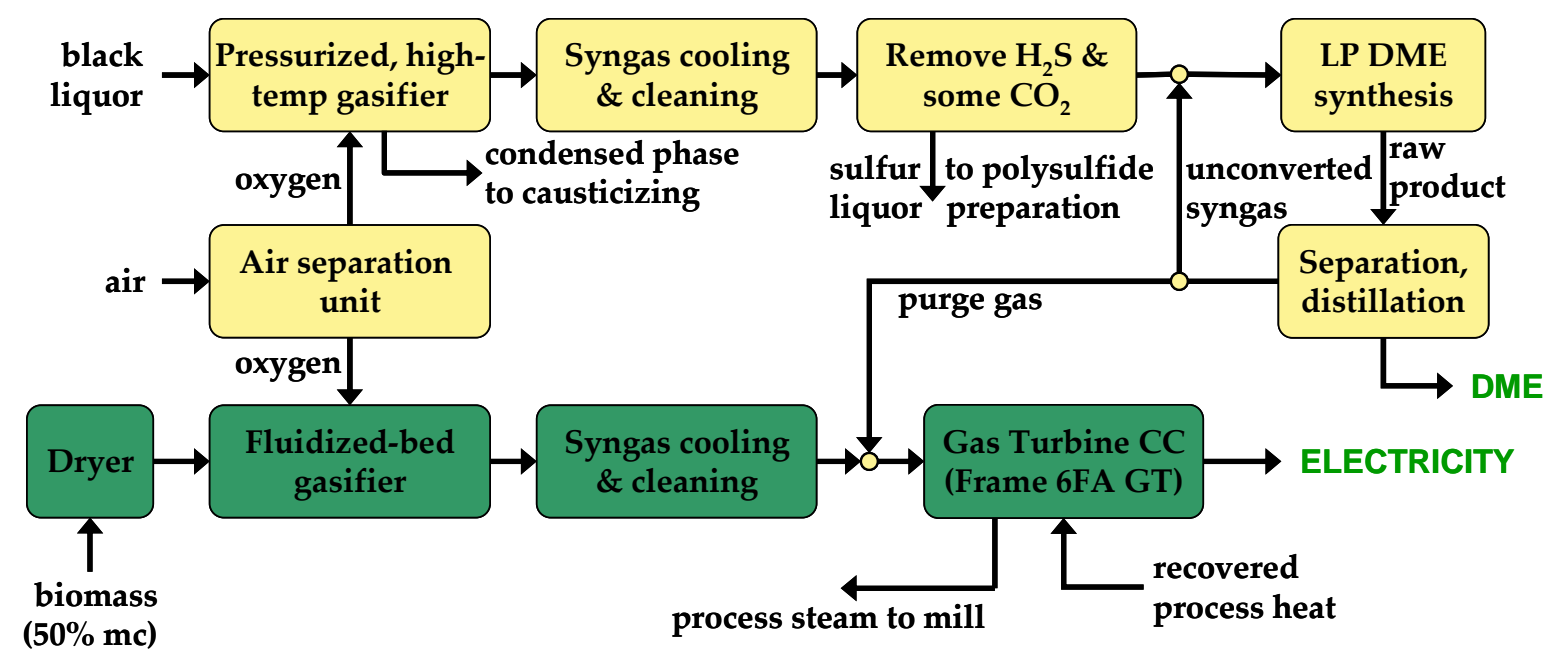

Figure 11. Schematic of biorefinery DMEb. Key differences from DMEa (Figure 10), represented by darker shading, include biomass gasifier and gas turbine combined cycle power island.

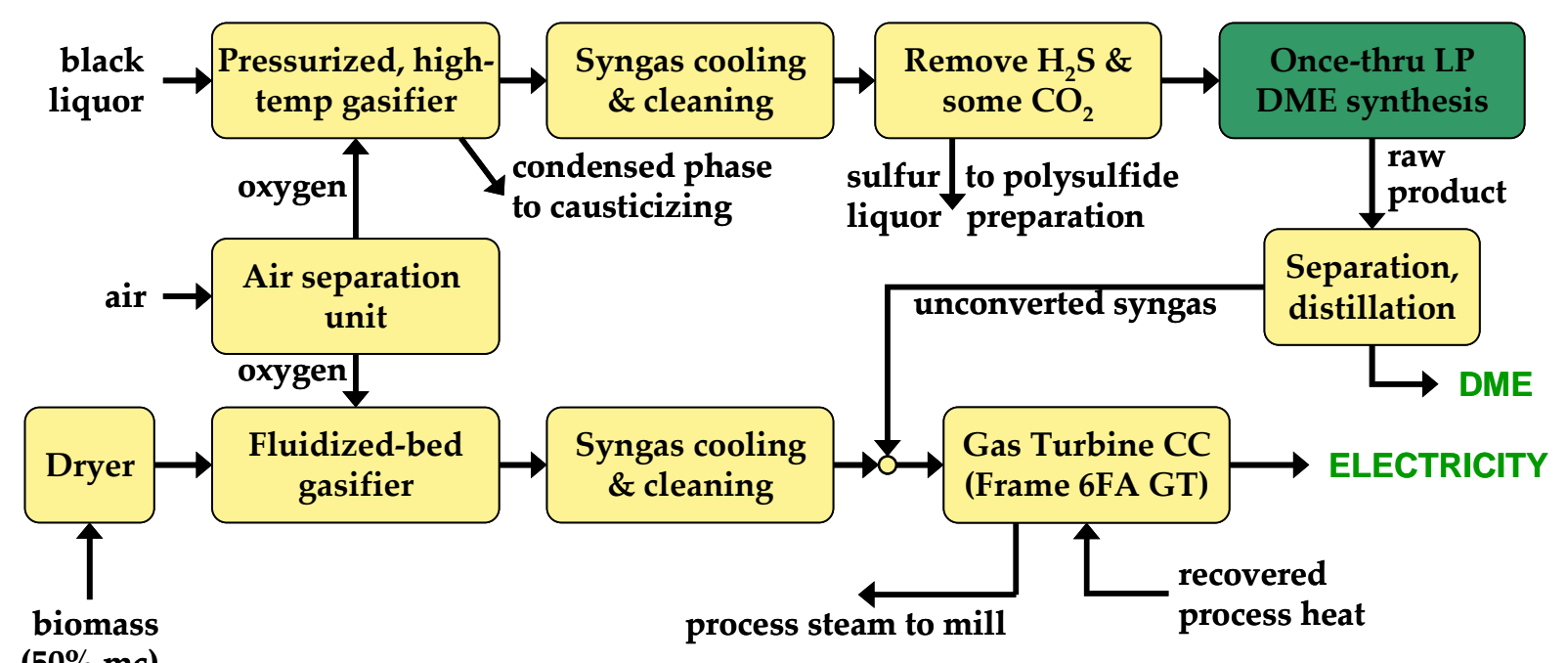

$(50 \% \mathrm{mc})$

Figure 12. Schematic of biorefinery DMEc. Key difference from DMEb (Figure 11), represented by darker shading, include synthesis reactor operating in single-pass (rather than recycle) mode.

For our FT biorefinery designs, which we developed after completing the detailed designs for our DME biorefineries, we chose to consider only single-pass synthesis due to the much higher single-pass conversion of syngas that can be achieved with FT synthesis compared to DME synthesis.

Our FTa configuration is conceptually identical to the DMEc design, allowing for a meaningful comparison between FTL and DME. In this FT design, syngas from black liquor that is not converted to FTL in a single pass through the synthesis reactor is used, together with syngas from gasified biomass, to fuel a GTCC (Figure 13). The input of woody biomass residues for the FTa design is slightly higher than for DMEc (Table 6), as required to be able to meet the pulp and paper mill's process steam needs. 
The FTb and FTc configurations involve modifications to the FTa design to examine the impact of a lower fuels-to-electricity production ratio (FTb) and a higher fuels-to-electricity production ratio (FTc). Both involve an increase over FTa in consumption of woody residues. The design for FTb (Figure 14) utilizes a larger gas turbine (Frame 7FA), which requires more woody residues to be gasified to provide gas turbine fuel.

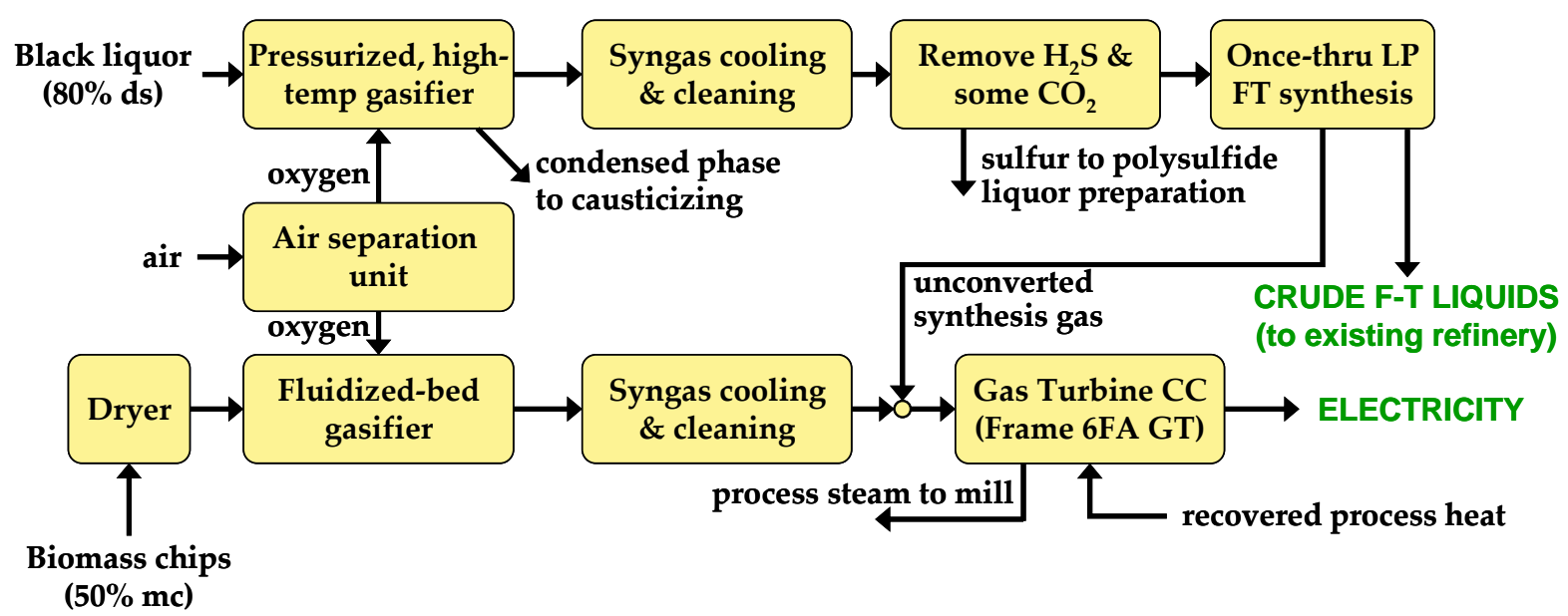

Figure 13. Schematic of biorefinery FTa. Key features of all FT designs are single-pass synthesis and gasification of woody biomass. In FTa, the gasified biomass and unconverted syngas fuel the gas turbine combined cycle power island.

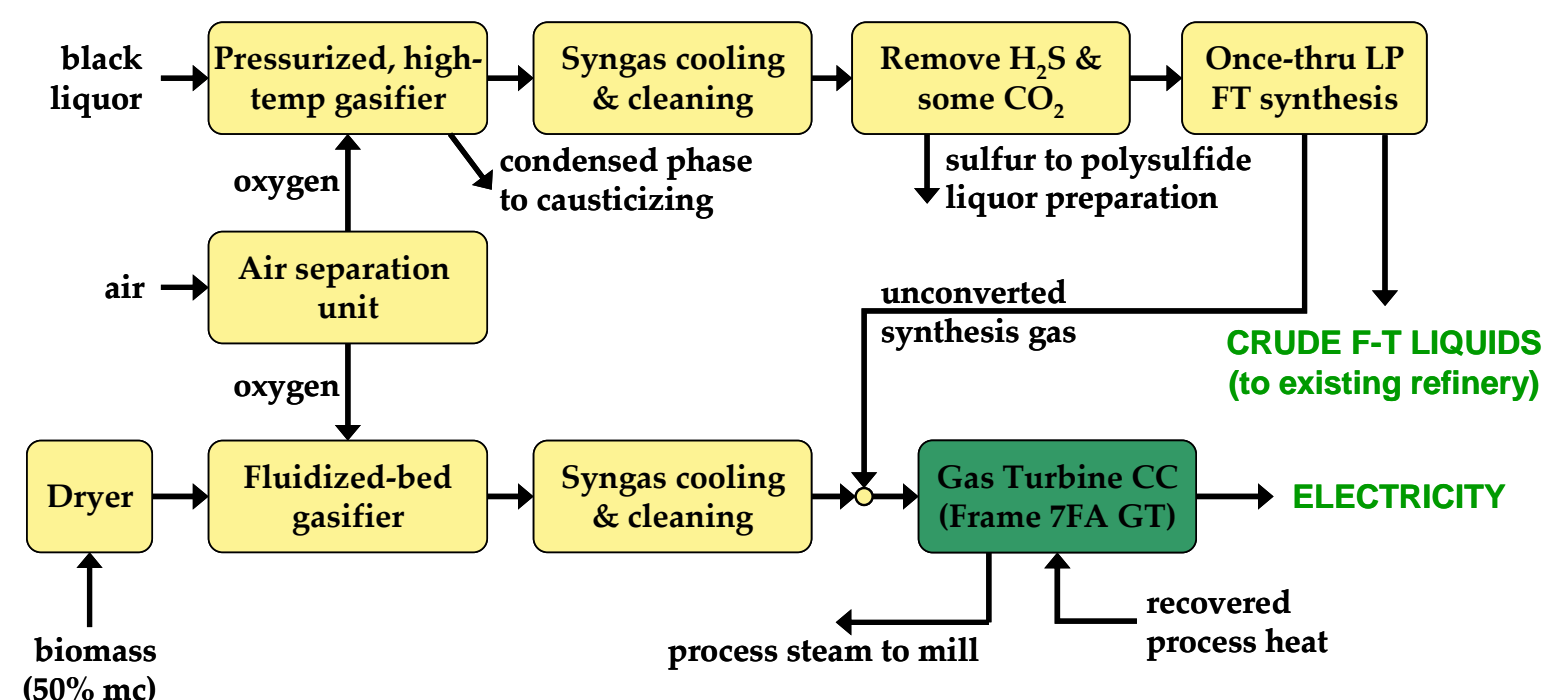

Figure 14. Schematic of biorefinery FTb. The key difference compared to FTa is highlighted by the darker shading: a larger gas turbine, requiring greater woody biomass consumption.

The design for FTc involves passing all syngas (from both black liquor and biomass gasification) through the FT synthesis reactor and using only unconverted syngas to fuel the (6FA) gas turbine (Figure 15). In this case, the amount of woody biomass gasified is set such that the amount of unconverted syngas from the FT reactor is just sufficient to meet the gas turbine's fuel needs.

For the production of mixed-alcohols (Figure 16) we adopt a design similar to FTc in that syngas from black liquor and woody residue gasification are combined for processing through the 
synthesis reactor. In the MA design, however, because the single-pass syngas conversion is much lower than for synthesis of FTL we recycle $76 \%$ of the unconverted syngas. The unrecycled portion of the syngas fuels the gas turbine combined cycle power island.

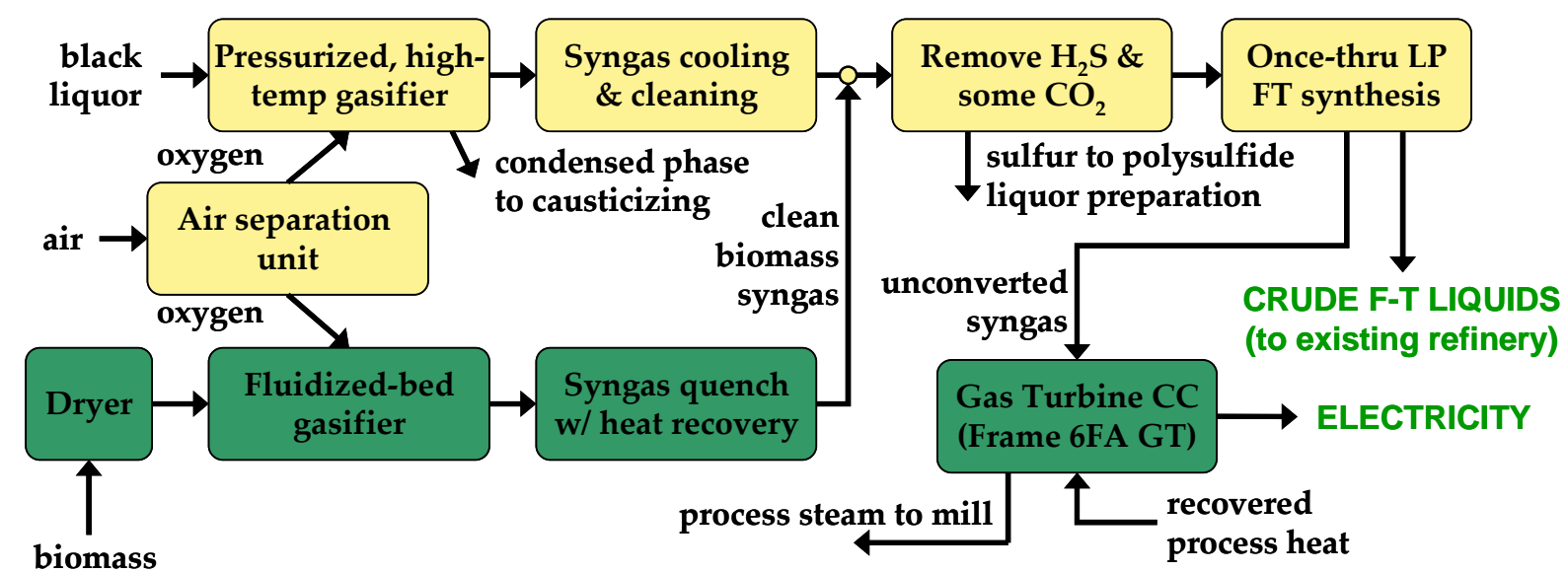

$(50 \% \mathrm{mc})$

Figure 15. Schematic of biorefinery FTc. Similar to FTa, except that gasified woody biomass supplements gasified black liquor flowing to the synthesis island.

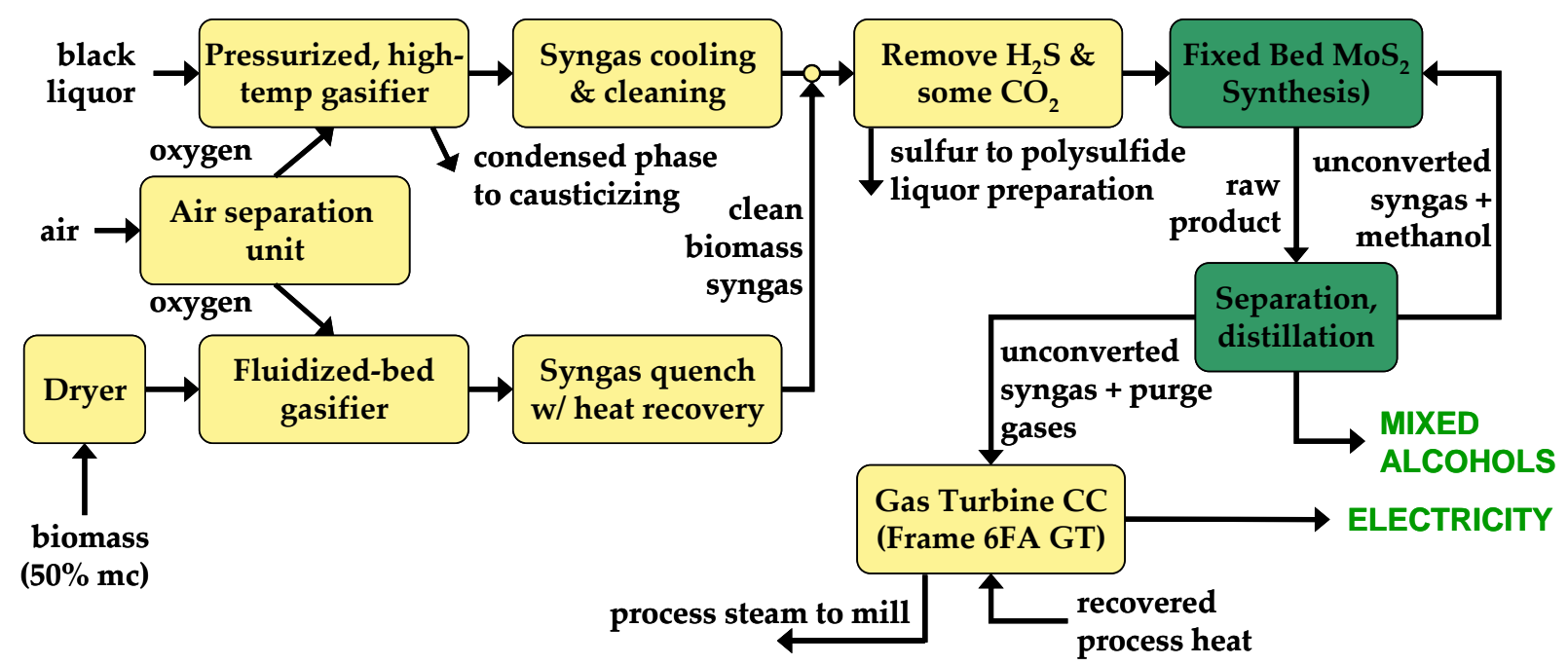

Figure 16. Schematic of biorefinery MA. The design is similar to FTc in that syngas from both the black liquor gasifier and the biomass gasifier are processed through the synthesis reactor. MA differs from FTc in that a significant fraction of the unconverted synthesis gas is recycled for further conversion, as indicated by the more darkly-shaded blocks.

\section{Biorefinery Design and Performance Simulation}

We have developed detailed designs and calculated detailed mass and energy balances for each of the biorefinery designs described in the previous section. In this section we describe our design and simulation approach, tools, assumptions, and results, as well as comparisons with other results in the literature. See Volume 2 for full details of the design and simulation work. 


\subsection{Approach and Design/Simulation Tools}

A key objective of our process design work was to develop detailed equipment configurations and operating parameter values to maximize system efficiency within practical thermodynamic and capital cost constraints, so as to optimize overall financial performance. The final, detailed equipment arrangements and operating conditions are the outcome of significant screening work, which included testing a considerable number of alternatives and doing sensitivity analyses. This does not mean that the final configurations and operating parameters presented in this report are necessarily optimal, although we believe that performance improvements achievable by a more thorough optimization would be marginal. Significant improvements of efficiencies, power output or fuel output are likely to be achieved only by significant changes in the characteristics of the basic technologies, e.g. more effective catalysts, more efficient gas turbine, different gasification technologies, etc. Finally, the process configurations described below were arrived at only after reviewing detailed mass/energy balance simulation results from initial designs with Nexant engineers and revising the initial designs accordingly to improve performance and/or reduce capital costs and parasitic power consumption.

A further objective in our work was to develop a set of biorefinery designs and performance results that would facilitate meaningful comparisons with the earlier designs we developed for a Tomlinson boiler power/recovery system and for a BLGCC power/recovery system. Toward this end, our process energy and mass balance calculations utilized the same computer code (called "GS" - see Volume 2) as in our BLGCC work. GS was originally developed at Politecnico di Milano and Princeton University beginning in the mid-1980s to predict the performance of complex electric power cycles involving both gas and steam turbines. The code has been built into a powerful and flexible tool that can accurately predict the performance of a wide variety of systems for electricity production or cogeneration, including systems where the feedstock is gasified to generate a syngas that undergoes a sequence of physical and chemical processes. In our biorefinery calculations, we applied GS to predict energy and mass balances around the types of equipment that were also found in our BLGCC designs. Most significantly, these included the black liquor gasification island, the gas turbine combined cycle power island, hog fuel boilers, and steam-rankine cycle power island. We also used GS to simulate woody biomass gasification in our biorefinery configurations, an application for which GS has previously been applied [59]. (Our BLGCC designs did not include woody biomass gasification.)

Because GS is not well designed to handle calculations involving chemical synthesis and refining, we utilized an additional software tool, Aspen Plus, to simulate the performance of these aspects of our biorefineries. Aspen Plus is a widely used commercial chemical process simulation package originally developed for petrochemical refining applications. It includes a wide range of standard equipment modules (distillation columns, flash tanks, fixed-bed reactors, slurry reactors, and many others) that can be combined by the user to simulate specific configurations of interest. It is also possible to embed in an Aspen Plus flowsheet Fortran subroutines to simulate compounds or chemical kinetics that are not already part of standard modules found in the Aspen Plus code. We used this "user-subroutine" function to embed into our process flowsheets the kinetic fuel synthesis models for DME, Fischer-Tropsch liquids, and mixed-alcohols that we developed from empirical kinetic data in the literature. We also used Aspen Plus to simulate the acid gas removal island where $\mathrm{H}_{2} \mathrm{~S}$ and $\mathrm{CO}_{2}$ are captured from syngas. 
Because we used two different pieces of software to simulate different elements of our biorefineries, it was necessary to follow a somewhat cumbersome iterative sequence of GS and Aspen runs to ensure a wholly consistent set of final results in each case (Figure 17). Volume 2 describes the details of this procedure. While it is complex, the calculation procedure we adopted has the feature that it takes advantage of the strongest elements of each computer code to produce results with accuracy similar to (or better than) the most detailed engineering studies that can be found in the literature.

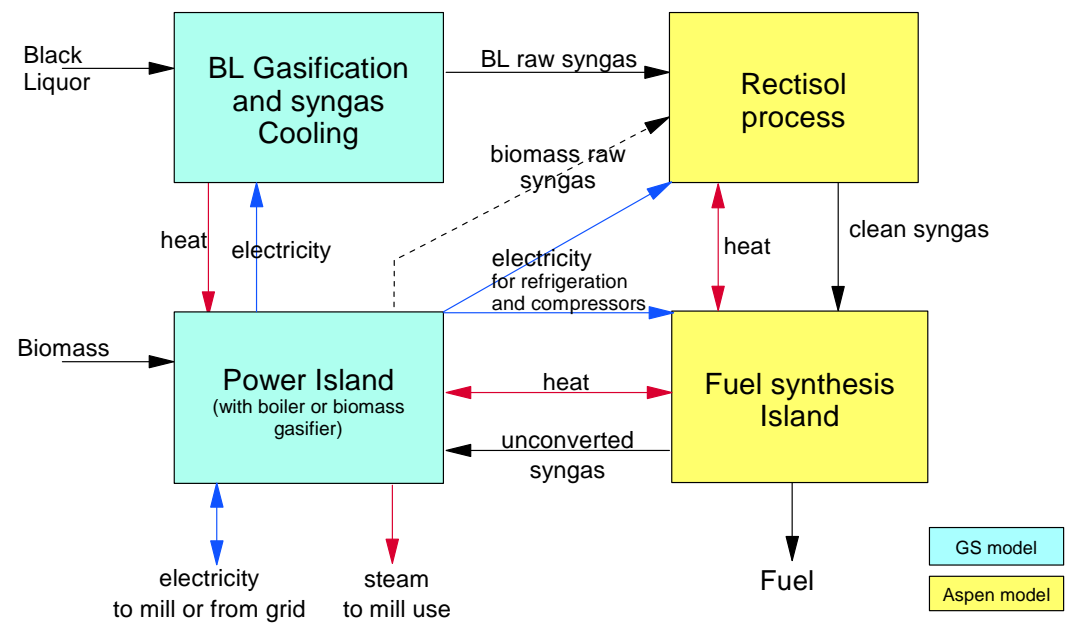

Figure 17. Interactions between GS and Aspen Plus during process simulations. The black liquor gasification island is calculated first with GS. Aspen is then run twice to simulate the acid gas recovery (Rectisol) system and the fuel synthesis island. Finally, GS is re-run, taking into account the results generated by the Aspen runs. See Volume 2 for additional details.

\subsection{Design and Simulation of Key Subsystems}

Before describing the detailed mass/energy balance results for each of the seven biorefineries, we describe details of the simulation of the black liquor gasification island and acid gas removal islands (which are common to all of the biorefineries), the biomass gasification island and gas turbine combined cycle island (which are found in all but one of the biorefineries), and the fuel synthesis islands for DME, FTL, and MA. Additional details for these subsystems are available in Volume 2, as are details for other components not discussed extensively here.

\subsubsection{Black Liquor Gasification Island}

The black liquor gasification (BLG) island is identical in all respects in the seven biorefineries and also identical to the BLG island in our previous BLGCC study [5]. ${ }^{6}$ The gasifier is simulated as a pressurized, oxygen-blown entrained-flow reactor. The input black liquor composition is given in Table 5. The basic operating conditions for the gasifier (Table 7) have been chosen in accordance with data published in the literature and information provided by Chemrec, the leading developer of this design of gasifier. The reactor is comprised of two main sections. In the upper section black liquor ( $80 \%$ dry solids) is gasified in oxygen $\left(95 \% \mathrm{O}_{2}\right.$, $3.65 \% \mathrm{Ar}, 1.35 \% \mathrm{~N}_{2}$ ) to produce syngas (the main components of which are $\mathrm{CO}, \mathrm{H}_{2}, \mathrm{CO}_{2}$, and

\footnotetext{
${ }^{6}$ In the course of the current work, we discovered a minor calculation error in the BLG simulation (relating to heat losses from the BLG) in our BLGCC study. We corrected this error in the BLG simultions in our biorefinery calculations, but we chose not to recalculate our earlier BLGCC simulations since the error was minor.
} 
also some $\mathrm{H}_{2} \mathrm{~S}$ ) and a molten inorganic stream (smelt, containing primarily sodium and sulfur compounds). In the lower section, the raw gas and smelt droplets are cooled by injection of condensate collected in the downstream syngas cooler. The smelt dissolves in the quench liquid to form green liquor, which is sent to chemical recovery after being cooled by heating the condensate used for the quench (Figure 18).

Table 7. Assumed operating parameters for black liquor gasifier simulations

\begin{tabular}{|l|l|}
\hline Reactor pressure & 35 bar $(483 \mathrm{psig})$ \\
\hline Pre-quench reaction temperature & $1000^{\circ} \mathrm{C}\left(1832^{\circ} \mathrm{F}\right)$ \\
\hline Heat loss to environment & $0.5 \%$ of black liquor higher heating value \\
\hline Heat to cooling flows & $2.0 \%$ of black liquor higher heating value \\
\hline Carbon conversion & $99.9 \%$ \\
\hline Methane in raw syngas & $1.5 \%$ by mass on a dry gas basis \\
\hline
\end{tabular}

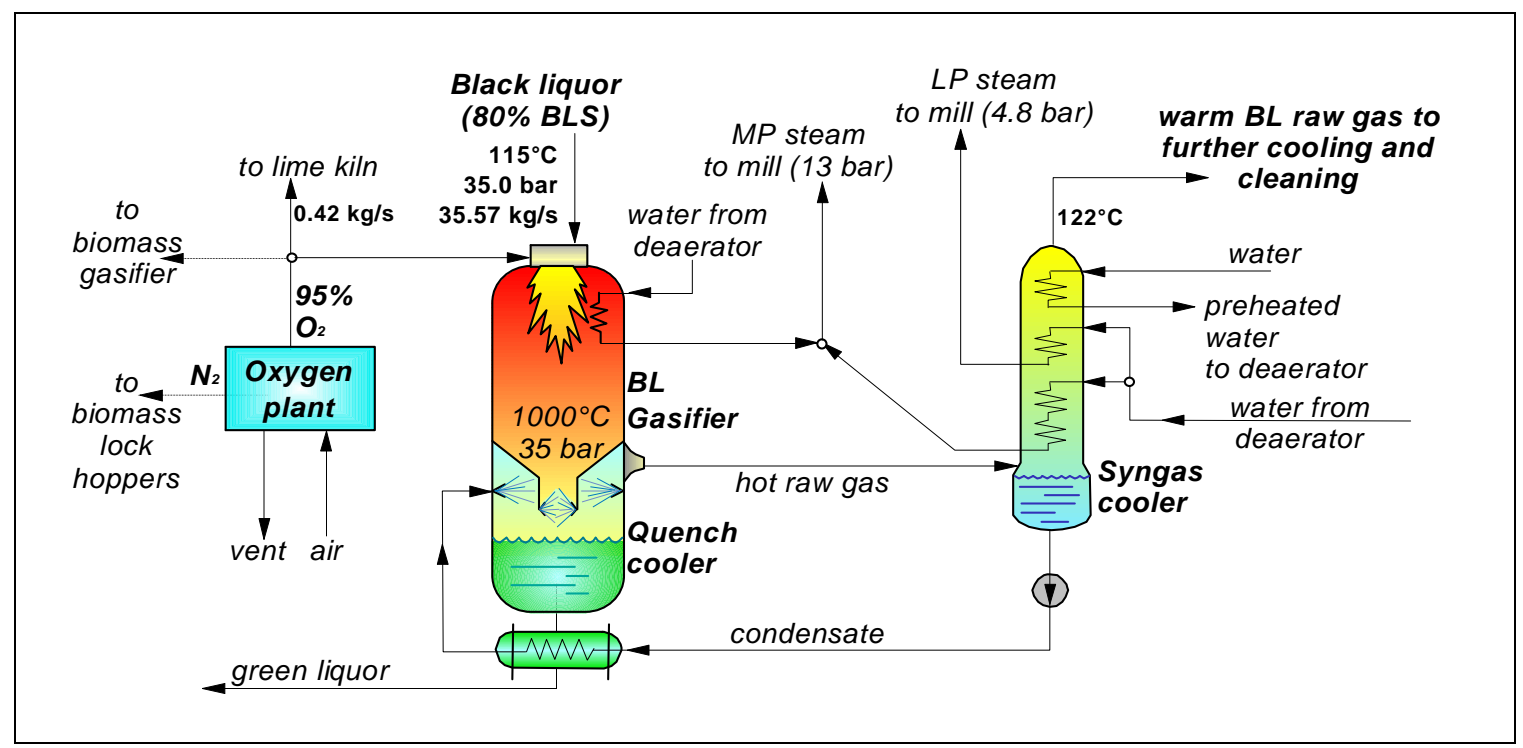

Figure 18. Equipment configuration for black liquor gasification.

The composition of the syngas leaving the gasifier (Table 8) is calculated assuming that $(i)$ the carbon conversion and methane concentration in the raw syngas are as specified in (Table 7); (ii) the small amount of unconverted carbon leaves the gasifier in the green liquor; (iii) ash and chlorides are inert; and (iv) all remaining material constitutes a mixture of gases and condensed phases at equilibrium, including the possibility for any sodium or potassium containing compound to be in either the liquid or solid state or both, depending on temperature and pressure. $^{7}$ This calculation scheme, which predicts that $57.5 \%$ of the sulfur in the black liquor goes into the gas phase, gives satisfactory agreement with specific information provided by Chemrec, as well as with qualitative indications found in the literature.

\footnotetext{
${ }^{7}$ Compounds which are considered in the equilibrium calculation are: $\mathrm{Ar}, \mathrm{CO}, \mathrm{CO}_{2}, \mathrm{COS}, \mathrm{H}_{2}, \mathrm{H}_{2} \mathrm{O}, \mathrm{H}_{2} \mathrm{~S}, \mathrm{NH}_{3}, \mathrm{~N}_{2}$, $\mathrm{Na}_{2} \mathrm{CO}_{3}, \mathrm{Na}_{2} \mathrm{SO}_{4}, \mathrm{Na}_{2} \mathrm{~S}, \mathrm{NaOH}, \mathrm{K}_{2} \mathrm{CO}_{3}$, and $\mathrm{K}_{2} \mathrm{SO}_{4}$. The molten compounds are assumed to form an ideal mixture.
} 
Table 8. Predicted raw syngas composition leaving the black liquor gasifier quench vessel.

\begin{tabular}{|c|c|}
\hline Component & Volume \% \\
\hline $\mathrm{CO}$ & 13.1 \\
\hline $\mathrm{H}_{2}$ & 13.7 \\
\hline $\mathrm{CH}_{4}$ & 0.75 \\
\hline $\mathrm{H}_{2} \mathrm{O}$ & 63.7 \\
\hline $\mathrm{CO}_{2}$ & 7.6 \\
\hline $\mathrm{H}_{2} \mathrm{~S}$ & 0.67 \\
\hline $\mathrm{COS}$ & 0.03 \\
\hline $\mathrm{N}_{2}$ & 0.14 \\
\hline $\mathrm{Ar}$ & 0.37 \\
\hline
\end{tabular}

The smelt-free raw syngas leaves the quench section of the gasifier at $217^{\circ} \mathrm{C}$ and 35 bar and is then cooled to about $120^{\circ} \mathrm{C}$ in the downstream heat exchanger. The heat released by the syngas in the warmest sections of this heat exchanger generates steam at two pressure levels, while the heat released in the cooler section is used to heat deaerator feed water. Most of the water in the syngas condenses, thereby releasing most of the energy picked up in the quench. Chemrec indicates that the flow of condensate in a counter-current heat exchanger leads to removal of trace alkali levels down to very low concentrations, which is required to protect downstream equipment.

\subsubsection{Acid Gas Removal/Sulfur Recovery System}

The $\mathrm{H}_{2} \mathrm{~S}$ carried in the syngas from black liquor gasification must be removed for two reasons: so that the sulfur can be recovered for reuse in pulping and so that catalysts found in the downstream reactors for fuels synthesis are not poisoned. Commercial technologies available for acid gas removal (AGR) include systems that absorb the gases into solvents via chemical or physical processes. Physical absorption requires high partial pressures of the acid gases to facilitate their absorption in an organic solvent. Chemical absorption does not require high partial pressures, but has the disadvantage of requiring a large amount of heat to regenerate the solvent. In our biorefinery designs, syngas is available upstream of the AGR at elevated pressure, so we have adopted physical absorption.

Two of the most widely used commercial physical AGR technologies are Rectisol ${ }^{\circledR}[60]$ and Selexol ${ }^{\circledR}$ [61]. Rectisol, which uses methanol for absorption, can remove $\mathrm{H}_{2} \mathrm{~S}$ to lower concentrations than Selexol, which uses an absorbing solvent made of dimethyl ether of polyethylene glycol. Since downstream catalysts in our biorefineries for DME and for FT synthesis require $\mathrm{H}_{2} \mathrm{~S}$ concentrations of the order of 0.1 ppmv to prevent sulfur poisoning [7], we use Rectisol $^{\circledR}$ AGR for our DME and FT biorefineries. A disadvantage of the Rectisol ${ }^{\circledR}$ system is the very low methanol temperature required for best performance, which contributes to a high parasitic refrigeration load. For synthesis of mixed alcohols, the catalyst we simulate is a molybdenum-sulfide based material that has a much higher tolerance for sulfur (at least 100 ppmv), so we have chosen a Selexol ${ }^{\circledR}$ AGR system for this biorefinery. Rectisol ${ }^{\circledR}$ would be a more expensive and unnecessary option in this case.

Rectisol ${ }^{\circledR}$ and Selexol ${ }^{\circledR}$ systems unavoidably co-absorb some $\mathrm{CO}_{2}$, but the affinity of the solvents for $\mathrm{CO}_{2}$ is not as high as for $\mathrm{H}_{2} \mathrm{~S}$. Thus, the level of $\mathrm{CO}_{2}$ absorption can be controlled to some extent while capturing most or all of the $\mathrm{H}_{2} \mathrm{~S}$. Removing $\mathrm{CO}_{2}$ from the syngas helps improve the performance of the downstream synthesis reactor (due to the resulting higher partial pressures of the main reacting species, $\mathrm{CO}$ and $\mathrm{H}_{2}$ ), but the benefits of removing $100 \%$ of the $\mathrm{CO}_{2}$ from the syngas will generally be outweighed by the greater complexity and cost for the Rectisol ${ }^{\circledR}$ design. 
Also, DME synthesis requires a certain (relatively low) level of $\mathrm{CO}_{2}$ in the syngas entering the reactor in order to maintain catalyst activity [58]. In the four DME and FT biorefinery designs utilizing once-through synthesis reactors (Table 6), about $80 \%$ of the $\mathrm{CO}_{2}$ is removed by the AGR system. The more complex AGR configuration required to remove $100 \%$ of $\mathrm{CO}_{2}$ is adopted in the two DME biorefinery designs where there is recycling of unconverted syngas back to the synthesis reactor. This is done to avoid excessive $\mathrm{CO}_{2}$ build-up in the recycle loop. In the case of the mixed-alcohols biorefinery, the Selexol AGR captures $18.4 \%$ of the $\mathrm{CO}_{2}$ along with $\mathrm{H}_{2} \mathrm{~S}$. It should be mentioned that removing such a low fraction of $\mathrm{CO}_{2}$ (leaving a relatively high concentration entering the synthesis reactor) may be detrimental to alcohol synthesis yield and increase costs. We were unable to evaluate the optimum degree of $\mathrm{CO}_{2}$ removal in the production of mixed alcohols from syngas because more kinetic data than are currently available in the literature are needed, along with more detailed cost estimates.

Once the acid gases have been captured by the AGR unit, they are delivered to a standard Claus/SCOT plant that converts the $\mathrm{H}_{2} \mathrm{~S}$ to elemental sulfur. This sulfur is then dissolved in a low-sulfidity white liquor (containing $\mathrm{Na}_{2} \mathrm{~S}$ formed in the gasifier smelt) to reconstitute the polysulfide pulping liquor. In our simulations, we have not modeled the Claus/SCOT unit in detail. Rather we have used estimates of steam and power consumption for the Claus/SCOT system as a whole and used these in the calculation of the parasitic energy demands of the biorefineries. The Claus plant generates steam at medium pressure (MP, 13 bar) and at low pressure (LP, 4.8 bar), which are exported to the MP and LP headers serving the mill. The amount of steam produced is proportional to the amount of $\mathrm{H}_{2} \mathrm{~S}$ converted to elemental sulfur. The tail gas exiting the Claus plant is further treated in the SCOT unit, which requires steam at 6.5 bar to regenerate the solvent used to absorb the residual $\mathrm{SO}_{2}$ in the tail gas.

\subsubsection{Biomass Gasification Island}

In the six biorefinery designs that include a gas turbine in the power island (Table 6), a mixture of hog fuel and purchased wood wastes are processed through the biomass gasification island, which includes a biomass dryer, a pressurized oxygen/steam-blown fluidized-bed gasifier, and gas cleanup. The resulting syngas is fed either directly to the gas turbine as fuel or it is mixed with the syngas from black liquor gasification prior to feeding to the fuel synthesis island, depending on the biorefinery design.

We have selected a pressurized, oxygen-blown circulating fluidized-bed design for biomass gasification, but there are a number of different biomass gasifier designs under commercial development $[62,63]$. For synthesis of fuels, a pressurized syngas undiluted by nitrogen is preferred for feeding to the synthesis reactor, since synthesis conversion rates generally increase with pressure and decrease with increasing fraction of inert components in the syngas (such as nitrogen). Also, reactor sizes (and capital cost) increase with content of inert components. If syngas can be produced directly from a gasifier without nitrogen dilution, the cost and complication of post-gasification removal of nitrogen can be avoided. Also, if gasification can be carried out at elevated pressure, the need for syngas compression prior to synthesis can be reduced or eliminated.

Two alternatives for producing nitrogen-free syngas are oxygen/steam-blown gasification or indirectly-heated (pyrolytic) gasification. Indirectly-heated gasifiers designed to date are not easily amenable to pressurization. Thus, pressurized oxygen/steam-blown gasification appears to be the most suitable near-term biomass gasification technology for our biorefinery designs. 
Since an air separation unit is needed onsite to provide oxygen to the black liquor gasifier, the incremental cost to also provide oxygen for biomass gasification is relatively modest.

Development and pilot-plant demonstration efforts with pressurized oxygen/steam-blown fluidized bed gasification date to the early-1980s in Sweden [64,65] and the mid-1980s in the USA [66,67]. Most such efforts were curtailed when world oil prices fell in the late 1980s. With growing interest in hydrogen as an energy carrier in the United States, there has been some recent re-assessment of pressurized oxygen-blown gasification there [68]. As well, a major Finnish technology development effort for production of FT fuels from woody biomass is focusing on pressurized oxygen-blown fluidized bed gasification, including plans for a demonstration of the technology before 2010 at a scale of 100 to 200 dry tonnes per day of biomass feed [69].

Operating experiences have shown that the moisture content of the biomass fed to a gasifier should be in the range $10-20 \%$ by weight [68]. For our analysis, we assume hog fuel and wood residues (Table 9) are available with 50\% moisture content, and we simulate drying to $20 \%$ moisture content using direct contact with the flue gases leaving the heat recovery steam generator (HRSG). The dryer exhaust temperature is set at a design value of $90^{\circ} \mathrm{C}$. Some dryer exhaust gas is recycled back to the dryer inlet, where it mixes with the HRSG exhaust gases to maintain a dryer inlet temperature no greater than $250^{\circ} \mathrm{C}$, which Brammer and Bridgwater [70] suggest as a maximum value to avoid onset of pyrolysis and to minimize risk of ignition during drying. We assume that a regenerative thermal oxidation (RTO) unit converts volatile organic compounds (VOCs) in the dryer exhaust gases before they are vented to the atmosphere. With the relatively low temperature of the gases used for drying, it may not be necessary to use a RTO system for VOC control, but we have chosen to include the RTO to be on the conservative side with our capital cost estimate. ${ }^{8}$ The parasitic electricity consumption for biomass handling and drying is assumed to be $5.6 \mathrm{kWh}$ per metric tonne of wet biomass (50\% moisture content) [59].

The dried biomass is delivered to lockhoppers pressurized using nitrogen from the air separation unit to feed to the gasifier, which operates at a pressure of 36 bar, a level that has been demonstrated, but only at pilot scales to date [71,72]. A more detailed engineering analysis (than is included in the scope of this work) is required to fully assess the relative benefits of biomass gasification at pressures higher or lower than 36 bar. We assume that the benefits of operating the gasifier at 36 bar (e.g., smaller reactor volume and reduced downstream syngas compression costs) will out-weigh the added complexity and operating costs associated with this pressure of operation.

We have simulated the performance of biomass gasification, together with an external tar cracking unit, as described in detail in Volume 2. Oxygen from the air separation unit and steam (produced in most cases from heat released in the fuel synthesis reactor) are injected as gasifier reactants and for fluidization. The mass flow of steam is $28 \%$ of the dry biomass feed rate, based on $[71,73]$, and the oxygen feed rate is set to achieve a specified temperature $\left(950^{\circ} \mathrm{C}\right)$ at the exit of the gasifier/cracker system. A cyclone separator at the exit of the gasifier captures unconverted char and ash and recycles these to the bed. With the recycling, we assume $100 \%$ carbon conversion to syngas. Exiting the cyclone, the raw syngas passes to a catalytic tar cracker designed to decompose large tar molecules into light gases. Use of dolomite as an insitu gasifier

\footnotetext{
${ }^{8}$ We have neglected the RTO fuel consumption in our calculations. Including it would not change our results significantly.
} 
bed material for partial tar cracking in a pressurized (air-blown) fluidized-bed gasifier has been demonstrated [74], but additional cracking is likely to be needed for synthesis applications. Nickel-based catalysts are promising for tar cracking in a separate vessel [75], as we have simulated here.

Table 9. Composition and heating value of hog fuel and wood waste.

\begin{tabular}{|c|c|}
\hline \multicolumn{2}{|c|}{ Bone Dry Hog Fuel and Wood Residues } \\
\hline C (mass\%) & 49.98 \\
\hline $\mathrm{H}(\mathrm{mass} \%)$ & 6.12 \\
\hline $\mathrm{O}(\mathrm{mass} \%)$ & 42.49 \\
\hline $\mathrm{N}(\mathrm{mass} \%)$ & 0.55 \\
\hline $\mathrm{S}(\mathrm{mass} \%)$ & 0.06 \\
\hline Ash (mass\%) & 0.80 \\
\hline LHV & $18.7 \mathrm{MJ} / \mathrm{kg}$ \\
\hline $\mathrm{HHV}$ & $20.0 \mathrm{MJ} / \mathrm{kg}$ \\
\hline \multicolumn{2}{|c|}{ As-Received Hog Fuel and Wood Residues } \\
\hline Moisture (wt\%) & $50 \%$ \\
\hline HHV & $10.0 \mathrm{MJ} / \mathrm{kg}$ \\
\hline LHV & $8.12 \mathrm{MJ} / \mathrm{kg}$ \\
\hline \multicolumn{2}{|c|}{ Hog Fuel and Wood Residues After Dryer } \\
\hline Moisture & $20 \%$ \\
\hline $\mathrm{HHV}$ & $16.0 \mathrm{MJ} / \mathrm{kg}$ \\
\hline LHV & $14.5 \mathrm{MJ} / \mathrm{kg}$ \\
\hline
\end{tabular}

For calculation purposes, we consider the gasifier and tar cracker reactions together. We assume that the syngas leaves the cracker at $950^{\circ} \mathrm{C}$, with all species at chemical equilibrium except for methane and tar, which we model as phenol $\left(\mathrm{C}_{6} \mathrm{H}_{6} \mathrm{O}\right)$. We specify the concentration of these latter two compounds at the cracker exit (Table 10), as discussed in Volume 2. Because of the presence of a cracking catalyst and the relatively high reaction temperature, assuming that all species but methane and tar are at chemical equilibrium at the cracker outlet appears reasonable. Experimental data [75] show that equilibrium is nearly reached even at the more moderate conditions of 5 bar and $900^{\circ} \mathrm{C}$.

Following the tar cracker, the further processing of the biomass syngas follows one of two pathways. In five of the biorefinery designs, this syngas is used exclusively as fuel for the gas turbine combined cycle (Table 6). In these cases, the syngas temperature is maintained at $375^{\circ} \mathrm{C}$ or higher through the entire flow path from the exit of the tar cracker to the inlet of the gas turbine combustor to ensure that any residual tar in the gas does not condense. Because the syngas temperature is maintained above the condensation temperature of any tars, it may not be strictly necessary to employ a tar cracker, but given the operating problems (fouled heat transfer surfaces, clogged pipes and valves, etc.) that can be caused by inadvertent tar formation, including the cracker is prudent. 
Table 10. Key simulation assumptions for biomass gasifier/tar cracker unit.

\begin{tabular}{|c|c|}
\hline Pressure & 36 bar (507 psig) \\
\hline Steam into gasifier (mass) & $28 \%$ of dry biomass flow \\
\hline Steam pressure & 38 bar (536 psig) \\
\hline Cracker exit temperature & $950^{\circ} \mathrm{C}\left(1742^{\circ} \mathrm{F}\right)$ \\
\hline Carbon conversion to gas & $100 \%$ \\
\hline Heat loss & $1 / 2 \%$ of biomass higher heating value \\
\hline \multirow{2}{*}{ Volume fraction at cracker outlet } & $\mathrm{CH}_{4}$ \\
\hline & 100ppmv \\
\hline
\end{tabular}

The syngas flow path between the cracker and the gas turbine combustor includes a gas cooler, a filter for removal of particulates and attached alkali compounds, and a free expander (Figure 19). The syngas is first cooled to $420^{\circ} \mathrm{C}$ or higher (depending on the design) in a fire-tube boiler (with the gas flowing vertically inside tubes), with the resulting saturated steam integrated into the HRSG. As the syngas cools, any alkali vapors in the gas condense (starting around $650^{\circ} \mathrm{C}$ ) onto the particulates carried with the gas. The particulates are captured in a ceramic or sintered-metal candle filter at a temperature of $400-500^{\circ} \mathrm{C}$, thereby preventing both alkali compounds and particulates from reaching the gas turbine. For gas turbine applications, syngas particulate and alkali concentrations must reach very low levels to avoid corrosion or erosion of turbine blades [76]. High-temperature candle filters operating at elevated pressures have not been commercially demonstrated in a biomass gasification application, but pilot-scale tests (with biomass and with coal) have been encouraging [74,77]. ${ }^{9}$ Finally, the syngas together with a fraction of the unconverted syngas from the fuel synthesis area feeds the gas turbine. Since the pressure of the biomass syngas at the candle filter exit is above that required at the gas turbine combustor inlet, an intermediate syngas expander is used to reduce the pressure and generate useful power.

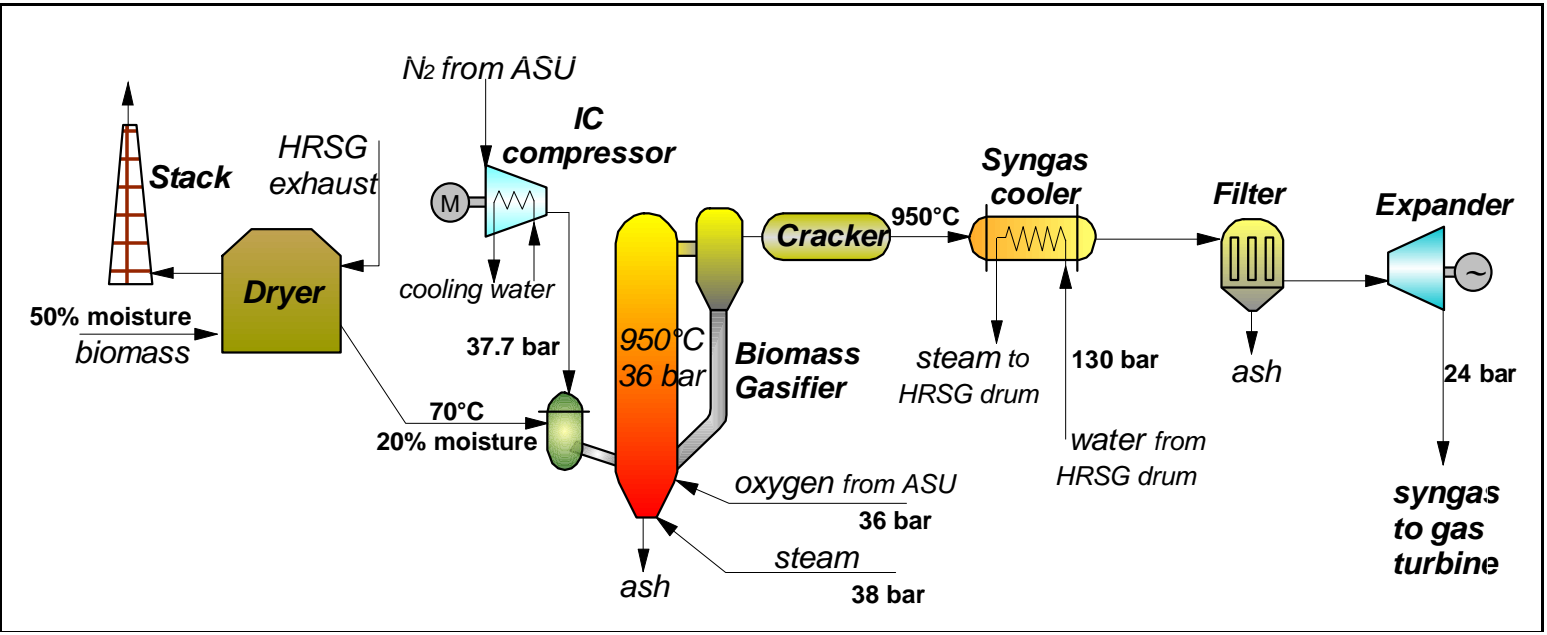

Figure 19. Biomass gasification island for biorefinery designs utilizing the biomass-derived syngas as gas turbine fuel.

In the two biorefinery designs where the biomass syngas mixes with the black liquor syngas and the mixture goes to the synthesis reactor, a different gas cleaning system from the one just described is adopted due to the more stringent gas quality requirements for synthesis [7]. In these designs, the hot syngas leaving the tar cracker is quenched by direct contact with a water

\footnotetext{
${ }^{9}$ If hot gas filtration of alkali ultimately proves commercially unviable, one might presumably adopt an alternative process configuration along the lines of that in Figure 20.
} 
spray (Figure 20), resulting in cooling of the syngas and removal of impurities. The syngas leaves the quench saturated with water at about $200^{\circ} \mathrm{C}$ and passes through a boiler and a water heater where heat released by water vapour condensation is recovered. The flow of condensate at about $120^{\circ} \mathrm{C}$ exiting these heat exchangers is recycled back and used as quench water. The cool, clean syngas is then mixed with the black liquor syngas before further cleaning in the sulfur removal step.

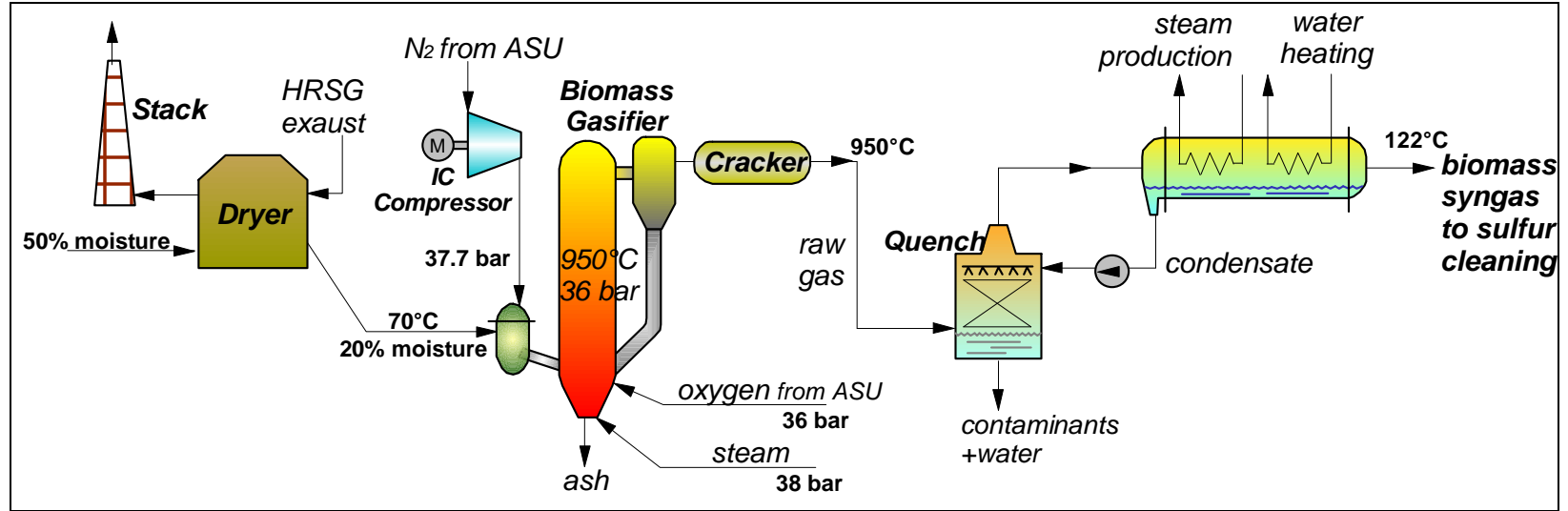

Figure 20. Biomass gasification island for biorefinery designs utilizing the biomass-derived syngas for liquid fuels synthesis.

\subsubsection{Gas Turbine Combined Cycle Island}

In six of our seven biorefinery designs, the gas turbine combined cycle uses syngas and recovered biorefinery process heat to generate electricity to meet the parasitic electricity load of the biorefinery and some or all of the electricity demand of the pulp/paper mill. In these cases the power island includes a gas turbine generator, a heat recovery steam generator (HRSG) operating primarily off the gas turbine exhaust heat, and a steam turbine generator (Figure 21). In several cases (DMEb, DMEc, FTa, and MA), a duct burner is placed between the gas turbine and the HRSG to allow burning of a small amount of syngas to supplement the gas turbine exhaust heat.

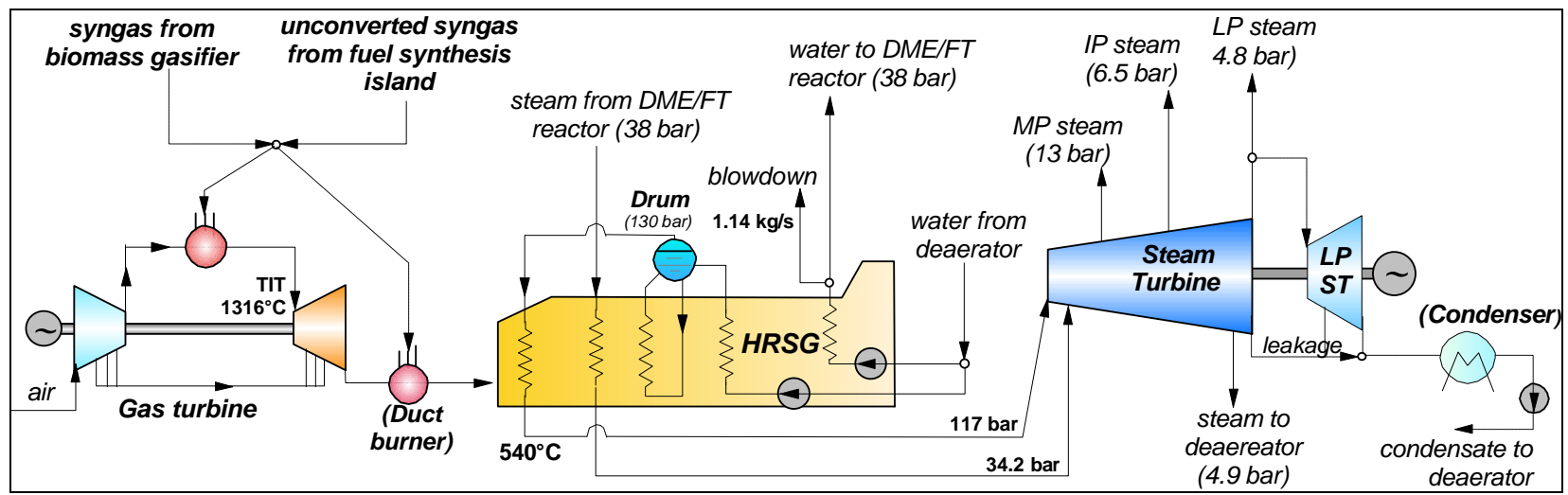

Figure 21. General layout for the gas turbine combined cycle power island.

For the gas turbine, we simulate the same machines (General Electric 6FA in five designs, and 7FA in one design) as in our prior BLGCC study (see Section 3.3.2.2). As in that study, the simulated performance is based on operating parameters and performance reported by General Electric for natural gas firing. After calibrating our performance against General Electric's published performance figures with natural gas as fuel, we adjusted our model to account for 
syngas as the fuel rather than natural gas. A key adjustment arises from the lower unit energy content of syngas compared to natural gas, which requires a larger mass flow of syngas to achieve the same turbine inlet temperature. This leads to higher mass flow through the expansion section of the gas turbine, which affects the match between compressor and expander operating conditions. Volume 2 describes details of the gas turbine model calibration and adjustments. While commercial applications of the 6FA and 7FA today are with natural gas or distillate fuel, a great deal of development work has been done and operating experience acquired in using these machines with synthesis gas in coal-integrated gasification combined cycle applications. General Electric now offers eight different gas turbine models for firing with syngas, ranging in outputs from $10 \mathrm{MW}$ to $300 \mathrm{MW}$ and including the 6FA and 7FA [78].

The gas turbine exhausts to a heat recovery steam generator (HRSG). The HRSG evaporation pressure and superheater exit temperature $\left(130 \mathrm{bar} / 540^{\circ} \mathrm{C}\right.$ with $6 \mathrm{FA}$ and $130 \mathrm{bar} / 565^{\circ} \mathrm{C}$ with 7FA) represent state-of-the-art levels for combined cycles. Because only clean combustion products pass over the boiler tubes in the HRSG, these conditions are higher than can be used with a recovery boiler or a wood-residue boiler. Steam generation in the HRSG is integrated with steam raised elsewhere in the biorefinery (syngas coolers and synthesis reactor) to maximize overall efficiency. In the mixed-alcohol case, the synthesis reactor operates at $350^{\circ} \mathrm{C}$, enabling the heat released by the synthesis reactions to be used to raise steam at $130 \mathrm{bar}$. In the DME and FT reactors, which operate at $260^{\circ} \mathrm{C}$, steam is raised at 38 bar. In all cases, the steam from the synthesis reactors is superheated in the HRSG. Medium-to-low temperature heat extracted from syngas at various points in the biorefinery are used to pre-heat the HRSG makeup water when possible. ${ }^{10}$ This is worthwhile in most cases because of the relatively high temperature of flue gas exiting the HRSG (necessitated by the inlet-gas temperature required at the biomass dryer).

Leaving the HRSG, the steam expands in a turbine from which process steam is extracted at 13 bar and at 4.8 bar for supply to the pulp/paper mill. (Because of the relatively large steam extraction at 13 bar, only a single HRSG evaporation pressure level is used; additional pressures would give negligible benefits.) The steam turbine is a back-pressure design in some cases and includes a condensing section in other cases. Because of the steam conditions leaving the HRSG, the previously-existing steam turbine at the power/recovery plant of the reference pulp/paper mill must be replaced by a new machine capable of handling the higher conditions. We have not considered any steam reheating because given the relatively small scale of plants considered in our biorefineries and the large amount of steam extracted at 13 bar, the economic attractiveness of reheating would be questionable.

In the one biorefinery configuration not utilizing a gas turbine in the power island (DMEa), we are able to adapt the back-pressure steam turbine previously existing at the reference pulp/paper mill for use in the power island, thereby avoiding the capital investment for a new steam turbine.

\footnotetext{
${ }^{10}$ For each biorefinery, the integration of heat exchange among components is optimized, within practical limits, to increase overall efficiency. Heat is transferred across relatively small temperature differences with a minimum temperature difference of $10^{\circ} \mathrm{C}$ for gas-liquid heat exchange and around $15^{\circ} \mathrm{C}$ for gas-gas heat exchange. There is considerable process heat recovery, but there is also low-temperature heat rejection to the environment in all cases.
} 


\subsubsection{Liquid Fuels Synthesis Island}

The conversion of clean synthesis gas into a liquid fuel involves passing the syngas over a catalyst that promotes the desired synthesis reactions and then refining the raw product to obtain the final desired liquid fuel.

Two basic designs for commercial synthesis reactors have been developed: gas-phase (or fixedbed) and liquid-phase (or slurry-bed). Fixed-bed reactors have a long commercial history, but liquid phase reactors have been gaining popularity in commercial applications because of attractive performance attributes and lower cost. Liquid phase reactors are now commercially offered for FTL, methanol, and DME synthesis. Liquid phase reactors for mixed-alcohol synthesis are still under development.

Fixed-bed and liquid-phase reactor designs differ primarily in their handling of reactor temperature control. Synthesis reactions are exothermic, such that the reactor temperature increases as the reactions proceed if no heat is removed. Higher temperatures promote faster reactions, but maximum (equilibrium) conversion is favored by lower temperatures. Also, catalysts are deactivated when overheated. Thus, the temperature rise in a synthesis reactor must be controlled. In commercial practice, a reactor operating temperature of $250-280^{\circ} \mathrm{C}$ for methanol, DME or FTL synthesis balances kinetic, equilibrium, and catalyst activity considerations. For mixed-alcohols synthesis, which is not yet a commercially established technology, higher reaction temperatures $\left(300-400^{\circ} \mathrm{C}\right)$ have been indicated with catalysts identified to date.

A gas-phase reactor incorporates the flow of syngas over a fixed-bed of catalyst pellets. With this design it is difficult to maintain isothermal conditions by direct heat exchange (due to low gas-phase heat transfer coefficients). To limit temperature rise, the synthesis reactions are typically staged, with cooling between reactor stages. Also, by limiting the initial concentration of $\mathrm{CO}$ entering the reactor (to 10-15 vol\%) the extent of the exothermic reactions can be controlled. Control of the $\mathrm{CO}$ fraction is achieved in practice by maintaining a sufficiently high recycle of unconverted $\mathrm{H}_{2}$-rich syngas back to the reactor.

In a liquid-phase reactor syngas is bubbled through an inert mineral oil containing powdered catalyst in suspension (Figure 22). Much higher heat release rates (i.e., extents of reaction) can be accommodated without excessive temperature rise as compared to a gas-phase reactor because of more effective reactor cooling by boiler tubes immersed in the fluid. The vigorous mixing, intimate gas-catalyst contact, and uniform temperature distribution enable a high conversion of feed gas to liquids in a relatively small reactor volume. Conversion by liquid-phase FT synthesis is especially high. A single-pass fractional conversion of $\mathrm{CO}$ of about $80 \%$ can be achieved [79], compared to less than $40 \%$ for conversion with traditional fixed-bed FT reactors. For the FT reactor conditions we assume in our simulations, the single-pass $\mathrm{CO}$ conversion is about $65 \%$.

\subsubsection{Dimethyl Ether}

Single-step DME synthesis reactors typically utilize a mix of two catalysts, one promoting the synthesis of methanol from syngas $\left(\mathrm{CO}+2 \mathrm{H}_{2} \rightarrow \mathrm{CH}_{3} \mathrm{OH}\right)$ and one promoting the dehydration of the methanol to DME $\left(2 \mathrm{CH}_{3} \mathrm{OH} \rightarrow \mathrm{CH}_{3} \mathrm{OCH}_{3}+\mathrm{H}_{2} \mathrm{O}\right)$. Both liquid-phase and fixed-bed reactors are offered commercially. 


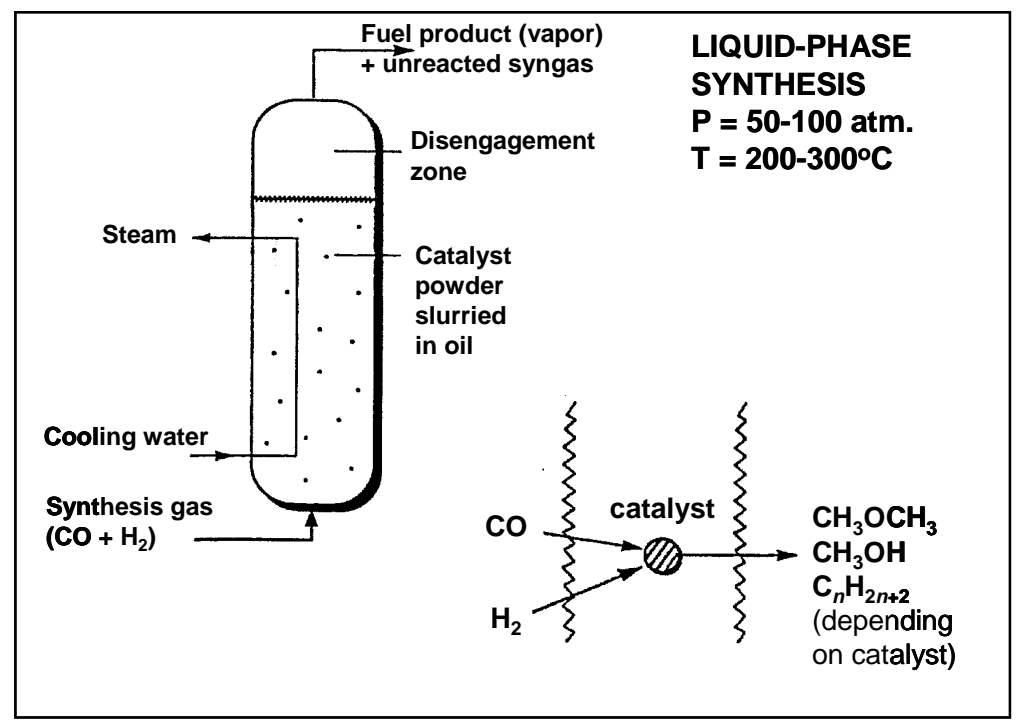

Figure 22. Simplified schematic of liquid phase synthesis reactor.

Leading developers of liquid-phase DME synthesis reactors are DME Development, Inc., a Japanese consortium of nine companies led by NKK and Nippon Sanso [32,80,81], and Air Products and Chemicals [82,83,84,85,86,87]. The Institute of Coal Chemistry of the Chinese Academy of Sciences [88] has also been developing slurry-phase DME synthesis technology. DME Development, Inc. recently completed nearly two years of testing of a 100 tpd DME slurry-phase reactor in Kushiro, Hokkaido (Japan), and is offering the technology for commercial applications [32]. The Kushiro demonstration was preceded by testing of a five ton per day capacity reactor completed in 1999 by NKK [89], who prior to that (with support from the Japanese Ministry of International Trade and Industry) worked with the Taiheiyo Coal Mining Co., Sumitomo Metal Industries, and Japan's Center for Coal Utilization to develop the DME slurry reactor technology with coal applications in mind.

The DME reactor design of Air Products is derived from its liquid-phase methanol (LPMEOH) synthesis process developed in the 1980s. A commercial-scale LPMEOH demonstration plant (250 tonnes per day methanol capacity) has been operating since 1997 with gas produced by the Eastman Chemical Company's coal gasification facility in Kingsport, Tennessee [90]. The construction of this facility was preceded by extensive testing in a 10 tpd process development unit (PDU) in LaPorte, Texas. The PDU was operated in 1999 to generate test data on direct DME synthesis [91,92].

Fixed-bed DME synthesis reactor designs are also commercially available. The leading supplier of this design is Halder-Topsoe. ${ }^{11}$ Mobil and Snamprogetti S.p.A. hold patents for DME synthesis processes [94,95], but at present are not pursuing commercial development of the technology. The Institute of Chemical Physics of the Chinese Academy of Sciences (Dalian) has done some work on fixed-bed DME synthesis technology [96].

\footnotetext{
${ }^{11}$ The fixed-bed design of Halder-Topsoe includes three stages of synthesis reactors with cooling between each stage and recycle of unconverted syngas [25]. The patent for this process specifies a feed gas CO concentration of less than $10 \%$ and a recycle volume of unconverted syngas ranging from $93 \%$ to $98 \%$ of the total unconverted syngas [93]. The fraction of CO converted on a single pass through each reactor stage (assuming a three-stage intercooled set of reactors) ranges from $16 \%$ to $34 \%$, depending on the $\mathrm{H}_{2} / \mathrm{CO}$ ratio.
} 
For our DME simulations, we adopt a liquid-phase synthesis reactor design, and we utilize a kinetic model developed in prior work [73] using kinetic rate data available in the published literature for the key reactions involved in DME synthesis. Volume 2 discusses our model.

In all three of our DME configurations, only syngas from black liquor is used for synthesis of liquids (Table 6). Leaving the Rectisol ${ }^{\circledR}$ area, the clean syngas is compressed to 68 bar and then pre-heated to $100^{\circ} \mathrm{C}$ before it arrives to the synthesis island. Just ahead of the synthesis reactor, the syngas (now at 66 bar) is heated to $240^{\circ} \mathrm{C}$ using the product stream from the synthesis reactor. The gas then enters the liquid-phase DME reactor in which isothermal synthesis conditions are maintained at $260^{\circ} \mathrm{C}$ by immersed steam generation tubes. In a single pass of syngas only a portion of the $\mathrm{CO}$ and $\mathrm{H}_{2}$ are converted to DME. The product gas mixture passes to the product separation area, where a series of flash tanks separates most of the unconverted synthesis gas from DME, methanol and water. Further separation of the liquid products is achieved by cryogenic distillation. The distillation area includes three columns: the first separates $\mathrm{DME} / \mathrm{methanol} /$ water and $\mathrm{CO}_{2}$ from residual light gases $\left(\mathrm{CO}, \mathrm{H}_{2}\right.$, etc. $)$; the second separates DME from methanol/water; and the third separates water from methanol. The small amount of methanol is heated to $250^{\circ} \mathrm{C}$ and sent to an adiabatic dehydration reactor producing DME and water. A downstream flash tank separates the most volatile part of the product, including all DME, which is returned to the second distillation column for purification. The liquid fraction is recycled to the third distillation column. The final DME product has a purity of 99.8\%. Process heat exchange in the separation area is optimized to minimize heating and refrigeration requirements. External heat requirements are met using steam from the power island.

In the DMEa and DMEb configurations, $97 \%$ of the syngas that is unconverted in one pass through the synthesis reactor is compressed and recycled to the reactor to increase overall conversion to DME. The purge stream (3\%) is sent as fuel to the power island. In the DMEc configuration, the recycle loop is eliminated and all syngas not converted to liquids on a single pass is sent as fuel to the power island.

\subsubsection{Fischer-Tropsch Liquids}

Commercial Fischer-Tropsch catalysts include iron and cobalt based materials. Cobalt catalysts produce a large heavy-wax fraction that can be easily and with high selectivity refined into desired lighter products by subsequent hydrocracking (breaking up of the large hydrocarbon molecules into desired final products in a hydrogen-rich environment). Hydrocracking of the large straight-chain hydrocarbons formed by FT synthesis can be done under much less severe temperature conditions $\left(350-400^{\circ} \mathrm{C}\right.$ for cracking to $\mathrm{C}_{5}-\mathrm{C}_{18}$ range hydrocarbons) than is required for hydrocracking of aromatic molecules found in conventional petrochemical refining. Ironbased catalysts produce a broader product mix that requires a greater level of refining than with cobalt catalysts. Also, unlike cobalt catalysts, iron catalysts promote water-gas shift activity (CO $+\mathrm{H}_{2} \mathrm{O} \rightarrow \mathrm{H}_{2}+\mathrm{CO}_{2}$ ), making them well suited for use with syngas characterized by $\mathrm{H}_{2} / \mathrm{CO}$ ratios below the stoichiometic value of 2.2 for FT synthesis.

In our analysis, we simulate a liquid-phase design for the FTL synthesis reactor. Liquid-phase FTL reactors are commercially available today from several vendors [12,97]. We utilize a kinetic model developed in prior work by Larson et al. [73] based on a model proposed by Fox and Tam [98] and drawing on published kinetic rate information, as described in Volume 2 of this study. Consistent with the preceding discussion, our model is for an iron-based catalyst 
because of the low $\mathrm{H}_{2} / \mathrm{CO}$ ratio of the syngas feed in our biorefinery designs (1.04 to 1.11). The powdered iron-based catalyst is suspended in a liquid bed made up of the heavy hydrocarbon fraction (wax) produced by the FT reactions.

Because of the high single-pass conversion that can be achieved with slurry-phase FT synthesis, our three FTL biorefineries all utilize "once-through" synthesis, with unconverted syngas going to the power island as fuel. In FTa and FTb, the syngas entering the synthesis reactor is derived only from black liquor. In FTc, the syngas from black liquor and from biomass are combined to feed the synthesis reactor.

The operating pressure of the synthesis reactor is set to 30.7 bar, which requires no upstream syngas compression. The incoming syngas stream to the synthesis reactor is preheated to $245^{\circ} \mathrm{C}$ and boiler tubes immersed in the slurry generate steam at $38 \mathrm{bar}$, limiting the reactor temperature to $260^{\circ} \mathrm{C}$. The synthesis reactions produce a raw mix of products that must be refined to finished products. A flash step is used to separate light gases (including unconverted syngas and light gases produced in the FT reaction) from the heavier compounds that constitute the raw FTL product (a mixture of distillate, naphtha, and wax fractions). The light gases are sent to the power island as fuel. The raw FTL product - "FT crude" - could be refined onsite to finished products like diesel or gasoline blendstocks. However, because of the complexity and cost of refining at the relatively small scales of our biorefineries (compared to typical sizes for petroleum refineries), Nexant engineers with whom we reviewed our preliminary designs recommended the FT crude be transported by trucks (with heated tanks to maintain the wax fraction as a liquid) to existing petroleum refineries for processing to finished products. Accordingly, we assume the FT crude is exported from the biorefinery as a petroleum crude substitute. $^{12}$

\subsubsection{Mixed Alcohols}

Compared with FTL or DME synthesis, the technology for synthesis of mixed alcohols is considerably less commercially advanced, and there is sparse published literature on which to base detailed reactor performance estimates. Catalysts that have been examined in the past can be divided into four categories [99]: ruthenium-based catalysts, modified methanol catalysts, modified Fischer-Tropsch catalysts, and molybdenum-sulfide based catalysts. Among these, the $\mathrm{MoS}_{2}$ based catalysts (originally discovered by researchers at Dow and Union Carbide in the 1980s) have received considerable recent attention due to their high tolerance for sulfurcontaminated syngas, their water-gas shift activity, and their high activity and selectivity for linear alcohols. Selectivity is an especially important characteristic because if all possible chemical reactions between $\mathrm{CO}$ and $\mathrm{H}_{2}$ are allowed to compete without constraints, reactions other than those for synthesis of higher alcohols will thermodynamically out-compete reactions for synthesis of higher alcohols. In particular, the formation of Fischer-Tropsch hydrocarbons ( $\alpha$-olefins and $n$-paraffins) from $\mathrm{CO}$ and $\mathrm{H}_{2}$ is thermodynamically favored over the formation of higher alcohols. ${ }^{13}$ For this reason, to maximize performance of alcohol synthesis catalysts, high selectivity is an essential feature.

\footnotetext{
${ }^{12}$ Our financial analysis (described later) assumes sale of the FT crude at the value of crude petroleum (on an equivalent energy basis). We do not model refining of the raw product to finished products.

${ }^{13}$ The equilibrium constant, $\mathrm{K}_{\mathrm{eq}}$, is higher for hydrocarbons than for alcohols.
} 
For catalysts that have been identified to date, required reaction temperatures have been in the range of $300-400^{\circ} \mathrm{C}$. Because of the difficulty of maintaining an inert liquid in the liquid state at these temperatures, most development efforts on synthesis reactors are focusing on gas-phase reactors, although at least one company claims to be developing a liquid-phase technology for mixed alcohol synthesis [48]. We have assumed a gas-phase reactor in our biorefinery design for synthesis of mixed alcohols, and we engaged the catalyst research group headed by Prof. Forzatti at Politecnico di Milano to develop a kinetic model of the synthesis reactor. The kinetic model was developed by Prof. Lietti and Prof. Tronconi in Forzatti's group. As discussed in Section 2.3, the model is based on the most recent (mid-1990s) publicly-available empirical data for the performance of a particular $\mathrm{MoS}_{2}$ catalyst [100]. Volume 2 of our study provides details of the modeling effort.

Our mixed alcohol biorefinery utilizes the combined black liquor and biomass syngas flows as the fresh feed gas for the synthesis reactor. Because the performance of both the acid gas removal system $\left(\right.$ Selexol ${ }^{\circledR}$ ) and the mixed-alcohol synthesis reactor improve with pressure, we utilize an intercooled compressor to raise the syngas pressure to 106 bar as it approaches the Selexol ${ }^{\circledR}$ area. Following the Selexol ${ }^{\circledR}$ system the syngas is mixed with a recycle flow of unconverted syngas and a recycle flow of methanol, both coming from downstream of the synthesis reactor. This mixture is heated to $330^{\circ} \mathrm{C}$ before it enters the synthesis reactor. Heat generated by the reactions is recovered as 130 bar steam to maintain the reactor temperature at $350^{\circ} \mathrm{C}$.

The hot effluent from the reactor is cooled to $36^{\circ} \mathrm{C}$ by a sequence of heat exchange with the reactor inlet flow and then cooling water. At $36^{\circ} \mathrm{C}$ most of the alcohols condense, enabling separation of unconverted gas from the liquids. Of the unconverted gas, $76 \%$ is compressed and recycled back to the synthesis reactor. The remaining gas is preheated and expanded to about 25 bar (to recover useful power), humidified using a saturator and then used as fuel for the gas turbine. The recovered liquids are sent to a distillation column where methanol and lighter compounds are separated from the alcohols, recompressed and recycled to the synthesis reactor. The bottoms from the distillation column contain ethanol and higher alcohols along with water. A molecular sieve is used to separate the alcohols from water. The purge gas from the molecular sieve, composed of water vapor with a small percentage of alcohols, is compressed and sent to the gas turbine to recover the energy content and to increase the mass flow through the turbine so as to increase power production.

The final mixture of $\mathrm{C}_{2+}$ alcohols can be used directly as a gasoline blendstock or separated into component alcohols for chemicals use. We have not simulated the separation of alcohols, but we have examined the potential impact on overall economics that might result from doing so (Section 8).

Finally, it is important to note that our kinetic model predicts a considerably lower overall yield and significantly different composition of alcohols from values reported in the literature, e.g. by Aden et al. [46]. Because literature results are not based on kinetic models, however, it is difficult to make detailed comparisons between our kinetic-model results and others' reported results. The catalyst we have modeled is the only one for which there is sufficient empirical data published for building a kinetic model. In general, others' results (including claims of technology developers) show much higher yields and much greater selectivity for $\mathrm{C}_{2+}$ alcohols than we predict. More complete sets of empirical data for other catalysts are needed to better 
understand and document the potential for synthesis of mixed alcohols. There may also be arrangements for recycle of unconverted syngas different from the design we have used that would improve overall system performance [101]. This is another area where further work might prove fruitful.

\subsection{Technology Summary}

Table 11 summarizes the key technologies incorporated into each of our seven biorefinery designs. The column labeled "status" indicates the proximity to commercial offering for each technology. The majority of components are already in wide commercial use (in non-biorefinery applications). All but one of the technologies not in the commercial category fall into the category of technologies that have been or are currently being demonstrated at pilot scale, such that relatively near term (2010 time frame) commercial deployment is feasible. Only one technology (mixed-alcohols synthesis) appears to be at a relatively under-developed stage, though as noted in Section 2.3, several companies claim they will offer mixed-alcohol synthesis technology commercially in the near term.

Table 11. Summary of technologies included in our biorefinery designs including commercial status of each technology.

\begin{tabular}{|c|c|c|c|c|c|c|c|c|c|}
\hline & & Status $^{a}$ & FTa & $\mathrm{FTb}$ & FTc & DMEa & DMEb & DMEc & MA \\
\hline $\begin{array}{l}\text { Black Liquor } \\
\text { Gasification }\end{array}$ & $\begin{array}{l}\text { High-temp gasifier } \\
\text { Quench } \\
\mathrm{O}_{2} \text { feed }\end{array}$ & $\begin{array}{l}\text { pilot } \\
\text { pilot } \\
\text { com }\end{array}$ & $\dot{4}$ & $\dot{4}$ & $\dot{4}$ & $\dot{4}$ & $\dot{4}$ & 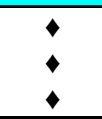 & $\dot{4}$ \\
\hline $\begin{array}{l}\text { Woody } \\
\text { Biomass } \\
\text { Conversion }\end{array}$ & $\begin{array}{l}\text { Fluid-bed gasifier } \\
\text { Syngas cooler } \\
\text { Hot gas filter } \\
\text { Quench cleanup } \\
\mathrm{O}_{2} \text { feed } \\
\text { Boiler }\end{array}$ & $\begin{array}{l}\text { pilot } \\
\text { pilot } \\
\text { pilot } \\
\text { com } \\
\text { com } \\
\text { com }\end{array}$ & $\vec{\bullet}$ & $\vec{\bullet}$ & 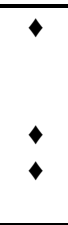 & $\downarrow$ & $\vec{b}$ & $\vec{\bullet}$ & $\begin{array}{l}* \\
\forall\end{array}$ \\
\hline $\begin{array}{l}\mathrm{H}_{2} \mathrm{~S} \text { Capture } \\
\text { and Recovery }\end{array}$ & $\begin{array}{l}\text { Rectisol }^{(8)} \\
\text { Selexol }^{\circledR} \\
\text { Claus/SCOT }\end{array}$ & $\begin{array}{l}\text { com } \\
\text { com } \\
\text { com }\end{array}$ & $\checkmark$ & $\checkmark$ & $\checkmark$ & $\checkmark$ & $\downarrow$ & 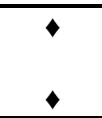 & $\bullet$ \\
\hline Fuel Synthesis & $\begin{array}{l}\text { Slurry bed reactor } \\
\text { Fixed-bed reactor } \\
\text { Syngas recycle }\end{array}$ & $\begin{array}{l}\text { com } \\
\text { lab } \\
\text { com }\end{array}$ & $\downarrow$ & $\downarrow$ & $\downarrow$ & 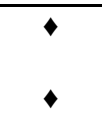 & 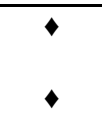 & 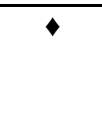 & $\bullet$ \\
\hline & Gas turbine & com & $\checkmark$ & $\checkmark$ & 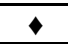 & & $\checkmark$ & 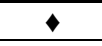 & $\checkmark$ \\
\hline Power Island & $\begin{array}{l}\text { Back pressure ST } \\
\text { Condensing ST }\end{array}$ & $\begin{array}{l}\text { com } \\
\text { com }\end{array}$ & $\downarrow$ & $\downarrow$ & $\downarrow$ & $\checkmark$ & 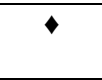 & 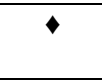 & $\bullet$ \\
\hline
\end{tabular}

(a) Commercial status. com $=$ commercially-offered; pilot $=$ demonstrated at pilot scale; lab $=$ demonstrated in laboratory.

\subsection{Detailed Biorefinery Mass/Energy Balance Results}

\subsubsection{Process Flow Sheets and Performance Analysis}

Figure 23 through Figure 29 show the results of our detailed biorefinery process designs and mass/energy balance simulations. The following sections discuss each of these, and more detailed discussions are available in Volume 2. Table 12 summarizes performance results for all of the biorefineries and also includes, for comparison, results from our prior BLGCC study for the Tomlinson and BLGCC systems. Recall that in all cases all of the pulp/paper mill's process steam demands are being met by the power/recovery/fuel system. Other key features of the biorefinery designs are as summarized in Table 6. 


\subsubsection{DME Flowsheets}

The liquid fuel produced by all the DME biorefineries comes only from the conversion of syngas from black liquor. The DME production train in DMEa (Figure 23) is identical to that in DMEb (Figure 24). Each has a production capacity of 511 metric tonnes per day of DME (168 MW lower heating value, LHV) and converts $48 \%$ of the LHV of the black liquor into DME. In DMEc (Figure 25), DME is also made only from gasified black liquor, but because a oncethrough synthesis configuration is used rather than recycle, the DME output is lower: $226 \mathrm{t} / \mathrm{d}$, or $21 \%$ of the black liquor LHV.

For the power island, DMEa utilizes woody biomass as the main fuel for a steam-Rankine cycle, DMEb uses a gasifier-GTCC with gasified woody biomass as the main fuel, and DMEc uses a gasifier-GTCC with gasified woody biomass and unconverted syngas for fuel. In all three cases, the amount of biomass consumed is set so that the power island can meet the process steam needs of the pulp/paper mill. With this constraint, the gross power outputs of DMEb and DMEc are about 3.5 times that of DMEa, and the net power output (after meeting biorefinery parasitic demands) is close to zero for DMEa and about $90 \mathrm{MW}$ for DMEb and DMEc. In the latter two cases this power output is sufficient to meet about $90 \%$ of the pulp/paper mill's process electricity needs.

The bottom three rows of Table 12 show summary energy output-input ratios. The ratio of useful outputs from the biorefinery (mill process steam, net electricity, and DME) to total primary energy used to generate these outputs is close to 0.71 in all three cases. The ratio of exportable biorefinery products (net electricity and DME) to total fuel input ranges from 0.32 to 0.40. The value of this parameter for DMEb is higher than for DMEa because the only major difference between DMEa and DMEb is the replacement of the biomass boiler/steam cycle in $\mathrm{DMEa}$ with a more efficient biomass gasifier/GTCC in DMEb. The value for DMEc is lower than for DMEb primarily because the fuel to electricity output ratio for DMEb is higher than for DMEc, and since the "thermodynamic value" of fuel is lower than that of electricity, shifting the conversion toward more electricity decreases the ratio of (electricity+fuel) to total fuel input. This circumstance points out that the ratio between the sum (electricity+fuel) and total fuel input is not necessarily a good indicator of plant performance. It provides some information, but can be misleading.

The final row of Table 12 shows the effectiveness with which the gasification-based facilities utilize additional purchased energy inputs (primarily woody residues, but also some additional lime kiln fuel). This "effectiveness of purchased fuels use" exceeds $100 \%$, or nearly so, in all DME cases. ${ }^{14}$ This indicates that all of these designs are making very effective use of the additional energy inputs that characterize gasification compared to Tomlinson systems.

\footnotetext{
${ }^{14}$ We use the term effectiveness, rather than efficiency, since efficiency greater than $100 \%$ is strictly not possible. Values of effectiveness greater than $100 \%$ are possible because the denominator includes only biomass that is purchased for energy (and excludes black liquor and hog fuel).
} 
Table 12. Biorefinery performance estimates, with comparisons to Tomlinson and BLGCC. Units are megawatts unless otherwise indicated. Fuel values are given on a lower heating value basis.

\begin{tabular}{|c|c|c|c|c|c|c|c|c|c|}
\hline & \multicolumn{2}{|c|}{ Power Only } & \multicolumn{7}{|c|}{ Biorefineries } \\
\hline & Tomlin. & BLGCC & DMEa & DMEb & DMEc & FTa & FTb & FTc & MA \\
\hline \multicolumn{10}{|l|}{ FUEL INPUTS } \\
\hline Black liquor & 392.6 & 350.7 & 350.7 & 350.7 & 350.7 & 350.7 & 350.7 & 350.7 & 350.7 \\
\hline Hog fuel & 57.8 & 54.1 & 54.1 & 54.1 & 54.1 & 54.1 & 54.1 & 54.1 & 54.1 \\
\hline Total mill by-product fuels & 450.4 & 404.8 & 404.8 & 404.8 & 404.8 & 404.8 & 404.8 & 404.8 & 404.8 \\
\hline Purchased wood residues & 0 & 27.1 & 77.4 & 195.5 & 73.4 & 101.6 & 368.5 & 451.3 & 89.2 \\
\hline Natural gas to duct burner & -- & 12.9 & -- & -- & -- & -- & -- & -- & -- \\
\hline Lime kiln \#6 fuel oil & 31.1 & 35.9 & 35.9 & 35.9 & 35.9 & 35.9 & 35.9 & 35.9 & 35.9 \\
\hline Total purchased fuels & 31.1 & 75.9 & 113.3 & 231.4 & 109.3 & 137.5 & 404.4 & 487.2 & 125.1 \\
\hline Total fuel inputs & 481.5 & 480.7 & 518.1 & 636.2 & 514.1 & 542.3 & 809.2 & 892.0 & 529.9 \\
\hline \multicolumn{10}{|l|}{ STEAM TO PULP/PAPER MILL } \\
\hline LP (55 psig) s & 142.8 & 135.3 & 135.3 & 135.3 & 135.3 & 135.3 & 135.3 & 135.3 & 135.3 \\
\hline MP (175p & 69.3 & 64.9 & 64.9 & 64.9 & 64.9 & 64.9 & 64.9 & 64.9 & 64.9 \\
\hline Total process stea & 212.1 & 200.2 & 200.2 & 200.2 & 200.2 & 200.2 & 200.2 & 200.2 & 200.2 \\
\hline LIQUID FUEL PRODUCTION & -- & -- & 168.0 & 168.0 & 74.2 & 111.6 & 111.6 & 342.7 & 59.6 \\
\hline Barrels per day petroleum ec & -- & -- & 2362 & 2362 & 1043 & 1549 & 1549 & 4757 & 948 \\
\hline \multicolumn{10}{|l|}{ ELECTRICITY BALANCE } \\
\hline ine aross output & -- & 87.0 & -- & 89.5 & 82.9 & 83.9 & 186.5 & 89.7 & 89.7 \\
\hline Steam turbine gross output & 72.0 & 48.2 & 32.9 & 42.0 & 38.7 & 34.0 & 87.9 & 48.6 & 40.8 \\
\hline Syngas expander output & -- & -- & 2.58 & 5.01 & 1.96 & 1.65 & 4.26 & -- & 2.99 \\
\hline roduction & 72.0 & 135.1 & 35.5 & 136.5 & 123.6 & 119.5 & 278.7 & 138.3 & 133.5 \\
\hline Air separation unit power use ${ }^{b}$ & -- & $14.9^{\mathrm{c}}$ & 15.8 & 27.0 & 21.5 & 22.8 & 35.7 & 38.4 & 22.1 \\
\hline Synga & -- & -- & 1.95 & 1.95 & 2.17 & -- & -- & -- & 7.37 \\
\hline Gas c & -- & -- & 7.26 & 7.26 & -- & -- & -- & -- & 1.77 \\
\hline Steam & 6.7 & 1.2 & 1.38 & 2.30 & 1.52 & 1.31 & 3.76 & 5.40 & 2.75 \\
\hline fication island aux. & -- & 2.7 & 2.67 & 2.67 & 2.67 & 2.67 & 2.67 & 2.67 & 2.67 \\
\hline Biomass gasification island aux. & -- & -- & -- & 3.37 & 1.74 & 2.11 & 5.66 & 6.75 & 1.95 \\
\hline Biomass boiler auxiliaries & 1.00 & 1.2 & 1.75 & -- & -- & -- & -- & -- & -- \\
\hline Acid gas removal \& S recovery aux. & -- & 1.1 & 0.97 & 0.97 & 0.96 & 0.96 & 0.96 & 2.59 & 1.81 \\
\hline Refrigeration for AGR & -- & -- & 2.15 & 2.15 & 2.07 & 2.01 & 2.01 & 5.11 & 1.21 \\
\hline Synthesis island auxiliaries & -- & -- & 1.00 & 1.00 & 0.40 & -- & -- & -- & -- \\
\hline Total recovery area use & 7.7 & 21.1 & 34.9 & 48.7 & 33.0 & 31.8 & 49.8 & 60.9 & 41.6 \\
\hline Net Electricity Production & 64.3 & 114.1 & 0.56 & 87.8 & 90.5 & 87.7 & 228.9 & 77.3 & 91.9 \\
\hline Power in excess of Tomlinson & -- & 50.4 & -63.2 & 24.1 & 26.8 & 24.0 & 165.2 & 13.6 & 28.2 \\
\hline Process use (excl. recovery area) & 100.1 & 100.1 & 100.1 & 100.1 & 100.1 & 100.1 & 100.1 & 100.1 & 100.1 \\
\hline Mill electricity purchases & 35.8 & -15.2 & 99.6 & 12.3 & 9.58 & 12.4 & -128.8 & 22.8 & 8.21 \\
\hline \multicolumn{10}{|l|}{ Energy Ratios } \\
\hline Useful outputs/total inputs $^{d}$ & 0.574 & 0.654 & 0.712 & 0.717 & 0.710 & 0.737 & 0.668 & 0.695 & 0.664 \\
\hline Exportable outputs/total inputs ${ }^{e}$ & 0.133 & 0.237 & 0.325 & 0.402 & 0.320 & 0.368 & 0.421 & 0.471 & 0.286 \\
\hline Effectiveness of purchased fuel $u$ & -- & 1.11 & 1.27 & 0.956 & 1.28 & 1.27 & 0.740 & 0.780 & 0.928 \\
\hline
\end{tabular}

(a) Barrels (bbl) per day of equivalent petroleum-derived fuel potentially displaced by the biorefinery fuel. The potentially-displaced fuels are: diesel (6.15 GJ/bbl, LHV) for DME, crude oil (6.22 GJ/bbl, LHV) for FTL, and gasoline (5.43 GJ/bbl, LHV) for MA.

(b) The parasitic ASU electricity load shown here includes 0.58 MW more than the ASU load shown in the detailed mass/energy balance flowsheets. The additional $0.58 \mathrm{MW}$ is from upsizing of the ASU to provide $\mathrm{O}_{2}$ for delignification (see text discussion).

(c) In developing the biorefinery mass/energy balance simulations, a minor error was discovered in the previously-completed BLGCC simulation, resulting in a slightly lower $\mathrm{O}_{2}$ flow to the black liquor gasifier in the BLGCC case than in the biorefinery cases. We have not revised the BLGCC results, because the error was minor. The error accounts for the slight difference in electricity needed for the ASU between the BLGCC and DMEa cases, which should otherwise have identical parastic power demands.

(d) Defined as the sum of process steam, net electricity, and liquid fuel outputs divided by the sum of all fuel inputs.

(e) Defined as the sum of net electricity and liquid fuel production divided by the sum of all fuel inputs.

(f) Defined as the sum of net electricity and liquid fuel production for the gasification-based facility minus this quantity for the Tomlinson facility divided by the difference in total purchased fuel between the gasification and Tomlinson facilities. 


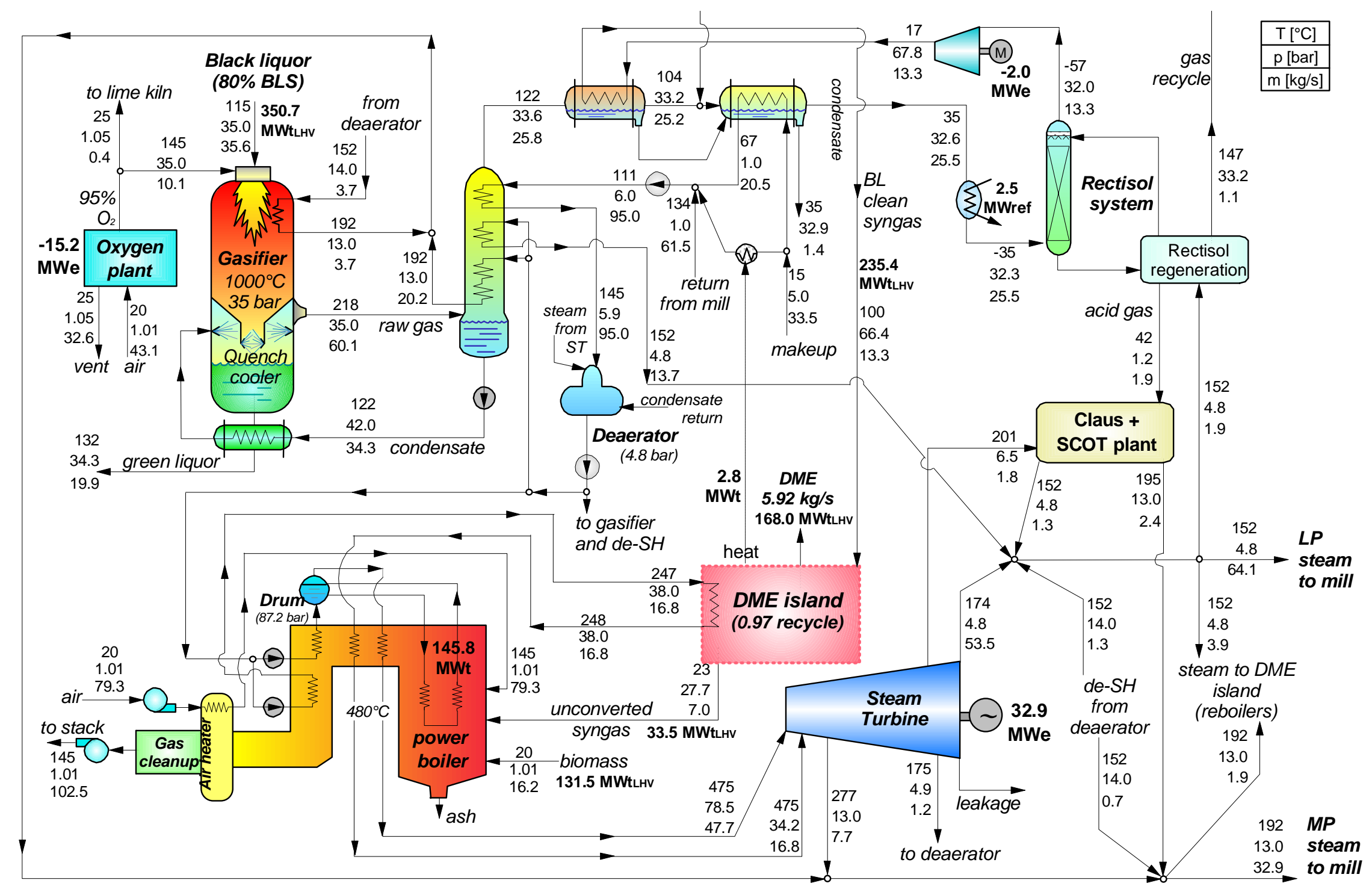

Figure 23. Mass and energy balance for DMEa. Key distinguishing features are the recycle synthesis loop and the hog fuel/purchased residues boiler/steam cycle power island. 


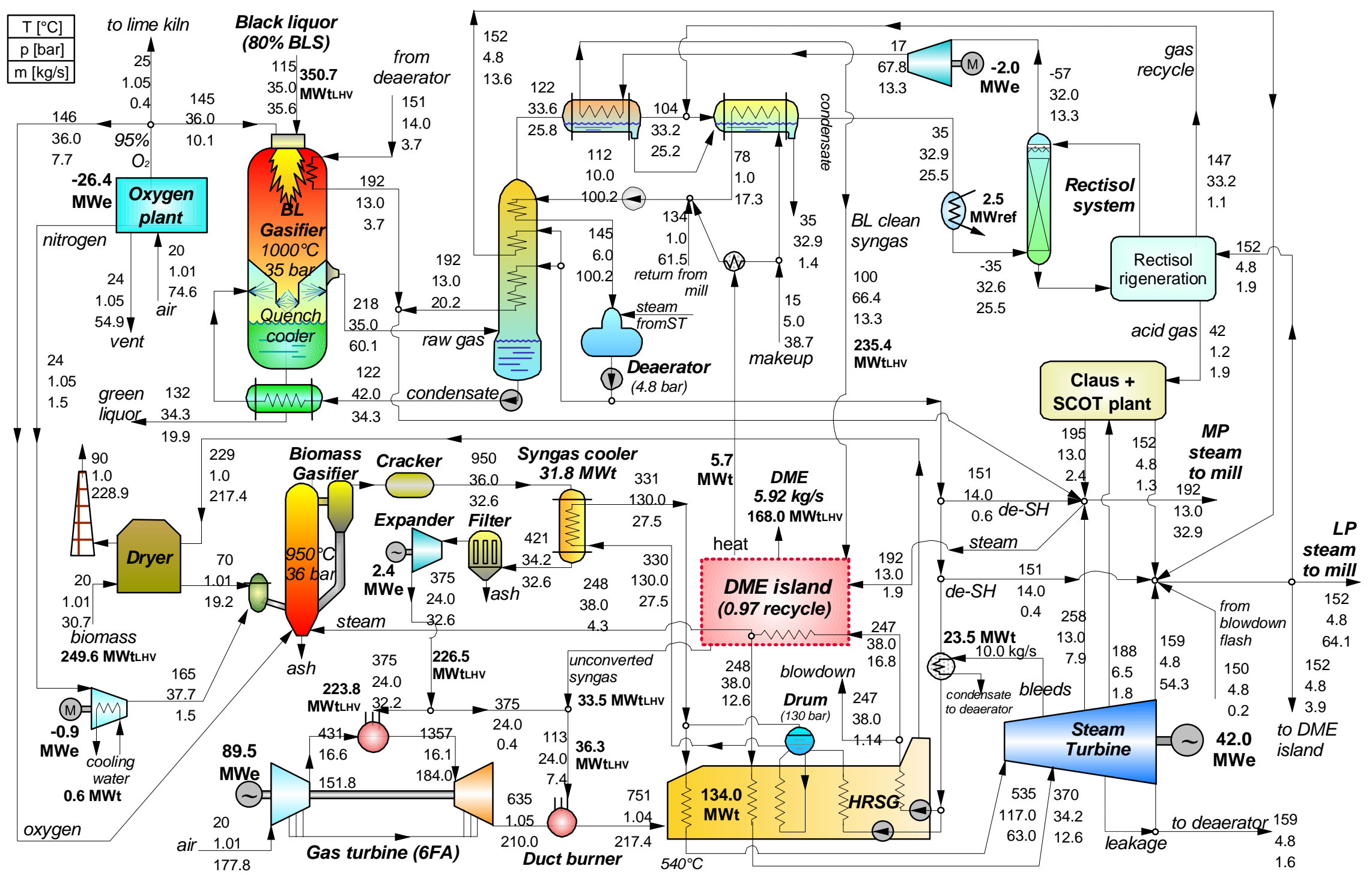

Figure 24. Mass and energy balance for DMEb. Key distinguishing features are the recycle synthesis loop and the hog fuel/residues gasifier gas turbine combined cycle power island. 


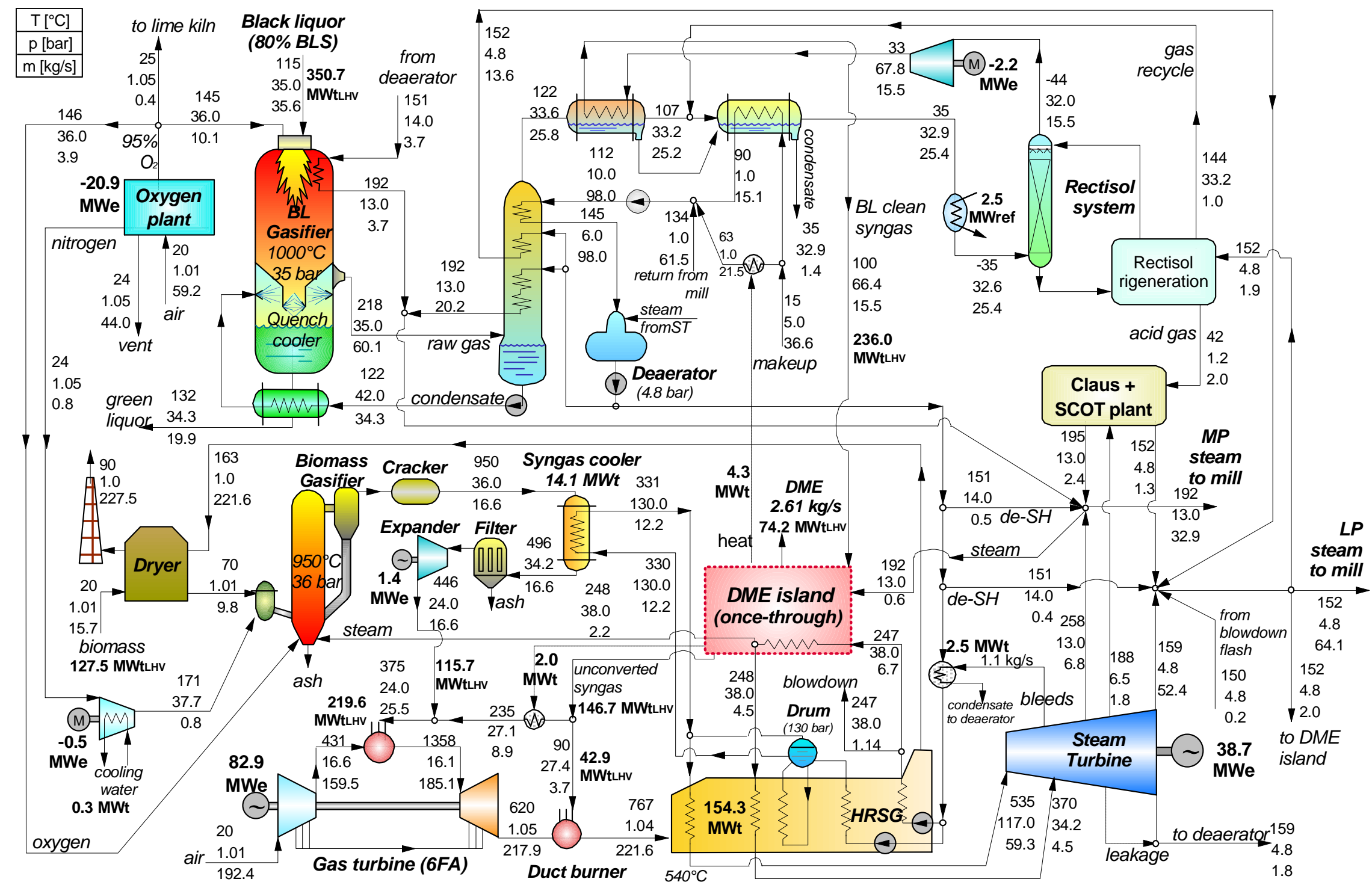

Figure 25. Mass and energy balance for DMEc. Key distinguishing features are the once-through synthesis reactor and the hog fuel/residues gasifier gas turbine combined cycle power island. 


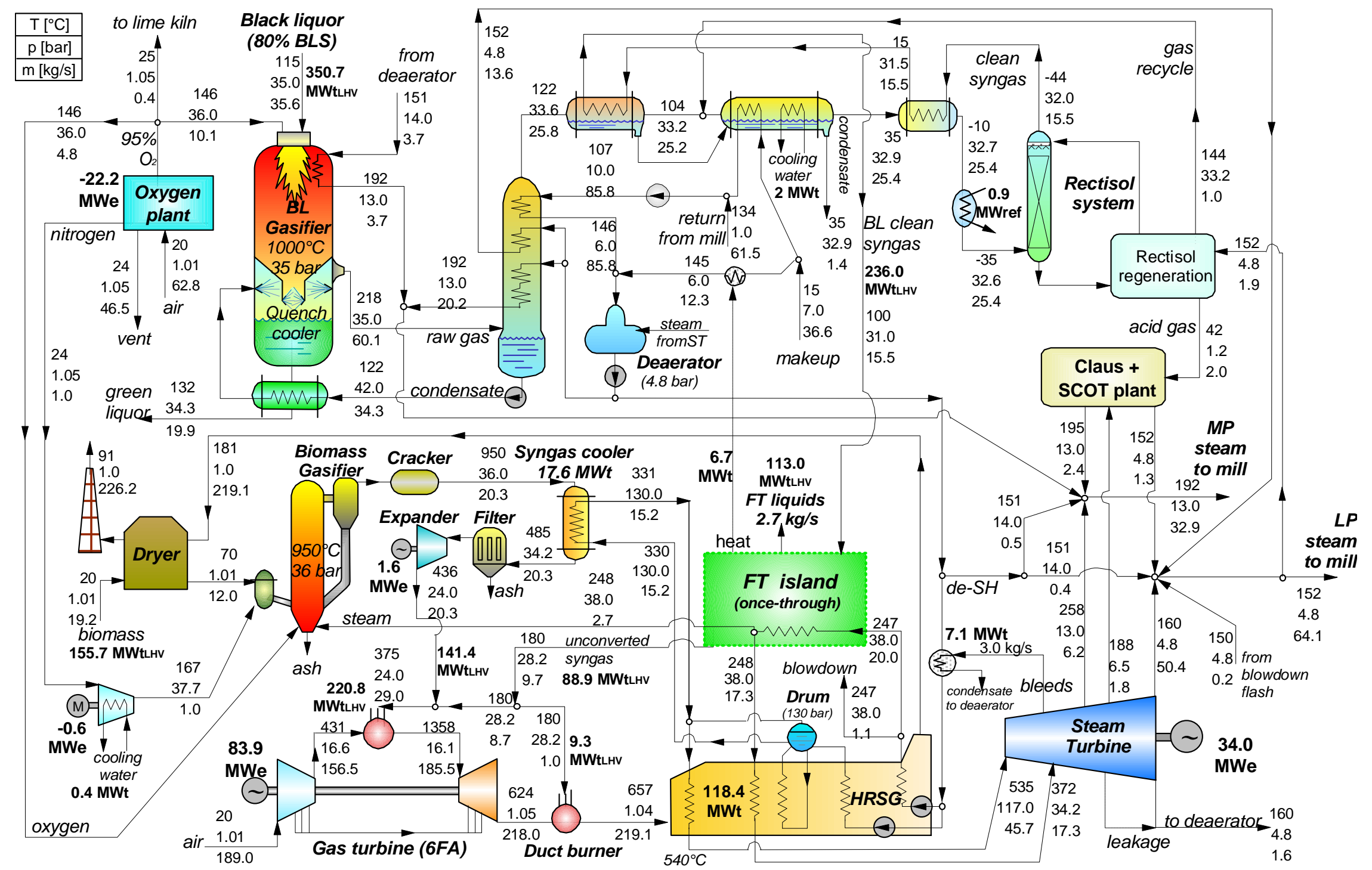

Figure 26. Mass and energy balance for FTa. Key distinguishing features are the once-through synthesis reactor and the hog fuel/residues gasifier gas turbine combined cycle power island. 


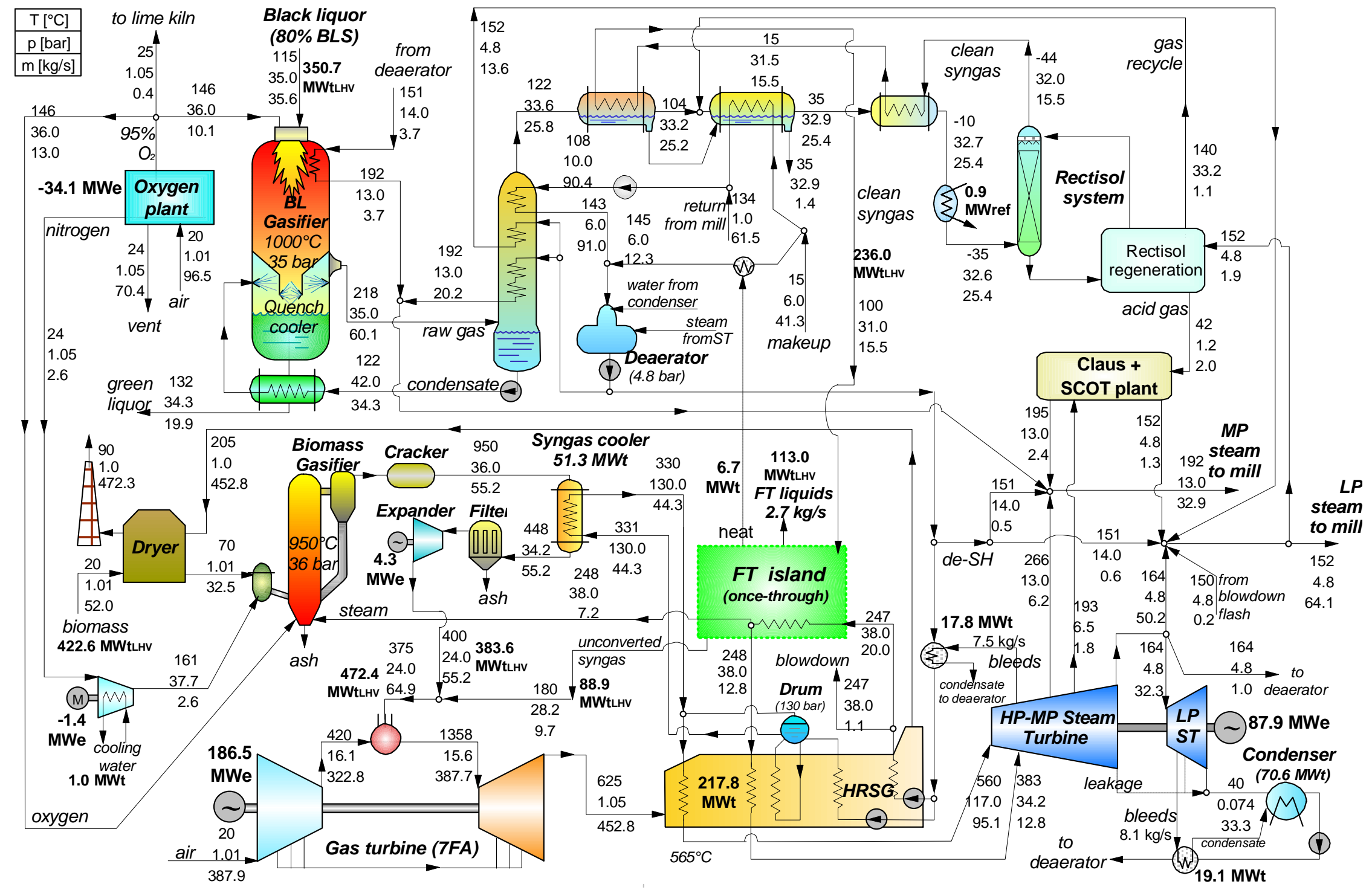

Figure 27. Mass and energy balance for FTb. Key distinguishing features are the once-through synthesis reactor and the hog fuel/residues gasifier gas turbine combined cycle power island with larger (7FA) gas turbine. 


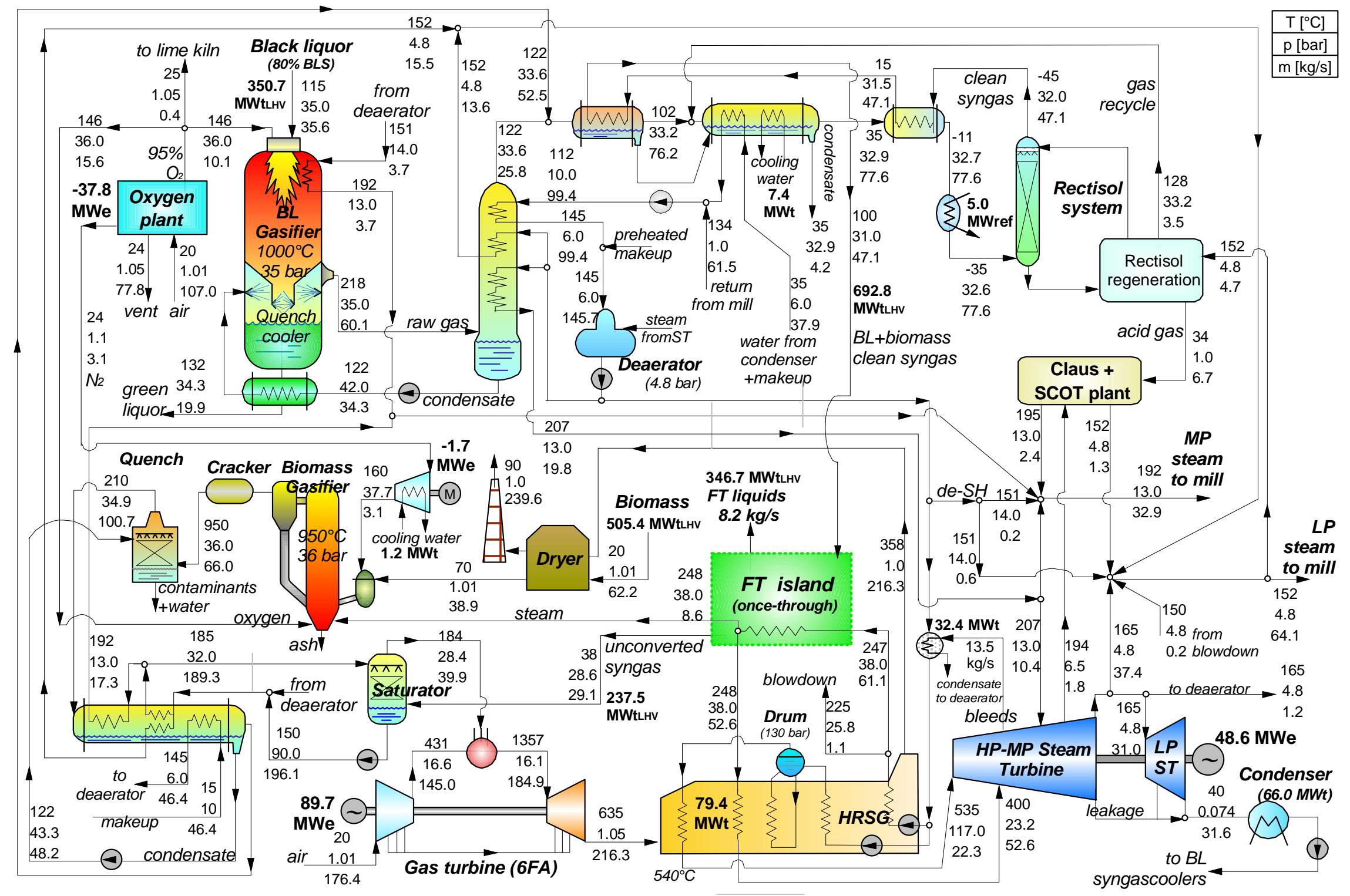

Figure 28. Mass and energy balance for FTc. Key distinguishing features are the once-through synthesis reactor fed with syngas from both black liquor and hog fuel/residues gasifiers. Unconverted syngas fuels the gas turbine combined cycle power island. 


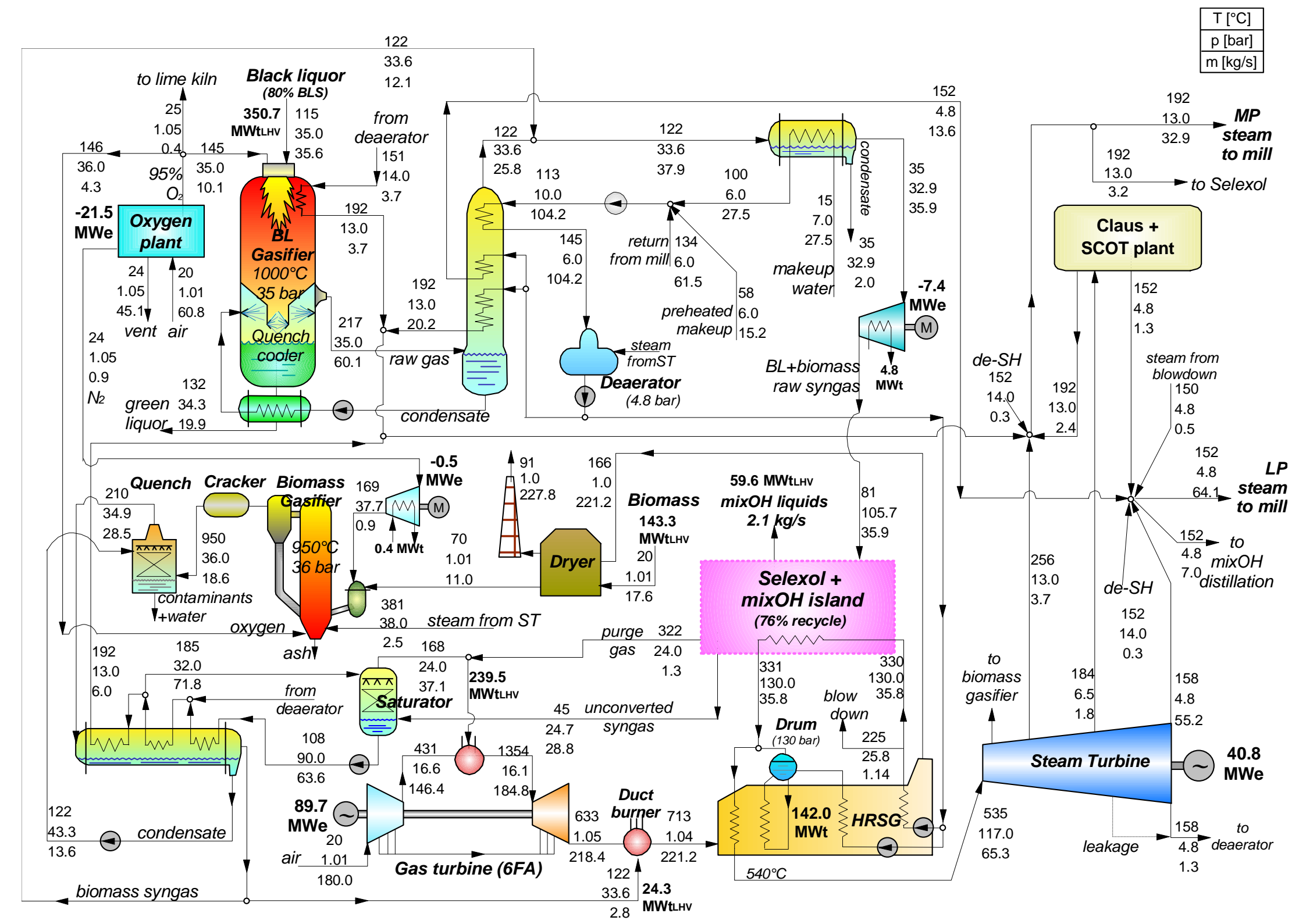

Figure 29. Mass and energy balance for MA. Key distinguishing features are the recycle synthesis island fed with syngas from both black liquor and hog fuel/residues gasifiers. Unconverted syngas fuels the gas turbine combined cycle power island. 


\subsubsection{FTL Flowsheets}

The three FTL flowsheets (Figure 26 to Figure 28) share the common feature of a once-through configuration for the synthesis island. FTa and FTb utilize only syngas from black liquor in the synthesis reactor. FTc combines syngas from biomass with that from black liquor, resulting in approximately three times as much FTL output as compared to the other two designs.

FTa and FTb each produce the same amount of liquid fuel, but gross and net electricity outputs for FTb are more than double those for FTa because of the larger gas turbine selected for the power island of FTb. FTb is the only biorefinery that is able to meet all of the pulp/paper mill's electricity demand and also export some to the grid. The use of purchased biomass is higher for FTb than for FTa in order to produce the syngas needed by the larger gas turbine.

The FTc design uses the same gas turbine as in FTa, but the gross output of the power island in FTc is higher than in FTa primarily because of the larger output from the steam turbine. The larger steam turbine output is due primarily to the larger amount of steam produced from heat generated in the much larger synthesis reactor. Gross electricity production is higher for FTc than for FTa, but net electricity production is lower due to higher parasitic electricity use in FTc arising primarily from the larger air separation unit. The liquids production in all of the FTc cases could be increased by recycling unconverted syngas to the synthesis reactor. However, the additional production of liquids would be relatively modest because a large fraction $(65 \%)$ of the $\mathrm{CO}$ in the syngas is converted in a single pass.

\subsubsection{MA Flowsheet}

In the mixed alcohol (MA) case, as in the FTc design, syngas from black liquor and biomass gasification are combined for feeding to the synthesis reactor. Because the single-pass conversion of syngas predicted by our mixed-alcohol synthesis model is very low, a portion of the unconverted syngas is recycled to increase liquid fuel output. The recycle fraction is set at a level of $76 \%$ in order that the remaining unconverted syngas is sufficient to fuel the gas turbine power island.

Even with recycle of unconverted syngas, the overall conversion of syngas to liquids is still low: $17 \%$ of the LHV of the syngas input to the synthesis island appears in the mixed alcohol product. This results in a relatively modest level of liquid output from the MA biorefinery, and two of the three "energy ratio" indicators are also relatively low (Table 12).

As noted in Section 5.2.5.3, our synthesis model is based on the most recently published and complete set of empirical data on the kinetic behavior of a particular $\mathrm{MoS}_{2}$-based catalyst [100]. Because catalysts for mixed alcohol production are not yet commercially established (in contrast to DME and FTL catalysts), the performance that can be expected from mature MA catalysts is not well established. It is likely to be better than we have predicted, but it is difficult to say how much better without additional empirical data being published. Some commercial developers of MA synthesis processes (see Section 2.3) claim much better catalyst performance than we predict in our simulation, but complete kinetic data in the peer-reviewed literature are not available to substantiate most of these claims. Nevertheless, because catalyst performance is highly sensitive to geometry and surface preparation method, even the same basic catalyst material (e.g., $\mathrm{MoS}_{2}$ ) can give very different performance results depending on preparation method. More published data are needed to improve the understanding of the extent to which 
our simulation results here under-predict performance that can be expected with future commercial MA catalyst systems. For the time being, our analysis of MA production may be considered conservative.

\subsubsection{Some comparisons among our designs}

Several comparisons among the performance predictions for our seven biorefinery designs and with the BLGCC and Tomlinson systems are informative.

The ratio of useful energy outputs to total energy inputs (third row from bottom in Table 12) is higher for the biorefineries than it is for the BLGCC case and substantially higher than the Tomlinson case. Similarly, the ratio of exportable energy to total energy inputs for the DME and FTL cases compare favorably against the Tomlinson and BLGCC systems. The high value of these ratios for the biorefineries reflect the more effective use of the biomass resource that comes with gasification-based conversion and with co-producing a larger number of energy carriers. Also, the very high values for "effectiveness of purchased energy use" for all of the gasificationbased systems indicate the very effective use of the additional energy inputs (relative to the Tomlinson case) that are part of these configurations.

A comparison between the BLGCC and DMEa cases is of interest because the former exports electricity only and the latter exports liquid fuels only, while both utilize a black liquor gasifier and both meet the pulp/paper mill's steam needs using hog fuel boilers. The DMEa case shows a higher useful energy output ratio, although this does not necessarily translate to better financial performance since considerable purchases of electricity by the pulp/paper mill would be required with the DMEa system.

One may also compare DMEc and FTa, which have nearly identical equipment configurations both utilize a once-through synthesis island and the same gas turbine in the power island. The FTa facility produces about $50 \%$ more liquid fuel (in LHV terms) due to a higher one-pass syngas conversion. However, purchased biomass use is higher in the FTa case because more of the fuel for the gas turbine must be provided from gasified biomass, since the amount of unconverted syngas from the synthesis reactor is lower.

The FTc and MA designs both utilize a feed of combined syngas from black liquor and from biomass gasification to the synthesis reactor. Because of the low MA synthesis rates, the purchased biomass that must be used to ensure sufficient fuel gas for the gas turbine is much more modest than in the FTc case. This is true even though the FTc case uses a once-through synthesis design and the MA case uses recycle, because the overall conversion of syngas to liquids (in LHV terms) is much higher for once-through FTL (49\%) than for recycle MA (17\%).

The MA and DMEb systems are similar insofar as they both utilize a recycle synthesis loop and the same gas turbine. The higher overall conversion of syngas to liquids in the DMEb case means that a larger amount of biomass must be purchased since there is less unconverted syngas available to fuel the gas turbine. The much higher value of the "exportable outputs" ratio for $\mathrm{DMEb}$ reflects the low efficiency of syngas conversion to liquids in the MA case.

\subsubsection{Quantitative energy-efficiency comparisons}

The comparative conclusions in the preceding section are supported by quantification of various efficiency parameters. Table 13 shows the values of several such parameters for our biorefinery 
designs and, for comparison, our Tomlinson system. ${ }^{15}$ We define these efficiency parameters (with all quantities expressed on a lower heating value basis) as follows:

$\eta_{\text {elec }}=$ net electricity produced divided by sum of all energy inputs, including black liquor, woody biomass, and lime kiln fuel oil.

$\eta_{\text {fuel }}=$ exportable liquid fuel produced divided by sum of all energy inputs

$\eta_{\text {heat }}=$ energy carried in the process steam divided by the sum of all energy inputs

$\eta_{\text {first }}=\eta_{\text {elec }}+\eta_{\text {fuel }}+\eta_{\text {heat }}$ (efficiency by first law of thermodynamics). (This is the same efficiency as reported in the third-from-last row in Table 12.)

The values of $\eta_{\text {first }}$ are helpful in appreciating the simple energy balances of each biorefinery system, but because each of the components of $\eta_{\text {first }}$ (electricity, liquid fuel, steam) have quite different thermodynamic (and economic) values, $\eta_{\text {first }}$, is not necessarily the most appropriate indicator of the "best" system.

The last row in Table 13 shows an electricity-equivalent efficiency that is a better indicator of the real thermodynamic quality of the multiple outputs from a biorefinery. The numerator of the electricity-equivalent efficiency for each case, $\eta_{\mathrm{el}}$ equiv, is the sum of the equivalent amounts of electricity that could be produced from each biorefinery. For example, clean liquid fuels like DME or mixed alcohols could be used directly in a combined cycle (the most efficient technology now available) to produce electricity. Similarly, steam produced at the biorefinery could be expanded through a steam turbine to generate power. The denominator of $\eta_{\text {el equiv }}$ is the sum of all energy inputs. Volume 2 describes the quantitative assumptions used to calculate the equivalent electricity production potential for each biorefinery. A ranking of the biorefineries by values of $\eta_{\text {first }}$ is different from a ranking by values of $\eta_{\text {el equiv }}$, reflecting the potentially misleading evaluation of efficiency using the first law efficiency.

Calculating $\eta_{\mathrm{el}}$ equiv enables a thermodynamic "apples-to-apples" comparison among systems that produce different products. Figure 30 summarizes both the $\eta_{\text {first }}$ and to $\eta_{\text {el equiv }}$ results. On the basis of $\eta_{\text {first }}$ or $\eta_{\text {el equiv }}$, all of the biorefinery cases show considerably higher values than the Tomlinson case, reflecting the intrinsically higher efficiency of gasification-based versus combustion-based conversion processes. Even the least-efficient biorefinery, DMEa (which coproduces only steam and liquid fuel) has a higher $\eta_{\text {el equiv }}$ than for the Tomlinson system. On the other hand, the higher values of $\eta_{\mathrm{el}}$ equiv for the biorefineries other than DMEa show that coproducing some electricity with steam and liquid fuel enables better thermodynamic use of the black liquor and biomass resources. The best thermodynamic option is FTb, with a $\eta_{\text {el equiv }}$ close to $42 \%$. This is due to the high electric generating efficiency achievable with the large scale combined cycle in FTb. One may conclude from a comparison of $\eta_{\text {el equiv }}$ for the biorefineries that gasification-based electricity generation from black liquor and biomass is thermodynamically more efficient than gasification-based liquid fuel production. Alternatively, one may conclude that there appears to be the potential for improving the thermodynamic efficiency of gasification-based liquid fuels production.

\footnotetext{
${ }^{15}$ We have chosen not to include the BLGCC system in these comparisons because the use of some natural gas as input energy with that design complicates the comparisons.
} 
Table 13. Energy efficiencies (LHV basis) for biorefineries and Tomlinson. See text for definitions.

\begin{tabular}{|l|c|c|c|c|c|c|c|c|}
\cline { 2 - 9 } \multicolumn{1}{c|}{} & \multicolumn{8}{c|}{ Biorefineries } \\
\cline { 2 - 9 } \multicolumn{1}{c|}{} & Tomlinson & DMEa & DMEb & DMEc & FTa & FTb & FTc & MA \\
\hline$\eta_{\text {elec }}(\%)$ & 13.4 & 0.2 & 13.9 & 17.7 & 16.3 & 28.4 & 8.7 & 17.4 \\
\hline$\eta_{\text {fuel }}(\%)$ & 0 & 32.4 & 26.4 & 14.4 & 20.6 & 13.8 & 38.4 & 11.2 \\
\hline$\eta_{\text {heat }}(\%)$ & 44.0 & 38.6 & 31.4 & 38.9 & 36.9 & 24.7 & 22.4 & 37.8 \\
\hline$\eta_{\text {first }}(\%)$ & 57.4 & 71.3 & 71.8 & 71.1 & 73.7 & 66.9 & 69.6 & 66.4 \\
\hline \hline$\eta_{\text {el equiv }}(\%)$ & 25.0 & 28.2 & 36.7 & 35.9 & 36.3 & 41.8 & 33.9 & 33.6 \\
\hline
\end{tabular}

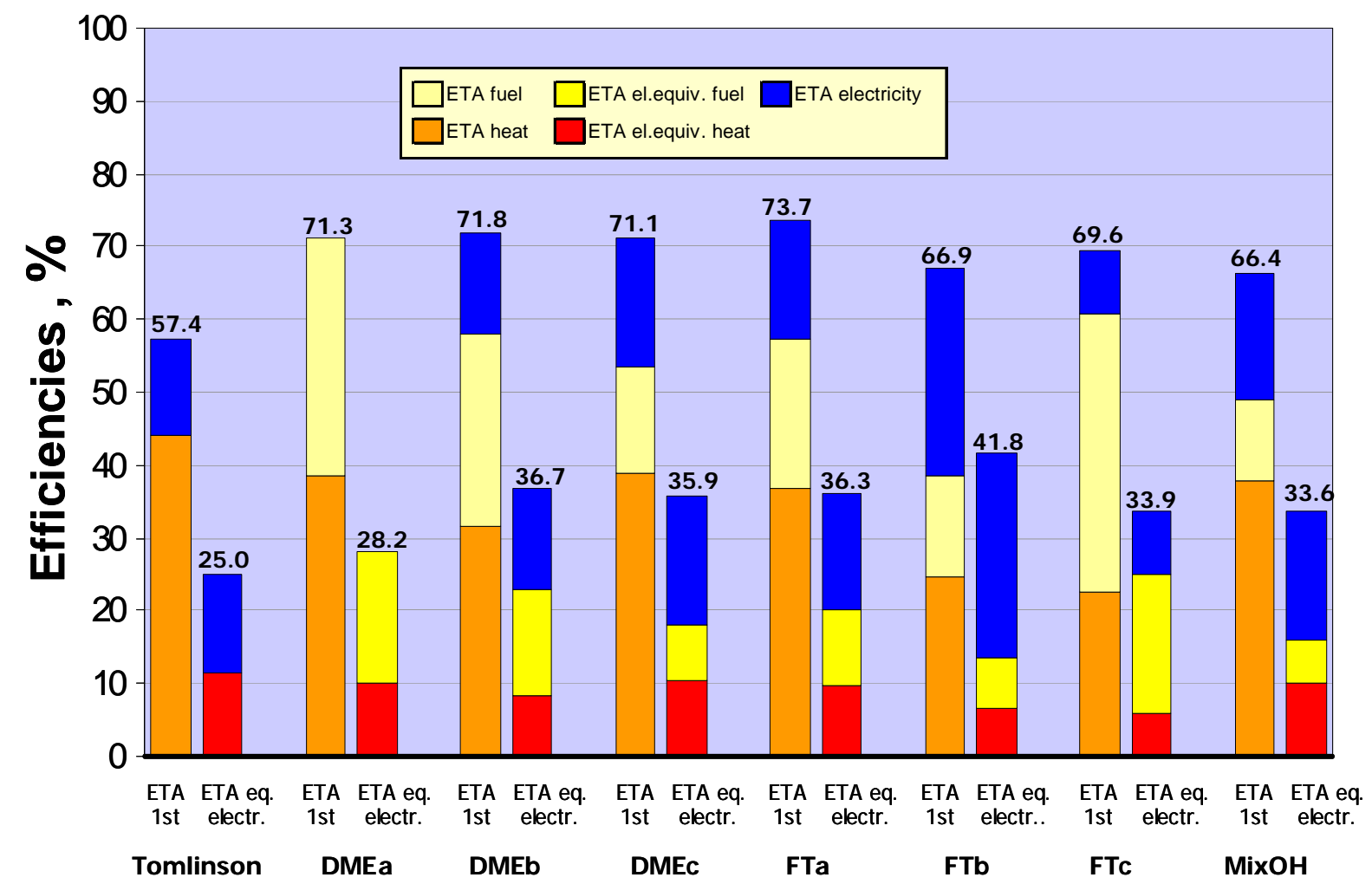

Figure 30. Energy efficiencies and contribution of each output (steam, electricity, and liquid fuel) to $\eta_{\text {first }}$ and to $\eta_{\text {el equiv. }}$

One additional efficiency comparison is informative. All of the biorefineries require more fuel inputs than the Tomlinson case. The added inputs are in the form of purchased residues and some lime kiln fuel. How well are these incremental energy inputs being used at the biorefineries? We addressed this question to some extent in the preceding section, but using the equivalent-electricity concept enables a more precise answer. Figure 31 shows the biorefinery incremental energy inputs, along with the incremental energy outputs. Note that the liquid fuel is always an incremental output with respect to the Tomlinson system. Using these inputs and outputs, we can calculate the effectiveness with which biorefinery utilizes the extra fuel (compared to the Tomlinson case) to generate extra electricity or to produce liquid fuels. The results are shown in the first two columns of Table 14. The third column in the table is the marginal equivalent-electricity efficiency, i.e the ratio between the extra equivalent-electricity for the biorefinery (numerator of $\eta_{\mathrm{el}}$ equiv minus electricity generated in Tomlinson case) divided 
by the extra energy inputs. This marginal equivalent-electricity efficiency spans a wide range of values depending on the biorefinery design, but in general the values are quite high, indicating that the added energy inputs are being used very efficiently.

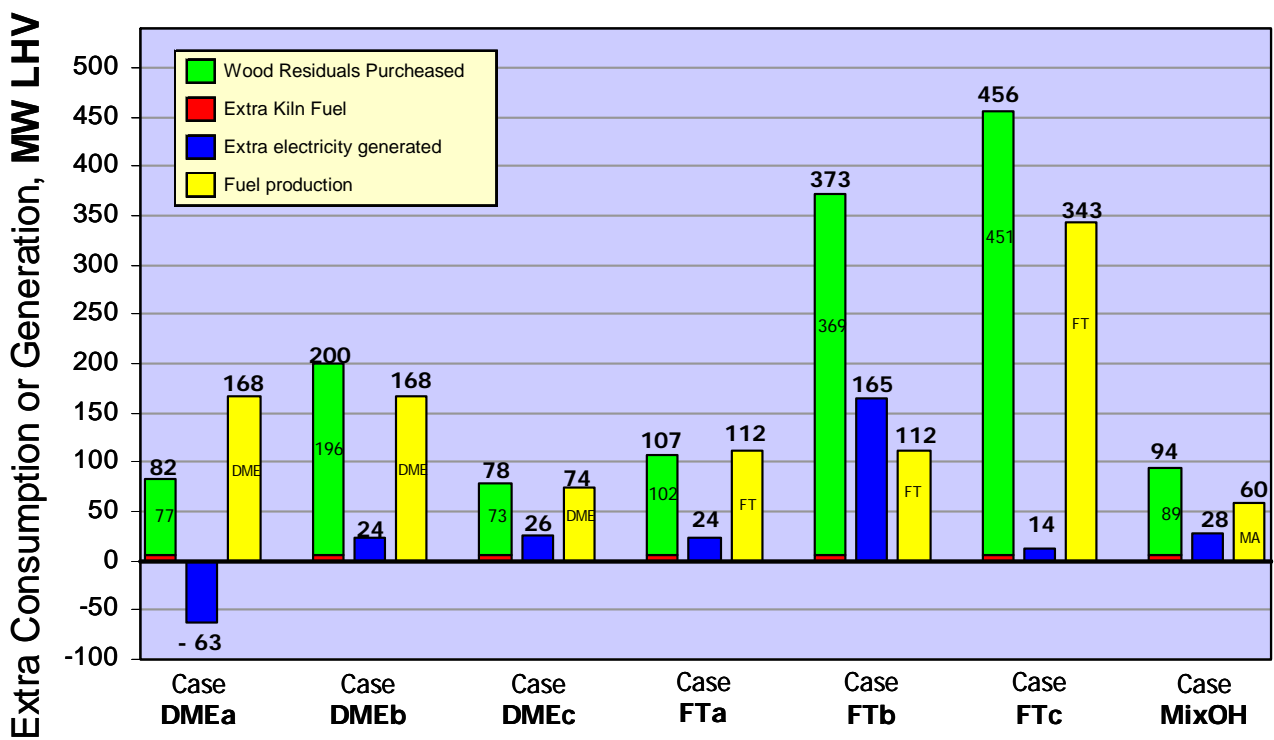

Figure 31. Incremental biorefinery energy inputs and outputs relative to the Tomlinson case.

Table 14. Incremental efficiencies for biorefineries relative to Tomlinson. ${ }^{a}$

\begin{tabular}{|l|c|c|c|}
\cline { 2 - 4 } \multicolumn{1}{c|}{} & \multicolumn{3}{c|}{ Marginal Efficiencies (\% LHV basis) } \\
\cline { 2 - 4 } \multicolumn{1}{c|}{} & Electricity & Liquid Fuel & Equivalent Electricity \\
\hline DMEa & -76.1 & 204.4 & 36.3 \\
\hline DMEb & 12.3 & 83.9 & 58.5 \\
\hline DMEc & 35.0 & 94.8 & 87.2 \\
\hline FTa & 23.1 & 104.8 & 75.4 \\
\hline FTb & 44.4 & 29.9 & 59.3 \\
\hline FTc & 3.1 & 75.1 & 40.7 \\
\hline MA & 30.6 & 63.4 & 65.4 \\
\hline
\end{tabular}

(a) The electricity and liquid fuel marginal efficiencies are calculated as incremental electricity or liquid fuel output divided by incremental energy inputs. See text for discussion of marginal equivalent electricity efficiency.

\subsubsection{Liquid fuel produced per unit of biomass input}

A commonly cited metric for liquid biofuels is the liquid yield per unit of biomass input, typically expressed in terms of gallons per dry ton. Figure 32 shows results for biofuel yields expressed in terms of gallons of gasoline energy equivalent per metric tonne of dry biomass feedstock (lower x-axis) and also in terms of gallons of ethanol equivalent per dry metric tonne of biomass (upper x-axi). Included in this figure are results from several studies in addition to ours: results for two stand-alone biorefinery designs developed by engineers at the National Renewable Energy Laboratory (NREL) for corn-stover conversion to ethanol via enzymatic hydrolysis routes, one based on vintage-2000 technology [102] and one based on advanced technology [103]; three results published by NREL for stand-alone production of alcohols via thermochemical routes, including one set of results derived from experimental data collected in a pilot-scale test in Gridley, California, where rice husks were converted to ethanol [104] and two sets of results from analyses by NREL engineers [46]; and three results for stand-alone 
switchgrass conversion to DME (two different plant designs) and to Fischer-Tropsch fuels, developed in in the Renewable Biomass for America's Energy Future (RBAEF) project [105]. The remaining ten results correspond to biorefineries integrated with pulp mills, including three results from a 2005 European Union study [4] and the seven designs described in this report. The biomass input in the case of the pulp mill biorefineries includes black liquor, hog fuel, and purchased residues.

All of the designs included in Figure 32 generate one or more co-products with the biofuel. This necessitates some adjustments to arrive at the results shown in the figure. All results above the horizontal dashed line in Figure 32 are for plant designs that include some level of electricity coproduction. To obtain a measure of the effective liquid fuel yield per unit of biomass feedstock for these cases, we have charged a portion of the input biomass to the electricity co-product. We have assumed that the amount of biomass charged to electricity is the amount that would be required to generate the same amount of electricity at a stand-alone biomass IGCC plant. We assume that such an IGCC plant would have a lower-heating value generating efficiency of 49.5\% [106]. Figure 33(a) illustrates the accounting we have used in these cases.

For the pulp mill biorefinery cases (below the dashed line in the figure), it is appropriate to make some additional adjustments to the biomass charged against liquid fuel production since these biorefineries serve to provide, in addition to liquid fuel, not only some electricity but also process steam to the pulp/paper mill and chemical recovery services. Accordingly, for the process designs below the dashed line, we charge only the purchased woody biomass residues against liquid fuels production. Black liquor and residues generated on site (hog fuel) are charged against the pulp mill's steam, power, and chemical recovery needs, since this is the way these inputs are used with Tomlinson systems that exist at all pulp mills in the United States today.

Additionally, several of the pulpmill biorefineries generate more electricity than the Tomlinson systems they would replace. In these cases, some of the purchased residues are charged to the added electricity production - see Figure 33(b). In several other cases, the pulp mill biorefinery produces less electricity than the Tomlinson systems they would replace. In these cases, some additional biomass purchases would be required to reach the same level of electricity production as with the Tomlinson. In these cases, this added biomass requirement is charged against liquid fuels production - see Figure 33(c).

The most striking feature of Figure 32 is that the adjusted liquid fuel yields are higher or substantially higher for all pulp mill biorefineries than for the "stand-alone" biorefineries that coproduce liquid fuels and electricity. The high adjusted yields for the pulp mill biorefineries arise primarily because of the "credits" allocated for the services they provide in addition to delivery of liquids. ${ }^{16}$ As noted above, the additional services include process steam and electricity to the pulp/paper mill and pulping-chemicals recovery. In effect, the biomass resource is utilized more efficiently by integrating the biorefinery with a pulp mill than by using biomass in a stand-alone biorefinery. The value of integration will also be apparent in cost analysis reported later.

\footnotetext{
${ }^{16}$ A liquid fuel yield of 126 gallons of gasoline equivalent per dry metric tonne of biomass (or 202 gallons of ethanol per dry metric tonne of biomass) would correspond to an energy conversion efficiency of biomass to liquid fuel of 100\% (LHV basis). Because of co-product credits, the adjusted liquid fuel yields shown in Figure 32 exceed this level in some cases and sometimes by a considerable amount.
} 


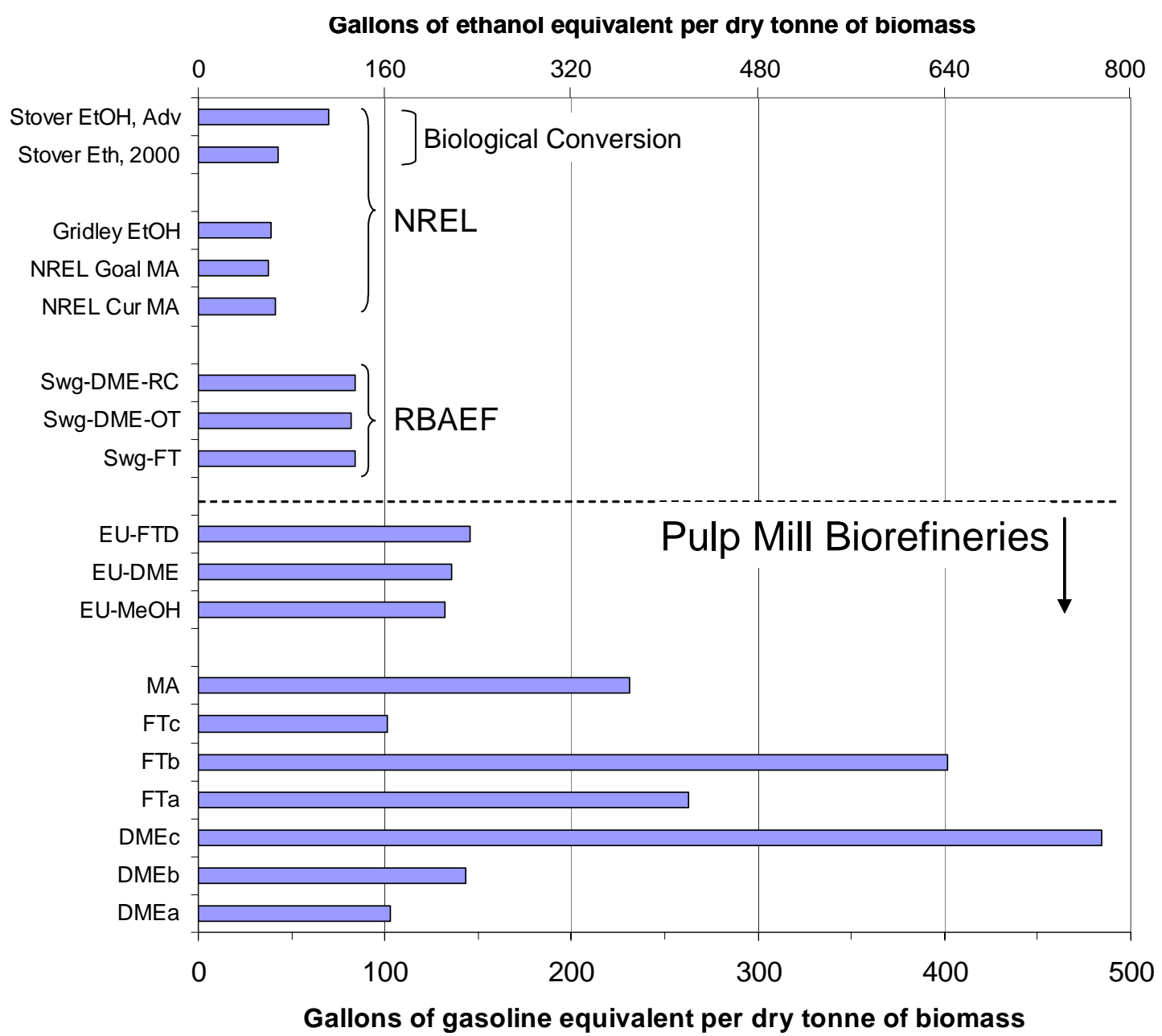

Figure 32. Comparison of adjusted liquid fuel yields (gallon of gasoline equivalent or gallon of ethanol equivalent) per metric tonne of dry biomass input. See text for discussion.

(a)

NREL and RBAEF Systems

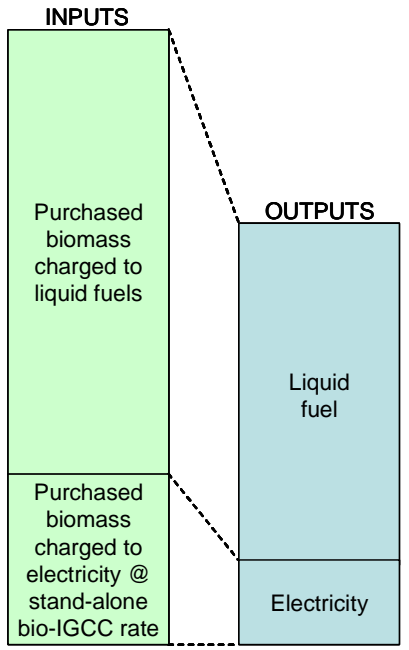

(b)

DMEb, DMEc, FTa, FTb, FTc, MA Pulp/Paper Mill Biorefineries

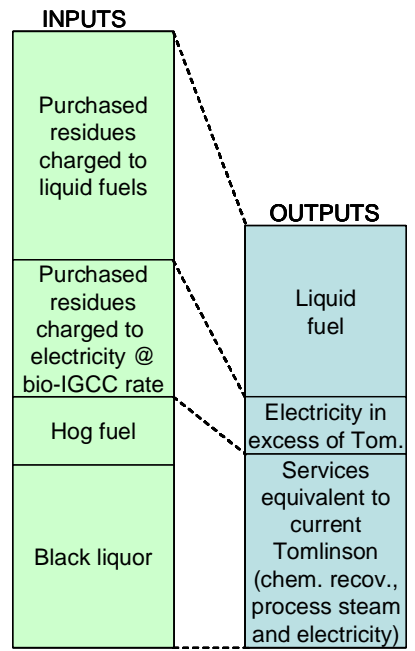

(C)

DMEa, EU-FTD, EU-DME, EU-MeOH Pulp/Paper Mill Biorefineries

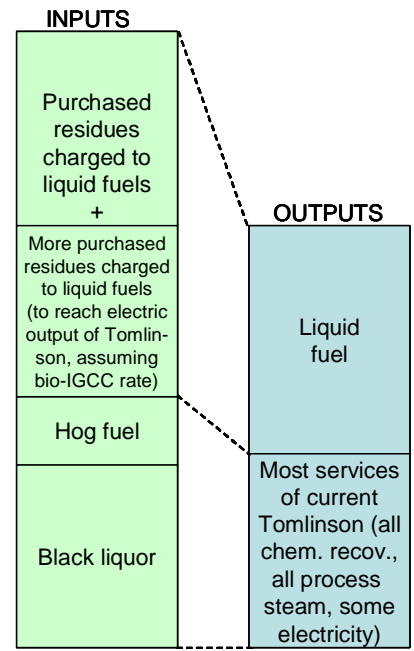

Figure 33. Accounting used to calculate the adjusted liquid fuel yields per unit of biomass input. 


\section{6 "Well-to-Wheels" Environmental Analysis}

\subsection{Overview and Approach}

In addition to energy aspects of the biorefinery systems discussed in Section 5.3, we have also examined environmental attributes. Water, air, and solid effluents are all of potential concern. In assessing the impact that biorefinery systems would have on these effluents relative to levels found with Tomlinson power/recovery systems, one may consider changes both in direct effluents and in effluents associated with the displacement of grid electricity generation and conventional petroleum-based motor fuels. In particular, to effectively estimate the full environmental impacts of biorefineries, the current analysis involves estimating the emissions impacts from resource extraction to end use. This so-called "well-to-wheels" (WTW) analysis is a common approach for making meaningful comparisons between different alternative and conventional fuels. This approach is necessary because of the different upstream production and conversion processes, different downstream vehicle/engine types for different fuels and significant differences in fuel properties and combustion characteristics.

Figure 34 illustrates the general approach to the WTW analysis conducted here. For the most part, this study has relied upon the detailed mass/energy balances described in Section 05.3, together with the sizable body of work that has been developed on WTW analysis for upstream (biomass collection and delivery) and downstream (fuel distribution and vehicle use) processes. For the upstream and downstream air emissions analysis, we rely in particular on the GREET (Greenhouse gases, Regulated Emissions, and Energy use in Transportation) model, developed by Argonne National Laboratory [107]. The GREET model was chosen for several reasons:

- It is publicly available

- It is spreadsheet based, which facilitated its integration into the current analysis

- It is well documented

- It includes all the fuels of interest (except mixed alcohols) ${ }^{17}$

- It has been developed and refined over a period of nearly ten years with sustained support from DOE

- Recent analysis using GREET for the Role of Biomass in America's Energy Future project has also added FT and DME from biomass to the list of fuel chains

- It offers the flexibility to modify assumptions as needed ${ }^{18}$

- The current version of GREET (1.7 Beta) reflects the latest in tailpipe emissions requirements for vehicles (TIER II), including the reduced sulfur content of gasoline and the use of low-sulfur diesel in light-duty vehicles.

\footnotetext{
${ }^{17}$ For the relevant fuel chain steps we used estimates for ethanol, correcting for the relative energy content and density of mixed alcohols.

${ }^{18}$ For example, the GREET model assumes woody biomass is derived from energy plantations, and so includes the energy use and emissions associated with pesticide and fertilizer use. However, it separates this from the emissions associated with the collection and transportation of biomass from farm to plant, such that we could take only those parts that were applicable to forest biomass (i.e., using collection and transportation only as a reasonable estimate for forest biomass).
} 
In general, the default values within the GREET model were used, but in some cases, adjustments were made, mainly to tailpipe emissions for some of the alternative fuels. For tailpipe emissions with alternative fuels, GREET generally defaults to the same value as for the conventional vehicle. Since GREET 1.7 reflects the latest emissions standards for vehicles, as a starting point this is a reasonable assumption. However, for certain pollutants, the alternative fuel should still produce lower emissions. For example, DME should produce lower $\mathrm{PM}$ and $\mathrm{NO}_{\mathrm{x}}$ emissions than a diesel vehicle using low-sulfur diesel. Other key considerations include accounting for the impacts of net electricity purchases/exports and accounting for potential differences in the biorefinery fuel chain relative to what is in established models (e.g., transportation distances). Volume 3 provides complete details on assumptions and data sources.

\subsection{Water and Solid Waste}

Water quality, temperature, and consumption are all potential concerns with biorefineries. Over time, as demand rises for limited fresh water supplies, these issues are likely to only become more important. Briefly, the issues are as follows:

- Water quantity: any water savings results in a direct financial benefit to a mill and also addresses growing concerns over the availability of fresh water for other purposes (e.g., agriculture, human consumption). ${ }^{19}$

- Water quality is of major concern for rare and endangered species, recreation, and for its effects on other users downstream (e.g., municipalities).

- Thermal discharge: The temperature of the cooling water discharge is also of concern for its effect on flora and fauna.

\section{The Forest Biorefinery Fuel Chain}

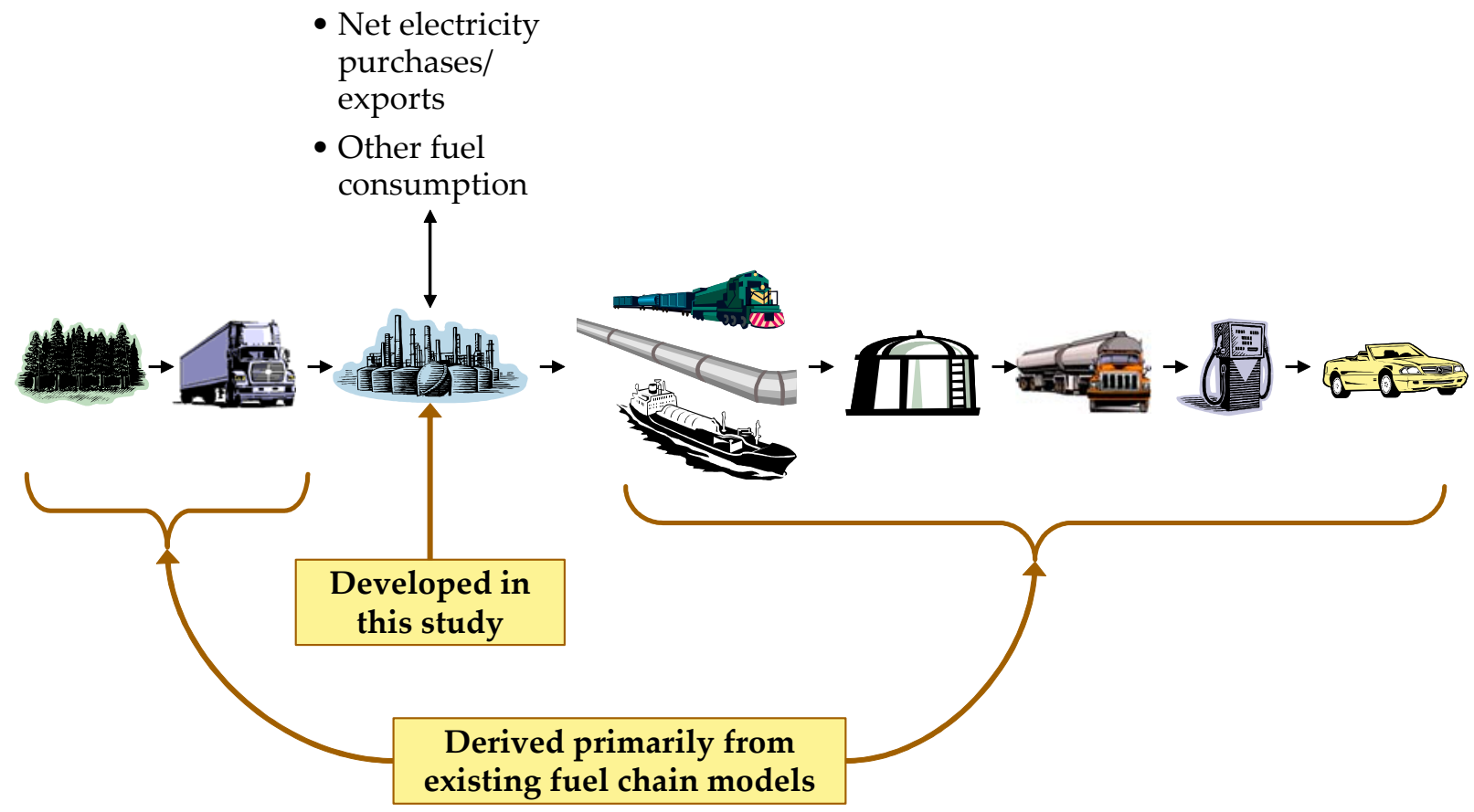

Figure 34: Well-to-Wheels Analysis Framework for Pulp and Paper Biorefineries

\footnotetext{
${ }^{19}$ Potential water savings, which were only assessed at a high level here, were not included in the financial analysis.
} 
Depending on the configuration (amount of fuels and electricity produced), the biorefinery will have different effects on water quantity and thermal discharge at a mill, but overall, the conversion to biorefineries is not expected to significantly impact water quality, especially when considering the impacts on displaced grid power (see Volume 2 for details). Wastewater streams from the direct-contact gas coolers in the biorefinery cases (which do not exist in a Tomlinson system) are used to constitute green liquor, and are thereby effectively recycled. Water use for condenser cooling will be the main source of thermal water pollution with either the biorefinery, BLGCC or Tomlinson technologies. In this regard, since the BLGCC system and five of the seven biorefinery configurations (all DME options, FTa and MA) use back-pressure steam turbines, there is no condenser and therefore no discharge of cooling water. Increases in cooling water requirements for the three DME and the MA configurations come from the need for some external cooling in the fuel synthesis island. For these configurations and for FTa, the net decrease in cooling water requirements relative to a Tomlinson system ranges from 1,000 to $2,000 \mathrm{~m}^{3} /$ hour, and related decreases in makeup water requirements are 35 to $70 \mathrm{~m}^{3} /$ hour. The upper end is comparable to the reduction of about $2,200 \mathrm{~m}^{3} /$ hour in cooling water and 80 $\mathrm{m}^{3}$ /hour in makeup water to the cooling towers for the BLGCC configuration. For FTb and FTc, which have condensing steam turbines but no fuel synthesis island cooling requirements, there is a net increase of about $3,000 \mathrm{~m}^{3} /$ hour in cooling water discharge and about $100 \mathrm{~m}^{3} /$ hour in makeup water requirements relative to the Tomlinson case. There are also smaller makeup water requirements for the biomass gasifier steam. The analysis has also assumed a $1 \%$ steam loss for the biorefinery in general. These add between about $1-30 \mathrm{~m}^{3} /$ hour of additional makeup water requirements, depending on the configuration.

Even though some configurations result in increases in water requirements, all but DMEa result in reductions in grid power production relative to the Tomlinson BASE. This would have associated reductions in cooling water and makeup water requirements, since traditional central station power plants have significant cooling water requirements. An additional benefit is also the avoided water usage in conventional fuel production, which has not been quantified. Moreover, the consequences of spills from petroleum and petroleum product transportation are also reduced. Also, some of the biofuels, namely DME and mixed alcohols, pose much lower risks of groundwater contamination in the event of a fuel leak or spill (e.g., at refueling stations). FT liquids, since they contain very low aromatics, should also pose a lower risk than conventional diesel and gasoline.

Solid waste issues relate to the quantity and toxicity of any solids that must be disposed of. In this regard, biorefineries are not expected to result in significant changes at the mill, in part because the solids produced (mainly ash from biomass) are not problematic to deal with. There will be the need to periodically replace catalysts and guard beds, such as zinc oxide (for $\mathrm{H}_{2} \mathrm{~S}$ ) and activated carbon (for other trace contaminants). Nevertheless, as with water usage, the impacts of displaced grid power (particularly for the coal component of that grid power) and conventional transportation fuel use, would likely result in important reductions of solid waste generation.

\subsection{Mill-Related Air Emissions}

The most significant effluent differences between biorefineries and Tomlinson systems are expected to be in air emissions. This is particularly expected to be the case in a WTW context. As discussed below, air emissions were estimated in detail for both the biorefineries and the Tomlinson power/recovery systems. For comparison, the BLGCC case from our earlier study is 
also shown, with the updated assumptions consistent with the current analysis (e.g., grid power emissions).

Actual air emissions data are available for modern Tomlinson systems. Since emissions data do not exist for BLGCC or biorefinery systems, estimates were made starting with data for coal IGCC and natural-gas combined cycle power systems and adjusting appropriately. Note that relative to the BLGCC configuration, sources of air emissions in a biorefinery are expected to be similar, namely the power island. The production of the biofuel itself does not lead to significant additional sources of air emissions at the biorefinery. For the portions of the fuel chain beyond the biorefinery, the GREET model was used, as described above. This covers biomass collection and transportation and biofuel transportation and vehicle use. Estimates for all systems also include emissions from the lime kiln and hog fuel boilers. Where it is part of the configuration, emissions from the duct burner of the gas turbine combined cycle are also included to provide complete comparisons between all options. Estimates for grid power offsets (for both avoided purchases and exported power relative to the Tomlinson) were also made.

The air emissions analysis presented below is not intended to serve as a complete lifecycle analysis of biorefinery emissions. Rather the estimates provide indicative results of the potential impacts of biorefinery options relative to "business as usual" in the pulp and paper industry. For example, upstream emissions for grid power (i.e., fuel production and transportation to the power plant) are not included, but these are relatively small compared to the power plant emissions themselves and to the total emissions from conventional motor fuel chains. To the extent that most of the biorefinery configurations result in more displaced grid power than the Tomlinson case, the emissions benefits estimated in this study can be considered conservative because they do not also factor in emissions reductions related to fuel supply for power plants.

Air emissions fall into three basic categories: criteria pollutants, hazardous air pollutants (HAPs), and greenhouse gases (GHGs). This study includes quantitative estimates for the criteria pollutants: sulfur dioxide $\left(\mathrm{SO}_{2}\right)$, nitrogen oxides $\left(\mathrm{NO}_{\mathrm{x}}\right)$, carbon monoxide $(\mathrm{CO})$, volatile organic compounds (VOCs), particulate matter (PM), ${ }^{20}$ and total reduced sulfur (TRS). Estimates are also made for carbon dioxide $\left(\mathrm{CO}_{2}\right)$, the major greenhouse gas. HAPs and other emissions issues are discussed qualitatively. ${ }^{21}$

\footnotetext{
${ }^{20}$ For PM, the main concern is with the health impacts of fine particulates smaller than 10 and 2.5 microns in diameter $\left(\mathrm{PM}_{10}\right.$ and $\mathrm{PM}_{2.5}$, respectively). However, data for $\mathrm{PM}_{10}$ and $\mathrm{PM}_{2.5}$ are not always reported with data for total PM emissions. For this reason, estimates here are for total PM. To estimate $\mathrm{PM}_{10}$ and $\mathrm{PM}_{2.5}$ emissions, the reader may assume the following: For solid fuel combustion, if there is a PM control step, such as an electrostatic precipitator, the $\mathrm{PM}_{10}$ emissions are 50-80\% of total PM emissions and $\mathrm{PM}_{2.5}$ emissions are 25-70\% [108,114]. For natural gas combustion, the U.S. EPA assumes that all PM emissions are smaller than 2.5 microns so that PM, $\mathrm{PM}_{10}$ and $\mathrm{PM}_{2.5}$ emissions are equal [109].

${ }^{21}$ According to Miner [110] EPA's HAP rules focus on HAP metal emissions from recovery furnaces, using total particulate matter as a surrogate for metals emissions. For existing furnaces, they require reductions in emissions of organic HAPs, e.g. methanol, that arise from direct contact evaporators, associated black liquor oxidation systems, or wet bottom ESPs. EPA also decided that recovery furnace $\mathrm{HCl}$ emissions do not merit reductions, since the risks posed by the $\mathrm{HCl}$ emissions were determined to be minimal. Further EPA has opted not to address dioxin/furan emissions since there is no known control technology that could be applied to reduce them. Also, the industry believes dioxin/furan emissions from recovery furnaces are inconsequential. EPA did decide to impose a methanol (VOC surrogate) emission limit on new kraft recovery furnaces.
} 
A distinctive feature of biorefinery technologies is the expected low relative emissions for most of the criteria pollutants compared to a modern Tomlinson system employing sophisticated pollution controls (Table 15). Low emissions are an intrinsic characteristic of gas turbine technology and of syngas conversion to fuels in part because considerable upstream removal of contaminants in the raw syngas is required to protect the gas turbine and various catalyst beds from damage, as well as to recover pulping chemicals from the syngas. Also, gas turbine combustion is inherently efficient and low in emissions, as is the combustion of purge gases in duct burners or existing boilers. ${ }^{22}$ It is worth noting that there could be emissions benefits from burning purge gases in existing power boilers (as in the DMEa case), for example as a reburn fuel to reduce $\mathrm{NO}_{\mathrm{x}}$. Also, if excess purge gas could replace fuel oil in lime kilns, there may be further emissions benefits. These benefits have not been estimated here.

Biomass is a renewable fuel from a GHG perspective if the $\mathrm{CO}_{2}$ emitted in its use is photosynthetically removed from the atmosphere by replacement biomass growth. There are some fossil fuel GHG emissions associated with the biomass-to-biofuel chain, which have been included in this analysis. However, no attempt has been made to estimate emissions resulting from land use changes or from the growing of the biomass itself, which is assumed to be from existing commercial timberland. Thus, the estimates here of total net emissions of $\mathrm{CO}_{2}$ and other pollutants described below for each configuration do account for the harvesting and transportation of the incremental biomass used compared to the Tomlinson case, as well as the downstream steps of transporting and distributing the biofuels, but with the assumption that wood-derived energy (for power or fuels) produces no net $\mathrm{CO}_{2}$ emissions, other than from the fossil fuels used in the process. For completeness, Volume 3 shows actual emissions of $\mathrm{CO}_{2}$ associated with the wood-derived power and fuels (in addition to the net emissions). Biomass combustion also generates small amounts of non- $\mathrm{CO}_{2}$ greenhouse gases - specifically, methane and nitrous oxide $\left(\mathrm{N}_{2} \mathrm{O}\right)$. However, even after considering the potency of methane and nitrous oxide as greenhouse gases, these emissions are expected to be small, and therefore, they have not been included in the analysis. ${ }^{23}$ However, the exploration and production of petroleum and natural gas does result in relatively large methane emissions, so that it is reasonable to expect that biorefineries would achieve net $\mathrm{CH}_{4}$ reductions on a WTW basis when they replace Tomlinson systems.

An additional feature of biorefineries not evaluated here, but that could be important to overall mill operations as it relates to environmental discharges, is the potential to more tightly integrate and eliminate various waste steams. ${ }^{24}$ In "next generation" mills, the desire is to "close up" various emissions sources as much as possible. For example, the pulp \& paper industry has been trying to develop a cost-effective way to eliminate the effluent from bleached kraft pulp mills. The most likely approach for eliminating these effluents (primarily bleach plant filtrates) involves sending them to the recovery furnace, yet few mills currently recycle bleach plant filtrates to the recovery furnace because these furnaces are sensitive to a number of elements contained in the filtrates (chlorides and potassium being of special note) and the costs of removing these substances are high. If gasification turns out to be more amenable to this type of

\footnotetext{
${ }^{22}$ All syngas-to-fuel conversion processes result in some unconverted syngas, sometimes called "purge gas". These gases are low in contaminants and burn cleanly in gas turbines, duct burners or in existing boilers or unit operations.

${ }^{23}$ For example, see [112].

${ }^{24}$ Personal communication with Reid Miner and Dr. John Pinkerton of NCASI, 3 December, 2002.
} 
overall mill integration, this would be a significant advantage over conventional recovery systems.

\subsubsection{Tomlinson Boiler Air Emissions}

Modern Tomlinson boilers are characterized by emissions of criteria pollutants that are similar overall to grid power (some are higher, like $\mathrm{CO}$ and PM, while others are lower, like $\mathrm{SO}_{2}$ and $\mathrm{NO}_{\mathrm{x}}$ ). The most significant pollutants, in terms of both environmental impacts and relative emissions rates from Tomlinson boilers, are $\mathrm{NO}_{\mathrm{x}}$ and particulates (Table 15). While many furnaces already have particulate controls in place, there is no effective form of $\mathrm{NO}_{\mathrm{x}}$ aftertreatment (see below). Furnace rebuilds and replacements trigger the New Source Review (NSR) process, which generally results in process modifications being made to reduce TRS emissions. ${ }^{25}$ Installation of more efficient particulate control is also common following a NSR, and generally, modern furnaces have better design and controls than older ones, which results in lower overall emissions.

Table 15: Qualitative indication of relative environmental impact of different mill-level emissions, together with relative emission rates for controlled and uncontrolled Tomlinson furnaces and with Biorefinery technology ( $\mathrm{VL}=$ very low, $\mathrm{L}=$ low, $\mathrm{M}=$ moderate, $\mathrm{H}=$ high).

\begin{tabular}{|c|c|c|c|c|}
\hline $\begin{array}{l}\text { Pollutant/ } \\
\text { Discharge }\end{array}$ & $\begin{array}{l}\text { Relative } \\
\text { Environmental } \\
\text { Impact of } \\
\text { Pollutant }\end{array}$ & $\begin{array}{l}\text { Relative Emissions } \\
\text { Rates from } \\
\text { Tomlinson Furnaces } \\
\text { (uncontrolled) }\end{array}$ & $\begin{array}{c}\text { Relative } \\
\text { Emissions Rates } \\
\text { with Controls on } \\
\text { Tomlinson }\end{array}$ & $\begin{array}{c}\text { Relative } \\
\text { Emissions Rates } \\
\text { Expected with } \\
\text { Biorefineries }\end{array}$ \\
\hline $\mathrm{SO}_{2}$ & $\mathrm{H}$ & L & $L$ (not required) & VL \\
\hline NOx & $\mathrm{H}$ & M & $M^{d}$ & VL \\
\hline co & L & M (can be highly variable) & $M^{d}$ & VL \\
\hline VOCs & $\mathrm{H}$ & L & $L^{d}$ & VL \\
\hline $\mathbf{P M}^{\mathbf{b}}$ & $\mathrm{H}$ & $\mathrm{H}^{\mathrm{c}}$ & L-M & VL \\
\hline $\mathrm{CH}_{4}$ & L-M & L & $L^{d}$ & VL \\
\hline HAPs & $\mathrm{M}-\mathrm{H}$ & $\mathrm{L}^{\mathrm{c}}$ & $\mathrm{L}^{\mathrm{c}}$ & VL \\
\hline TRS & L & L & $L^{d}$ & VL \\
\hline $\begin{array}{l}\text { Waste } \\
\text { Water }\end{array}$ & $\mathrm{M}-\mathrm{H}$ & L & L & VL-L \\
\hline Solids & L & L & L & L \\
\hline \multicolumn{5}{|c|}{$\begin{array}{l}\text { a) General importance, not specifically for the } P \& P \text { industry. } \\
\text { b) } P M=\text { particulate matter. Of greatest concern with PM emissions are fine particulates smaller than } 10 \text { and } 2.5 \text { microns in diameter } \\
\text { (PM } M_{10} \text { and } P M_{2.5} \text { respectively). } \\
\text { c) Current } M A C T I I \text { rules are expected to result in about a } 10 \% \text { reduction of HAPs and a modest reduction in PM. } \\
\text { d) Not generally practiced other than by maintaining good combustion efficiency. } \\
\text { e) Total reduced sulfur. }\end{array}$} \\
\hline
\end{tabular}

The only regulatory trend regarding add-on controls to a Tomlinson system is to require installation of dry-bottom electrostatic precipitators (ESPs) on new kraft recovery furnaces. This is being driven by the current EPA MACT II $^{26}$ regulations designed to reduce HAP emissions

\footnotetext{
${ }^{25}$ Typically direct-contact evaporators and black liquor oxidation units are eliminated to reduce TRS emissions.

${ }^{26}$ MACT stands for "maximum achievable control technology" and was put in place to reduce HAPs.
} 
from combustion sources in the pulp and paper industry. The MACT II rules will also result in reduced PM emissions, which are captured with $>99 \%$ efficiency by ESPs. The pulp and paper industry must be in compliance with MACT II as of March $2004 .^{27}$ Thus, compliance with MACT II forms the basis for comparisons here. This and other assumptions used in this study to estimate emissions in the Tomlinson case are summarized in Table 16. Volume 3 provides additional details on the resulting emission factors.

Table 16: Study assumptions for emissions characteristics of modern Tomlinson furnaces. ${ }^{a}$

\begin{tabular}{|c|c|c|}
\hline Pollutant $^{b}$ & Characteristics & Study Assumption \\
\hline $\mathrm{CO}_{2}$ & $\begin{array}{l}\text { Since biomass is the fuel source for Tomlinson boilers (other than } \\
\text { fuel oil or gas used at startup), net } \mathrm{CO}_{2} \text { emissions are zero. }\end{array}$ & $\begin{array}{l}\text { Zero, per discussion in } \\
\text { Section } 6.3 \text {. }\end{array}$ \\
\hline $\mathrm{SO}_{2}$ & $\begin{array}{l}\text { Scrubbers are not needed since } \mathrm{SO}_{2} \text { emissions are typically low by } \\
\text { virtue of the design and operation of a Tomlinson furnace and the } \\
\text { higher solids firing rates in newer units. } \mathrm{SO}_{2} \text { typically measures less } \\
\text { than } 10 \mathrm{ppm} @ 8 \% \mathrm{O}_{2} \text {. }\end{array}$ & 10 ppm @ 8\% O \\
\hline $\mathrm{NO}_{\mathrm{x}}$ & $\begin{array}{l}\mathrm{NO}_{x} \text { remains the biggest issue for Tomlinson boilers. Emissions are } \\
\text { typically in the } 100-130 \text { ppm range } @ 8 \% \mathrm{O}_{2}(\sim 2.5 \mathrm{lb} / \text { ton black liquor } \\
\text { solids). Conventional } \mathrm{NO}_{x} \text { after-treatment (e.g., SCR, SNCR) has not } \\
\text { been considered technically feasible [110]. The BACT standard is } \\
\text { essentially combustion controls, e.g., a Tomlinson boiler is effectively } \\
\text { a staged combustion device with multiple inlets for combustion air. } \\
\text { These are "typical" approaches to controlling } \mathrm{NO}_{x} \text { with combustion } \\
\text { modifications. }\end{array}$ & 100 ppm @ 8\% O 2 \\
\hline CO & $\begin{array}{l}\mathrm{CO} \text { can be highly variable but is typically low and is controlled by } \\
\text { maintaining efficient combustion. }\end{array}$ & 100 ppm @ 8\% O 2 \\
\hline VOCs & VOCs are typically low, e.g., formaldehyde is about $1 \mathrm{ppm}$ & $\begin{array}{l}0.16 \mathrm{lb} / \text { ton black liquor } \\
\text { solids }\end{array}$ \\
\hline $\mathrm{PM}_{10}$ & PM is controlled to $>99 \%$ efficiency using ESPs & $\begin{array}{l}0.57 \mathrm{lb} / \text { ton black liquor } \\
\text { solids }^{c}\end{array}$ \\
\hline TRS & $\begin{array}{l}\text { Total reduced sulfur (TRS) is also low with a new furnace using an } \\
\text { indirect-contact evaporator and no black liquor oxidation unit. }\end{array}$ & $\begin{array}{l}0.04 \mathrm{lb} / \text { ton black liquor } \\
\text { solids }\end{array}$ \\
\hline
\end{tabular}

(a) Sources: [111,112,113,114,115,116,117]

(b) Biomass combustion also generates small amounts of non- $\mathrm{CO}_{2}$ greenhouse gases - specifically, methane and nitrous oxide. However, even after considering the potency of methane and nitrous oxide as greenhouse gases, these emissions are small. As a result, they have not been included in the analysis. For example, see NCASI [118].

(c) This value is for total PM, but since an ESP is used, total PM is assumed to be very close to $\mathrm{PM}_{10}$.

\subsubsection{Gas Turbine Air Emissions}

Gas turbine air emissions burning syngas from black liquor and/or biomass are likely to closely mirror those of modern gas turbines operating on natural gas, since the emissions are mainly associated with the combustion process taking place in the gas turbine. Instead of natural gas the biorefinery power island will burn clean syngas from biomass gasification, unconverted syngas from fuel synthesis, or a combination of the two. ${ }^{28}$ Modern gas turbines are characterized by very low emissions of criteria pollutants. In this study we have assumed that mills would generally not

${ }^{27}$ MACT II may be revisited by EPA in 2009 (ten years after promulgation of the rule) to assess any "residual risk" but it is unclear if this will actually occur or if it is revisited, if it will result in new regulations.

${ }^{28}$ One uncertainty relates to the amount and chemical form of nitrogen (if any) that might be carried in the syngas originating from nitrogen in the black liquor. Where wet scrubbing is used in the biorefineries, nitrogen compounds may be removed in that step. 
be located in ozone non-attainment areas and therefore would not be required to install $\mathrm{NO}_{\mathrm{x}}$ after-treatment such as SCR. Thus $\mathrm{NO}_{\mathrm{x}}$ emissions are assumed to be consistent with dry low$\mathrm{NO}_{\mathrm{x}}$ gas turbine combustion, in the range of $25 \mathrm{ppm}$ at $15 \% \mathrm{O}_{2} \cdot{ }^{29}$ Emissions of $\mathrm{CO}$ and VOCs are inherently low with gas turbines due to efficient combustion. PM in the syngas must be removed to very low levels in order to protect the gas turbine from damage, so PM emissions will also be low. There is considerable experience with successful use of inexpensive carbon bed filters for removal of mercury and other trace elements from fuel gas in coal gasification systems. ${ }^{30}$ A similar approach is assumed to be viable for the biorefinery power island.

Operating experience with coal IGCC systems also provides a basis for estimating likely biorefinery power island air emissions, taking account of some important differences between black liquor/biomass and coal gasification. First, coal is much higher in ash and metals (other than alkali). Second, sulfur recovery efficiencies will be higher with black liquor (near 100\%) because the goal is to capture sulfur for reuse in the pulping process, and in most cases, catalysts are easily poisoned by even trace amounts of sulfur. ${ }^{31}$ In comparison, coal IGCC plants are typically designed for sufficient sulfur removal (e.g., 98\%) to meet permitting requirements. In the case of biomass syngas used directly in power generation (i.e., not used in fuel synthesis first), no sulfur removal is necessary.

Table 17 summarizes emissions characteristics for gas turbines assumed in this study. Volume 3 provides additional details on the resulting emissions factors.

\section{Table 17: Study assumptions for emissions characteristics of gas turbines burning syngas at} biorefineries

\begin{tabular}{|c|c|c|}
\hline Pollutant & Characteristics & Study Assumption \\
\hline $\mathrm{CO}_{2}$ & $\begin{array}{l}\text { For any biomass-derived fuels used, net } \mathrm{CO}_{2} \text { emissions are } \\
\text { assumed to be zero (see discussion in Section 6.3) }\end{array}$ & $\begin{array}{l}\text { Varies, depending } \\
\text { on fuel mix }\end{array}$ \\
\hline $\mathrm{SO}_{2}$ & $\begin{array}{l}\mathrm{SO}_{2} \text { emissions are expected to be very low. In the case of the use } \\
\text { of unconverted syngas, the fuel gas is scrubbed of nearly all } \mathrm{H}_{2} \mathrm{~S} \text {. } \\
\text { In the case of the use of biomass syngas, the gas is not scrubbed } \\
\text { of } \mathrm{H}_{2} \mathrm{~S} \text {, but biomass is low in sulfur ( } 0.06 \% \text { by weight, dry basis). }\end{array}$ & $\begin{array}{l}\text { Varies, depending } \\
\text { on the fuel used }\end{array}$ \\
\hline $\mathbf{N O}_{\mathbf{x}}$ & $\begin{array}{l}\text { Dry low- } \mathrm{NO}_{x} \text { combustion can reduce emissions with natural gas to } \\
\text { as low as } 9 \text { ppm @ } 15 \% \mathrm{O}_{2} \text {. For } \mathrm{BLGCC} \text { operation we have } \\
\text { assumed a more conservative value. }\end{array}$ & 25 ppm @15\% O \\
\hline $\mathrm{CO}$ & $\begin{array}{l}\mathrm{CO} \text { is generally low from gas turbine combustors due to efficient } \\
\text { combustion. }\end{array}$ & $\begin{array}{l}0.033 \mathrm{lb} / \mathrm{MMBtu} \text { fuel } \\
\text { input }\end{array}$ \\
\hline VOCs & $\begin{array}{l}\text { VOCs are generally low with gas turbines due to efficient } \\
\text { combustion - uncontrolled values are assumed. }\end{array}$ & $\begin{array}{l}0.0021 \mathrm{lb} / \mathrm{MMBtu} \\
\text { fuel input }\end{array}$ \\
\hline PM & $\begin{array}{l}\text { PM are generally very low for gas turbine operation. Upstream } \\
\text { syngas cleanup is assumed to control PM to very low levels. }\end{array}$ & $\begin{array}{l}0.0066 \mathrm{lb} / \mathrm{MMBtu} \\
\text { fuel input }\end{array}$ \\
\hline TRS & $\begin{array}{l}\text { Total reduced sulfur (TRS) is essentially zero, since the fuel gas is } \\
\text { scrubbed of } \mathrm{H}_{2} \mathrm{~S} \text { to return the sulfur to the pulping process. }\end{array}$ & Zero \\
\hline
\end{tabular}

References: [119, 120, 121, 122,123,124,125,126]

${ }^{29}$ Current BACT (best available control technology) for coal IGCC power plants is 15 ppm NOx @ 15\% $\mathrm{O}_{2}$ (www.gepower.com, accessed 6/16/2003).

${ }^{30}$ For example, such filters have been in use for many years at the Eastman Chemicals coal gasification facility in Kingsport, Tennessee, where methanol is made from gasified coal.

${ }^{31}$ Mixed alcohol catalysts are sulfur tolerant, but for FT and DME, essentially complete sulfur removal is required. 
Other sources of emissions in the BLGCC and four of the biorefineries in this study are the gas turbine exhaust duct burners using unconverted syngas (or in the BLGCC case, a mixture of syngas and natural gas). Emissions from duct burners are assumed to be similar to state-of-the art natural gas combustion. Additional details are provided in Volume 3.

\subsection{Grid Power Air Emissions and Offsets}

Varying amounts of power are generated in the different biorefinery cases. All except DMEa produce more net electricity than the Tomlinson case. Only the FTb case produces enough electricity to export power to the grid, however, after meeting mill process needs. The increase in power generation between the biorefinery cases and the Tomlinson case would therefore result in an equal amount of power generation offsets from the grid (again, with the DMEa case as the exception). ${ }^{32}$ The environmental value of these grid power offsets is an important consideration and will vary depending on what type of power is being displaced. ${ }^{33}$

Determining what type of grid power would be displaced is difficult, particularly in the context of a national impacts analysis. Even though the biorefinery would produce baseload power, the operation of existing baseload power plants (typically large coal, nuclear and hydropower plants, as well as gas-fired combined cycle plants) is not likely to change significantly by the addition of biorefineries at pulp/paper mills. Similarly, peaking and intermediate-load power plants, which would typically be smaller, older coal- or oil-fired plants, gas turbines and dispatchable hydropower, run intermittently and thus do not provide a good direct point of comparison, since their operation is dictated by the real-time needs of balancing supply and demand. Other renewable energy sources, like wind, solar and small hydro are also not likely to be directly displaced by biorefineries (or any other dispatchable power plant). These plants typically run whenever the resource is available and the grid can accept the power, with the load-following plants adjusting their output accordingly. Furthermore, these plants typically have very low marginal operating costs and would therefore be cost-effective to run whenever the resource is available.

A more complicated analysis would be to estimate the marginal mix of power, as this is what would be displaced by the "next kWh" of generation added to the grid. Even if this were done, the concept of the marginal mix has limited meaning in a national context, since the marginal mix is mainly relevant for a specific regional power pool. A simpler analysis would use the grid average, since data are readily available.

Given the scope and level of effort for this project, the grid-average approach was chosen, consistent with the recommendation of the Steering Committee in our prior BLGCC study [5]. The projected average fuel mix for electricity generation used to estimate the grid emissions offsets is shown in Table 18, based on the DOE's most recent Reference Case forecast (for $\mathrm{CO}_{2}$,

\footnotetext{
${ }^{32}$ As with our previous BLGCC study, we ignore any transmission and distribution energy losses associated with grid power, even though for displaced purchases, there would be some additional benefits in this regard.

33 The impacts of biorefineries on HAP emissions were not quantified in the analysis. Given increasing concerns over HAPs emissions, a useful follow-on activity would be to quantify the benefits of biorefineries vis-à-vis HAP emissions. Of particular significance would be the hydrochloric acid and mercury emissions that would be reduced if coal-generated power on the grid were displaced by biorefinery electricity.
} 
$\mathrm{SO}_{2}$, and $\mathrm{NO}_{\mathrm{x}}$ ) [134] and from EPA estimates of recent historical emissions (for $\mathrm{CO}$, VOC, and $\left.\mathrm{PM}_{10}\right)$.

Table 18: Total average U.S. grid emissions (including non-fossil fuel sources) assumed in estimating grid offsets. ${ }^{a}$

\begin{tabular}{|c|c|c|c|}
\cline { 2 - 4 } \multicolumn{1}{c|}{} & \multicolumn{3}{c|}{$\mathbf{l b} / \mathbf{M W h}$} \\
\cline { 2 - 4 } \multicolumn{1}{c|}{} & $\mathbf{2 0 1 0}$ & $\mathbf{2 0 2 0}$ & $\mathbf{2 0 3 5}$ \\
\hline $\mathbf{C O}_{2}$ & 1,340 & 1,303 & 1,316 \\
$\mathbf{S O}_{2}$ & 2.836 & 1.684 & 0.851 \\
$\mathbf{N O}_{\mathbf{x}}$ & 1.125 & 0.886 & 0.584 \\
$\mathbf{C O}$ & 0.234 & 0.172 & 0.108 \\
$\mathbf{V O C}$ & 0.024 & 0.018 & 0.011 \\
$\mathbf{P M}_{10}$ & 0.326 & 0.239 & 0.150 \\
\hline
\end{tabular}

(a) Sources: [134,127,128,129, Navigant Consulting, Inc. analysis].

(b) Extrapolated from the EIA forecast [134], which only goes to 2030.

The grid power emission assumptions here are similar to those used in our prior BLGCC study [5], with two important changes:

1. $\mathrm{PM}_{10}$ emissions: The EPA, in its National Emissions Inventory (NEI) Air Pollutant Emissions Trends Data (formerly called the Air Pollutant Emissions Trends Data), has changed the way it reports $\mathrm{PM}_{10}$ data. Specifically, beginning with 1999 data, EPA now reports "primary $\mathrm{PM}_{10}$ " which includes both filterable and condensable $\mathrm{PM}_{10}$. Prior to this change EPA only reported filterable $\mathrm{PM}_{10}$ for electric utilities. This is the main reason for the higher $\mathrm{PM}_{10}$ emissions in Table 18 compared to the values used in our earlier BLGCC study.

2. EPA's new Clean Air Interstate Rule (CAIR): Promulgated in March 2005, the CAIR is intended to significantly reduce emissions of fine particulates $\left(\mathrm{PM}_{2.5}\right), \mathrm{NO}_{\mathrm{x}}$, and $\mathrm{SO}_{2}$. As a result, the grid power emissions factors for $\mathrm{NO}_{\mathrm{x}}$ and $\mathrm{SO}_{2}-$ this study does not estimate $\mathrm{PM}_{2.5}$ - are substantially lower than in the earlier study, particularly in the out-years (2020 and beyond). This has a significant impact on the net emissions benefits of power generation at biorefineries, as far as $\mathrm{SO}_{2}$ and $\mathrm{NO}_{\mathrm{x}}$ are concerned.

\subsection{Emissions from the Biorefinery Fuel Chain}

As depicted in Figure 34, the biorefinery itself is only one source of emissions along the full fuel chain. In this section we summarize the approach for estimating emissions from the various parts of the biofuels fuel chain. The detailed emissions and energy use figures for each stage of the fuel chain can be found in Volume 3.

\subsubsection{Biomass Collection and Transportation}

For purchased biomass residues, we estimate the energy use and emissions associated with harvesting and transporting the wood to the mill. We ignore the energy use and emissions associated with pulpwood logs, since this is a pre-existing use of biomass not primarily related to the production of energy. We do, however take credit for any reductions in pulpwood log requirements resulting from higher pulping yields, and compute the collection and transportation 
energy use and emissions on the net increase in biomass use at the mill, as a result of the conversion to a biorefinery. ${ }^{34}$

We used the GREET defaults for energy use and emissions associated with the collection and transportation of woody biomass from woody biomass energy plantations (i.e., excluding the energy and emissions associated with fertilizers, pesticides and farm equipment used for growing the biomass). We also increased GREET's default 1-way transport distance from 40 to 75 miles.

\subsubsection{Biorefinery}

Biorefinery emissions are estimated for the lime kiln and gas turbine, except in the DMEa case, where there is no gas turbine and the hog fuel and purchased residues (and some unconverted syngas) are burned in boilers. Although the use of syngas could help reduce emissions from the hog fuel boiler (e.g., as a "reburn" fuel to reduce $\mathrm{NO}_{\mathrm{x}}$ ), we have only made adjustments to the $\mathrm{SO}_{2}$ emissions, since the unconverted syngas is scrubbed of sulfur. The DMEb, DMEc, FTa, and MA cases (like the BLGCC case) also make use of a duct burner to augment steam production in the heat recovery steam generator. Duct burner emissions are included in those cases.

In the FTa, FTb and FTc cases, we also included an estimate of the energy use and emissions for refining the crude FT product into a finished product (32\% FT gasoline and 68\% FT diesel split, based on energy ${ }^{35}$ ). For FT gasoline we used the default GREET estimates for conventional gasoline refining, and for FT diesel we used GREET's conventional diesel refining estimates. We chose not to use reformulated gasoline (RFG) or low-sulfur diesel (LSD) because crude FT is free of sulfur and aromatics, and therefore relatively easy to refine. Thus, the refining efficiencies are slightly higher than for RFG or LSD.

\subsubsection{Fuel Transportation and Distribution}

The GREET model includes emissions estimates for the transportation and distribution of a wide range of biofuels and conventional fuels (and intermediates, such as crude oil). We have used these estimates for the biorefinery cases as given in Table 19.

Table 19: Correspondence between the biorefinery fuel and the fuel chain available in GREET fuel transportation and distribution

\begin{tabular}{|c|c|l|}
\hline Biorefinery Fuel & GREET Fuel & \multicolumn{1}{c|}{ Adjustments } \\
\hline DME & DME & Assumed only rail and truck transport (i.e., used locally) \\
\hline Crude FT & Crude Oil & Assumed only rail transport from biorefinery to petroleum refinery \\
\hline FT Gasoline & Conventional Gasoline & $\begin{array}{l}\text { None (assumes FT gasoline blended with regular gasoline for } \\
\text { transport) }\end{array}$ \\
\hline FT Diesel & FT Diesel & None \\
\hline Mixed Alcohols & Ethanol & Assumed only rail and truck transport (i.e., used locally) \\
\hline
\end{tabular}

\footnotetext{
${ }^{34}$ For example, if the conversion to a biorefinery results in increased pulping yields, resulting in the reduction 5 units of wood to process for the same amount of finished product, but the purchased biomass requirements (for energy) are 75 additional units, the impacts of biomass collection are estimated on just 70 units of biomass, the net increase.

${ }^{35}$ Our FT plants are designed to produce a synthetic crude product that is shipped to an existing petroleum refinery for upgrading to finished products. Larson et al. [105], using the same kinetic model as we have used, but including onsite upgrading to finished product, indicate that the finished product is produced as a split of $68 \%$ diesel and $32 \%$ motor gasoline (on an energy basis).
} 


\subsubsection{Vehicles End Use}

A number of vehicle options are possible, depending on the fuel. Table 20 shows the combinations assessed here. The analysis is limited to light-duty vehicles. In the case of DME, this fuel is most likely in the near term to be used in centrally-refueled heavy duty vehicles (buses, delivery trucks, etc.), as discussed in Section 2.2. However, we have chosen to focus on light-duty vehicles to provide a conservative estimate of WTW air emissions impacts.

Reductions in air emissions are likely to be larger with heavy duty vehicles than what we have estimated here. (In our financial analyses presented in Section 8, we also consider the use of DME as an LPG replacement, but we have not carried out a full environmental impact assessment of this scenario. Similarly, our financial analysis for mixed alcohols included a scenario where higher alcohols are separated out and used to replace petroleum-derived chemicals, but we have not assessed the air emissions impacts of this scenario.)

Table 20: Correspondence between the biorefinery fuel and the fuel chain available in GREET vehicle end use

\begin{tabular}{|l|l|}
\hline Biorefinery Fuel & Vehicle Options Analyzed \\
\hline DME & $\begin{array}{l}\text { Compression ignition direct injection (CIDI) engine } \\
-100 \% \text { DME (dedicated vehicle converted/optimized for DME use) }\end{array}$ \\
\hline FT Gasoline & $\begin{array}{l}\text { Spark ignition (SI) engine } \\
\text { - Low-level (10\%) blend of FT gasoline with conventional gasoline } \\
\text { - } 100 \% \text { FT gasoline }\end{array}$ \\
\hline FT Diesel & $\begin{array}{l}\text { CIDI } \\
\text { - Low-level (10\%) blend of FT diesel with low-sulfur diesel } \\
\text { - } 100 \% \text { FT diesel }\end{array}$ \\
\hline Mixed Alcohols & $\begin{array}{l}\text { SI engine } \\
\text { - Low-level (10\%) blend of mixed alcohols with conventional gasoline (similar to E10) } \\
\text { - High level (85\%) blend of mixed alcohol with conventional gasoline in flex-fuel vehicle } \\
\text { (similar to E85 FFV) }\end{array}$ \\
\hline
\end{tabular}

In developing the biofuels tailpipe emissions factors, some adjustments were made to the GREET model default values, since they typically assume that the alternative fuel vehicle emissions are the same (in $\mathrm{g} / \mathrm{mile}$ ) as conventional petroleum fuels. For example, the GREET defaults for DME use in compression-ignition, direct-injection (CIDI) engines make no adjustment for $\mathrm{PM}_{10}$ or $\mathrm{NO}_{\mathrm{x}}$, even though an engine optimized for $\mathrm{DME}$ is expected to produce virtually no tailpipe $\mathrm{PM}_{10}$ emissions and substantially reduced $\mathrm{NO}_{\mathrm{x}}$. Nevertheless, because v1.7 of GREET includes the latest in tailpipe emissions requirements and the use of low-sulfur diesel, the baseline emissions are already relatively low. Thus, additional improvements from biofuel use are expected to be modest. The adjustments made to DME tailpipe emissions are based on Oguma and Shinichi [130]. Adjustments to FT gasoline and FT diesel as neat fuels are based on Delucchi [131]. Adjustments were also made to $\mathrm{CO}_{2}$ emissions based on the carbon content of the different fuels. For example, GREET has no $\mathrm{CO}_{2}$ factors for mixed alcohols, so the GREET $\mathrm{CO}_{2}$ emissions for ethanol were adjusted based on the relative carbon content of the two fuels. The specific assumptions made are included in Volume 3.

\subsubsection{Fuel Blends versus Neat Fuels}

Although DME requires engine modifications for a diesel-engine vehicle to run on pure DME, FT fuels and mixed alcohols can be used in low-level (like E10) or high-level (like E85) blends with conventional fuels or as neat fuels ( $100 \%$ biofuels) with little or no engine modifications. Our baseline cases assume low-level blends, consistent with how most biofuels are used today. 
Under these circumstances, tailpipe emissions of criteria pollutants are not expected to be substantially different than with conventional fuels. However, with high-level blends or neat fuels, engines can be optimized to take advantage of the desirable characteristics of the biofuels, resulting in lower tailpipe emissions. For the most part, the impact of this is modest, but for a selected set of pollutants and biorefinery cases, the differences are more pronounced. This analysis, presented in Volume 3, provides indicative results of the incremental benefits of neat biofuels over low-level blends. In this comparison, we have not assumed any differences in vehicle efficiencies, and as such the impacts of blends vs. neat fuels is limited to selected tailpipe emissions. Net $\mathrm{CO}_{2}$ emissions per unit of biofuel are essentially unchanged because vehicle efficiencies are assumed to be the same in both the low-level and high-level blend/neat fuel cases.

\subsection{Energy Use and Emissions from Conventional Fuel Chains}

The default GREET assumptions form the basis for comparing the biofuel fuel chain options to conventional fuel chain options. These assumptions are for a 2010 timeframe. As discussed above, in that timeframe conventional vehicles in the United States are expected to have relatively low tailpipe emissions because of the implementation of TIER II standards and the use of low-sulfur diesel. Table 21 shows which of GREET's conventional fuel chains have been used for comparisons to the biorefinery fuels. The specific assumptions that are used are summarized in Volume 3.

Table 21: Biorefinery fuel and the corresponding conventional fuel chain used to estimate net emissions impacts

\begin{tabular}{|l|l|}
\hline Biorefinery Fuel & Conventional Fuel Chain Benchmark \\
\hline DME & Low-sulfur diesel in a CIDI engine \\
\hline FT Gasoline & $50: 50$ mix (fleet average) of conventional gasoline and RFG in an SI engine \\
\hline FT Diesel & Low-sulfur diesel in a CIDI engine \\
\hline Mixed Alcohols & $50: 50$ mix (fleet average) of conventional gasoline and RFG in an SI engine \\
\hline
\end{tabular}

\subsection{Net Emissions Estimates for the Case Study Biorefinery Systems}

Total fuel cycle emissions for each biorefinery are shown here based on the above discussions and the detailed emission factors described in Volume 3. Included in the figures below are the following:

\section{Emissions Sources}

- Emissions associated with biomass collection and transport for the incremental biomass used (as discussed above) in the biorefinery cases relative to the Tomlinson case.

- All major emissions sources affected by the conversion of the mill to a biorefinery (lime kiln, biomass boiler, Tomlinson boiler, gas turbine, duct burner).

- Transportation and distribution of the biofuel (including, in the FT cases, an estimate of the emissions due to crude FT transportation and upgrading)

- Biofuel end-use (for simplicity, this is shown with transportation and distribution, although end-use is the largest portion)

Emissions Offsets

- Displaced grid power emissions 
- Conventional fuel chain emissions (well-to-wheel - shown as a single figure)

- Biomass $\mathrm{CO}_{2}$ - consistent with the analysis by Larson, et al. [5], $\mathrm{CO}_{2}$ emissions associated with biomass usage are included in the analysis but then are netted out, since they are assumed to be re-absorbed photosynthetically by subsequent biomass growth. Note that this does not net out the emissions associated with biomass collection and transportation described above. ${ }^{36}$

Note that the analysis assumes constant emission factors over time with the exception of grid power. Therefore, the values shown here for the year 2010 will change over time as grid emissions change. In particular, as shown earlier in Table $18, \mathrm{SO}_{2}$ and $\mathrm{NO}_{\mathrm{x}}$ emissions from the grid are expected to decrease significantly over the forecast period. The temporal impacts on annual emissions reductions are given later in this report.

\subsubsection{Carbon Dioxide}

Figure 35 shows the resulting impacts for $\mathrm{CO}_{2}$, for the case study mill in the year 2010 . Note that in each case, the net $\mathrm{CO}_{2}$ emissions reductions are greater than for the Tomlinson case. Not surprisingly, the main driver for this is the amount of additional biomass used, although from a $\mathrm{CO}_{2}$ standpoint it is also more advantageous to displace electricity than fuels. For example, the FTb configuration consumes moderately less additional biomass than FTc yet produces the greatest net $\mathrm{CO}_{2}$ reductions. Also, the DMEa and DMEc configurations use almost the same quantity of additional biomass but the latter produces much more power, resulting in greater $\mathrm{CO}_{2}$ reduction for DMEc. Finally, the MA case uses only slightly more biomass than DMEa and DMEc, but produces mostly power, and so still has a greater net $\mathrm{CO}_{2}$ benefit than DMEa, which produces mostly fuels. This is driven by the fact that coal accounts for about $50 \%$ of the grid power that would be displaced, and coal is more carbon intensive per unit of contained energy than petroleum fuels.

Figure 36 provides the details of the net $\mathrm{CO}_{2}$ calculation, showing the different emissions sources and offsets and the resulting net emissions that are shown in Figure 35. The remaining similar detailed-accounting figures for the other pollutants are given in Volume 3.

\footnotetext{
${ }^{36}$ In this study, we make no attempt to account for other changes in greenhouse gas emissions associated with land use changes and biomass growth that are not directly related to collection and transportation (e.g., changes in soil carbon content or in methane emissions from decomposition of forest slash).
} 
Figure 35: Change in annual full fuel chain net $\mathrm{CO}_{2}$ emissions at the reference mill in 2010.

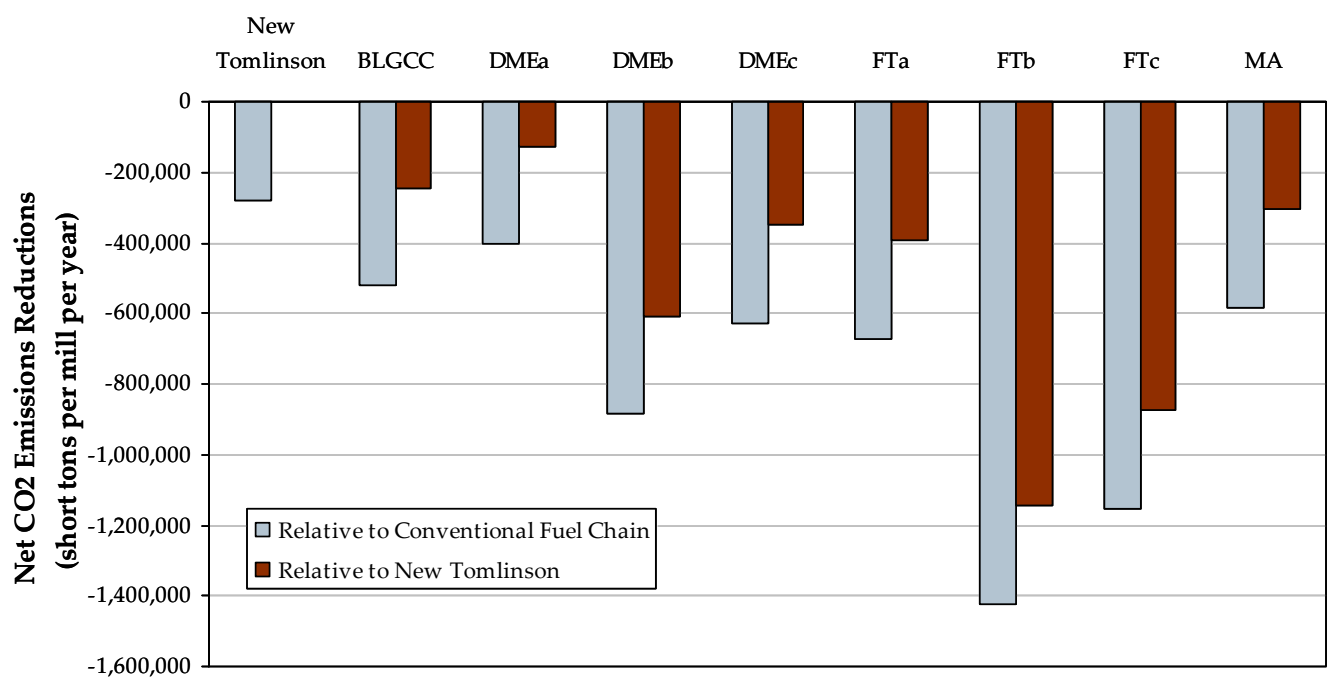

Notes:

Transportation of the crude FT product to the oil refinery included in FT cases.

Excludes any emissions from land use changes and biomass growth that are not related to harvesting and transportation.

FT cases assume FT gasoline blend in gasoline engines and FT diesel blend in CIDI engines. MA case assumes low-level blend with gasoline.

Figure 36: Changes in annual full fuel-chain $\mathrm{CO}_{2}$ emissions and offsets at the reference mill in 2010 (million tons per year).

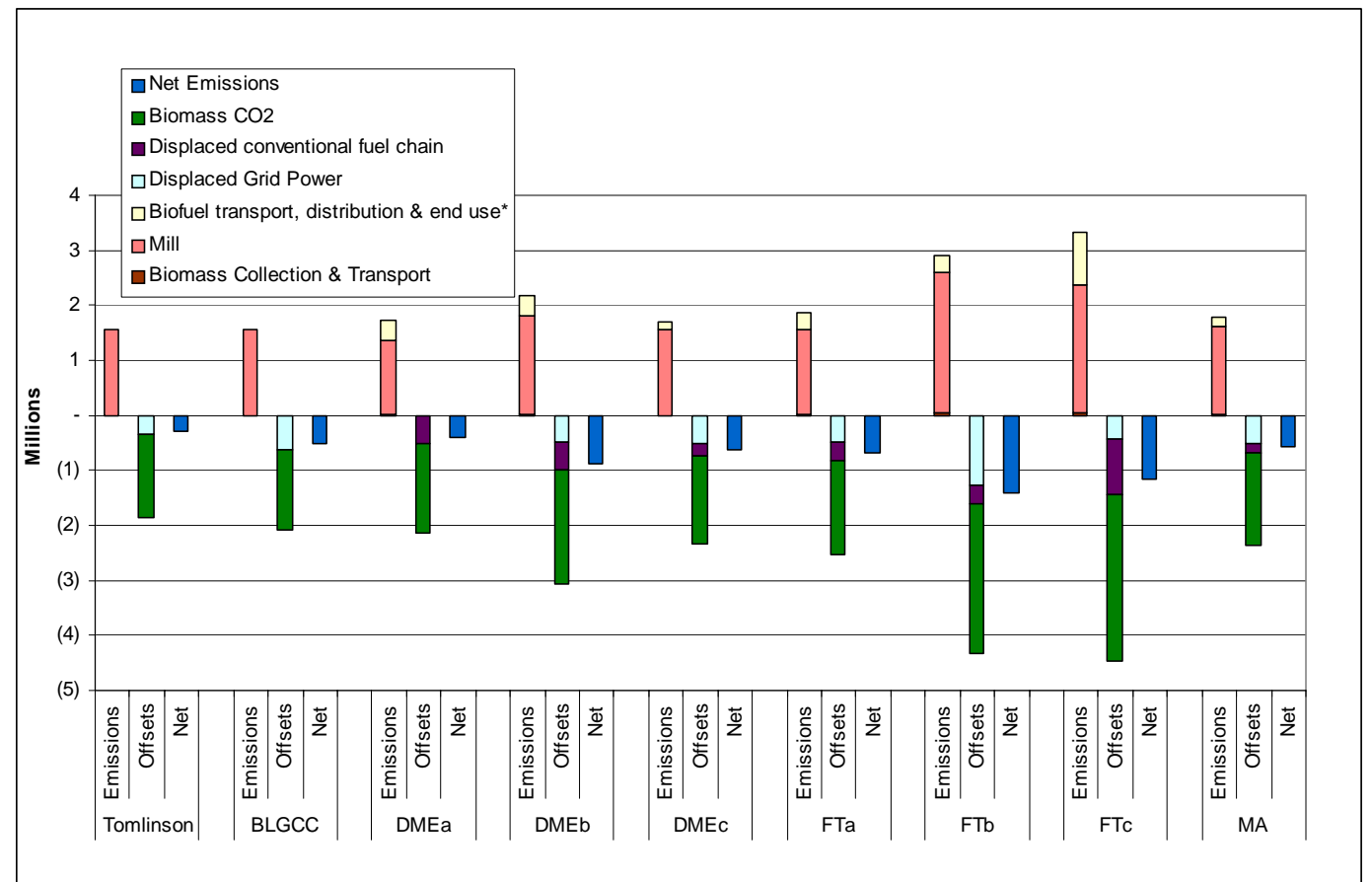

* Transportation of the crude FT product to the oil refinery included in FT cases.

Note: excludes any emissions from land use changes and biomass growth that are not related to harvesting and transportation.

Note on vehicle end use: FT cases assume FT gasoline blend in gasoline engines and FT diesel blend in CIDI engines. MA case assumes low-level blend with gasoline.

\subsubsection{Sulfur Dioxide}

Figure 37 shows the resulting impacts for $\mathrm{SO}_{2}$. The main driver is the amount of grid power displaced, since the grid is the main source of $\mathrm{SO}_{2}$ emissions, and the use of conventional transportation fuels generates relatively little $\mathrm{SO}_{2}$, especially with the transition to low-sulfur 
diesel. As such, the configuration with the greatest $\mathrm{SO}_{2}$ benefits are the BLGCC and FTb cases. The DMEa case, which only produces enough power to meet the biorefinery internal requirements, actually results in a net increase in $\mathrm{SO}_{2}$ emissions, since greater grid electricity purchases are required than with the Tomlinson case.

Figure 37: Change in annual full fuel-chain net $\mathrm{SO}_{2}$ emissions at reference mill in 2010.

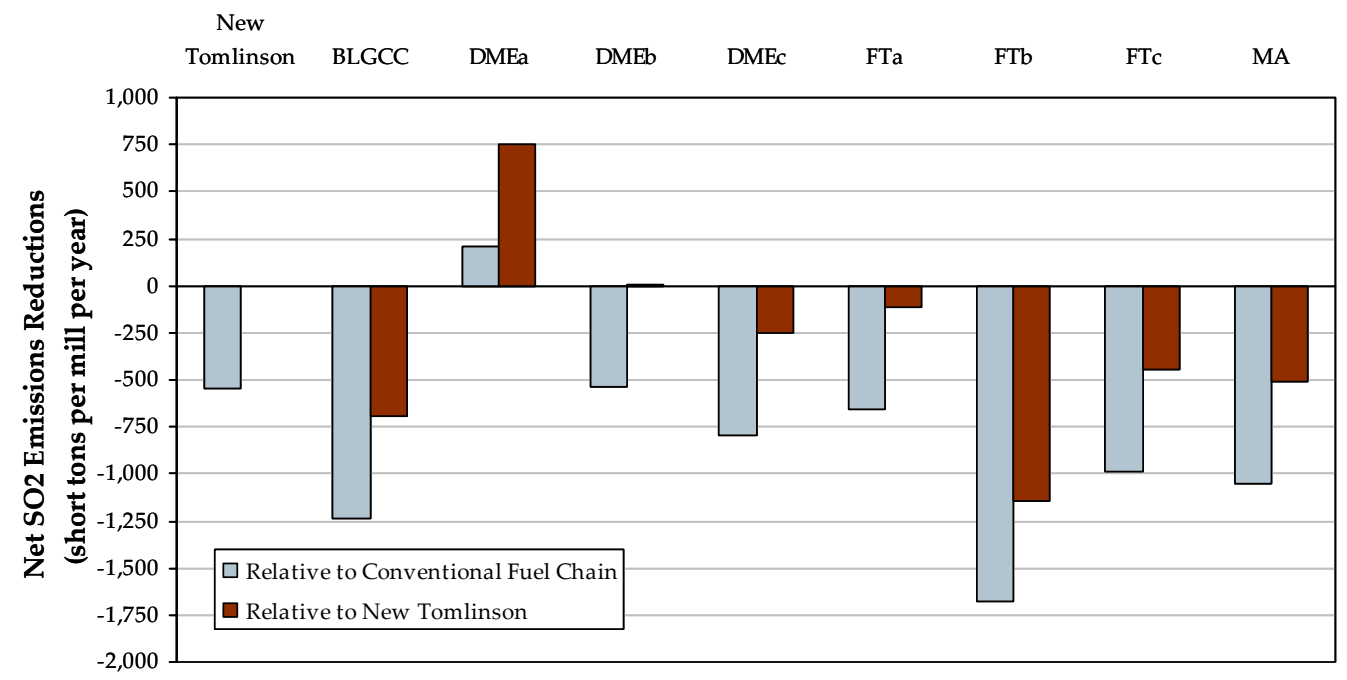

Notes:

Transportation of the crude FT product to the oil refinery included in FT cases.

Excludes any emissions from land use changes and biomass growth that are not related to harvesting and transportation.

FT cases assume FT gasoline blend in gasoline engines and FT diesel blend in CIDI engines. MA case assumes low-level blend with gasoline.

\subsubsection{Nitrogen Oxides}

Figure 38 shows the resulting impacts for $\mathrm{NO}_{\mathrm{x}}$. It is important to note that $\mathrm{NO}_{\mathrm{x}}$ emissions are in several cases higher than from conventional energy sources (the grid and conventional transportation fuels), but still, in all cases the biorefinery emissions are lower than the Tomlinson case. The relatively favorable grid and conventional fuel chain $\mathrm{NO}_{\mathrm{x}}$ emissions are driven by the lower expected grid power emissions from implementation of the EPA's Clean Air Interstate Rule, as well as the use of low-sulfur diesel, which will permit the use of tailpipe $\mathrm{NO}_{\mathrm{x}}$ emissions controls on diesel cars. It is also worth noting that in the cases that use large amounts of additional biomass (DMEb, FTb, and FTc), this stage in the fuel chain is an important source of $\mathrm{NO}_{\mathrm{x}}$ emissions, because of the use of heavy duty diesel vehicles for biomass collection and transport (see Volume 3 for details).

\subsubsection{Volatile Organic Compounds}

Figure 39 shows the resulting impacts for VOCs. The main emissions source is the vehicle tailpipe, but other important sources are the upstream processing of petroleum based fuels and the hog fuel and black liquor boilers. ${ }^{37}$ The other emission sources -syngas combustion and grid power, have comparatively low VOC emissions. As a result, all of the biorefinery cases, as well as the BLGCC case, result in significant VOC reductions relative to the Tomlinson case.

\footnotetext{
${ }^{37}$ VOC emissions from biomass dryers (used in six of the biorefinery designs) are assumed to be zero, since a regenerative thermal oxidizer unit is included as part of the dryer.
} 
Figure 38: Change in annual full fuel-chain net $\mathrm{NO}_{x}$ emissions at the reference mill in 2010.

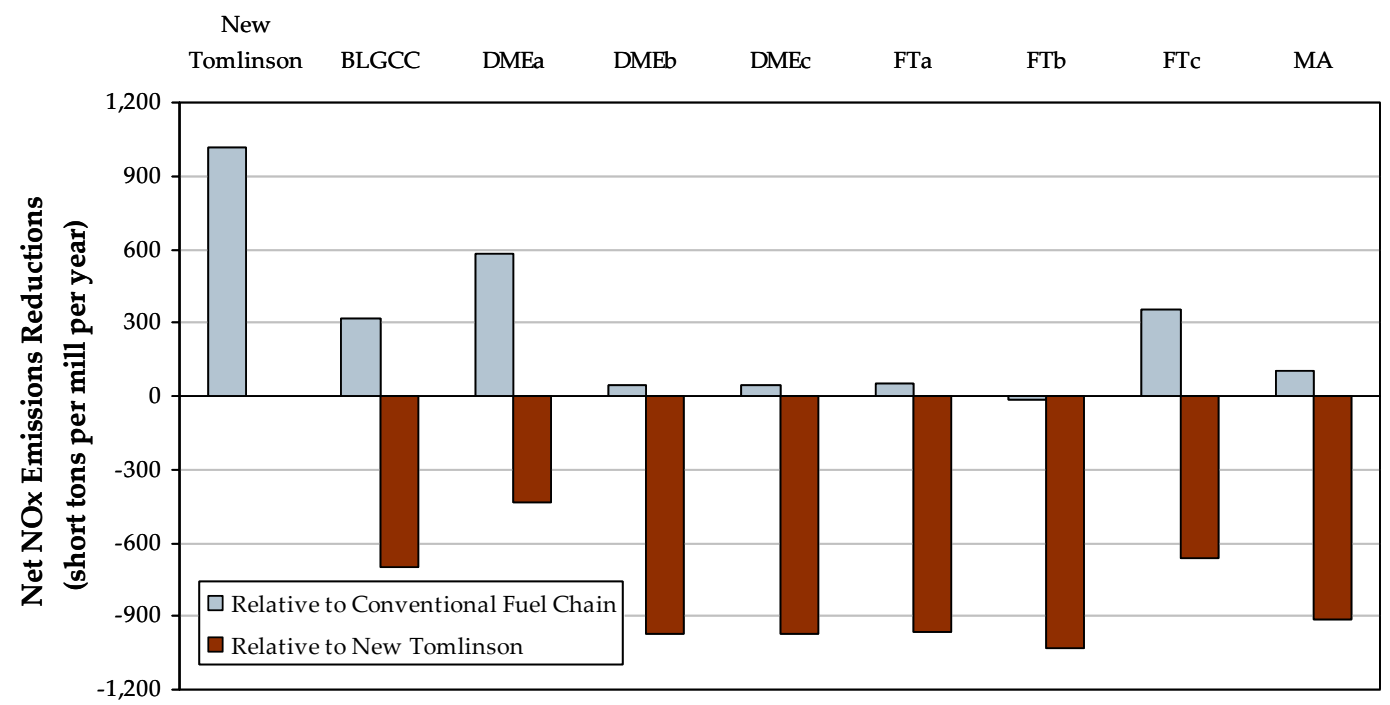

Notes:

Transportation of the crude FT product to the oil refinery included in FT cases.

Excludes any emissions from land use changes and biomass growth that are not related to harvesting and transportation.

FT cases assume FT gasoline blend in gasoline engines and FT diesel blend in CIDI engines. MA case assumes low-level blend with gasoline.

Figure 39: Change in annual full fuel-chain net VOC emissions at the reference mill in 2010.

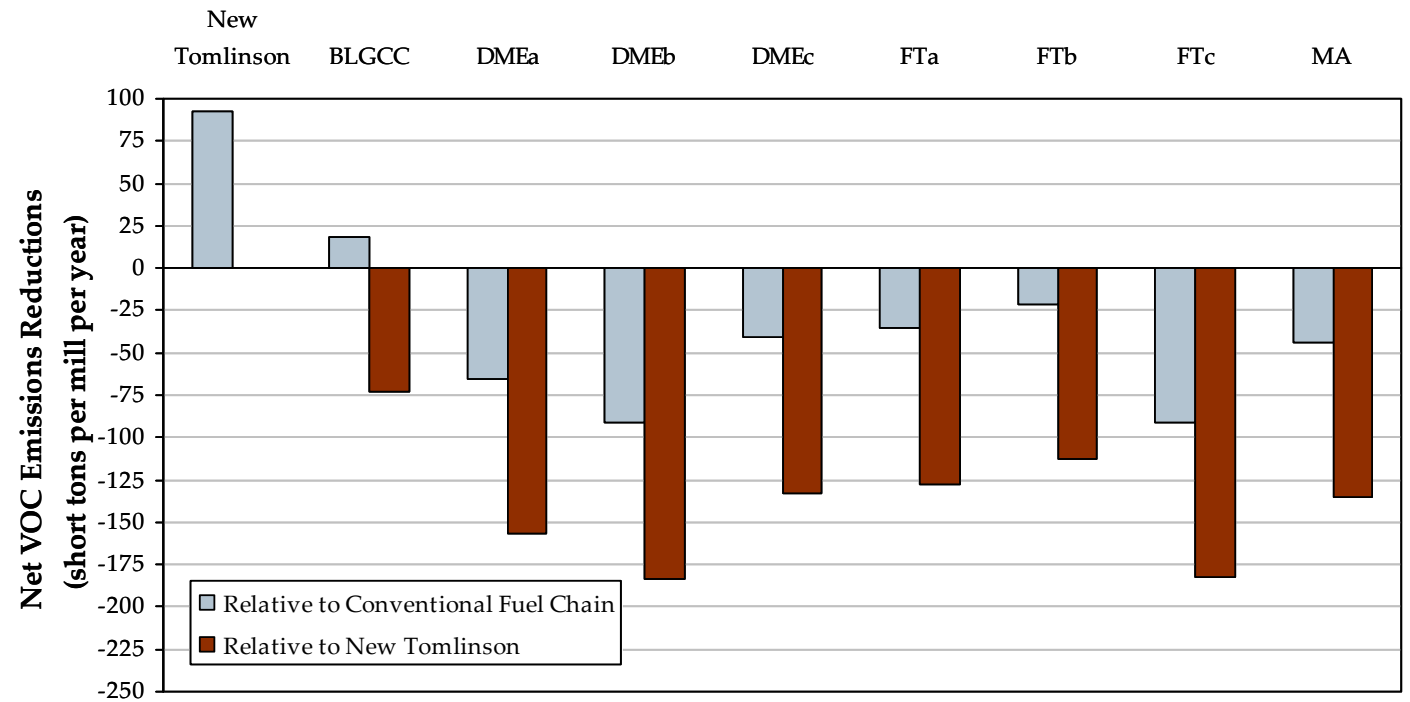

Notes:

Transportation of the crude FT product to the oil refinery included in FT cases.

Excludes any emissions from land use changes and biomass growth that are not related to harvesting and transportation.

FT cases assume FT gasoline blend in gasoline engines and FT diesel blend in CIDI engines. MA case assumes low-level blend with gasoline.

\subsubsection{Carbon Monoxide}

Figure 40 shows the resulting impacts for CO. The situation is similar to VOCs - that is, the main emissions source is the vehicle tailpipe. The hog fuel boiler is the next most important source so that the DMEa case, which involves burning substantially more biomass in a boiler, results in a net increase in $\mathrm{CO}$ emissions. The BLGCC case (which also retains a hog fuel boiler) 
therefore only produces moderate $\mathrm{CO}$ reductions. All other cases (which eliminate the hog fuel boiler) produce large $\mathrm{CO}$ reductions relative to the Tomlinson case.

\subsubsection{Particulate Matter}

Figure 41 shows the resulting impacts for $\mathrm{PM}_{10}$. The two main drivers for large reductions relative to the Tomlinson case are the displacement of grid power and mill-level reductions from replacing combustion in boilers with combustion in gas turbines. Tailpipe emissions are also reduced in some cases, but the GREET model includes brake and tire wear in its total PM 10 estimates and these are unaffected by fuel choice and are actually larger than the assumed tailpipe $\mathrm{PM}_{10}$ emissions.

\subsubsection{Total Reduced Sulfur}

Figure 42 shows the resulting impacts for TRS. The only assumed sources are the lime kiln and Tomlinson boiler; other existing sources of TRS emissions are not included in the analysis, as they are assumed to be the same in all cases. TRS emissions increase somewhat from the lime kiln due to increased load with black liquor gasification, but this is more than offset by the elimination of the Tomlinson boiler. Because no other sources are assumed, the effects are identical for all the biorefinery configurations.

Figure 40: Change in annual full fuel-chain net CO emissions at the reference mill in 2010.

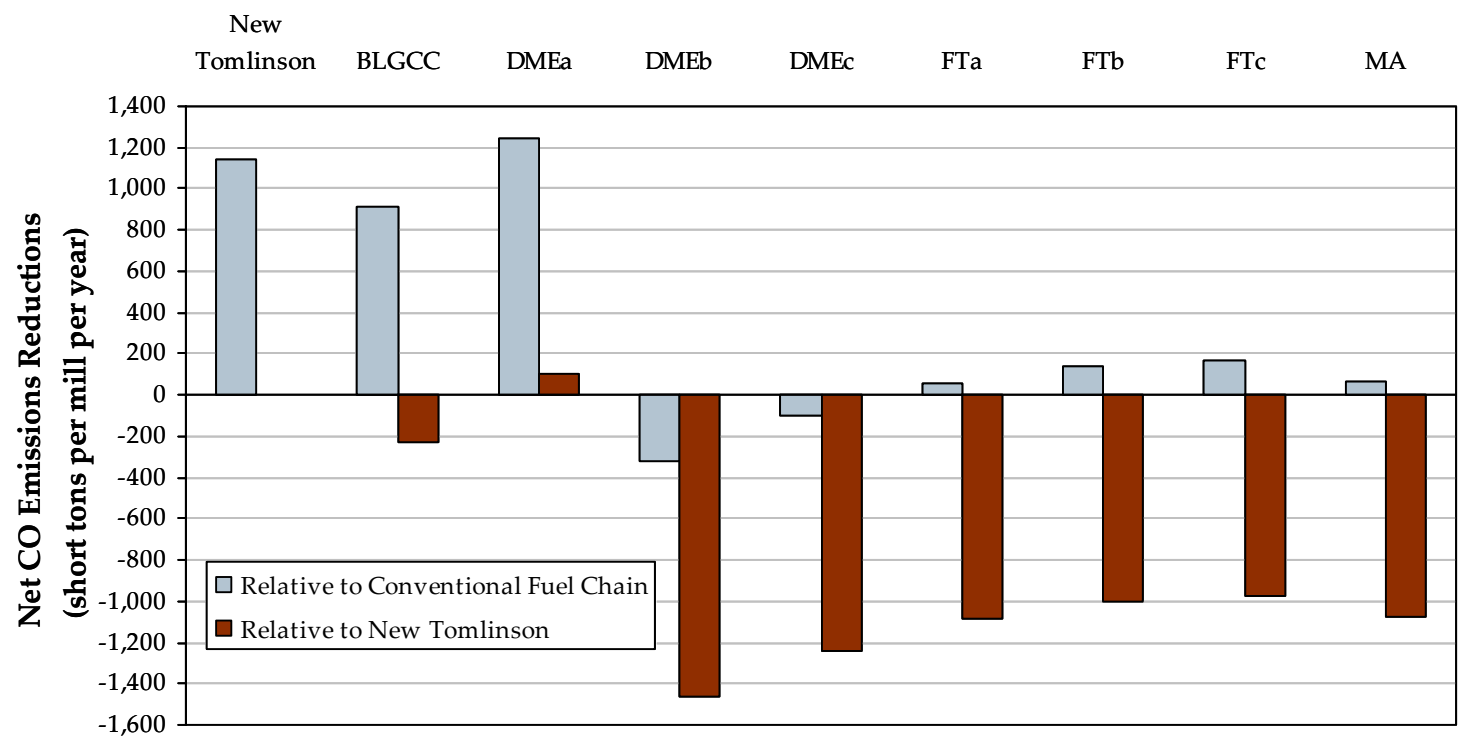

Notes:

Transportation of the crude FT product to the oil refinery included in FT cases.

Excludes any emissions from land use changes and biomass growth that are not related to harvesting and transportation.

FT cases assume FT gasoline blend in gasoline engines and FT diesel blend in CIDI engines. MA case assumes low-level blend with gasoline. 
Figure 41: Change in annual full fuel-chain net $\mathrm{PM}_{10}$ emissions at the reference mill in 2010.

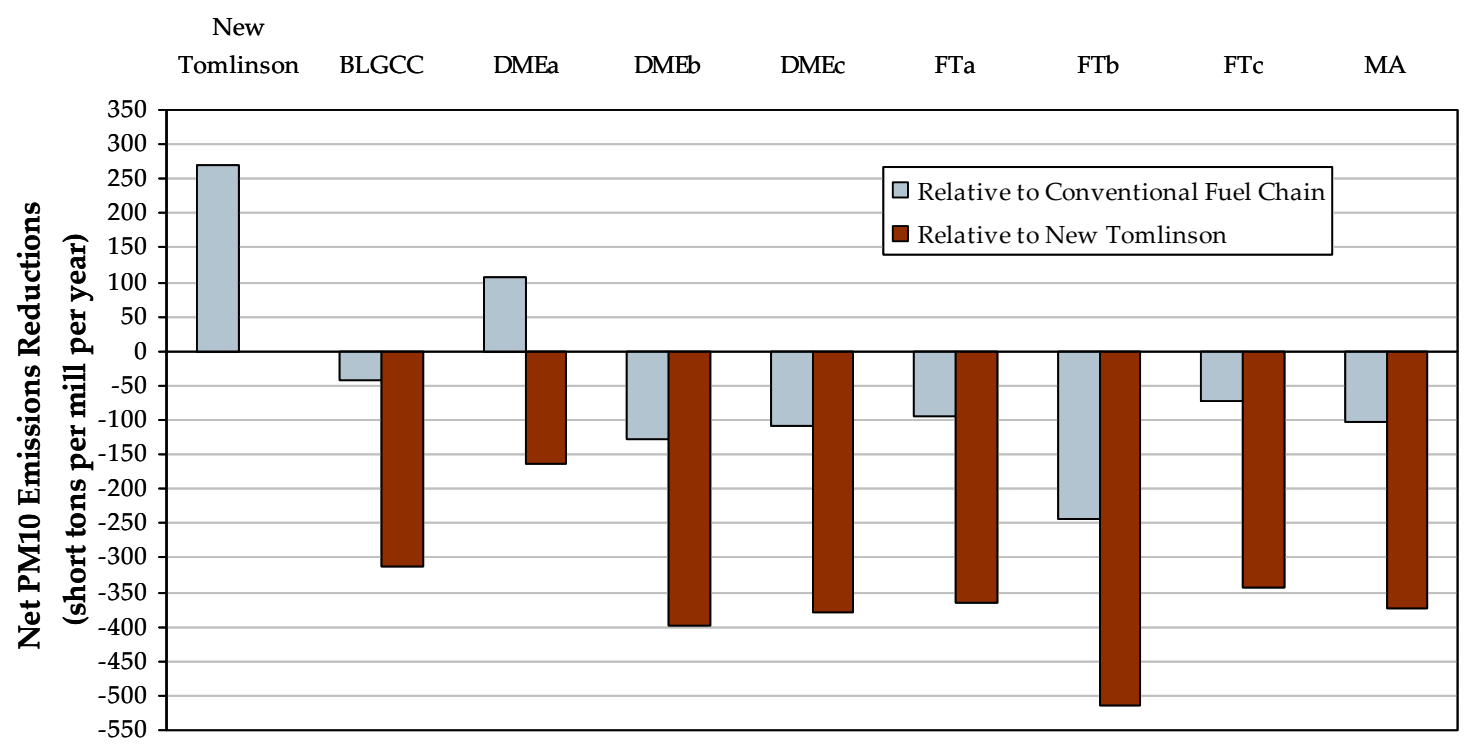

Notes:

Transportation of the crude FT product to the oil refinery included in FT cases.

Excludes any emissions from land use changes and biomass growth that are not related to harvesting and transportation.

FT cases assume FT gasoline blend in gasoline engines and FT diesel blend in CIDI engines. MA case assumes low-level blend with gasoline.

Figure 42: Change in annual full fuel-chain net TRS emissions at the reference mill in 2010.

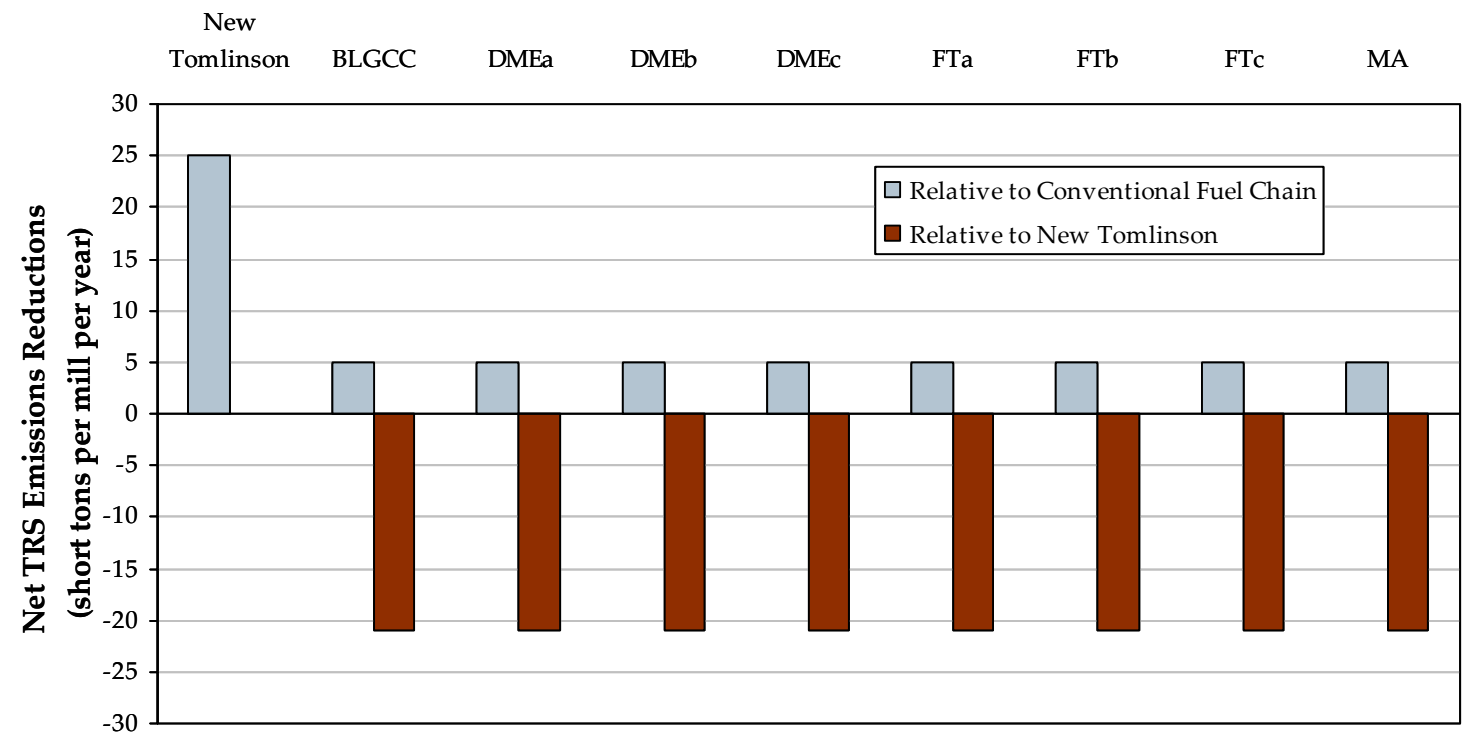

Notes:

Transportation of the crude FT product to the oil refinery included in FT cases.

Excludes any emissions from land use changes and biomass growth that are not related to harvesting and transportation.

FT cases assume FT gasoline blend in gasoline engines and FT diesel blend in CIDI engines. MA case assumes low-level blend with gasoline.

TRS emissions are for combustion sources only. 


\section{Biorefinery Capital Cost Estimates}

\subsection{Approach and Assumptions}

As a basis for estimating prospective returns on investments in pulp mill biorefineries, engineers at Nexant, LLC, an independent engineering consulting firm originally created as a subsidiary of the Bechtel Corporation in 2000, were engaged to estimate installed capital costs for the biorefinery designs developed in this work. Nexant has considerable experience in design and engineering of combustion and gasification-based power plants and liquids production facilities. We selected Nexant to assist with the cost-estimation work in part because they prepared the cost estimates in our earlier study for the Tomlinson and BLGCC systems. Thus, there is consistency with the earlier study in the biorefinery cost estimates described here.

Early in the cost estimation process, we asked Nexant engineers to review preliminary mass and energy balances and provide recommendations for modifications. We modified the flowsheets based on their recommendations, and provided them with revised flowsheets, which they used as a basis for their equipment sizing and costing calculations. After reviewing their draft cost estimates, we made additional modifications to the flowsheets in most cases to try to further reduce capital costs. Nexant then provided their final cost estimates based on these revised flowsheets.

We subsequently made some additional flowsheet adjustments (minor ones in most cases) to reach the final versions shown in this report. In consultation with the lead Nexant design/costestimating engineer, we made adjustments to Nexant's final cost estimates to account for the flowsheet changes in these cases. The changes to the DME and FTL flowsheets were minor. The changes to the MA flowsheet were more significant (due primarily to mid-course improvements we made in our kinetic model for MA synthesis). Nexant engineers did not estimate the capital cost for the DMEb design, but because all of the equipment in the DMEb design is found in either the DMEa or DMEc designs, we were able to develop a consistent cost estimate for DMEb using commonly-accepted capacity-cost scaling factors.

We asked Nexant to provide capital cost estimates by major plant area to within $\pm 30 \%$ accuracy. For some pieces of equipment (e.g., black liquor gasifier, gas turbine, air separation unit, and Selexol island), costs were simply escalated (from $2002 \$$ to $2005 \$$ ) from the cost estimates Nexant made for our earlier BLGCC study [5] and then scaled, as appropriate, to the required equipment capacities. In other cases where there was no cost estimate from our prior study (e.g, biomass gasifier, heat exchangers, synthesis reactors, and distillation columns), Nexant carried out sizing calculations and used their experience-based in-house cost database to estimate capital costs. In still other cases (e.g., biomass boiler, biomass dryer, Rectisol), vendor quotes were obtained and used as the basis for estimating installed costs.

Nexant was asked to assume " $\mathrm{N}^{\text {th }}$ plant" levels of technology maturity and operational reliability in their cost estimates. In this regard, each of the systems included in our study utilize two black liquor gasifier vessels, each with $50 \%$ of the needed total capacity. A single biomass gasifier vessel was used in configurations with biomass gasification. These choices represent a high level of gasifier reliability. Given that at most large pulp mills today the Tomlinson recovery boiler is typically a single unit handling $100 \%$ of the black liquor recovery duty, it was judged 
feasible that a black liquor or biomass gasifier ultimately could reliably operate with no spare capacity in an " $\mathrm{N}^{\text {th }}$ plant" implementation.

The scope of the capital cost estimates includes equipment in all major areas shown on the detailed mass/energy balance flowsheets presented earlier, with the following exceptions:

- Steam turbine. In the Tomlinson case, the steam turbine pre-existing at the reference mill is assumed to be kept. However, since in this case there is excess steam available after meeting process needs, it was determined to be financially beneficial to add a small $\left(8 \mathrm{MW}_{\mathrm{e}}\right)$ condensing turbine to enable greater electricity generation. In all other cases, except DMEa, the existing steam turbine is replaced, and the cost for a new turbine is included in the capital estimate. In the DMEa case, a large fraction of the woody biomass used for energy is burned in existing hog fuel boilers. Since the steam pressure from these boilers is already matched to the inlet pressure of the existing back-pressure steam turbine, the existing turbine is retained. A modest allowance is included in the capital cost to maintain the efficiency of the turbine while derating its output to $33 \mathrm{MW}_{\mathrm{e}}$. (The pre-existing turbine capacity is higher than this because it had been utilizing steam from both hog fuel and black liquor boilers.)

- Hog fuel boilers. Hog fuel boilers are present in the Tomlinson, BLGCC, and DMEa cases. Boilers available at the pre-existing mill are assumed to be available to raise steam after the new power/fuel/recovery systems have been installed. The bark and waste wood available from the wood yard operations in the Tomlinson case represent $58 \mathrm{MW}$ (LHV) of thermal input. Mills typically have excess hog fuel boiler capacity available on-site, and we make the same assumption about this as in the BLGCC study [5]: the total available existing hog fuel capacity is $81 \mathrm{MW}_{\text {th }}$ (LHV, or $100 \mathrm{MW} \mathrm{HHV).} \mathrm{Hog} \mathrm{fuel} \mathrm{boiler} \mathrm{capacity} \mathrm{needed} \mathrm{in} \mathrm{excess} \mathrm{of}$ this amount (as is the case in DMEa) is included in the capital cost estimate.

- Lime kiln and related equipment. The incremental causticizing and calcining capacity needed in the gasification cases is estimated to be $16 \%$ of the existing capacity [5]. This is modest enough that it can be met by enriching the lime-kiln combustion air with oxygen from the air separation unit (ASU). The cost for burner modifications in the kiln and for an ASU of sufficient capacity to deliver the requisite amount of $\mathrm{O}_{2}$ to the lime kiln (in addition to $\mathrm{O}_{2}$ for gasification) are included in the capital cost estimate.

- Polysulfide generation systems. In all biorefinery cases, as in the BLGCC case [5], polysulfide pulping liquor is generated in a mixing tank maintained at a temperature $<100^{\circ} \mathrm{F}$. The cost for this polysulfide generating unit is included in the capital cost estimate.

- In all gasification-based cases, we have included an estimate for upsizing the ASU to enable production of oxygen for delignification, which is a very cost-effective way to replace oxygen that was previously being purchased at the reference mill for this purpose. ${ }^{38}$

\subsection{Capital Costs}

Table 22 summarizes the installed capital cost and non-fuel operating and maintenance cost estimates for all biorefinery cases. The table also includes estimates for the Tomlinson and

\footnotetext{
${ }^{38}$ If purchased $\mathrm{O}_{2}$ costs $\$ 100 /$ tonne, the avoided costs of purchased $\mathrm{O}_{2}$ at the reference mill (assuming $23 \mathrm{~kg} \mathrm{O}_{2}$ for delignification per metric tonne of pulp produced (Table 5) and 8330 annual operating hours) would be $\$ 1.14$ million per year. Accounting for the cost of about $600 \mathrm{~kW}$ of additional parasitic electricity load with a larger ASU, the payback time on the incremental ASU investment cost (discussed in next section) would be of the order of one year in all cases.
} 
BLGCC cases from our prior study (escalated here to $2005 \$$ from the $2002 \$$ in our previous study). Figure 43 shows capital cost percentages for the biorefineries by major plant area.

Table 22. Estimated overnight installed capital costs (thousand 2005\$) and non-fuel operating and maintenance costs (thousand 2005\$ per year). Installed capital costs include engineering, equipment, installation, owner's costs (including initial catalyst), contingencies, and spare parts.

\begin{tabular}{|c|c|c|c|c|c|c|c|c|c|}
\hline \multirow{2}{*}{ THOUSAND 2005\$ } & \multicolumn{2}{|c|}{ Power/Steam $^{\mathrm{a}}$} & \multicolumn{7}{|c|}{ Biorefinery -- Power/Steam/Liquid Fuel } \\
\hline & Tomlin. & BLGCC & DMEa & DMEb & DMEc & FTa & FTb & FTc & MA \\
\hline Recovery boiler & 125,018 & 0 & 0 & 0 & 0 & 0 & 0 & 0 & \\
\hline Steam system modifications ${ }^{b}$ & 11,136 & 0 & 3,000 & 0 & 0 & 0 & 0 & 0 & \\
\hline Air separation unit (ASU) & 0 & 42,628 & 43,053 & 61,561 & 52,933 & 55,001 & 72,762 & 77,823 & 54,080 \\
\hline ASU increment for $\mathrm{O}_{2}$ delig. $^{\mathrm{C}}$ & 0 & 1,118 & 1,061 & 879 & 954 & 933 & 805 & 776 & 948 \\
\hline$B L$ gasifier \& green liquor filter ${ }^{d}$ & 0 & 63,720 & 63,720 & 63,720 & 63,720 & 63,720 & 63,720 & 63,720 & 63,720 \\
\hline Nitrogen compressor & 0 & 0 & 0 & 1,188 & 810 & 1,071 & 1,757 & 2,013 & 5,181 \\
\hline Acid gas $r$ & 0 & 19,003 & 37,732 & 37,732 & 27,321 & 27,321 & 27,321 & 42,164 & 24,529 \\
\hline Syntl & 0 & 0 & 49,344 & 49,344 & 16,287 & 22,019 & 22,019 & 38,767 & 83,548 \\
\hline Combined cycle pow & 0 & 89,243 & 0 & 105,303 & 100,091 & 90,018 & 171,895 & 104,300 & 90,348 \\
\hline Wood yard expansion ${ }^{e}$ & & & 867 & 2,697 & 789 & 1,303 & 4,832 & 5,788 & 1,077 \\
\hline Biomass dryer, i & 0 & 0 & 0 & 50,295 & 32,523 & 37,286 & 72,507 & 45,558 & 31,383 \\
\hline Biomass gasifier & 0 & 0 & 0 & 28,354 & 18,320 & 20,867 & 41,365 & 47,063 & 22,949 \\
\hline Biomass syngas & 0 & 0 & 0 & 8,484 & 4,998 & 5,666 & 11,372 & 0 & \\
\hline Bion & 0 & & 0 & 0 & 0 & 0 & 0 & 34,425 & 16,092 \\
\hline ss syngas expander & 0 & 0 & 0 & 3,778 & 2,661 & 2,670 & 9,410 & 0 & \\
\hline el boiler & 0 & 0 & 50,736 & 0 & 0 & 0 & 0 & 0 & \\
\hline Other ${ }^{g}$ & 0 & 2,359 & 2,359 & 2,359 & 2,359 & 2,359 & 2,359 & 2,359 & 2,359 \\
\hline Overnight Installed Capital Cost & 136,154 & 218,072 & 251,873 & 415,695 & 323,766 & 330,234 & 502,125 & 464,755 & 396,215 \\
\hline Annual non-fuel O\&M cost ${ }^{\mathrm{h}}$ & 5,446 & 8,723 & 10,075 & 16,628 & 12,951 & 13,209 & 20,085 & 18,590 & 15,84 \\
\hline
\end{tabular}

(a) Escalated (from $2002 \$$ to $2005 \$$ ) from Larson et al. [5], except for O\&M costs, which are calculated as indicated in note (f). Also, the ASU increment for $\mathrm{O}_{2}$ delignification ws not originally included in [5].

(b) In the Tomlinson case, the modifications include, primarily, the addition of a condensing section to the pre-existing back pressure turbine. In the DMEa case, the steam system modifications include, primarily, adjustments to the pre-existing back pressure turbine to maintain efficiency while reducing rated gross output to $33 \mathrm{MW}_{\mathrm{e}}$. (Output of the pre-existing turbine is higher than this since it is designed to use steam from both hog fuel boiler and black liquor boiler.)

(c) The ASU size is increased (beyond the size shown in the detailed biorefinery energy/mass balance diagrams) to also produce the oxygen needed by the oxygen delignification system at the pulp mill. The incremental cost is estimated from the base ASU cost using a cost-capacity scaling exponent of 0.65 .

(d) $2 \times 50 \%$ capacity gasifiers.

(e) The original biorefinery cost estimates made by Nexant did not include costs for expanding the wood yard to handle the larger wood flows associated with the biorefineries (compared to a mill with a Tomlinson system). We have estimated the costs for additional wood yard capacity by scaling wood yard costs given by Weyerhaeuser [132]. Original costs in $1999 \$$ were escalated to $2005 \$$ using the GDP deflator and then scaled with wood mass flow raised to the 0.77 exponent [73]. The wood mass flow is the net change in total wood flow (pulpwood and wood residues) between the biorefinery case and the Tomlinson case.

(f) RTO = regenerative thermal oxidizer used to destroy volatile organic compounds (VOCs) in the dryer exhaust gases. The original biorefinery cost estimate made by Nexant for the dryers did not include RTO. Themens [133] estimates that the cost for a RTO fitted to a partial gas recirculating direct contact rotary wood chip dryer (the type assumed in Nexant's capital cost estimate) is about $50 \%$ of the cost of the dryer alone. Accordingly, we have multiplied the original dryer cost estimated by Nexant by 1.5 to arrive at the figures in this table.

(g) This includes an allowance for modifications needed to the lime kiln to boost capacity by firing with oxygen-enriched air and for a polysulfide mixing tank.

(h) Assumed to be $4 \%$ of overnight installed capital costs. 


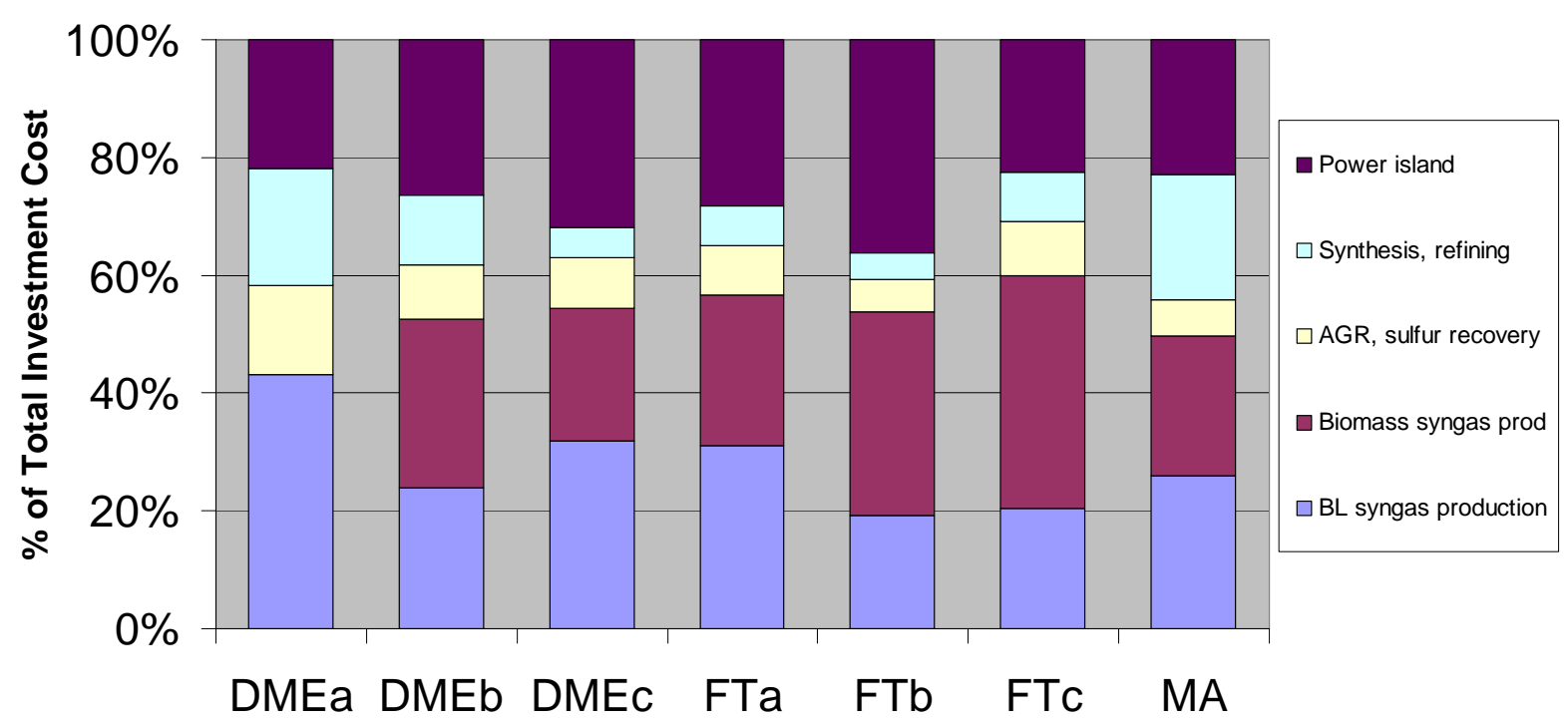

Figure 43. Percentage breakdown of biorefinery investment costs.

The following observations are made with respect to this table and figure:

- In all biorefineries, the production of raw synthesis gas, which includes the air separation unit, the gasifier(s), and gas cooling, accounts for $40 \%$ to $50 \%$ of the total investment cost in most cases, and $60 \%$ in FTc. The power island is the other large cost component, accounting for $25-35 \%$. Acid gas removal and sulfur recovery account for a relatively modest fraction $(5-15 \%)$, as is the case with the synthesis and refining island (5-20\%).

- In the process designs that utilize recycle of unconverted syngas (DMEa, DMEb, and MA), the synthesis island represents a considerably larger cost than in systems with once-through process configurations. For example, DMEb and DMEc both utilize the same rate of fresh syngas feed to the synthesis island but DMEb also recycles unconverted gas to the synthesis reactor. The capital investment for the synthesis island is three times higher in DMEb than in DMEc. The cost for the MA synthesis island is far higher than for any of the other synthesis islands due to the relatively poor catalyst performance predicted by our MA reactor model, necessitating vessels that can accommodate a large amount of catalyst.

- Two different technologies are used among the biorefineries for capture of $\mathrm{H}_{2} \mathrm{~S}$, and different configurations of the same technology are used in different cases depending on the design objective. All of the FT and DME cases use Rectisol ${ }^{\circledR}$ for $\mathrm{H}_{2} \mathrm{~S}$ capture. The design configuration and capacity of the Rectisol ${ }^{\circledR}$ system for FTa, FTb, and DMEc are identical (as reflected in the identical capital costs). In these cases, the primary objective is to remove $\mathrm{H}_{2} \mathrm{~S}$. Some co-capture of $\mathrm{CO}_{2}$ is also required, but $\mathrm{CO}_{2}$ removal to very low concentrations is not needed; a single absorber column to remove both gases is sufficient in this design. The design for FTc is similar in configuration, but handles a larger feed flow of syngas, accounting for a higher capital cost. The DMEa and DMEb systems are designed to remove all $\mathrm{H}_{2} \mathrm{~S}$ and all $\mathrm{CO}_{2}$. The high level of $\mathrm{CO}_{2}$ removal is required to avoid buildup of inert $\mathrm{CO}_{2}$ in the recycle stream. This Rectisol ${ }^{\circledR}$ design calls for two sequential absorbers (one tuned to $\mathrm{H}_{2} \mathrm{~S}$ capture and one tuned to $\mathrm{CO}_{2}$ capture), accounting for the higher capital cost compared to the single-absorber design at the same scale. The MA system (and BLGCC system in the earlier study) utilizes Selexol ${ }^{\circledR}$ technology because $\mathrm{H}_{2} \mathrm{~S}$ removal is not required to sub-ppm 
levels (for which Rectisol ${ }^{\circledR}$ is better suited). For applications suitable for Selexol ${ }^{\circledR}$, this system will generally have lower capital cost than a Rectisol ${ }^{\circledR}$ system designed for the same application.

\subsubsection{Specific Capital Investments per Unit of Biofuel Production}

For comparison with other biofuel production systems, it is of interest to compare the capital investment required per unit of liquid fuels production capacity. Figure 44 shows the specific capital investment for the pulp mill biorefinery designs developed in this study, along with specific investment costs for biofuel production systems from other published studies. The other studies correspond to those described in Section 0 and Figure 32, except in Figure 44 we have chosen to show only systems that we judge are at comparable distances from commercial maturity, i.e., those that are near commercially-ready. Thus, we have included NREL's estimate for corn-stover to ethanol by enzymatic hydrolysis, but we have excluded NREL's projections for advanced lignocellulosic conversion to ethanol and we have excluded NREL's and our own mixed-alcohols analyses, key components of which have not yet been demonstrated at pilot scale and which appear to require $\mathrm{R} \& \mathrm{D}$ breakthroughs to achieve cost/performance targets.

Because biorefineries produce energy products (and/or chemical services) in addition to liquid fuels, it is appropriate for comparison purposes to charge some fraction of the capital investment to the other products and services in order to produce a fair comparison of liquid-fuel capital intensity. For the biorefineries not attached to pulp mills in Figure 44, we have charged a portion of the investment cost against the electricity co-product of these biorefineries. We have charged capital against electricity capacity at a rate of $\$ 968 / \mathrm{kW}$, the estimated overnight investment cost for an advanced, large-scale stand-alone biomass-IGCC electricity generating facility, once the technology reaches commercial maturity [106]. This accounting is shown in Figure 45(a).

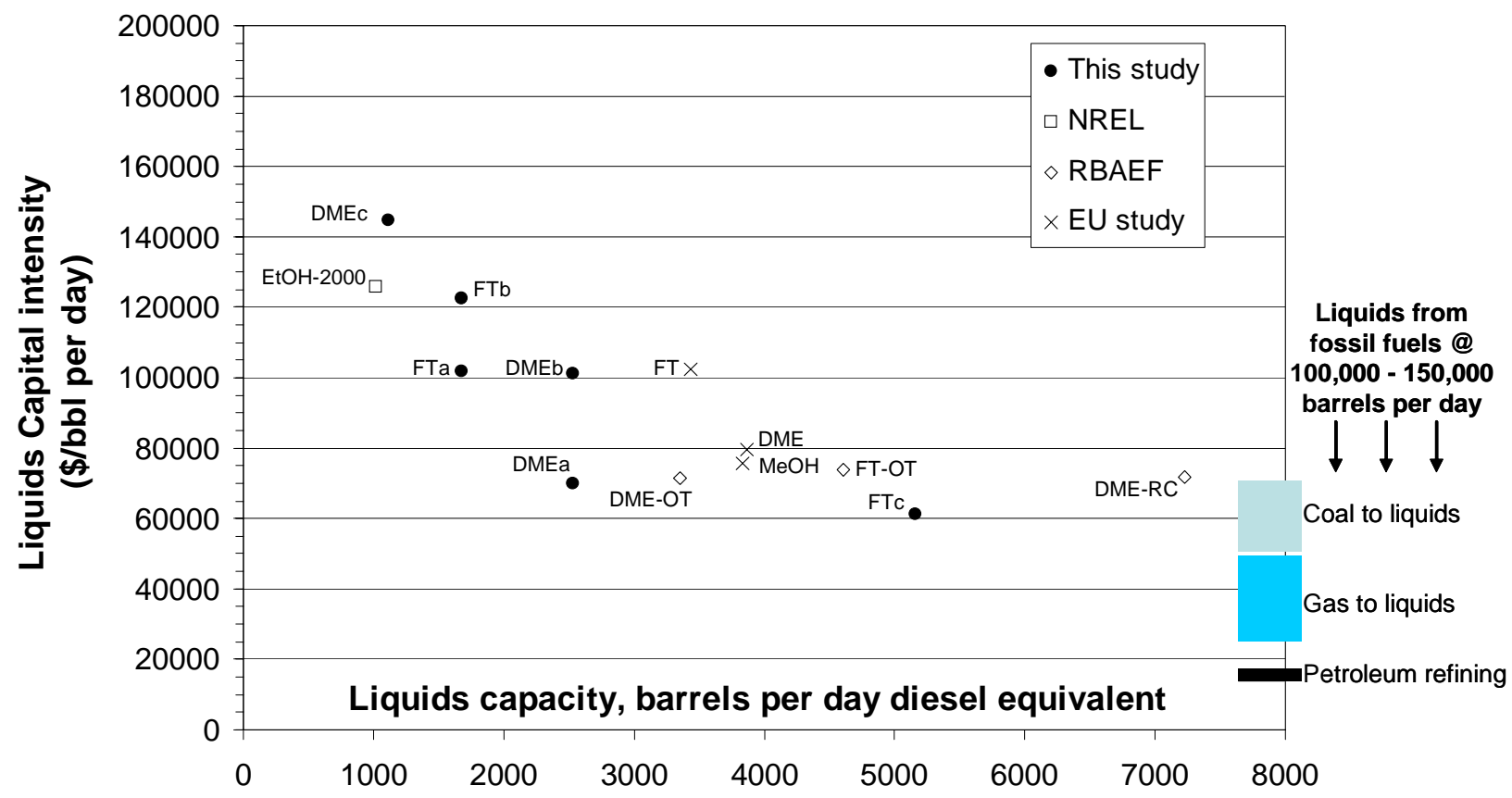

Figure 44. Effective capital investment intensity (2005\$ per barrel diesel-equivalent per day) for liquid fuels production as a function of liquids production capacity. See text for assumptions. 
In the case of the pulp mill biorefineries, considering that they provide all of the services of a Tomlinson system in addition to producing liquid fuels, the capital investment represented in Figure 44 is the difference between the total investment for the biorefinery and the investment for a Tomlinson power/recovery system (representing the non-liquid fuel services provided by the biorefinery), with a correction made if the biorefinery's electricity generating capacity differs from the Tomlinson's generating capacity - see Figure 45(b) and Figure 45(c). ${ }^{39}$

\section{NREL and RBAEF Systems}

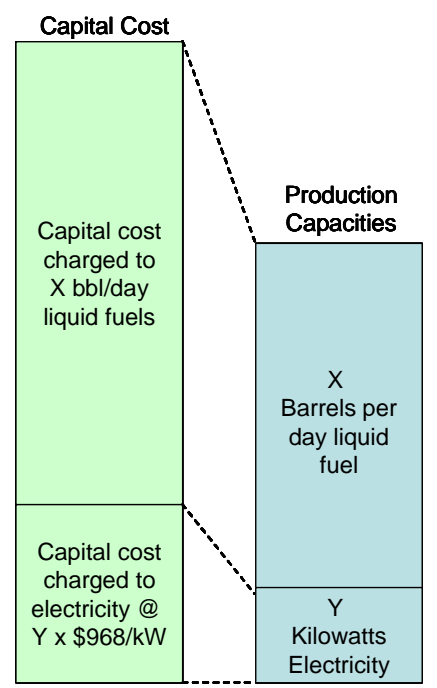

(a)
DMEb, DMEc, FTa, FTb, FTc, MA Pulp/Paper Mill Biorefineries

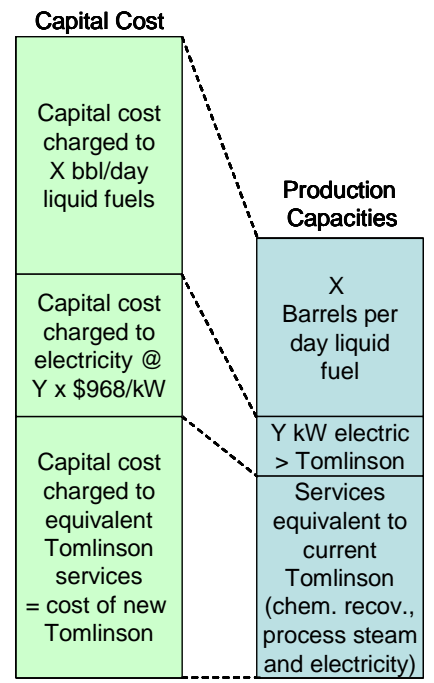

(b)
DMEa, EU-FTD, EU-DME, EU-MeOH Pulp/Paper Mill Biorefineries

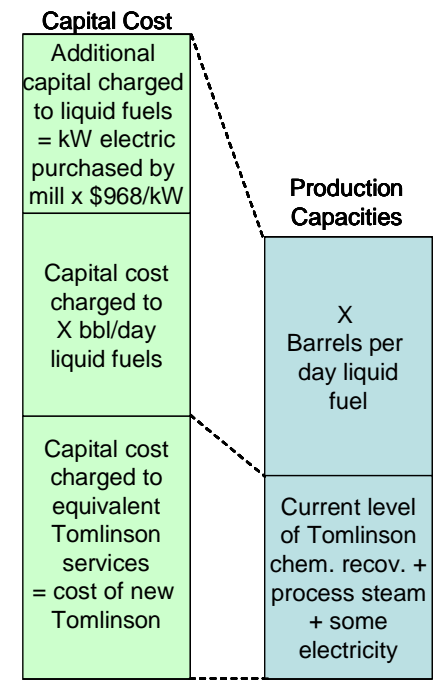

(c)

Figure 45. Accounting used to calculate the capital intensity of liquid biofuel production.

Capital intensities for the biofuel systems vary significantly, depending on the specific plant design. Figure 44 shows some dependence of specific investment cost on scale of liquid production, but the full scale range shown on the graph is tiny compared to typical scales for fossil fuel conversion. Some reference points are shown on the right in Figure 44 to provide perspective: large-scale petroleum refining ( 150,000 bpd) involves much lower specific investment costs - about $\$ 15,000$ per bpd. Large gas-to-liquid plants have costs of $\$ 25,000$ to $\$ 50,000$ per bpd, and large coal-to-liquids plants have costs of $\$ 50,000$ to $\$ 70,000$ per bpd [134]. Thus, the investment costs we estimate here for relatively small biorefineries are in the same range as investment costs for coal-to-liquids facilities with installed capacities 20 to 50 times as large. That small biorefinery systems have capital intensities on a par with much larger coal-toliquids facilities derives largely from the benefit provided by integrating the biorefinery with the pulp and paper mill.

Another representation of capital costs commonly used in the fossil fuel industry is the "development" (capital) costs per annual barrel of liquid fuel capacity. In the oil and gas industry, this indicator is normally associated with exploration and extraction costs associated with developing an oil or gas field, but here we apply the figure to the conversion step in the

\footnotetext{
${ }^{39}$ A charge of (\$968/kW x DeltaCapacity, where DeltaCapacity = Tomlinson electric capacity - Biorefinery electric capacity) is added to the difference in total investment cost between the biorefinery and the Tomlinson.
} 
processing chain. As expected from the comparisons shown in Figure 44, the development costs for liquid biofuels at pulpmill biorefineries fall above costs for oil refining and gas-to-liquids production but overlap with the range of coal-to-liquids development costs (Table 23).

Table 23. Effective capital investment required per barrel of annual production capacity.

\begin{tabular}{|c|c|c|c|c|c|c|c|c|c|}
\cline { 2 - 10 } \multicolumn{1}{c|}{} & \multicolumn{4}{c|}{ Small Biorefineries } & \multicolumn{3}{c|}{ Large Fossil Fuels } \\
\cline { 2 - 11 } & DMEa & DMEb & DMEc & FTa & FTb & FTc & CTL & GTL & Oil Refining \\
\hline \$ per bbl/year & 192 & 277 & 396 & 279 & 336 & 167 & $140-190$ & $70-140$ & $40-50$ \\
\hline
\end{tabular}

\subsection{Effective Levelized Cost of Liquid Fuel Production}

Anticipating the detailed financial analysis results to be presented in the following section, we give an estimate here of the levelized cost of producing liquid fuels at each of our biorefineries. Among other uses, these estimates can be compared with production cost estimates that have been made for other biofuels. In order to estimate the costs for producing liquid fuels alone (excluding costs attributable to production of steam, electricity, and chemical recovery services), we use the capital investment charged to liquid fuel (from Section 7.2.1) and the biomass charged against liquid fuel (from Section 0) in our calculation. We also assume an annual operating and maintenance cost of $4 \%$ of the capital investment. To facilitate a comparison with the widely-cited cost of $\$ 1.07$ per gallon for ethanol made at a facility using advanced enzymatic hydrolysis processing of corn stover [103], we adopt for our levelized cost calculation the same discounted cash flow methodology and assumptions as used by National Renewable Energy Laboratory (NREL) analysts who developed that estimate. ${ }^{40}$ NREL's \$1.07/gallon estimate was in year-2000 dollars. Converting (using the GDP deflator) to $2005 \$$ (for comparison with our cost estimates) brings the NREL estimate to $\$ 1.2 /$ gallon.

Table 24 shows our levelized cost estimates in three different units: $\$ / \mathrm{GJ}_{\mathrm{LHV}}, \$ /$ barrel of equivalent petroleum fuel, and \$/gallon of ethanol equivalent. The effective levelized cost for production of synthetic FT crude ranges from $\$ 51$ to $\$ 82$ per barrel of crude oil equivalent, or $\$ 0.7$ - $\$ 1.2 /$ gallon of ethanol equivalent. DME costs $\$ 0.8$ to $\$ 1.3 /$ gallon of ethanol equivalent. The mixed-alcohols are the most costly at $\$ 2.4 /$ gallon of ethanol equivalent. While the latter option appears to require some fundamental research and development to reduce costs, the effective costs of FT and DME with technology that could be deployed at commercial-scale in the 2010-2015 time frame are at approximately the same level as projected costs for ethanol made by advanced enzymatic hydrolysis of lignocellulose. Achieving the projected costs for the latter in a commercial facility in the 2010-2015 timeframe will be challenging, since some R\&D breakthroughs are required in advance of pilot-scale demonstration.

\footnotetext{
${ }^{40}$ NREL's parameter assumptions included $100 \%$ equity investment, $10 \%$ discount rate, $5 \%$ working capital, $39 \%$ taxes, MACRS depreciation schedule, 20-year life, and a 6 month start-up time, during which revenues are $50 \%$ of normal, variable costs are $75 \%$ of normal, and fixed costs are $100 \%$ of normal. We use all of these values. NREL also assumes a 2.5 year construction time, with an expenditure schedule of $8 \%$ in the first six months, $61 \%$ in the next 12 months, and $31 \%$ in the final 12 months. We use a 3-year construction time and expenditures of $8 \%$ in the first year, $60 \%$ in the second year, and $32 \%$ in the third year. The NREL analysis assumes a delivered cost for corn-stover biomass of $\$ 33$ per dry metric tonne (15\% moisture content asreceived), or $\$ 2.3 / \mathrm{GJ}_{\mathrm{LHV}}$. We use a delivered wood-residues biomass price (50\% moisture content) of $\$ 1.5 / \mathrm{GJ} \mathrm{JHV}_{\mathrm{LH}}$. The NREL analysis assumed 8,406 annual operating hours. We assume 8,330 hours/year, the typical operating time for pulp mills today.
} 
Table 24. Effective levelized cost of liquid fuels production at pulp mill biorefineries.

\begin{tabular}{|c|c|c|c|c|c|c|c|}
\hline & FTa & FTb & FTc & DMEa & DMEb & DMEc & MA \\
\hline & \multicolumn{7}{|c|}{ \$ per GJ (LHV) } \\
\hline Capital & 7.38 & 8.87 & 4.55 & 5.18 & 7.40 & 10.46 & 18.76 \\
\hline Working capital & 0.26 & 0.31 & 0.16 & 0.18 & 0.26 & 0.37 & 0.66 \\
\hline Taxes & 0.72 & 0.47 & 1.87 & 1.85 & 1.32 & 0.39 & 0.82 \\
\hline O\&M & 2.06 & 2.49 & 1.24 & 1.42 & 2.05 & 2.94 & 5.26 \\
\hline Biomass & 1.73 & 2.08 & 1.06 & 1.21 & 1.73 & 2.45 & 4.40 \\
\hline \multirow[t]{2}{*}{ Total } & 12.16 & 14.23 & 8.88 & 9.83 & 12.76 & 16.60 & 29.90 \\
\hline & \multicolumn{7}{|c|}{$\$$ per bbl equivalent petroleum fuel $^{a}$} \\
\hline Capital & 42.4 & 51.0 & 26.1 & 29.7 & 42.5 & 60.0 & 63.4 \\
\hline Working capital & 1.5 & 1.8 & 0.9 & 1.0 & 1.5 & 2.1 & 2.2 \\
\hline Taxes & 4.1 & 2.7 & 10.8 & 10.6 & 7.6 & 2.2 & 2.8 \\
\hline O\&M & 11.9 & 14.3 & 7.1 & 8.1 & 11.8 & 16.8 & 17.8 \\
\hline Biomass & 9.9 & 12.0 & 6.1 & 6.9 & 9.9 & 14.1 & 14.9 \\
\hline \multirow[t]{2}{*}{ Total } & 69.8 & 81.7 & 51.0 & 56.4 & 73.2 & 95.3 & 101.1 \\
\hline & \multicolumn{7}{|c|}{ \$ per gallon of ethanol equivalent } \\
\hline Capital & 0.59 & 0.71 & 0.37 & 0.42 & 0.60 & 0.84 & 1.51 \\
\hline Working capital & 0.02 & 0.02 & 0.01 & 0.01 & 0.02 & 0.03 & 0.05 \\
\hline Taxes & 0.06 & 0.04 & 0.15 & 0.15 & 0.11 & 0.03 & 0.07 \\
\hline O\&M & 0.17 & 0.20 & 0.10 & 0.11 & 0.17 & 0.24 & 0.42 \\
\hline Biomass & 0.14 & 0.17 & 0.09 & 0.10 & 0.14 & 0.20 & 0.35 \\
\hline Total & 0.98 & 1.15 & 0.71 & 0.79 & 1.03 & 1.34 & 2.41 \\
\hline
\end{tabular}

(a) Equivalent petroleum fuel is crude oil for the FT product, motor diesel for DME, and motor gasoline for MA.

\section{Mill-Level Financial Analysis}

To assess the prospective economics of integrated biorefineries at the mill level, comprehensive cash flow analyses are carried out assuming that an investment would be made to replace an existing Tomlinson system (with performance characterized by the Tomlinson described in Section 3.3.1 and summarized in Table 12) that had reached the end of its working life. Specifically, the internal rate of return (IRR) is calculated on the incremental capital investment required for a biorefinery over a new Tomlinson system. The net present value (NPV) is also calculated, assuming a specified return on equity (hurdle rate). The IRR and NPV are calculated both without and with consideration of the potential economic value of environmental benefits.

In addition to a baseline set of results, sensitivity analyses are carried out around key input parameter values, namely capital costs and future energy prices. The baseline and sensitivity analyses are done initially without assigning any value to environmental benefits of biorefining, nor with any financial incentives included. Then, a separate set of financial results are generated with environmental credits and incentives included. In the latter analyses, it is assumed that $100 \%$ of the wood-derived fuels used at the mill are renewable and (considering their photosynthetic origin) result in no net $\mathrm{CO}_{2}$ emissions to the atmosphere. 


\subsection{Assumptions}

\subsubsection{General}

The financial analysis is intended to account for all major changes to mill operations that would result from the conversion from a Tomlinson-based system to an integrated biorefinery. The capital expenditures are almost entirely in the power/recovery area, but the analysis also considers the reduced wood costs due to higher digester yield with polysulfide pulping, the increased use of \#6 fuel oil in the lime kiln, the purchase of natural gas (in BLGCC case only), the purchase of wood residues, the sale of electricity and biofuels, and other factors affecting incremental costs and potential savings. Avoided costs (e.g., avoided grid power purchases) are treated as revenues in the cash flow analysis.

Key inputs to the financial analysis, which are consistent with those from our earlier BLGCC analysis [5], include:

- The detailed mass/energy balances and engineering cost estimates for each of the process configurations described in earlier sections of this report,

- Expected future prices for natural gas, fuel oil, purchased wood residuals, electricity purchased by the mill and electricity sold to the grid, as discussed in the next section, and

- Financial assumptions (e.g., construction period, debt/equity split, cost of debt and return on equity, inflation rate, project life, and income tax rate), as summarized in Table $25{ }^{41,42}$

Sensitivity analysis is undertaken to examine variations from a baseline set of assumptions regarding energy and feedstock prices, capital costs, monetization of renewable energy and environmental benefits and the application of renewable energy production tax credits and other incentives.

One footnote regarding economic opportunities with pulp mill biorefining. There are a number of potential options for enhancing the integration of a biorefinery with existing mill operations that might generate additional revenues and/or cost savings. We have included one such option in our analysis - enlarging the air separation unit (beyond the size needed to supply $\mathrm{O}_{2}$ for gasification) to provide $\mathrm{O}_{2}$ for delignification, replacing previously purchased $\mathrm{O}_{2}$ (see footnote 38). Other integration options could include sale or internal use (for production of paper filler material) of $\mathrm{CO}_{2}$ captured at the acid gas removal island; ${ }^{43}$ sale of argon generated by the ASU; and other options. In the context of the present study, such measures would likely improve the calculated IRRs, but not substantially so we have not included any other than the ASU upsizing.

\footnotetext{
${ }^{41}$ Since the power/recovery economics must ultimately be evaluated within the financial performance of the entire company, any negative net cash flows in early years (e.g., during construction and startup) were assumed to generate tax savings that could be captured elsewhere by the mill owner in that year. These savings were therefore factored into the IRR results shown here.

${ }^{42}$ The biorefinery ownership structure (e.g., 100\% mill, 100\% energy company, $100 \%$ third party, or some mix of these) will be critically important in actual implementation. However, different structures were not examined here, since this would complicate the analysis without fundamentally changing the relative costs/benefits of Tomlinson versus biorefinery technology - the comparison of interest in this study.

${ }^{43}$ At some pulp and paper mills today, $\mathrm{CO}_{2}$ is stripped from lime kiln flue gases for this purpose.
} 
Table 25: Summary of key input assumptions for the financial analysis.

\begin{tabular}{|c|c|}
\hline \multicolumn{2}{|l|}{ Financial Parameters } \\
\hline Inflation Rate & $2.14 \%$ \\
\hline Debt Fraction & $50 \%$ \\
\hline Equity Fraction & $50 \%$ \\
\hline Interest Rate on Debt & $8 \%$ \\
\hline Return on Equity (hurdle rate) ${ }^{\mathrm{a}}$ & $15 \%$ \\
\hline Income Tax Rate (combined Federal \& State) & $40 \%$ \\
\hline Property Tax \& Insurance & $2 \%$ \\
\hline Economic Life (years) & 25 \\
\hline Depreciation Method & 20-year MACRS rate schedule ${ }^{b}$ \\
\hline Construction time for Tomlinson systems & 24 months \\
\hline Construction time for BLGCC \& Biorefinery systems & 30 months \\
\hline \multicolumn{2}{|l|}{ P\&P Industry/Mill Assumptions } \\
\hline O\&M cost inflator (\% per year, current $\$)^{c}$ & $2.67 \%$ \\
\hline Annual Operating Hours & 8,330 \\
\hline \multicolumn{2}{|l|}{ Start-up Assumptions (\% of full output) } \\
\hline Year 1 of Operation & $80 \%$ \\
\hline Year 2 of Operation (and beyond) & $100 \%$ \\
\hline
\end{tabular}

(a) This is the discount rate used for the NPV calculations

(b) The Modified Accelerated Cost Recovery System (MACRS) is a property depreciation system defined by the Internal Revenue Service that applies to assets placed in service after 1986. It results in more rapid depreciation than straight-line depreciation.

(c) Based on [135].

\subsubsection{Energy Price Forecasts}

One of the most challenging aspects of the biorefinery economic analysis is deciding what future energy prices to use. While energy price forecasting is difficult under any circumstances, it is compounded by recent historically high prices and the high degree of uncertainty regarding the future. The U.S. DOE Annual Energy Outlook (AEO) [134] forms the basis of the price scenarios developed here and provides a bracket for future energy prices. Specifically, both the AEO's Reference and High Price cases are used. The High Price case is representative of an extrapolation of mid-2006 prices, with crude oil climbing gradually to $\$ 90-95 /$ barrel by 2030 (in constant \$2004). In contrast, the Reference case has crude oil stabilizing in the $\$ 45-55 / \mathrm{barrel}$ range over the forecast period. The Low Price case, where oil returns to $\$ 28-35 / \mathrm{barrel}$, and stays there, is not considered here, as it is deemed the least likely of the three possibilities.

Thus, we use the AEO Reference and High Price cases to create two energy price scenarios for our analysis. We call these the Reference Energy Prices (REP) and Tight Supplies Energy Prices (TSEP) scenarios. As we describe in detail below, we utilize year-by-year values for oil and other energy prices over the 25 years spanned in each of these two scenarios. The scenarios can be characterized in short-hand by the levelized world crude oil price calculated from our year-byyear oil price assumptions. In the REP scenario, this levelized price is $\$ 50$ per barrel. In the TSEP scenario, this levelized price is $\$ 78$ per barrel.

An additional challenge in developing price forecasts for DME, FT crude and mixed alcohols for use as fuels is that none exist in the literature. Therefore, prices for other fuels must be used to 
estimate what the selling price might be for these alternatives. Moreover, the available forecasts are for wholesale prices, but it is necessary here to estimate plant gate prices, which would be lower, to account for transportation to the wholesale terminal. The AEO has a wholesale price forecast for ethanol, but not for any other alternative fuel. Also, the AEO includes the effects of current incentives for ethanol, but does not explicitly break them out. Thus, there is no forecast available for ethanol or any other alternative fuel that looks at what the price would be, at the plant gate, without incentives. Since the major incentive for ethanol is the excise tax credit, which is given to blenders and not producers, it is also not possible to know how much, if any, of the credit actually flows to the producer. Plus, this value would fluctuate from year to year depending on market conditions.

Despite some limitations, since the only biofuel for which there is an actual forecast is ethanol, this forms the starting point for estimating prices for the biofuels being studied here. There are two main considerations in developing the plant gate price:

- The need to subtract from the AEO wholesale ethanol price, an estimate of the cost of transportation from the plant gate

- The need to estimate the impact of the excise tax credit so as to estimate a price without incentives (needed for our baseline economic analysis)

Addressing the first issue is straight forward - we assume that the cost of transportation is 15 $\phi /$ gallon in the near term, falling to $10 \phi /$ gallon by 2009 and $5 \phi /$ gallon by 2016 . The gradual reduction reflects the expected economies of scale from increased biofuels production and the increasing sophistication of the biofuels supply chain. In comparison, transportation of petroleum products, which typically occurs via pipeline, is less than $5 \notin /$ gallon.

The second issue is more complex. Figure 46 illustrates the approach used for ethanol and mixed alcohols. (For mixed alcohols - MA - we assume a pricing structure exactly like ethanol, corrected for the slightly higher energy content per gallon, i.e., MA has the same price in \$/MMBtu as ethanol). Our estimate of the marginal production cost of ethanol today provides a floor price for these fuels, which is almost never reached with the approach outlined in Figure 46. One output of the approach is an estimate (albeit a crude one) of the amount of the excise tax credit that flows to the producer in any given year. We assume that all biofuels receive this same credit (corrected for energy content), and that the fraction of that credit that flows to producers is the same as for ethanol, corrected for energy content. ${ }^{44}$ In this way, the forecasts for all of the biofuels reflect the AEO's estimate of the price premium (if any) that the market is willing to bear for biofuels relative to conventional fuels, both with and without the applicability of the excise tax credit. This is important because the AEO Reference Case price projections (used in our REP scenario) suggest that ethanol prices remain above what one would expect if it were valued only on energy content relative to gasoline. This implies that the market continues to be willing to pay a premium for ethanol over gasoline (perhaps reflecting a Federal RFS or the value of ethanol for emissions reductions and/or octane enhancement). For consistency, we reflect this premium in all the biofuels prices. In comparison, in our TSEP scenario, where fossil fuels are much more expensive, ethanol is priced much closer to gasoline, corrected for energy content, and therefore, almost none of the tax credit effectively flows to the producer.

\footnotetext{
44 There are currently different levels of the excise tax credit for different biofuels, but for ease of comparison, we have assumed that they are eventually harmonized - on an energy basis - as part of evolving energy policy.
} 


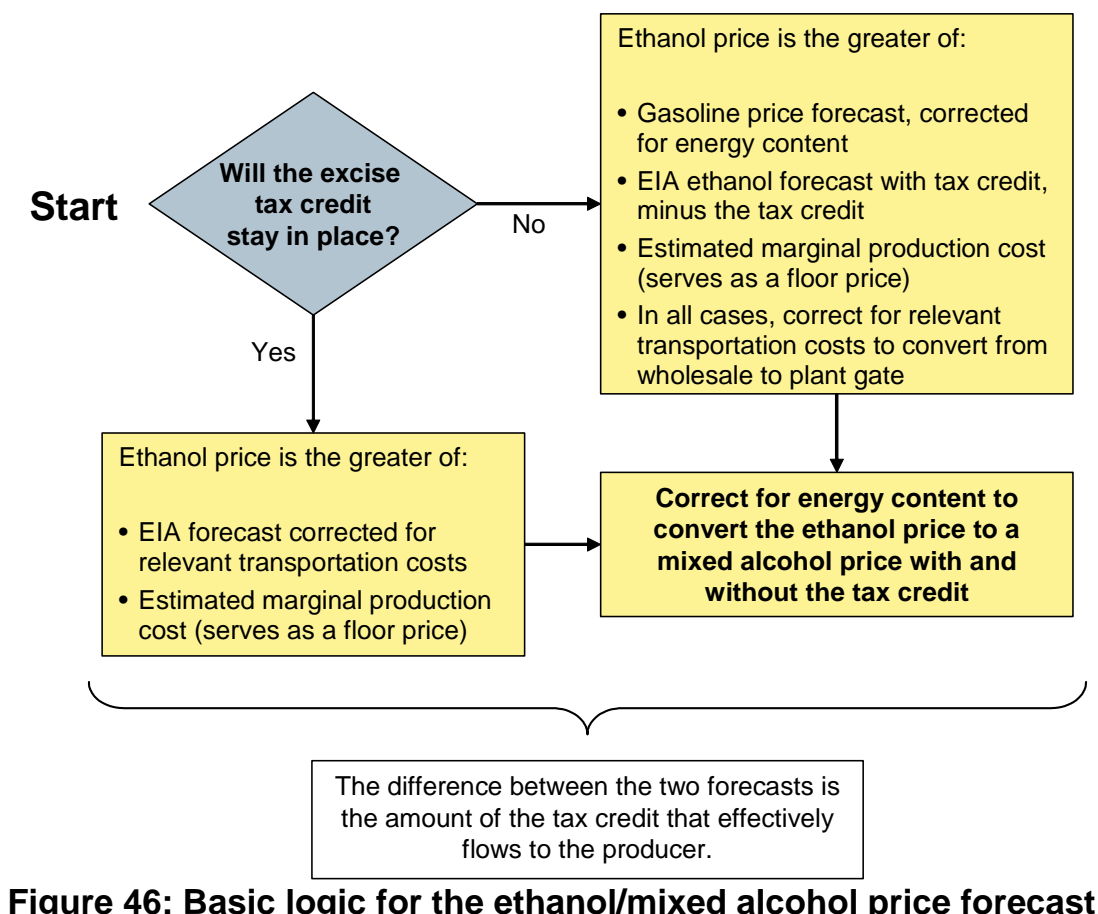

For biorefinery DME and FT crude products, Figure 47 illustrates our basic logic for estimating prices. It is similar to the approach for ethanol and MA, except that there is no direct forecast from the AEO, as there is with ethanol. As discussed above the impact of the excise tax on the producer is assumed to be the same as is calculated for ethanol, corrected for energy content.

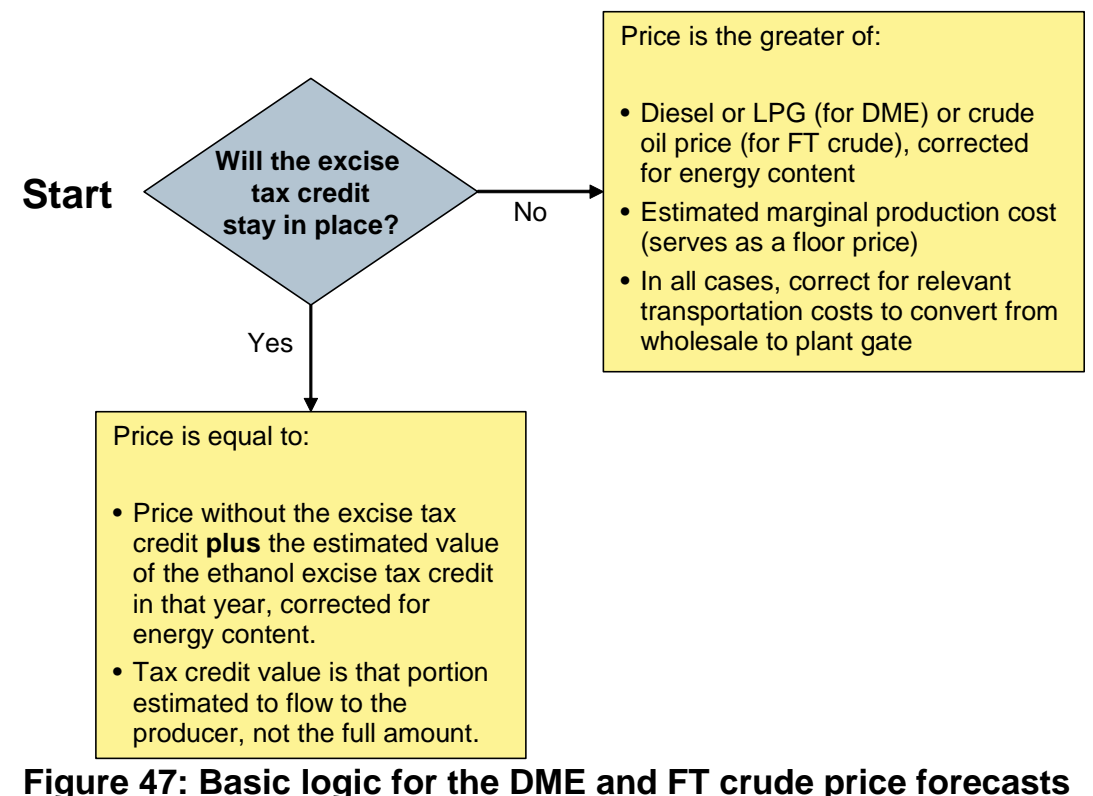

For the prices of electricity, natural gas and residual fuel oil (\#6 oil), all of which are inputs to the biorefinery, the EIA national average forecasts for industrial customers are used, without making any adjustments. For electricity exported, the EIA estimate of the wholesale cost component of electricity generation is used. This value is slightly lower than the industrial retail 
price. Table 26 summarizes all the energy commodity prices used, expressed as levelized prices (over the assumed 25-year, 2010-2034, analysis period). The actual year-by-year estimates are provided in Figure 48 through Figure 50. Based on the AEO forecasts for ethanol, gasoline, diesel and LPG, and the approach described above, mixed alcohols receives the highest price in the market, followed by DME and then FT crude. ${ }^{45}$

Table 26: Levelized costs (in constant 2005\$) for energy commodities (plant gate, no incentives). Fuel prices are on a higher heating value basis. ${ }^{a}$

\begin{tabular}{|l|c|c|}
\hline Energy Commodity & $\begin{array}{c}\text { Reference Energy Prices } \\
\text { (REP) Scenario }\end{array}$ & $\begin{array}{c}\text { Tight Supplies Energy } \\
\text { Price }\end{array}$ \\
\hline World crude oil price & $\$ 50 / \mathrm{bbl}$ Scenario \\
\hline Electricity - avoided purchases & $\$ 53.3 / \mathrm{MWh}$ & $\$ 56.2 / \mathrm{MWh}$ \\
\hline Electricity - sales to grid & $\$ 48.2 / \mathrm{MWh}$ & $\$ 51.8 / \mathrm{MWh}$ \\
\hline Natural gas purchases & $\$ 5.82 / \mathrm{MCF}$ & $\$ 7.00 / \mathrm{MCF}$ \\
\hline Residual fuel oil purchases & $\$ 1.00 /$ gallon & $\$ 1.62 /$ gallon \\
\hline DME sales as motor diesel substitute & $\$ 0.72 /$ gallon & $\$ 1.10 /$ gallon \\
\hline DME sales as LPG substitute & $\$ 0.66 /$ gallon & $\$ 0.99 /$ gallon \\
\hline FT crude sales as petroleum crude substitute & $\$ 0.96 /$ gallon & $\$ 1.54 /$ gallon \\
\hline FT crude sales as petroleum crude substitute & $\$ 64.7 / \mathrm{barrel}$ \\
\hline Mixed alcohol sales & $\$ 40.3 / \mathrm{barrel}$ & $\$ 1.77 /$ gallon \\
\hline Ethanol sales & $\$ 1.43 /$ gallon & $\$ 1.35 /$ gallon \\
\hline Methanol sales & $\$ 1.09 /$ gallon & $\$ 0.67 /$ gallon \\
\hline Propanol sales & $\$ 0.54 /$ gallon & $\$ 3.90 /$ gallon \\
\hline Purchased wood & $\$ 3.64 /$ gallon & $\$ 1.53 /$ MMBtu \\
\hline
\end{tabular}

(a) The prices for fuels, when reported on a per-unit energy basis (in this table and elsewhere in this report), are given on a higher heating value basis, since this is conventionally how fuel prices are reported in the United States.

(b) These plant gate values correspond to the refinery-gate world oil prices given in the first row of the table, since there would be transportation costs added for the FT crude to reach a refinery.

(c) Propanol is used to represent all higher alcohols in the kinetic model used to model mixed alcohol production.

It is also possible that blenders/wholesalers may apply either a discount or premium to the purchase of biofuels. For example, if handling the biofuel is more complex than the conventional fuel or entails special equipment, they may only be willing to buy it at a discount to the energy equivalent fossil fuel price. Conversely, if the biofuel has superior performance characteristics, it may command a performance premium over the conventional alternative. ${ }^{46}$ So as not to further complicate the analysis of fuel prices, no such discount/premium has been assumed in the baseline forecasts beyond what is implied by the AEO forecast for ethanol. However, for FT crude we do consider a performance premium of $10 \phi /$ gallon as a sensitivity. This would be driven by the refiner viewing the FT crude more favorably than crude petroleum because of its properties (especially zero sulfur and high cetane number). Although DME is an ultra-clean diesel alternative, it was assumed that any performance premium would be negated by the need to retrofit vehicles to use it. When compared to LPG, DME would not result in any material

\footnotetext{
${ }^{45}$ We project the wholesale price for LPG as EIA's industrial price projection minus $20 \%$, since EIA does not project wholesale price. Historically, LPG prices track crude oil prices, but the EIA Reference Case forecast shows a gradual divergence, with LPG becoming more expensive in relative terms. The assumption behind this diversion in the EIA forecast is not known, but it may be that EIA expects a tightening in LPG supplies in the long term.

${ }^{46}$ Separately from this, biofuels mandates could lead to higher prices, particularly if supply falls short of demand needed for compliance.
} 
performance improvement. Similarly, it has been assumed that MA are viewed as identical to ethanol from a performance and handling perspective, and therefore do not command a premium or incur a discount relative to ethanol.

Figure 48: Study assumptions for electricity prices.

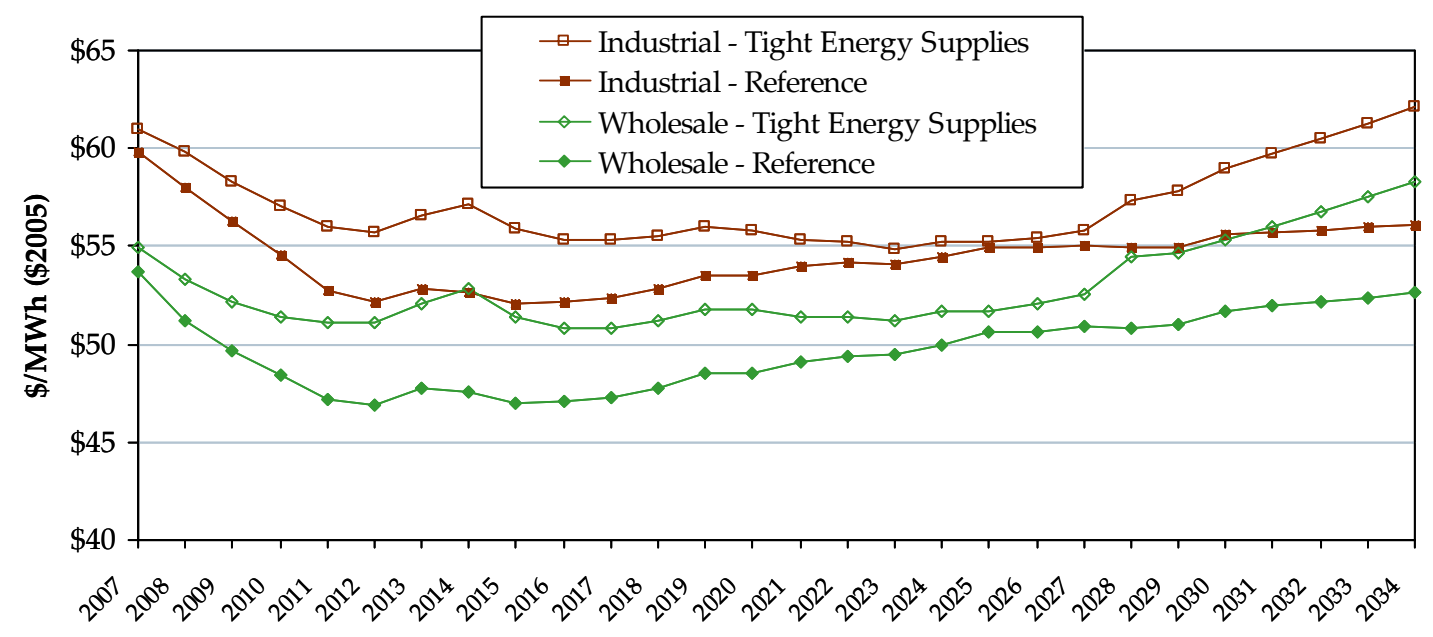

The industrial price is used for avoided electricity purchases.

The wholesale price is used for the sale of exported power.

Source: DOE Energy Information Administration Annual Energy Outlook 2006 national average price forecasts. The Tight Energy Supplies scenario is based on the "high price" case in the AEO and is consistent with an extrapolation of current prices. The Reference scenario is based on the "reference price" case in the AEO and is based on a moderation of energy prices consistent with petroleum in the $\$ 45-55 /$ barrel range.

Figure 49: Study assumptions for purchased wood, \#6 oil and natural gas prices (\$/MMBtu, HHV).

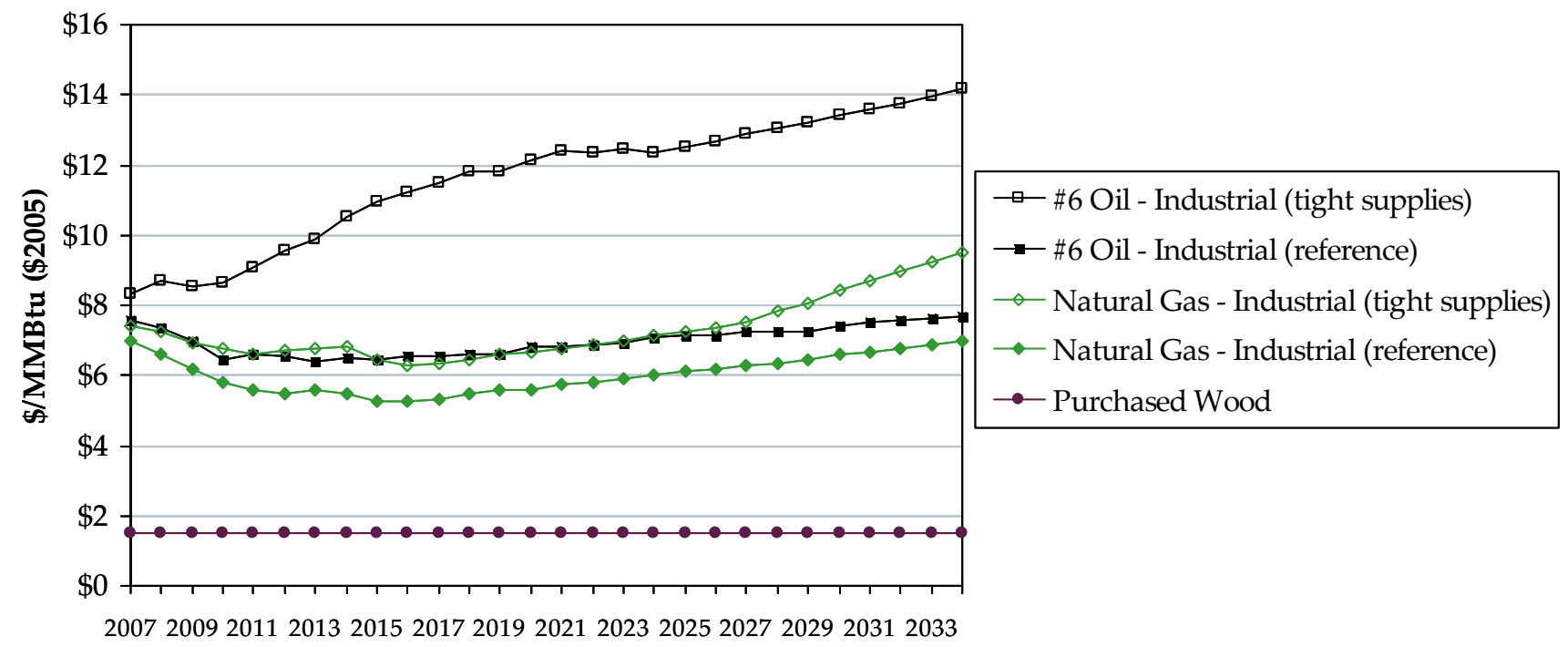

Source: DOE Energy Information Administration Annual Energy Outlook 2006 national average price forecasts. The Tight Energy Supplies scenario is based on the "high price" case in the AEO and is consistent with an extrapolation of current prices. The Reference scenario is based on the "reference price" case in the AEO and is based on a moderation of energy prices consistent with petroleum in the $\$ 45-55 / \mathrm{barrel}$ range. 
Figure 50: Biorefinery product prices forecasts - no incentives (\$/MMBtu, HHV).

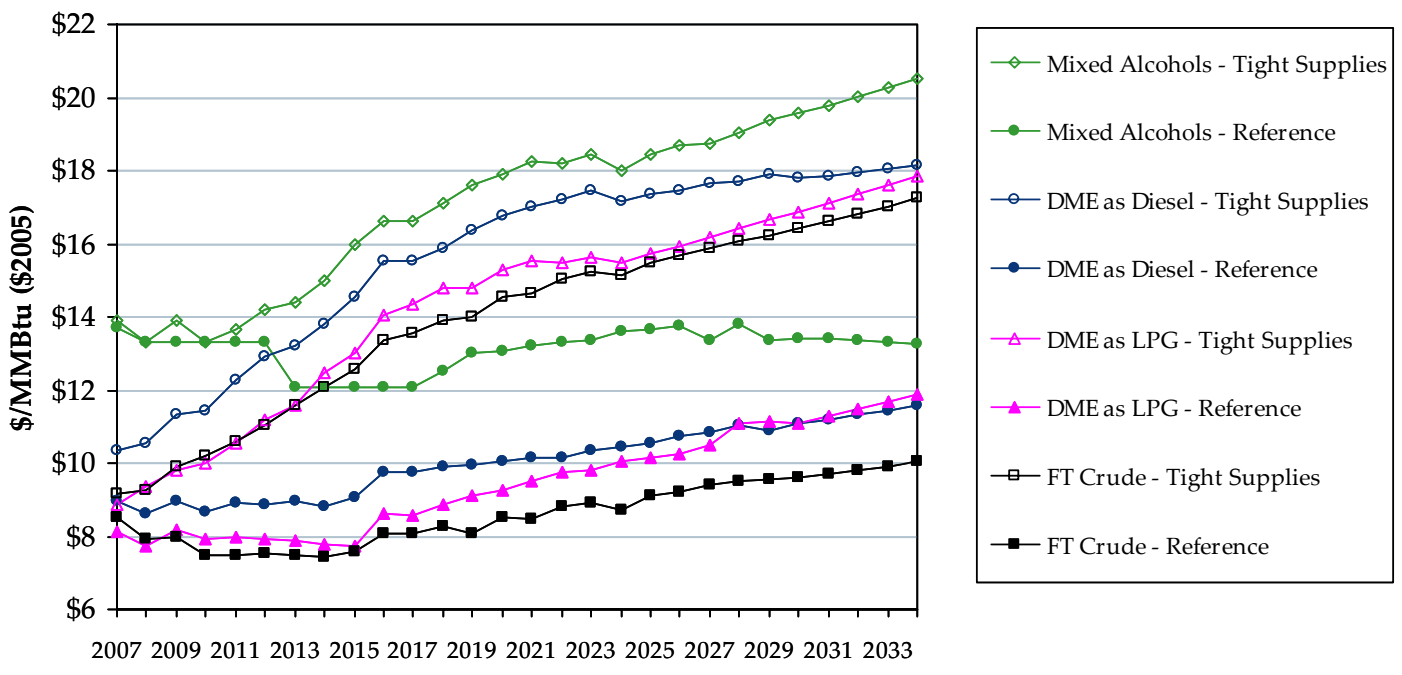

Source: Based on the DOE Energy Information Administration Annual Energy Outlook 2006 national average price forecasts. The Tight Energy Supplies scenario is based on the "high price" case in the AEO and is consistent with an extrapolation of current prices. The Reference scenario is based on the "reference price" case in the AEO and is based on a moderation of energy prices consistent with petroleum in the $\$ 45-55 /$ barrel range. FT Crude is based on low sulfur crude oil on an energy basis. Mixed alcohols are the same as ethanol on an energy basis. Note that the AEO prices have been corrected for wholesale vs. plant gate and other factors. See main text for additional explanation of the approach to estimating product prices.

\subsubsection{Incentives and the Monetary Value of Environmental Attributes}

An important aspect of biorefinery economics will be the ability to convert environmental and renewable energy benefits of the technology into monetary value, e.g., by selling excess $\mathrm{NO}_{\mathrm{x}}$ allowances or garnering a premium for renewable electricity sold to meet a renewable portfolio standard or voluntary green power program. In the longer term, carbon trading or some other scheme to reduce emissions of greenhouse gases may also come into play. Other factors affecting biorefinery economics include existing and potential federal and state incentives (biofuels excise tax credits, tax exemptions and production tax credits) designed to promote the development of renewable energy resources.

The impact on IRR of environmental improvements arising from the application of biorefinery technology is examined here by applying a range of monetary values to a selected set of plausible incentives and environmental attributes (Table 27). These values are estimated in most cases based on existing types of incentives and programs, assuming similar incentives might apply, as detailed in the notes to Table 27. A number of other programs and incentives could provide additional value, but for various reasons, were not included at the present time (Table 28). Notably, this list includes the current Federal Renewable Fuel Standard (RFS). The RFS, a minimum biofuels content requirement for transportation fuels, is potentially very significant. However, in its current form, two factors led to the decision to exclude it from the current analysis, (i) the final rules, to be set by the EPA, are not yet in place, and (ii) the current RFS, calling for 7.5 billion gallons of renewable fuels production by 2012 and a percentage fixed at the 2012 level beyond 2012, appears likely to be reached well before 2012, in which case there will be relatively little RFS premium available for production in excess of that mandated by the RFS. Moreover, since the AEO seems to imply a premium for ethanol (based on energy content), adding an explicit premium for the RFS may be double counting. 
Table 27. Values assumed for financial incentives and monetized environmental benefits.

\begin{tabular}{|c|c|c|}
\hline Potential Credit & Basis for Credit & Approach to Analysis \\
\hline $\begin{array}{l}\text { Volumetric } \\
\text { Excise Tax } \\
\text { Credit }\end{array}$ & $\begin{array}{l}\text { - Existing } 51 \text { \&/gallon credit for ethanol } \\
\text { - Based on discussion in the text, the value of the credit } \\
\text { as reflected in the plant gate price received for } \\
\text { ethanol averages } 46.4 \$ / g a l l o n \text { in our REP scenario } \\
\text { and } 42.7 \$ / g a l l o n \text { in the TSEP scenario. }\end{array}$ & $\begin{array}{l}\text { - Although different credits exist for different } \\
\text { biofuels today, not all biofuels currently qualify for } \\
\text { a tax credit } \\
\text { - It was assumed that in the future the tax credit } \\
\text { would be harmonized across all biofuels at the } \\
\text { same level as the current ethanol credit, corrected } \\
\text { for energy content. }^{\text {a }} \\
\text { - Credit is assumed to run for the entire } 25 \text {-year } \\
\text { analysis period }\end{array}$ \\
\hline $\begin{array}{l}\text { Gasification } \\
\text { Investment Tax } \\
\text { Credit }\end{array}$ & $\begin{array}{l}\text { - EPAct 2005, Sec. } 1307 \text { contains a gasification } \\
\text { investment tax credit allowing } 20 \% \text { income tax credit } \\
\text { against gasification-related investments }\end{array}$ & $\begin{array}{l}\text { - From CAPEX estimates, estimate fraction that is } \\
\text { "gasification related" and apply } 20 \% \text { credit to this } \\
\text { amount in year } 1 \text {. }\end{array}$ \\
\hline $\begin{array}{l}\text { Renewable } \\
\text { Electricity } \\
\text { Premium }^{\text {a }}\end{array}$ & $\begin{array}{l}\text { - MWh sales into a voluntary "green power" program or } \\
\text { to satisfy a mandated Renewable Portfolio Standard } \\
\text { (RPS), e.g. through sale of renewable energy } \\
\text { certificates (RECs) or "green tags". } \\
\text { - Green power programs continue to grow in popularity } \\
\text { and more than } 20 \text { U.S. states have implemented an } \\
\text { RPS. } \\
\text { - RECs are emerging as the dominant accounting } \\
\text { system for RPS and other attribute-based standards, } \\
\text { such as labeling, emission performance standards, } \\
\text { and substantiation of marketing claims. }\end{array}$ & $\begin{array}{l}\text { - Value of } \$ 20 / M W h \text {, indexed to inflation, consistent } \\
\text { with existing price for RPS compliance and } \\
\text { voluntary green power. } \\
\text { - Applies to all incremental electricity generation } \\
\text { above Tomlinson level, consistent with existing } \\
\text { definitions of "new renewable generation," e.g., as } \\
\text { in the current Massachusetts RPS. } \\
\text { - Premium is assumed to run for the entire } 25 \text {-year } \\
\text { analysis period, indexed to inflation }\end{array}$ \\
\hline $\begin{array}{l}\text { Renewable } \\
\text { Energy } \\
\text { Production Tax } \\
\text { Credit (PTC) }^{\text {b }}\end{array}$ & $\begin{array}{l}\text { - Existing Federal renewable energy production tax } \\
\text { credit for open loop biomass. }\end{array}$ & $\begin{array}{l}\text { - } \$ 9 / \mathrm{MWh} \text { for ten years from initial operation, } \\
\text { indexed to inflation.c } \\
\text { - Applied to all incremental renewable generation } \\
\text { over the Tomlinson level (but in theory, may apply } \\
\text { to ALL renewable generation if the plant is } \\
\text { considered a "new generator"). }\end{array}$ \\
\hline Carbon Credit & $\begin{array}{l}\text { - Future "cap and trade" system similar to that for } \mathrm{SO}_{2} \\
\text { allowances }\end{array}$ & $\begin{array}{l}\text { - } \$ 25 \text { per metric t } \mathrm{CO}_{2} \text {, indexed to inflation (base } \\
\text { year = 2010), for entire } 25-y r \text { analysis period. } \\
\text { - Applied to net reductions, including grid offsets } \\
\text { and conventional fuel chain offsets. }\end{array}$ \\
\hline $\begin{array}{l}\text { Biofuel } \\
\text { Performance } \\
\text { Premium }\end{array}$ & $\begin{array}{l}\text { - Superior performance and/or properties of biofuels } \\
\text { relative to conventional fuels }\end{array}$ & $\begin{array}{l}\text { - } 10 \text { \$/gallon for crude } \mathrm{FT}^{\mathrm{e}} \\
\text { - Premium is assumed to run for the entire } 25 \text {-year } \\
\text { analysis period, not indexed to inflation. }\end{array}$ \\
\hline
\end{tabular}

(a) Currently, non-ethanol alcohols receive a $60 \phi / g a l$ tax credit, ethers derived from alcohols receive the alcohol gallon equivalent of the tax credit, and "renewable diesel" as defined in Section 1346 of the 2005 EPAct, receives a \$1/gal credit. The computed values of the tax credits used here are: DME, 45.6 $/ \mathrm{gal}$; mixed alcohols, $67.2 \phi /$ gal; crude FT, $72.4 \phi / g a l$.

(b) Currently, there exist active government-sanctioned markets for renewable energy certificates (RECs) in Texas (ERCOT), New England (NEPOOL), the mid-Atlantic states (PJM), the European Union, Australia and New Zealand, and elsewhere. In the United States, market prices for compliance RECs range from about \$5-50/MWh depending on the region. In most cases, there is a ceiling price for RECs. In Massachusetts it is $\$ 50 / \mathrm{MWh}$ (with inflation adjustments). The cap is set by establishing a penalty for non-compliance with required REC purchases. Voluntary green power markets also place a premium on renewable electricity and may use RECs or may simply charge a premium for the power. The average premium for these programs is around $\$ 20 / \mathrm{MWh}$.

(c) Under Section 45 of the Internal Revenue Code, qualifying renewable energy technologies receive a Renewable Energy Production Tax Credit (PTC), currently valued at $0.9 \phi / \mathrm{kWh}$ (indexed to inflation) for the first ten years of operation for "open loop" biomass.

(d) Because significant environmental benefits of biorefineries occur as a result of displacing grid power and conventional fuels, the emissions analysis here includes these in the estimate of the total value of carbon credits. The rationale is that the biorefinery creates the benefit and therefore the monetary value associated with it. In practice, it may be difficult to monetize these indirect emissions benefits, but we have included them here to illustrate their potential value.

(e) This estimate is lower than an estimate made by UOP [136] of \$312/ton total value (or equivalent to a premium of $~ 21$ $\phi / \mathrm{gal}$ ) to a refinery with petroleum prices at $\$ 40 / \mathrm{bbl}$. It is higher than an estimate made by Texaco [137], and close to an estimate made by EIA [138] of the impact of the ultra low sulfur diesel requirements on retail diesel prices of $9 \phi / g a l l o n$. The authors note here that some members of the Steering Committee of this project (Figure 4) thought that a $10 \phi /$ gallon premium for the crude FT product might be optimistically high. Nevertheless, the analysis presented here shows that even at this level, this premium has only a minor impact on the economics. 
Table 28. Renewable energy programs and incentives not included in the financial analysis.

\begin{tabular}{|c|c|}
\hline $\begin{array}{l}\text { Potentially Available } \\
\text { Credit }\end{array}$ & Rationale for not including in the current analysis \\
\hline $\begin{array}{l}\text { Volumetric income } \\
\text { tax credits }\end{array}$ & $\begin{array}{l}\text { - Cannot be taken in addition to the excise tax credit and the excise tax credit is more } \\
\text { popular as it is easier to claim. }\end{array}$ \\
\hline $\begin{array}{l}\text { Small ethanol } \\
\text { producer credit }\end{array}$ & $\begin{array}{l}\text { - Currently for ethanol and biodiesel only } \\
\text { - Limited to the first } 15 \text { million gallons of output for producers smaller than } 60 \text { million } \\
\text { gallons/year, so would not apply in all cases. }\end{array}$ \\
\hline $\begin{array}{l}\text { Federal Renewable } \\
\text { Fuels Standard }\end{array}$ & $\begin{array}{l}\text { - Final RFS rules not yet in place, so value is difficult to estimate } \\
\text { - Current RFS targets are likely to be easily reached, suggesting minimal value for the } \\
\text { RFS premium } \\
\text { - EIA AEO } 2006 \text { price forecast for ethanol already appears to build in some premium for } \\
\text { ethanol, which has been reflected in our price scenarios. }\end{array}$ \\
\hline $\begin{array}{l}\text { Biomass Production } \\
\text { Incentive }\end{array}$ & - Currently tied to forest fire mitigation projects only and limited to $\$ 500,000$ per grant. \\
\hline $\begin{array}{l}\text { Production } \\
\text { incentive for } \\
\text { cellulosic biofuels } \\
\text { (from EPAct 2005) }\end{array}$ & $\begin{array}{l}\text { - Difficult to predict value (program rules not yet determined) } \\
\text { - Not clear if black liquor would qualify }\end{array}$ \\
\hline $\begin{array}{l}\text { Biorefinery } \\
\text { demonstration } \\
\text { program }\end{array}$ & - Not considered applicable to Nth plant \\
\hline $\mathrm{NO}_{\mathrm{x}}$ Allowances & $\begin{array}{l}\text { - Larson, et al. [5] showed these were not significant and impacts here would be less } \\
\text { (NOx impact is partly at the tailpipe, not at the mill or power plant) } \\
\text { - Difficult to monetize if savings occur beyond mill boundary } \\
\text { - Would apply only in "SIP call" states }\end{array}$ \\
\hline $\begin{array}{l}\mathrm{NO}_{x} \text { Emissions } \\
\text { Reductions Credits } \\
\text { (ERC) }\end{array}$ & $\begin{array}{l}\text { - Applies today only in ozone non-attainment areas, which largely exclude areas with } \\
\text { pulp and paper mills } \\
\text { - Prices vary considerably by state }\end{array}$ \\
\hline
\end{tabular}

\subsection{Results of Financial Analysis}

Table 29 summarizes the annual material and energy flows used in our cash flow/IRR analyses, considering 8,330 annual hours of full-load operation (as assumed in [5]).

\subsubsection{BLGCC}

Figure 51 shows for the BLGCC system the internal rate of return (IRR) relative to a new Tomlinson system for a range of incremental capital investment levels (including our baseline cost estimate from Table 22) and for our two energy price scenarios. For a desired IRR and assumed energy price scenario, this figure shows the acceptable incremental capital investment relative to the investment for a new Tomlinson system. Under the baseline set of assumptions (labeled "Our Capital Cost Estimate") and our Reference Energy Price (REP) scenario, the incremental investment of $\$ 82$ million gives an IRR of $21.7 \%$. The calculated NPV is $\$ 24.7$ million. The added capital investment needed for the BLGCC plus purchase of additional wood residuals, lime kiln fuel, and a small amount of natural gas are compensated by the benefits of electricity sales, reduced pulpwood requirements (Table 29), and avoided power purchases compared with the Tomlinson case, leading to respectable financial performance. Under our Tight Supplies Energy Price (TESP) scenario, the IRR and NPV are not significantly different from those in the REP scenario since electricity is the only export revenue, and electricity prices are not significantly different between the two scenarios. 
Figure 52 shows the sensitivity of the BLGCC incremental IRR to the assumed price of biomass purchased for energy (not for paper production) and electricity price, assuming the invested capital corresponds to "Our Capital Cost Estimate" shown in Figure 51. The prices for these two commodities can vary independently of the broader energy markets, and should also show stronger regional variation than prices for petroleum-based fuels. This chart can therefore be used to estimate variations in IRR depending on where a plant may be located. Not surprisingly, for the BLGCC configuration, variations in electricity price have a much stronger effect than variations in purchased biomass price, since electricity is the sole energy product and there is relatively little biomass purchased.

The above financial results were generated assuming no financial incentives or monetary values assigned to environmental or renewable energy attributes of biorefinery products. Figure 53 shows the IRRs for the BLGCC configuration (relative to an investment in a new Tomlinson system) when a range of different incentives or monetized environmental benefits are included under our REP scenario.

Figure 51: Allowable incremental capital cost for BLGCC relative to new Tomlinson to achieve different target IRR values under the REP and TSEP scenarios.

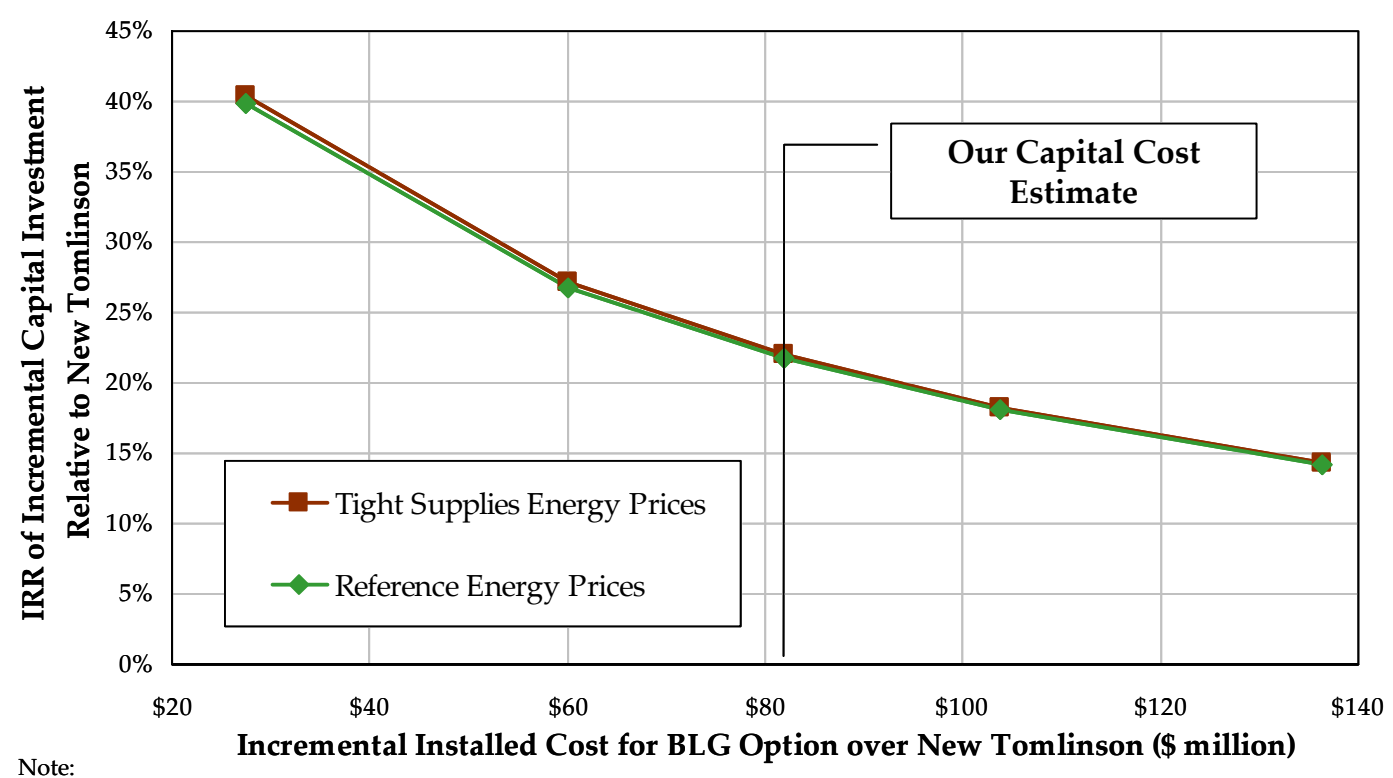

Our estimate of the capital cost for the BLGCC system is $\$ 218$ million, and for the New Tomlinson is $\$ 136.2$ million. This chart is meant to show the impact of different capital costs and product prices, all else equal. 
Table 29. Annual material and energy flows for the alternative power/recovery/biorefinery systems.

\begin{tabular}{|c|c|c|c|c|c|c|c|c|c|c|}
\hline \multirow{2}{*}{ Parameter } & \multirow{2}{*}{ Units per year } & \multirow{2}{*}{ Tomlinson } & \multicolumn{8}{|c|}{ Biorefinery Cases } \\
\hline & & & BLGCC & DMEa & DMEb & DMEc & FTa & FTb & FTc & $M A^{d}$ \\
\hline \multicolumn{11}{|c|}{ Annual Material Flows } \\
\hline Mill Operating Hours & Hours & \multicolumn{9}{|c|}{8,330} \\
\hline Total Pulp Production & Bone dry short tons & \multicolumn{9}{|c|}{548,277} \\
\hline Total Wood to Mill & Bone dry short tons & $1,309,943$ & \multicolumn{8}{|c|}{$1,223,482$} \\
\hline Hog Fuel Production & Bone dry short tons & 117,895 & \multicolumn{8}{|c|}{110,113} \\
\hline Wood Purchases for Energy & Bone dry short tons & $\begin{array}{ll}-- \\
-\end{array}$ & 55,155 & 157,746 & 398,483 & 149,697 & 207,161 & 751,009 & 919,753 & 181,893 \\
\hline Avoided Pulpwood Purchases & Bone dry short tons & --- & \multicolumn{8}{|c|}{86,461} \\
\hline Black Liquor Production & Short tons BL solids & $1,041,250$ & \multicolumn{8}{|c|}{940,534} \\
\hline Biofuel Production & Million Gallons & --- & $\begin{array}{ll}-- \\
\end{array}$ & 69.29 & 69.29 & 30.61 & 28.30 & 28.30 & 86.93 & 16.76 \\
\hline \multicolumn{11}{|c|}{ Annual Energy Flows (on higher heating value basis for fuels) } \\
\hline Mill Electricity Use ${ }^{\mathrm{a}}$ & MWh & \multicolumn{9}{|c|}{833,800} \\
\hline $\begin{array}{l}\text { Net Electricity Production } \\
\text { (without extra } \mathrm{O}_{2} \text { Production) }\end{array}$ & MWh & 535,619 & 955,451 & 9,496 & 736,705 & 759,113 & 735,289 & $1,911,568$ & 648,824 & 770,275 \\
\hline $\begin{array}{l}\text { Net Electricity Production } \\
\text { (with extra } \mathrm{O}_{2} \text { Production) }\end{array}$ & $\mathrm{MWh}$ & 535,619 & 950,610 & 4,667 & 731,859 & 754,259 & 730,443 & $1,906,714$ & 643,979 & 765,416 \\
\hline Net Electricity Purchased & MWh & 298,181 & --- & 829,133 & 101,940 & 79,541 & 103,357 & --- & 189,821 & 68,383 \\
\hline Net Electricity Exported & MWh & \begin{tabular}{l|l}
-- \\
-1
\end{tabular} & 116,811 & --- & --- & --- & --- & $1,072,914$ & --- & -- \\
\hline Incremental Electricity $^{\mathrm{C}}$ & MWh & --- & 414,991 & $(530,952)$ & 196,240 & 218,640 & 194,824 & $1,371,095$ & 108,360 & 229,797 \\
\hline Natural Gas Purchased & MMBtu & --- & 407,129 & --- & --- & --- & --- & --- & --- & --- \\
\hline Total Lime Kiln Fuel & MMBtu & 940,806 & \multicolumn{8}{|c|}{$1,085,764$} \\
\hline Incremental Lime Kiln Fuel & MMBtu & --- & \multicolumn{8}{|c|}{144,958} \\
\hline Hog Fuel + Wood Residues & MMBtu & $2,023,835$ & $2,842,613$ & $4,607,176$ & $8,747,851$ & $4,468,733$ & $5,457,111$ & $14,811,308$ & $17,713,706$ & $5,022,505$ \\
\hline Purchased Wood Residuals & MMBtu & --- & 948,663 & $2,713,226$ & $6,853,901$ & $2,574,783$ & $3,563,161$ & $12,917,358$ & $15,819,756$ & $3,128,555$ \\
\hline Biofuel Production & MMBtu & --- & --- & $5,239,067$ & $5,239,067$ & $2,314,618$ & $3,396,896$ & $3,396,896$ & $10,434,890$ & $1,866,613$ \\
\hline
\end{tabular}

(a) Excludes power/fuels/recovery parasitic loads.

(b) Net production is after subtracting power/fuels/recovery parasitic loads. The case labeled "without extra $\mathrm{O}_{2}$ production" corresponds to the mass-energy balances presented in Figure 23 through Figure 29. The case labeled "with extra $\mathrm{O}_{2}$ production" includes the incremental power requirements to generate additional purified oxygen with the ASU to replace existing mill $\mathrm{O}_{2}$ requirements for oxygen delignification. The ASU at a biorefinery presents to opportunity to meet other $\mathrm{O}_{2}$ needs of the mill that may be currently being met with purchased $\mathrm{O}_{2}$. Because of the favorable economics of doing so (see footnote 38), all our financial results include $\mathrm{O}_{2}$ production for use in $\mathrm{O}_{2}$ delignification.

(c) This is the incremental electricity produced relative to the new Tomlinson case. All electricity is generated from biomass so is therefore considered $100 \%$ renewable (in the financial analysis). In the BLGCC case, some natural gas is used in the duct burner to enhance steam production, but since the electricity generated is nevertheless assumed to come from biomass.

(d) Values shown are for the case where the mixed-alcohols product is sold as a single commodity. 
Figure 52: Allowable incremental capital cost for BLGCC relative to new Tomlinson to achieve different target IRR values with indicated biomass and power prices under our Reference Energy Price scenario and for baseline incremental capital cost estimate.

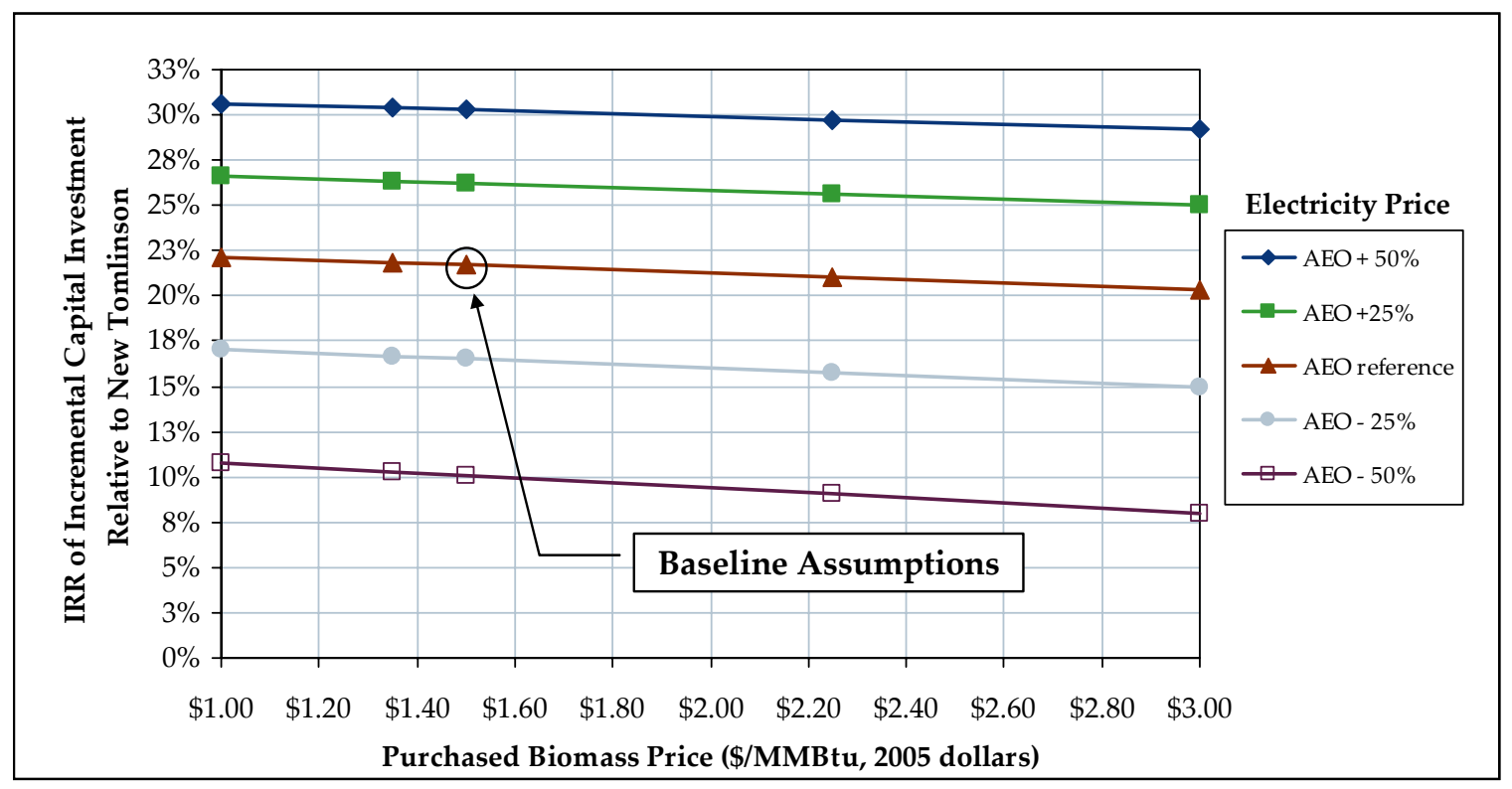

Some benefits, e.g., the sale of renewable energy certificates ${ }^{47}$ (RECs) and a production tax credit (PTC), would be additive, ${ }^{48}$ as would be the impact of fuel excise tax credits, so the impact of a plausible combination of benefits is also shown along with impacts of individual benefits. Credits for emissions reductions are not shown as additive to RECs or a PTC, although it is possible that different emissions reductions could be additive with each other as well as with RECs or PTCs. ${ }^{49}$ Also, since the ability of a biorefinery to monetize carbon credits is not straight-forward, it is only shown separately to highlight its potential value. Still, even if the biorefinery could not directly monetize the benefit of its net $\mathrm{CO}_{2}$ reductions, different GHG reduction programs would still add value to a biorefinery by increasing the cost of conventional options. In that regard, the $\mathrm{CO}_{2}$ calculations here can be viewed as a measure of the potential impact of such programs.

For the BLGCC case, four key incentives all provide similar impacts on IRR, with the highest incremental returns associated with environmental credits that are tied to incremental production of renewable electricity. This analysis assumed a \$20/MWh premium for green power, but higher premiums in line with current values for RECs are possible. Still, coupled with renewable energy production tax credit and the gasification credit, IRRs in excess of $35 \%$ for BLGCC are

${ }^{47}$ For eligible renewable resources, every MWh of generation also produces a renewable energy certificate (REC). These RECs can then be sold to satisfy renewable portfolio standards or to meet voluntary green power programs. RECs are rapidly becoming the "currency" for the trading of renewable energy attributes.

${ }^{48}$ For example, in Texas today, wind farms receive a Federal PTC at the same time they receive payments for the Renewable Energy Certificates they generate that are used to satisfy the Texas renewable portfolio standard.

${ }^{49}$ Different emissions credits (e.g., $\mathrm{NO}_{\mathrm{x}}$ allowances and $\mathrm{CO}_{2}$ credits) could be additive to each other and to a PTC, and possibly to a REC, but some important certifying agencies (e.g., the Center for Resource Solutions, which provides "Green-e" certification) have taken the position that the attributes of "tradable renewable certificates" cannot be unbundled and must be sold together. This would effectively prevent someone from selling $\mathrm{CO}_{2}$ credits and then using the same electricity associated with the $\mathrm{CO}_{2}$ credit to sell a renewable energy certificate. These issues are not yet fully resolved. 
estimated. Obviously, the biofuel excise tax credit has no impact on BLGCC. The results are almost identical under the TSEP scenario, and these results are not shown here.

Figure 53: IRR of incremental capital invested for BLGCC relative to new Tomlinson, with different environmental benefits monetized and for our Reference Energy Price (REP) scenario.

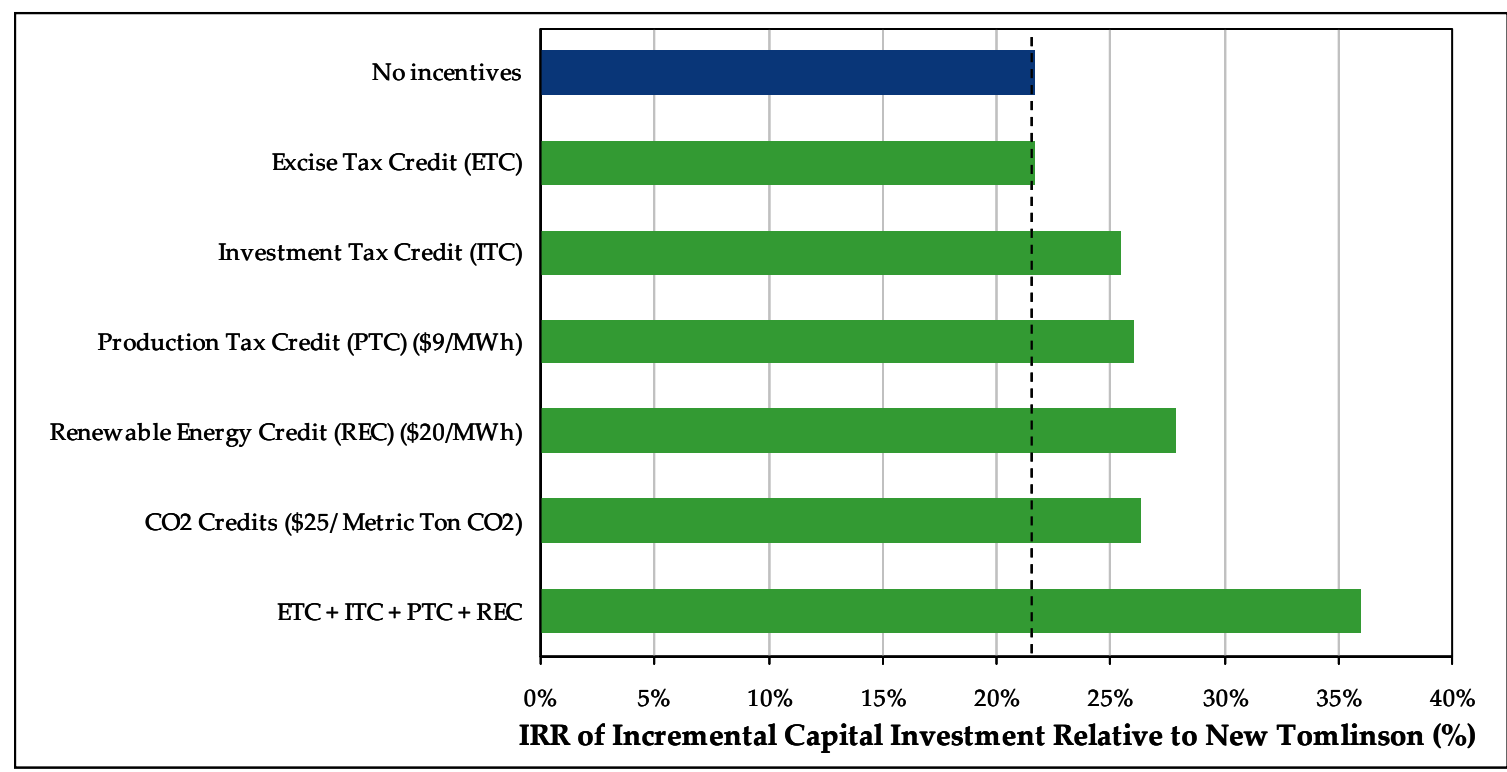

Note: Investment tax credit $=20 \%$ gasification tax credit

\subsubsection{DME Results}

We have carried out two sets of financial analysis for DME biorefineries. One set of analyses considers the DME product being sold as a motor fuel for compression ignition vehicles. The second set considers DME being blended with LPG for sale into the LPG market. Because the results of these two sets of analyses are quite similar for each of the three DME biorefinery configurations, we show details of both sets of analysis only for the DMEa configuration. For $\mathrm{DMEb}$ and DMEc, we show only the results for DME as a vehicle fuel.

\subsubsection{DMEa}

Figure 54 shows, for the DMEa biorefinery configuration and with DME as a motor diesel fuel, the IRR on capital invested relative to a new Tomlinson investment. With "Our Capital Cost Estimate" and the REP scenario, the IRR is $16.4 \%$, with a calculated negative NPV of $\$ 7.4$ million. The DMEa biorefinery produces no electricity for sale, so the economics are very sensitive to the assumed energy price scenario. Under the TSEP scenario, the IRR and NPV are $29.2 \%$ and positive $\$ 98.2$ million, respectively. The high cost of purchasing all of the mill's electricity needs (100 MW) also negatively affects the overall incremental economics.

Figure 55 shows the sensitivity of the IRR to the assumed biomass-energy and electricity prices. As just noted, the economics are very sensitive to electricity price. Moreover, the economics are less favorable at higher electricity prices. This is opposite of the situation for all other biorefinery configurations, which generate substantial amounts of electricity, and thus benefit from higher 
electricity prices. So, even though the baseline assumptions produce reasonable returns, this configuration is particularly sensitive to electricity price variability. ${ }^{50}$

Figure 54: Allowable incremental capital cost for DMEa biorefinery (with DME sold as vehicle fuel) relative to new Tomlinson investment for different target IRR values under our two energy price scenarios.

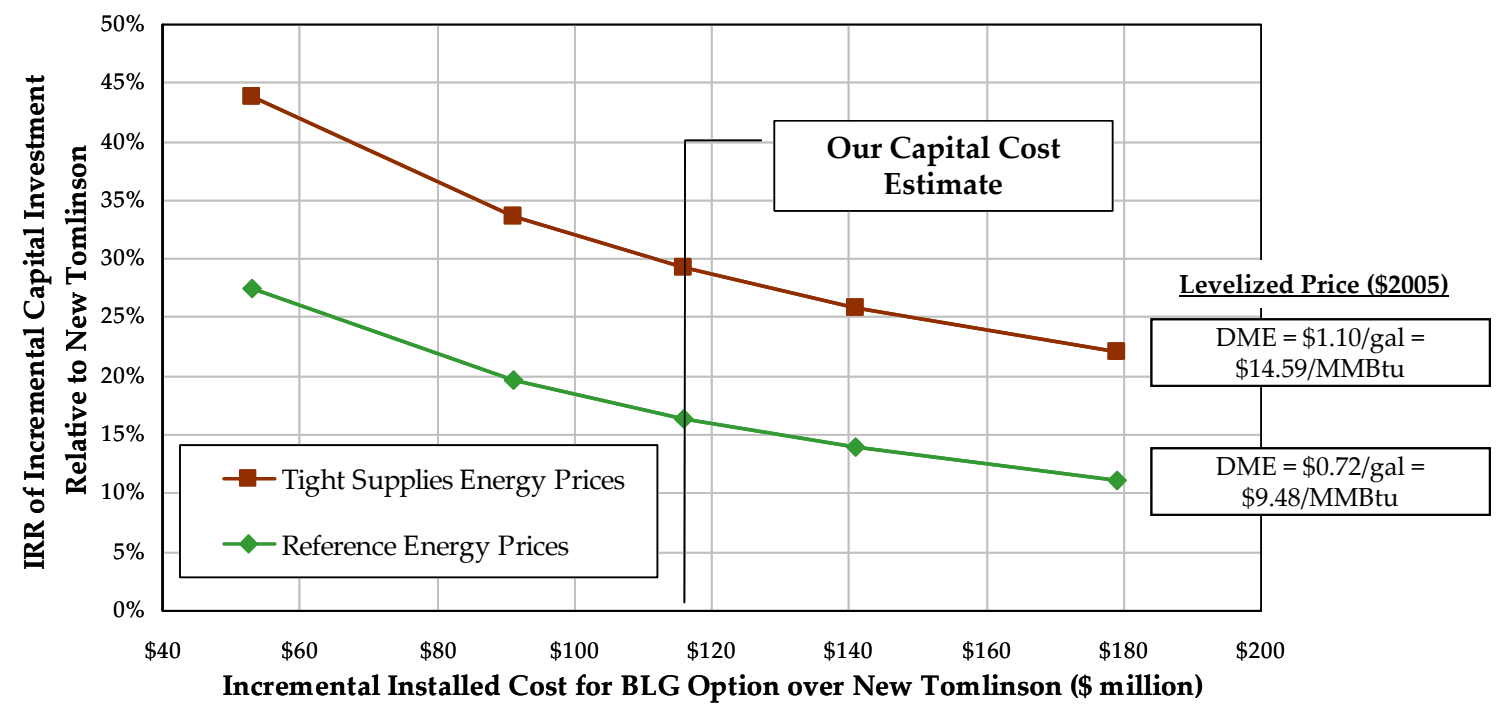

Note:

Our estimate of the capital cost for the BLG system is $\$ 252$ million, and for the New Tomlinson is $\$ 136.2$ million. This chart is meant to show the impact of different capital costs and product prices, all else equal.

Figure 55: IRR on incremental capital cost for DMEa biorefinery (with DME sold as vehicle fuel) relative to new Tomlinson system with indicated biomass and power prices and other energy prices as in the REP scenario.

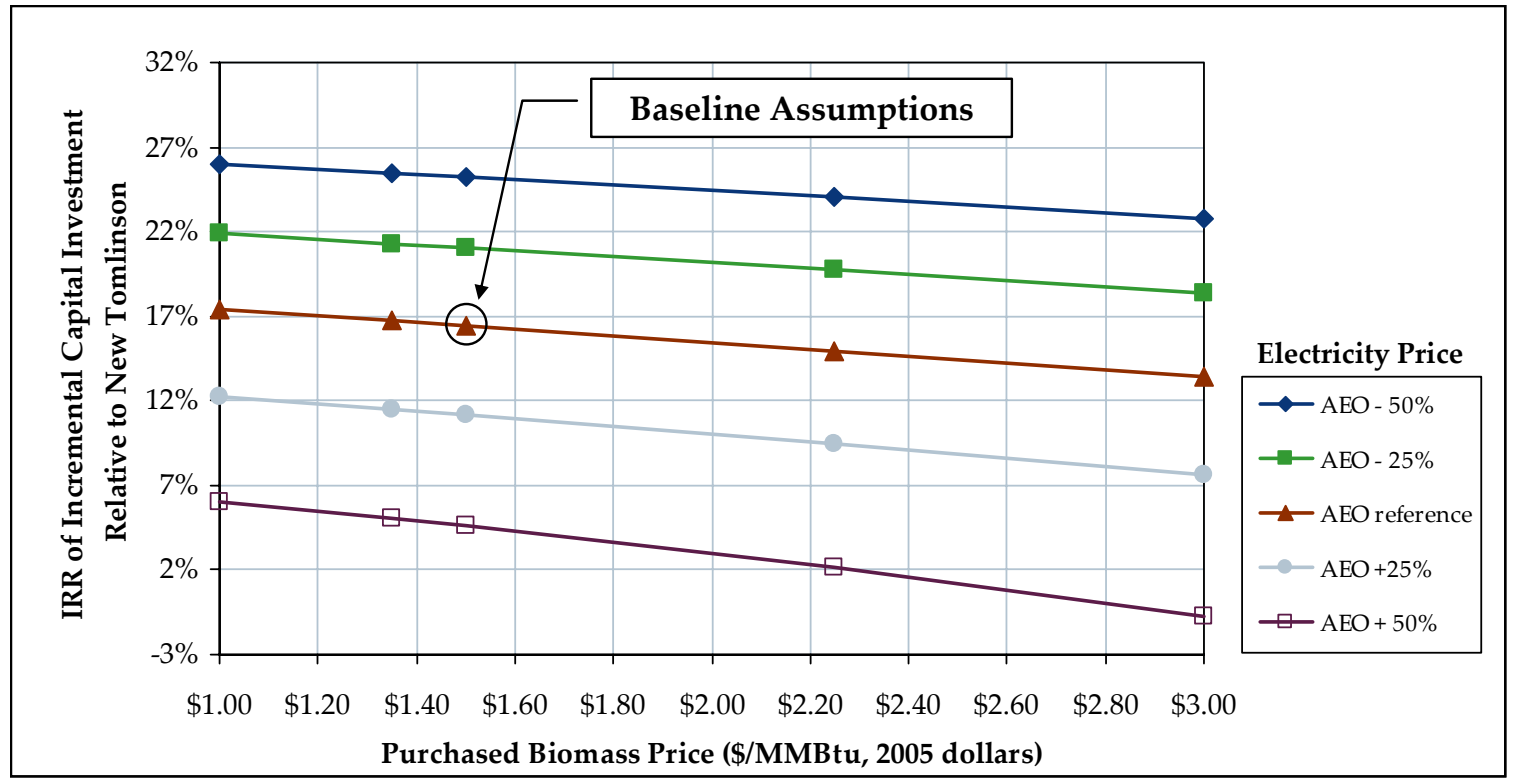

${ }^{50}$ It is interesting to note that this is somewhat analogous to the impact of higher natural gas prices on corn-ethanol production. In that case, conventional dry mill ethanol plants require significant inputs of natural gas, roughly 35,000-40,000 Btu for every gallon of ethanol. Thus, as natural gas prices have risen over the last 2-3 years, this has led to an increase in production costs of about 10-20 $\varnothing$ /gallon, or about $10-20 \%$ of total production costs. 
When incentives are considered (Figure 56 and Figure 57), the excise tax credit has by far the greatest impact as there is no impact for electricity-related incentives. The ETC nearly doubles the IRR under the REP scenario. Its relative impact under the TSEP scenario is smaller, but still significant, resulting in IRRs reaching over 40\%. Also, since relatively little additional biomass is used in this configuration, the impact of carbon credits is minimal.

Figure 56: IRR on incremental capital investment in DMEa biorefinery (with DME sold as vehicle fuel) relative to a new Tomlinson system with different environmental benefits monetized under REP scenario.

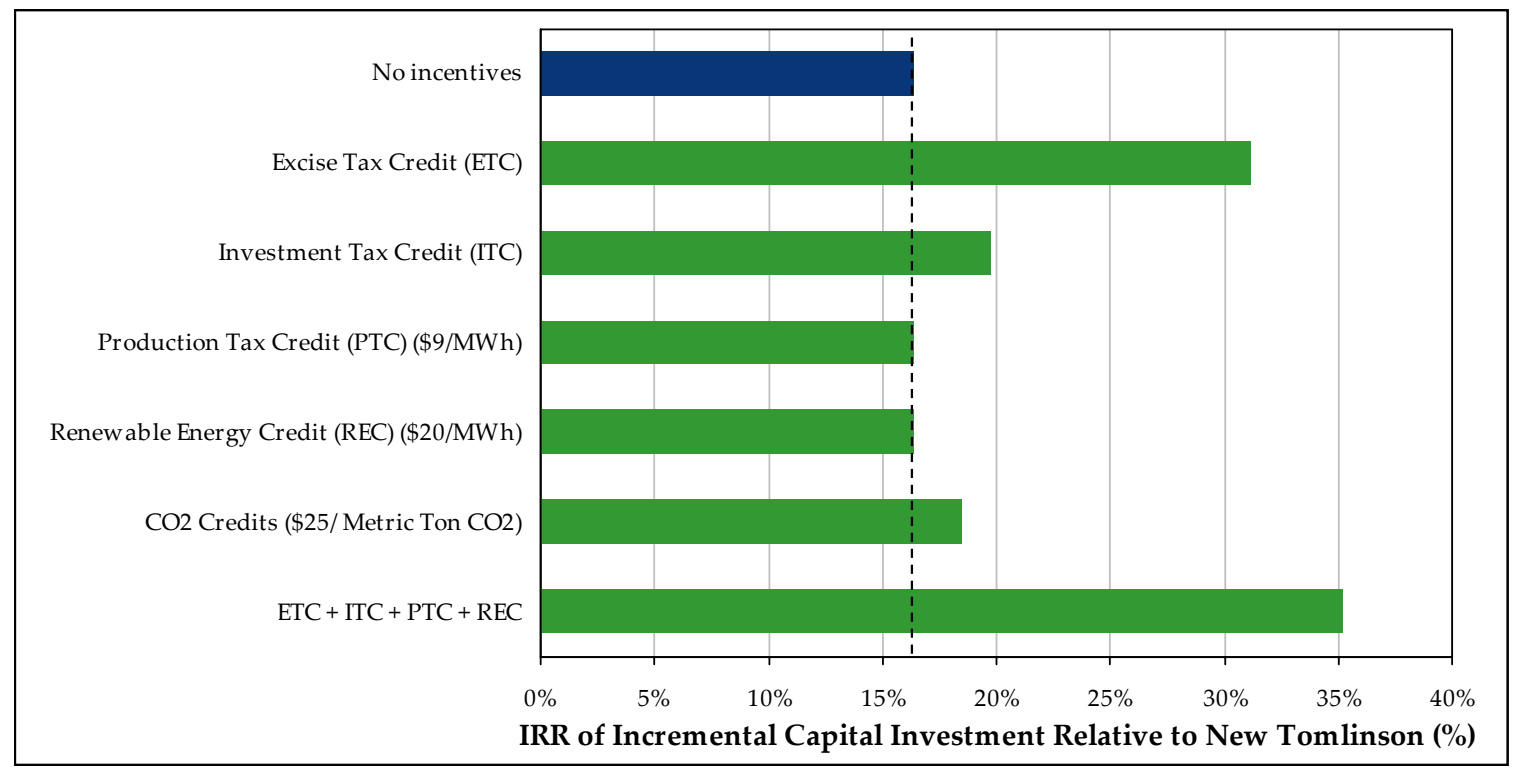

Note: Investment tax credit $=20 \%$ gasification tax credit

Figure 57: IRR on incremental capital investment in DMEa biorefinery (with DME sold as vehicle fuel) relative to a new Tomlinson system with different environmental benefits monetized and for our TSEP scenario.

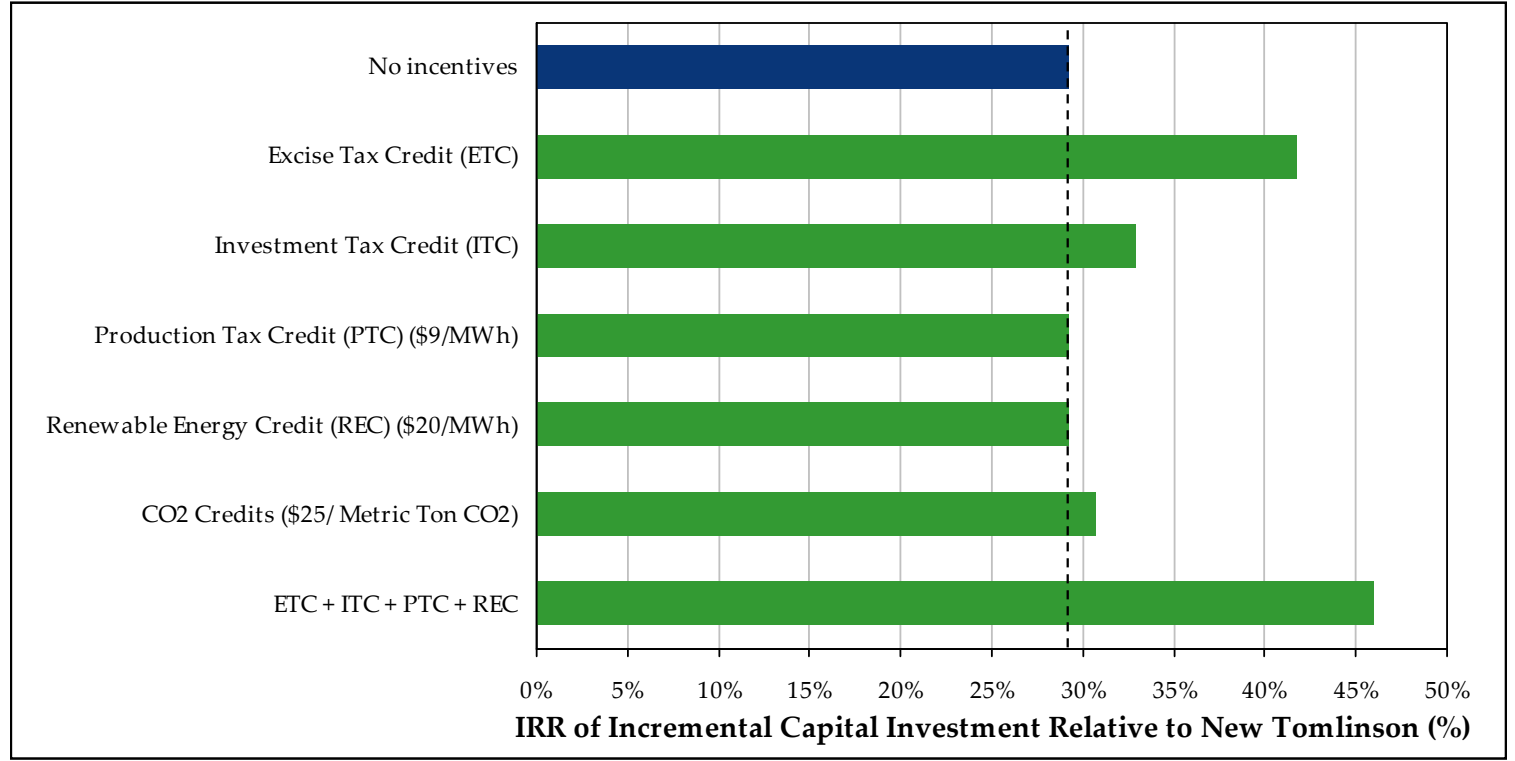

Note: Investment tax credit $=20 \%$ gasification tax credit 
Figure 58 shows results for the DMEa biorefinery when DME is used as an LPG substitute. IRRs are a little lower than when DME is sold as a vehicle fuel because of the lower assumed selling price into the LPG market. In reality, if DME becomes an energy commodity, there would likely be a single DME price in the market, such that the results here for the LPG and vehicle cases might bracket potential returns.

Figure 59 shows the sensitivity of the IRR to the assumed biomass-energy and electricity prices. Again, results are slightly lower than when DME is considered as a diesel substitute.

Figure 58: Allowable incremental capital cost for DMEa biorefinery (with DME sold as LPG substitute) relative to new Tomlinson investment for different target IRR values under our two energy price scenarios.

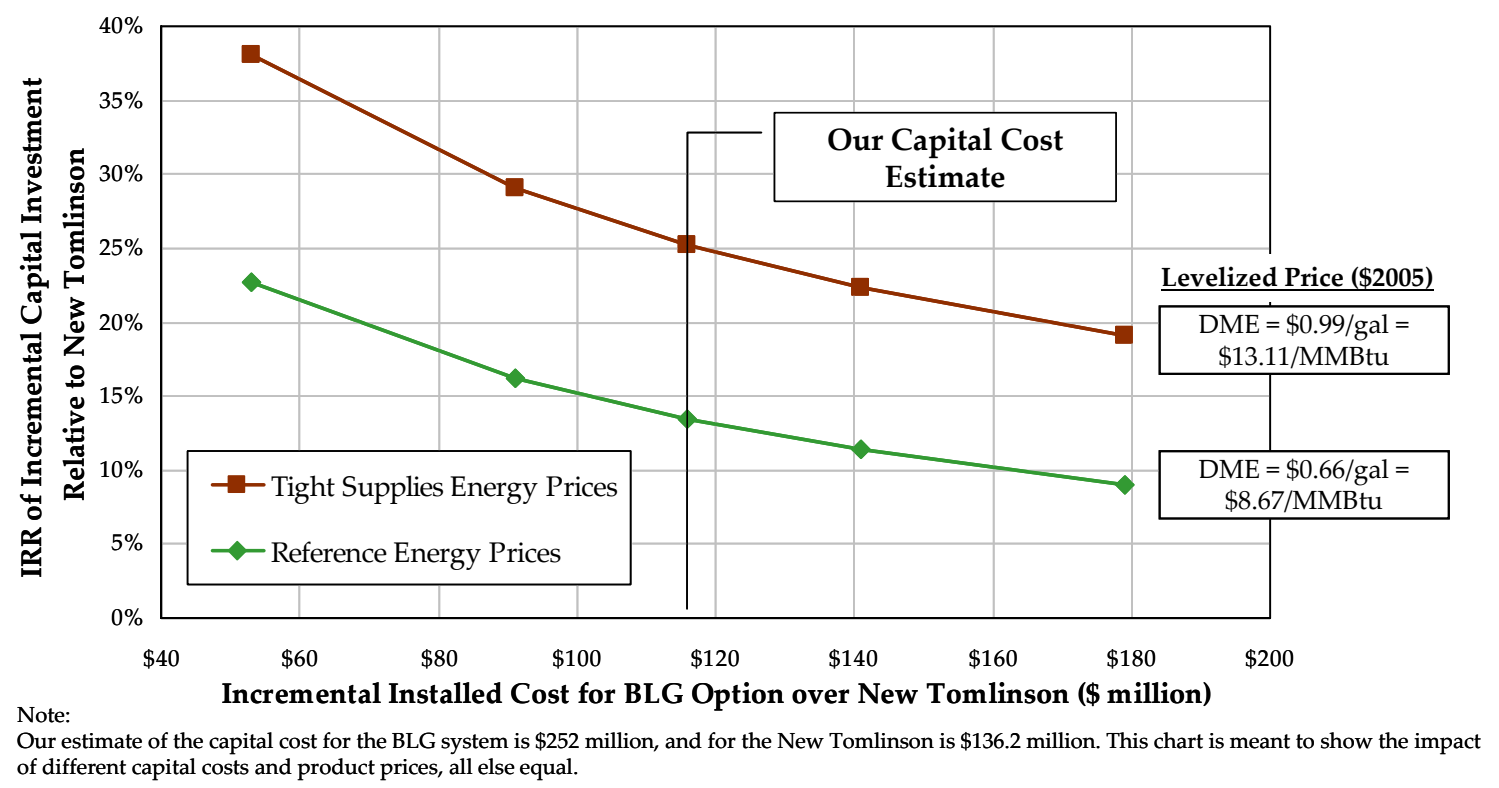

Figure 59: IRR on incremental capital cost for DMEa biorefinery (with DME sold as LPG substitute) relative to new Tomlinson system with indicated biomass and power prices and other energy prices as in the REP scenario.

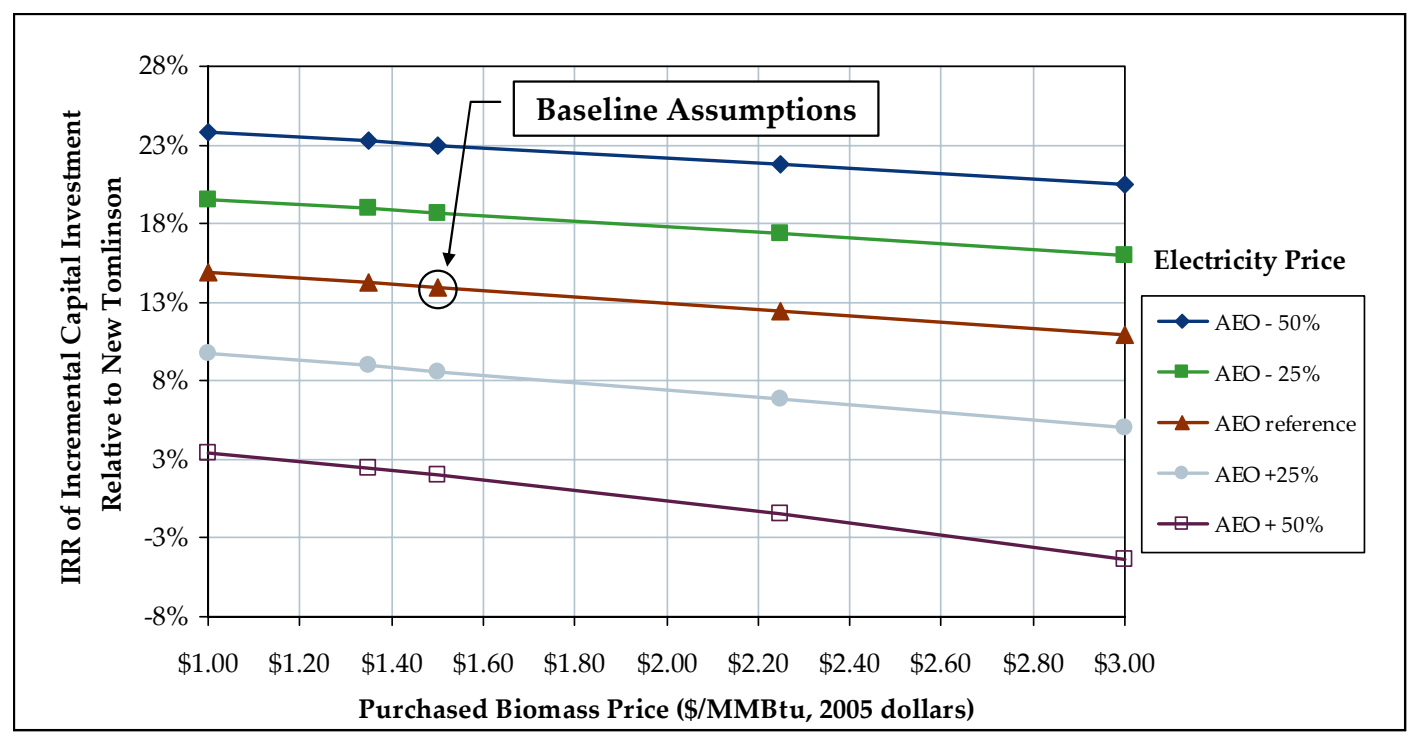


When incentives are considered (Figure 60 and Figure 61), the excise tax credit has by far the greatest impact. It more than doubles the IRR under the REP scenario. Its relative impact in the TSEP scenario is smaller, but still significant. It is important to note that the excise tax credit applies to motor fuels and so may not be applicable to DME used to substitute LPG. However, there is precedent for claiming the excise tax credit for biodiesel when it is used as a heating fuel, and we assume here that it is in general the spirit of the law to provide a credit for the use of a renewable fuel that displaces a fossil fuel. Thus, even for DME blended into LPG for nontransportation applications, we apply the tax credit.

Figure 60: IRR on incremental capital invested in DMEa biorefinery (with DME sold as LPG substitute) relative to new Tomlinson with environmental benefits monetized under REP scenario.

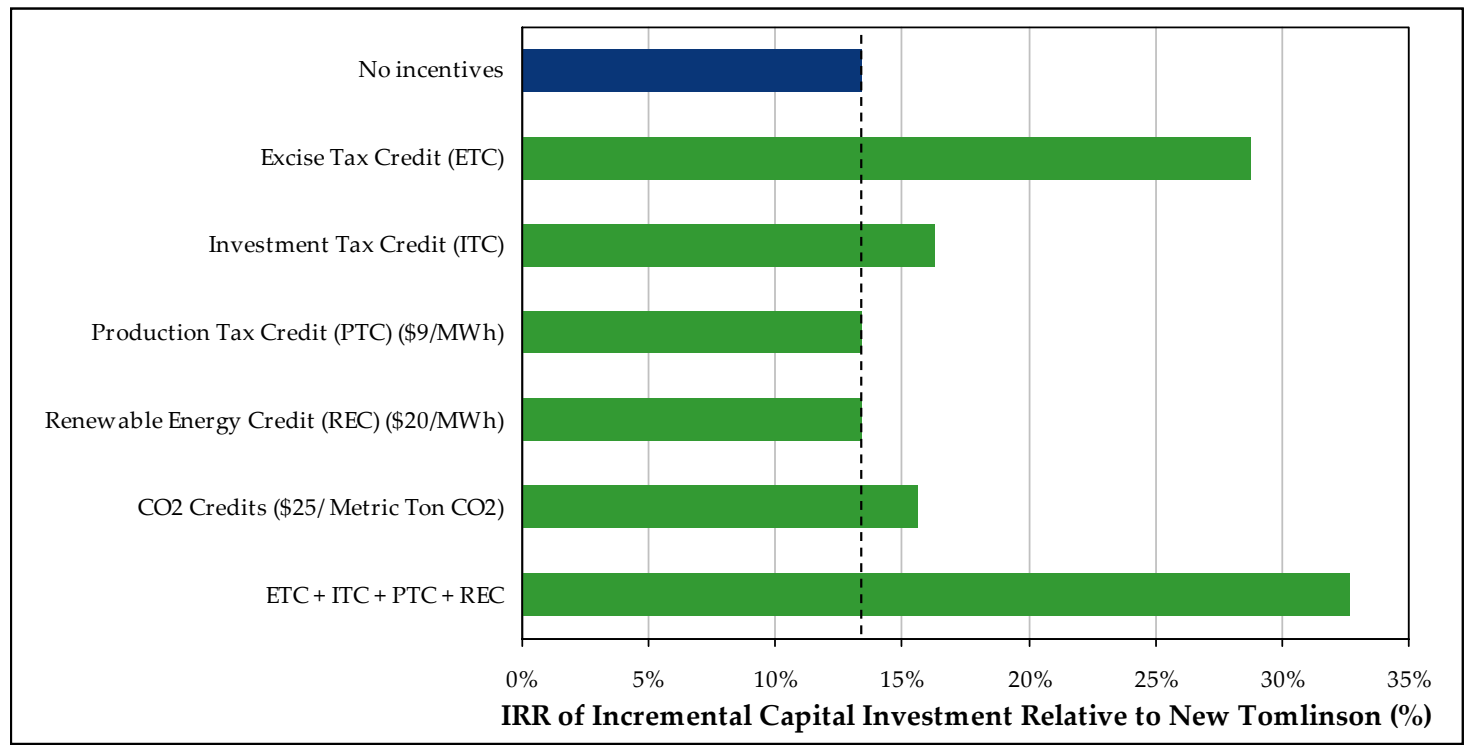

Note: Investment tax credit $=20 \%$ gasification tax credit

Figure 61: IRR on incremental capital invested in DMEa biorefinery (with DME sold as LPG substitute) relative to new Tomlinson, with environmental benefits monetized in TSEP scenario.

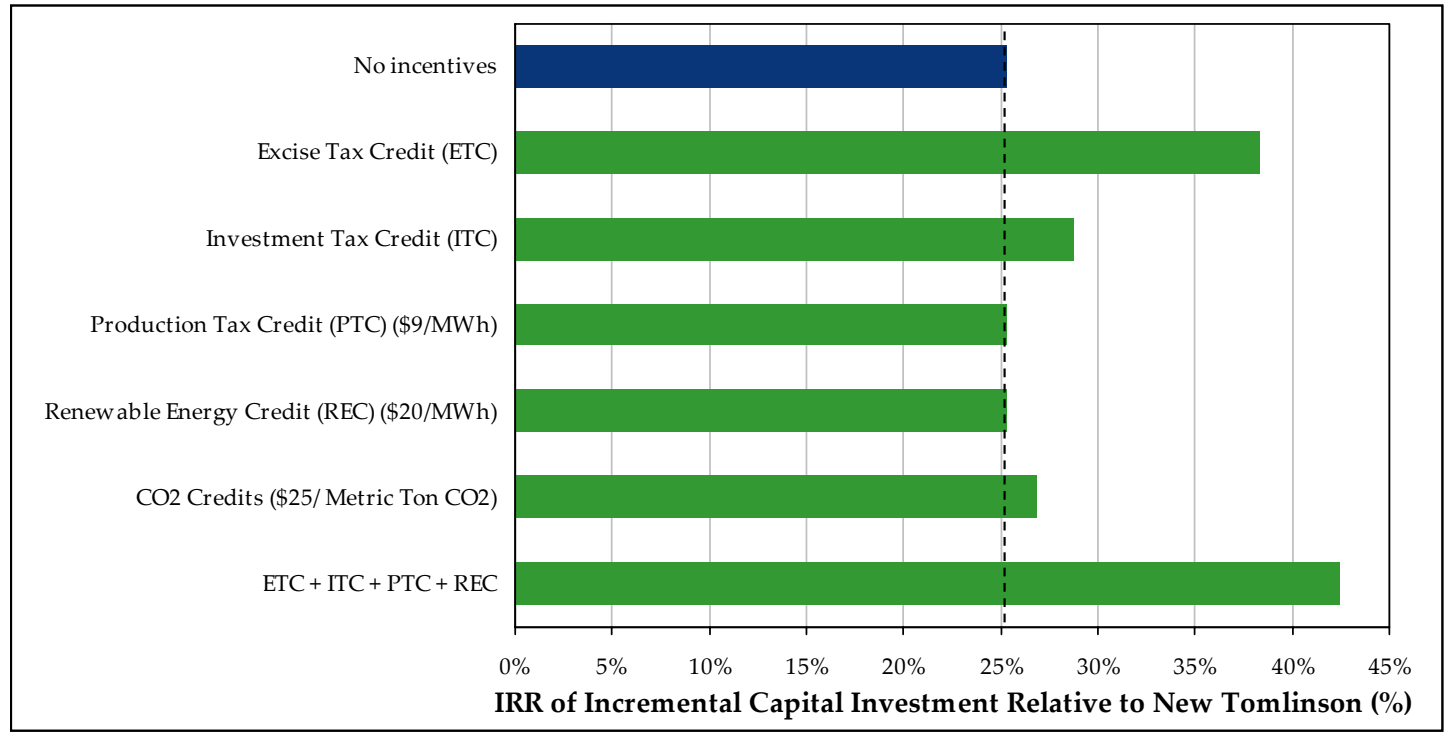

Note: Investment tax credit $=20 \%$ gasification tax credit 


\subsubsection{DMEb}

Figure 62 shows, for the DMEb biorefinery (with DME sold as a vehicle fuel) the IRR on investments relative to investment in a new Tomlinson system. With "Our Capital Cost Estimate" and the REP scenario, the incremental investment (\$280 million) gives an IRR of $16.2 \%$, with a calculated NPV of $\$ 13.5$ million. Under the TSEP scenario, the IRR and NPV are $23.6 \%$ and $\$ 112$ million, respectively.

Figure 63 shows the sensitivity of the IRR to the assumed biomass-energy and electricity prices. When compared to DMEa, this configuration exhibits little sensitivity to electricity price and moderate sensitivity to biomass price. This is because in this configuration, the biorefinery produces most of the electricity requirements of the mill. Because more biomass is used than in DMEa, the overall economics are somewhat sensitive to the assumed price, but overall since biomass is relatively inexpensive compared to other commodities, this impact is not that significant.

Figure 62: Allowable incremental capital cost for DMEb biorefinery (with DME sold as vehicle fuel) relative to new Tomlinson investment for different target IRR values under our two energy price scenarios.

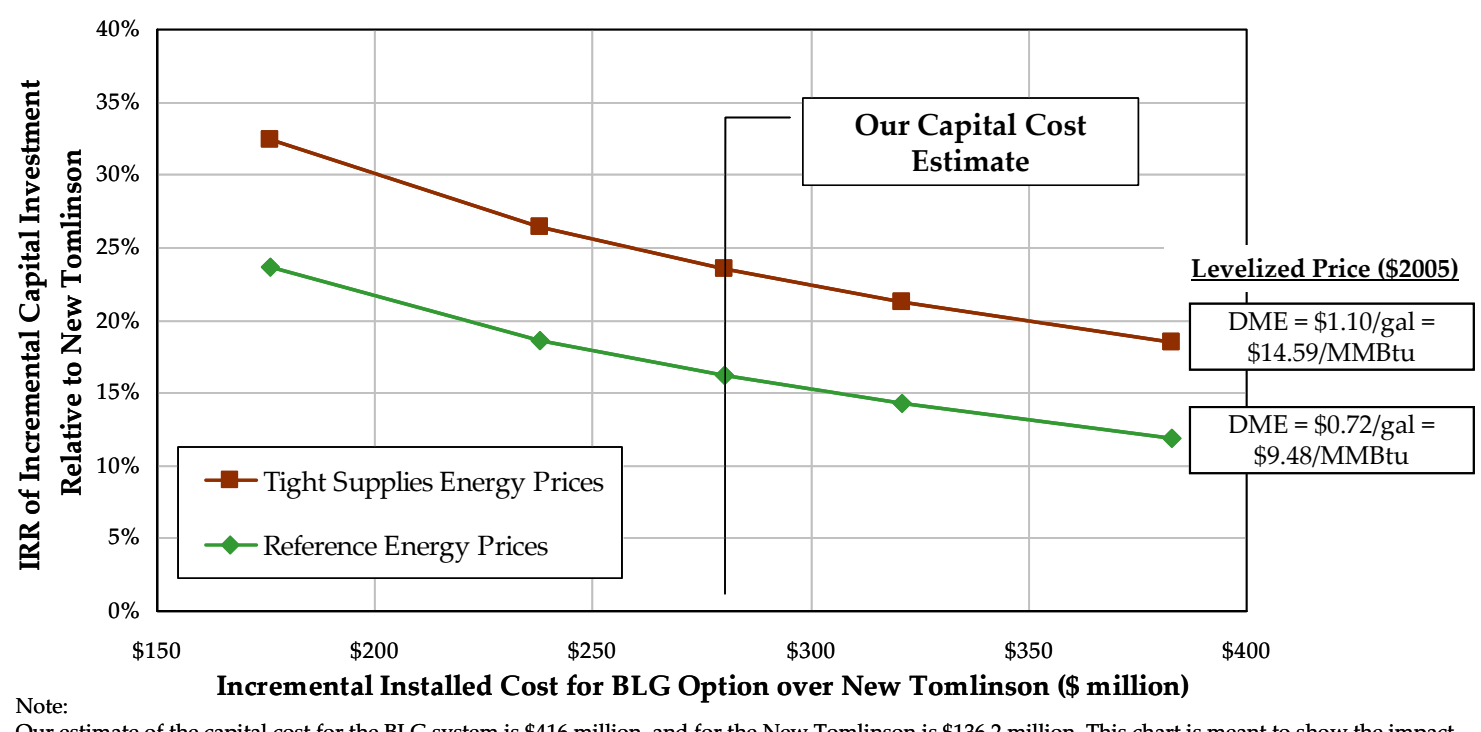

Our estimate of the capital cost for the BLG system is $\$ 416$ million, and for the New Tomlinson is $\$ 136.2$ million. This chart is meant to show the impact of different capital costs and product prices, all else equal.

When incentives are considered (Figure 64 and Figure 65), the excise tax credit again has by far the greatest impact, but there is now also a modest impact from electricity-related incentives. However, because the IRR with no incentives is greater than for the DMEa case, the relative impacts of added incentives on IRR are lower here than in DMEa. Also, because the DMEb case has a larger initial capital investment, the same incremental revenues from the excise tax credit have a smaller impact on IRR. Still, the combination of incentives brings the IRR to nearly $29 \%$ in the REP scenario and to more than $35 \%$ in the TSEP scenario. 
Figure 63: IRR on incremental capital cost for DMEb biorefinery (with DME sold as vehicle fuel) relative to new Tomlinson system with indicated biomass and power prices and other energy prices as in the REP scenario.

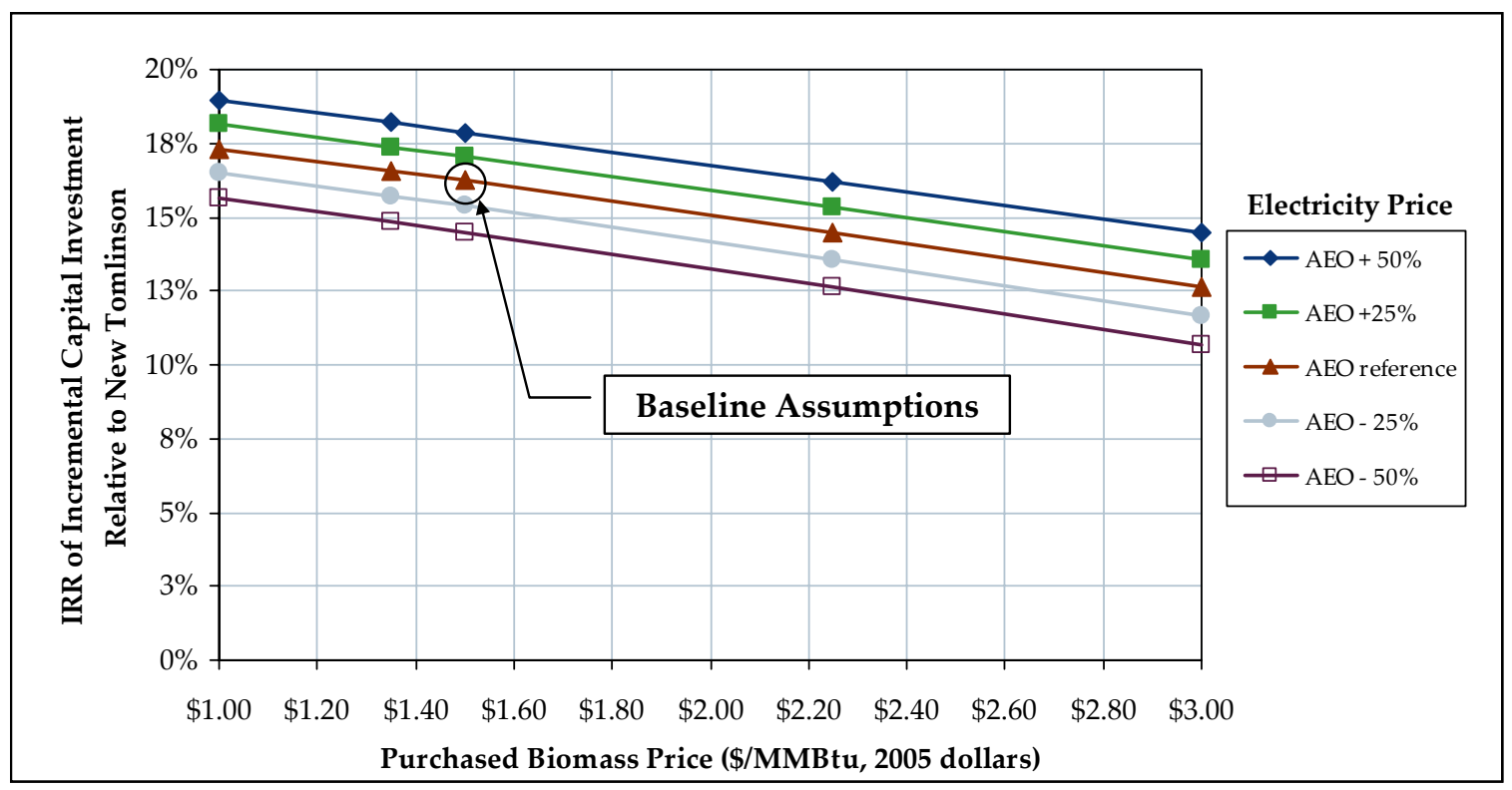

Figure 64: IRR on incremental capital investment in DMEb biorefinery (with DME sold as vehicle fuel) relative to a new Tomlinson system with different environmental benefits monetized under REP scenario.

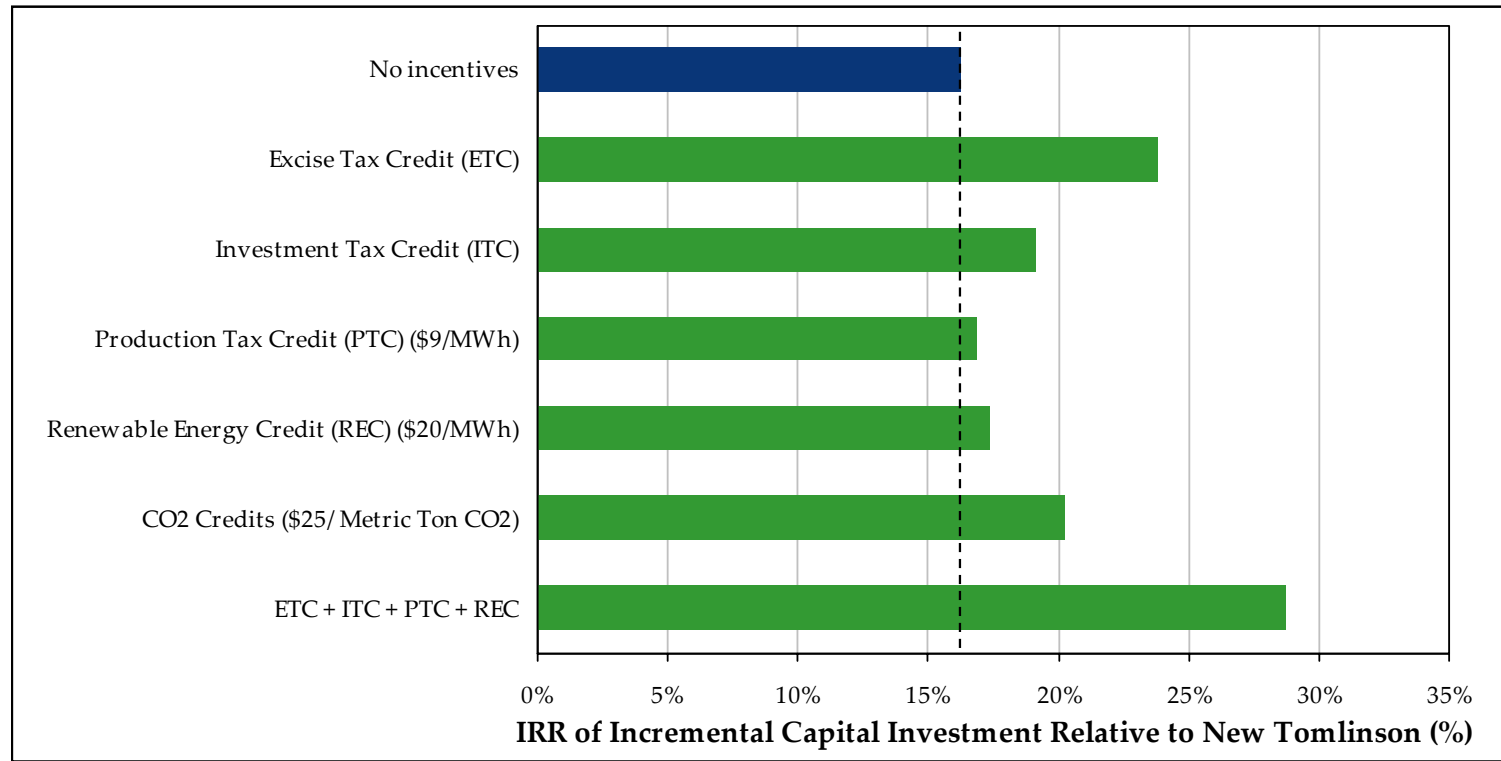

Note: Investment tax credit $=20 \%$ gasification tax credit 
Figure 65: IRR on incremental capital investment in DMEb biorefinery (with DME sold as vehicle fuel) relative to a new Tomlinson system with different environmental benefits monetized and for our TSEP scenario.

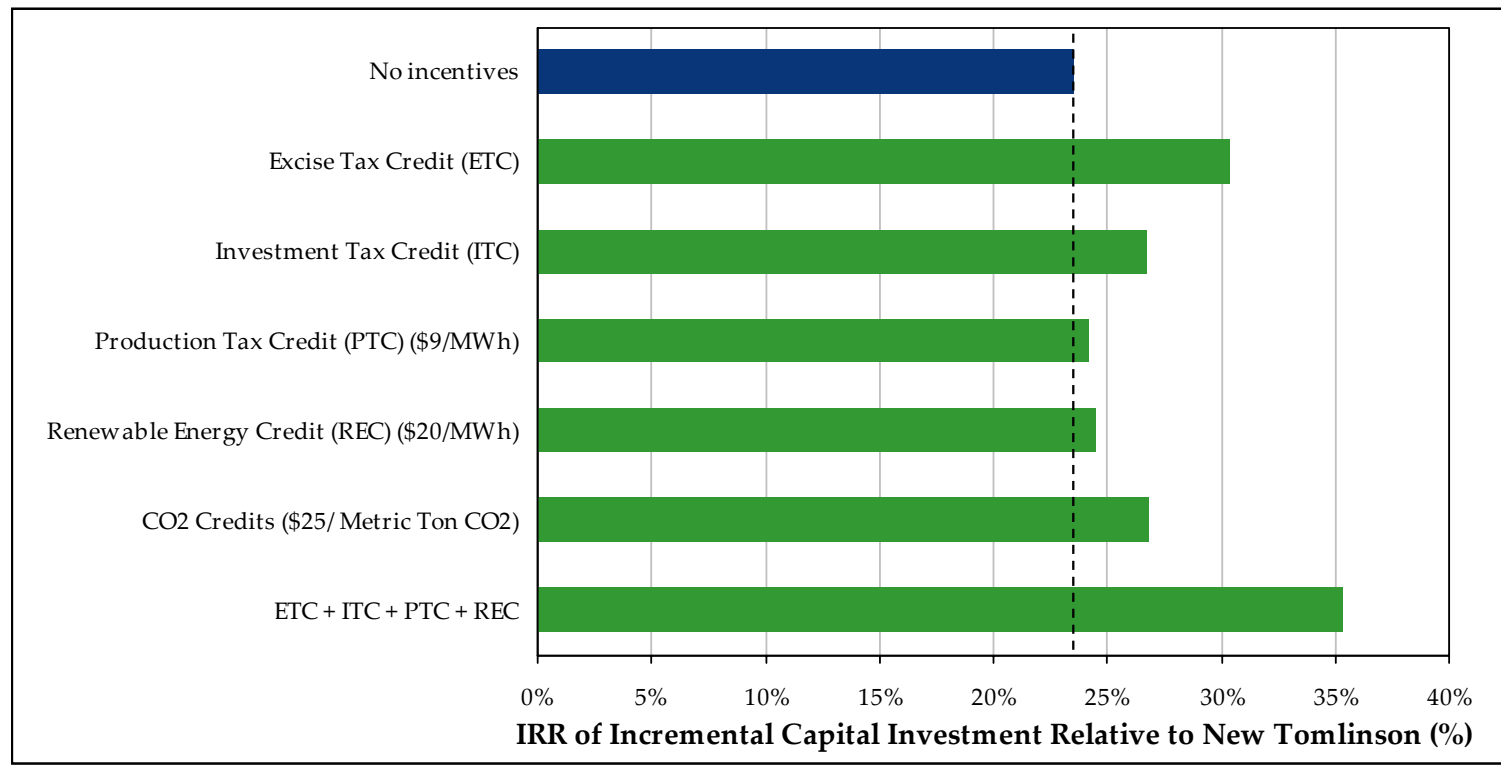

Note: Investment tax credit $=20 \%$ gasification tax credit

\subsubsection{DMEc}

Figure 66 shows, for the DMEc biorefinery (with DME sold as vehicle fuel) the IRR relative to a new Tomlinson investment. With "Our Capital Cost Estimate" and under the REP scenario, the incremental investment (\$188 million) gives an IRR of $15.4 \%$, with a calculated NPV of $\$ 3.2$ million. Under the TSEP scenario, the IRR and NPV are $20.6 \%$ and $\$ 46.9$ million, respectively. Figure 67 shows the sensitivity of the IRR to the assumed biomass-energy and electricity prices under the REP scenario.

Figure 66: Allowable incremental capital cost for DMEc biorefinery (with DME sold as vehicle fuel) relative to new Tomlinson investment for different target IRR values under our two energy price scenarios.

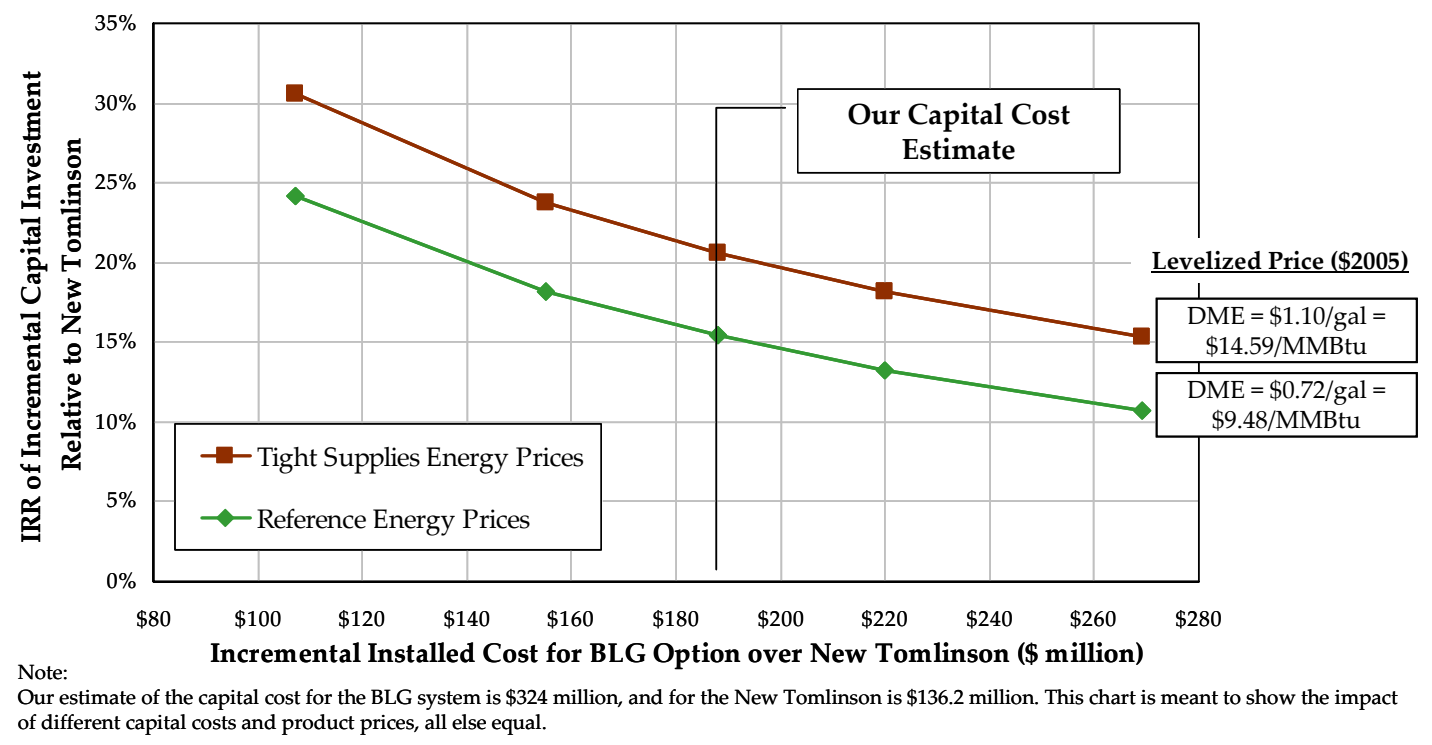


Figure 67: IRR on incremental capital cost for DMEc biorefinery (with DME sold as vehicle fuel) relative to new Tomlinson system with indicated biomass and power prices and other energy prices as in the REP scenario.

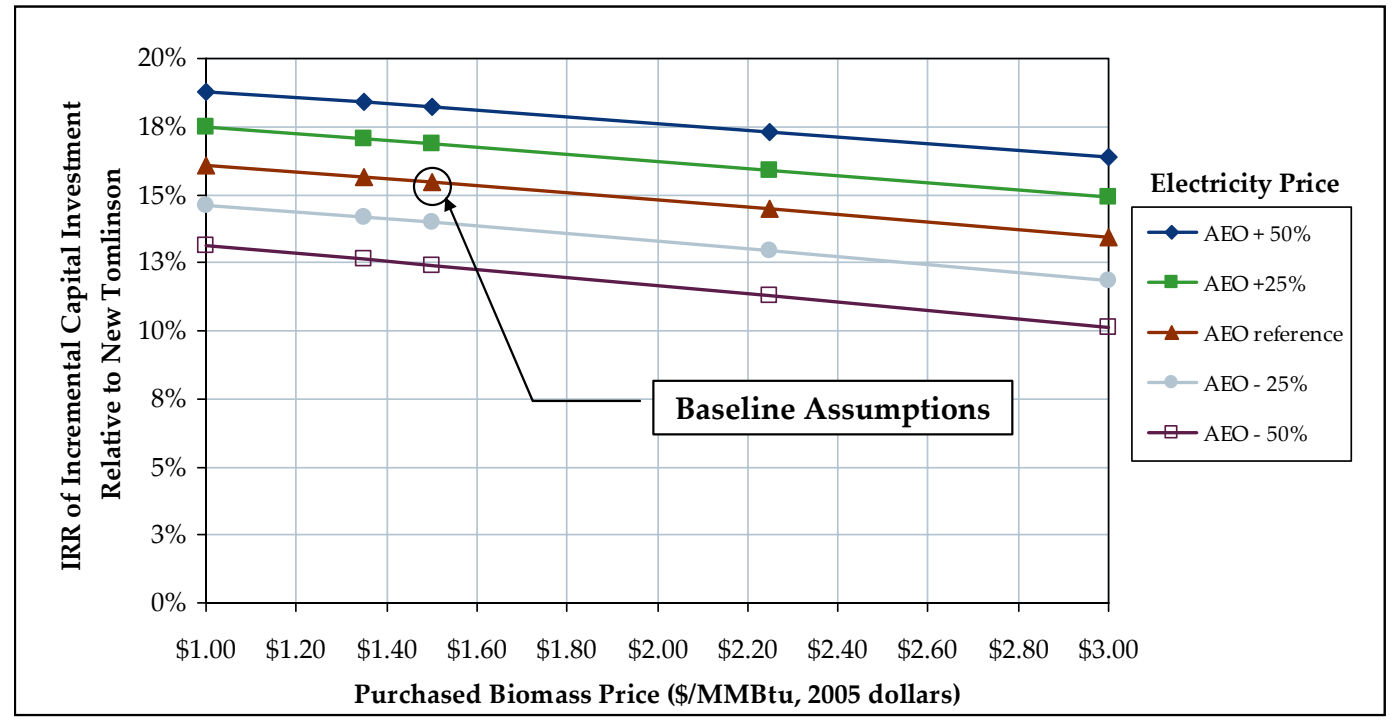

When incentives are considered (Figure 68 and Figure 69), the excise tax credit has the greatest impact, but not to the same extent as for other DME configurations because less fuel and more power are produced than in the other cases. Nevertheless, the overall results when considering all the possible incentives, are similar to DMEb under the REP scenario. In the TSEP scenario, the $\mathrm{DMEb}$ case, which produces more fuel, fares better because there is a greater spread between transport fuel prices than between electricity prices in the two energy price scenarios.

Figure 68: IRR on incremental capital in DMEc biorefinery (with DME sold as vehicle fuel) relative to a new Tomlinson with different environmental benefits monetized under REP scenario.

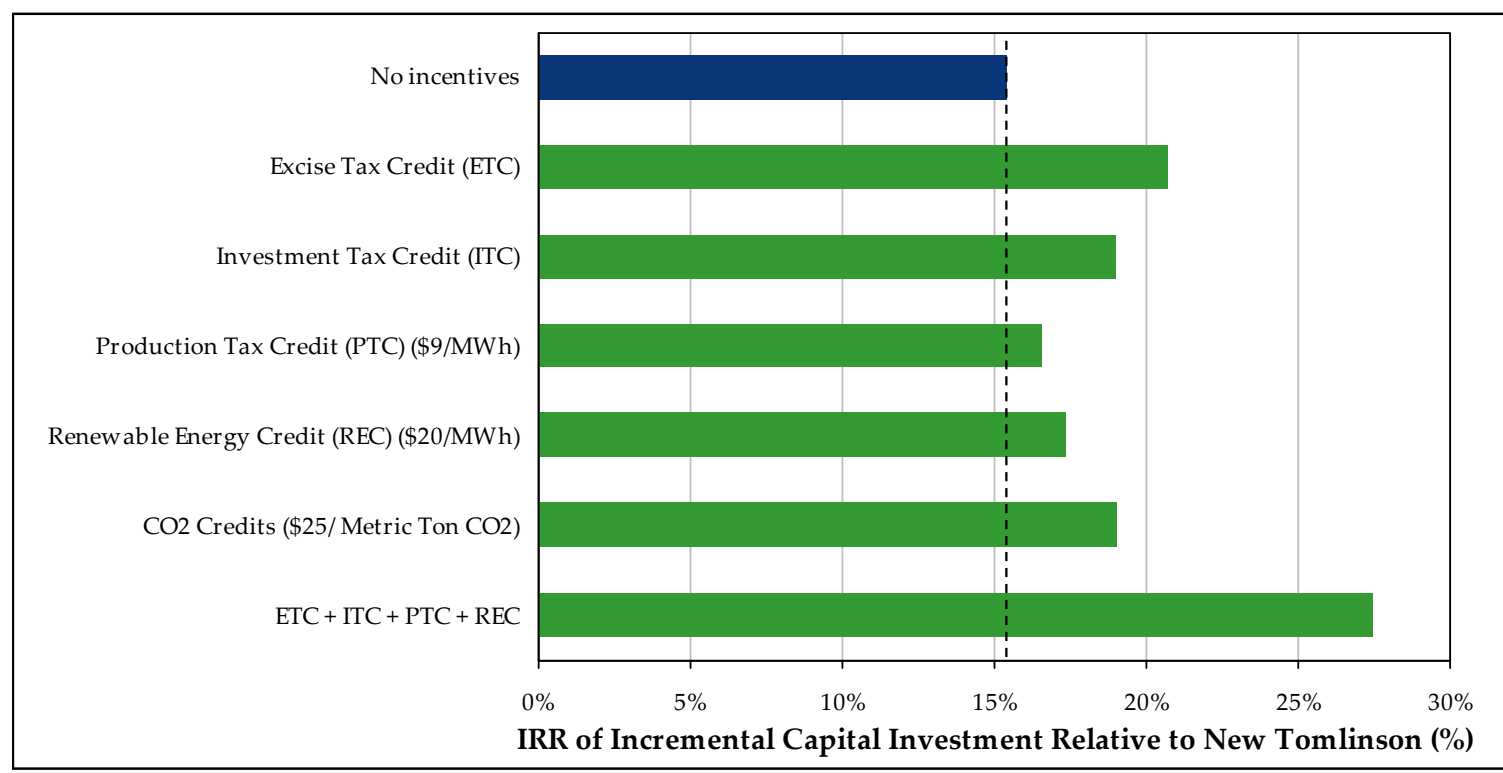

Note: Investment tax credit $=20 \%$ gasification tax credit 
Figure 69: IRR on incremental capital investment in DMEc biorefinery (with DME sold as vehicle fuel) relative to a new Tomlinson system with different environmental benefits monetized and for our TSEP scenario.

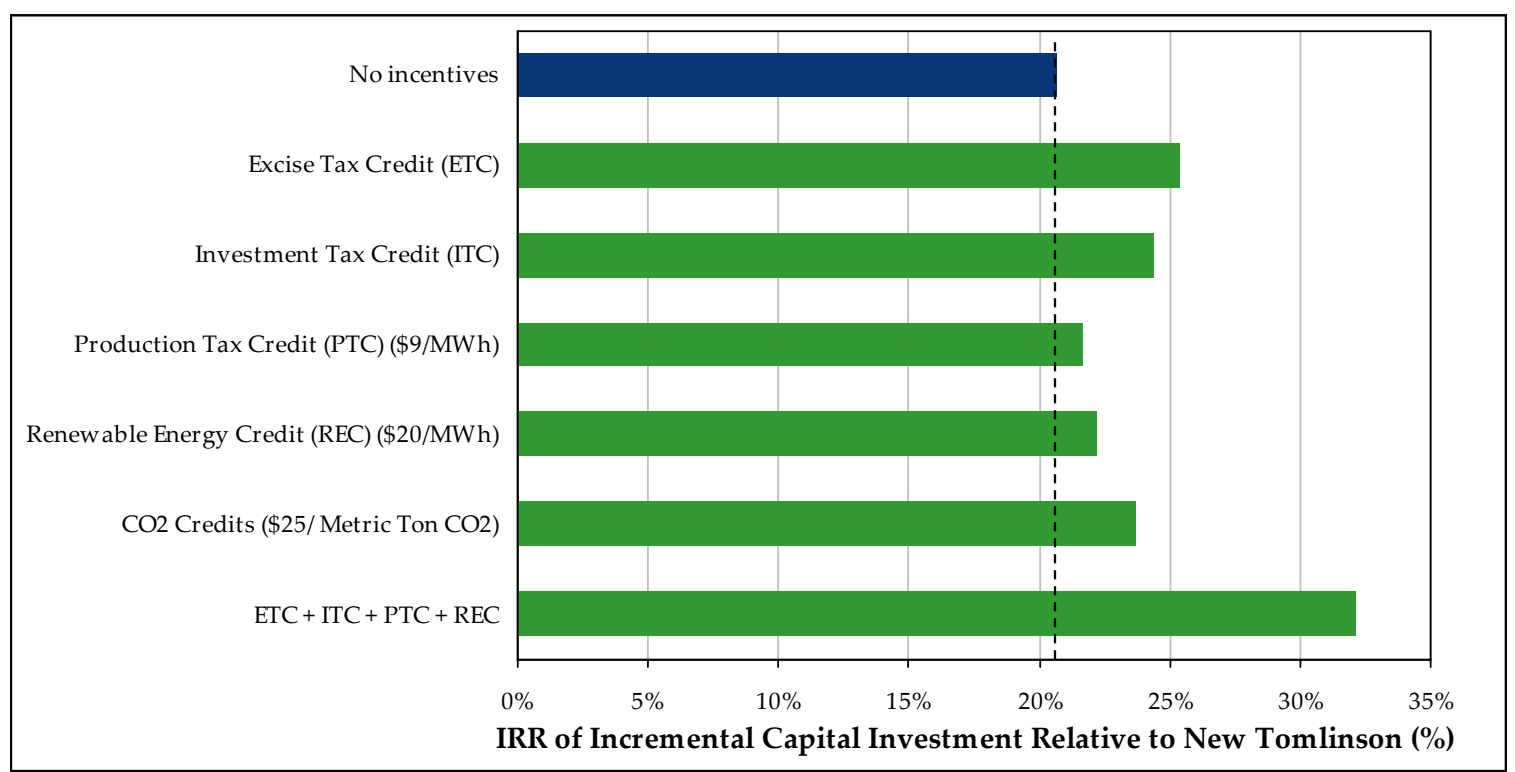

Note: Investment tax credit $=20 \%$ gasification tax credit

\subsubsection{FT Results}

The FT analysis considers that the raw liquid product at the biorefinery gate has the value of crude petroleum at a petroleum refinery gate less transportation costs to move the FT crude from the biorefinery to an existing petroleum refinery for upgrading to finished product. The attractive characteristics of the FT crude (e.g., zero sulfur content and high cetane number distillate fraction) are not assigned any enhanced value over crude oil under our baseline set of assumptions.

\subsubsection{FTa}

Figure 70 shows, for the FTa configuration, the IRR relative to a new Tomlinson investment. With "Our Capital Cost Estimate" and under the REP scenario, the incremental investment (\$194 million) gives an IRR of $14.2 \%$, with a calculated NPV of negative $\$ 5.9$ million. Under the TSEP scenario, the IRR and NPV are $20.9 \%$ and $\$ 53.6$ million, respectively.

Figure 71 shows the sensitivity of the IRR to the assumed biomass-energy and electricity prices. The FTa configuration is moderately sensitive to both electricity price and purchased biomass price.

When incentives are considered (Figure 72 and Figure 73), the excise tax credit has the greatest impact, followed by the carbon credits. When the bundle of incentives is considered the IRR is nearly 28\% under the REP scenario and exceeds $33 \%$ under the TSEP scenario. The impact of a $10 \notin /$ gallon performance premium, which may be a relatively high premium, ${ }^{51}$ is to increase the IRR by 1 to 1.5 percentage points.

\footnotetext{
${ }^{51}$ The premium value of FT crude over petroleum crude is unknown, but the $10 \phi /$ gallon we assumed here may be on the upper end of what is realistic. Two members of the project steering committee suggested (at the final project review meeting, October 2006) that a value of 1.3 to 3.6 /gallon (\$1 to $\$ 1.5$ per barrel) might be more realistic.
} 
Figure 70: Allowable incremental capital cost for FTa biorefinery relative to new Tomlinson investment for different target IRR values under our two energy price scenarios.

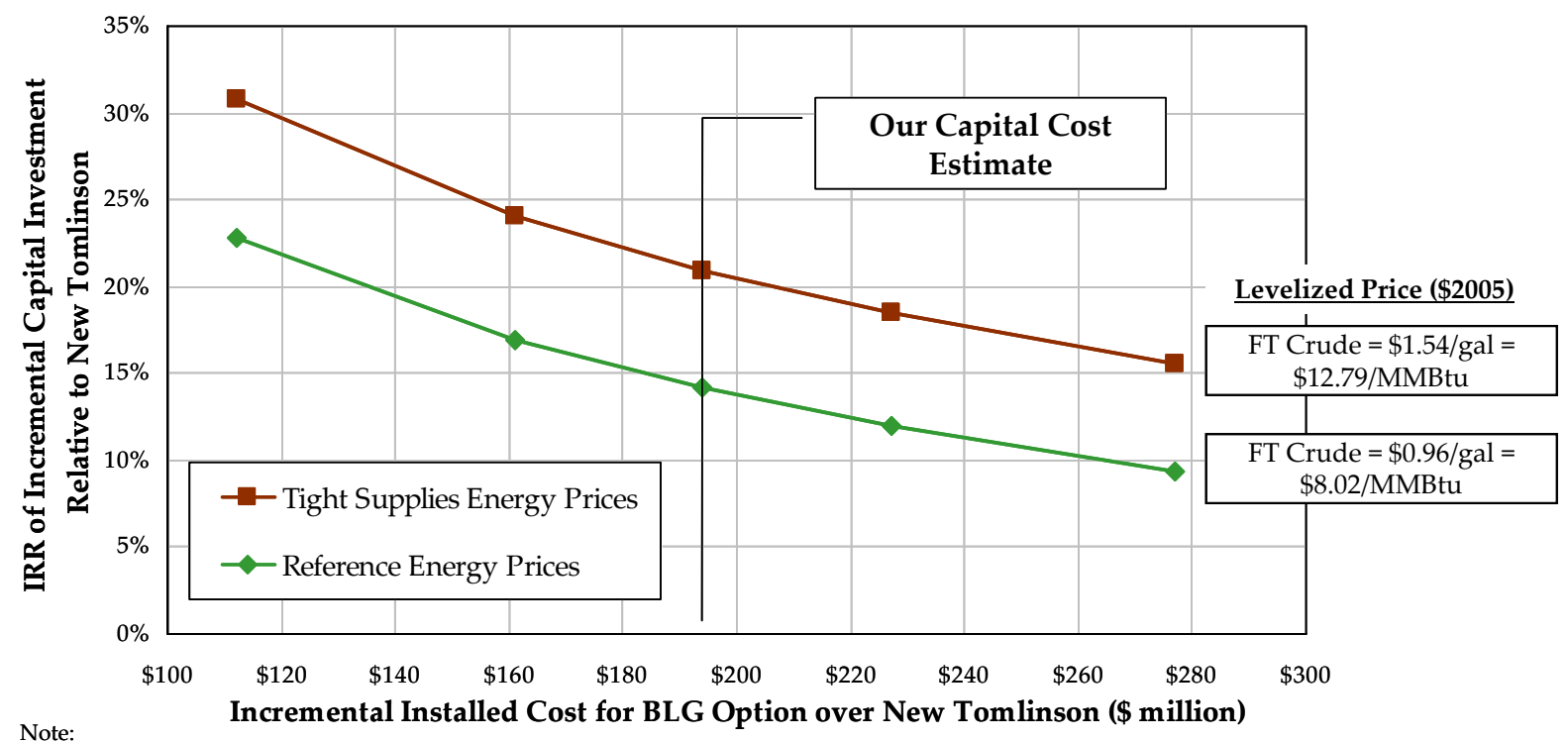

Note: Incremental Installed Cost for BLG Option over New Tomlinson (\$ million)

Our estimate of the capital cost for the BLG system is $\$ 330$ million, and for the New Tomlinson is $\$ 136.2$ million. This chart is meant to show the impact of different capital costs and product prices, all else equal.

Figure 71: IRR on incremental capital cost for FTa biorefinery relative to new Tomlinson system with indicated biomass and power prices and other energy prices as in the REP scenario.

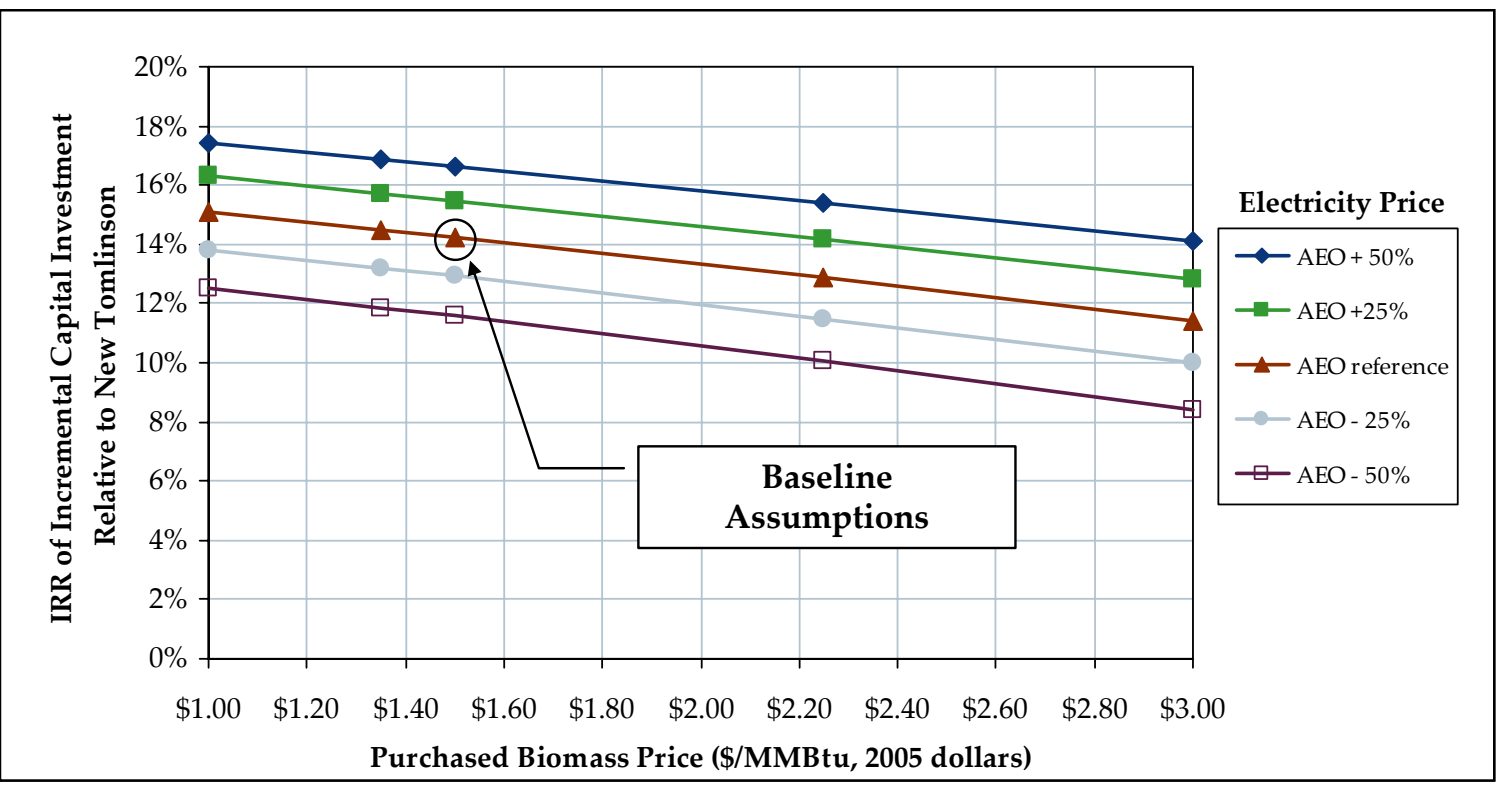


Figure 72: IRR on incremental capital investment in FTa biorefinery relative to a new Tomlinson system with different environmental benefits monetized under our REP scenario.

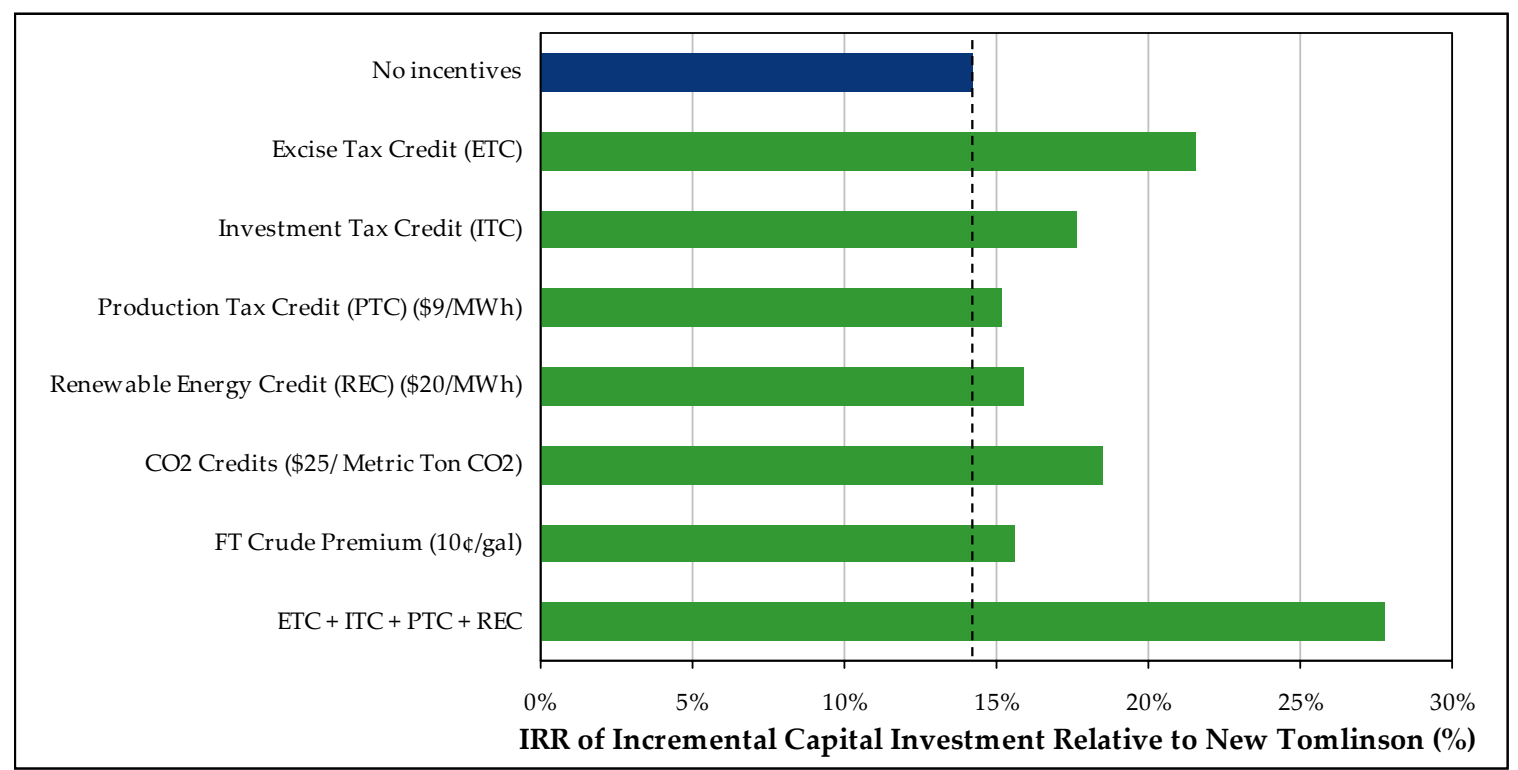

Note: Investment tax credit $=20 \%$ gasification tax credit

Figure 73: IRR on incremental capital investment in FTa biorefinery relative to a new Tomlinson system with different environmental benefits monetized under our TSEP scenario.

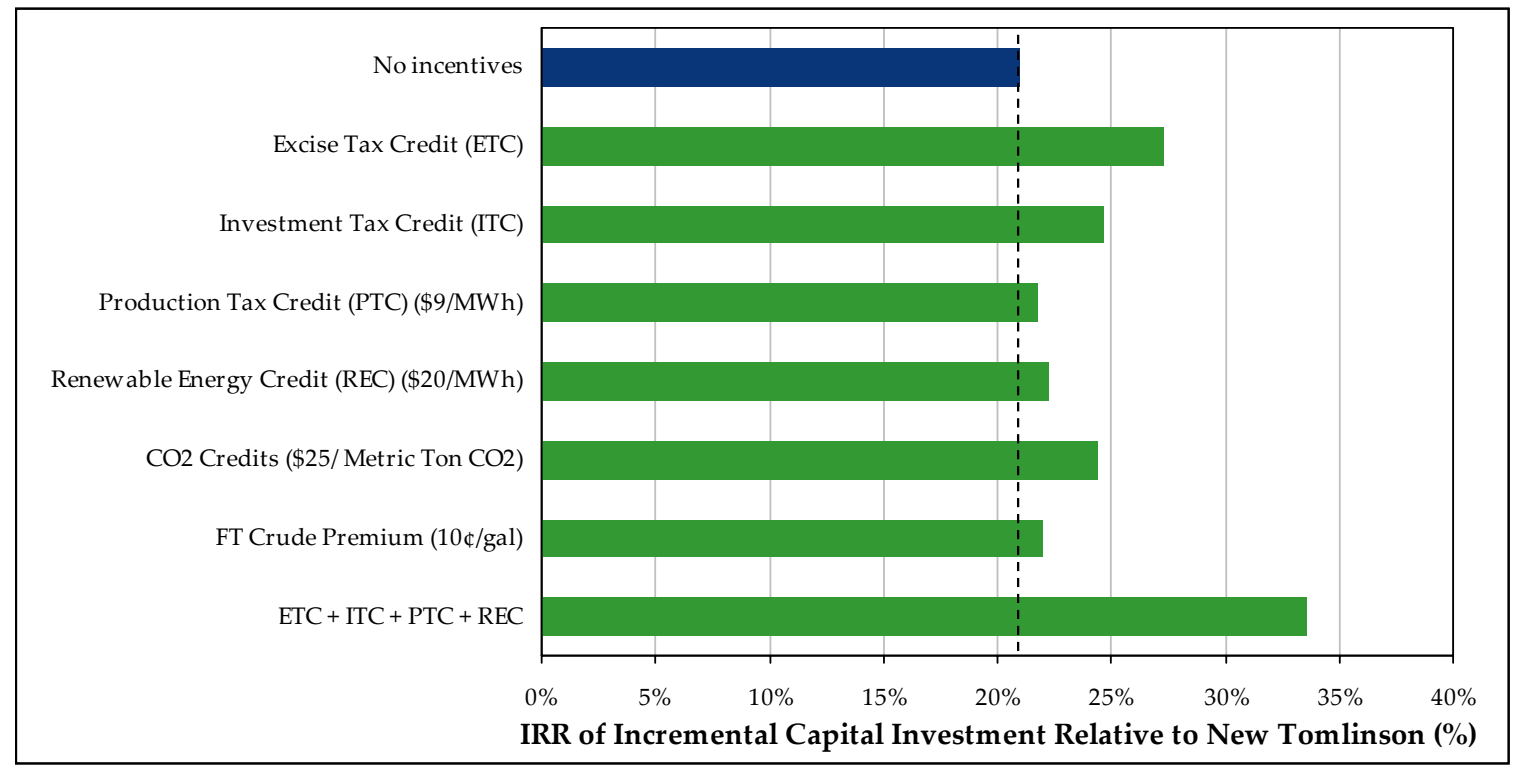

Note: Investment tax credit $=20 \%$ gasification tax credit

\subsubsection{FTb}

Figure 74 shows, for the FTb configuration, the IRR relative to a new Tomlinson investment. With "Our Capital Cost Estimate" and under the REP scenario, the incremental investment (\$366 million) gives an IRR of $18.2 \%$. The calculated NPV is $\$ 46.8$ million. Under the TSEP scenario, the IRR and NPV are $22.7 \%$ and $\$ 121$ million, respectively. The results are better than the FTa 
case, driven by the economies of scale of a larger power island and the relatively low cost of purchased biomass compared to other commodities.

Figure 75 shows the sensitivity of the IRR to the assumed biomass-energy and electricity prices. The FTb configuration is relatively sensitive to both parameters, given the fact that electricity is a major co-product and biomass is a significant input - there is only one case (FTc) that uses more biomass than FTb.

Figure 74: Allowable incremental capital cost for FTb biorefinery relative to new Tomlinson investment for different target IRR values under our two energy price scenarios.

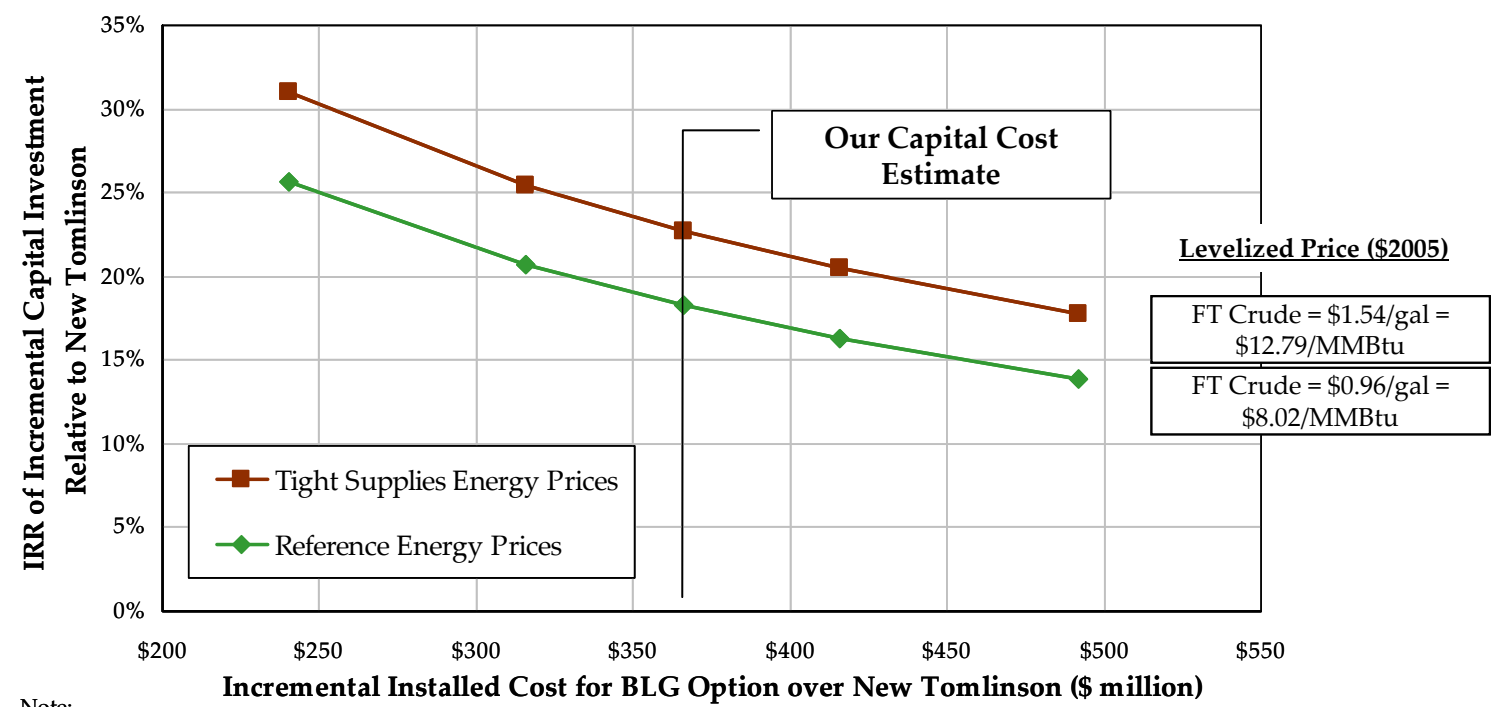

Note:

Our estimate of the capital cost for the BLG system is $\$ 502$ million, and for the New Tomlinson is $\$ 136.2$ million. This chart is meant to show the impact of different capital costs and product prices, all else equal.

Figure 75: IRR on incremental capital cost for FTb biorefinery relative to new Tomlinson system with indicated biomass and power prices and other energy prices as in the REP scenario.

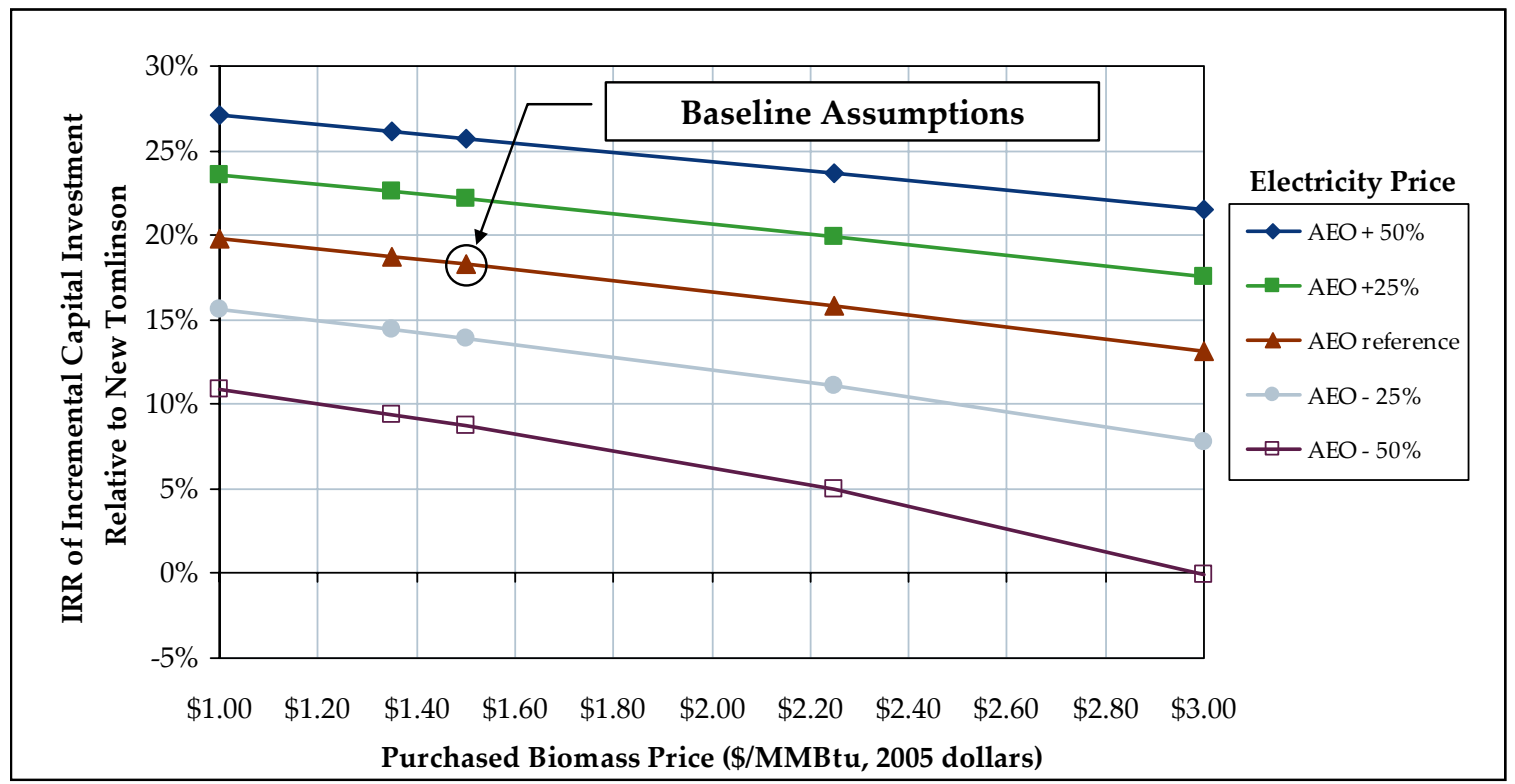


When incentives are considered (Figure 76 and Figure 77), the renewable electricity credit is the most important, followed by the carbon credits. This is due to electricity being the major product and, based on this study's assumptions, displacing grid power results in greater net carbon reductions per unit of biomass consumed than displacing transportation fuels.

When the bundle of incentives is considered the IRR exceeds $34 \%$ under the REP scenario and exceeds 38\% under the TSEP scenario, making this one of the most attractive options. Note that we have not included the FT performance premium in the bundle of incentives, which would increase the IRR slightly.

Figure 76: IRR on incremental capital investment in FTb biorefinery relative to a new Tomlinson system with different environmental benefits monetized under our REP scenario.

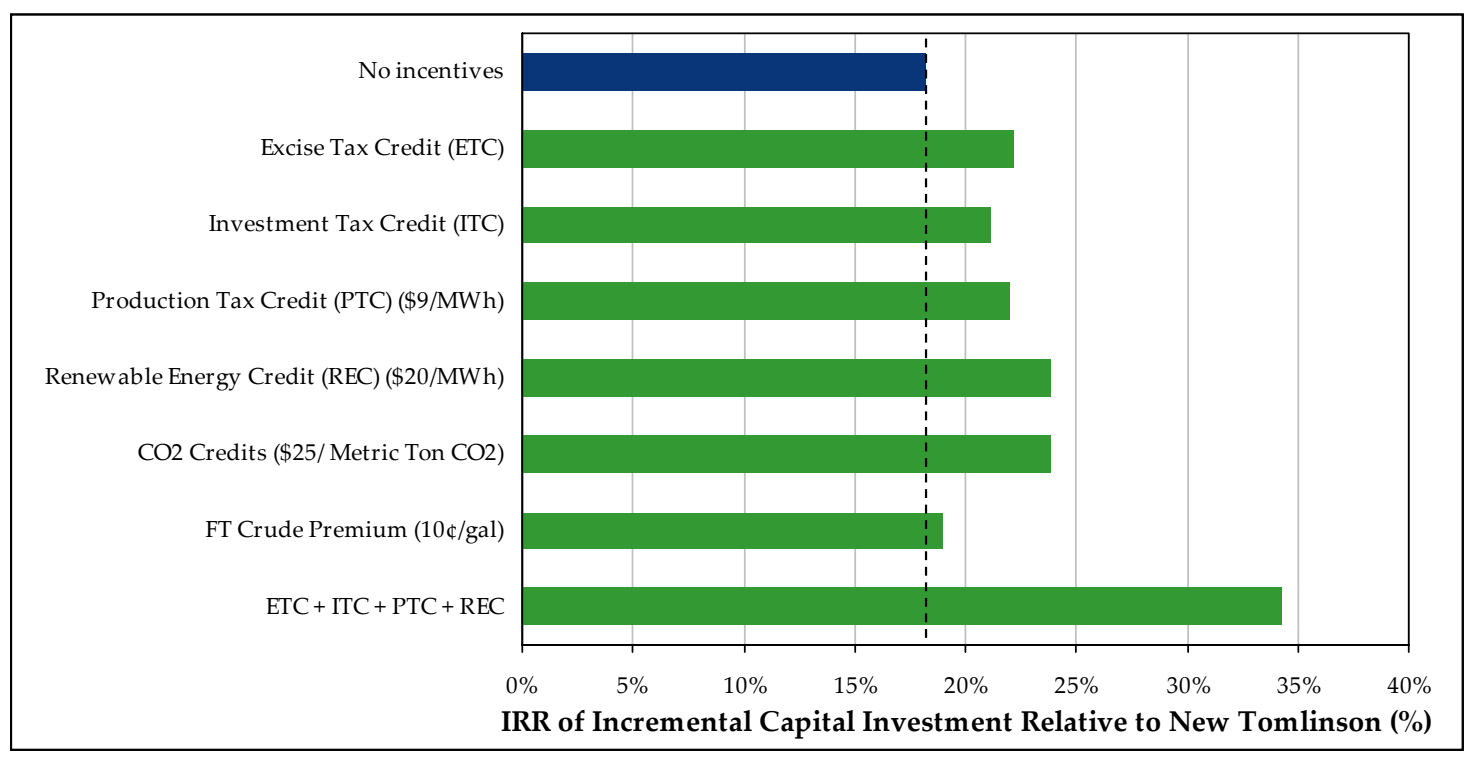

Note: Investment tax credit $=20 \%$ gasification tax credit

Figure 77: IRR on incremental capital investment in FTb biorefinery relative to a new Tomlinson system with different environmental benefits monetized under our TSEP scenario.

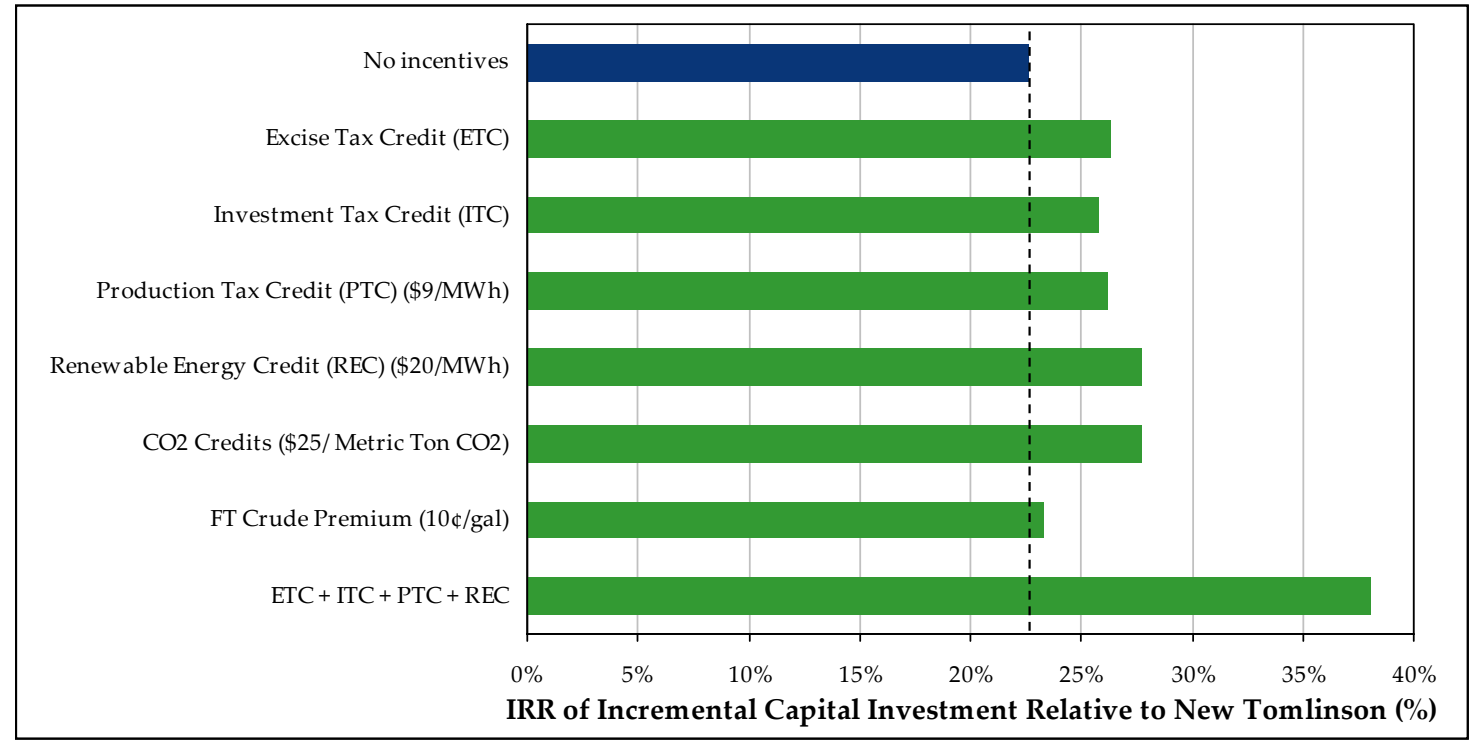

Note: Investment tax credit $=20 \%$ gasification tax credit 


\subsubsection{FTc}

Figure 78 shows, for the FTc configuration, the IRR relative to a new Tomlinson investment. With "Our Capital Cost Estimate" and under the REP scenario, the incremental investment of $\$ 329$ million gives an IRR of $17.7 \%$. The calculated NPV is \$37 million. Under the TSEP scenario, the IRR and NPV are $28 \%$ and $\$ 219$ million, respectively. FTc has very similar baseline financial performance to FTb, but shows greater improvement in the TSEP scenario because of the greater emphasis on fuel production versus electricity production.

Figure 79 shows the sensitivity of the IRR to the assumed biomass-energy and electricity prices. Because fuel is the dominant product, FTc financial performance shows very little sensitivity to electricity price. There is a relatively strong correlation with biomass price, however, because this configuration uses more purchased biomass than any other option.

Figure 78: Allowable incremental capital cost for FTc biorefinery relative to new Tomlinson investment for different target IRR values under our two energy price scenarios.

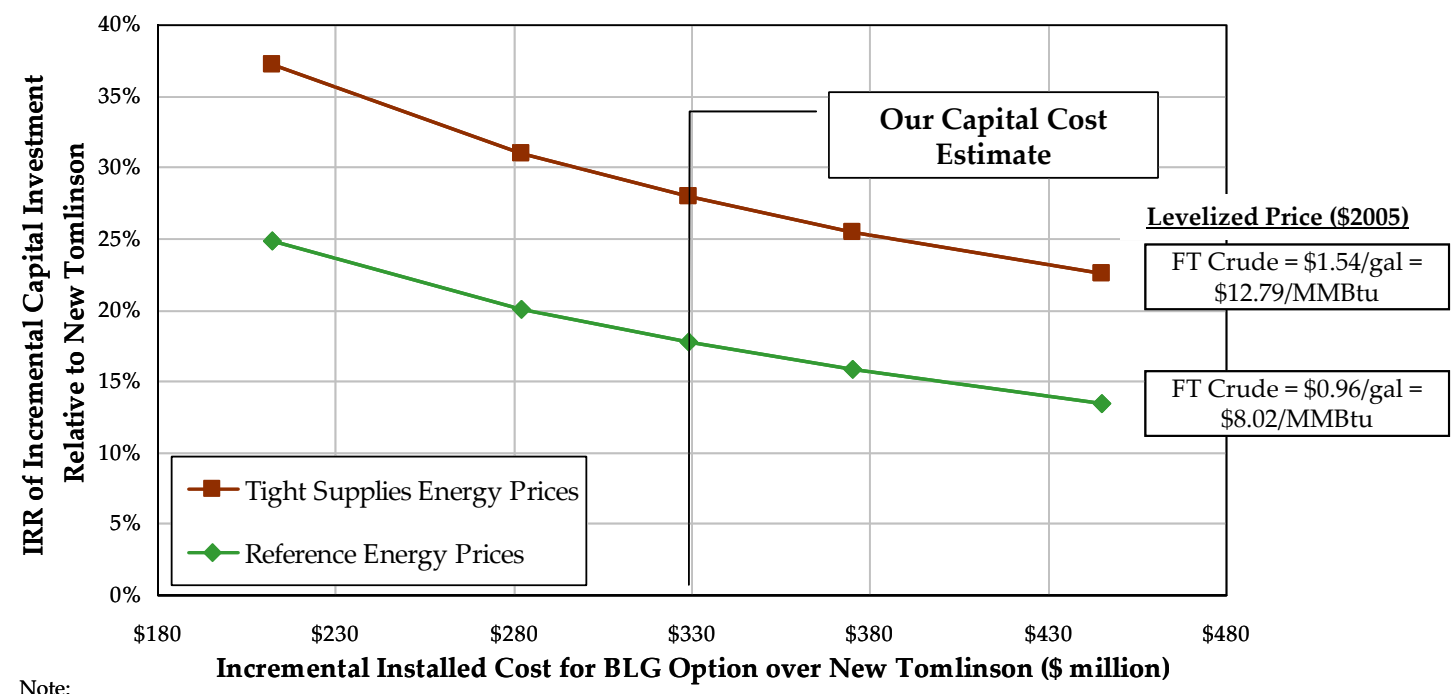

Our estimate of the capital cost for the BLG system is $\$ 465$ million, and for the New Tomlinson is $\$ 136.2$ million. This chart is meant to show the impact
Ond of different capital costs and product prices, all else equal.

Figure 79: IRR on incremental capital cost for FTc biorefinery relative to new Tomlinson system with indicated biomass and power prices and other energy prices as in the REP scenario.

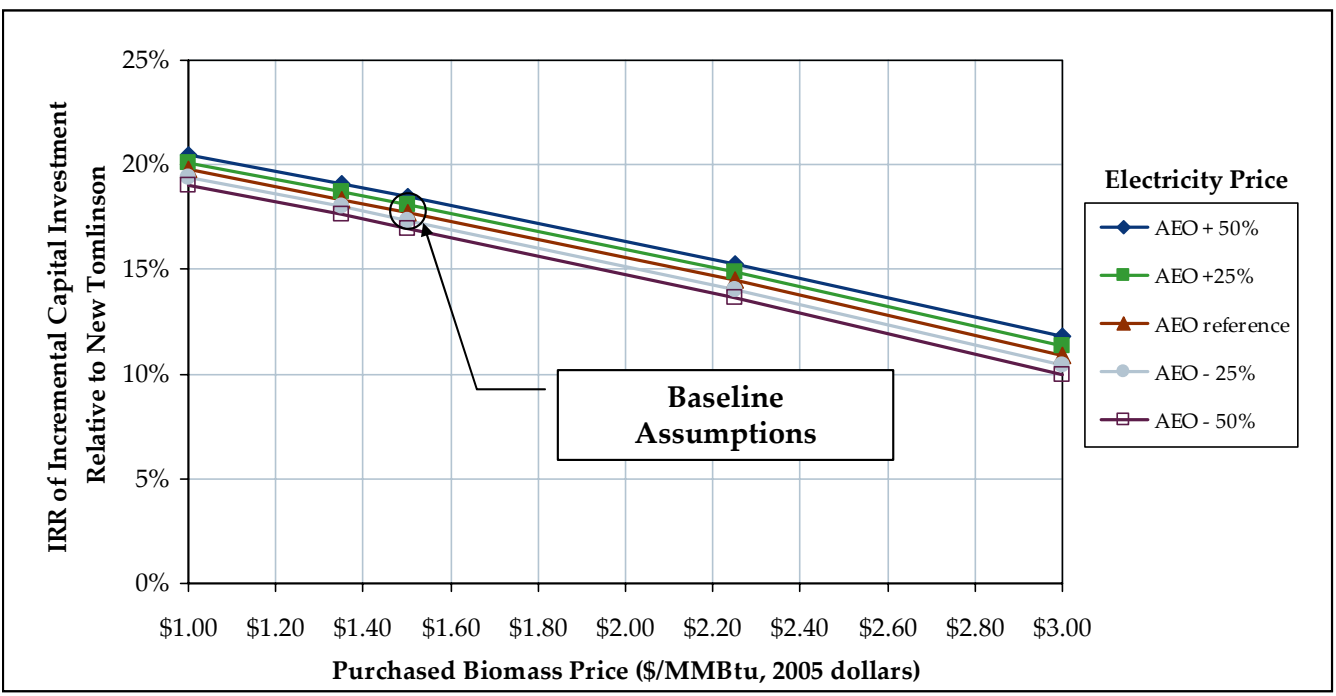


When incentives are considered (Figure 80 and Figure 81), the excise tax credit is the most important, followed by the carbon credits and investment tax credit. When the bundle of incentives is considered the IRR exceeds 33\% under the REP scenario and approaches $43 \%$ under the TSEP scenario. The bundle of incentives does not include the FT performance premium, which would increase the IRR slightly.

Figure 80: IRR on incremental capital investment in FTc biorefinery relative to a new Tomlinson system with different environmental benefits monetized under our REP scenario.

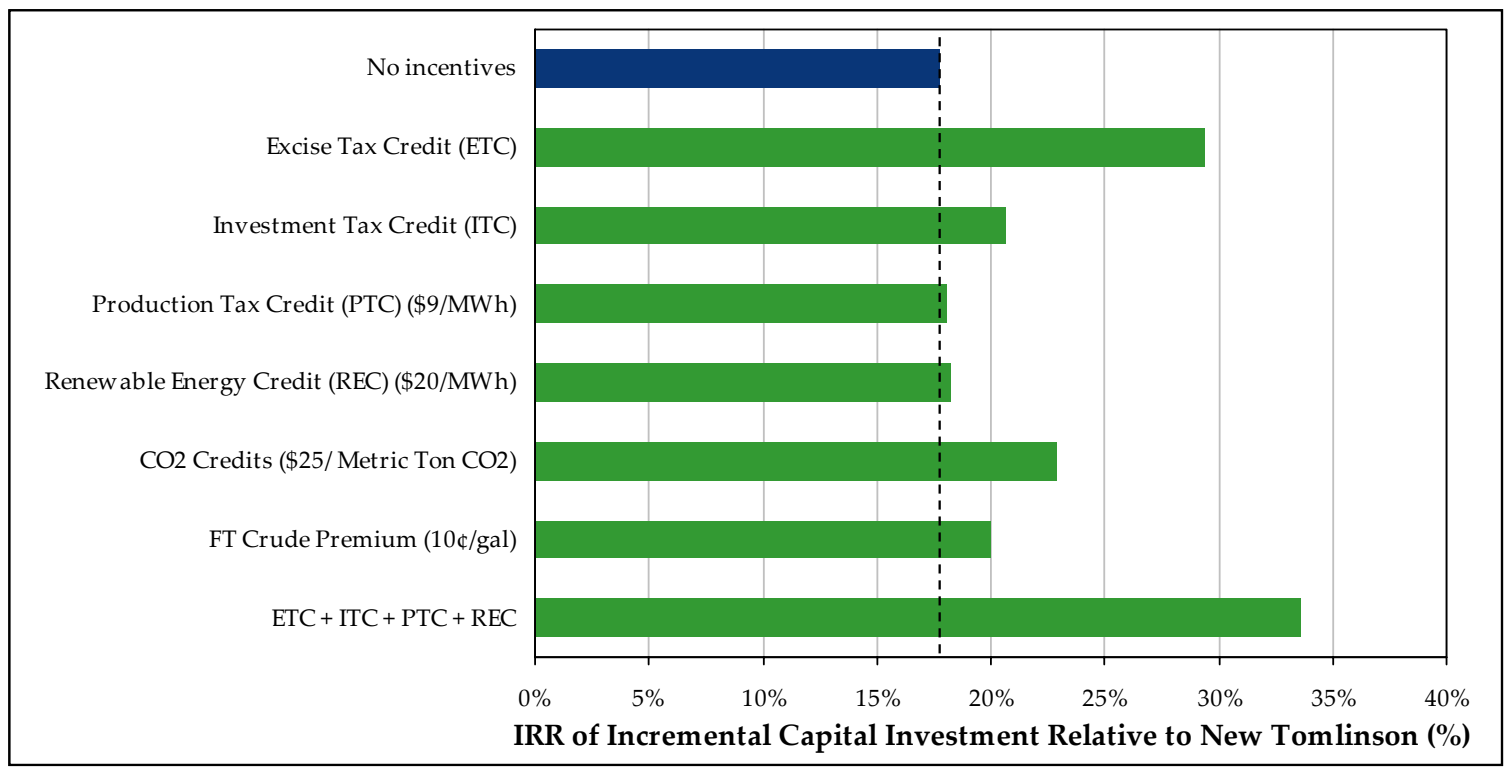

Note: Investment tax credit $=20 \%$ gasification tax credit

Figure 81: IRR on incremental capital investment in FTc biorefinery relative to a new Tomlinson system with different environmental benefits monetized under our TSEP scenario.

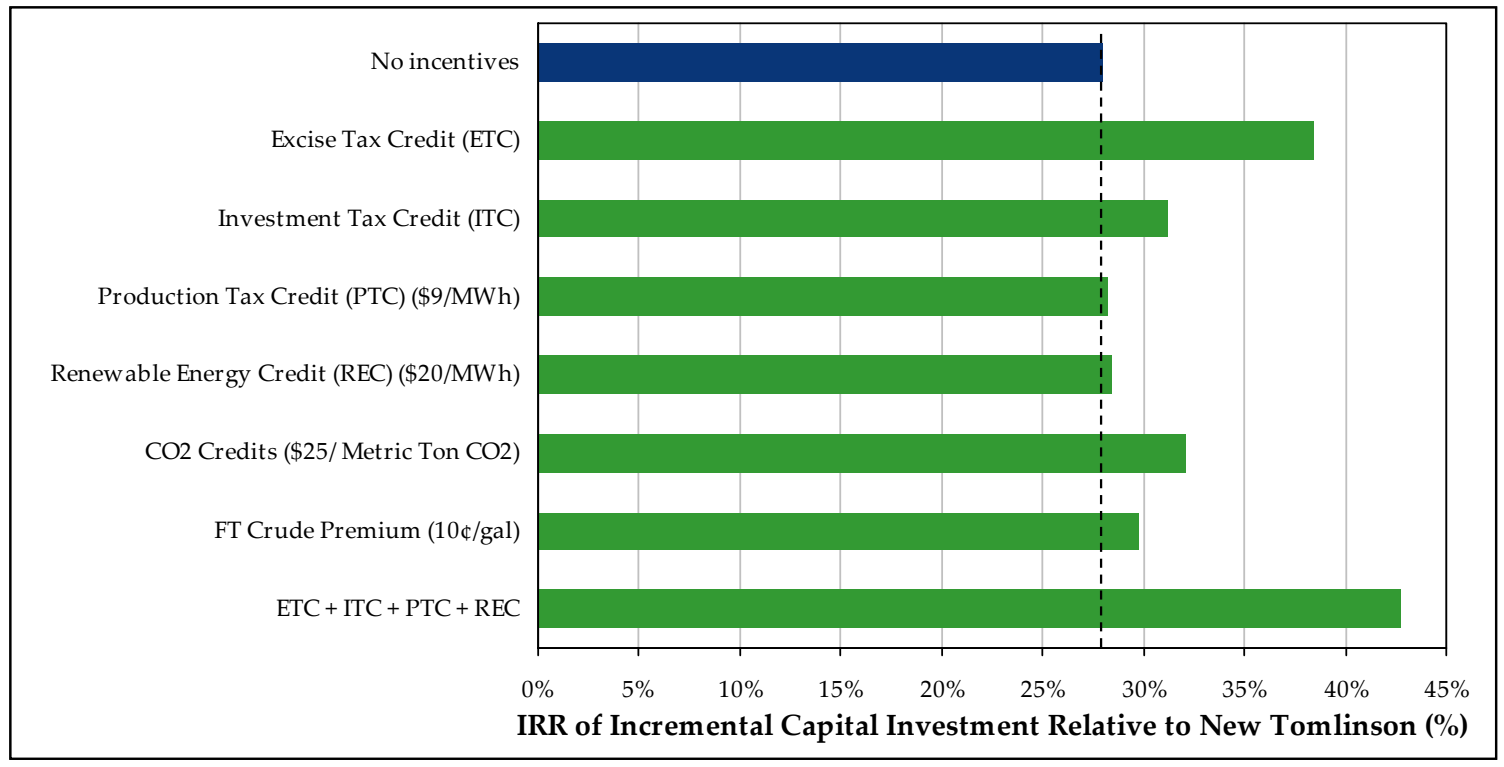

Note: Investment tax credit $=20 \%$ gasification tax credit 
An interesting comparison is between the FTa and FTc cases, which allows, at least at a high level, an examination of the scale economies gained by up-sizing the synthesis area of the plant. Since both cases use the same gas turbine, the main distinction between the two configurations is the scale of the synthesis island (and, connected to this, the scale of biomass gasification needed to supply the synthesis island). The FTc case has a little more than three times the synthesis island capacity of the FTa case, yet requires just $41 \%$ more capital investment in absolute terms (\$465 million vs. \$330 million). When considering the difference in the incremental capital investment over the new Tomlinson, the FTc case has a $71 \%$ increase in the investment required (\$329 million vs. \$194 million). The increase in liquids production scale from FTa to FTc, factoring in higher O\&M costs for the larger system and other changes in annual operating costs (e.g., interest expenses), results in an increase in the net annual cash flow of approximately \$20 million per year in the REP scenario and approximately \$50 million per year in the TSEP scenario. The IRR on the incremental capital invested between the FTc and FTa cases is $22.5 \%$ in the REP scenario and $37.5 \%$ in the TSEP scenario. The corresponding NPVs are $\$ 43$ million and $\$ 166$ million. Thus, one may conclude from this analysis that there are strong economies of scale to be gained with synfuels production.

\subsubsection{MA (Mixed Alcohol) Results}

We present two sets of results for the MA biorefinery economic analysis. In one case, we assume that the MA liquid fuel product is sold as a mixture for use in blending with gasoline (much as ethanol is sold today). In a second set of results, we assume some additional capital investments are made to enable the separation of the component alcohols in the mixture, with the resulting ethanol sold as fuel and higher alcohols sold into chemicals markets. Table 30 shows the composition of the alcohol mixture predicted in our mass/energy balance simulations. In our simulations, we use propanol as a surrogate for all other higher alcohols. Our simulation results give a much higher fraction of $\mathrm{C}_{3+}$ alcohols than other work that has been published (e.g., [46]), even as our total alcohols yield (as discussed earlier) is lower. While yield is the main factor affecting economics when the mixed alcohols are sold as a mixture, the relative yield of ethanol and $\mathrm{C}_{3+}$ alcohols has a major bearing on the economics when the achohols are separated for sale into individual markets.

Table 30. Composition of mixed alcohol product.

\begin{tabular}{|c|c|}
\hline Component & Percent by Volume $^{\mathbf{a}}$ \\
\hline Methanol & $1 \%$ \\
\hline Ethanol & $55 \%$ \\
\hline Propanol & $44 \%$ \\
\hline
\end{tabular}

(a) the raw mixed alcohol product also includes some water.

\subsubsection{MA sold as mixture}

Figure 82 shows, for the MA biorefinery, the IRR relative to investment in a new Tomlinson

system. In this chart, the mixed alcohols are sold as a single commodity that is assumed to have the same price as ethanol, corrected for energy content. Under the baseline set of assumptions ("Our Capital Cost Estimate") and the REP scenario, the incremental investment of \$260 million gives an IRR of only $10.4 \%$ and a NPV of negative $\$ 40$ million. Under the TSEP scenario, the IRR and NPV improve to $13.1 \%$ and negative $\$ 18.4$ million, respectively. The financial performance for the MA biorefinery is weaker than any of the DME or FT options due to the low liquid yields and high capital costs, with the latter driven largely by the very large synthesis 
reactor volume needed to support the large amount of catalyst. Even with significantly lower assumed capital costs (Figure 82), the MA configuration would not meet the hurdle rate.

Figure 83 shows the sensitivity of the IRR to the assumed biomass-energy and electricity prices. There is no combination of biomass and electricity price within the range we have examined for which this configuration meets our hurdle rate.

When incentives are considered (Figure 84 and Figure 85) and the MA product is still sold as a single commodity, the full bundle of incentives is needed to achieve an IRR that exceeds the $15 \%$ hurdle rate under the REP scenario. With the TSEP scenario the hurdle rate can be met if either the excise tax credit or the investment tax credit or the $\mathrm{CO}_{2}$ credit is available. With the bundle of incentives, the IRR reaches $22 \%$ in this scenario. Note that under the TSEP scenario, the impact of the excise tax credit, on an IRR basis, is lower than in the REP scenario because the baseline fuel prices are higher.

Figure 82: Allowable incremental capital cost for MA biorefinery (with MA sold as a fuel) relative to new Tomlinson investment for different target IRR values under our two energy price scenarios.

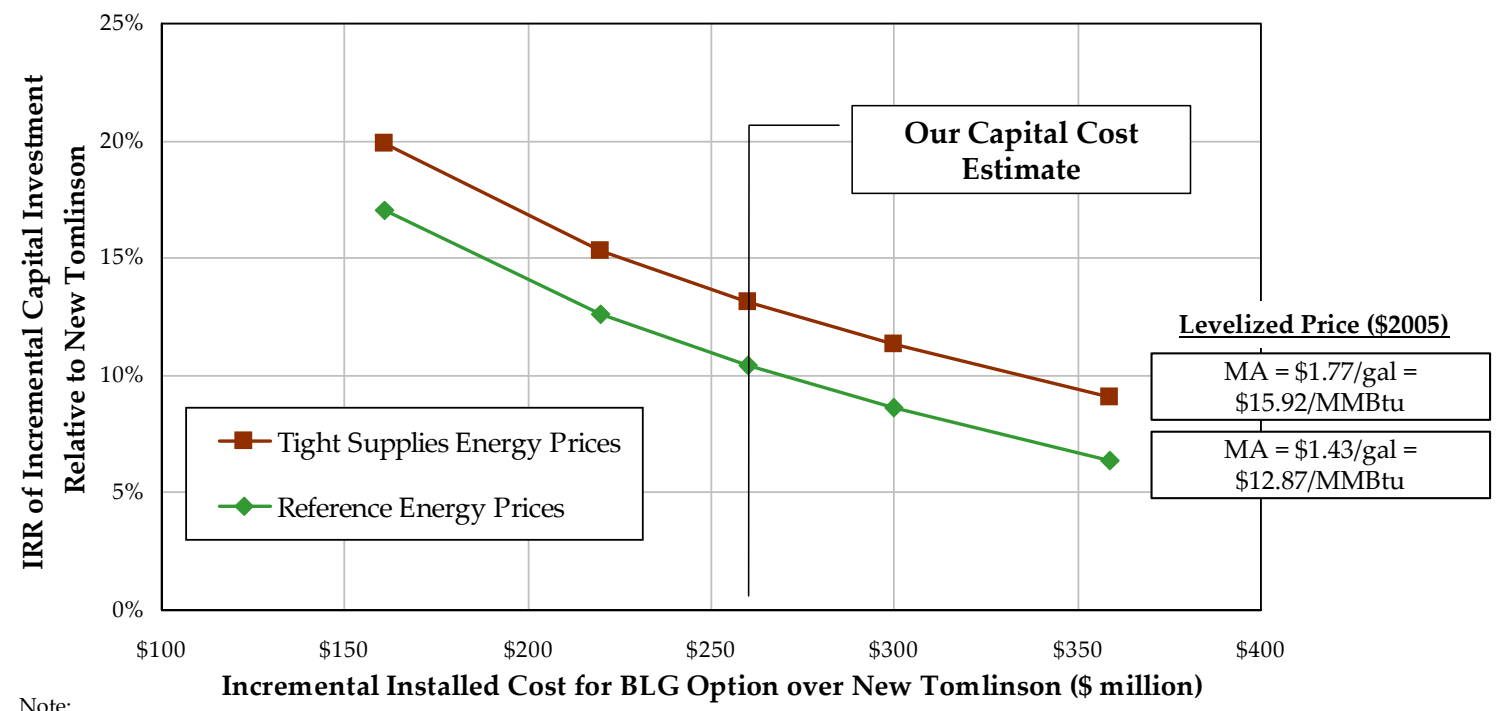

Our estimate of the capital cost for the BLG system is $\$ 396$ million, and for the New Tomlinson is $\$ 136.2$ million. This chart is meant to show the impact of different capital costs and product prices, all else equal. 
Figure 83: IRR on incremental capital cost for MA biorefinery (with MA sold as fuel) with indicated biomass and power prices and other energy prices as in the REP scenario.

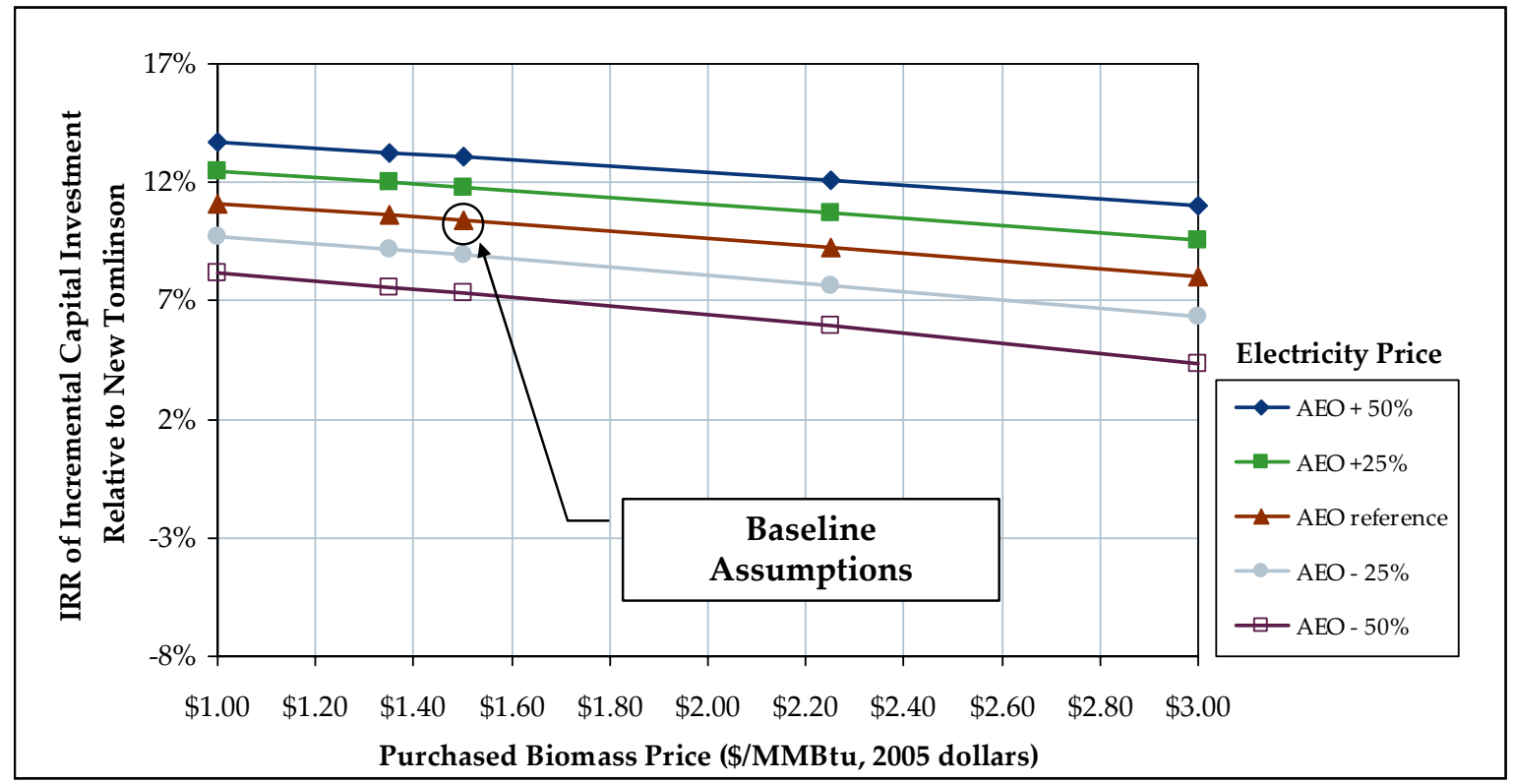

Figure 84: IRR on incremental capital investment in MA biorefinery (with MA sold as a fuel mixture) relative to a new Tomlinson system with different environmental benefits monetized under our REP scenario.

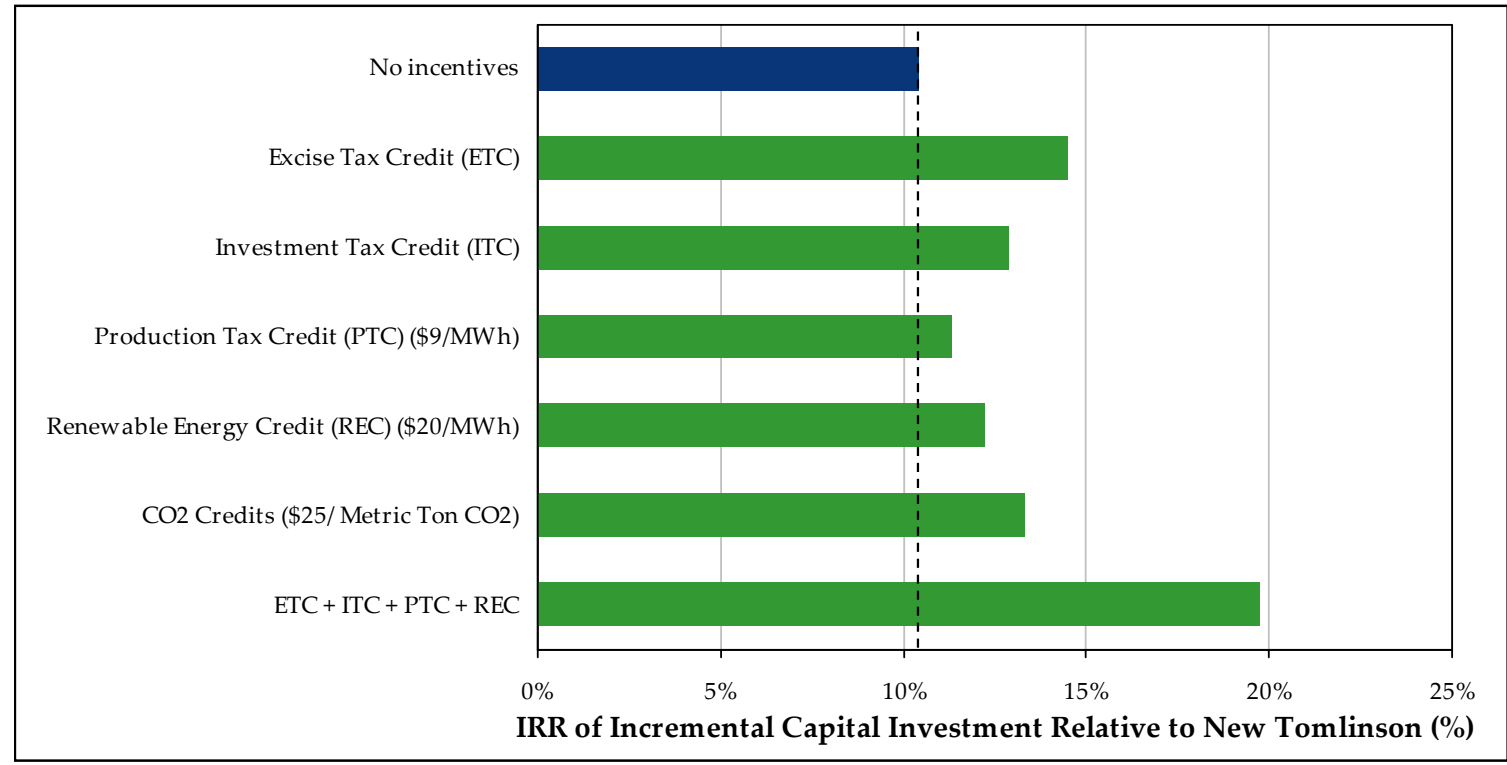

Note: Investment tax credit $=20 \%$ gasification tax credit 
Figure 85: IRR on incremental capital investment in MA biorefinery (with MA sold as a fuel mixture) relative to a new Tomlinson system with different environmental benefits monetized under our TSEP scenario.

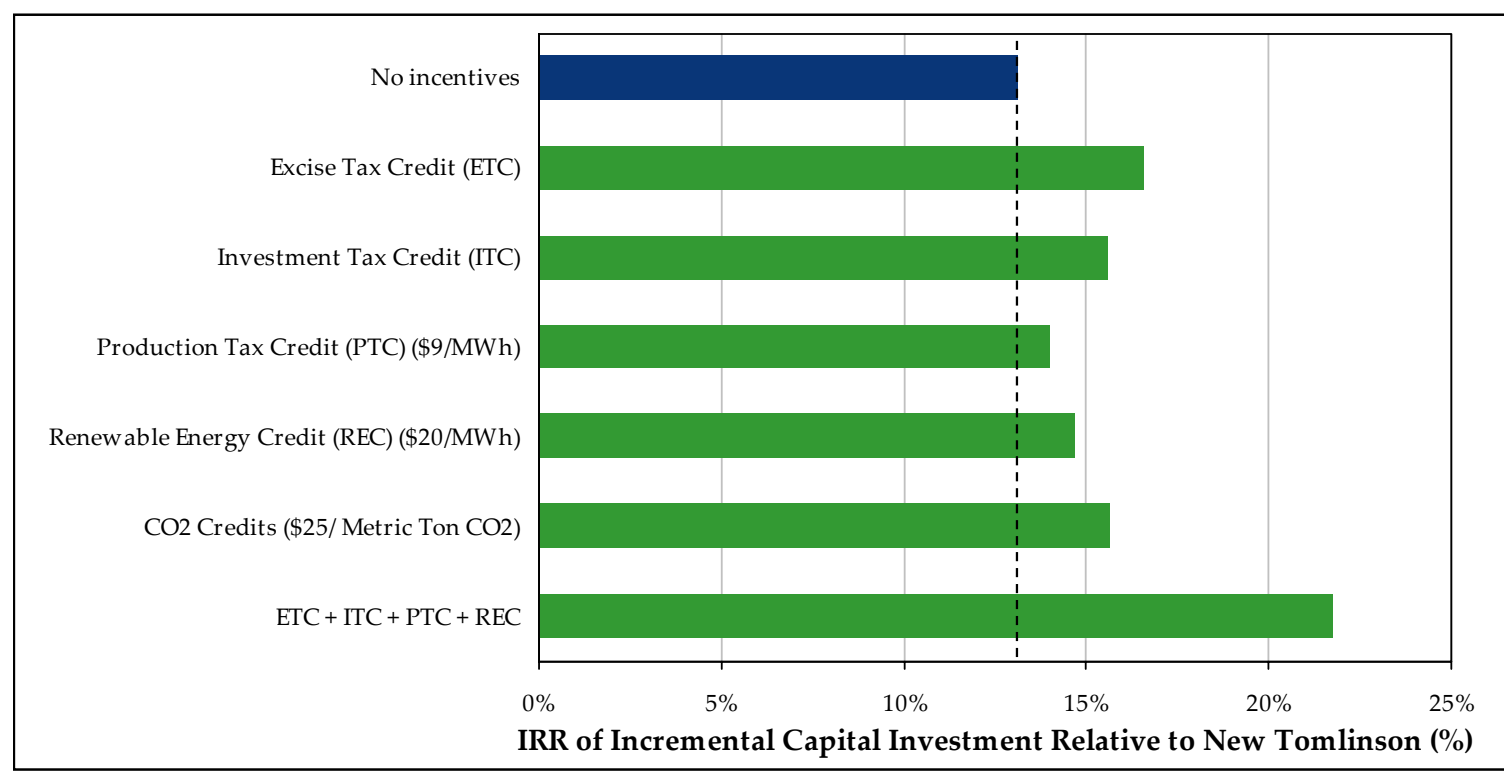

Note: Investment tax credit $=20 \%$ gasification tax credit

\subsubsection{MA sold as components}

By separating the MA product into component alcohols, it may be feasible to improve the economics over those described in the previous section because the additional capital investment needed to separate the alcohols is relatively modest, while the sale prices for higher alcohols as chemicals are much higher than fuel prices. For example, as of August 2006, Dow Chemical [139] was quoting a price for $n$-propanol of $\$ 1.04 / \mathrm{lb}$, or about $\$ 6.90 /$ gallon, more than double the spot price at the time for fuel ethanol of about $\$ 3 /$ gallon. Isopropanol was listing for $\$ 0.84 / \mathrm{lb}$, still well above the price of ethanol. In the past, these prices have been lower [140,141], with a spread between ethanol and propanol closer to $\$ 2.50 /$ gallon. We have chosen to use a price differential of \$2.50/gallon between ethanol and higher alcohols. We have further used an NREL estimate of $\$ 0.11 /$ gallon as the incremental capital-plus-operating cost of separating the MA product into separate alcohols [142], the ethanol portion of which is sold as motor fuel and the other components of which are sold as chemical commodities.

Figure 86 shows, for the MA biorefinery with alcohols sold separately, the IRR relative to an investment in a new Tomlinson system. With "Our Capital Cost Estimate" and the REP scenario, the incremental investment of $\$ 260$ million $^{52}$ gives an IRR of $31 \%$. The NPV is \$203 million. Under the TSEP scenario, the IRR and NPV are $32.7 \%$ and $\$ 243$ million, respectively. Figure 87 shows the sensitivity of the IRR to the assumed biomass-energy and electricity prices.

Because $\mathrm{C}_{3+}$ alcohols are a major fraction of the product mix (Table 30) the modest costs for separating them from the ethanol are more than compensated by the much higher selling price. The markets for higher alcohols are much smaller than for ethanol, but they are large enough to support the output of several pulp mill biorefineries.

\footnotetext{
${ }^{52}$ The incremental investment here is without the capital cost associated with separating component alcohols from each other. For ease of this calculation, we have included the \$0.11/gallon separation cost (capital plus operating costs) as strictly an operating cost.
} 
When incentives are considered (Figure 88 and Figure 89), the impacts are relatively minor when compared to the other configurations because the initial IRR is so high that the incremental value of the credits is smaller. When the bundle of incentives is considered, the IRR is $39.5 \%$ in the REP scenario. It is slightly better $(41.3 \%)$ in the TSEP scenario.

Figure 86: Allowable incremental capital cost for MA biorefinery (with MA sold as components) relative to new Tomlinson investment for different target IRR values under our two energy price scenarios. $^{52}$

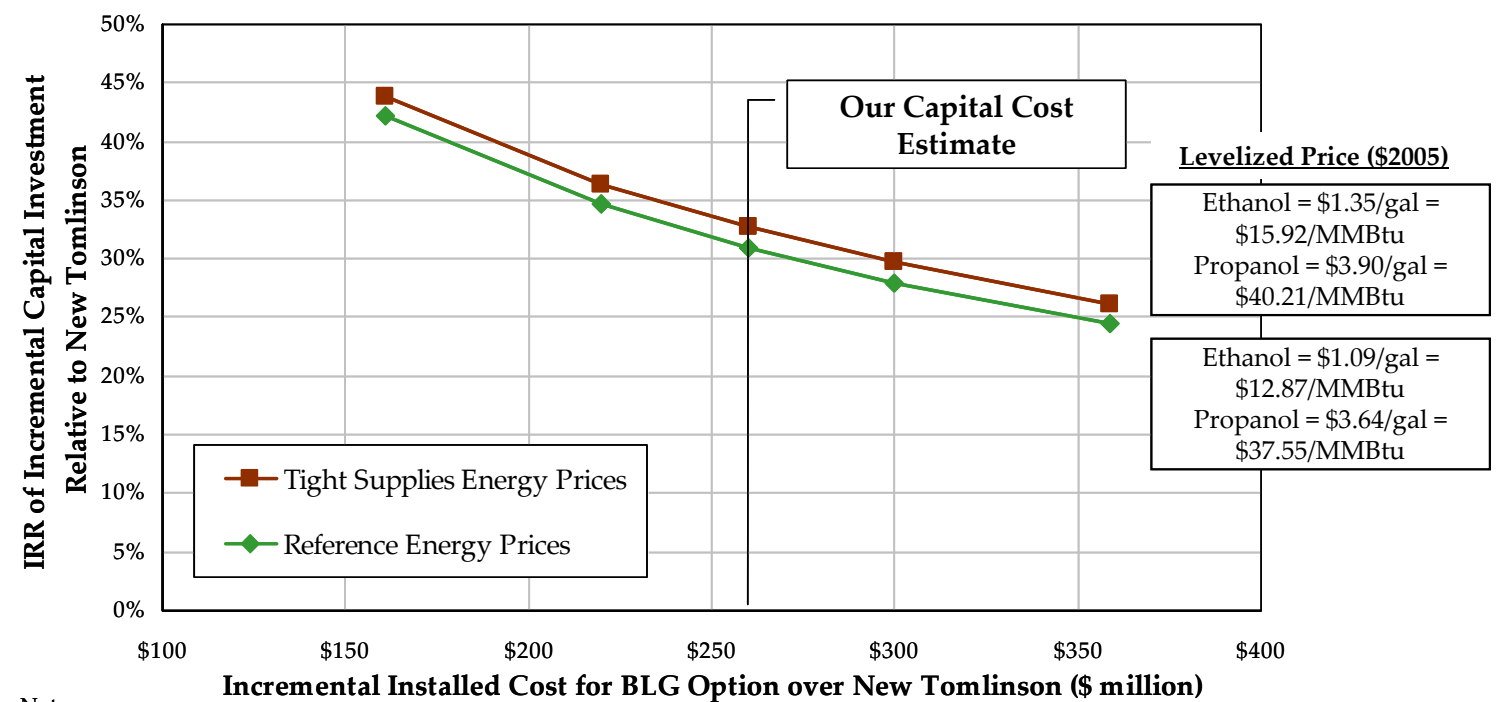

Note:

Incremental Installed Cost for BLG Option over New Tomlinson (\$ million)

Our estimate of the capital cost for the BLG system is $\$ 396$ million, and for the New Tomlinson is $\$ 136.2$ million. This chart is meant to show the impact of different capital costs and product prices, all else equal.

Figure 87: IRR on incremental capital cost for MA biorefinery (with MA sold as components) relative to new Tomlinson system with indicated biomass and power prices and other energy prices as in the REP scenario.

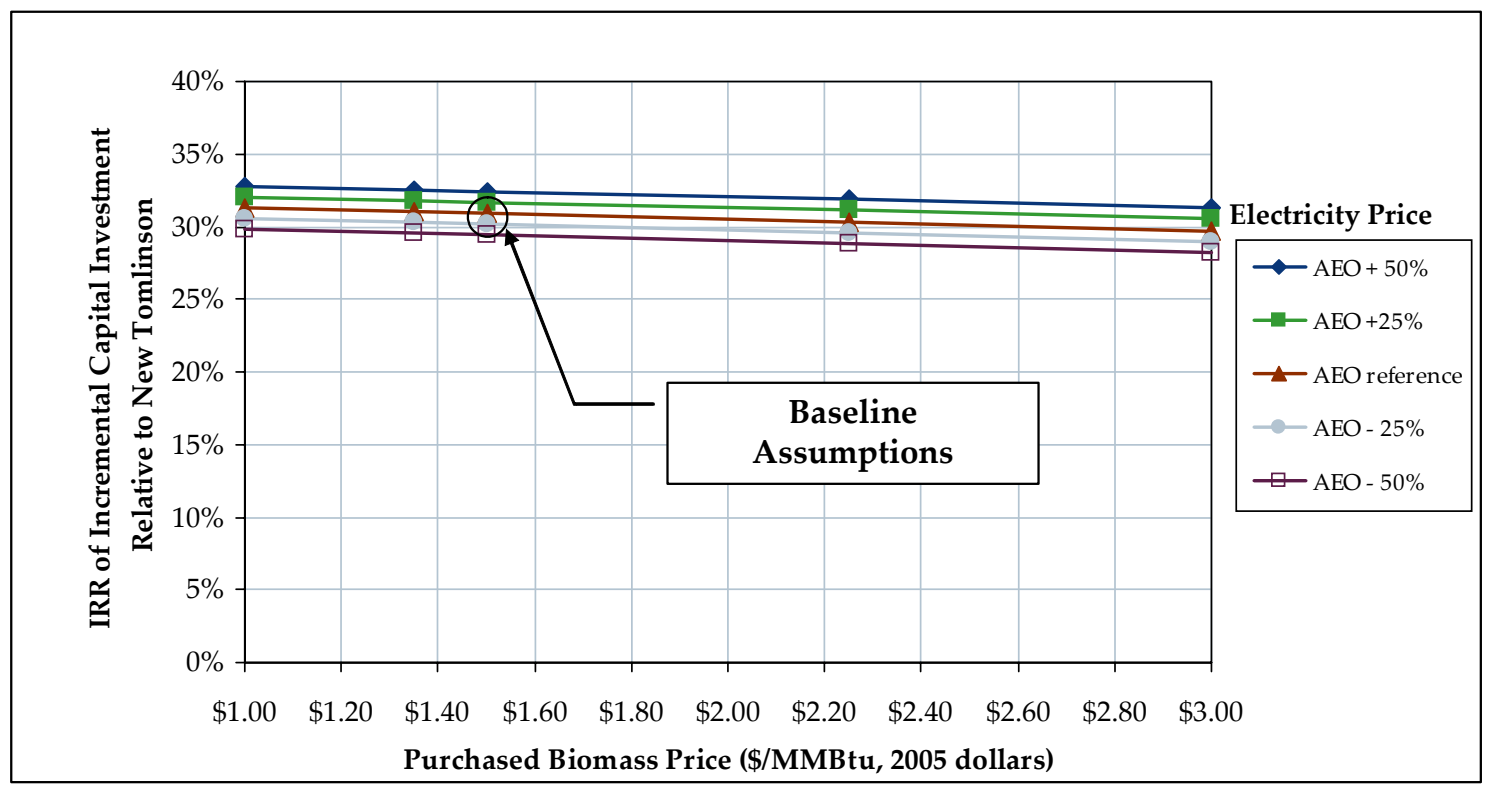


Figure 88: IRR on incremental capital investment in MA biorefinery (with MA sold as components) relative to a new Tomlinson system with different environmental benefits monetized under our REP scenario.

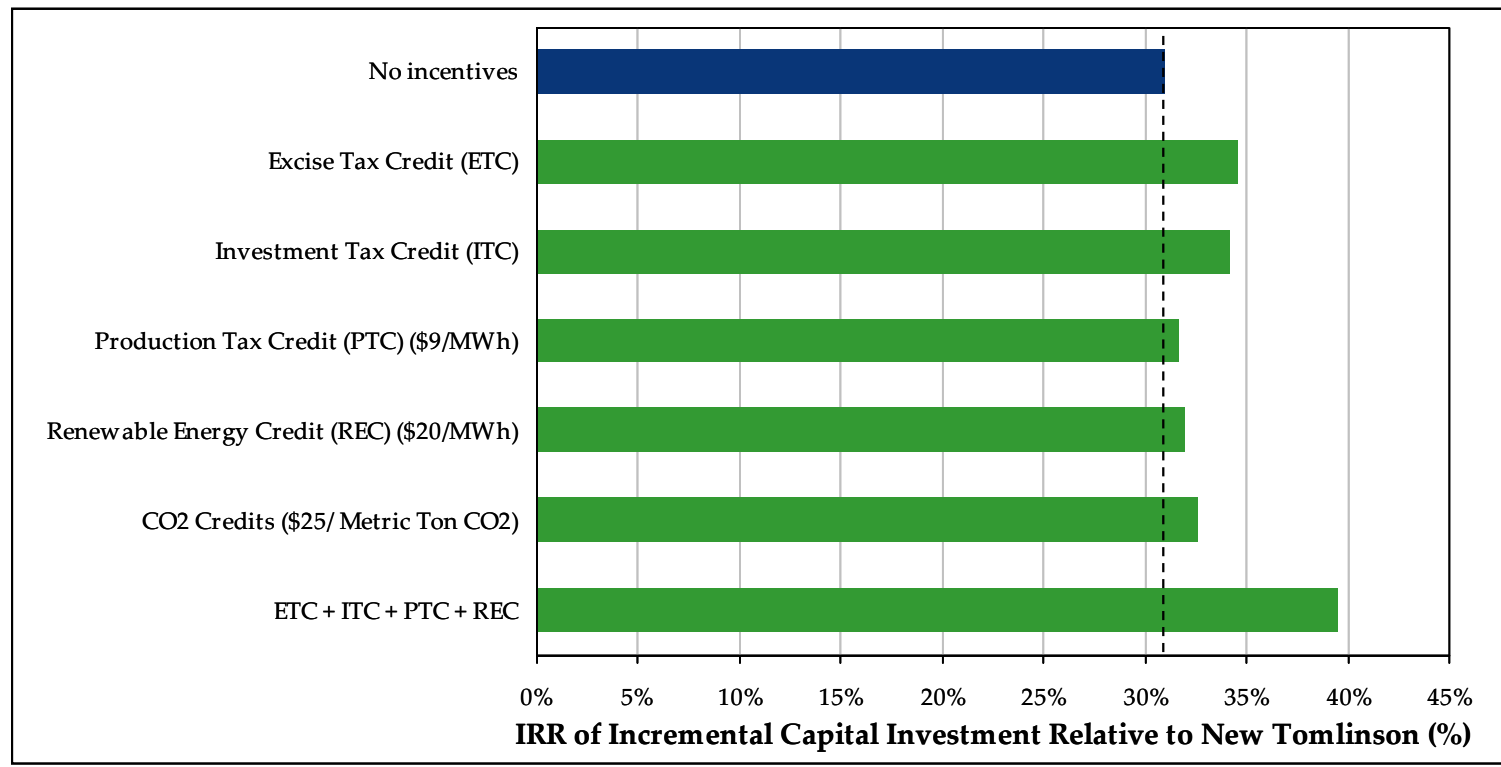

Note: Investment tax credit $=20 \%$ gasification tax credit

Figure 89: IRR on incremental capital investment in MA biorefinery (with MA sold as components) relative to a new Tomlinson system with different environmental benefits monetized under our TSEP scenario.

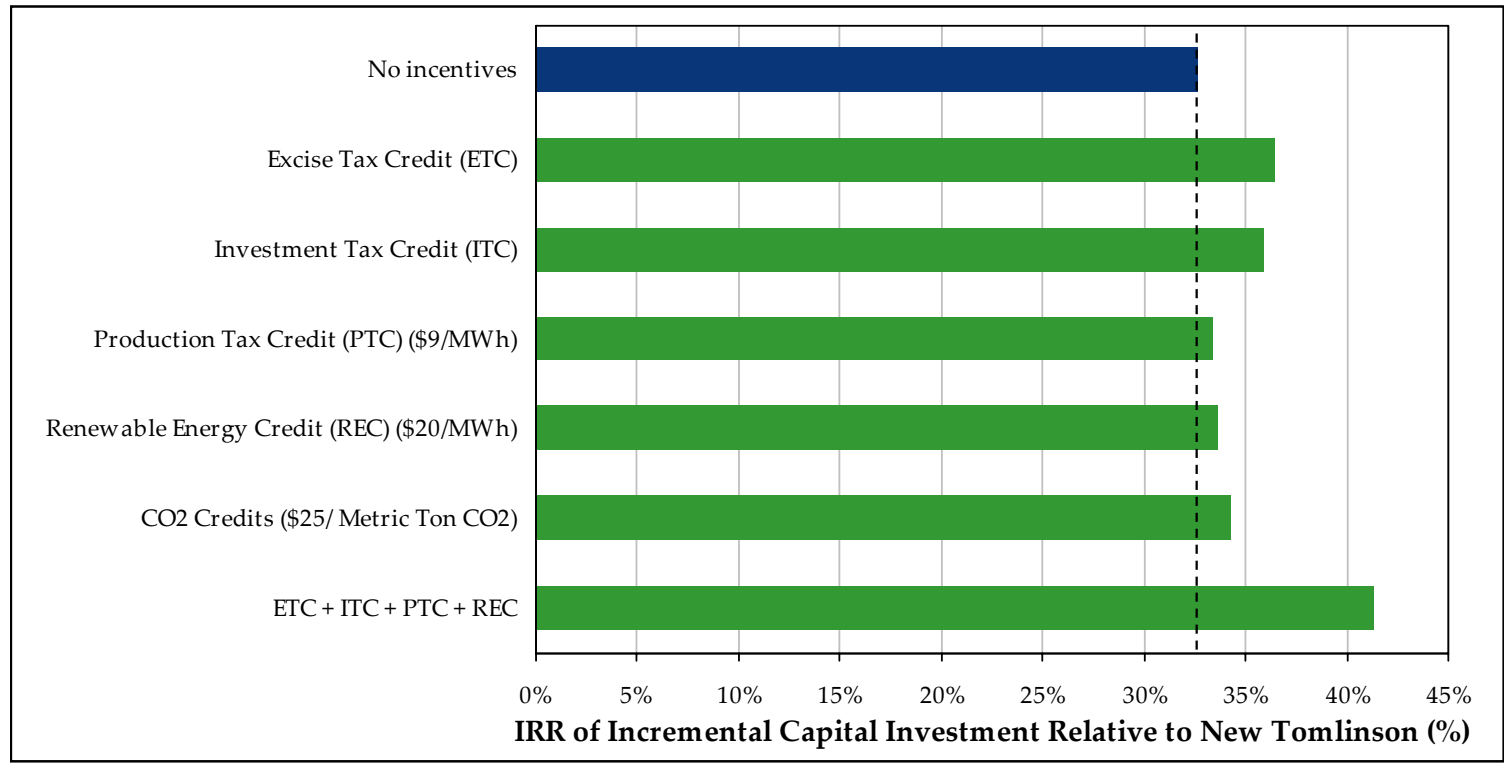

Note: Investment tax credit $=20 \%$ gasification tax credit

If the volume of higher alcohols produced at biorefineries were large relative to the market, this could have the effect of suppressing prices and thus reducing the benefit of separating the alcohols. The U.S. market for higher alcohols is estimated at about 3.7 billion pounds/year (see Table 1). The MA biorefinery considered here would produce about 10 million gallons/year of propanol and higher alcohols, or about 70 million pounds/year. Thus, pulpmill biorefineries may 
not exert a material impact on pricing, even if several mills were to pursue mixed alcohol production for sale into the chemicals market.

\subsection{Summary Discussion of Financial Results}

By way of summarizing the financial analyses, our baseline set of IRR and NPV results are presented for all cases in Table 31 (no incentives) and Table 32 (with bundled incentives).

In the no-incentives cases, the incremental IRRs for most configurations under the Reference Energy Prices scenario meet the assumed hurdle rate of $15 \%$. The large FT cases (FTb and FTc) demonstrate the most attractive economics, after the BLGCC case. In the Tight Supplies Energy Prices scenario, which represents an extrapolation of mid-2006 oil prices, with fuel prices increasing gradually in real terms through 2030, the incremental IRRs of all but the MA configuration exceed the hurdle rate by a comfortable margin, indicating that the economics are very favorable. FTb and FTc are very attractive, along with DMEa and DMEb, and all of these surpass the IRR of the BLGCC configuration by several percentage points, since the BLGCC configuration is largely unaffected by changes in petroleum prices.

The weakest financial performance is displayed by the mixed-alcohol configuration when the liquid product is sold as a single fuel commodity, but separating the alcohols for sale as chemicals provides for very high returns, even without incentives. The lower financial performance of the MA configuration in the former case is due largely to the low yield of liquid product coupled with high capital costs. If the yields were more in line with DME or FT, then the economics of this configuration would be more in line as well. These results differ from the only prior published systems analysis of mixed alcohols synthesis from biomass of which we are aware [46]. This prior analysis showed somewhat more favorable results, but used a simplified approach to estimating synthesis reactor performance. Taken with such prior analyses, the results shown here suggest the need for more work to better understand the performance and costs that can be expected for production of mixed alcohols from syngas with "Nth plant" technology. This is unlike the situation for DME and FT synthesis, where the commercial potential is, by comparison, well understood.

Table 31: Summary of IRR and NPV results for all cases, assuming no incentives.

\begin{tabular}{|l|c|c|c|c|}
\cline { 2 - 5 } \multicolumn{1}{c|}{} & \multicolumn{2}{c|}{ Reference Energy Price Scenario } & \multicolumn{2}{c|}{ Tight Supplies Energy Price Scenario } \\
\cline { 2 - 5 } \multicolumn{1}{c|}{} & IRR (\%) & NPV (\$ million) & IRR (\%) & NPV (\$million) \\
\hline BLGCC & $21.7 \%$ & $\$ 24.7$ & $22.0 \%$ & $\$ 25.4$ \\
\hline DMEa (diesel) & $16.4 \%$ & $\$ 7.4$ & $29.2 \%$ & $\$ 98.2$ \\
\hline DMEb (diesel) & $16.2 \%$ & $\$ 13.5$ & $23.6 \%$ & $\$ 112$ \\
\hline DMEc (diesel) & $15.4 \%$ & $\$ 3.2$ & $20.6 \%$ & $\$ 46.9$ \\
\hline DMEa (LPG) & $13.5 \%$ & $\$(8.2)$ & $21.5 \%$ & $\$ 70$ \\
\hline DMEb (LPG) & $14.8 \%$ & $\$(2)$ & $20.9 \%$ & $\$ 83.8$ \\
\hline DMEc (LPG) & $14.5 \%$ & $\$(3.6)$ & $22.7 \%$ & $\$ 53.4$ \\
\hline FTa & $14.2 \%$ & $\$(5.9)$ & $28.0 \%$ & $\$ 121$ \\
\hline FTb & $18.2 \%$ & $\$ 46.8$ & $13.1 \%$ & $\$ 219$ \\
\hline FTc & $17.7 \%$ & $\$ 37$ & $32.7 \%$ & $\$(18.4)$ \\
\hline MA & $10.4 \%$ & $\$(40)$ & $\$ 203$ & \\
\hline MA (sep.) & $30.9 \%$ & & & $\$ 243$ \\
\hline
\end{tabular}

When multiple environmental values are explicitly included in the analysis in the form of incentives and price premiums (Table 32), the financial performance is overwhelmingly attractive for all but the mixed alcohols configuration (no product separation), with IRRs generally being in excess of $30 \%$ in the Reference Energy Prices scenario. The IRRs are even 
better in the Tight Supplies Energy Prices scenario, but not as high as might be expected, in part because in that price scenario, the amount of the excise tax credit (which is in most cases the most important incentive) that is reflected in the plant gate price is lower than in the Reference Energy Prices scenario. This would be expected in a high-price environment, where the market is sufficient to provide producers with adequate margins.

Table 32: Summary of IRR and NPV results for all cases, assuming bundled incentives, including ETC, ITC, PTC, and RECs.

\begin{tabular}{|l|c|c|c|c|}
\hline & \multicolumn{2}{|c|}{ Reference Energy Price Scenario } & \multicolumn{2}{c|}{ Tight Supplies Energy Price Scenario } \\
\hline & IRR (\%) & NPV (\$ million) & IRR (\%) & NPV (\$million) \\
\hline BLGCC & $36.0 \%$ & 77.1 & $36.3 \%$ & 27.8 \\
\hline DMEa (diesel) & $35.2 \%$ & 120 & $46.0 \%$ & 210 \\
\hline DMEb (diesel) & $28.8 \%$ & 159 & $35.4 \%$ & 134 \\
\hline DMEc (diesel) & $27.5 \%$ & 91.1 & $32.1 \%$ & 181 \\
\hline DMEa (LPG) & $32.7 \%$ & 104 & $42.4 \%$ & 228 \\
\hline DMEb (LPG) & $27.4 \%$ & 143 & $33.4 \%$ & 122 \\
\hline DMEc (LPG) & $26.6 \%$ & 84.3 & $30.7 \%$ & 160 \\
\hline FTa & $27.8 \%$ & 101 & $33.6 \%$ & 358 \\
\hline FTb & $34.3 \%$ & 284 & $42.8 \%$ & 455 \\
\hline FTc & $33.5 \%$ & 275 & $21.7 \%$ & 63.1 \\
\hline MA & $19.7 \%$ & 41.9 & $41.3 \%$ & 351 \\
\hline MA (sep.) & $39.5 \%$ & 312 & & \\
\hline
\end{tabular}

(a) ETC = Excise Tax Credit, ITC = Gasification Investment Tax Credit, PTC $=$ Production Tax Credit, REC = Renewable Energy Credit (electricity)

\section{National Impacts of a Pulp Mill Biorefinery Industry}

Building on the mill-level analyses in prior sections of this report, we present here an analysis of potential energy and environmental impacts at the national level in the United States, assuming alternative rates of commercial deployment of biorefinery systems.

\subsection{Market Penetration Scenarios}

Three technology market penetration scenarios were developed in our prior BLGCC analysis [5], and these form the basis for the scenarios used here. The biorefinery commercial deployment rates in these scenarios are based on the well-documented S-shaped trajectory for commercial market penetration of new industrial technologies [143]: when a new technology enters the market, the initial period is characterized by a low penetration rate by early adopters, while the bulk of the market waits for lower costs and/or more proven performance; rapid adoption by the broader market follows the slow initial phase; adoption then tails off as the technology approaches saturation of the technical market potential.

The technical market potential (maximum physical limit) was estimated here based on a detailed industry database of existing recovery boilers. ${ }^{53}$ Given the uncertainty regarding the timing of introduction of biorefineries, some simplifying assumptions were made for the market penetration analysis:

\footnotetext{
53 The Black Liquor Recovery Boiler Committee (BLRBC) of the American Forest and Paper Association maintains a database of individual recovery boilers with information on capacity, location, age, rebuild year (if any), and in some cases, the nature of the rebuild. This database can be used to calculate the average boiler size, average boiler age when a rebuild occurred ( 20 years), and to identify which boilers will be ready for replacement in any given future year.
} 
- The current industry capacity was taken as the starting point for the analysis. Given the recent contraction of the industry this was felt to be a reasonable starting assumption. Also, because further industry consolidation and mill closures are expected, and few if any new mills are likely to be built, the analysis is based on total capacity rather than the number of mills in operation.

- The analysis assumes 2010 as the first year a biorefinery will be commercially operating. Any boiler requiring rebuild or replacement prior to 2010 is assumed to be rebuilt using conventional technology and thereby not available for replacement until the next rebuild cycle for that boiler. Starting in 2010, boilers coming due for rebuild or replacement are assumed to be eligible for repowering with black liquor gasification in biorefinery configurations, but due to the nature of the market penetration curve, broader adoption does not occur before about 2015. Thus, the market penetration analysis effectively captures the time required for validation and refinement of the commercial design, which would then be followed by broader adoption of the "Nth" plant design by the industry in the post-2013 timeframe.

- Based on data and forecasts supplied by the American Forest and Paper Association [144], an annual growth rate of $1.27 \%$ for total pulp production is estimated.

The output of the technical market potential analysis is a year-by-year estimate of the annual and cumulative boiler capacity eligible for replacement with black liquor gasification.

To quantify the market penetration, a Fisher-Pry model [145] was used to generate an S-curve trajectory calibrated based on knowledge of historical market adoption rates for new industrial technologies. New technologies that are capital intensive, have long equipment lives (>20 years), and entail major changes at the facility level (as opposed to changes to individual process steps), typically have market saturation times ${ }^{54}$ of 20-40 years. Other factors that influence market penetration include the growth rate of the industry, the industry's risk tolerance, and whether or not government regulations are forcing changes. These factors and the significant technology change that biorefining would represent for the pulp and paper industry, suggest that saturation times greater than 20 years could be expected. However, the situation with Tomlinson recovery boilers presents unique conditions that also suggest that more rapid penetration could occur. ${ }^{55}$ First, the Tomlinson boiler fleet is old and is facing the need for another major wave of rebuilds in the next 10-20 years. Second, competitive pressures from foreign producers may drive the U.S. pulp and paper industry to accelerate adoption of technologies like gasification and biorefining that can help maintain its competitive position in global markets. Third, increasing implementation of Renewable Portfolio Standards, Renewable Fuel Standards and other mechanisms to stimulate renewable energy markets in North America and Europe may create additional financial incentives to accelerate the deployment of biorefineries. ${ }^{56}$

To cover a range of possible market deployment scenarios, three market penetration scenarios were developed (Table 33). The "Base" market penetration scenario assumes a 20-year saturation time and relatively shorter replacement/rebuild cycles for Tomlinson boilers. The "Low" scenario assumes a 30-year saturation time and longer replacement/rebuild cycles. The

\footnotetext{
${ }^{54}$ Defined as the time required to go from a market penetration of $10 \%$ to $90 \%$ of the technical potential.

${ }^{55}$ The use of $\mathrm{ClO}_{2}$ took 55 years to fully penetrate into the US industry (from early ' 50 s to today). Similarly, oxygen delignification started in the 1970s and now has penetrated about $40 \%$ of the US industry. By comparison, in Finland it only took about 5 years to reach $100 \%$ penetration [146].

${ }^{56}$ For example, the Energy Policy Act of 2005 contains significant gasification-related incentives. 122
} 
"Aggressive" scenario assumes the same replacement/rebuild cycle as the Base scenario, but a 10-year saturation time. While this saturation time is more typical of rapid-payback, discretionary-spending investments, it is used here to illustrate what might be possible with the right set of circumstances. It can also be used to represent a situation in which peak oil has been reached or the United States' government takes more proactive measures to reduce GHG emissions than has been the case to date.

In all cases, the ultimate penetration of the technology is assumed to be $90 \%$ of the total industry capacity, to reflect the fact that some mills will never adopt biorefinery technology. The final element of the market penetration analysis is to apply a reasonable growth rate to the industry. Based on historical data and near-term forecasts provided by the AF\&PA, a growth rate of $1.27 \%$ per year was assumed, as noted earlier.

The assumptions in Table 33 give the market penetration estimates (in million lbs/day black liquor solids capacity) in Figure 90 used to assess the potential national impacts of biorefinery technologies in the United States. To avoid "graph-overload" in this volume of the report, only the results of selected impact calculations are shown in this volume. A complete set of impact analysis results is provided in Volume 3.

Table 33: Summary of biorefinery market penetration scenarios developed in this study.

\begin{tabular}{|c|c|c|c|}
\hline & $\begin{array}{l}\text { Low } \\
\text { Scenario }\end{array}$ & $\begin{array}{l}\text { Base } \\
\text { Scenario }\end{array}$ & Aggressive Scenario \\
\hline $\begin{array}{l}\text { Technical Market } \\
\text { Potential }^{\mathrm{a}}\end{array}$ & \multicolumn{3}{|c|}{$\begin{array}{l}\text { - } 180 \text { operable recovery boilers } \\
\text { - Combined capacity of } \sim 472 \text { million lbs/day dry solids ( } \sim 66 \text { million t/yr) }\end{array}$} \\
\hline Ultimate Adoption Rate & \multicolumn{3}{|c|}{ - $90 \%$ of the technical market potential } \\
\hline Industry Growth & \multicolumn{3}{|c|}{ - $1.27 \%$ per year, based on total black liquor capacity } \\
\hline Basis & \multicolumn{2}{|c|}{$\begin{array}{l}\text { - Traditional market penetration } \\
\text { "S" curve for capital intensive, } \\
\text { facility-level investments }\end{array}$} & $\begin{array}{l}\text { - Aggressive penetration curve } \\
\text { assuming that normal rules of } \\
\text { market penetration may not apply } \\
\text { due to the age of the Tomlinson } \\
\text { boiler fleet and other market drivers } \\
\text { (see main text for discussion) }\end{array}$ \\
\hline Saturation Time (years) ${ }^{\text {b }}$ & 30 & 20 & 10 \\
\hline $\begin{array}{l}\text { Age of "New" boilers } \\
\text { when replacement with } \\
\text { BLGCC is considered }\end{array}$ & 35 & 30 & 30 \\
\hline $\begin{array}{l}\text { Age of "Rebuilt" boilers } \\
\text { when replacement with } \\
\text { BLGCC is considered }\end{array}$ & 15 & 10 & 10 \\
\hline
\end{tabular}

(a) Because additional industry consolidation and mill closures are expected, and few if any new mills are likely to be built, the analysis is based on total capacity rather than number of mills.

(b) Defined as the time required to go from $10 \%$ penetration to $90 \%$ penetration.

An important consideration for the Aggressive market penetration scenario is whether or not this rate of deployment would be achievable in practice. At its peak rate of deployment (around the year 2018-2019 - see Figure 90), there would be capacity equivalent to 14 case study mills undergoing conversion to biorefineries, with a combined biofuels capacity of 190-970 million gallons/yr, depending on the configuration. The associated capital investment at that point of 
peak deployment would be approximately $\$ 3.5-6.6$ billion, or $\$ 1.6-4.7$ billion more than building new Tomlinson systems instead. The total cumulative 25 -year investment would be approximately \$24-45 billion (\$11-32 billion incremental to the cost of new Tomlinsons), or an average of about \$1.0-1.8 billion per year (\$0.4-1.3 billion incremental to new Tomlinsons). While these are large numbers, the current biofuels "boom" suggests that they are within the ability of the financial community ${ }^{57}$ to support. Consider the following recent statistics: ${ }^{.5}$

- As of October 2006, there were 45 corn-ethanol plants under construction, plus 7 expansions, for a total of $\sim 3.4$ billion gallons of capacity under construction.

- As of September 2006, there were 65 biodiesel plants under construction, plus 13 expansions, for a total of $\sim 1.4$ billion gallons of capacity under construction.

Assuming typical investment requirements of \$1-1.5 per gallon/year of ethanol capacity and \$0.80-1.0 per gallon/year of biodiesel capacity, the current round of biofuels plant construction in the United States involves an investment of \$4.5-6.5 billion. Thus, based on the number of facilities under construction, the combined capacity and the combined investment, even the Aggressive market penetration scenario appears feasible. There may be other factors that limit the rate of deployment, but for projects with attractive economics, access to capital does not appear to be a constraint, especially when one considers the current biofuels investments in the context of the much larger concurrent investments being made in renewable energy more broadly.

\subsection{Energy and Environmental Impacts}

There are a variety of potential energy and environmental impacts that could result from commercial deployment of pulp mill biorefinery systems, including fossil fuel savings, emissions reductions, economic development, job retention, and improved industry competitiveness. Easily quantifiable national benefits include total fossil fuel energy savings and greenhouse gas reductions. A more difficult benefit to quantify is the value of spin-offs from the R\&D that would be required to bring the pulp mill biorefinery technologies to market, but these developments could have far-reaching impacts on the bioenergy and biofuels industry more broadly, which, at the time of writing, is undergoing significant expansion and change.

The following national impacts are discussed in detail below:

- Fossil energy savings

- Renewable energy markets

- Emissions reductions

- Energy security and fuel diversity

- Economic development

- Reaping the benefits of government RD\&D

\subsubsection{Fossil Fuel Energy Savings}

Fossil fuel displacement is a strategic, national-level benefit that is relatively straight-forward to estimate. The benefits of fossil fuel displacement include the associated emissions reductions, the conservation of finite resources, the positive effects on fossil fuel price volatility, and in the case

\footnotetext{
${ }^{57}$ This includes traditional lenders, investment banks and private equity, all of whom have been investing in ethanol and biodiesel production capacity in the United States.

${ }^{58}$ Renewable Fuels Association and National Biodiesel Board websites, accessed October 2006. 
of petroleum, the reduction of imports, which enhances energy supply security. Generally, an economy that is less dependent on fossil fuels is less susceptible to the negative impacts of fuel price volatility, which has increased in recent years.

National fossil energy savings are estimated relative to the continued use of Tomlinson technology with the same degree of industry growth and assuming displaced grid electricity generation results in savings based on the average utility fuel mix and heat rate (which change over time - see Table 18). No improvement in mill energy efficiency over time is considered, which is likely conservative.

Figure 91 shows that pulp/paper mill biorefineries, relative to Tomlinson systems, have the potential to offset anywhere from about 200 to 1,200 trillion Btu/year (0.2 to 1.2 quads/yr) within 25 years of introduction (Aggressive market penetration scenario), depending on the biorefinery configuration being considered. These reductions are net reductions and consider all the fossil fuel use at the mill and the fossil fuel savings from displaced grid power and conventional transportation fuels. The BLGCC and DMEa cases provide the least fossil fuel savings because they involve the lowest level of purchased biomass use. FTb produces the largest impacts due to the large amount of biomass used and the quantity of grid power displaced, owing to the importance of coal in power generation.

Figure 90: Market penetration estimates used to assess energy and environmental impacts of biorefinery implementation in the United States.

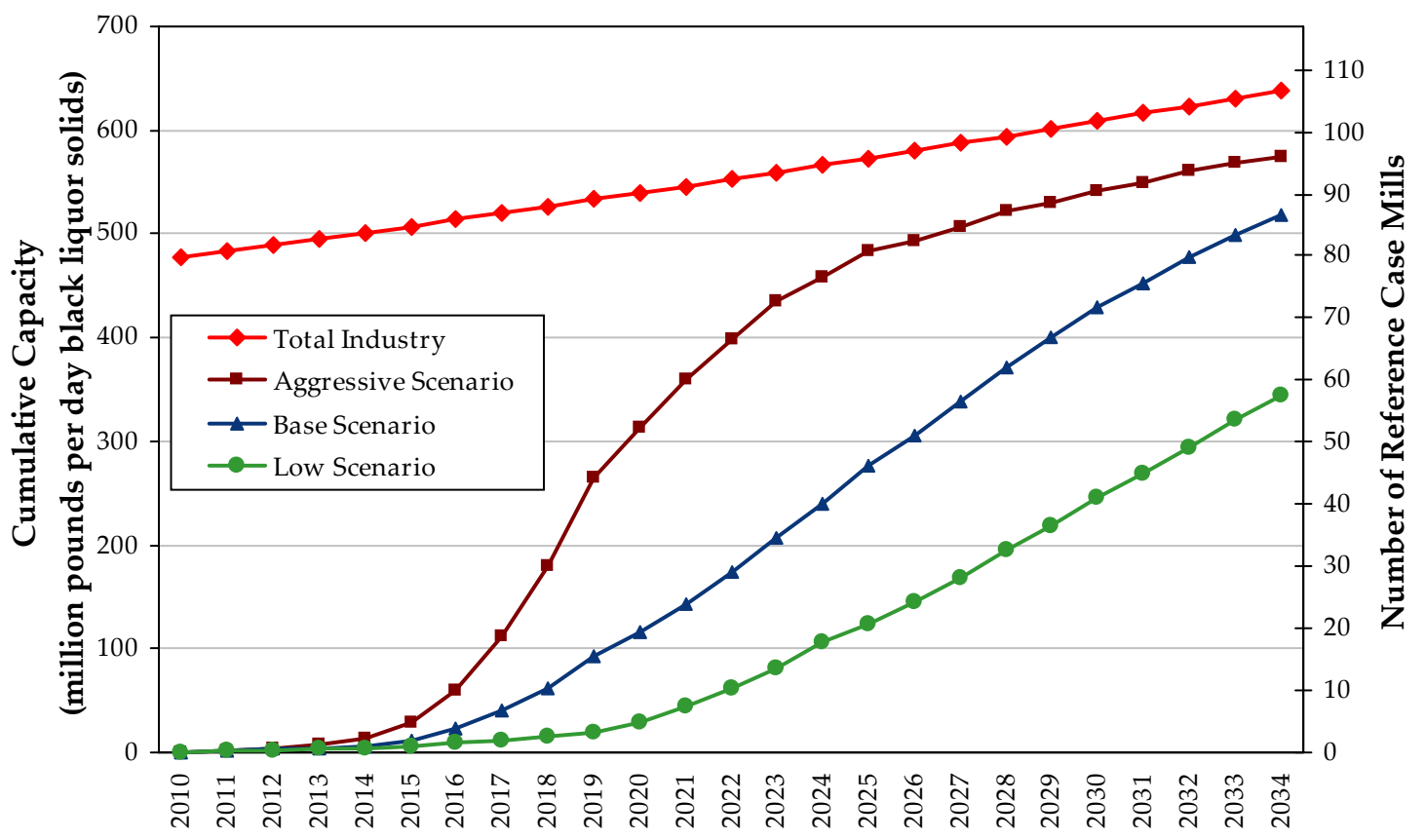


Figure 91: Net national fossil fuel savings relative to continued use of Tomlinson systems for the Aggressive biorefinery market penetration scenario.

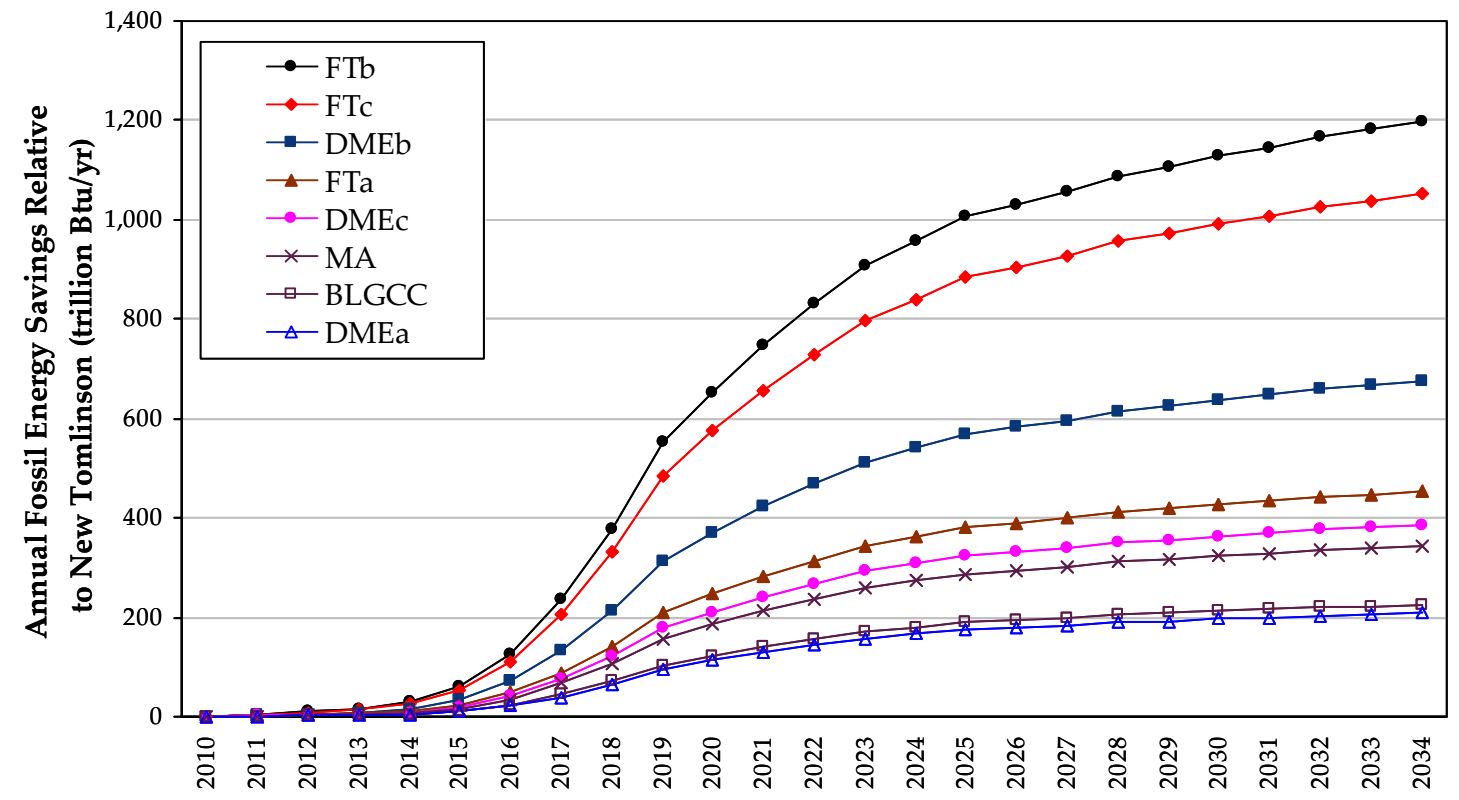

Note: Transportation of the crude FT product to the oil refinery included in FT cases.

Note on vehicle end use: FT cases assume FT gasoline blend in gasoline engines and FT diesel blend in CIDI engines. MA case assumes low-level blend with gasoline.

Figure 92 shows the cumulative fossil fuel savings in the three market penetration scenarios over the first 25 years following introduction. Net fossil fuel savings relative to continued use of Tomlinson systems range from 1 to 5.5 quads (Low scenario) up to 3 to 17 quads (Aggressive scenario). As noted above, this analysis assumes constant energy efficiency in pulp and paper manufacturing. Reductions in manufacturing energy intensities would lead to higher net energy savings than estimated here. ${ }^{59}$ The difference between the Low and Aggressive market penetration scenarios can be thought of as a proxy for the "lost" fossil fuel savings if implementation of pulp mill biorefineries is delayed. Alternatively the difference between the two scenarios might be viewed as the payoff on government support for more aggressive commercialization of biorefinery technologies.

\footnotetext{
${ }^{59}$ The case-study integrated pulp and paper mill in this analysis is relatively efficient (e.g., with process steam use about $10 \%$ lower than typical "best practice" in the U.S. industry today), but no additional efficiency gains are assumed over the 25 year analysis period. Efficiency gains could: (i) reduce or eliminate the need for fossil fuel use in the mill, such as lime kiln fuel, or reduce the need for purchased wood wastes; (ii) enable greater electricity generation from the same amount of renewale energy inputs; (iii) reduce mill electricity demand, enabling greater power exports. All of these benefits would translate directly to increased energy and emissions benefits, in addition to cost savings to the mill.
} 
Figure 92: Cumulative (25-year) national net fossil fuel savings relative to continued use of Tomlinson systems under different biorefinery market penetration scenarios.

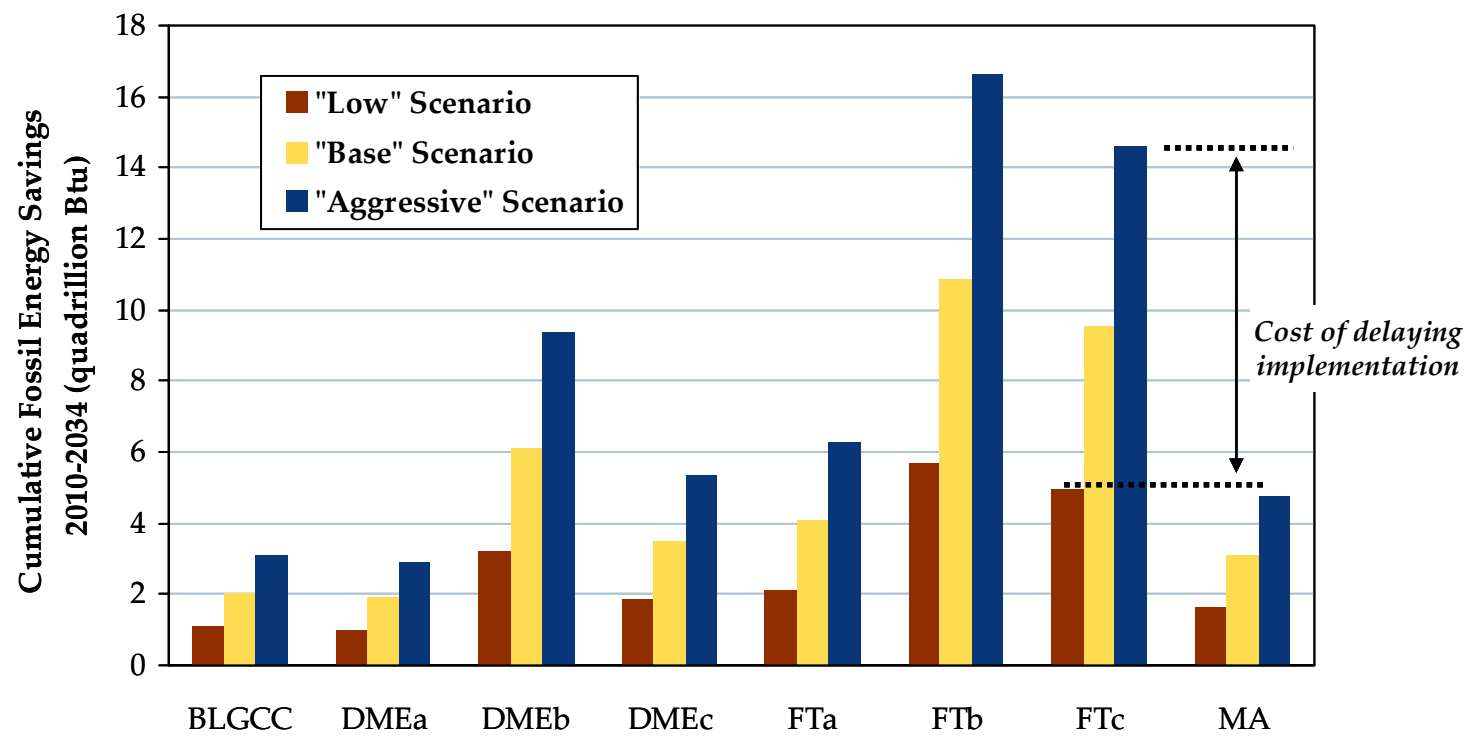

Note: Assumes that DME substitutes for diesel and that FT gasoline, FT diesel and Mixed Alcohols are used in lowlevel blends with conventional fuels.

\subsubsection{Renewable Energy Markets}

Distinct markets for renewable energy and its associated attributes are developing in the United States and elsewhere. In many cases the structure of the programs and markets effectively create markets for the attributes of renewable energy that are separate from energy markets, adding a second revenue stream for renewable energy producers. These markets may be regional, national or even international (e.g., with carbon trading). These markets are both voluntary and mandatory in nature. Voluntary markets are those in which renewables are cost competitive with conventional options (including the effects of financial incentives, if any), or consumers are willing to pay a premium for renewable energy, such as with green power. While these markets are growing in importance, the main driver that has emerged for renewable energy markets are various mandates: Renewable Portfolio Standards (RPS) for power generation and Renewable Fuel Standards (RFS) for transportation fuels. RPS mandates, currently in place in more than 20 states, if fully implemented will result in the addition of approximately 30,000 MW of new renewable generating capacity from 2003 to 2015. The Federal RFS, which basically replaces the Federal mandate for oxygenates in reformulated gasoline, targets a total consumption of 7.5 billion gallons of biofuels by 2012, almost double the 4 billion gallons produced in 2005. In addition, a growing number of states are setting their own biofuels targets. Emissions trading is another compliance-type market that is established in the United States for $\mathrm{SO}_{2}$ and $\mathrm{NO}_{\mathrm{x}}$. Emerging trading regimes for $\mathrm{CO}_{2}$ and other mechanisms that bring renewable energy projects into existing trading schemes, such as "set-aside" programs, could create additional value for renewable power and fuels in the future. ${ }^{60}$ These cap-and-trade regimes also increase the cost of conventional energy, which benefits renewable energy indirectly.

\footnotetext{
${ }^{60}$ Renewable "set-asides" are essentially free emissions allowances created by regulatory mechanisms and given to renewable energy producers, who can sell them in the marketplace to those who need allowances to operate. Because biomass is not an emissions-free source of power, it does not always qualify for set-aside allowances.
} 
Although compliance markets are very important, from a pulp/paper industry perspective it is important to note several issues:

- Most of the US pulp mill capacity is located in the Southeast. Currently, no Southeast US states have RPS, and several attempts to pass a Federal RPS have failed.

- The Federal RFS targets are actually quite modest and are likely to be met well before 2012 . If that occurs, the economic value of the RFS is expected to be minimal, unless targets are increased, which is under consideration by Congress.

- Biomass is not always RPS eligible, and even if it is, the definitions of eligible biomass resources and technologies vary, with black liquor not always considered a qualifying fuel for RPS compliance. However, gasification generally meets criteria for "advanced technology" in states where such criteria exist.

Biomass is potentially the most significant renewable energy resource in certain parts of the country, including the Southeast and Northeast, and is also very important in the Northwest and potentially in the Midwest (with the Midwest being driven more by agriculture than forest products). Given that the pulp and paper industry is the largest single industrial user of biomass for energy, biorefineries could play an important role in meeting current and future RPS and RFS mandates.

To illustrate the value of biorefineries in this context, Table 34 shows the technical potential of the pulp/paper industry to contribute to the current national RFS. The table does not factor in market penetration, but rather shows the maximum contribution possible. The contribution could vary considerably depending on the market penetration rate, but this analysis shows the contribution with the current size of the industry (2010 columns in the table) could be between $18 \%$ and $92 \%$ of the current RFS target for 2012 . With a larger scale pulp mill biorefinery industry (2034 columns in the table), that figure could range from about $24 \%$ to $123 \%$. Note that these are based on actual volumes, not corrected for energy content. Some additional points of comparison are worth noting:

- In 2005, U.S. ethanol and biodiesel production were approximately 4 billion and 75 million gallons, respectively

- Annual U.S. gasoline + diesel consumption is currently about 170 billion gallons

- U.S. crude oil imports from OPEC countries in 2005 averaged approximately 5.6 million barrels/day, or about 86 billion gallons per year.

- Total U.S. crude oil imports from all countries in 2005 averaged approximately 13.7 million barrels/day, or about 210 billion gallons per year.

- Total U.S. petroleum consumption in 2005 averaged approximately 21 million barrels per day, or about 322 billion gallons per year.

In this context, it is clear that pulpmill biorefineries have the potential to be major contributors to biofuels supply, but the magnitude of the current U.S. petroleum consumption suggests that pulpmill biorefineries are likely to be able to contribute less than $5 \%$ to overall petroleum usage. 
Table 34. Biofuel production potential (billion gal/year) for different biorefinery configurations. ${ }^{a}$ These are actual volumes, not corrected for energy content, and are for the total industry. The estimates are total technical potential and do not consider any market penetration scenario. The current RFS target is 7.5 billion gallons by 2012 .

\begin{tabular}{|c|c|c|c|c|c|c|c|c|c|}
\hline & \multicolumn{4}{|c|}{ For forecast 2010 pulp/paper industry size ${ }^{b}$} & \multicolumn{4}{|c|}{ For forecast 2034 pulp/paper industry size ${ }^{c}$} & \multirow{2}{*}{$\begin{array}{c}\text { Gallons of } \\
\text { liquid fuel } \\
\text { per net ton } \\
\text { purchased } \\
\text { biomass }^{\mathrm{e}}\end{array}$} \\
\hline & $\begin{array}{c}\text { Billion } \\
\text { galyr }\end{array}$ & $\begin{array}{c}\% \text { of } \\
\text { Current } \\
2012 \text { RFS } \\
\text { Target }\end{array}$ & $\begin{array}{c}\text { Biomass } \\
\text { Energy } \\
\text { Purchases } \\
\left(10^{6} \text { dry } t / y r\right)\end{array}$ & $\begin{array}{c}\text { Net } \\
\text { Biomass } \\
\text { Required } \\
\left(10^{6} \text { dry t/yr }\right)^{d}\end{array}$ & $\begin{array}{c}\text { Billion } \\
\text { gal/yr }\end{array}$ & $\begin{array}{c}\% \text { of } \\
\text { Current } \\
2012 \text { RFS } \\
\text { Target }\end{array}$ & $\begin{array}{l}\text { Biomass } \\
\text { Energy } \\
\text { Purchases } \\
\left(10^{6} \text { dry t/yr) }\right.\end{array}$ & $\begin{array}{c}\text { Net } \\
\text { Biomass } \\
\text { Required } \\
\left(\mathbf{1 0}^{6} \text { dry t/yr }\right)^{d}\end{array}$ & \\
\hline DMEa & 5.5 & $74 \%$ & 12.6 & 5.7 & 7.4 & $98 \%$ & 16.8 & 7.6 & $\sim 440$ \\
\hline DMEb & 5.5 & $74 \%$ & 31.7 & 24.8 & 7.4 & $98 \%$ & 42.4 & 33.2 & $\sim 175$ \\
\hline DMEc & 2.4 & $33 \%$ & 11.9 & 5.0 & 3.3 & $43 \%$ & 15.9 & 6.7 & $\sim 210$ \\
\hline FTa & 2.3 & $30 \%$ & 16.5 & 9.6 & 3.0 & $40 \%$ & 22.1 & 12.9 & $\sim 140$ \\
\hline FTb & 2.3 & $30 \%$ & 59.8 & 52.9 & 3.0 & $40 \%$ & 80.0 & 70.8 & $\sim 40$ \\
\hline FTc & 6.9 & $92 \%$ & 73.2 & 66.4 & 9.3 & $123 \%$ & 97.9 & 88.7 & $\sim 95$ \\
\hline MA & 1.3 & $18 \%$ & 14.5 & 7.6 & 1.8 & $24 \%$ & 19.4 & 10.2 & $\sim 90$ \\
\hline
\end{tabular}

(a) These are actual volumes, not corrected for energy content, and are for the total industry, based on the assumed annual capacity factor of the biorefineries. The estimates are total technical potential and do not consider any market penetration scenario. The current RFS target is 7.5 billion gallons by 2012 .

(b) The current size (2006) is slightly smaller. Figures here are based on the assumption of an annual growth rate of $1.27 \%$.

(c) Figures here are based on the assumption of an annual growth rate of $1.27 \%$.

(d) This is the total biomass (short tons) required after subtracting pulpwood savings from polysulfide pulping. These are for the entire biorefinery, including for pulpwood and for energy.

(e) This is the total annual liquid fuel production shown in this table divided by the total annual biomass purchases for energy shown in this table.

Table 34 also shows the annual wood requirements to produce these volumes of biofuels. In the highest case (FTc), this approaches 100 million dry tons per year (though due to substantial savings in pulpwood that result from higher-yielding pulping enabled by the use of black liquor gasification, the net wood requirement is less than the total biomass energy purchases). As a result of integrating the biorefinery with the pulp mill, the liquid fuel produced per unit of purchased wood energy (right-hand column of Table 34) is high in most cases, indicating very efficient use of the biomass resource.

To put in perspective the 100 million tons/year of biomass energy required, it is helpful to compare them to the amount of woody biomass available from existing forests as estimated in the "billion ton study" [1]. That study estimated that existing forests can sustainably provide 368 million dry tons per year of woody biomass. This includes approximately 142 million dry tons currently being used. Thus, there is an estimated 226 million dry tons of additional biomass available, more than twice the requirements of the most aggressive case we have examined. It is also worthwhile to note that the estimated U.S. forest standing inventory is in excess of 20 billion dry tons, such that 100 million dry tons/yr is less than $0.5 \%$ of the standing inventory, and a smaller figure than the expected net annual growth [1]. The figure of 100 million tons is also considerably lower than the estimate in [1] of the agricultural biomass available from perennial crops (as much as 377 million dry tons/yr) and crop residues (as much as 46 million dry tons/yr). 
Thus, even aggressive deployment of pulpmill biorefineries appears feasible without placing undue pressure on forest land usage or current agricultural commodities.

In addition, certain biorefinery configurations studied here produce significant amounts of power, in particular FTb, although other configurations could also be set up with a large power component through the use of additional biomass. If a national RPS were to be put in place or if Southeast states begin to adopt RPS or otherwise promote renewable energy development, biorefineries could also play a role in meeting the overall targets and would also ensure that many of the benefits of renewable energy (e.g., reduced emissions and local economic development) would be more evenly distributed around the country. ${ }^{61}$ Table 35 shows the potential contributions. Since power was not a major design criterion in most of our biorefinery configurations, the net increase in generation over continued use of Tomlinson systems is 1,0002,000 MW, whereas the BLGCC case provides a net increase of 4,600-6,200 MW. But FTb, which does emphasize power generation, would result in an increase of 15,000-20,000 MW while still producing 2.6-3.5 billion gallons of fuel annually.

The relative value of power versus fuels in the context of multiple, potentially competing, renewable energy mandates is likely to influence decisions relating to the biorefinery product slate and the desire to build some flexibility into that product slate, in order to take advantage of changes over time in markets for power versus fuels. There may also be regional differences driven by the existence and aggressiveness of state RPS mandates relative to regional transportation fuel requirements.

\subsubsection{National Emissions Reductions}

Here the potential national emissions impacts are discussed and illustrated for the Aggressive market penetration scenario. The impacts are similar for the other two market penetration scenarios, but generally reduced in proportion to the rate of market penetration. (See Volume 3.) The key assumptions used to generate these results include:

- Emissions savings estimates are made relative to continued use of Tomlinson systems for the same degree of market penetration and industry growth, i.e., the estimates show the difference between Tomlinson and biorefinery systems. ${ }^{62}$

- Estimates include all mill-level emissions sources, net offsets from grid power and the net impacts from the rest of the biofuels and conventional fuel chains, as discussed earlier.

- Grid-power emissions change over time (see Table 18) in line with expected changes in fuel mix and emissions as forecast by the DOE [134].

- Vehicle emissions and related fuel chain emissions are those consistent with the 2010 timeframe.

- $\mathrm{CO}_{2}$ emissions shown here exclude the $\mathrm{CO}_{2}$ originating from biomass. Refer to Volume 3 for quantification of biomass-associated $\mathrm{CO}_{2}$ emissions.

\footnotetext{
${ }^{61}$ Wind power is the leading source for new renewable energy today and would likely play a major role in meeting any future Federal RPS. However, good wind power sites are distributed unevenly across the country, which could turn some regions into major exporters of RECs and others into importers. In contrast, biomass is more evenly distributed across the country, and in fact some regions that are richer in biomass (e.g., Northwest, Southeast, Northeast) are actually poorer in wind potential.

${ }^{62}$ Even if the industry were to never deploy biorefinery technology, as the industry grows it will generate more power internally and therefore offset additional grid power. This "moving baseline" forms the basis for evaluating the incremental impacts of biorefineries. 
- Estimates do not assume any improvements in mill efficiency over time, which may be a conservative assumption (i.e., as mill efficiency improves more energy is available for power and biofuels production). ${ }^{59}$

Table 35. Power production potential (MW) for different biorefinery configurations - incremental power production relative to continued use of Tomlinson technology. ${ }^{a}$

\begin{tabular}{|l|c|c|c|}
\cline { 2 - 4 } \multicolumn{1}{c|}{} & $\begin{array}{c}\text { Net Incremental } \\
\text { Generation per } \\
\text { mill (MW) }\end{array}$ & $\begin{array}{c}\text { Total Pulp/Paper } \\
\text { Industry in 2010 } \\
\text { (MW) }^{\mathbf{c}}\end{array}$ & $\begin{array}{c}\text { Total Pulp/Paper } \\
\text { Industry in 2034 } \\
\text { (MW) }^{\mathbf{d}}\end{array}$ \\
\hline BLGCC & 50 & 4,618 & 6,176 \\
\hline DMEa & $(64)$ & $(5,909)$ & $(7,901)$ \\
\hline DMEb & 24 & 2,184 & 2,920 \\
\hline FTa & 26 & 2,433 & 3,254 \\
\hline FTb & 165 & 2,168 & 2,899 \\
\hline FTC & 13 & 15,258 & 20,404 \\
\hline MA & 28 & 2,206 & 1,613 \\
\hline
\end{tabular}

(a) These estimates are for the total industry and represent the technical potential without consideration of any market penetration scenario.

(b) From Table 12.

(c) The current size (2006) is slightly smaller. Figures here are based on the assumption of an annual growth rate of $1.27 \%$.

(d) Figures here are based on the assumption of an annual growth rate of $1.27 \%$.

Figure 93 illustrates the potential net national $\mathrm{CO}_{2}$ emissions benefits of biorefineries for the Aggressive market penetration scenario. Our pulp mill biorefinery designs, relative to continued use of Tomlinson technology, have the potential to offset as much as 110 million short tons of $\mathrm{CO}_{2}$ per year. This is equivalent to about $5 \%$ of the transportation sector $\mathrm{CO}_{2}$ emissions in the U.S. in 2004. The main driver affecting the amount of $\mathrm{CO}_{2}$ benefit is the amount of biomass used, but in comparing FTb to FTc, which use similar quantities of purchased biomass, electricity displacement results in greater $\mathrm{CO}_{2}$ reductions per unit of biomass consumed than petroleum fuel displacement. 
Figure 93. Net annual national $\mathrm{CO}_{2}$ emissions reductions relative to continued use of Tomlinson systems under the Aggressive biorefinery market penetration scenario.

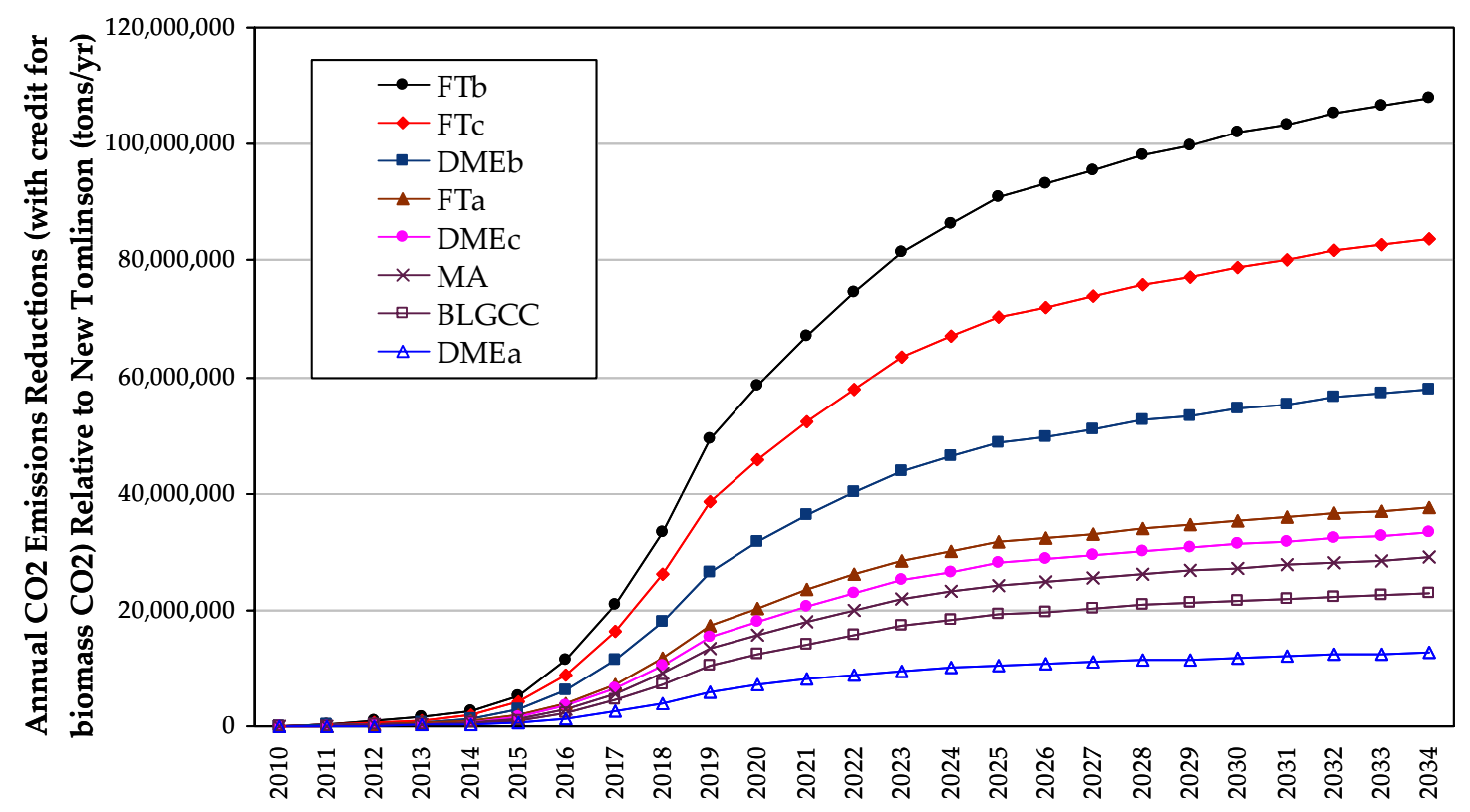

Transportation of the crude FT product to the oil refinery included in FT cases.

Note: excludes any emissions from land use changes and biomass growth that are not related to harvesting and transportation. Note on vehicle end use: FT cases assume FT gasoline blend in gasoline engines and FT diesel blend in CIDI engines. MA case assumes low-level blend with gasoline.

Figure 94 illustrates the potential net national $\mathrm{SO}_{2}$ emissions benefits of biorefineries for the Aggressive market penetration scenario. The picture is quite different than for $\mathrm{CO}_{2}$ for two reasons. First, conventional transportation fuel chains do not produce significant quantities of $\mathrm{SO}_{2}$. Second, as $\mathrm{SO}_{2}$ emissions from grid power decrease over time, so do the net annual reductions, particularly for configurations that generate a lot of power, like BLGCC and FTb. In fact, over time, if the grid achieves the levels of $\mathrm{SO}_{2}$ reductions projected in the DOE forecast, then for $\mathrm{FTb}$, it could change from a net reduction of $\mathrm{SO}_{2}$ to net increase around the year 2030. Also, in cases where the additional biomass is used directly for power generation (all cases except FTc and MA), it is not subject to acid gas scrubbing. Therefore, all the sulfur in that biomass, although relatively low, is emitted as $\mathrm{SO}_{2}$.

Nevertheless, pulp mill biorefineries, relative to Tomlinson systems, have the potential to offset more than 30,000 tons of $\mathrm{SO}_{2}$ per year, although this level of reduction may not be sustainable given the foregoing discussion of grid $\mathrm{SO}_{2}$ emissions. 
Figure 94. Net annual national $\mathrm{SO}_{2}$ emissions reductions relative to continued use of Tomlinson systems under the Aggressive biorefinery market penetration scenario.

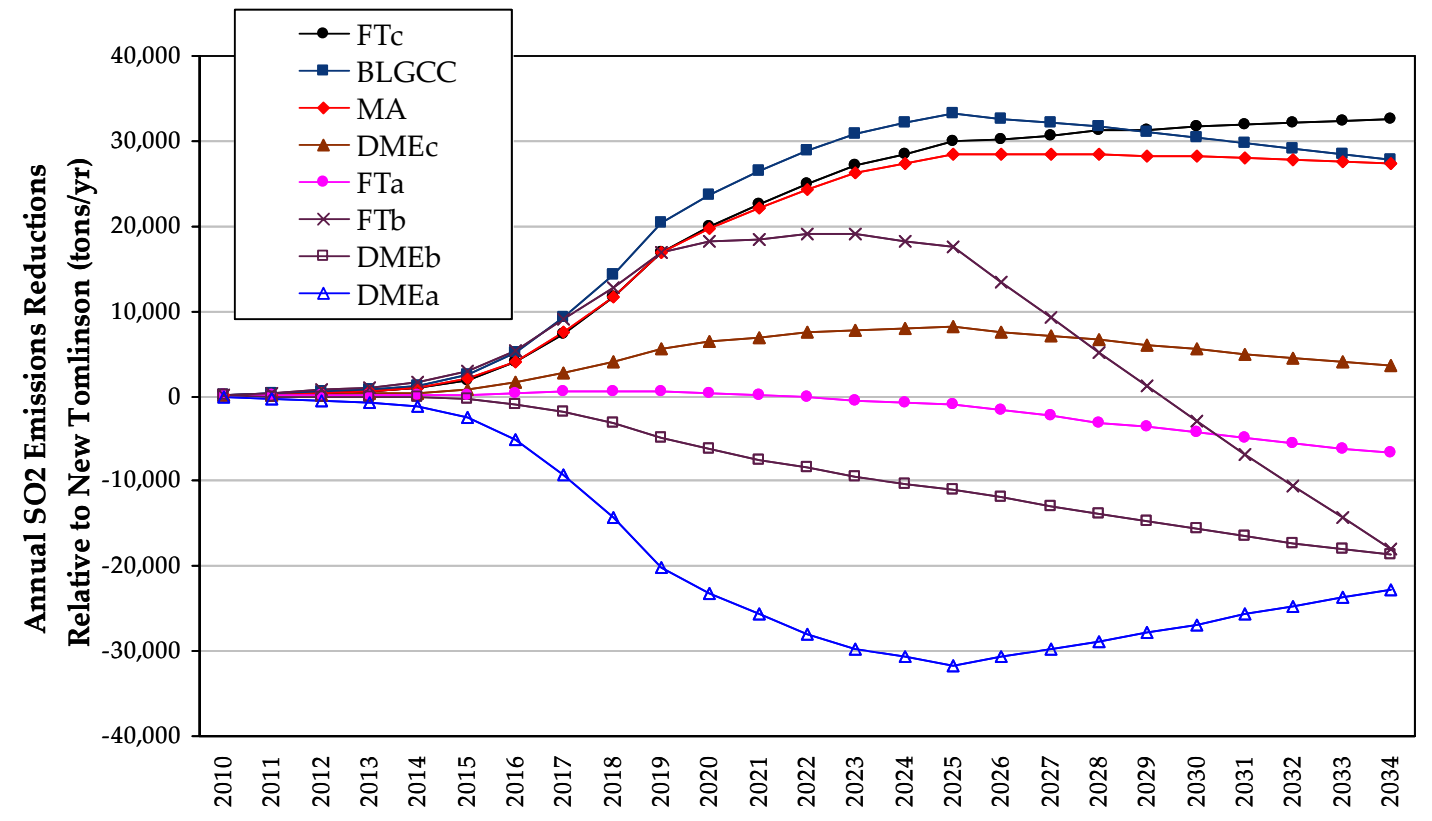

Transportation of the crude FT product to the oil refinery included in FT cases.

Note on vehicle end use: FT cases assume FT gasoline blend in gasoline engines and FT diesel blend in CIDI engines. MA case assumes low-level blend with gasoline.

Figure 95 illustrates the potential net national $\mathrm{NO}_{\mathrm{x}}$ emissions benefits of biorefineries for the Aggressive market penetration scenario. Pulp mill biorefineries, relative to continued use of Tomlinson systems, have the potential to offset up to nearly 90,000 tons of $\mathrm{NO}_{\mathrm{x}}$ per year. Displacement of both grid power and conventional fuels result in $\mathrm{NO}_{\mathrm{x}}$ benefits, but generally speaking, for the biorefinery configurations studied here, grid power is a greater source of emissions reductions, since gas-turbine-based generation has much lower $\mathrm{NO}_{\mathrm{x}}$ emissions than the grid average. Still, as with $\mathrm{SO}_{2}$, grid-based $\mathrm{NO}_{x}$ emissions are forecasted to fall significantly under the EPA CAIR program. For transportation fuels, DME results in lower tailpipe $\mathrm{NO}_{\mathrm{x}}$ emissions, whereas the use of mixed alcohols and FT fuels in low-level blends with gasoline or diesel are not expected to have significant $\mathrm{NO}_{\mathrm{x}}$ benefits. The impacts of using biofuels as neat fuels instead of in low-level blends is discussed later in this section and additional details are provided in Volume 3. Another consideration is that $\mathrm{NO}_{\mathrm{x}}$ emissions are higher for configurations that use large quantities of purchased biomass, because of the heavy duty vehicles used upstream to collect and deliver the biomass to the biorefinery. That is a key driver in the poorer net $\mathrm{NO}_{\mathrm{x}}$ results for FTb and FTc compared to FTa.

Figure 96 illustrates the potential net national VOC emissions benefits of biorefineries for the Aggressive market penetration scenario. Pulp mill biorefineries, relative to continued use of Tomlinson technology, have the potential to offset as much as 18,000 tons of VOCs per year. $\mathrm{DMEa}$ and DMEb fare well because DME handling is similar to propane and is a closed system so there are fewer fugitive emissions. Tailpipe VOC emissions can also be controlled with an oxidation catalyst. VOC emissions reductions for DMEc are lower because less DME is produced. For FTc and the remaining configurations, the main source of VOC reductions are in the conventional fuel chain upstream of the vehicle. Thus, FTc, which displaces the greatest 
amount of fuel results in the largest reductions. Estimates of VOC emissions from grid power and from the biorefinery fuel chains are small and so have less impact on the results.

Figure 95. Net annual national $\mathrm{NO}_{\mathrm{x}}$ emissions reductions relative to continued use of Tomlinson technology under the Aggressive biorefinery market penetration scenario.

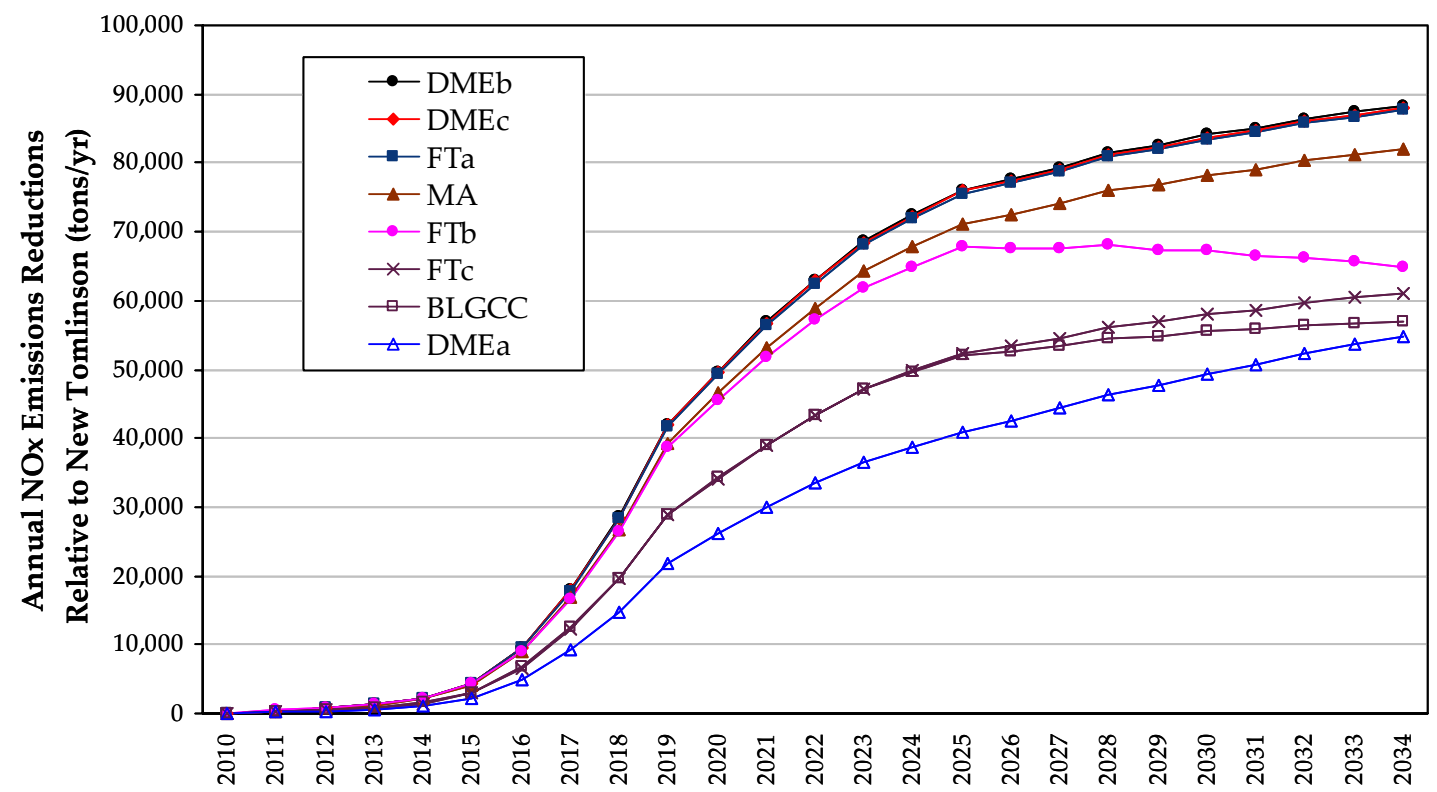

Transportation of the crude FT product to the oil refinery included in FT cases.

Note on vehicle end use: FT cases assume FT gasoline blend in gasoline engines and FT diesel blend in CIDI engines. MA case assumes low-level blend with gasoline.

Figure 96. Net annual national VOC emissions reductions relative to continued use of Tomlinson technology under the Aggressive biorefinery market penetration scenario.

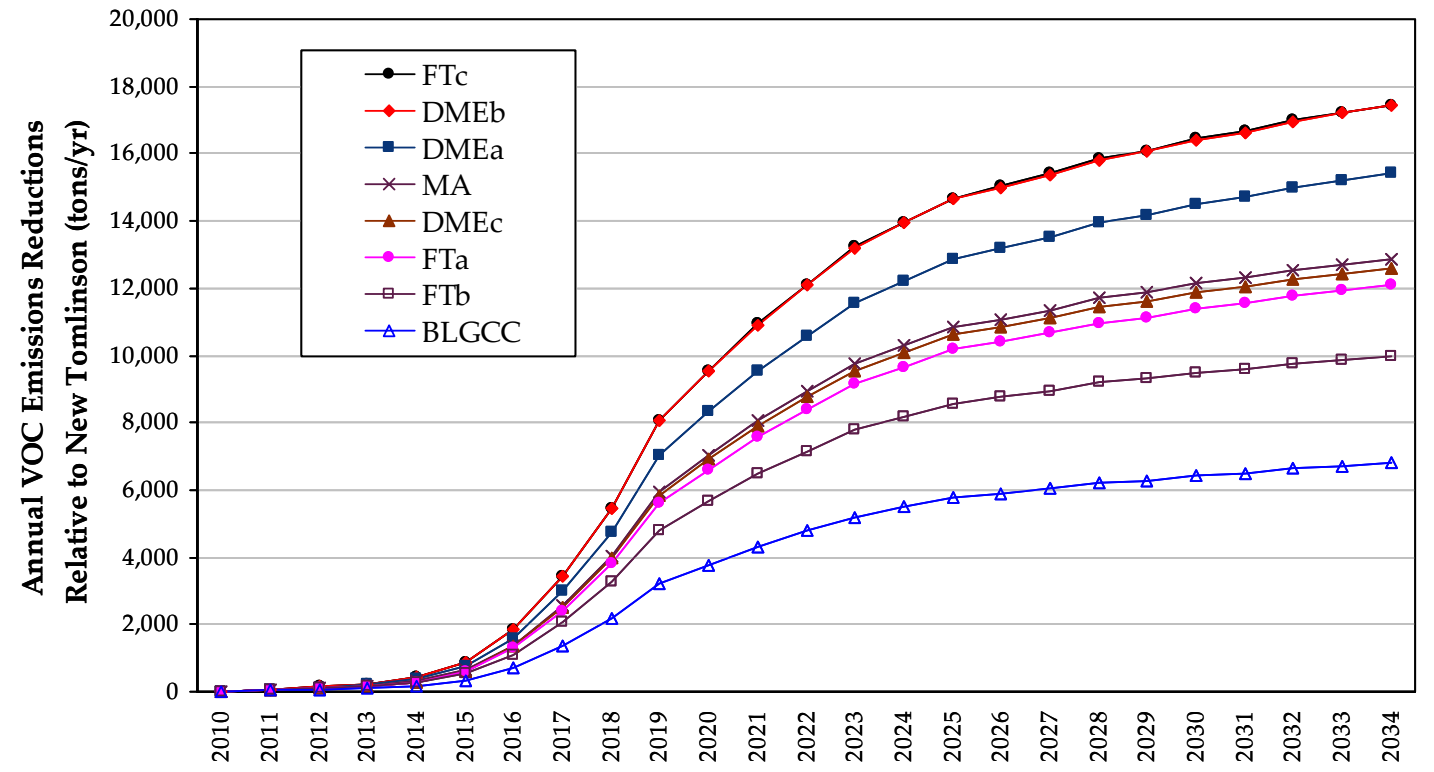

Transportation of the crude FT product to the oil refinery included in FT cases.

Note on vehicle end use: FT cases assume FT gasoline blend in gasoline engines and FT diesel blend in CIDI engines. MA case assumes low-level blend with gasoline. 
Figure 97 illustrates the potential net national $\mathrm{CO}$ emissions benefits of biorefineries for the Aggressive market penetration scenario. Pulp mill biorefineries, relative to continued use of Tomlinson systems, have the potential to offset as much as 140,000 tons of CO per year. With the exceptions of the BLGCC and DMEa configurations, the results are closely clustered regardless of the biofuels or relative mix of power and fuels. For BLGCC, grid power is already relatively low in CO emissions and for DMEa, the reductions from DME use are offset by the increased use of grid power. More importantly, for these two configurations, the use of hog fuel boilers for the additional biomass results in higher $\mathrm{CO}$ emissions than for those configurations that use biomass gasification.

Figure 97. Net annual national $\mathrm{CO}$ emissions reductions relative to continued use of Tomlinson technology under the Aggressive biorefinery market penetration scenario.

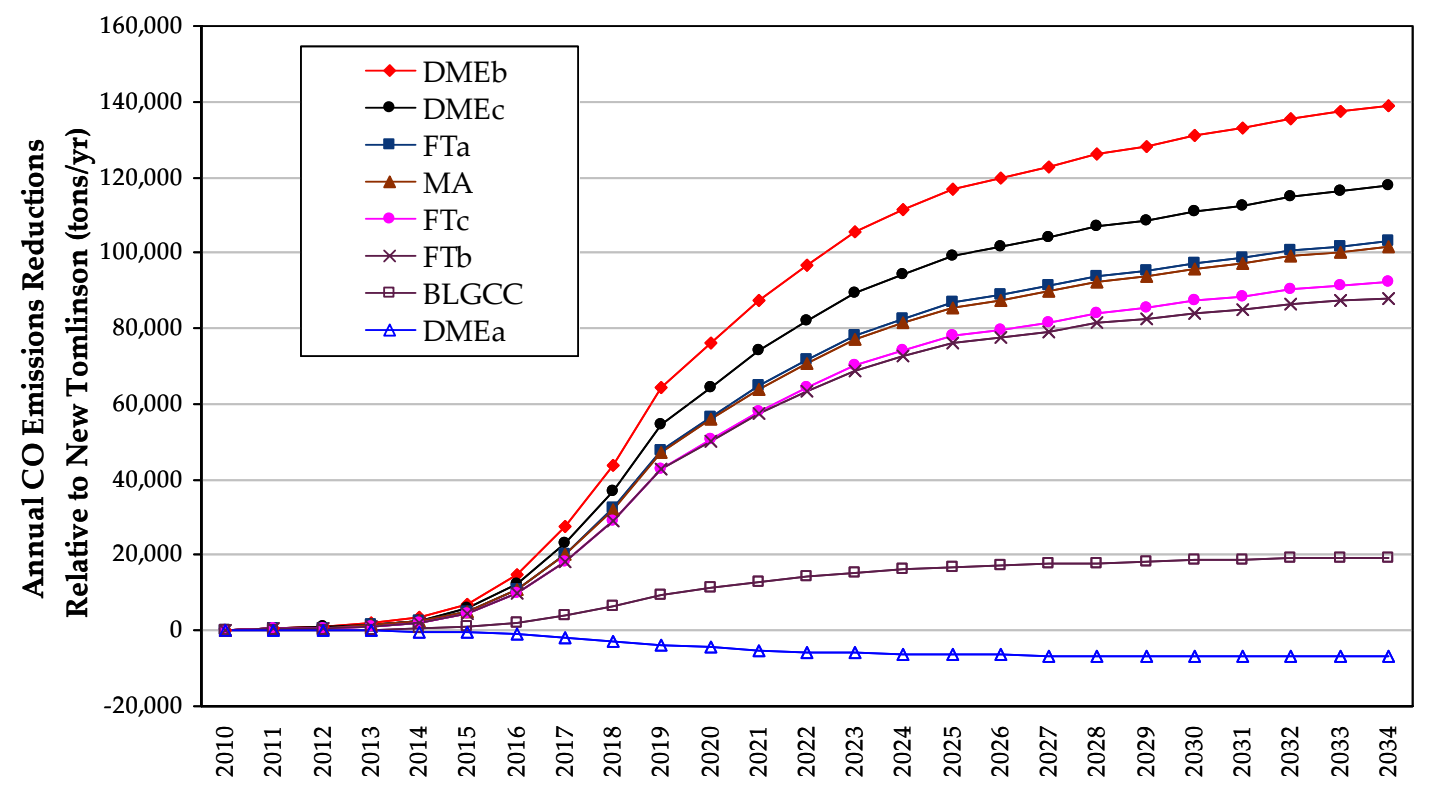

Transportation of the crude FT product to the oil refinery included in FT cases.

Note on vehicle end use: FT cases assume FT gasoline blend in gasoline engines and FT diesel blend in CIDI engines. MA case assumes low-level blend with gasoline.

Figure 98 illustrates the potential net national $\mathrm{PM}_{10}$ emissions benefits of biorefineries for the Aggressive market penetration scenario. Pulp mill biorefineries, relative to continued use of Tomlinson technology, have the potential to offset nearly 40,000 tons of $\mathrm{PM}_{10}$ emissions per year, depending on the configuration. Emissions reductions come from the displacement of both power and conventional transportation fuels, with the former generally being a more significant source of reductions. This is because the conventional vehicle $\mathrm{PM}_{10}$ emissions are assumed to be quite low. Also, $\mathrm{PM}_{10}$ emissions from vehicles include brake and tire wear, which are assumed to be the same in all cases. 
Figure 98. Net annual national $\mathrm{PM}_{10}$ emissions reductions relative to continued use of Tomlinson technology under the Aggressive biorefinery market penetration scenario.

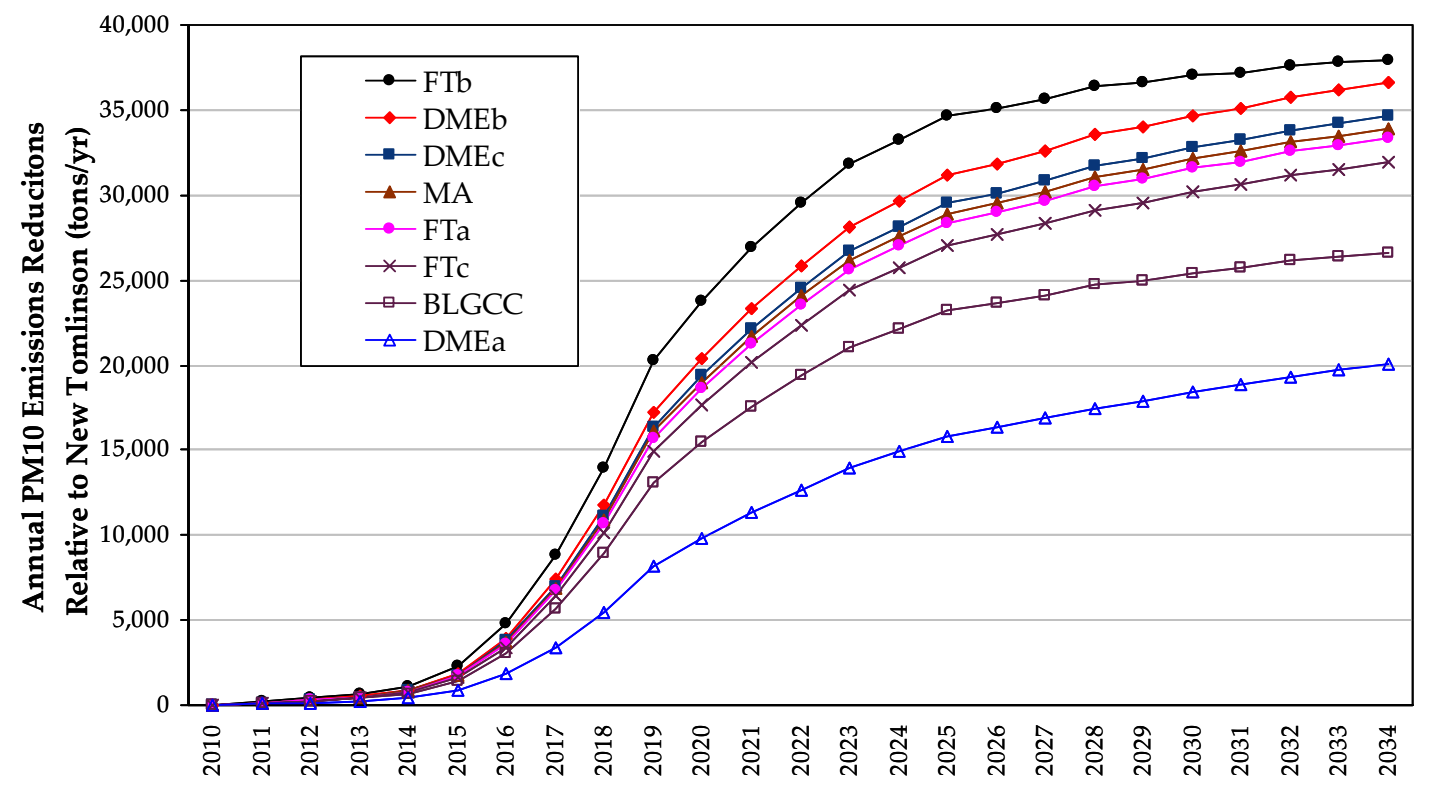

Transportation of the crude FT product to the oil refinery included in FT cases.

Note on vehicle end use: FT cases assume FT gasoline blend in gasoline engines and FT diesel blend in CIDI engines. MA case assumes low-level blend with gasoline.

Conversion to biorefineries is also expected to reduce TRS emissions. In the analysis presented here, the only sources of TRS are assumed to be the Tomlinson recovery boiler and the lime kiln. TRS emissions increase somewhat from the lime kiln due to increased load with black liquor gasification, but this is more than offset by the elimination of the Tomlinson boiler. Mill-level estimates were presented earlier in Section 6.7.7.

\subsubsection{Use of Neat Biofuels vs. Low-Level Blends}

All of the foregoing results assumed that mixed alcohols and FT biofuels were used in low-level blends with their conventional counterparts, for example a $10 \%$ blend of mixed alcohols with gasoline and a $10 \%$ blend of FT diesel with low-sulfur diesel. However, with some relatively minor engine modifications these fuels can also be used in either high-level blends or as neat $(100 \%)$ biofuels. Data are either limited or non-existent regarding light-duty vehicle performance on neat biofuels. Nevertheless, based on a review of the literature, it is reasonable to expect reductions in certain tailpipe emissions when vehicles are optimized for biofuels usage. Based on [130,131], the key emissions changes that could be expected are:

- VOC emissions: tailpipe VOCs may be further reduced (relative to those assumed in preparing Figure 96) when neat FT diesel is used instead of low-sulfur diesel. Also, evaporative VOC emissions should be lower when mixed alcohols are used in a flex fuel vehicle compared to gasoline vehicles.

- CO emissions: CO may be reduced (from levels indicated in Figure 97) when neat FT diesel is used instead of low-sulfur diesel.

- There would be modest reductions in $\mathrm{SO}_{2}$ and possibly $\mathrm{NO}_{\mathrm{x}}$, but these are expected to be minimal. 
Volume 3 provides the specific tailpipe emissions factors assumed and contains figures that show these potential reductions at the national level.

\subsubsection{Energy Security and Fuel Diversity}

The nation's transportation sector remains more than 95\% dependent of petroleum. No other sector of the economy is so dependent on a single energy source. Much has been written and said in recent months about the nation's "addiction to oil" and the resulting consequences, including environmental degradation, negative balance of trade, energy insecurity, and its distorting effect on foreign policy. It is not the objective here to provide a detailed accounting of these issues, but rather to highlight the fact that biorefineries offer the potential to diversify the fuel mix in transportation away from oil and towards a domestic renewable resource. Figure 99 shows that petroleum displacement represents a significant portion of the total fossil fuel displacement potential with biorefineries. Cumulative petroleum displacement could exceed 2.2 billion barrels of oil over a 25-year period under the Aggressive market penetration scenario. By the end of the forecast period, the corresponding annual petroleum savings in the FTc configuration (the one with the largest oil savings) would be approximately 165 million barrels per year, or 0.45 million barrels per day. This is equivalent to nearly $10 \%$ of the 2005 level of imports to the United States of oil from OPEC countries. As with the rest of the analysis here, the values shown include the net effects along the entire fuel chain, including, for example, the need to use petroleum in the transportation and distribution of biofuels.

Figure 99: Cumulative (25-year) national net fossil fuel and petroleum savings relative to continued use of Tomlinson systems under the Aggressive biorefinery market penetration scenario.

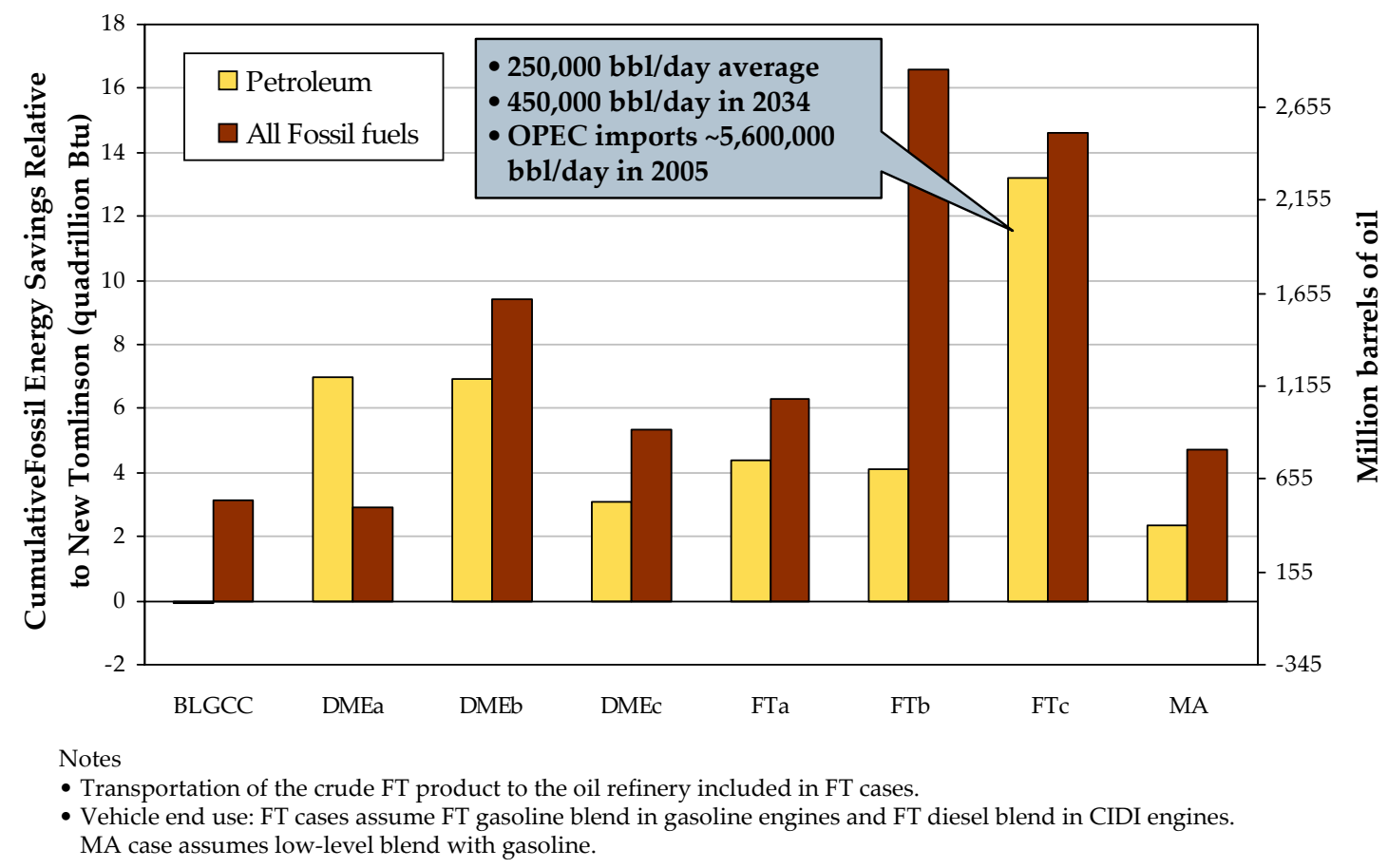

The nation's power sector uses a much more diverse fuel mix than the transportation sector, but it too is heavily dependent on fossil fuels, and has become increasingly dependent on gas-fired combined cycle technology for new power generation capacity. The shift to gas-fired GTCC technology has been driven by several factors, including low capital and operating costs, high 
efficiency, low emissions, rapid construction, and small footprint. These factors have made GTCC technology the lowest cost option for new power plants at the start of this century. They also greatly facilitate financing and siting relative to other central station generation options. However, the increasing reliance on natural gas has some important energy cost, fuel diversity and energy security implications:

- Natural-gas fired power plants will increasingly set the marginal price for power.

- Natural gas prices have risen significantly since the early 2000s and they have also been volatile and are expected to remain so, driven in part by increasing summer demand for power generation. ${ }^{63}$ As of mid-2006, natural gas spot prices remained well above historical long-term averages, and may remain there as natural gas demand grows and domestic production matures. With limited ability to import gas into North America, the United States will continue to be susceptible to the gas price volatility it has experienced in the last 2-3 years. $^{64}$

- In the post-9/11 world, natural gas supply infrastructure is seen as vulnerable to disruption by terrorist attack. Thus, the electric industry is vulnerable both directly (via attacks on electric infrastructure) and indirectly (via attacks on natural gas infrastructure)

With the rise in natural gas prices, GTCC technology has become less favored and many utilities are rethinking the role of coal and nuclear power in meeting future power needs. This too presents its own set of problems. Biorefineries that have a significant power component have the potential to help address all of these concerns. First, they provide a way to diversify the electric power fuel mix, thereby reducing dependence on fossil fuels. Not only does this conserve finite resources, but it has the potential, along with other renewable energy technologies, to ease natural gas price volatility by easing pressure on the supply-demand balance for natural gas. Second, biorefineries represent a form of distributed generation, and would be more numerous and dispersed than other central station power plants of equal total capacity. All else equal, this would make the overall electricity supply infrastructure less vulnerable to disruption, for example by terrorist attacks or other causes.

\subsubsection{Economic Development}

Biorefineries could have important economic development benefits, stemming from the enhancement of the competitiveness of the pulp/paper industry. The financial analysis illustrated the potential for attractive financial returns and significantly increased cash flows relative to Tomlinson systems. The related economic development benefits include preserving and growing employment in the industry and potentially adding to rural and semi-rural employment by creating increased demand for raw materials for paper production and biomass supply and, in the longer term, energy and other products derived from biomass. On a national scale these impacts are likely to be modest, but in certain regions or states (especially the Southeast), the impacts

\footnotetext{
${ }^{63}$ For example, the summer months are used to add natural gas to underground storage, for use during winter, but with increasing amounts of natural gas being used in the summer for power generation, this creates the possibility of having too little gas in storage heading into the winter heating season. All else equal, this tends to increase price volatility, as occurred in the winter of 2000-2001.

${ }^{64}$ Environmental considerations are also decreasing the ability of large gas users like electric utilities to fuel switch (e.g., to \#2 oil). This is making demand for gas less elastic than in the past. Similarly, gas production can only respond so quickly to match demand. Thus, while overall supply and demand are in relative balance, short term drivers (e.g., a cold winter or hot summer) can lead to price volatility by temporarily upsetting the supply-demand balance.

138
} 
could be very significant. However, if biorefineries help catalyze a new, larger, bio-energy industry, the economic impacts would be more substantial at the national level as well.

\subsubsection{Reaping the Benefits of Government RD\&D}

The U.S. Department of Energy has been supporting research, development, and demonstration (RD\&D) of black liquor and biomass gasification technologies for over 20 years at varying levels [147]. It is clear that much has been learned as a result of this government investment, such that gasification technologies are now on the cusp of commercial viability. (There probably have also been unanticipated and un-quantifiable R\&D spin-off values.)

While a return on investment in RD\&D is difficult to quantify, it is possible to estimate the cost of delaying the additional RD\&D needed for gasification technology to reach commercial readiness. With delayed commercial deployment, some energy and emissions savings that would otherwise have occurred would be foregone. Such delay in market introduction might be represented by the difference between the Low and Aggressive market penetration scenarios described earlier. The difference in cumulative energy savings between the scenarios can be viewed as the cost of delaying implementation, or conversely, the benefits of more aggressive deployment and of "front loading" the market penetration curve. If biorefineries were to penetrate slowly rather than rapidly into the market, the cumulative (25-year) energy savings would be roughly 2-12 quads less (Figure 92). Assuming a rough average fossil fuel price range of $\$ 5-10 / \mathrm{MMBtu}$ (which corresponds to $\$ 29$ to $\$ 58$ per barrel of crude oil or 1.7 to $3.4 \phi / \mathrm{kWh}$ of electricity), the corresponding added energy costs would be $\$ 10$ to $\$ 120$ billion over this period.

For certain emissions it is also possible to estimate a market value since there are existing capand-trade markets. At $\$ 625 /$ ton (the recent price for $\mathrm{SO}_{2}$ allowances ${ }^{65}$ ), and assuming prices remain at this level in real terms, $\mathrm{SO}_{2}$ reductions have a cumulative value of up to $\$ 301$ million over the 25-year period following commercial introduction of biorefineries. (In some of the configurations, the net $\mathrm{SO}_{2}$ benefit is negative because of the large decreases expected in grid power $\mathrm{SO}_{2}$ emissions discussed earlier.) $\mathrm{NO}_{x}$, if valued at $\$ 2,100 /$ ton over the same period, has a market value as high as of \$1.5-2.6 billion in the Aggressive market penetration scenario. If a system for trading $\mathrm{CO}_{2}$ is put in place, the $\mathrm{CO}_{2}$ value could be as high as $\$ 37$ billion in the Aggressive market penetration scenario at a price of $\$ 25 /$ metric ton of $\mathrm{CO}_{2}$. While it will likely be difficult for biorefineries to capture all of these additional revenue streams, these estimates provide an indication of the value to the nation of emissions reductions that biorefineries could enable. Thus, in addition to energy costs savings, the value of lost $\mathrm{SO}_{2}, \mathrm{NO}_{\mathrm{x}}$, and $\mathrm{CO}_{2}$ emissions reductions (Table 36) due to slower market penetration, could also be in the billions of dollars.

${ }^{65}$ Evolution Markets, accessed 8/4/2006. 
Table 36. Cumulative market value (25 year) of certain emissions reductions relative to Tomlinson systems under the three market penetration scenarios in this study

\begin{tabular}{|c|c|c|c|}
\hline \multicolumn{4}{|c|}{ Aggressive Market Penetration Scenario (million 2005\$) } \\
\hline & $\mathrm{SO}_{2} @ \$ 625 / \mathrm{MT}$ & $\mathrm{NO}_{\mathrm{x}} @ \$ 2,100 / \mathrm{MT}$ & $\mathrm{CO}_{2} @ \$ 25 / \mathrm{MT}$ \\
\hline BLGCC & $\$ 314$ & $\$ 1,757$ & $\$ 7,939$ \\
\hline DMEa & ---- & $\$ 1,476$ & $\$ 4,386$ \\
\hline DMEb & ---- & $\$ 2,617$ & $\$ 20,082$ \\
\hline DMEc & $\$ 69$ & $\$ 2,609$ & $\$ 11,529$ \\
\hline FTa & ---- & $\$ 2,597$ & $\$ 13,014$ \\
\hline FTb & $\$ 86$ & $\$ 2,206$ & $\$ 37,405$ \\
\hline FTc & $\$ 301$ & $\$ 1,802$ & $\$ 29,017$ \\
\hline MA & $\$ 278$ & $\$ 2,441$ & $\$ 10,028$ \\
\hline \multicolumn{4}{|c|}{ Base Market Penetration Scenario (million 2005\$) } \\
\hline BLGCC & $\$ 196$ & $\$ 1,135$ & $\$ 5,182$ \\
\hline DMEa & ---- & $\$ 975$ & $\$ 2,853$ \\
\hline DMEb & ---- & $\$ 1,701$ & $\$ 13,096$ \\
\hline DMEc & $\$ 40$ & $\$ 1,696$ & $\$ 7,520$ \\
\hline FTa & --- & $\$ 1,689$ & $\$ 8,488$ \\
\hline FTb & $\$ 27$ & $\$ 1,404$ & $\$ 24,407$ \\
\hline FTc & $\$ 194$ & $\$ 1,172$ & $\$ 18,921$ \\
\hline MA & $\$ 177$ & $\$ 1,586$ & $\$ 6.542$ \\
\hline \multicolumn{4}{|c|}{ Low Market Penetration Scenario (million 2005\$) } \\
\hline BLGCC & $\$ 99$ & $\$ 589$ & $\$ 2,710$ \\
\hline DMEa & --- & $\$ 515$ & $\$ 1,488$ \\
\hline DMEb & --- & $\$ 887$ & $\$ 6,845$ \\
\hline DMEc & $\$ 19$ & $\$ 884$ & $\$ 3,931$ \\
\hline FTa & --- & $\$ 881$ & $\$ 4,437$ \\
\hline $\mathrm{FTb}$ & $\$ 4$ & $\$ 721$ & $\$ 12,761$ \\
\hline FTc & $\$ 100$ & $\$ 612$ & $\$ 9,889$ \\
\hline MA & $\$ 90$ & $\$ 827$ & $\$ 3,420$ \\
\hline
\end{tabular}

\section{Conclusions and Next Steps}

One may consider a modern pulp and paper mill as a first-generation forest biorefinery, with steam, power and other products being produced alongside the wide range of paper products we normally associate with the industry. Black liquor and biomass gasification are key technology platforms for realizing the forest biorefinery of the future. Our analysis has shown that gasification-based pulp mill biorefinery technologies, once fully commercialized, offer the potential for attractive investment returns. They also offer the potential for important contributions toward national petroleum savings, emissions reductions, improved energy security, and rural economic development - contributions that could be two times or larger the size of contributions from the existing U.S. corn-ethanol industry.

These potential private and public benefits arise, fundamentally, because of the integration of biorefining with pulp and paper production, such that the biorefinery is providing chemical recovery services, process steam, and process electricity in addition to exporting liquid fuel and perhaps some electricity. We have analyzed in detail a variety of integrated pulp/paper mill biorefinery designs encompassing a broad range of product slates. An overarching finding is that integration can effectively enable more efficient use of biomass resources for liquid biofuel production compared to non-integrated biofuel production (Figure 32). Integration also can effectively reduce the capital investment required per unit of biofuel production to levels comparable to investments needed for coal-to-liquids facilities that are an order of magnitude or more larger than prospective pulp mill biorefineries (Figure 44). Finally, integration can 140 
effectively reduce the cost of producing gasification-based biofuels to $\sim \$ 1$ per gallon of ethanol equivalent (Table 24), which would make them competitive with the 2012 cost target developed by analysts at the National Renewable Energy Laboratory for ethanol made from lignocellulosic biomass by enzymatic hydrolysis/fermentation processes.

The one caveat to this broad conclusion stems from our results for mixed alcohols production. Our analysis relied on the very limited data that have been published on the performance of mixed-alcohol synthesis catalysts. Catalysts that perform better than the one we modeled are needed for mixed-alcohol fuel to be as competitive as production of DME or Fischer-Tropsch liquids. On the other hand, even with the mixed-alcohol catalyst we used in our design, separating the component alcohols for sale into chemicals markets provides very attractive returns - in fact higher returns than any of the fuel options examined in our analysis.

Our analysis highlighted the fact that all of the component technologies needed for gasificationbased biofuels production at a pulp/paper mill biorefinery are either already commercially used (in non-biorefinery applications) or are undergoing pilot-scale demonstration (Table 11), such that with some modest additional targeted research and development work commercial-scale facilities could begin to be built in the 2010-2015 timeframe. Again, the one caveat to this conclusion is catalysts for synthesis of mixed-alcohols from syngas. Development and demonstration at significant scale of synthesis catalysts that perform better than the one we modeled are needed to gain confidence that mixed-alcohols could be produced competitively as a fuel.

While the $\mathrm{N}^{\text {th }}$ plant financial performance levels for integrated biorefineries appear largely attractive (even with a modest $-\$ 50 / b b l$ - oil price assumption and without considering incentives or monetization of environmental benefits), they may not be sufficiently attractive to motivate technology commercialization efforts by the private-sector alone, since the first few plants can be expected to give lower financial performance than $\mathrm{N}^{\text {th }}$ plants, and risks will be higher. Sustained higher oil prices would provide improved financial performance, but relying on such oil prices for financial returns would be considered risky by investors in the first few plants.

Capturing incentives and monetizing environmental benefits would be another means by which financial performance would improve, but there are uncertainties associated with this route as well. For example, some environmental values that we included in our analysis will be difficult for private investors to capture, e.g., indirect benefits arising from grid emissions offsets. ${ }^{66}$ Moreover, black liquor (and biomass in general) does not currently benefit from the same level of tax credits or image as "green" electricity generated directly from the wind or the sun. This is an important consideration, since electricity is a significant co-product from most of the biorefinery configurations we have analyzed.

Nevertheless, it is worth noting that in the last few years the policy environment for renewable energy has improved considerably at both the state and federal levels. For example, production tax credit (PTC) eligibility has continued to expand to additional resources, and the 2005 Energy Policy Act (EPAct) further expanded it to include spent pulping liquors. In 2004, the federal

\footnotetext{
${ }^{66}$ On the other hand, there may be environmental benefits we have not included in our quantitative analysis, but which might be able to be captured by investors, e.g., HAPs, water pollution, the impacts of reduced pulpwood required due to polysulfide pulping, etc. Further analysis of these issues may be warranted.
} 
excise tax credit was expanded to a range of biofuels and their derivatives and the EPAct extended its time horizon and the eligible biofuels. EPAct also created other biofuels incentives and programs, the impact of which are not yet fully known. In parallel, state governments have continued their leadership on renewable energy programs. The number of states with Renewable Portfolio Standards (RPS) has increased from 14 in 2003 to more than 20 in late 2006, and several states with existing RPS programs have increased their targets (e.g., California, Texas, Wisconsin). States have also begun to adopt their own renewable fuel mandates, and many provide a range of biofuel incentives. At the same time momentum continues to build for setting limits on greenhouse gas emissions, most notably in California and the Northeast states.

Thus, while some of the key incentives will require legislative renewals to apply in the future, it seems reasonable to expect that they will be extended. If anything, the core drivers behind the policies - energy security, economic development and environmental protection, especially climate change - will only get stronger in the future. But, it is possible that as the biofuels industry matures, incentive structures could evolve differently than how we have modeled them. For example, it is possible that the excise tax credit could be modified from a fixed value to a variable value, with the value based on the market price for transportation fuels. In this case a scenario of high energy prices and large tax credits (one set of conditions included in our modeling) would not be sustainable. Similarly, market-based programs, like the Federal Renewable Fuels Standard, could partially replace tax subsidies as the means of monetizing energy and environmental benefits of biofuels. Thus, the impacts of incentives that we have shown here should be viewed as indicative, rather than definitive.

Given the above discussion, a public-private partnership will likely be needed, and can be justified on the basis of the public and private benefits that will accrue, for building and operating the first few pulp/paper mill biorefineries. Moreover, given that production of fuels and chemicals is largely outside the experience of today's forest products industry, strategic partnerships involving the forest products industry and other relevant industries (e.g., petroleum, electricity) would be beneficial. Assuming forest biorefinery technologies are successfully commercialized, the private sector capital needed for broader deployment is likely to become available. In recent years, private investors have shown that they are ready, willing and able to make significant capital available to the renewable energy industry. Today, global investment in wind power, solar power and first-generation biofuels (ethanol and biodiesel) exceeds $\$ 25$ billion annually.

There are several areas where further analytical efforts might be helpful in supporting commercialization efforts. Four of these are mentioned here.

One area relates to the potential supply of biomass energy feedstocks to pulp/paper mill biorefineries. Our analysis in the present study indicates that, based on the "billion ton" study [1], there are plentiful forest biomass resources in the United States to support both growing pulp/paper production, as well as a vigorous gasification-based biorefinery industry over at least the next two to three decades. The billion ton study estimated that existing forests can sustainably provide some 226 million dry tons of biomass above and beyond currently used woody biomass, while our estimate is that a fully-implemented biorefinery industry might require of the order of 100 million dry tons per year of additional biomass. Furthermore, it was suggested by members of the Steering Committee of this project (Figure 4) that the amount of wood available on a sustainable basis from existing forests would be even higher than estimated 
in the billion ton study if management of those forests shifted to practices geared towards energy, timber and fiber production and not just timber and fiber. Nevertheless, it is important to understand at regional and local levels, the potential availability and costs of woody biomass residue feedstocks for biorefining. Examining potential wood supply in the Southeasten United States, where most of the country's pulp/paper capacity is located, would be especially important. A related analysis might examine how, over time, a gasification-based biorefinery industry might grow beyond the use of forest residues to the use of dedicated biomass energy crops or crop residues. The billion ton study has estimated that the agricultural biomass available from perennial crops could be as much as 377 million dry tons/yr and from crop residues could be as much as 46 million dry tons/yr.

A second area for further analysis would be to understand at the same level of detail as in this current study the potential costs and benefits of biorefineries where energy is extracted from wood prior to pulping (e.g., conversion of hemicellulose into ethanol by enzynamic hydrolysis/fermentation processes) in combination with gasification-based downstream conversion of black liquor and biomass. Extracting energy prior to pulping will reduce the amount of black liquor available for downstream energy conversion, such that performance and economics are likely to be considerably different from those reported in the current study. Key issues to examine include understanding what biorefinery configurations provide for the most effective integration with the pulp/paper mill and what the implications are for overall economics.

A third area where additional analysis may be fruitful stems from one of the conclusions of the current study, namely that gasification-based (gas turbine) electricity production for export from a pulp/paper mill will provide higher returns (though not necessarily higher NPV) than gasification-based liquid fuels production under our baseline assumptions $(\$ 50 / \mathrm{bbl}$ oil price scenario, no financial incentives). This result may be due to the fact that the scale of a pulp/paper mill's biomass energy supply is closer to the "natural" scale for gas turbine power generation than for synfuels production. If gasification-based energy facilities could be scaled up, financial performance would likely improve more for synfuels production than for electricity production. In this context, it would be of interest to assess biorefinery strategies for co-utilizing biomass and fossil fuel feedstocks in order to be able to gain scale economies in the conversion process. Co-utilization of coal is of particular interest since it is domestically produced, is relatively inexpensive, and is already utilized to some degree as a supplemental boiler fuel at many pulp/paper mills.

One final suggested area for additional analysis follows from the previous one. Larger-scale facilities would enable consideration to be given to capture and underground storage of $\mathrm{CO}_{2}$ as a means to further reduce net greenhouse gas emissions associated with biorefining. ${ }^{67}$ This is an especially important consideration with co-utilization of fossil fuels at a biorefinery, since net emissions of $\mathrm{CO}_{2}$ would otherwise increase. With carbon capture and storage, carbon of recent photosynthetic origin (i.e., carbon entering a biorefinery as biomass) that is captured at the biorefinery and sent for long-term underground storage, is effectively a negative carbon

\footnotetext{
${ }^{67}$ In the biorefinery designs we developed in the present study, $\mathrm{CO}_{2}$ is removed from syngas as a requisite part of the process and then vented to the atmosphere. With relatively little additional capital investment, the $\mathrm{CO}_{2}$ could be compressed instead for pipeline delivery to a storage site. The strong scale economies associated with building a new pipeline infrastructure will argue for larger-scale synfuels production in order to supply larger quantities of $\mathrm{CO}_{2}$ to the pipeline.
} 
emission. Biomass is the only renewable energy resource for which this is possible. The carbon emissions offset by using the biorefinery product in place of a fossil fuel are supplemented by a further reduction of carbon emissions due to storing away from the atmosphere some of the carbon originally contained in the biomass. If coal were to be co-utilized with biomass to make liquid fuels, the negative emission effect provided by the biomass could help reduce or offset completely the carbon emissions associated with the coal [148].

Carbon capture and storage (CCS) schemes are difficult to justify financially without a monetizable value for the carbon emissions they would avoid, but such a policy regime seems likely to be implemented in the United States within 5 to 10 years' time, i.e., on the time scale within which a gasification-based forest biorefining industry may launch commercially. Thus, understanding the potential viability of CCS and its cost implications for biorefining may provide important input to strategic planning of biorefinery investments in the 2015-2020 time frame. 


\section{References}

1. Perlack, R.D., Wright, L.L., Turhollow, A., Graham, R.L., Stokes, B., and Erback, D.C., Biomass as Feedstocks for a Bioenergy and Bioproducts Industry: The Technical Feasibility of a Billion-Ton Annual Supply, ORNL/TM-2005/66 for USDA and USDOE, April 2005.

2. E.D. Larson, R.H. Williams, and H. Jin, "Electricity and Fuels from Biomass with Carbon Capture and Storage," Proceedings of $8^{\text {th }}$ International Conference on Greenhouse Gas Control Technologies, Trondheim, Norway, 19-22 June 2006.

3. See Proceedings of the $5^{\text {th }}$ Annual Conference on Carbon Capture and Sequestration, US Dept. of Energy, Alexandria, VA, 8-11 May 2006, and Proceedings of $8^{\text {th }}$ International Conference on Greenhouse Gas Control Technologies, Trondheim, Norway, 19-22 June 2006.

4. Ekbom, T., Berglin, N., and Logdberg, S., "Black Liquor Gasification with Motor Fuel Production - BLGMFII: A techno-economic feasibility study on catalytic Fischer-Tropsch synthesis for synthetic diesel production in comparison with methanol and DME as transport fuels," P21384-1, Nykomb Synergetics AB, Stockholm, December 2005.

5. Larson, E.D., Consonni, S., and Katofsky, R.E., "A Cost-Benefit Assessment of Biomass Gasification Power Generation in the Pulp and Paper Industry," final report, Princeton Environmental Institute, Princeton, NJ, 8 October 2003. (Downloadable from www.princeton.edu/ energy)

6. Werpy, T. and Petersen, G. (editors), "Top Value Added Chemicals from Biomass: Vol. I: Results of Screening for Potential Candidates from Sugars and Synthesis Gas," for Office of Biomass Program, EE/RE, US Dept. of Energy, August 2004.

7. Spath, P.L. and Dayton, D.C., "Preliminary Screening Technical and Economic Assessment of Synthesis Gas to Fuels and Chemicals with Emphasis on the Potential for Biomass-Derived Syngas," NREL/TP-510-34929, National Renewable Energy Laboratory, December 2003.

8. Energy Information Administration, Monthly Energy Review, US Dept. of Energy, Washington, DC, March 2006.

9. Energy Information Administration, Annual Energy Outlook 2006, with Projections to 2030, DOE/EIA0383(2006), U.S. Department of Energy, February 2006.

10. Dry, M.E. 2002. “The Fischer-Tropsch Process: 1950-2000,” Catalysis Today, 71: 227-241.

11. Oukaci, R. 2002. "Fischer-Tropsch Synthesis," presented at the 2nd Annual Global GTL Summit, London, 2830 May.

12. Rahmim, I.I. 2003. "Gas-to-Liquid Technologies: Recent Advances, Economics, Prospects," presented at the 26th IAEE Annual International Conference, Prague, June.

13. Larson, E.D. and Jin, H., "Biomass Conversion to Fischer-Tropsch Liquids: Preliminary Energy Balances," Proceedings of the 4th Biomass Conference of the Americas, Elsevier Science, Oxford, UK, pp. 843-853, 1999.

14. Larson, E.D. and Jin, H., "A Preliminary Assessment of Biomass Conversion to Fischer-Tropsch Cooking Fuels for Rural China," Proceedings of the 4th Biomass Conference of the Americas, Elsevier Science, Oxford, UK, pp. 855-863, 1999.

15. Bechtel, 1998. "Aspen process flowsheet simulation model of a Battelle biomass-based gasification, FischerTropsch liquefaction and combined-cycle power plant," DE-AC22-93PC91029-16, May, US Dept. of Energy, Pittsburgh, Pennsylvania.

16. Tijmensen, M.J.A. 2000. "The Production of Fischer Tropsch Liquids and Power through Biomass Gasification," Ph.D. thesis, Dept. of Science, Technology and Society, Utrecht University, Utrecht, The Netherlands, November, 66 pp. 
17. Tijmensen, M.J.A., Faaij, A.P.C., Hamelinck, C.N. nad van Hardeveld, M.R.M. 2002. "Exploration of the Possibilities for Production of Fischer Tropsch Liquids and Power via Biomass Gasification," Biomass and Bioenergy, 23: 129-152.

18. Hamelinck, C.N., Faaij, A.P.C., den Uil, H., and Boerrigter, H. 2003. "Production of FT Transportation Fuels from Biomass; Technical Options, Process Analysis and Optimisation, and Development Potential," report NWS-E-2003-08, Copernicus Inst., Dept. of Science, Technology and Society, Utrecht University, Utrecht, The Netherlands, March, 69 pp.

19. Hamelinck C.N., Faaij, A.P.C., den Uil, H., and Boerrigter, H. 2004, "Production of FT Transportation Fuels from Biomass; Technical Options, Process Analysis and Optimisation, and Development Potential," Energy, 29:1743-1771.

20. Boerrigter, H. and van der Drift, A. 2003. "Liquid Fuels from Biomass: The ECN Concept(s) for Integrated FT-Diesel Production Systems," presented at the Biomass Gasification Conference, Leipzig, Germany, 1-2 October.

21. Shell Deutschland Oil GmbH, 2005. "Shell Partners with CHOREN in the World's First Commercial SunFuel Development," press release, August 17.

22. M. Rudloff, "Operation Experiences of Carbo-V Process for FTD Production," Synbios: Second Generation Automotive Biofuel Conference, Stockholm, 18-20 May 2005.

23. Schulze, O., "Advanced Gas Cleaning for Biomass Gasification," presented at International Energy Agency Task 33 (Thermal Gasification of Biomass) Spring Technical Meeting, Dresden, Germany, 12-14 June 2006.

24. T.H. Fleisch, "Small is Beautiful," World GTL Summit, London, 18-19 May 2005.

25. Hansen, J.B., Voss, B., Joensen, F., and Sigurdardottir, I.D., "Large-Scale Manufacture of Dimethyl Ether -- a New Alternative Diesel Fuel from Natural Gas" SAE Paper 950063, 1995.

26. International DME Association (www.aboutdme.org).

27. Naqvi, S., "Dimethyl Ether as Alternate Fuel," Report 245, Process Economics Program, SRI Consulting, Menlo Park, California, June, 2002.

28. T.H. Fleisch, "DME and IDA: Progress, Opportunities, and Challenges," Second International DME Conference, London, 15-17 May 2006.

29. Z. Huang, "An Overview of DME Activities in China," Second International DME Conference, London, 1517 May 2006.

30. Anonymous, "SEK 62 Million for Volvo for Continued Development of DME Technology," press release, Swedish Energy Agency, Stockholm, 16 June 2006.

31. H. Landalv and H. Salsing, "DME at Volvo, and Recent Combustion Research," Second International DME Conference, London, 15-17 May 2006.

32. Y. Ohno, "The Role of DME in the World: A Perspective," Second International DME Conference, London, 15-17 May 2006.

33. Stahl, K., Waldheim, L., Morris, M., and Gardmark, L., "Liquid Fuel Activities at Vaxjo Varnamo Biomass Gasification Center, VVBGC,” First International DME Conference, Paris, 12-14 October 2004.

34. Marklund, M. Gebart, R., and Tegman, R., "Sclae-Up Method for High Temperature Black Liquor Gasification in Prssurized Entrained Flow Gasifiers," presented at the 7th International Colloquium on Black Liquor Combustion and Gasification,” Jyvaskyla, Finland, 2 August 2006.

35. M. Marchiona, "LPG/DME Mixtures: Domestic and Automotive Uses," 4th Meeting of the International DME Association, Lyngby, Denmark, 29-30 April 2002.

36. D. Griffith, "DME Interchangeability with LPG - A Theoretical Study," $4^{\text {th }}$ Meeting of the International DME Association, Lyngby, Denmark, 29-30 April 2002. 
37. J. Rockall and B. de Calan, "DME Opportunities in LP Gas Markets," Second International DME Conference, London, 15-17 May 2006.

38. World LP Gas Association, Statistical Review of Global LP Gas 2005, Paris, 2005.

39. M. Oguma and S. Goto, "Evaluation of Medium Duty DME Truck Performances - field test results and trace level emissions measurement," Second International DME Conference, London, 15-17 May 2006.

40. Renewable Fuels Association, "From Niche to Nation: Ethanol Industry Outlook 2006," Washington DC, 2006. (Accessed June 19, 2006 at http://www.ethanolrfa.org/objects/pdf/outlook/outlook_2006.pdf)

41. "BP and Dupont Announce Partnership to Develop Advanced Biofuels," press release, 20 June 2006, accessed at http://www.bp.com/genericarticle.do?categoryId=2012968\&contentId=7018942, 27 June 2006.

42. Greene, N. (principal author), "Growing Energy: How Biofuels Can Help End America's Dependence on Oil," Natural Resources Defense Council, New York, December 2004.

43. W. Bruce (BRI Energy President) testimony in front of United States Senate Natural Resources Committee, Washington, DC, 1 May 2006.

44. Powelson, R., "Company plans big ethanol plant in Oak Ridge," 1 May 2006 article accessed 14 June 2006 at http://www.knoxnews.com/kns/local_news/article/0,1406,KNS 347 4664543,00.html.

45. Nexant, "Equipment Design and Cost Estimation for Small Modular Biomass Systems, Synthesis Gas Cleanup, and Oxygen Separation Equipment, Task 9: Mixed Alcohols from Syngas State of Technology," for National Renewable Energy Laboratory, Golden, CO, May 2005.

46. Aden, A., Spath, P., and Atherton, B., "The Potential of Thermochemical Ethanol via Mixed Alcohols Production," Milestone Completion Report, National Renewable Energy Laboratory, Golden, CO, 31 October 2005.

47. BCT, Inc., http://www.bio-conversiontechnologies.com/Bio-Conversion\%20Technologies/Home.html

48. Power Energy Fuels, Inc., http://www.powerenergy.com.

49. Nova Fuels, Inc., http://www.novafuels.com/index.cfm.

50. Syntec Biofuel, Inc. http://www.syntecbiofuel.com/index.html.

51. Jameel, H. and Renard, J., "Pulping Options with Black Liquor Gasification," Proceedings of the Colloquium on Black Liquor Combustion and Gasification (L. Baxter and K. Whitty, chairmen), Park City, Utah, 13-16 May 2003.

52. Consonni, S., Larson, E.D., Kreutz, T.G. and Berglin, N., "Black Liquor Gasifier/Gas Turbine Cogeneration," J. of Engineering for Gas Turbines and Power, 120: 442-449, 1998.

53. Whitty, K. and Nilsson, A., "Experience from a High Temperature, Pressurized Black Liquor Gasification Pilot Plant," Proceedings of the Tappi Chemical International Recovery Conference, Tappi Press, Atlanta, pp. 655-662, 2001.

54. Chemrec, "Chemrec Pressurized BLG (Black Liquor Gasification) - Status and Future Plans," presented at the 7th International Colloquium on Black Liquor Combustion and Gasification," Jyvaskyla, Finland, 2 August 2006.

55. Mansour, M.N., Chandran, R.R. and Rockvam, L., "The Evolution of and Advances in Steam Reforming of Black Liquor," Proceedings of the Tappi Chemical Recovery Conference, Tappi Press, Atlanta, 2001.

56. Whitty, K., "Conversion of Black Liquor in a Fluidized Bed Steam Reformer," presented at the 7th International Colloquium on Black Liquor Combustion and Gasification," Jyvaskyla, Finland, 2 August 2006.

57. Lindstrom, M., Kirkman, A., Jameel, H., Cheng, J., Huggins, C. and Bray, B., "Economics of Integrating Black Liquor Gasification with Pulping: Part I, Effect of Sulfur Profiling," Proceedings of the Pulping and Engineering Conference, Tappi Press, Atlanta, 2002.

58. Larson, E.D. and Ren, T. 2003, "Synthetic fuels production by indirect coal liquefaction," Energy for Sustainable Development, VII(4): 79-102. 
59. S. Consonni and E.D. Larson, "Biomass-Gasifier/Aeroderivative Gas Turbine Combined Cycles, Part A: Technologies and Performance Modeling, and Part B: Performance Calculations and Economic Assessment," ASME Journal of Engineering for Gas Turbines and Power, Vol. 118, July 1996, pp. 507-525.

60. The Rectisol ${ }^{\circledR}$ Process for Gas Purification, Lurgi Engineering Oel-Gas-Chemie, brochure available at http://www.lurgi.com.

61. Sharp, C.R., Kubek, D.J., Kuper, D.E., Clark, M.E., and DiDio, M., "Recent Selexol Operating Experience with Gasification, including CO2 Capture," Fifth European Gasification Conference, 8 - 10 April 2002 Noordwijk, The Netherlands.

62. Babu, S.P., "Observations on the Current Status of Biomass Gasification," 2 May 2005, published at http://www.gastechnology.org/webroot/downloads/en/IEA/58_BiomassGasification.pdf.

63. Knoef, H.A.M. (editor), Handbook Biomass Gasification, BTG Biomass Technology Group, Enschede, The Netherlands, September 2005.

64. Engstrom, S., Lindman, N., Rensfelt, E., and Waldheim, L. 1981. "A New Synthesis Gas Process for Biomass and Peat," Energy from Biomass and Wastes V, Institute of Gas Technology, Chicago.

65. Strom, E., Liinanki, L., Sjostrom, K., Rensfelt, E., Waldheim, L., and Blackadder, W. 1984. "Gasification of Biomass in the MINO-Process," Bioenergy 84, Vol. III (Biomass Conversion), H. Egneus and A. Ellegard (eds), Elsevier Applied Science Publishers, London, pp. 57-64.

66. Kosowski, G.M., Onischak, M., and Babu, S.P. 1984. "Development of Biomass Gasification to Produce Substitute Fuels," Proceedings of the 16th Biomass Thermochemical Conversion Contractors' Meeting, Pacific Northwest Laboratory, Richland, WA, pp. 39-59.

67. Evans, R.J., Knight, R.A., Onischak, M., and Babu, S.P. 1987. "Process Performance and Environmental Assessment of the Renugas Process," Energy from Biomass and Wastes X, D.L. Klass (ed.), Elsevier Applied Science (London) and Institute of Gas Technology (Chicago), pp. 677-694.

68. Lau, F.S., Bowen, D.A., Dihu, R., Doong, S., Hughes, E.E., Remick, R., Slimane, R., Turn, S.Q., and Zabransky, R. 2003. "Techno-economic analysis of hydrogen production by gasification of biomass," final technical report for the period 15 Sept 2001 - 14 Sept 2002, contract DE-FC36-01GO11089 for US Dept. of Energy, Gas Technology Inst., Des Plaines, IL, June (rev.), 145 pp.

69. McKeough, P. and Kurkela, E., "Production of Transportation Fuels from Biomass at Pulp and Paper Mills the Finnish Approach," presented at the $7^{\text {th }}$ International Colloquium on Black Liquor Combustion and Gasification," Jyvaskyla, Finland, 2 August 2006

70. Brammer J.G. and Bridgwater A.V., 1999. "Drying technologies for an integrated gasifcation bio-energy plant," Renewable and Sustainable Energy Reviews, 3: 243-289.

71. Lau, F.S., Carty, R.H., Onischak, M., and Bain, R.L., "Development of the IGT Renugas Process," Conference on Strategic Benefits of Biomass and Waste Fuels, Electric Power Research Institute, Washington, DC, 30 March - 1 April, 1993.

72. Blackadder, W.H., Lundberg, H., Rensfelt, E., and Waldheim, L., "Heat and Power Production via Gasification in the Range 550 MWe," in Advances In Biomass Thermochemical Conversion, A.V. Bridgwater (ed.), Balckie Academic \& Professional Press, London, 1994.

73. Larson, E.D., Jin, H., and Celik, F.E. 2005, "Gasification-Based Fuels and Electricity Production from Biomass, Without and With Carbon Capture and Storage," Princeton Environmental Institute, Princeton University, Princeton, NJ, October.

74. Sydkraft, Elforsk, and Nutek, 2001. Varnamo Demonstration Plant: The Demonstration Program, 1996-2000, Berlings Skogs, Trelleborg, Sweden, 133 pp.

75. Simell P., Kurkela, E., Stahlberg P. and Hepola, J., "Catalytic hot gas cleaning of gasification gas." Catalysis Today, 27(1-2): 55-62, 1996. 
76. Wright, I.G., Leyens, C., and Pint, B.A., "An Analysis of the Potential for Deposition, Erosion, or Corrosion in Gas Turbines Fueled by the Products of Biomass Gasification or Combustion," Paper 2000-GT-19, American Society of Mechanical Engineers, New York, NY, 2000.

77. Lippert, T.E., Bruck, G.J., Sanjana, Z.N., Newby, R.A., and Bachovchin, D.M., " Westinghouse Advanced Particle Filter System,” Proceedings of Advanced Coal Fired Power Systems Review Meeting, Federal Energy Technology Center, Pittsburgh, PA, 1996.

78. See General Electric web site: www.gepower.com.

79. Bechtel Group, Inc. 1990. Slurry Reactor Design Studies. Slurry vs. Fixed-Bed Reactors for Fischer-Tropsch and Methanol: Final Report, US Dept. of Energy Project No. DE-AC22-89PC89867, Pittsburgh Energy Technology Center, Pittsburgh.

80. Adachi, Y., Komoto, M., Watanabe, I., Ohno, Y. and Fujimoto, K. 2000. "Effective Utilization of Remote Coal Through Dimethyl Ether Synthesis," Fuel, 79: 229-234.

81. Fujimoto, K., Shikada, T. and Yamaoka, Y. 1995. "Method of producing dimethyl ether," US pat. 5466720, Nov. 14.

82. Brown, D.M., Bhatt, B.L., Hsiung, T.H., Lewnard, J.J. and Waller, F.J. 1991. "Novel Technology for the Synthesis of Dimethyl Ether from Syngas," Catalysis Today, 8:279-304.

83. Lewnard, J.J., Hsiung, T.H., White, J.F. and Brown, D.M. 1990, "Single-Step Synthesis of Dimethyl Ether in a Slurry Reactor," Chemical Engineering Science, 45(8): 2735-2741.

84. Lewnard, J.J., Hsiung, T.H., White, J.F. and Bhatt, B.L. 1993. "Liquid phase process for dimethyl ether synthesis," US pat. 5,218,003, June 8.

85. Air Products and Chemicals, Inc. 1993. "Synthesis of Dimethyl Ether and Alternative Fuels in the Liquid Phase from Coal-Derived Synthesis Gas," report DOE/PC/89865-T8, U.S. Dept. of Energy, Pittsburgh Energy Tech. Center, Pittsburgh, PA, Feb.

86. Peng, X.D., Toseland, B.A. and Tijm, P.J.A. 1999. "Kinetic Understanding of the Chemical Synergy Under LPDME Conditions-Once-Through Applications," Chemical Engineering Science, 54: 2787-2792.

87. Peng, X.D., Wang, A.W., Toseland, B.A. and Tijm, P.J.A. 1999. "Single-Step Syngas-to-Dimethyl Ether Processes for Optimal Productivity, Minimal Emissions, and Natural Gas-Derived Syngas," IEC Research, Nov.

88. Niu, Y. 2000. "Dimethyl Ether - Clean Fuel in the 21st Century," Inst. of Coal Chemistry, Chinese Academy of Sciences, presented at the Workshop on Polygeneration, Working Group on Energy Strategies and Technologies, China Council for International Cooperation on Environment and Development, Beijing, May.

89. NKK Corporation, 2003. (http://www.nkk.co.jp/nkknews/40-1/art02.html).

90. Eastman Chemical and Air Products and Chemicals, 2003. "Project Data on Eastman Chemical Company's Chemicals-from-Coal Complex in Kingsport, TN," prepared for US Department of Energy (under cooperative agreement DE-FC22-92PC90543).

91. Air Products and Chemicals, Inc. 2001. "Liquid Phase Dimethyl Ether Demonstration in the LaPorte Alternative Fuels Development Unit," prepared for US Dept. of Energy by APCI, Allentown, Pennsylvania, January.

92. Air Products and Chemicals, Inc. 2002. "Market Outlook for Dimethyl Ether (DME)," prepared for US Dept. of Energy by APCI, Allentown, Pennsylvania, April.

93. Voss, B., Joensen, F. and Hansen, J.B., 1999. "Preparation of fuel grade dimethyl ether," US pat. 5908963, June 1.

94. Zahner, J.C. 1977. "Conversion of modified synthesis gas to oxygenated organic chemicals," US pat. 4011275, March 8.

95. Pagani, G. 1978. "Process for the production of dimethyl ether,” US pat. 4098809, July 4. 
96. Xu H., Ge Q., Li W., Hou S., Yu C. and Jia M. 2001. "The synthesis of dimethyl ether from syngas obtained by catalytic partial oxidation of methane and air," presented at the 6th Natural Gas Conversion Conference, Girdwood, Alaska, 17-22 June.

97. Fleisch, T.H., "Status of GTL technology and business," presented at the Princeton Biorefinery Project Steering Group Meeting, 30-31 January 2006.

98. Fox III, J. M. and Tam, S.S. 1995. "Correlations of Slurry Reaction Fischer-Tropsch Yield Data”, Topics in Catalysis, 2: 285-300.

99. Liu Z., Li X., Close M.R., Kugler E.L., Peterson J.L., and Dadyburjor D.B., "Screening of Alkali-Promoted Vapor-Phase-Synthesized Molybdenum Sulfide Catalysts for the Production of Alcohols from Synthesis Gas," Ind. Eng. Chem. Res., 36, 3085-3093, 1997.

100. Gunturu A.K., Kugler E.L., Cropley J.B. and Dadyburjor D.B. "A Kinetic Model for the Synthesis of HighMolecular-Weight Alcohols over a Sulfided Co-K-Mo/C Catalyst”, Ind. Eng. Chem. Res. 37: 2107-2115, 1998.

101. R. Bain (personal communication), National Renewable Energy Laboratory, Golden, CO, 27 Nov. 2006.

102. McAloon A, Taylor F, Yee W (Agricultural Research Service, Eastern Regional Research Centre, US Dept Agriculture), Ibsen K, Wooley R (Biotechnology Center for Fuels and Chemicals, NREL), "Determining the cost of producing ethanol from corn starch and lignocellulosic feedstocks, " NREL/TP-580-28893, National Renewable Energy Lab, October 2000.

103. Aden A, Ruth M, Ibsen K, Jechura J, Neeves K, Sheehan J, Wallace B (NREL), Montague L, Slayton A, Lukas J (Harris Group, Seattle, Washington), "Lignocellulosic biomass to ethanol process design and economics utilizing co-current dilute acid hydrolysis and enzymatic hydrolysis for corn stover," NREL/TP510-32438, National Renewable Energy Lab, June 2002.

104. TSS Consultants, "Gridley Ethanol Demonstration Project Utilizing Biomass Gasification Technology: Pilot Plant Gasifier and Syngas Conversion Testing, August 2002-June 2004,” NREL/SR-510-37581, National Renewable Energy Laboratory, Golden, CO, February 2005.

105. Larson, E.D., Jin, H., and Celik, F.E., "Large-Scale Gasification-Based Co-Production of Fuels and Electricity from Switchgrass," draft submitted to Biomass and Bioenergy, October 2006.

106. Jin, H., Larson, E.D., and Celik, F.E., "Performance and Cost Analysis of Future, Commercially-Mature Gasification-Based Electric Power Generation from Switchgrass," draft submitted to Biomass and Bioenergy, October 2006.

107. Argonne National Laboratory, "Greenhouse Gases, Regulated Emissions, and Energy Use in Transportation (GREET) Model, version 1.7 (beta), released January 18, 2006.

108. Environmental Protection Agency, AP-42, Compilation of Air Pollutant Emission Factors. Section 1.6:Wood Residue combustion in Boilers. Research Triangle Park, NC: U.S. Environmental Protection Agency, March 2002.

109. Environmental Protection Agency, AP-42, Compilation of Air Pollutant Emission Factors. Section 1.4: Natural Gas Combustion. Research Triangle Park, NC: U.S. Environmental Protection Agency, July 1998.

110. Miner, R., NCASI, Personal Communication, 21 August 2003.

111. National Council for Air and Stream Improvement, Inc., "An Analysis of Kraft Recovery Furnace NOx Emissions and Related Parameters." Technical Bulletin No. 636. New York, NY: National Council of the Paper Industry for Air and Stream Improvement, Inc., July 1992.

112. National Council for Air and Stream Improvement, Inc., "Calculation Tools for Estimating Greenhouse Gas Emissions from Pulp and Paper Mills. Version 1.0," Research Triangle Park, NC: National Council for Air and Stream Improvement, Inc., December, 2002.

113. National Council for Air and Stream Improvement, Inc., "Compilation of Speciated Reduced Sulfur Compound and Total Reduced Sulfur Emissions Data for Kraft Mill Sources," Technical Bulletin No. 849. Research Triangle Park, NC: National Council for Air and Stream Improvement, Inc., August 2002. 
114. National Council for Air and Stream Improvement, Inc., "Performance of EPA Stack Sampling Methods for PM10, PM2.5 and Condensible Particulate Matter on Sources Equipped With Electrostatic Precipitators," Technical Bulletin No. 852, Research Triangle Park, NC: National Council for Air and Stream Improvement, Inc., September, 2002.

115. National Council for Air and Stream Improvement, Inc., "Table: Summary of 'Air Toxic' Emissions from NDCE Kraft Recovery Furnaces," Personal facsimile communication from John Pinkerton, December, 2002.

116. National Council for Air and Stream Improvement, Inc., "Sulfur Dioxide and Nitrogen Oxides Emissions from Pulp And Paper Mills In 2000,” NCASI Special Report No. 02-06, December 2002.

117. National Council for Air and Stream Improvement, Inc., "Factors Affecting NOx Emissions from Lime Kilns,” Technical Bulletin No. 855, Research Triangle Park, NC: National Council for Air and Stream Improvement, Inc., January 2003.

118. National Council for Air and Stream Improvement, "Calculation Tools for Estimating Greenhouse Gas Emissions from Pulp and Paper Mills, Version 1.0," a project for ICFPA, available at www.ncasi.org, August 2006.

119. Gasification Technologies Council, "Gasification Offers Significant Environmental and Economic Benefits," accessed at http://www.gasification.org, 16 June 2003.

120. Orr, D. and Maxwell, D., "A Comparison of Gasification and Incineration of Hazardous Wastes: Final Report,” DCN 99.803931.02. Austin, TX: Radian International, LLC, March 2000.

121. Ratafia-Brown, J.A., Manfredo, L.M., Hoffmann, J.W., and Massood, R. (Science Applications International Inc.) and Gary J. Stiegel (U.S. DOE/National Energy Technology Laboratory), "An Environmental Assessment of IGCC Power Systems," presented at 19th Annual Pittsburgh Coal Conf., September 2002.

122. Simbeck, D, "Future of U.S. Coal-Fired Power Generation: Band-Aids or Corrective Surgery," presented at the Gasification Technologies Conference, San Francisco, October 2002.

123. Simbeck, D., "Process Screening Analysis of Alternative Gas Treating and Sulfur Recovery for Gasification," presented at the Nineteenth Annual Pittsburgh Coal Conf., September 2002.

124. Teco Energy, "Polk Power Station IGCC”, DOE/NARUC Clean Coal Technology Forum, 8 December 2002.

125. Ubis, T., Bressan, L. and O'Keefe, L., "The 800 MW PIEMSA IGCC Project," presented at the Gasification Technologies Conference, San Francisco, October 2000.

126. Environmental Protection Agency, AP-42, Compilation of Air Pollutant Emission Factors. Section 3.1: Stationary Gas Turbines. Research Triangle Park, NC: U.S. Environmental Protection Agency, April 2000.

127. Energy Information Administration, Annual Energy Outlook 2005 with Projections to 2030. DOE/EIA-0383 (2005). Washington, DC: U.S. Dept. of Energy, January, 2005.

128. Environmental Protection Agency (EPA). Inventory of U.S. Greenhouse Gas Emissions and Sinks: 1990-2003. EPA 430-R-05-003. Washington, DC: U.S. Environmental Protection Agency, April, 2005.

129. Environmental Protection Agency (EPA), National Emissions Inventory Trends Report, updated July 18, 2005. See also the NEI Air Pollutant Emissions Trends Data at www.epa.gov/ttn/chief/trends.

130. Oguma, M. and Goto, S. "Evaluation of Medium Duty DME Truck Performances - Field Test Results and Trace Level Emissions Measurement." Presented at the 2nd International DME Conference (DME2), London, UK, May 15-17, 2006.

131. Delucchi, Mark, Institute for Transportation Studies, UC Davis, “A Lifecycle Emissions Model (LEM): Lifecycle Emissions from Transportation Fuels, Motor Vehicle, Transportation Modes, Electricity Use, Heating and Cooking Fuels, and Materials, Documentation of methods and data," UCD-ITS-RR-03-17, Main Report, December, 2003.

132. Weyerhaeuser Company, "Biomass Gasification Combined Cycle," final report under contract DE-FC3696GO10173 to U.S. Department of Energy, Federal Way, Washington, 2000, 160 pages.

133. M. Themens, Barr-Rosin Ltd., Boisbriand, Quebec, Canada, personal communication, 21 Nov. 2006. 
134. Energy Information Administration, Annual Energy Outlook 2006, with Projections to 2030, DOE/EIA0383(2006), U.S. Department of Energy, February 2006.

135. Office of Compensation Levels and Trends. Employment Cost Index. Bureau of Labor Statistics, Washington, DC, October 2002.

136. Marker, T. (UOP), "Opportunities for Forest Biorenewables in Oil Refineries," unpublished presentation at meeting of this project's Steering Committee, 3 June 2005.

137. Texaco Energy Systems, "Early Entrance Coproduction Plant," DOE cooperative agreement, No. DE-FC2699FT40658, 2001.

138. Energy Information Administration, Annual Energy Outlook 2002 with Projections to 2020. DOE/EIA-0383 (2002). Washington, DC: U.S. Dept. of Energy, January 2002.

139. Dow Chemical, "Dow Announces June 1 Price Increases for Oxygenated Solvents," press release, 2 May 2006.

140. National Renewable Energy Laboratory, "Production of Mixed Alcohols from Spent Pulping Liquors," presented at DOE's Syngas to Value-Added Fuel Products Meeting, Washington DC, 9 March, 2005.

141. Aulich, T., "Ethanol Market Opportunities Beyond Gasoline", presented at Governors' Ethanol Coalition Meeting, Sioux Falls, South Dakota, 1 August 2003.

142. A. Aden, National Renewable Energy Laboratory, personal communication 2006.

143. Gilshannon, S.T. and Brown, D.R., Review of Methods for Forecasting the Market Penetration of New Technologies, Pacific Northwest National Laboratory, December 1996.

144. American Forest \& Paper Association, personal communication from Elizabeth Davies, 22 May 2006.

145. Fisher, J.C. and Pry, R.H., "A Simple Substitution Model of Technological Change," Technological Forecasting and Social Change, 3:75-88, 1971.

146. Homer, G. Air Liquide, personal communication, 31 January 2006.

147. National Research Council, Division on Engineering \& Physical Sciences, Board on Energy and Environmental Systems, Committee on Benefits of DOE R\&D in Energy Efficiency and Fossil Energy, Energy Research at DOE, was it worth it? Energy Efficiency and Fossil Energy Research 1978-2000, Appendix E: Case Studies for the Energy Efficiency Program, National Academy Press, Wash. DC, 2001.

148. R.H. Williams, E.D. Larson, and H. Jin, "Comparing Climate-Change Mitigating Potentials of Alternative Synthetic Liquid Fuel Technologies Using Biomass and Coal," Proceedings, Fifth Annual Conference on Carbon Capture and Sequestration, US Department of Energy, Washington DC, 8-11 May 2006. 


\section{A Cost-Benefit Assessment of Gasification-Based Biorefining in the Kraft Pulp and Paper Industry}

\section{Volume 2 \\ Detailed Biorefinery Design and Performance Simulation}

FINAL REPORT

Under contract DE-FG26-04NT42260 with the U.S. Department of Energy and with cost-sharing by the American Forest and Paper Association

21 December 2006

Eric D. Larson

Princeton Environmental Institute

Princeton University

Princeton, NJ

elarson@princeton.edu

Stefano Consonni and Silvia Napoletano

Department of Energy Engineering

Politecnico di Milano

Milan, Italy

stefano.consonni@polimi.it

Ryan E. Katofsky

Navigant Consulting, Inc.

Burlington, MA

rkatofsky@navigantconsulting.com

Kristiina Iisa and Jim Frederick

Institute of Paper Science and Technology

School of Chemical and Biomolecular Engineering Georgia Institute of Technology

Atlanta, GA

Kristiina.Iisa@ipst.gatech.edu

Jim.Frederick@ipst.gatech.edu
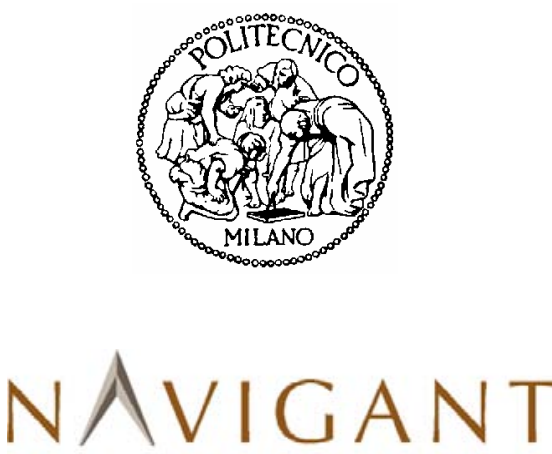

C O N S U L T I N G

With contributions from:

Wang Xun

Department of Energy Engineering

Politecnico di Milano 


\section{Table of contents}

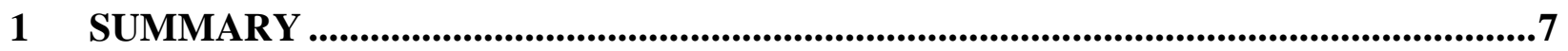

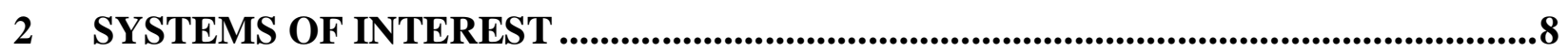

2.1 Summary and nomenclature of plant configurations.....................................................

3 CALCULATION OF MASS AND ENERGY BALANCES ….....................................10

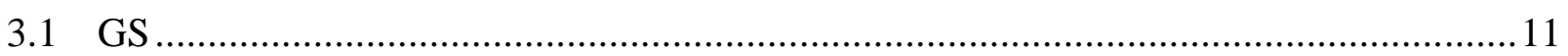

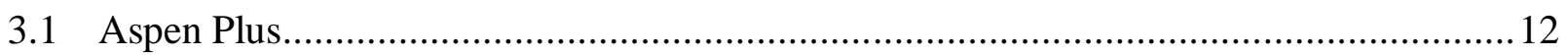

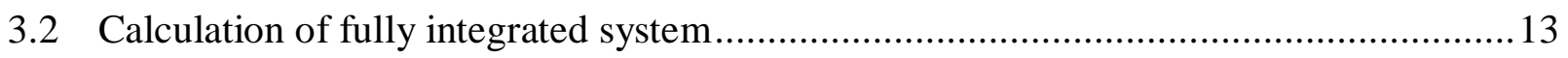

4 ASSUMPTIONS AND TECHNOLOGICAL ISSUES................................................16

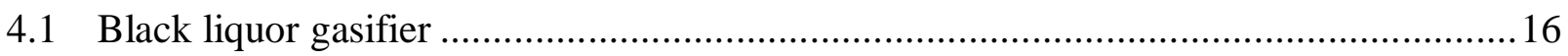

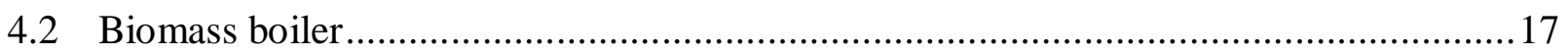

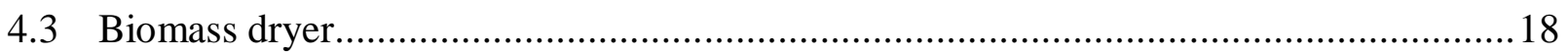

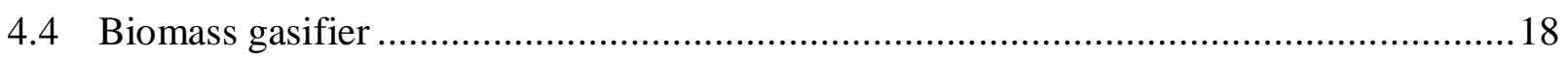

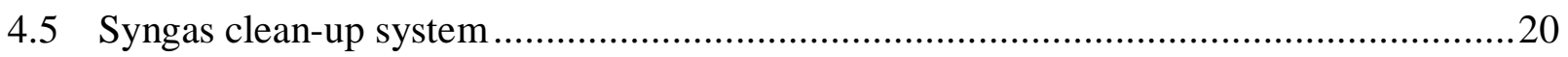

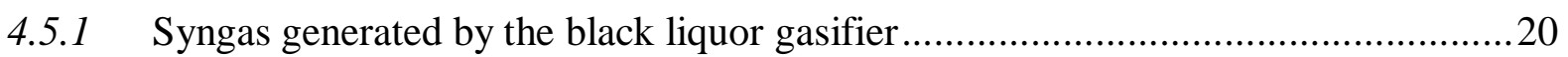

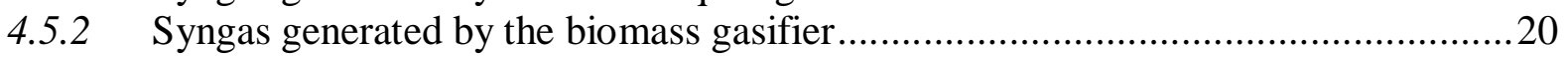

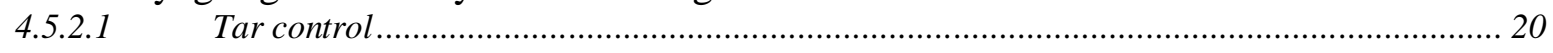

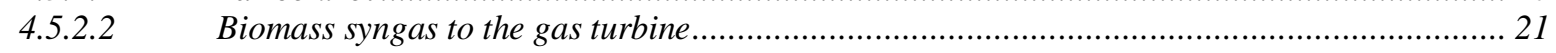

4.5.2.3 Biomass syngas to the Fuel Synthesis Island...…………………………………..... 22

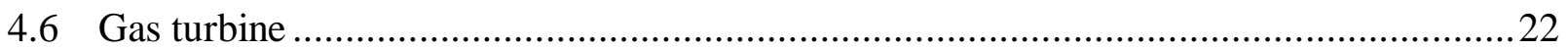

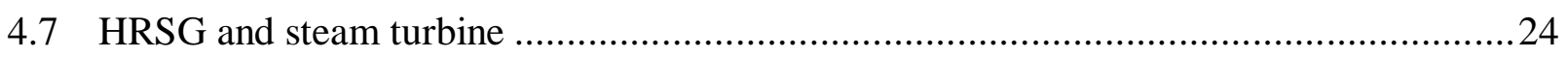

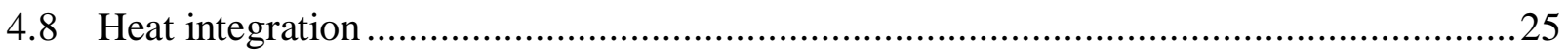

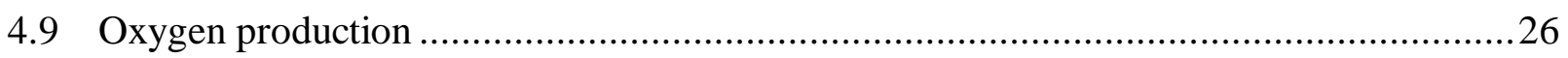

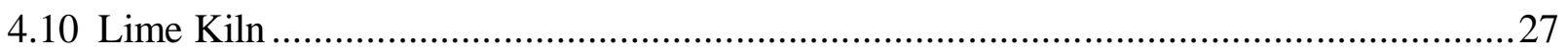

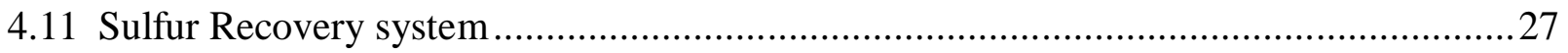

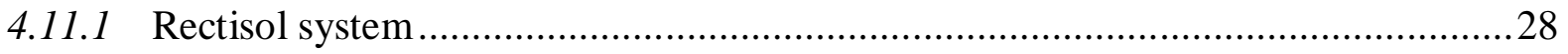

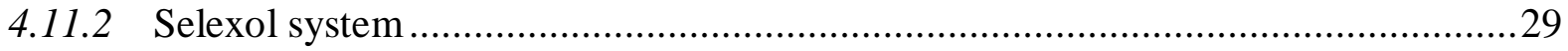

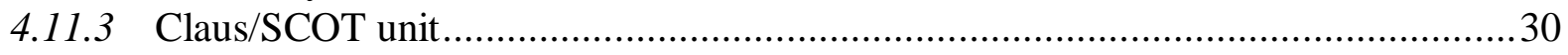

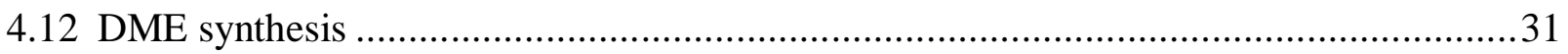

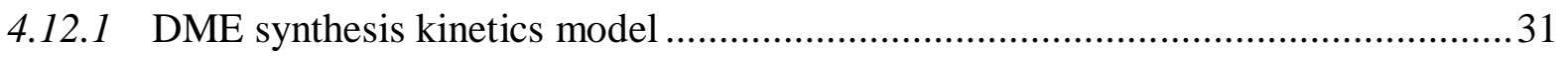

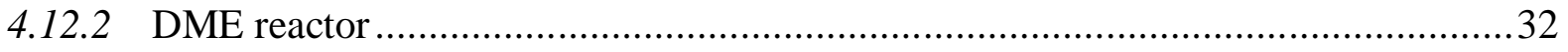

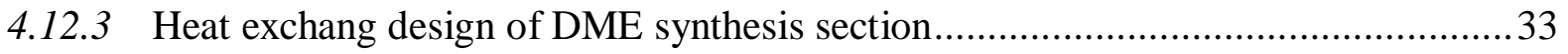

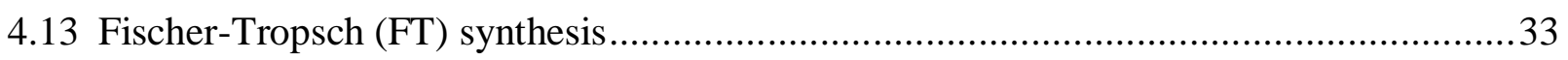

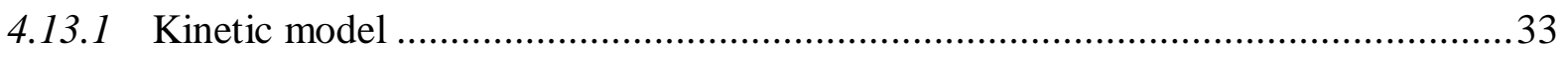

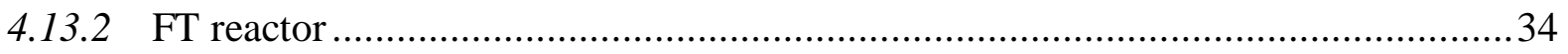

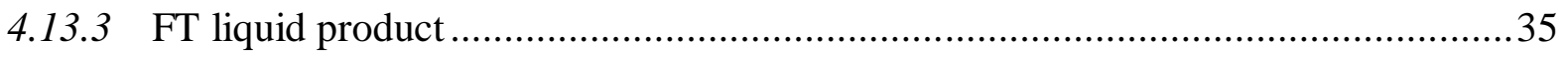

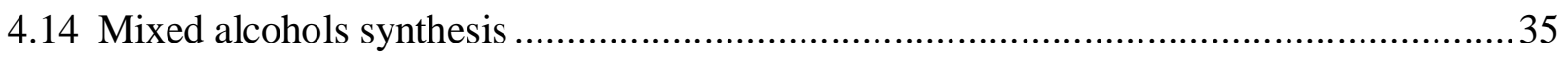

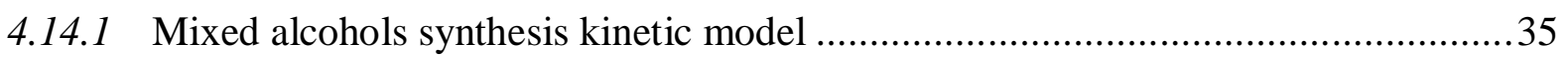

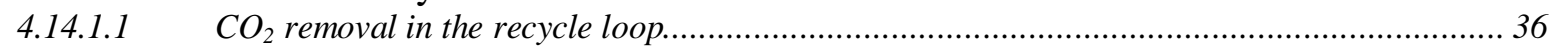

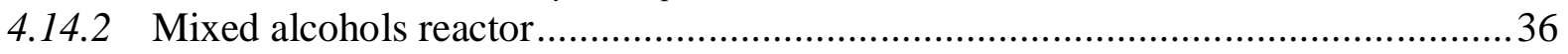


5 PROCESS CONFIGURATIONS AND OPERATING CONDITIONS.

5.1 Summary of technologies adopted for the major subsystems .......................................... 38

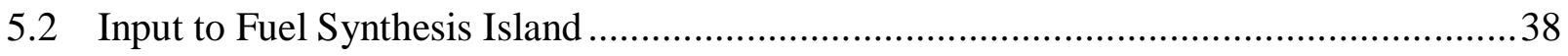

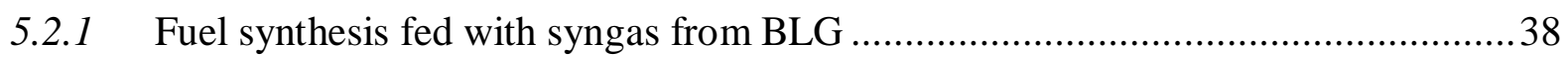

5.2.2 Fuel synthesis fed with syngas from BLG and from biomass gasification................39

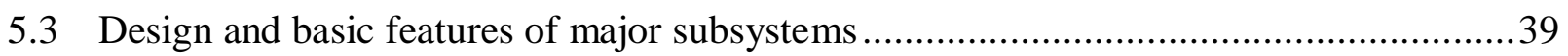

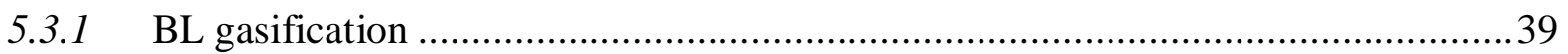

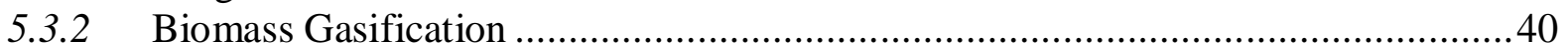

5.3.2.1 Biomass gasification with syngas cooler ……………………………………………..... 40

5.3.2.2 Biomass gasification with quench ………………………………………………. 41

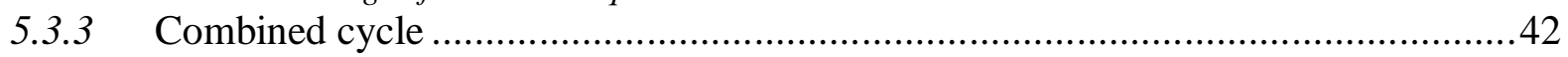

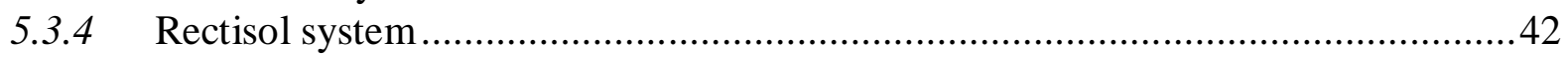

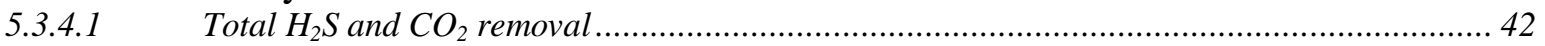

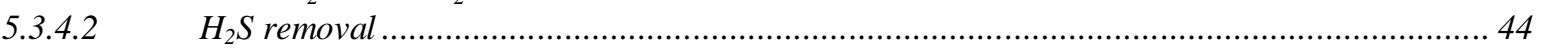

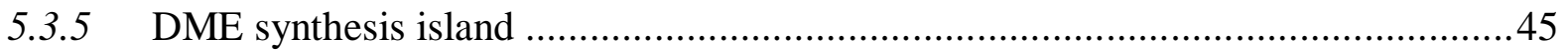

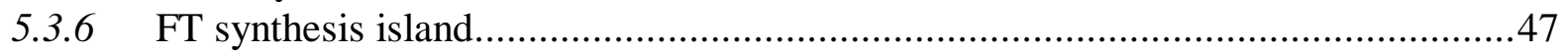

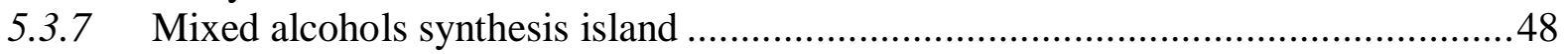

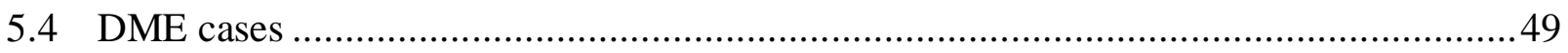

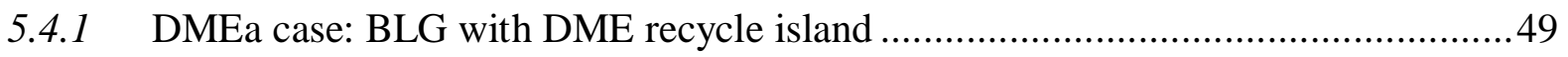

5.4.1.1 BL syngas cooling ............................................................................................... 49

5.4.1.2 Power boiler and steam cycle ................................................................................ 50

5.4.2 DMEb case: BLG and BGCC with DME recycle ...............................................50

5.4.3 DMEc case: BLG and BGCC with DME once-through production ........................51

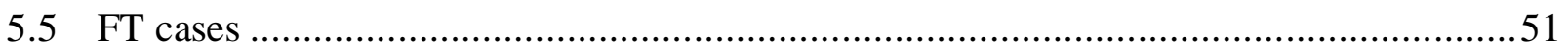

5.5.1 FTa case: BLG with FT production and BGCC with medium GT..........................51

5.5.2 FTb case: BLG with FT production and BGCC with large GT ............................51

5.5.3 FTc case: BLG and BG with FT production and $\mathrm{CC}$ with medium GT ...................51

5.6 MixOH case: BLG and BG with mixed alcohols production and $\mathrm{CC}$ with medium

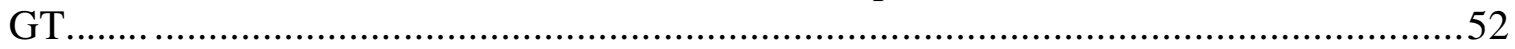

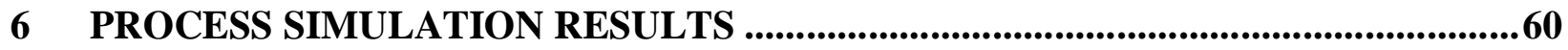

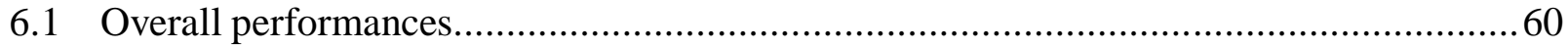

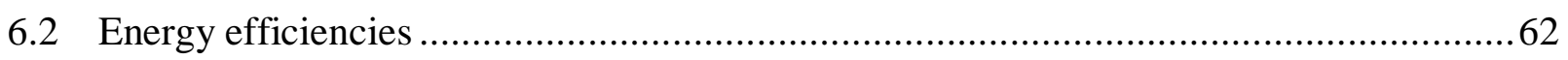

6.3 Biorefinery designs vs. conventional Tomlinson systems ............................................64

$7 \quad$ REFERENCES .........................................................................................................................67

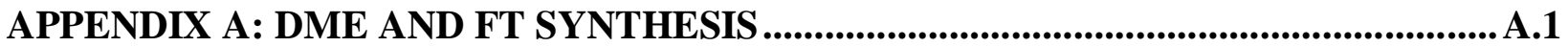

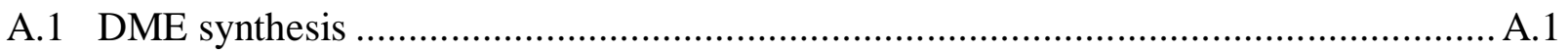

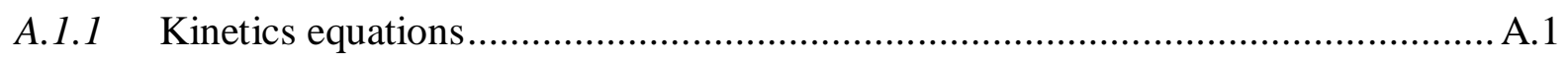

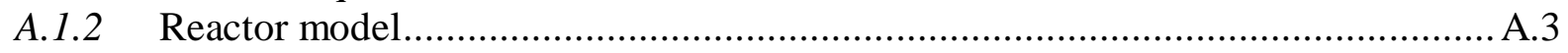

A.1.3 Comparisons with experiment results ......................................................... A.3

A.1.4 Sensitivity study of DME synthesis section ..................................................... A.5

A.1.4.1 Effect of reactor pressure variation...........................................................................

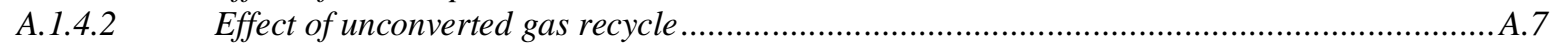

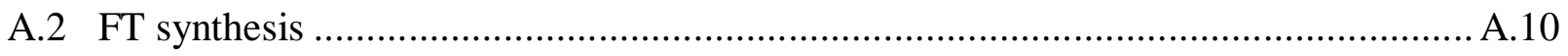




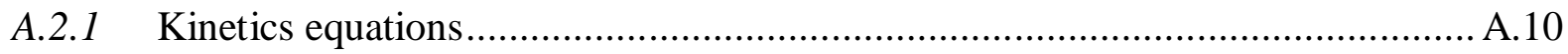

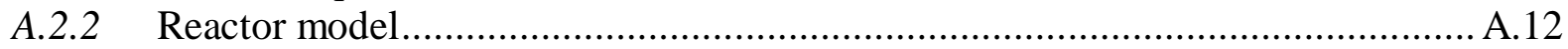

APPENDIX B: KINETIC MODEL FOR MIXED ALCOHOL SYNTHESIS .................... B.1

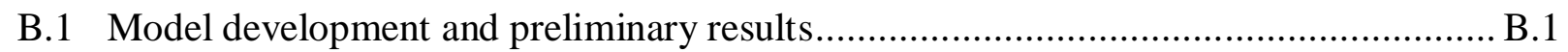

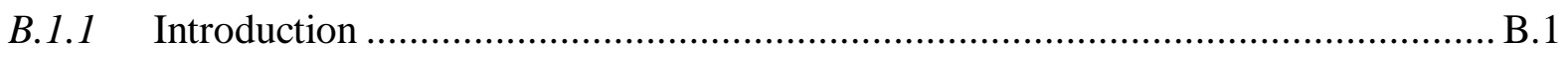

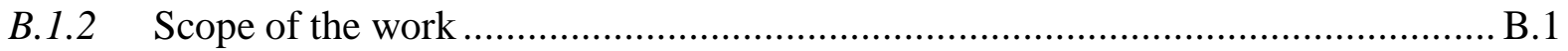

B.1.3 Development of the kinetic model.............................................................. B.2

B.1.4 Reactor simulation and validation of the kinetic model ................................... B.6

B.1.5 Simulation study of the effects of the operating variables ............................... B.13

B.1.6 Implementation of the kinetic model in a Fortran subroutine ............................ B.17

B.1.7 Comparison between the results obtained using ASPEN and the Fortran

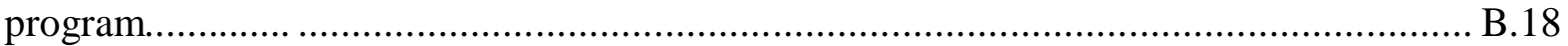

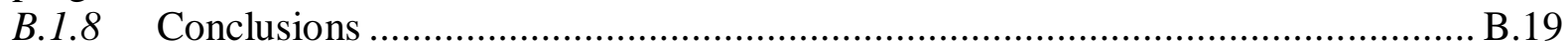

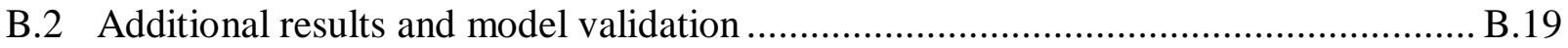

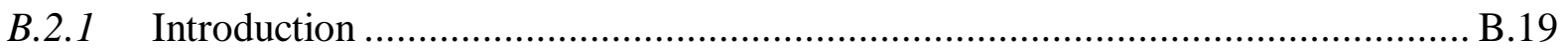

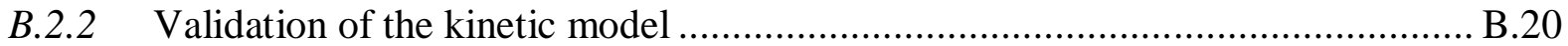

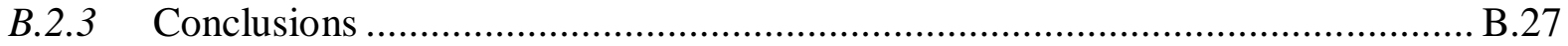

B.3 Literature cited …………………................................................................ B.28

\section{APPENDIX C: ANALYSIS AND SIMULATION OF A RECTISOL-BASED ACID GAS

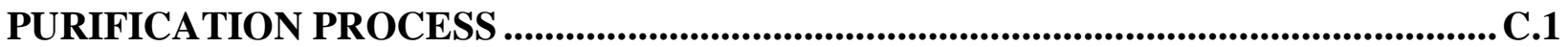

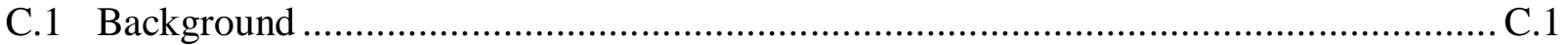

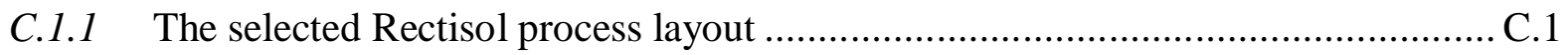

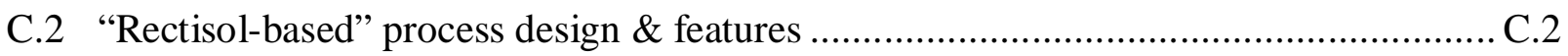

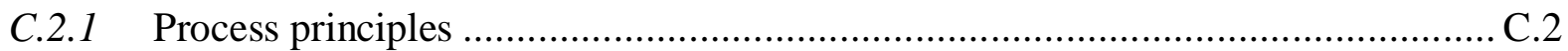

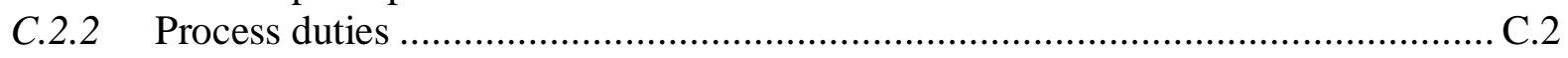

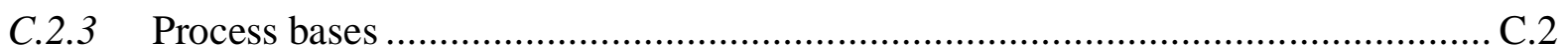

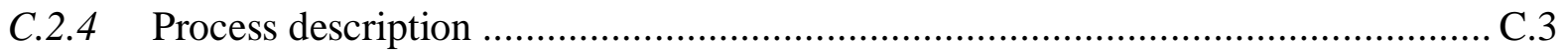

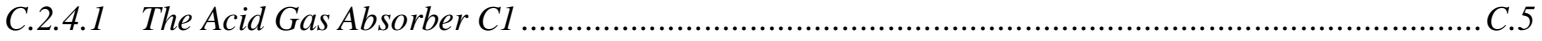

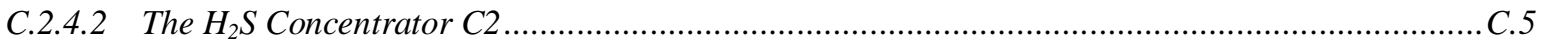

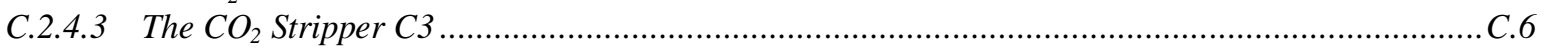

C.2.4.4 The Solvent Regenerator C4 ......................................................................................................

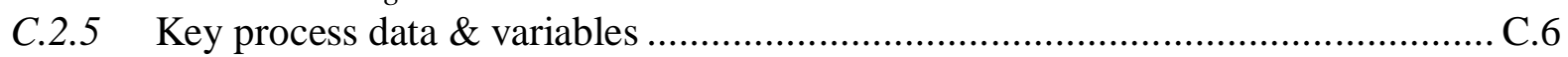

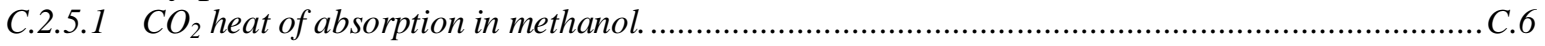

C.2.5.2 Different $\mathrm{H}_{2} \mathrm{~S}$ and $\mathrm{CO}_{2}$ solubility in methanol................................................................. . .

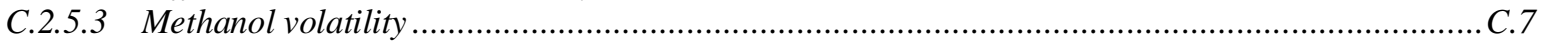

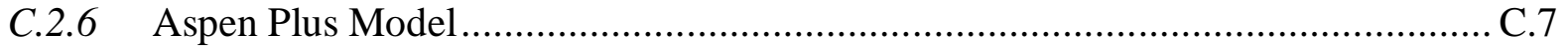

C.2.7 Aspen Plus Model results and discussion.......................................................

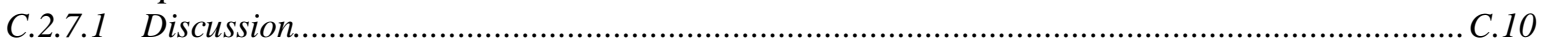

C.2.7.2 Addenda

C.2.8 Aspen Plus Model for the abatement of $\mathrm{H}_{2} \mathrm{~S}$ only ...............................................

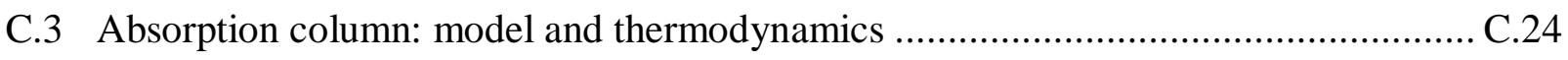

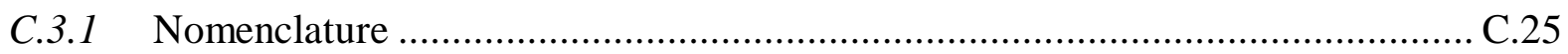

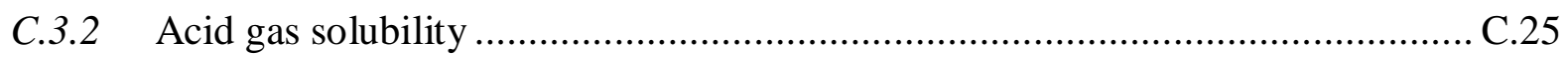

C.3.3 Heat of absorption of $\mathrm{CO}_{2}$ in methanol ( $-\Delta \mathrm{H}$ abs) ......................................... C.25 
C.3.4 Thermodynamic model

C.3.5 Heat and material balance equations in the absorption column

C.3.6 ABSORBER.xls user interface.

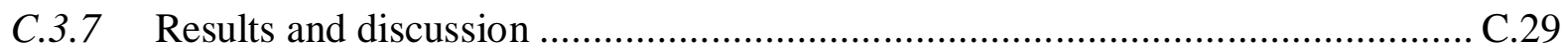

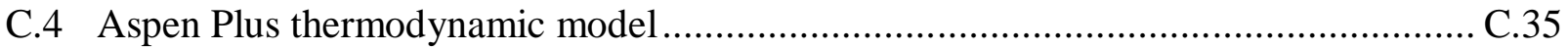

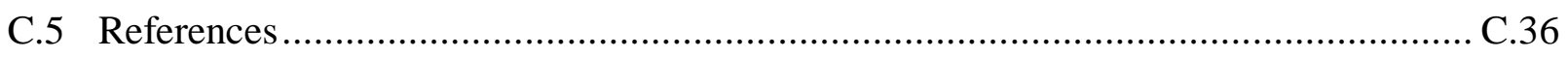

Note: "Navigant is a service mark of Navigant International, Inc. Navigant Consulting, Inc. (NCI) is not affiliated, associated, or in any way connected with Navigant International, Inc., and NCI's use of "Navigant" is made under license from Navigant International, Inc. 


\section{NOMENCLATURE}

$\begin{array}{ll}\text { ASF } & \text { Anderson-Schulz-Flory (distribution) } \\ \text { BLGCC } & \text { Black Liquor Gasification Combined Cycle } \\ \text { BLGF } & \text { Black Liquor Gasification Fuel } \\ \text { CC } & \text { Combined Cycle } \\ \text { CSTR } & \text { Continuous Stirred Tank Reactor } \\ \text { DME } & \text { Dimethyl Ether } \\ \text { FSI } & \text { Fuel Synthesis Island } \\ \text { FT } & \text { Fischer Tropsch } \\ \text { GHSV } & \text { Gas Hourly Space Velocity } \\ \text { GI } & \text { Gasification Island } \\ \text { GT } & \text { Gas Turbine } \\ \text { GTL } & \text { Gas To Liquid } \\ \text { HRSG } & \text { Heat Recovery Stream Generator } \\ \text { HP } & \text { High Pressure } \\ \text { IGCC } & \text { Integrated Gasification Combined Cycle } \\ \text { IP } & \text { Intermediate Pressure } \\ \text { LP } & \text { Low Pressure } \\ \text { LPDME } & \text { Liquid Phase DME (reactor) } \\ \text { MixOH } & \text { Mixed Alcohols } \\ \text { MP } & \text { Medium Pressure } \\ \text { PFR } & \text { Plug-Flow Reactor } \\ \text { ppmv } & \text { parts per million by volume } \\ \text { SRU } & \text { Sulfur Recovery Unit } \\ \text { WGS } & \text { Water Gas Shift }\end{array}$




\section{SUMMARY}

This volume illustrates the technologies, the assumptions and the modelization adopted to estimate the heat and mass balances of the biorefinery systems considered in this study.

Accurately calculating the mass/heat balances is crucial not only to verify the feasibility of a conceptual design and the applicability of a technological option, but also to estimate economic returns and environmental impacts. The modelization presented in this volume allows calculating all the parameters needed to appraise the overall plant performances:

- operating conditions of the most important components;

- extra-biomass input required to satisfy the mill steam demand;

- auxiliary power consumption;

- steam and cold duties;

- net power production;

- net fuel production.

These data are the basis to estimate capital and operating costs, and thus economic returns. The plant scheme and the operating conditions considered for each case are the outcome of significant screening work, which included the test of a considerable number of alternatives and sensitivity analyses. The basic feature that characterizes a plant scheme is the liquid fuel generated in the Fuel Synthesis Island (FSI), for which we've considered three cases:

- DME

- raw Fischer-Tropsch

- Mixed Alcohol

The type of fuel however does not fully characterize our plant configurations. The other basic options specified are:

- the arrangement of the Fuel Synthesis Island (with or without syngas recycle);

- the type of gas turbine (if any);

- the type of biomass gasifier (if any).

The combination of these options generates a relatively large number of alternative configurations. In this study we've focused on a total of seven cases which appear particularly meaningful and interesting: three for DME, three for Fischer-Tropsch and one for Mixed Alcohol. Although these seven cases do not exhaust the range of possible options, they give clear indications on the potential and the implications of pulpmill biorefinery systems.

Given the complexity of the systems to be modeled and the variety of the technologies involved, the modelization has been particularly challenging. A BLGF plant comprises subsystems that fall in the realm of combustion and process technology (gasifier, heat exchangers, burners, etc.), others typical of the chemical industry (gas clean-up system, reactors, distillation columns, etc. ) and others belonging to power plant technology (steam cycle, gas turbine, compressors and expanders, etc.). As a consequence, no single simulation tool is ideally suited for modeling the whole integrated biorefinery. In this study we've combined the use of two computer codes:

- GS, a code developed for research purposes at Politecnico di Milano and Princeton University;

- Aspen Plus, a code originally developed at MIT and now commercialized by AspenTech Inc.

Despite some complexity, the calculation algorithm based on these two codes provides an accuracy similar (or higher) to that of the most detailed engineering studies that can be found in the literature. 
The technologies and the design parameters considered for each major sub-system are in between the state-of-the-art and the projections for the timeframe of the "Nth plant" biorefinery.

The results summarized in the last chapter of this volume allow appraising the merits of each plant option. The variety of the plant configurations analyzed in the study gives a wide range of power and fuel productions, as well as of efficiencies.

\section{SYSTEMS OF INTEREST}

The systems considered in this study are determined by alternative combinations of a few key processes:

- black liquor gasification

- biomass gasification (in one case biomass combustion)

- syngas cooling and clean-up

- catalytic synthesis of a liquid fuel from syngas

- co-generation of power and heat

The various technologies that can be used for these basic processes give rise to a large number of alternative configurations. The configurations considered in this study have been selected as among the most interesting and viable options to co-produce electricity, heat and liquid fuels under the constraint of handling all of the available black liquor and meeting the steam demand of the reference pulp and paper mill.

The plant scheme and the operating conditions considered for each case are the outcome of significant screening work, which included the test of a considerable number of alternatives and sensitivity analyses. This doesn't mean that the schemes and the set of operating parameters considered here are necessarily optimal, although we believe the performance improvements achievable by a more thorough optimization would be marginal. Significant improvements of efficiencies, power output or fuel output are likely to be achieved only by significant changes in the characteristics of the basic technologies, e.g. more effective catalysts, more efficient gas turbine, different gasification technology, etc.

Schematically, the systems modelled in this study consist of five basic "islands":

- black liquor gasification island

- biomass gasification island (or, in one scheme, biomass boilers)

- $\quad$ syngas heat recovery and syngas clean-up island

- fuel synthesis island

- power island

The gasification island includes a cryogenic Air Separation Unit for the production of oxygen. The black liquor and biomass gasification islands are essentially the same for all the cases considered (except for the size of the biomass gasification island, which changes very significantly from one case to another). The heat recovery section has been tailored to the characteristics of each plant scheme to maximize the benefits of heat integration. The syngas clean-up island is centered around a Rectisol unit, except for the mixed alcohol case which adopts a Selexol system. The fuel synthesis island is the section that gives the basic characterization to the plant scheme. We have considered the following cases:

- production of DME from black liquor syngas, with no syngas recycle

- production of DME from black liquor syngas, with syngas recycle

- production of raw Fischer-Tropsch fuel from black liquor syngas, no syngas recycle

- production of raw Fischer-Tropsch fuel from a mix of black liquor and biomass syngas, no syngas recycle 
- production of mixed alcohol from a mix of black liquor and biomass syngas, with syngas recycle.

The cases of DME with syngas recycle and Fischer-Tropsch fuel from black liquor syngas have been further differentiated based on the type of power island. For DME with syngas recycle we've considered a case with power boilers (no biomass gasifier) and just a steam cycle, and a case with a biomass gasifier and a combined cycle. For the case of Fischer-Tropsch fuel from black liquor syngas we've considered a case with a medium-size, $70 \mathrm{MW}$ class gas turbine (GE 6FA) and another case with a large, $170 \mathrm{MW}$ class gas turbine (GE 7FA).

\subsection{Summary and nomenclature of plant configurations}

As already mentioned, the basic feature that characterizes a plant scheme is the type of liquid fuel generated in the Fuel Synthesis Island (FSI):

- DME

- raw Fischer-Tropsch

- Mixed Alcohol

The type of fuel however is not enough to fully characterize the plant configuration. The other basic options specified are:

- the arrangement of the Fuel Synthesis Island (with or without syngas recycle);

- the type of gas turbine (if any);

- the type of biomass gasifier (if any)

\begin{tabular}{|c|c|c|c|c|c|c|}
\hline \multicolumn{2}{|c|}{ Arrangement of Fuel Synthesis Island } & \multicolumn{2}{|c|}{ with syngas recycle } & \multicolumn{2}{|c|}{ once-through } & \multirow[b]{2}{*}{ syngas utilization } \\
\hline Gas turbin & & none & $\begin{array}{l}\text { medium } \\
\text { scale } \\
\text { (6FA) }\end{array}$ & $\begin{array}{l}\text { medium } \\
\text { scale } \\
\text { (6FA) }\end{array}$ & $\begin{array}{l}\text { large } \\
\text { scale } \\
\text { (7FA) }\end{array}$ & \\
\hline \multirow{3}{*}{$\begin{array}{l}\text { Biomass } \\
\text { gasifier: }\end{array}$} & NO (power boilers) & DMEa & & & & syngas from BL goes to FSI \\
\hline & YES, with syngas cooler & & DMEb & $\begin{array}{c}\text { DMEc } \\
\text { FTa }\end{array}$ & FTb & $\begin{array}{l}\text { syngas from BL goes to FSI, } \\
\text { syngas from biomass gasifier } \\
\text { goes to gas turbine }\end{array}$ \\
\hline & YES, with quench & & MixOH & FTc & & $\begin{array}{l}\text { syngas from BL and from } \\
\text { biomass gasifier are mixed, and } \\
\text { the whole flow goes to FSI }\end{array}$ \\
\hline
\end{tabular}

light blue background = back-pressure steam turbine

orange background = duct burner + back-pressure steam turbine

yellow background = steam turbine with low pressure section

\section{Tab. 1. Overview of plant configurations}

The overall picture is summarized in Tab. 1, where the nomenclature is as follows:

DMEa Production of DME, FSI with syngas recycle, no gas turbine (power island comprises just a steam cycle). The extra steam required to meet the mill demand is generated by power boilers and the FSI is fed (necessarily) with the syngas generated by black liquor. Given the need for the power boilers, no excess steam is available and the steam turbine is backpressure.

$\mathrm{DMEb}$ Like DMEa, but with a biomass gasifier that generates enough syngas to fully fire a medium-scale gas turbine. In this case the steam demand of the mill is met by burning some syngas in a duct burner ahead of the HRSG of the combined cycle. 
Given the need for the duct burner, no excess steam is available and the steam turbine is backpressure.

DMEc Like DMEb, but without syngas recycle in the FSI. Similarly to DMEb, also in this case some syngas must be burnt into a duct burner ahead of the HRSG of the combined cycle and the steam turbine is backpressure.

FTa Production of Fischer-Tropsch fuel, once-through FSI, biomass gasifier that generates enough syngas to fully fire a medium-scale gas turbine. The steam demand of the mill is met by burning some syngas in a duct burner ahead of the HRSG of the combined cycle and the steam turbine is backpressure.

FTb Like FTa, but with a large scale, $170 \mathrm{MW}$ class gas turbine. The much larger size of the gas turbine eliminates the need for the duct burner. Steam production is much larger than needed by the mill, so the steam turbine includes a low pressure (condensing) section to increase power generation.

FTc Like FTa, but with the FSI fed by the mix of all the syngas generated by black liquor and all the syngas generated by biomass. The much higher fuel production increases steam production in the exothermic FT reactor and eliminates the need for a duct burner to meet the mill steam demand. Similarly to FTb, steam production is larger than needed by the mill and the steam turbine includes a low pressure condensing section.

$\mathrm{MixOH}$ Production of mixed alcohols with the same rationale of scheme FTc, i.e. the FSI is fed by the mix of all the syngas generated by black liquor and all the syngas generated by biomass. In this case however, the low conversion achievable in the mixed alcohol reactor makes syngas recycle in the FSI imperative. Despite the syngas recycle, fuel conversion and thus steam production in the FSI are relatively low and the steam demand of the mill can be met only by burning some syngas in a duct burner placed, as usual, ahead of the HRSG of the combined cycle. Since no excess steam is available, the steam turbine is backpressure.

When biomass syngas feeds the gas turbine (DMEb, DMEc, FTb, FTc) we've considered a biomass gasifier with syngas cooler. The syngas exiting the syngas cooler is filtered through ceramic candles and then fed to the gas turbine. Although not yet demonstrated at commercial scale, pilot-scale testing has been successful (e.g., at Varnamo, Sweden), and it is believed that this arrangement can be compatible with requirements of the gas turbine in commercial service.

When the syngas generated from biomass is mixed with the syngas generated from black liquor and the mixture feeds the FSI we've considered a biomass gasifier with quench. In this case the catalyst of the FSI requires deep removal of all contaminants from the syngas and gas clean-up must necessarily take place at low temperature. The penalties brought about by quenching the syngas are therefore limited, because the syngas has to be cooled to low temperature anyhow. On the other hand, a quench gasifier would be lower cost than the gasifier with syngas cooler design.

\section{CALCULATION OF MASS AND ENERGY BALANCES}

The calculation of mass and energy balances is the fundamental step required to estimate performances and costs of the technologies considered in this study. Mass and energy balances determine how much electricity and fuel can be generated by a given black liquor flow, as well as how much extra fuel (biomass or possibly fossil fuel) is needed to supply the mill steam 
requirements. Mass and energy balances also give the basic information needed to size and to estimate the cost of the most relevant equipment. All this allows estimating the capital costs and the operating costs, as well as the unit cost of the final products (electricity and/or fuel).

The mass and energy balances and the overall performances of each pulpmill biorefinery configuration have been evaluated by combining the use of two computer codes:

- GS, a code developed for research purposes at Politecnico di Milano and Princeton University;

- $\quad$ Aspen Plus, a code originally developed at MIT and now managed and commercialized by AspenTech Inc.

The following gives a brief description of each code and of the algorithm adopted to calculate the mass and energy balances.

\section{$3.1 \quad$ GS}

GS is a computer code originally developed at Politecnico di Milano and Princeton University to predict the performance of complex Gas-Steam cycles. The code is a powerful and flexible tool that can accurately predict the performances of a wide variety of systems for electricity production or cogeneration, including systems where the feedstock is gasified to generate a syngas that undergoes a sequence of physical and chemical processes. As such, GS has also been used extensively for the analysis of gasification-based power systems, including black liquor gasification plants.

The system of interest is defined as an ensemble of components, each belonging to one of sixteen basic types: pump, compressor, turbine, heat exchanger, combustor, gas turbine expander, chemical reactor, mixer, flow splitter, heat recovery steam cycle, air splitter plant, shaft connecting different machines, saturator, solid oxide fuel cell, intercooled compressor, steam cycle. The variety of elementary components and the possibility to interconnect them modularly provide high flexibility.

Once the system to be calculated has been defined and the coherence of the component characteristics and their inter-connections have been verified, the code sequentially calculates the mass, energy and atomic species balances of all plant components until it reaches the convergence of thermodynamic conditions and component characteristics calculated at each iteration. After reaching convergence, the code can carry out a complete entropy (or "SecondLaw") analysis to calculate the destruction of exergy and reversible work within each component and their input/output flows for the whole system.

The model accounts for all major phenomena and mechanisms affecting the performances of a wide variety of energy conversion systems: heat losses; variation of turbomachinery efficiency with scale and stage similarity parameters; constraints imposed by choking of flow at the gas turbine expander inlet, gas turbine cooling, incomplete chemical reactions, etc.; with proper input adjustments it can also predict basic off-design conditions.

The thermodynamic properties of all molecular species are calculated using a consistent methodology and the same data bases: JANAF tables for all gaseous species; SI steam tables for water and steam ${ }^{1}$. Chemical equilibrium is predicted by the same algorithm adopted in STANJAN, a code originally developed at Stanford by prof. William Reynolds. Thus, GS can simulate accurately the performance of reactors where the whole output flow or a subset of it is at chemical equilibrium.

\footnotetext{
${ }^{1}$ For methanol, ethanol, butane and butane, enthalpy and entropy are taken from Perry, Nasa coefficients by Bonnie McBride of NASA Lewis Center [from EDL website: www.galcit.caltech.edu/EDL/index.html].
} 


\subsection{Aspen Plus}

Aspen Plus is a widely used commercial chemical process simulation package originally developed for petrochemical refining applications. Due to its capability to simulate the operating conditions of chemical plants and to accommodate calculation of chemical kinetics, it well suited to calculate the chemical processing of syngas and the refining of the resulting products.

Aspen plus was originally developed at the MIT under a DOE project to simulate coal conversion processes. Now it has been widely accepted in the chemical industry as a design tool because of its ability to simulate a variety of steady-state processes ranging from single unit operations to complex processes involving many units.

Aspen plus was chosen as the simulation platform for our modeling of the syngas to fuel/chemical synthesis/separation process, as well as the gas purification section. The purpose of developing this simulation is to understand how co-production is affected by the constraints imposed by the chemical process, to evaluate different kinds of plant configurations, to find out ways to improve the performance of current designs. The features that make Aspen plus suitable to these purposes are:

Powerful database of chemical species properties. Compared to power production systems, the fuel synthesis island and the gas purification section include more types of chemicals (hydrocarbons, oxycompounds, sulfides, etc) which exhibit real gas behavior (i.e. departure from ideal gas law, including phase change). Having the correct thermophysical properties for such a large amount of compounds is crucial to predicting the performances of processes based on real gas effects like distillation columns, vapor-liquid separators, absorbers, strippers, etc. Aspen includes powerful packages with a variety of methods to predict the thermodynamic properties of the species and the mixtures being calculated.

A variety of models for the processes (flash, two-phase reaction, distillation, absorption, regeneration, etc.) carried out in syngas to liquid plants. Unlike power production, the synthesis of chemicals or fuels is often controlled by chemical kinetics and its simulation requires some form of kinetic model. In addition to simple models based on stoichiometry or chemical equilibrium, Aspen includes generalized models for kineticallycontrolled reactors which can be used to estimate the mass and energy balance of the basic types reactors: fixed bed, stirred, slurry bed or bubbling slurry bed. The model library of Aspen also includes a number of gas-solid, gas-liquid and gas-gas separators that allow estimating the yield and the utilities load of the whole synthesis island. The Aspen model can be used to illustrate the trade-offs among the design parameters that determine the performance of a co-production system, as well as to test the sensitivity to the operating conditions and the specifications of the major components.

The ability to embed user-compiled models into the simulation process. While the framework of the physical and chemical models that can be run with Aspen has general applicability, it is obviously impossible to include beforehand all types of compounds, reactors or kinetic rate expressions that can be encountered in specific applications. The lack of data on a specific process can be easily overcome by interfaces that allow users to embed their own models into Aspen simulations. In fact, for this project the fuel synthesis island has been simulated by embedding kinetic models of DME, Fischer-Tropsch and Mixed Alcohol synthesis into the Aspen framework. The specific kinetic expressions and the kinetic models required to simulate the synthesis of each type of fuel have been implemented in a Fortran subroutine called by the Aspen module that calculates the synthesis reactor. By developing appropriate in-house models, each user can tailor the simulation procedure to address specific 
requirements, not only for kinetic expressions, but also for aspects related to fluid dynamics, heat transfer, etc.

\subsection{Calculation of fully integrated system}

Aspen or GS alone cannot carry out satisfactory simulations of the fully integrated systems targeted in this project. This is why after a number of tests it was decided to use each code only for the systems for which it is most suited (Fig. 1 and Fig. 2): Aspen, for the Rectisol system and the fuel synthesis island; GS, for the gasification island and the power island.

In addition, GS was also used for the final pass giving the heat and mass balances of the whole integrated system, i.e. the actual final output for each plant configuration. This approach gives the maximum possible accuracy at the expense of the complexity of the calculation procedure, which requires a somewhat awkward but unavoidable sequence of GS and Aspen runs. The overall performances of each integrated system are calculated by going through the following steps, with the output generated at each step being the input required for one of the subsequent steps.

1. Run the GS model of the BL gasification island to predict the flow rate and the characteristics (composition, temperature, pressure) of the raw syngas at the inlet of the gas clean-up island, which are the inputs for the Aspen model of the Rectisol process.

2. Run the Aspen model of the Rectisol process to calculate flow rate and conditions of the clean syngas, as well as all other parameters needed to calculate the energy balance of the whole plant (cold and heat duty, flow rate and characteristics of streams other than the clean gas, etc.). In the MixOH case, syngas cleaning is carried out by the Selexol process and its utilities and material balances have been provided directly by UOP, licensor of the process.

3. Run the Aspen model of the fuel synthesis island using as input the outputs of the GS simulation of the gasification island and the Aspen simulation of the Rectisol system. This gives the amount of fuel available for export, as well as the flow rate and conditions (composition, temperature, pressure) of the unconverted syngas available for the power island, the refrigeration duty of the fuel synthesis island, the heat exchanged with power island, etc.

4. Run the GS model of the gasification island and power island altogether to predict the performances of the fully integrated system. This final calculation takes into account the Rectisol process and the fuel synthesis island as previously calculated by Aspen (heat exchanges, refrigeration duty, output flows, utilities, etc.), as well as the requirements of ancillary systems like the Claus and SCOT plant.

As long as no iteration is needed, this procedure requires a total of four runs in series (one GS + two Aspen + one final GS) and can be managed without excessive penalties, as shown in Fig. 3. This is the case for all plant configurations considered here except two: FTc and MixOH. In these cases the syngas generated by the biomass gasifier is mixed with the syngas generated from black liquor and the whole syngas flow is used for fuel production. The gas turbine is fed with the unconverted syngas from the fuel synthesis area (calculated by Aspen) and its flow rate must match the amount needed to fully fire the gas turbine. This requires repeating iteratively the calculation from step 2 to step 4, changing the amount of biomass fed to the biomass gasifier until the amount of unconverted syngas calculated by Aspen at step 3 equals the amount estimated by GS at step 4 for the gas turbine (Fig. 4). The complexity of this iteration procedure 
makes it difficult (though not impossible) to carry out systematic investigations like sensitivity or parametric analyses.

A more straightforward procedure would obviously be desirable, but it would require the development of new software tools for the integration of Aspen and GS (or possibly other pieces of software). Aside from issues of software intellectual property (Aspen is a highly protected commercial package), such effort is much beyond the scope of this project. Despite its complexity, the calculation procedure adopted here appears therefore the best way to take advantage of the tools currently available. The approach provides an accuracy similar to (or greater than) that of the most detailed engineering studies that can be found in the literature.

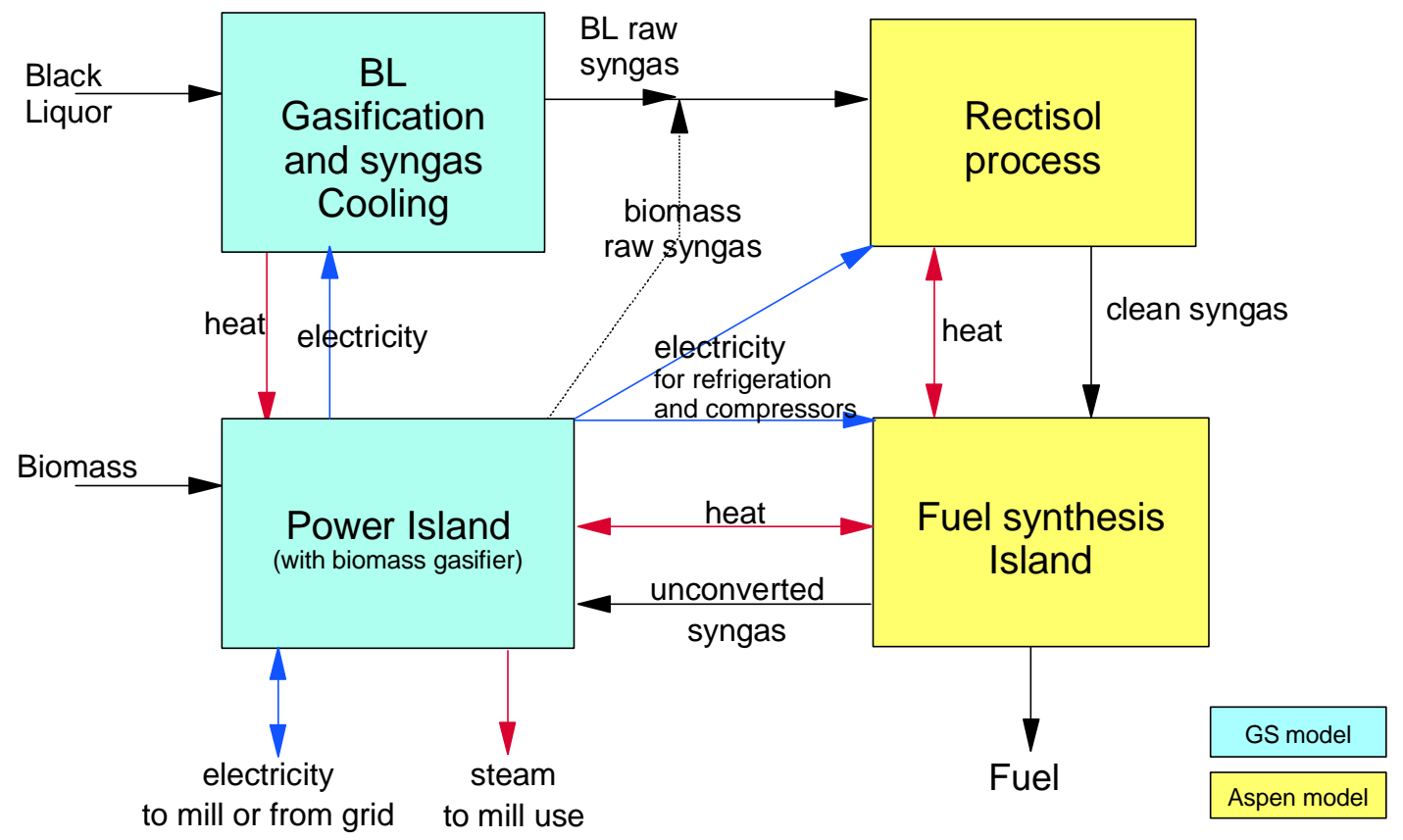

Fig. 1. Diagram of computer codes used for DME and FT cases. The BL gasification island is calculated first with GS. Then, Aspen is run twice to simulate the Rectisol system and the fuel synthesis island. Finally, GS is run again to simulate the whole integrated system, taking into account the results generated by Aspen for the Rectisol system and the fuel synthesis island. 


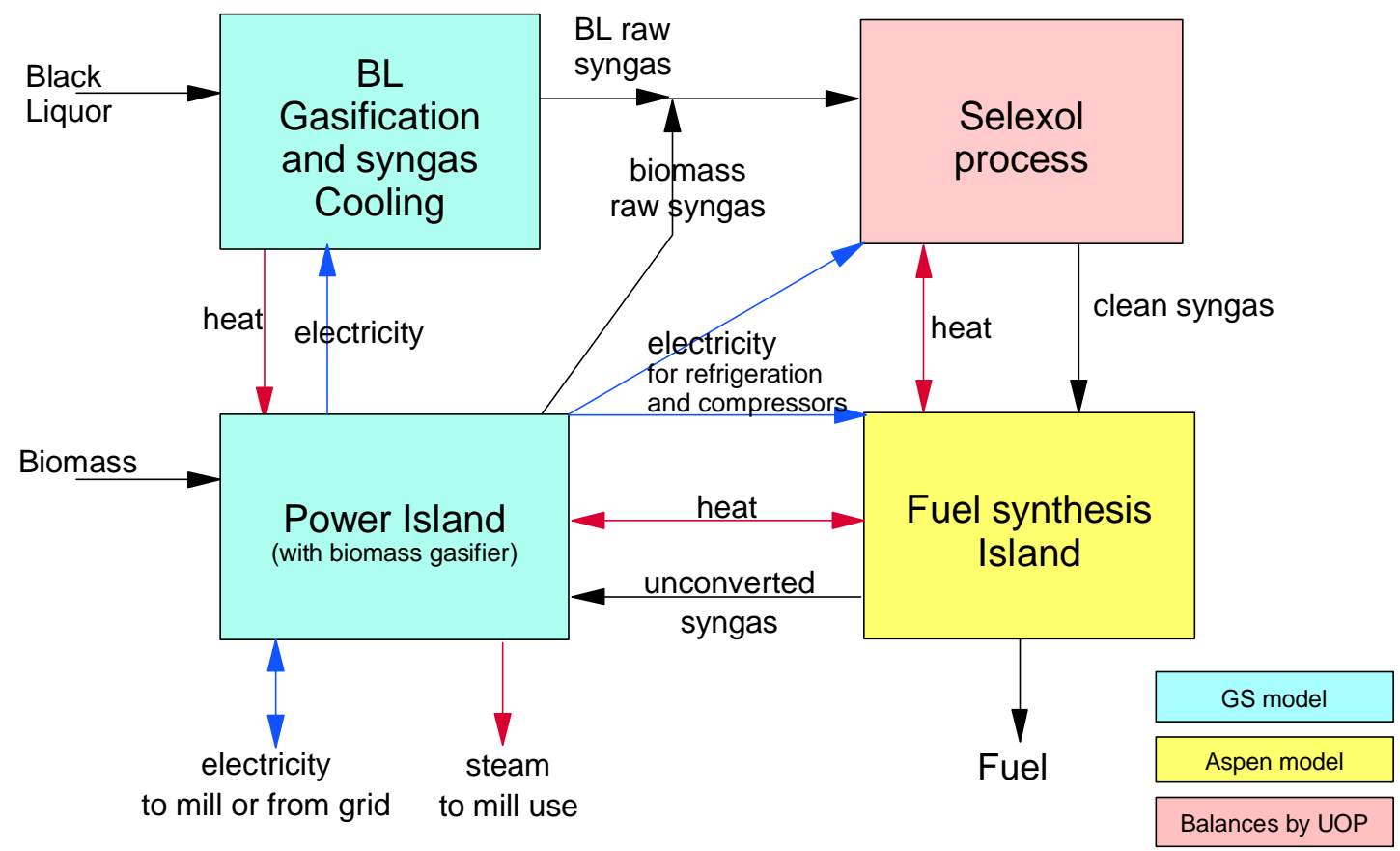

Fig. 2. Diagram of computer codes use for the MixOH configuration. The mass and energy balances of the Selexol system were provided directly by UOP, licensor of the process.

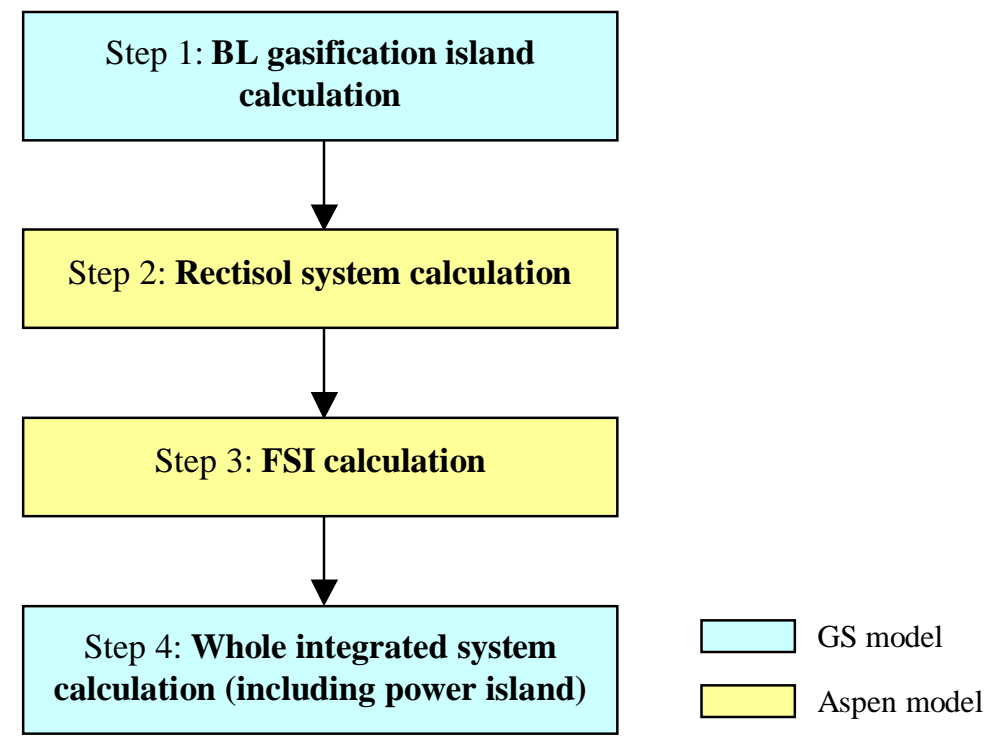

Fig. 3. Calculation algorithm for DMEa, DMEb, DMEc, FTa and FTb. 


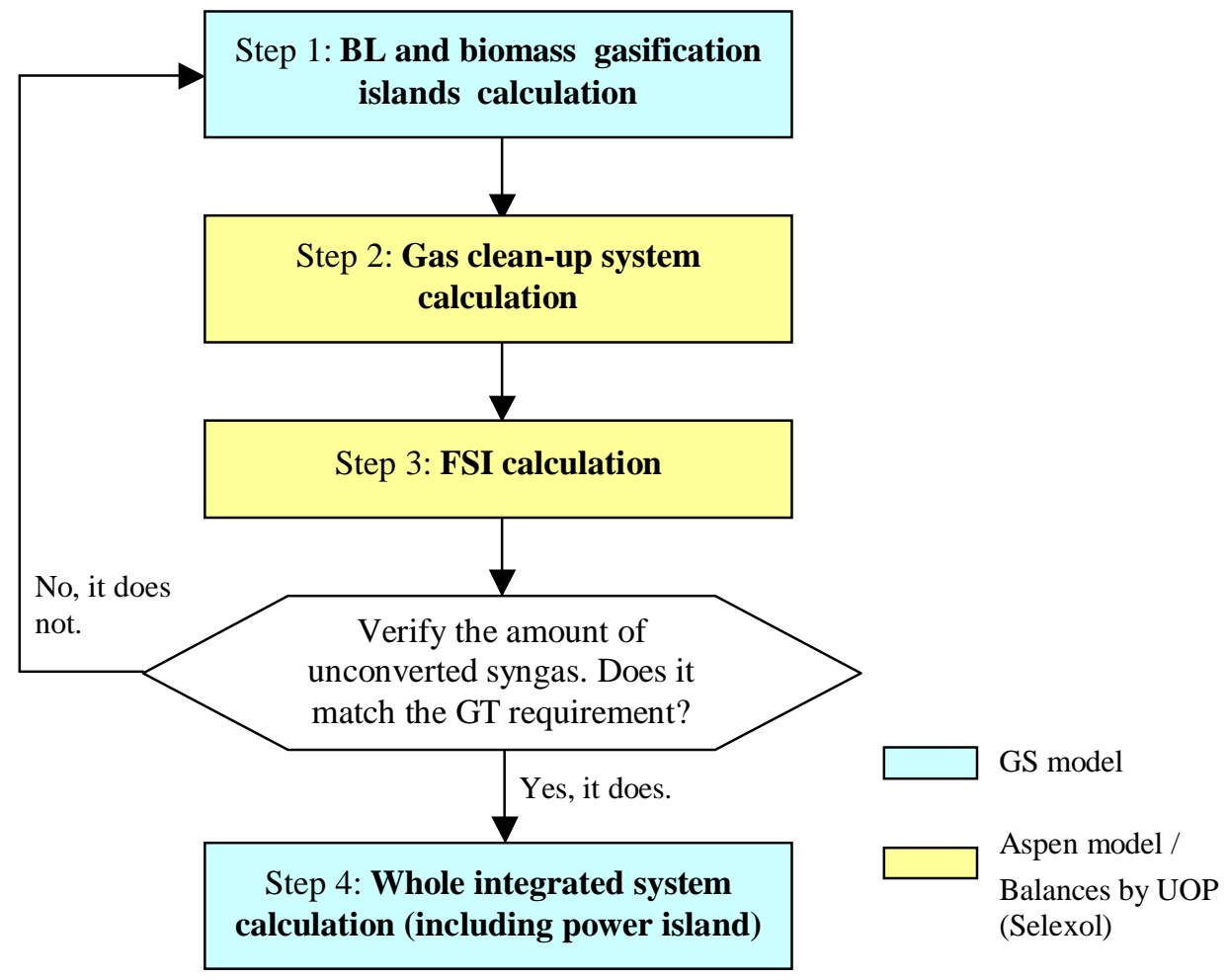

Fig. 4. Calculation algorithm for FTC and MixOH. The iteration between the final calculation by GS and the Aspen calculation of the Rectisol system (only for the FTc case) and of the FSI is required to adjust the amount of unconverted syngas to the value needed to fully fire the gas turbine. For $\mathrm{MixOH}$, the mass and energy balances of the Selexol system have been provided directly by UOP, licensor of the process.

\section{ASSUMPTIONS AND TECHNOLOGICAL ISSUES}

\subsection{Black liquor gasifier}

The black liquor gasifier considered in this study refers to the technology under development by Chemrec, a Swedish company. The gasifier is a high-temperature, highpressure, entrained flow, oxygen-blown reactor comprising two main sections: an upper section where black liquor is gasified at temperatures around $1000^{\circ} \mathrm{C}$ and a bottom section where the syngas is quenched and the smelt is collected in a bath to produce green liquor.

The gasifier basic operating conditions (Tab. 2) have been chosen in accordance with data published in the literature and information provided by the manufacturer. The composition of the syngas exiting the gasifier has been calculated assuming that:

- Carbon conversion and methane in raw gas are as specified in Tab. 2 (unconverted carbon leaves the gasifier together with the green liquor);

- Ash and chlorides behave as inert material;

- All the remaining material constitutes a gas/condensed-phase mixture at equilibrium comprising the following species: $\mathrm{Ar}, \mathrm{CO}, \mathrm{CO}_{2}, \mathrm{COS}, \mathrm{H}_{2}, \mathrm{H}_{2} \mathrm{O}, \mathrm{H}_{2} \mathrm{~S}, \mathrm{NH}_{3}, \mathrm{~N}_{2}$, 
$\mathrm{Na}_{2} \mathrm{CO}_{3}, \mathrm{Na}_{2} \mathrm{SO}_{4}, \mathrm{Na}_{2} \mathrm{~S}, \mathrm{NaOH}, \mathrm{K}_{2} \mathrm{CO}_{3}, \mathrm{~K}_{2} \mathrm{SO}_{4}$, where the species containing sodium and potassium can be either liquid or solid or both, depending on temperature and pressure.

This calculation scheme, which determines the sulfur split between the syngas and the solid/liquid phase, gives satisfactory agreement with specific information provided by the manufacturer of the gasifier, as well as with qualitative indications found in the literature.

\begin{tabular}{|lr|}
\hline \multicolumn{2}{|c|}{ Black Liquor Gasifier } \\
\hline Pressure of raw syngas & 35 bar $(483 \mathrm{psig})$ \\
\hline $\begin{array}{l}\text { Temperature of raw syngas } \\
\text { before quench }\end{array}$ & $\begin{array}{r}1000^{\circ} \mathrm{C} \\
\left(1832^{\circ} \mathrm{F}\right)\end{array}$ \\
\hline Heat loss to environment & $0.5 \%$ of $\mathrm{BL} \mathrm{HHV}$ \\
\hline Heat to cooling flows & $2.0 \%$ of $\mathrm{BL} \mathrm{HHV}$ \\
\hline Carbon conversion & $99.9 \%$ \\
\hline Methane in raw syngas & $1.5 \%$ mass in raw gas \\
\hline
\end{tabular}

Tab. 2. Basic BL gasifier operating parameters

\subsection{Biomass boiler}

In the DMEa plant, the waste heat recoverable from the gasification island and the fuel synthesis island is insufficient to meet the mill steam demand, and additional steam is generated by a biomass boiler. The thermal power that must be supplied by this boiler is larger than the assumed capacity of the biomass boiler already existing at the mill; thus, additional biomass boiler capacity is needed (for our reference mill, existing biomass boilers are assumed to be able to accommodate $100 \mathrm{MW}$ HHV of biomass input, while in DMEa, meeting the mill steam demand requires around $200 \mathrm{MW}$ HHV of biomass input).

For added biomass boiler capacity, we have assumed the same design specifications as for the existing boilers, i.e. generation of steam at 87.2 bar, $480^{\circ} \mathrm{C}$. This allows keeping the same back-pressure steam turbine at the existing plant. The new boiler would also provide saturated water at 38 bar to the DME reactor, where steam is generated to maintain a constant reaction temperature of $260^{\circ} \mathrm{C}$. Saturated steam from the DME reactor is superheated up to $480^{\circ} \mathrm{C}$ in the boiler and then admitted to the steam turbine. The basic operating parameters assumed for the wood residual boiler are summarized in Tab. 3.

\begin{tabular}{|lr|}
\hline \multicolumn{2}{|c|}{ Wood Residual Boiler } \\
\hline Air T, preheater outlet & $145^{\circ} \mathrm{C}\left(293^{\circ} \mathrm{F}\right)$ \\
\hline Gas T, preheater outlet & $230^{\circ} \mathrm{C}\left(446^{\circ} \mathrm{F}\right)$ \\
\hline Outlet flue oxygen (vol. wet) & $4.0 \%$ \\
\hline Evaporation pressure & $87.2 \mathrm{bar}(1250 \mathrm{psig})$ \\
\hline Superheater outlet & $480^{\circ} \mathrm{C}\left(896^{\circ} \mathrm{F}\right)$ \\
\hline Superheater $\Delta \mathrm{p}$ & $10.0 \%$ \\
\hline Heat loss to environment & $1.0 \%$ \\
\hline Deaerator pressure & 4.8 bar $(55 \mathrm{psig})$ \\
\hline
\end{tabular}

Tab. 3. Basic operating parameters of additional power boiler fed with wood residuals 


\subsection{Biomass dryer}

In the plants where the power island includes a gas turbine (i.e. all cases except DMEa), a mixture of hog fuel and purchased wood wastes are fed to a biomass gasifier; the syngas generated by such gasifier is either fed to the gas turbine (DMEb, DMEc, FTa and FTb) or mixed with the syngas generated by the black liquor gasifier prior to the fuel synthesis island (FTc and $\mathrm{MixOH})$.

Operating experiences have shown that the moisture content of the biomass fed to the gasifier should be in the range 10-20\% [Lau et al., 2003]. This is much below the typical moisture content of hog fuel and wood wastes, which is around 50\%. To obtain proper gasification conditions, we have assumed therefore that the biomass feedstock is dried by direct contact with the flue gas exiting the HRSG to reduce its moisture content from $50 \%$ to $20 \% 2$.

The temperature of the flue gas exiting the HRSG is adjusted to give a temperature of the moist gas exiting the drier of $90^{\circ} \mathrm{C}$. A high drier inlet temperature must be avoided to minimize release of volatile organic compounds (VOCs) and risk of ignition; Brammer and Bridgwater [1999] mention a maximum value of $250^{\circ} \mathrm{C}$. To achieve this temperature, the moist gas at the drier exit is recycled to the drier inlet and mixed with the gas exiting the HRSG at a temperature higher than $250^{\circ} \mathrm{C}$; the fraction to be recycled is calculated to give a drier inlet temperature (downstream of mixing with the HRSG exhausts), of $250^{\circ} \mathrm{C}$.

As for auxiliary power consumption, based on data reported by Consonni and Larson [1996] we've assumed an electricity consumption of $20 \mathrm{~kJ}$ per $\mathrm{kg}$ of wet biomass for biomass handling and drying (5.6 kWh per tonne of wet biomass).

\subsection{Biomass gasifier}

The biomass gasifier considered in this study is a pressurized oxygen- and steam-blown, fluidized-bed reactor similar to the one being developed by GTI [Lau et al., 2003]. In our case the use of oxygen as the oxidant does not imply major economic penalties because an Air Separation Unit (ASU) must be present anyhow to supply the oxygen needed by the black liquor gasifier. On the other hand, the oxygen-blown design gives a syngas with superior heating value, with benefits on equipment size (and cost) and the operation of crucial components downstream: higher combustion stability for the gas turbine combustor, higher fuel conversion for the fuel synthesis reactor. The amount of oxygen supplied to the gasifier determines the partial oxidation of biomass and thus the gasification temperature, which is assumed to be $950^{\circ} \mathrm{C}$. This value appears a reasonable compromise between the need to avoid ash softening, which becomes more likely when temperature increases, and the need to minimize tar in the syngas, which increases when the syngas outlet temperature decreases. This temperature is selected to avoid any ash softening.

In the designs currently being pursued, the gasifier vessel is actually followed by a cracker for the breakup of the large molecules that constitute tar. In our simulations the gasifier and the cracker are calculated altogether in a single step, assuming that the syngas at the cracker exit is at $950^{\circ} \mathrm{C}$, with all species at chemical equilibrium except for methane and tar, the latter modeled as phenol $\left(\mathrm{C}_{6} \mathrm{H}_{6} \mathrm{O}\right)$. The concentration of methane and tar at the cracker exit are specified in input at approximately the same values detected experimentally by Simell et al. [1996]. Given the presence of a catalyst in the cracker (nickel-based catalysts appear most suited) and the relatively

\footnotetext{
${ }^{2}$ We actually model the dryer as a mixer and an indirect-contact heat exchanger. First, the water to be evaporated to obtain the required outlet moisture content (in our case 20\%) is mixed with the flue gas exiting the HRSG; then, the moisturized gas heats the dried biomass from the ambient temperature $\left(20^{\circ} \mathrm{C}\right)$ to the temperature assumed at the drier exit, in our case $70^{\circ} \mathrm{C}$.
} 
high temperature, assuming that all species but methane and tar are at chemical equilibrium at the cracker outlet appears reasonable. Experimental data reported by Simell et al. [1996] show equilibrium is nearly reached even at the moderate conditions of 5 bar and $900^{\circ} \mathrm{C}$.

In addition to oxygen, the gasifier is fed also with steam to fluidize the bed. The operating pressure is 36 bar, which is in the range of pressurized systems under development [Lau et al. 1993; Blackadder et al. 1994]. In the configurations where the biomass syngas is mixed with the BL syngas (i.e. FTc and $\mathrm{MixOH}$ ), pressurized gasification allows mixing the two streams without the need for biomass syngas gas compression; this is beneficial, because the losses due to fuel gas compression are typically higher then those due to the compression of the fluidizing agent. On the other hand, in the configurations where the biomass syngas is supplied to the gas turbine, pressurized gasification allows the production of useful power by a gas expander. These benefits will have to be weighed against the complexity and the operating costs of biomass feeding to a pressurized reactor. In our case biomass is pressurized in lock hoppers with a stream of pure $\mathrm{N}_{2}$ provided from the ASU plant; the lock-hoppers energy consumption is that for inert gas compression.

Tab. 4 summarizes the assumptions adopted for the biomass gasifier, while Tab. 5 gives the composition and the heating vale of hog fuel and purchased wood wastes, which are assumed to be the same.

\begin{tabular}{|c|c|c|}
\hline \multicolumn{3}{|c|}{ Biomass gasifier } \\
\hline Pressure & & 36 bar (507 psig) \\
\hline Steam mass flow & & $28 \%$ of DS \\
\hline Steam pressure & & 38 bar (536 psig) \\
\hline Outlet temperature & & $950^{\circ} \mathrm{C}\left(1742^{\circ} \mathrm{F}\right)$ \\
\hline Heat loss & & $0.5 \%$ of biomass $\mathrm{HHV}$ \\
\hline \multirow{2}{*}{ Mol fraction at cracker outlet } & $\mathrm{CH}_{4}$ & $1 \%$ \\
\hline & Tar & $0.2 \mathrm{~g} / \mathrm{Nm}^{3}$ \\
\hline
\end{tabular}

Tab. 4. Basic biomass gasifier operating parameters

\begin{tabular}{|cc|}
\hline Bone dry wood: & mass fraction \\
\hline $\mathrm{C}$ & $49,98 \%$ \\
\hline $\mathrm{H}$ & $6,12 \%$ \\
\hline $\mathrm{O}$ & $42,49 \%$ \\
\hline $\mathrm{N}$ & $0,55 \%$ \\
\hline $\mathrm{S}$ & $0,06 \%$ \\
\hline Ash & $0,80 \%$ \\
\hline LHV & $18,66 \mathrm{MJ} / \mathrm{kg}$ \\
\hline HHV & $20 \mathrm{MJ} / \mathrm{kg}$ \\
\hline Feed wood: & \\
\hline Moisture & $50 \%$ \\
\hline HHV & $10,01 \mathrm{MJ} / \mathrm{kg}$ \\
\hline LHV & $8,12 \mathrm{MJ} / \mathrm{kg}$ \\
\hline Dried wood: & \\
\hline Moisture & $20 \%$ \\
\hline HHV & $16,01 \mathrm{MJ} / \mathrm{kg}$ \\
\hline LHV & $14,45 \mathrm{MJ} / \mathrm{kg}$ \\
\hline
\end{tabular}

Tab. 5. Composition and heating value of hog fuel and wood waste 


\subsection{Syngas clean-up system}

The syngas generated by the gasification of black liquor or biomass must be cooled and properly treated to insure proper and reliable operation of the equipment fed with the syngas. The technologies to be used and the extent to which the gas must be purified depend on the syngas composition and the requirements of the systems downstream. Consequently, the arrangement and the processes assumed here have been tailored to the characteristics of the various system configurations.

\subsubsection{Syngas generated by the black liquor gasifier}

The syngas generated from black liquor exhibits relatively high concentrations of particulates, alkali, chlorine and sulfur. In the high-temperature gasification technology considered here most of the particulates and the alkali should be removed by the quench and in the heat exchanger placed immediately downstream of the gasifier, where the condensate generated by cooling the saturated syngas below its dew point flows counter-current with the gas, thus acting like a scrubber. This condensation cooling alone should remove most of the soluble species (alkali and acid gases) and particulates. On the other hand, given the very stringent requirements of the FSI downstream, we've considered two further treatments to achieve deep gas clean-up: low-temperature wet scrubbing and Rectisol. Despite its high cost, the latter is the most reliable process now available to achieve the purity required by the catalysts adopted to synthesize DME and FT fuels. In the MixOH case, the $\mathrm{MoS}_{2}$ catalyst considered for the mixed alcohol synthesis requires some $\mathrm{H}_{2} \mathrm{~S}$ in the syngas and the very deep removal achievable with Rectisol is unnecessary. In this case we've therefore considered a wet scrubber followed by a Selexol system, which is less costly than Rectisol.

\subsubsection{Syngas generated by the biomass gasifier}

The clean-up requirements for the syngas generated by biomass are different depending on whether the syngas is fed to the gas turbine or the FSI. The following summarizes the technologies and the operating parameters assumed in each case. The need to control tar is the same in both cases.

\subsubsection{Tar control}

Tars are condensable organic compounds formed during gasification. They condense at temperatures around $350^{\circ} \mathrm{C}$ and their deposition on cool surfaces can cause severe operating problems: fouled heat transfer surfaces, constricted piping, clogged valves, etc. The tar concentration in the syngas is a function of gasification temperature and of the properties of the feedstock. Wood gasification (and biomass gasification in general) generates much more tar than coal gasification due to lower reactor temperatures utilized. A number of design features (e.g. splitting oxidant injection into a primary and secondary flow) can be effective in reducing tar formation; however, a process for tar destruction is likely to be necessary to achieve the low concentrations required for reliable plant operation. In our case we have assumed that the gas leaving the gasifier goes through a fixed bed catalytic reactor where tars are cracked into species with lower molecular weight. A nickel-based catalyst appears preferable, because at high pressure the catalytic action of dolomite or other carbonate rocks may be inadequate, even at $950^{\circ} \mathrm{C}$. Pilot-scale tests have shown that nickel-based catalysts at elevated temperature (around $900^{\circ} \mathrm{C}$ ) have high activity for tar destruction; they also catalyze ammonia decomposition, and about $80 \%$ ammonia conversion are achieved in the cracker. Then the amount of ammonia in the 
product gas at the cracker exit is slightly higher than at equilibrium ${ }^{3}$ [Simell et al., 1996]. High temperature is needed also to avoid the formation of solid carbon, which could deposit and cause catalyst deactivation, as well as to compensate the deactivation caused at high pressure by $\mathrm{H}_{2} \mathrm{~S}$.

At present, many nickel-based catalysts are commercially available because of their application in the steam reforming of hydrocarbons. They have demonstrated high activity also for tar destruction, although they undergo rapid deactivation due to poisoning by impurities and coke formation. Additional research is needed to develop formulations with longer lifetime.

In the model adopted here, the total oxygen flow supplied to the gasifier and the cracker is adjusted to achieve the specified temperature of $950^{\circ} \mathrm{C}$ at the cracker exit, assuming that the gas composition is at equilibrium except for methane and tar. In the configurations with the syngas cooler, where the biomass syngas is treated with just a ceramic candle filter, its temperature is maintained always above $375^{\circ} \mathrm{C}$ to prevent tar condensation. In the configurations with the quench, the biomass syngas is mixed with the black liquor syngas and treated in a Rectisol or Selexol system at low temperature.

\subsubsection{Biomass syngas to the gas turbine}

In cases DMEa, DMEb, FTa and FTb the gas turbine is fed with a mixture of syngas generated by the biomass gasifier and unconverted syngas from the fuel production island. In cases FTc and MixOH the gas turbine is fed solely with unconverted syngas.

The fuel gas fed to the gas turbine must not contain particulate or contaminants that can damage the turbine blades by erosion or corrosion. Additional contaminants of concern from an emission standpoint are nitrogen compounds, especially ammonia derived from nitrogen in biomass feedstock.

Unlike unconverted syngas, the syngas generated by the biomass gasifier contains contaminants that must be removed to prevent damage to the equipment downstream. In the configurations where the biomass syngas goes only to the GT (DMEa, DMEb, FTa and FTb) we have considered hot clean-up (ceramic filter operating around $450^{\circ} \mathrm{C}$ ) that allows maintaining the syngas at high temperature. A commercially proven, low-temperature technology like quench and wet scrubbing would be simpler and safer, but less efficient. Consistent with our overall analysis, we assume that hot gas cleaning will be equally reliable in a commercial $\mathrm{N}^{\text {th }}$ plant.

\subsection{Particulate removal}

Particulates can cause severe turbine blade erosion even at very small concentrations. This is why gas turbine manufacturers specify stringent limits (around $5 \mathrm{ppm}$ by weight) for their concentration in the fuel gas. Since conventional cyclones can't attain such low concentrations, high efficiency filtration devices like ceramic or metallic candle filters must be placed at an appropriate point of the syngas path.

In our modelization we have assumed that the bulk of the ash in the raw gas is removed by a cyclone at the gasifier exit, while all remaining particulates are separated by a ceramic (or metallic) filter operating at the temperature that allows maintaining the syngas above $375^{\circ} \mathrm{C}$ also downstream of the syngas expander and after mixing with unconverted syngas. Maintaining the syngas above $375^{\circ} \mathrm{C}$ is supposed to prevent the condensation of tars. At the same time, the operating temperature of the filter (around $450^{\circ} \mathrm{C}$ ) is low enough to induce the condensation of most alkali on the solid particles removed by the filter.

\footnotetext{
${ }^{3}$ At equilibrium the ammonia content is $60-50 \mathrm{ppm}$ at $905-960^{\circ} \mathrm{C}$.
} 
At present, high temperature filters are not a commercial process yet. They are being tested in some pilot-plant gasifier and additional development and demonstrations are required to prove their effectiveness and commercial viability.

\subsection{Alkali removal}

Alkali compounds cause corrosion of the ceramic filter and of turbine blades. The alkali in the biomass are vaporized during gasification and end up in the product gas. At high temperatures these contaminants are volatile, but below $500^{\circ} \mathrm{C}$ the vapors condense and deposit on entrained solids. Thus, cooling below $500^{\circ} \mathrm{C}$ before particulate removal may be sufficient to remove alkali compounds down to levels specified by gas turbine manufacturers.

In the process design considered here, raw syngas is first cooled in a syngas cooler to about $450^{\circ} \mathrm{C}$, and then filtered. As already mentioned, this would result in the removal of alkali in the filter while avoiding tar condensation.

\begin{tabular}{|lr|}
\hline \multicolumn{2}{|c|}{ Syngas cooler } \\
\hline$\Delta \mathrm{p} / \mathrm{p}$ & $2 \%$ \\
\hline Heat loss & $2 \%$ \\
\hline $\begin{array}{l}\text { Min temperature } \\
\text { at GT inlet }\end{array}$ & $375^{\circ} \mathrm{C}\left(662^{\circ} \mathrm{F}\right)$ \\
\hline \multicolumn{2}{|c|}{ Filter } \\
\hline$\Delta \mathrm{p} / \mathrm{p}$ & $3 \%$ \\
\hline
\end{tabular}

Tab. 6. Basic operating parameters for the biomass syngas cooler and filter

\subsubsection{Biomass syngas to the Fuel Synthesis Island}

In cases FTc and MixOH all the syngas generated by the biomass gasifier and by the BL gasifier is used to produce liquid fuel. The two streams originated by the two gasifiers merge into a single flow which is treated in a physical absorption system: Rectisol for FTc, Selexol for MixOH. Rectisol can achieve the deep removal of sulfur required by FT catalysts (less than 1 ppm of $\left.\mathrm{H}_{2} \mathrm{~S}\right)$. Selexol can attain a more moderate $\mathrm{H}_{2} \mathrm{~S}$ removal $\left(\mathrm{H}_{2} \mathrm{~S}\right.$ around $\left.10 \mathrm{ppm}\right)$, which however is adequate for the sulfur-tolerant $\mathrm{MoS}$ catalyst of the $\mathrm{MixOH}$ reactor ${ }^{4}$.

Unlike the case where the syngas generated from biomass feeds the gas turbine, in this case quenching and scrubbing the syngas doesn't result in a reduction of system efficiency, because the physical clean-up system requires low temperature anyhow. This is why we have assumed that the syngas generated from biomass is quenched into a scrubber both to reduce its temperature and to remove alkali, tars and impurities, as well as most of the water vapor. Wet scrubbing has several advantages: it is a well-known and widely used technology and it removes particulates, tar and other contaminants very effectively; on the other hand, it generates contaminated water, which requires waste water treatment.

\subsection{Gas turbine}

The calculations carried out for this study refer to two General Electric engines: 6FA (medium scale) and 7FA (large scale). These machines belong to the most advanced generation of heavy-duty machines now in wide commercial service, also known as "F" technology.

\footnotetext{
${ }^{4}$ In a system based on a MoS catalyst some $\mathrm{H}_{2} \mathrm{~S}$ in the syngas is actually necessary to make up for the small amounts of sulfur inevitably lost in the catalytic process.
} 
Performance predictions have been calibrated based on data published by General Electric; a few relevant inputs to the gas turbine model have been fine tuned to achieve the best possible agreement with the overall performance published by GE. Tab. 7 compares the performances quoted by GE with those generated by the calculation model for operation on natural gas fuel at ISO conditions $\left(15^{\circ} \mathrm{C}, 1\right.$ atm).

Compared to natural gas firing, feeding the gas turbine with a biomass-derived syngas increased mass flow through the turbine because, due to the relatively low heating value of the biomass syngas, a larger fuel flow rate is needed to reach a given Turbine Inlet Temperature (TIT). The larger mass flow through the turbine affects the match between the turbine and the compressor, which must obviously operate in such a way that the compressor outlet pressure equals (once combustor pressure drop is accounted for) the turbine inlet pressure.

The calculation carried out in GS assumes that the expander operates under aerodynamically choked conditions i.e. its "reduced" (non-dimensional) mass flow is constant. This corresponds to the operating conditions of essentially all commercial gas turbines. In this situation a larger mass flow can be accommodated only by increasing the pressure ahead of the turbine, i.e. by increasing the compressor pressure ratio. Higher pressure ratios move the compressor toward the stall limit, and thus there is a limit to the mass flow increase that can be tolerated by the gas turbine. In our calculations we have assumed that:

- The Turbine Inlet Temperature (TIT) is the same as with natural gas firing;

- The compressor can operate with a compression ratio up to 5\% above its value with natural gas;

- Further increases in fuel flow must be accommodated by reducing the air flow entering the compressor, which in most engines can be easily accomplished by adjusting the inlet guide vanes.

Due to the different flow rate and thermo-physical properties of syngas compared to natural gas, maintaining the same TIT of the natural-gas version implies higher temperatures throughout the expansion and thus - everything else equal - higher blade metal temperatures and shorter life of the hot parts of the engine. This is why syngas-fired gas turbines are typically de-rated (TIT lower by $10-30^{\circ} \mathrm{C}$ ) to maintain the same life and reliability of the natural gas-fired version. Our assumption of no change in TIT implies an increase in Turbine Outlet Temperature (TOT) of 10$20^{\circ} \mathrm{C}$ and can be justified by considering that by the time the $\mathrm{N}^{\text {th }}$ pulpmill biorefinery plant is realized, TIT and TOT of state-of-the-art gas turbines will be significantly higher than those adopted today.

As to the $5 \%$ increase in pressure ratio, it is within the range typically tolerable by the compressors of heavy-duty engines. Whether such an increase is compatible with lower air flow can only be verified by the gas turbine manufacturer (when air flow is decreased by closing the Inlet Guide Vanes, the compressor stall margin decreases).

Other issues raised by the use of syngas in a gas turbine are related to combustor stability, emissions and fuel injector pressure loss, which may be substantially different from those with natural gas. The first two are mainly related to syngas chemical composition and heating value; the third is related to flow rate. Based on pilot-scale experimental work and the experience accumulated in Integrated Gasification Combined Cycles (IGCC), refineries and steel plants, combustion stability should not be a major issue as long as the fuel calorific value is above 4-6 $\mathrm{MJ} / \mathrm{m}_{\mathrm{n}}{ }^{3}\left(1 \mathrm{~m}_{\mathrm{n}}{ }^{3}=1 \mathrm{~m}^{3}\right.$ at the "normal" conditions of $\left.1 \mathrm{~atm}, 0^{\circ} \mathrm{C}\right)$. In the systems considered here, the fuel fed to the gas turbine has a heating value higher than $6 \mathrm{MJ} / \mathrm{m}_{\mathrm{n}}{ }^{3}$, so no particular flame stability problems are envisaged. The increase in pressure loss to be applied across the fuel injectors can be accommodated either by increasing the fuel pressure (which however will 
increase fuel compression work and thus reduce overall net efficiency) or by increasing the injector cross-sectional area (which requires some extra design work and thus would increase cost for the first units built). In our calculations we assumed a fuel pressure at least $50 \%$ higher than the combustor pressure.

Although special provisions may be needed to operate gas turbines on syngas, it is worth noting that a great deal of development work has been done and significant operating experience has been accumulated in coal-fired IGCC plants. For example, General Electric offers eight different gas turbines models, ranging from 10-300 MW, for use with syngas, including the two models evaluated here (www.gepower.com).

\begin{tabular}{|c|c|c|c|c|c|c|c|c|c|c|}
\hline & \multicolumn{7}{|c|}{$6 \mathrm{FA}, 60 \mathrm{~Hz}$} & \multicolumn{3}{|c|}{ 7FA, $60 \mathrm{~Hz}$} \\
\hline & \multicolumn{2}{|c|}{$\begin{array}{l}\text { conventional } \\
\text { applications }\end{array}$} & $\begin{array}{l}\text { Case } \\
\text { DMEb }\end{array}$ & $\begin{array}{l}\text { Case } \\
\text { DMEc }\end{array}$ & $\begin{array}{l}\text { Case } \\
\text { FTa }\end{array}$ & $\begin{array}{l}\text { Case } \\
\text { FTc }\end{array}$ & \begin{tabular}{|c|} 
Case \\
MixOH
\end{tabular} & \multicolumn{2}{|c|}{$\begin{array}{l}\text { conventional } \\
\text { applications }\end{array}$} & $\begin{array}{l}\text { Case } \\
\text { FTb }\end{array}$ \\
\hline fuel & \multicolumn{2}{|c|}{ natural gas } & syngas & syngas & syngas & syngas & syngas & \multicolumn{2}{|c|}{ natural gas } & syngas \\
\hline ambient conditions & \multicolumn{2}{|c|}{$\begin{array}{c}\text { ISO }\left(15^{\circ} \mathrm{C}, 1\right. \\
\text { atm })\end{array}$} & \multicolumn{5}{|c|}{$20^{\circ} \mathrm{C}, 1 \mathrm{~atm}$} & \multicolumn{2}{|c|}{$\begin{array}{c}\mathrm{ISO}\left(15^{\circ} \mathrm{C}, 1\right. \\
\text { atm })\end{array}$} & $\begin{array}{c}20^{\circ} \mathrm{C} \\
1 \mathrm{~atm}\end{array}$ \\
\hline air flow, $\mathrm{kg} / \mathrm{s}$ & 204.0 & 204.0 & 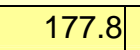 & 192.4 & 189.0 & 176.4 & 180.0 & 432.0 & 432.0 & 387.9 \\
\hline compressor outlet $\mathrm{T},{ }^{\circ} \mathrm{C}$ & n.a. & 409 & 431 & 431 & 431 & 431 & 431 & n.a. & 402 & 420 \\
\hline fuel flow, $\mathrm{kg} / \mathrm{s}$ & n.a. & 4.43 & 32.2 & 25.5 & 29.0 & 39.9 & 14.9 & n.a. & 9.6 & 64.9 \\
\hline fuel LHV, MJ/kg & n.a. & 48.91 & 6.95 & 8.60 & 7.61 & 5.95 & 8.80 & n.a. & 48.91 & 7.28 \\
\hline fuel mol weight, $\mathrm{kg} / \mathrm{Mol}$ & n.a. & 16.3 & 20.5 & 20.5 & 22.6 & 25.1 & 21.1 & n.a. & 16.3 & 21.5 \\
\hline exhaust flow, kg/s & n.a. & 208.43 & 210.0 & 217.9 & 218.0 & 216.3 & 218.4 & n.a. & 441.6 & 452.8 \\
\hline pressure ratio & 15.7 & 15.7 & 16.5 & 16.5 & 16.5 & 16.5 & 16.5 & 15.5 & 15.5 & 16.0 \\
\hline TIT, ${ }^{\circ} \mathrm{C}$ & n.a. & 1,316 & 1,316 & 1,316 & 1,316 & 1,316 & 1,316 & n.a. & 1,316 & 1,316 \\
\hline TOT, ${ }^{\circ} \mathrm{C}$ & 604 & 604 & 635 & 620 & 624 & 635 & 633 & 602 & 603 & 626 \\
\hline power output, MW & 75.9 & 75.7 & 89.5 & 82.9 & 83.9 & 89.7 & 89.7 & 171.7 & 171.6 & 186.5 \\
\hline LHV efficiency, \% & 34.8 & 34.9 & & & & & & 36.2 & 36.7 & \\
\hline DP at compr. inlet, $\mathrm{kPa}$ & n.a. & 0.0 & 1.0 & 1.0 & 1.0 & 1.0 & 1.0 & n.a. & 0.0 & 1.0 \\
\hline $\mathrm{DP}$ at turbine outlet, $\mathrm{kPa}$ & n.a. & 0.0 & 4.0 & 4.0 & 4.0 & 4.0 & 4.0 & n.a. & 0.0 & 4.0 \\
\hline & $\begin{array}{l}\mathrm{GE} \\
\text { data }\end{array}$ & & & our c & ation & & & $\begin{array}{l}\mathrm{GE} \\
\text { data }\end{array}$ & our & lation \\
\hline
\end{tabular}

Tab. 7. Comparison between gas turbine performance published by General Electric and predictions with simulation software GS

\subsection{HRSG and steam turbine}

In the plant configurations with a gas turbine (all but DMEa), the gas turbine exhaust generates steam in a Heat Recovery Steam Generator (HRSG). The steam evaporation pressure and superheat temperature assumed here $\left(130\right.$ bar and $\left.540 / 565^{\circ} \mathrm{C}\right)$ correspond to the state-of-theart of combined cycle systems and are more advanced than those adopted in the biomass boilers because the combustion products discharged by the gas turbine are much "cleaner" than those generated in the biomass boiler and do not raise severe erosion or corrosion issues. To take advantage of these more advanced steam conditions we've assumed that the existing steam turbine is replaced by a new machine designed for such admission conditions, as well as sized for the nominal flow of the new, integrated plant.

For DMEa, where steam is generated at more moderate conditions by recovering waste heat from the black liquor gasification island and the FSI, as well as by the existing hog fuel boilers; in this case we've assumed to maintain the existing steam turbine, which will have to be slightly modified (basically, introduce partial admission and modify the first few stages) to adapt it to the new operating conditions. 


\begin{tabular}{|lr|}
\hline \multicolumn{2}{|c|}{ HRSG } \\
\hline Evaporation pressure & 130 bar (1870 psig) \\
\hline Evaporation pressure in DME and FT reactors & 38 bar (536 psig) \\
\hline Evaporation pressure in MixOH reactor & 130 bar (1870 psig) \\
\hline Superheater $\Delta \mathrm{p} / \mathrm{p}$ & $10 \%$ \\
\hline Superheater temperature (large scale GT) & $565^{\circ} \mathrm{C}\left(1049^{\circ} \mathrm{F}\right)$ \\
\hline Superheater temperature (medium scale GT) & $540^{\circ} \mathrm{C}\left(1004^{\circ} \mathrm{F}\right)$ \\
\hline Heat loss & $0.7 \%$ of heat released by gas \\
\hline Blow-down & $1.14 \mathrm{~kg} / \mathrm{s}$ \\
\hline Deaerator pressure & 4.8 bar $(55 \mathrm{psig})$ \\
\hline Condenser pressure (plants FTb and FTc) & 0.074 bar $(1.07 \mathrm{psia})$ \\
\hline
\end{tabular}

Tab. 8. Basic operating parameters for the HRSG and the steam cycle

At the scale of our power islands, a combined cycle would normally feature at least two evaporation pressures in the HRSG. In our case however we've considered only one evaporation pressure at 130 bar because for our back-pressure cycle with massive steam extraction at relatively high pressure (13 bar) additional evaporation pressures would give negligible benefits.

The heat released by the exothermic fuel synthesis reactions is carried away by generating saturated steam. Such steam generation is crucial to maintain the reactor at constant temperature and ensure its proper operation and expected life. In the MixOH case we've assumed a reactor temperature of $350^{\circ} \mathrm{C}$ and thus steam can be generated at the same pressure of the HRSG drum (saturation temperature at 130 bar is $330.8^{\circ} \mathrm{C}$ ). Instead, the DME and FT reactors work at $260^{\circ} \mathrm{C}$ and generate steam at 38 bar (saturation temperature $247.3^{\circ} \mathrm{C}$ ). In these cases the HRSG provides saturated water to the fuel reactors, and the saturated steam generated there goes back to the HRSG to be superheated. After being superheated, this medium-pressure steam is admitted to the steam turbine through a secondary port. The optimal superheat temperature of the mediumpressure steam admitted to the steam turbine is approximately equal to that of the mainstream flow at the secondary admission port, i.e. the value that minimizes the irreversibilities of mixing between the mainstream flow and the additional flow admitted at medium pressure. In our DME and FT cases we've assumed a superheat temperature of $370-400^{\circ} \mathrm{C}$, very near to the optimum value that maximizes the electrical efficiency.

Steam reheat has not been considered because at the scale of our power islands and given the large amount of steam extracted for the mill it would be economically questionable.

Tab. 8 summarizes the design parameters assumed for the HRSG. In plants FTb and FTc the steam recovered using the gas turbine exhaust heat, the gasification island heat, and the FSI heat is more than the amount needed by the mill, and thus the steam turbine includes a low pressure section that expands the steam down to 0.074 bar (condensation temperature $40^{\circ} \mathrm{C}$ ). In all other cases the steam turbine is back pressure and steam production is adjusted (by changing the biomass input to the biomass boilers or the biomass gasifier) to match the mill demand.

\subsection{Heat integration}

Given the large amounts of waste heat made available by syngas cooling, syngas clean-up and fuel synthesis, a proper integration ensuring the best use of such heat is crucial to the achievement of superior performances. A good match between the processes that generate heat and those that require heat can also reduce costs and refrigeration requirements; this is particularly true for the Rectisol system, which requires a refrigeration plant of considerable size 
(several $\mathrm{MW}_{\text {ref }}$ ) to cool the syngas much below ambient temperature. The design of heat transfer processes is also crucial to the achievement of proper operating conditions of key components: in the syngas coolers, the generation of steam gives the high heat transfer coefficients needed to maintain acceptable metal temperatures; in the fuel synthesis reactor, steam generation is essential to prevent catalyst overheating and achieve high conversion efficiencies.

The heat released by high temperature syngas streams from the black liquor gasifier and the biomass gasifier are cooled to generate HP steam for the power island and the mill. Whenever possible, the heat made available at medium or low temperature is used to preheat make-up water. This is particularly relevant for the plants with a large biomass gasifier, where the biomass dryer placed ahead of the gasifier and fed with the HRSG exhausts requires a large thermal input. Higher thermal inputs to the dryer are provided by increasing the temperature of the gas at the outlet of the HRSG, which therefore exhibits a deficit of the low-temperature heat needed to preheat the water.

Despite the efforts to optimize the heat exchanger network, some low temperature heat must be rejected to the environment and requires a cooling medium. We've assumed that enough cooling water is available at the plant to bring the temperature of the streams to be cooled down to $35^{\circ} \mathrm{C}$. This is particularly relevant for the Rectisol system, where to limit the refrigeration power it is important that the syngas be cooled to the lowest possible temperature prior to its input into the refrigeration plant. Without adequate amounts of cooling water, net electricity production can be significantly lower than reported here, with somewhat higher capital costs.

To minimize irreversibilities and thus maximize efficiency, we've assumed that heat is transferred across relatively small temperature differences: minimum temperature difference $10^{\circ} \mathrm{C}$ for gas-liquid heat transfer; minimum temperature difference $\sim 15^{\circ} \mathrm{C}$ for gas-gas heat transfer. In an actual situation these temperature differences are subject to economic optimization, to determine the best trade-off between efficiency and capital costs.

Heat exchangers operating at medium or low temperature are assumed to incur negligible heat losses, whereas for the HRSG we've assumed a heat loss of $0.7 \%$ of the heat transferred (Tab. 8). For the syngas cooler of the biomass gasifier, which handles gas between $950^{\circ} \mathrm{C}$ and $450-500^{\circ} \mathrm{C}$, we've assumed a heat loss of $2 \%$ of heat transferred.

\subsection{Oxygen production}

95\% pure oxygen (with $3.65 \%$ Ar and $1.35 \% \mathrm{~N}_{2}$ ) is supplied to the oxygen-blown gasifiers by a stand-alone, conventional cryogenic Air Separation Unit (ASU) which generates oxygen at atmospheric pressure. Compression up to gasification pressure (36 bar) is carried out by an intercooled oxygen compressor. Some performance improvement may be gained by integrating the ASU with the power plant, which however should be carefully weighed against the implications and the unknowns of the added complexity of the plant and the start-up and shutdown procedures. We assume a non-integrated ASU in our designs.

The oxygen consumption of the gasifiers is determined by the composition, moisture content and heating value of the material to be gasified, as well as by the temperature to be reached (in our case, $1000^{\circ} \mathrm{C}$ for the black liquor gasifier, $950^{\circ} \mathrm{C}$ for the biomass gasifier). The BL gasifier oxygen requirement - as well as the whole heat/mass balances - is very sensitive to the Oxygen/Carbon ratio in the dry BL solids. Given the uncertainties about the actual composition of black liquor under polysulfide operating conditions, further work is needed to get reliable estimates of dry solids composition and properties at the conditions at which a mill would operate when integrated with a BL gasification system. 
With gasification, the load of the lime kiln increases as a consequence of different smelt composition and a different breakdown between the sulfur that goes in the gas and in the smelt. Since the load increase is limited, we've assumed that it can be accommodated by firing the kiln with oxygen enriched air. A small increase in the size of the Air Separation Unit provides a lowcost source of oxygen for this purpose. The ASU size is further increased a little to also provide oxygen for the $\mathrm{O}_{2}$ delignification unit existing at the mill. (See additional discussion on this topic in Volume 1.)

In the configurations with a biomass gasifier, the ASU also provides the nitrogen required by the biomass lock-hoppers.

\subsection{Lime Kiln}

Because of an increase of sodium carbonate leaving the gasifier in the condensed phase, black liquor gasification requires a higher causticization load compared to processing in a Tomlinson boiler. The higher causticization load requires a higher lime kiln capacity and higher lime kiln fuel consumption per unit of black liquor solids processed.

In the previous BLGCC study [Larson, Consonni and Katofsky, 2003] we've estimated a $16 \%$ increase in lime kiln load based on the assumption that the ratio of Active Alkali in the pulping liquor to the wood feed to the digester for the polysulfide process is the same of the conventional process utilizing Tomlinson recovery boilers. This assumption must be verified based on a more careful estimate of the heat/mass balances of polysulfide pulping. It is worth noting that, due to the higher yield of the polysulfide process assumed with gasification, the increase in kiln load ( $\mathrm{kW}$ or $\mathrm{kg} / \mathrm{s}$ of fuel oil) is significantly smaller than the increase in specific lime requirements ( $\mathrm{t}$ of lime per $\mathrm{t}$ of BLS), which is $28 \%$.

Given the relatively modest increase in the capacity required for the lime kiln, it is assumed that the extra capacity needed is met by oxygen-enrichment of combustion air.

\subsection{Sulfur Recovery system}

The $\mathrm{H}_{2} \mathrm{~S}$ in the gas phase at the exit of the BL gasifier must be removed both to recover the sulfur for the pulp mill and to prevent damages to the equipment downstream. Sulfur compounds and other contaminants can poison the catalysts used for fuel synthesis, as well as corrode the gas turbine and the heat transfer equipment.

The removal of $\mathrm{H}_{2} \mathrm{~S}$ and other contaminants can be carried out by a number of technologies based on chemical or physical absorption. The latter is favored by high pressures and low temperatures, which increase the solubility of the species to be captured into the liquid solvent used to carry them away. Unlike chemical absorption, physical absorption does not require large amounts of heat to regenerate the solvent; on the other hand, it requires high partial pressure of the gases to be removed. In our schemes gas clean-up is carried out at pressures between 32 and 105 bar; this situation is favorable for physical absorption, which therefore has been assumed in all cases.

Specifically, we've considered two of the most widespread commercial physical absorption processes that have accumulated significant operating experience with syngas treatment: Rectisol and Selexol. The former makes use of methanol as the solvent and operates at cryogenic temperatures (from $-25^{\circ} \mathrm{C}$ to $-60^{\circ} \mathrm{C}$ or even lower); the latter makes use of dimethyl ether of polyethylene glycol and typically operates at nearly ambient temperature $\left(20-30^{\circ} \mathrm{C}\right)$. Rectisol can reduce the concentration of $\mathrm{H}_{2} \mathrm{~S}$ to much lower levels then Selexol; however, its much lower operating temperatures give higher power consumption and the complex plant arrangement results in higher capital costs. 
The catalysts considered here for the production of DME and FT are very sensitive to sulfur poisoning and require very low concentrations of $\mathrm{H}_{2} \mathrm{~S}$, of the order of $0.1 \mathrm{ppmv}$. Such a concentration is beyond reach for Selexol and necessarily requires Rectisol, which therefore has been assumed for all DME and FT cases. In addition to $\mathrm{H}_{2} \mathrm{~S}$, Rectisol also captures most of the $\mathrm{CO}_{2}$ : without special provisions, up to $80 \%$ of the amount at inlet. This is a desirable feature because low $\mathrm{CO}_{2}$ concentrations in the gas fed to the FSI improve its conversion to liquid fuel. The removal of all the $\mathrm{CO}_{2}$ requires a more complex and thus more expensive design, which has been adopted only when the unconverted syngas is recycled (cases DMEa and DMEb), to avoid excessive $\mathrm{CO}_{2}$ build-up in the recycle loop.

The catalysts considered for the production of mixed alcohols is a Mo-based sulfide that can tolerate $\mathrm{H}_{2} \mathrm{~S}$ concentration three orders of magnitude higher, around $100 \mathrm{ppmv}$; some $\mathrm{H}_{2} \mathrm{~S}$ is actually needed in the gas to make up for the sulfur inevitably lost by the catalyst. This circumstance suggests Selexol as a more suitable process for the $\mathrm{MixOH}$ case, and this is the option we have used.

\subsubsection{Rectisol system}

Given the significant consumption of utilities (especially refrigeration power, which translates to electric power requirements), the Rectisol system has been modeled in detail with Aspen Plus to quantify the requirements of refrigeration power, steam and electricity with an accuracy comparable to the estimates for the other major subsystems. The model, the configurations and the results generated with Aspen Plus are illustrated in detail in Appendix C. Although this model cannot provide detailed design information, it is helpful to define the plant configuration, choose the most suitable operating conditions and estimate the mass and heat balances.

The base configuration has been set up to achieve a concentration of $\mathrm{H}_{2} \mathrm{~S}+\mathrm{COS}$ below 1 ppm and a concentration of $\mathrm{CO}_{2}$ below $1 \%$ by volume. As reported in Tab. 9, the acid gases removed from the syngas are released in three streams:

- one containing essentially all the $\mathrm{H}_{2} \mathrm{~S}$ and COS removed from the syngas; the concentration of $\mathrm{H}_{2} \mathrm{~S}+\mathrm{COS}$ in this stream is higher than $40 \%$ by vol., making it fully compatible with treatment in a Claus plant;

- one consisting mainly of $\mathrm{CO}_{2}$ (more than $97 \%$ by volume) with no $\mathrm{H}_{2} \mathrm{~S}$ nor $\mathrm{COS}$, which can be vented to the atmosphere or used in chemical industry.

- a tailgas with about $50 \% \mathrm{CO}_{2}$ and $50 \% \mathrm{~N}_{2}$, also with no $\mathrm{H}_{2} \mathrm{~S}$ nor COS. This tailgas stream can be discharged to atmosphere. However, if some ppm of $\mathrm{H}_{2} \mathrm{~S}$ would still be present in this flow, a LO-CAT or other process can effectively remove trace $\mathrm{H}_{2} \mathrm{~S}$.

The base configuration has been adopted for cases DMEa and DMEb, where the very high recycle rate in the FSI (97\%) necessarily requires a thorough removal of the $\mathrm{CO}_{2}$ to prevent its build-up in the recycle loop of the unconverted syngas. When the FSI is without unconverted syngas recycle, (as DMEc, FTa, FTb and FTc) the complete removal of $\mathrm{CO}_{2}$ is unnecessary and the Rectisol plant can be significantly simplified to use only a single absorption column ${ }^{5}$. In this case the concentration of $\mathrm{CO}_{2}$ in the clean syngas is about $5 \%$, depending on the inlet raw syngas composition (Tab. 9).

\footnotetext{
${ }^{5}$ Two columns are required for complete removal of $\mathrm{CO}_{2}$.
} 


\begin{tabular}{|c|c|c|c|c|}
\hline & & \begin{tabular}{|c|}
$\mathrm{H}_{2} \mathrm{~S}+\mathrm{CO}_{2}$ total \\
removal, $\mathrm{BL}$ syngas \\
DMEa, DMEb
\end{tabular} & $\begin{array}{c}\mathbf{H}_{2} \mathbf{S} \text { removal, } \mathbf{B L} \\
\text { syngas } \\
\text { DMEc, } \mathrm{FTa}, \mathrm{FTb} \\
\end{array}$ & $\begin{array}{c}\mathrm{H}_{2} \mathrm{~S} \text { removal, } \\
\begin{array}{c}\mathrm{BL}+\text { biomass syngas } \\
\text { FTc }\end{array} \\
\end{array}$ \\
\hline \multicolumn{5}{|l|}{ Clean gas } \\
\hline $\mathrm{H}_{2} \mathrm{~S}+\mathrm{COS}$ content & ppm vol & $<0.1$ (a) & $<0.1$ (a) & $<0.1$ (a) \\
\hline $\mathrm{CO}_{2}$ content & $\%$ vol & $<1$ (a) & 6 & 5 \\
\hline \multicolumn{5}{|l|}{$\mathrm{CO}_{2}$-concentrated gas } \\
\hline $\mathrm{CO}_{2}$ content & $\%$ vol & 98 & 98 & 99 \\
\hline $\mathrm{H}_{2} \mathrm{~S}+\mathrm{COS}$ content & $\%$ vol & none (a) & none (a) & none (a) \\
\hline \multicolumn{5}{|l|}{ Tailgas } \\
\hline $\mathrm{CO}_{2}$ content & $\%$ vol & 50 & 32 & 38 \\
\hline $\mathrm{N}_{2}$ content & $\%$ vol & 49 & 68 & 62 \\
\hline $\mathrm{H}_{2} \mathrm{~S}+\mathrm{COS}$ content & $\%$ vol & none (a) & none (a) & none (a) \\
\hline \multicolumn{5}{|c|}{ Acid gas stream (feed to Claus/SCOT plant) } \\
\hline $\mathrm{H}_{2} \mathrm{~S}+\mathrm{COS}$ content & $\%$ vol & 44 & 41 & 13 \\
\hline $\mathrm{CO}_{2}$ & $\%$ vol & 53 & 56 & 84 \\
\hline \multicolumn{5}{|l|}{ Duties } \\
\hline Heat & $\mathrm{MWt}$ & 4 & 4 & 10 \\
\hline Refrigeration & MWref & 6.8 & $5-6.6(b)$ & 16.0 \\
\hline \multicolumn{5}{|l|}{ Power consumption } \\
\hline Refrigeration system & MWel & 2.1 & $2-2.1$ (b) & 5.1 \\
\hline Other auxiliaries & MWel & 1.0 & 0.96 & 2.6 \\
\hline
\end{tabular}

(a) Values adopted as specifications for the Rectisol system.

(b) Values depending on inlet raw gas temperature.

Tab. 9. Main operating conditions of Rectisol system

\subsubsection{Selexol system}

Selexol is a proprietary technology licensed by UOP where the gas to be treated is contacted with dimethyl ether of polyethylene glycol at nearly ambient temperatures. The concentration of $\mathrm{H}_{2} \mathrm{~S}+\mathrm{COS}$ can be brought down to around $10 \mathrm{ppmv}$, a value that is too high for the DME and FT catalysts but is acceptable for the $\mathrm{MoS}_{2}$ catalyst assumed for MixOH synthesis.

In the arrangement with unconverted gas recycle assumed for the $\mathrm{MixOH}$ synthesis island it is convenient to operate the Selexol absorber and the mixed alcohol reactor at the same pressure to avoid the need to expand and recompress the recycle gas. Typical pressures in Selexol absorbers are 30-70 bar; higher pressures would favor the absorption of acid gases and most likely improve performances, but are beyond the experience gained by the licensor of the technology. Alcohol synthesis is favored by high pressures and a desirable value for the mixed alcohol reactor is 135-140 bar. In our case we have assumed that both the Selexol absorber and the mixed alcohol reactor operate at about 100 bar, which appears to be a reasonable compromise between the need to favor alcohol synthesis and the extensions of operating parameters that could be accepted by the supplier of a Selexol plant.

The Selexol system has not been modeled in detail. Estimates of performance and utilities consumption have been supplied directly by UOP (Tab. 10). These estimates have been used as inputs for the calculation of the overall performance of the whole biorefinery plant by GS. 


\begin{tabular}{|lr|}
\hline \multicolumn{2}{|c|}{ Selexol Design Information } \\
\hline Feed gas gas: & $45^{\circ} \mathrm{C}$ \\
\hline Temperature & $104.5 \mathrm{bar}$ \\
\hline Pressure & $36 \mathrm{~kg} / \mathrm{s}$ \\
\hline Mass flow & $1.2 \% \mathrm{vol}$ \\
\hline $\mathrm{H}_{2} \mathrm{~S}$ content & $20 \%$ vol \\
\hline $\mathrm{CO}_{2}$ content & $25^{\circ} \mathrm{C}$ \\
\hline Clean gas: & $104 \mathrm{bar}$ \\
\hline Temperature & $18 \%$ \\
\hline Pressure & $30 \mathrm{ppm} \mathrm{vol}$ \\
\hline $\mathrm{H}_{2} \mathrm{~S}$ content & $35^{\circ} \mathrm{C}$ \\
\hline $\mathrm{CO}_{2}$ content & $1.9 \mathrm{bar}$ \\
\hline Acid gas stream (feed to Claus/SCOT plant): & $3.7 \mathrm{~kg} / \mathrm{s}$ \\
\hline Temperature & $24 \%$ vol \\
\hline Pressure & $70 \%$ vol \\
\hline Mass flow & \\
\hline $\mathrm{H}_{2} \mathrm{~S}$ content & \\
\hline $\mathrm{CO}_{2}$ content & \\
\hline
\end{tabular}

Tab. 10. Main flows characteristics of the Selexol system

\subsubsection{Claus/SCOT unit}

The acid gas flow from the Rectisol process is treated in a Claus plant where $\mathrm{H}_{2} \mathrm{~S}$ is converted into elemental sulfur. This sulfur is dissolved into a low-sulfidity white liquor (containing the $\mathrm{Na}_{2} \mathrm{~S}$ formed in the gasifier smelt) to regenerate the polysulfide pulping liquor.

The Claus plant generates MP (13 bar) and LP (4.8 bar) steam, which is exported to the MP and LP headers that feed the mill. The amount of steam generated is assumed to be proportional to the amount of $\mathrm{H}_{2} \mathrm{~S}$ converted to elemental sulfur. The tail gas of the Claus plant is treated in a SCOT unit, which requires IP steam (6.5 bar) to regenerate the solvent used to absorb $\mathrm{SO}_{2}$. The assumptions adopted for the Claus/SCOT unit are reported in Tab. 11.

The single components of the Claus/SCOT plant have not been modeled in detail. Power consumption, steam production and steam consumption (Tab. 11) are estimated base on data taken from [Larson, Consonni and Katofsky, 2003] and from Nexant [S. Kramer, personal communication, June 2006] for the whole Sulfur Recovery Unit (SRU).

In the FTc case the concentration of $\mathrm{H}_{2} \mathrm{~S}$ in the gas sent to the Claus plant is below $15 \%$ and the attainment of the temperatures needed by the Claus process may require a non conventional arrangement, for example with some pre-heating of the gas to be burned in the furnace. 


\begin{tabular}{|lr|}
\hline \multicolumn{2}{|c|}{ Claus/SCOT steam } \\
\hline IP steam to SCOT plant & $\begin{array}{r}6.5 \mathrm{bar}(80 \mathrm{psig}) \\
2.4 \mathrm{~kg} / \mathrm{kg} \mathrm{H}_{2} \mathrm{~S} \text { captured }\end{array}$ \\
\hline MP steam from Claus plant to mill & $13 \mathrm{bar}(175 \mathrm{psig})$ \\
\hline LP steam from Claus plant to mill & $3.3 \mathrm{~kg} / \mathrm{kg} \mathrm{H}_{2} \mathrm{~S}$ captured \\
\hline
\end{tabular}

Tab. 11. Assumptions adopted in this study for production and consumption of steam

\subsection{DME synthesis}

\subsubsection{DME synthesis kinetics model}

The direct synthesis of DME from syngas assumed in our FSI takes place in two steps: methanol synthesis and in situ methanol dehydration. The process comprises the following reactions:

$$
\begin{array}{ll}
\mathrm{CO}+2 \mathrm{H}_{2} \Leftrightarrow \mathrm{CH}_{3} \mathrm{OH} & \Delta \mathrm{H}^{0}{ }_{298}=-94.084 \mathrm{~kJ} / \mathrm{mol} \\
\mathrm{CO}_{2}+3 \mathrm{H}_{2} \Leftrightarrow \mathrm{CH}_{3} \mathrm{OH}+\mathrm{H}_{2} \mathrm{O} & \Delta \mathrm{H}^{0}{ }_{298}=-52.814 \mathrm{~kJ} / \mathrm{mol} \\
\mathrm{CO}+\mathrm{H}_{2} \mathrm{O} \Leftrightarrow>\mathrm{H}_{2}+\mathrm{CO}_{2} & \Delta \mathrm{H}^{0}{ }_{298}=-41.270 \mathrm{~kJ} / \mathrm{mol} \\
2 \mathrm{CH}_{3} \mathrm{OH} \Leftrightarrow \mathrm{CH}_{3} \mathrm{OCH}_{3}+\mathrm{H}_{2} \mathrm{O} & \Delta \mathrm{H}^{0}{ }_{298}=-19.76 \mathrm{~kJ} / \mathrm{mol}
\end{array}
$$

Reactions (1)-(3) are catalyzed by a methanol synthesis catalyst (e.g. CuO/ZnO/Al2O3) and reaction (4) is catalyzed by an acidic catalyst (e.g. $\gamma$-aluminum). Reactions (1) to (4) show a high degree of synergy provided that the operation conditions are optimized enough to remove methanol effectively. Water formed in reactions (1) and (2) is removed via the water gas shift (WGS) reaction (3) to produce hydrogen which kinetically favors the production of methanol.

The low $\mathrm{H}_{2} / \mathrm{CO}$ ratio $(0.5-1)$ of the syngas derived from coal or biomass makes it well suited to a Continuous Stirred Tank Reactor (CSTR) configuration. This is the case of the Liquid Phase process (LPDME), where the synthesis reaction takes place in a slurry of inert oil and liquid reaction products with powdered catalyst-laden particles. This working condition provides good mixing and an effective means to carry away heat. Based on this advantage, LPDME has been selected as the DME synthesis technology.

It was decided to base the analysis and the simulation of the process taking place in the LPDME reactor on the model for methanol synthesis proposed by Graaf [Graaf et al. 1988, Graaf et al. 1896], based on an extensive set of accurate kinetic experiments, and the methanol dehydration model developed by $\mathrm{Ng}$ et al. [1999]. The model we use was originally developed by Larson and Ren [2003] and further modified by Celik, et al. [2004].

The main assumptions of the kinetic model are the following:

a) the slurry is thermally stable and chemically inert;

b) the particles carrying the catalyst are small enough to allow neglecting internal diffusion;

c) mass transfer is fast enough to make liquid-phase diffusion of negligible relevance;

d) the catalyst is uniformly distributed across the reactor;

e) the heat generated by the synthesis reactions is carried away fast enough to make the reactor isothermal;

f) the methanol synthesis reaction is catalyzed only by $\mathrm{CuO} / \mathrm{ZnO} / \mathrm{Al}_{2} \mathrm{O}_{3}$; the dehydration reaction is catalyzed only by $\gamma$ - alumina; 
g) by-products are ignored; the only species involved are $\mathrm{CO}, \mathrm{CO}_{2}, \mathrm{H}_{2}, \mathrm{H}_{2} \mathrm{O}, \mathrm{CH}_{4} \mathrm{O}, \mathrm{DME}$, $\mathrm{CH}_{4}, \mathrm{~N}_{2}$ and Ar.

Under stirred conditions the LPDME process can be treated as a CSTR and modeled by the Aspen block RCSTR. The kinetic mechanism with the characteristics listed above is supplied to Aspen in the form of a user-defined kinetic model. Tab. 12 reports the input of this user-defined model adopted for this study. See Appendix A for further details about the kinetic model assumed for the DME synthesis.

\begin{tabular}{|l|l|}
\hline & \multicolumn{1}{c|}{ Block Input parameters } \\
\hline Reaction temperature & $260^{\circ} \mathrm{C}$ \\
\hline Reaction pressure & 62.5 bar \\
\hline \multicolumn{1}{|c|}{ Real variables } & \\
\hline No.1 & Catalyst A loading for methanol synthesis reaction \\
\hline No.2 & GHSV (gas hourly space velocity) \\
\hline No.3 & Catalyst B loading for methanol dehydration reaction \\
\hline No.4 & Ratio of catalyst B/ catalyst A \\
\hline
\end{tabular}

Tab. 12. Parameter inputs required for the Aspen RCSTR block used to model the DME reactor

\subsubsection{DME reactor}

DME can be synthesized by two types of reactors: fixed bed and slurry bed. As already mentioned, in this project we focus on the slurry bed reactor, where the syngas is bubbled through a slurry of high-boiling inert oil and suspended powdered catalyst particles. The reason of this choice is two-fold:

\section{CO conversion and power co-production}

The $\mathrm{CO}$ conversion ratios achievable in a single pass through the synthesis reactor can vary within a wide range. Low one-pass yields require the recycle of large amounts of unconverted gas to achieve acceptable $\mathrm{CO}$ conversion ratios and liquid fuel production. The nearly isothermal conditions and the effective gas-liquid-solid heat/mass transfer of the LPDME allows reaching DME molar fractions in the reactor output gas of the order of $5 \%{ }^{6}$. Such one-pass performance is inadequate for a plant aimed at producing just DME; however, in our co-production schemes unconverted syngas is effectively used to produce power, so that moderate $\mathrm{CO}$ conversion ratios can still be attractive. In fact, the basic goal of a coproduction system is achieving the most favorable breakdown of useful outputs (in our case fuel, power and heat), rather than maximizing a single product. In addition to higher energy utilization efficiency and higher economic benefits, co-production may also bring about lower overall emissions.

\section{Temperature control}

The temperature within the DME reactor must be controlled accurately both to prevent hot spots that could damage the catalyst and because temperature increases would shift the exothermic reactions that form DME away from the products. The relatively high heat of

${ }^{6}$ The heat generated by the exothermic synthesis reaction tends to increase temperature and thus to slow down the reaction. The high heat fluxes achievable in the slurry bed reactor help in maintaining nearly isothermal conditions and thus high reaction speeds. High mass transfer rates are desirable to prevent the build-up of products around the catalyst particles, which would also slow down the reaction by shifting chemical equilibrium towards the reactants. 
reaction of DME synthesis (significantly higher than that of methanol) makes this issue particularly relevant.

The operating conditions of the slurry bed reactor are particularly favorable for effective temperature control. The reactant gas forms small bubbles which react and exchange heat as they rise through the slurry. The heat taken up by the slurry is released to tubes immersed into the reactor which carry a two-phase mixture of water and steam. The high overall heat transfer coefficients of the two-phase mixture inside the tubes and the liquid outside allows handling high fluxes, giving a compact and relatively inexpensive reactor design. An added, important benefit of good temperature control is the longer life of the catalyst.

\subsubsection{Heat exchang design of DME synthesis section}

The production of high purity DME requires both heat duties and cold duties. Heat is needed to heat the reactants of the DME reactor and the dehydration reactor, as well as for the reboilers of the distillation columns. Cooling is needed for the condensers of the distillation towers that separates light gases, DME, methanol and water. Besides, different streams (reactants, reactors effluents, etc.) must be heated or cooled to pre-determined temperatures.

To ensure the most efficient use of the energy available, the heat exchangers within the FSI have been arranged to match the heat duties and the cold duties as much as possible. Some cooling is provided by the expansion of an in-process stream at high pressure; the remainder by cooling water and a refrigeration plant.

\subsection{Fischer-Tropsch (FT) synthesis}

\subsubsection{Kinetic model}

The simplest kinetic models for Fischer-Tropsch synthesis are single- $\alpha$ models such as that proposed by Lox and Froment [1993], who assume fixed growth probability for all olefins $\left(\mathrm{C}_{\mathrm{n}} \mathrm{H}_{2 n}\right)$ and paraffins $\left(\mathrm{C}_{\mathrm{n}} \mathrm{H}_{2 n+2}\right)$. Fox and Tam [1995] present a triple- $\alpha$ model for FT synthesis, which can more accurately predict product distributions than single- $\alpha$ models. We have adopted a model, based on Fox and Tam's approach, that was developed by Larson et al. [2005]. With Fox and Tam's approach, the rate of olefin formation varies depending on the carbon number, and the paraffin formation rate is related to the olefin formation rate.

Our simulations assume a slurry bed reactor where an iron catalyst is dispersed in the FT wax product. The advantages of the slurry bed are the same already mentioned for DME, with the added benefit that for FT synthesis the $\mathrm{CO}$ conversion achievable with a single pass is extremely high: at the operating conditions considered here, the kinetic model of the FT reactor gives a $\mathrm{CO}$ conversion of nearly $65 \%$. The main disadvantage is the complexity of catalyst separation from the FT waxes. Due to its WGS activity, the iron catalyst is particularly suited to the low $\mathrm{H}_{2} / \mathrm{CO}$ syngas generated by the black liquor and biomass gasifiers.

The main assumptions adopted for the FT synthesis model are:

- the slurry is thermally stable and chemically inert,

- the particles carrying the catalyst are small enough to allow neglecting internal diffusion;

- mass transfer is fast enough to make liquid-phase diffusion of negligible relevance;

- the catalyst is uniformly distributed across the reactor;

- the heat generated by the synthesis reactions is carried away fast enough to make the reactor isothermal; 
- Oxygenated by-products are ignored.

- FT components with two to four carbons (C2-C4) we lump together as light gases and represent as equivalent $\mathrm{C} 4$; $\mathrm{C} 5-\mathrm{C} 11$ are grouped as FT gasoline fraction and represented as equivalent C9. C12-C18 are grouped as FT diesel fraction and represented as equivalent $\mathrm{C} 15$ component. C19+ are grouped as FT wax fraction and represented as equivalent C21 pseudocomponent.

In addition to hydrocarbon reaction rates, there are also reaction rates to be considered for $\mathrm{CO}, \mathrm{H}_{2}, \mathrm{CO}_{2}$ and $\mathrm{H}_{2} \mathrm{O}$. In this regard, our model considers the following reactions (see Appendix A for further details about the kinetic model assumed for FT synthesis):

$$
\begin{aligned}
& \mathrm{CO}+\mathrm{H}_{2} \mathrm{O} \Leftrightarrow \mathrm{CO}_{2}+\mathrm{H}_{2} \\
& \mathrm{CO}+3 \mathrm{H}_{2} \Leftrightarrow \mathrm{CH}_{4}+\mathrm{H}_{2} \mathrm{O} \\
& a_{1} \mathrm{CO}+\left(2 a_{1}+1\right) \mathrm{H}_{2} \Leftrightarrow \mathrm{C}_{a_{1}} \mathrm{H}_{2 a_{1}+2}+a_{1} \mathrm{H}_{2} \mathrm{O} \quad\left(a_{1} \text { is between } 2 \text { to } 4\right) \\
& a_{2} \mathrm{CO}+\left(2 a_{2}+1\right) \mathrm{H}_{2} \Leftrightarrow \mathrm{C}_{a_{2}} \mathrm{H}_{2 a_{2}+2}+a_{2} \mathrm{H}_{2} \mathrm{O} \quad\left(a_{2} \text { is between } 5 \text { to } 11\right) \\
& a_{3} \mathrm{CO}+\left(2 a_{3}+1\right) \mathrm{H}_{2} \Leftrightarrow \mathrm{C}_{a_{3}} \mathrm{H}_{2 a_{3}+2}+a_{3} \mathrm{H}_{2} \mathrm{O} \quad\left(a_{3} \text { is between } 12 \text { to } 18\right) \\
& a_{4} \mathrm{CO}+\left(2 a_{4}+1\right) \mathrm{H}_{2} \Leftrightarrow \mathrm{C}_{a_{4}} \mathrm{H}_{2 a_{4}+2}+a_{4} \mathrm{H}_{2} \mathrm{O}\left(a_{4} \text { is } 19 \text { or above }\right) \\
& b_{1} \mathrm{CO}+2 b_{1} \mathrm{H}_{2} \Leftrightarrow \mathrm{C}_{b_{1}} \mathrm{H}_{2 b_{1}}+b_{1} \mathrm{H}_{2} \mathrm{O} \quad\left(b_{1} \text { is between } 2 \text { to } 4\right) \\
& b_{2} \mathrm{CO}+2 b_{2} \mathrm{H}_{2} \Leftrightarrow \mathrm{C}_{b_{2}} \mathrm{H}_{2 b_{2}}+b_{2} \mathrm{H}_{2} \mathrm{O} \quad\left(b_{2} \text { is between } 5 \text { to } 11\right) \\
& b_{3} \mathrm{CO}+2 b_{3} \mathrm{H}_{2} \Leftrightarrow \mathrm{C}_{b_{3}} \mathrm{H}_{2 b_{3}}+b_{3} \mathrm{H}_{2} \mathrm{O} \quad\left(b_{3} \text { is between } 12 \text { to } 18\right) \\
& b_{4} \mathrm{CO}+2 b_{4} \mathrm{H}_{2} \Leftrightarrow \mathrm{C}_{b_{4}} \mathrm{H}_{2 b_{4}}+b_{4} \mathrm{H}_{2} \mathrm{O} \quad\left(b_{4} \text { is } 19 \text { or above }\right)
\end{aligned}
$$

\subsubsection{FT reactor}

Due to the high yields achievable with a single pass, in all cases we've considered a oncethrough arrangement. Like DME synthesis, under stirred conditions FT synthesis can also be treated as a CSTR and modeled by the Aspen block RCSTR. The kinetic mechanism is provided to Aspen in the form of a user-defined model. The input and output parameters for this userdefined kinetic model are reported in Tab. 13.

\begin{tabular}{|l|l|}
\hline & \multicolumn{1}{|c|}{ Block Input parameters } \\
\hline Reaction temperature & $260^{\circ} \mathrm{C}$ \\
\hline Reaction pressure & $30.7 \mathrm{bar}$ \\
\hline Real variables & \\
\hline No.1 & Catalyst loading for FT synthesis reaction \\
\hline No.2 & GHSV $=5800$ liters $/ \mathrm{kgcata} . \mathrm{h}^{7}$ \\
\hline
\end{tabular}

Tab. 13. Assumptions adopted for the Aspen RCSTR block used to model the FT reactor

\footnotetext{
${ }^{7}$ Liters are at normal temperature and pressure, i,e. at $20^{\circ} \mathrm{C}$ and 1,013 bar.
} 


\subsubsection{FT liquid product}

The raw liquid product of the FT synthesis reactor is a mixture of distillate, naphtha and wax which needs further processing to upgrade it to gasoline and diesel fuel. Because of the complexity of this process and the small scale of our biorefinery (compared to refineries fed with fossil fuels), we've assumed that the raw liquid is exported to an existing petroleum refinery without further processing. The raw FT product must be kept warm in order to maintain the waxes as liquid, thus requiring trucks with heated tanks.

\subsection{Mixed alcohols synthesis}

\subsubsection{Mixed alcohols synthesis kinetic model}

Alcohols and other oxygenated liquids are viewed as desirable gasoline additives both to improve the octane number and to reduce engine emissions. Catalysts used for the production of higher alcohols from synthesis gas can be divided into four categories [Liu et al., 1997]:

- the first one is based on a soluble Ru complex used as an homogeneous catalyst;

- the second can be described as modified methanol catalysts, e.g. alkali-doped $\mathrm{ZnO} /$ chromia or $\mathrm{Cu}$-based catalysts;

- the third comprises mixed-metal Fischer-Tropsch catalysts, e.g. Co and Fe on a support;

- the last comprises alkali-promoted $\mathrm{MoS}_{2}$ catalysts.

Mo-based systems are promising due to their high tolerance to sulfur compounds in the feed gas, high WGS reaction activity, high activity and selectivity for linear alcohols. The last characteristic is very important, because the formation of hydrocarbons ( $\alpha$-olefins and $n$ paraffins) from $\mathrm{CO}$ and $\mathrm{H}_{2}$ is thermodynamically favored with respect to the formation of higher alcohols, i.e. $\mathrm{K}_{\text {eq }}$ (the equilibrium constant) of hydrocarbons are higher than $\mathrm{K}_{\mathrm{eq}}$ of alcohols; consequently, the synthesis of higher alcohols requires selective catalysts capable of finding a way around the tendency favoured by thermodynamics to drive the process toward alcohols.

Given the lack of any published models in the literature, for this study a new kinetic model has been developed to estimate CO conversion and alcohols formation over a Mo-based catalyst. The model has been developed at the Dept. of Chemistry of Politecnico di Milano by the group led by prof. P. Forzatti, who for many years has been at the forefront of research on heterogeneous catalytic processes (see Appendix B for a full description of the model developed by prof. Lietti and Tronconi). The kinetic model is based on the experimental data published by Gunturu et al. [1998] on the synthesis of methanol and higher alcohols from syngas by means of a C-supported, K-promoted Co-Mo sulfide catalyst (Mo-Co-K/C). The work of Gunturu et al. provides data on the whole set of reactions for higher alcohols synthesis, as well as rate expressions and estimates of kinetic parameters.

The kinetic model based on Gunturu's data has been implemented into a Fortran code, which has been subsequently embedded into the Aspen model of the plant section devoted to mixed alcohol synthesis. Similarly to the model for DME synthesis and FT synthesis, the model of mixed alcohol synthesis is executed by Aspen when calculating the mass and energy balance of the Fuel Synthesis Island.

The simplified reaction scheme adopted for the synthesis of higher alcohols is the following:

$$
\begin{aligned}
& \mathrm{CO}+2 \mathrm{H}_{2} \leftrightarrow \mathrm{CH}_{3} \mathrm{OH} \\
& \mathrm{CH}_{3} \mathrm{OH}+\mathrm{H}_{2} \rightarrow \mathrm{CH}_{4}+\mathrm{H}_{2} \mathrm{O}
\end{aligned}
$$




$$
\begin{aligned}
& \mathrm{CH}_{3} \mathrm{OH}+\mathrm{CO}+2 \mathrm{H}_{2} \rightarrow \mathrm{C}_{2} \mathrm{H}_{5} \mathrm{OH}+\mathrm{H}_{2} \mathrm{O} \\
& \mathrm{C}_{2} \mathrm{H}_{5} \mathrm{OH}+\mathrm{CO}+2 \mathrm{H}_{2} \rightarrow \mathrm{C}_{3} \mathrm{H}_{7} \mathrm{OH}+\mathrm{H}_{2} \mathrm{O} \\
& \mathrm{CO}+\mathrm{H}_{2} \mathrm{O} \leftrightarrow \mathrm{CO}_{2}+\mathrm{H}_{2}
\end{aligned}
$$

In this lumped reaction scheme, the production of methanol from $\mathrm{CO}$ and $\mathrm{H}_{2}$ (reaction 15) is considered reversible and limited by chemical equilibrium. Further, it is assumed that all hydrocarbon products are produced from methanol and comprise only methane (reaction 16). The formation of ethanol (reaction 17) and the formation of propanol (reaction 18) proceed by reaction of $\mathrm{CO}$ and $\mathrm{H}_{2}$ with methanol and with ethanol, respectively, according to a consecutive scheme. $\mathrm{CO}_{2}$ formation is accounted for by the WGS reaction (reaction 19) which is assumed to be always at equilibrium.

Alcohols with carbon number higher than three $\left(\mathrm{C}_{4}+\right.$ alcohols $)$ are formed in quantities so small that they are irrelevant to the mass/energy balances and thus are neglected; in fact, $\mathrm{C}_{4+}$ carbon selectivity is less than 4\% [Aden et al. 2005]. As for ethers (dimethyl ether, diethyl ether) and other oxygenates not explicitly identified as alcohols, they have been lumped into the hydrocarbon fraction, i.e. methane.

Since the experimental data reported by Gunturu refer to an inlet flow with no $\mathrm{CO}_{2}$, in the kinetic model developed here $\mathrm{CO}_{2}$ is assumed to behave as an inert and its influence on the reaction rates is due solely to the decrease of the partial pressure of the reactants. As long as the $\mathrm{CO}_{2}$ concentration in the syngas is only a few percentage points, this assumption is most likely realistic. On the other hand, large concentrations of $\mathrm{CO}_{2}$ could influence the kinetic characteristics of the catalyst and reduce its activity and/or its selectivity to higher alcohols. In the $\mathrm{MixOH}$ case considered here the concentration of $\mathrm{CO}_{2}$ in the reactor inlet gas is about $30 \%$, a value for which an impact on the catalyst behavior cannot be excluded. Consequently, the alcohols production calculated by our model may be optimistic and requires verification with further experimental data on conditions with high $\mathrm{CO}_{2}$ concentration.

\subsubsection{1 $\mathrm{CO}_{2}$ removal in the recycle loop}

The high $\mathrm{CO}_{2}$ content in the syngas fed to the mixed alcohol reactor is due to the recycle loop, which returns to the reactor the by-product $\mathrm{CO}_{2}$ generated by the alcohol synthesis. The $\mathrm{CO}_{2}$ concentration at the reactor inlet could be drastically reduced by removing nearly all the $\mathrm{CO}_{2}$ in the recycle flow by the same Selexol system that removes $\mathrm{H}_{2} \mathrm{~S}$. This arrangement would be more expensive due not only to the larger mass flow through the Selexol (which would handle the recycled syngas together with the fresh syngas) but also to the more complex and costly arrangement of the Selexol plant required to remove both $\mathrm{H}_{2} \mathrm{~S}$ and $\mathrm{CO}_{2}$. Moreover, the recycled stream includes a large amount of methane (a byproduct of the synthesis reactions) which would be captured in significant amounts in the column designed to capture the $\mathrm{CO}_{2}$. Most of this methane would be subsequently released together with $\mathrm{CO}_{2}$ in the flash chambers for Selexol regeneration and its effective recovery would be problematic. Since the penalties due to methane capture appear much more severe than those possibly due to lower catalyst activity, we've considered a scheme without thorough $\mathrm{CO}_{2}$ removal from the syngas.

\subsubsection{Mixed alcohols reactor}

Similarly to the synthesis of DME and FT fuel, alcohol synthesis is also exothermic and the heat of reaction must be effectively removed to prevent temperature increases that may sinter and thus deactivate the catalyst. 
Differently from what we assumed for DME and FT, for mixed alcohols we've assumed a fixed bed reactor because slurry technology for mixed alcohol synthesis is not commercially proven. In particular, the availability of a suitable inert liquid and the feasibility of an appropriate catalyst/liquid separation system are yet to be demonstrated. On the other hand, in a fixed bed reactor the arrangement of the evaporator tubes that carry away heat is particularly critical. Due to these factors, the best arrangement and the actual design of the mixed alcohol reactor need further investigation. Tab. 14 summarizes the main assumptions adopted for the mixed alcohol island.

\begin{tabular}{|l|l|}
\hline Clean syngas gas parameters & $\mathrm{H}_{2} \mathrm{~S}$ molar fraction $=50 \mathrm{ppm}$ \\
\hline Unconverted syngas recycle ratio & $90 \%$ \\
\hline Methanol recycle ratio & $100 \%$ \\
\hline \multirow{3}{*}{ Reactor } & Type: Fixed bed \\
& Reaction temperature $=350^{\circ} \mathrm{C}$ \\
& Pressure $=100$ bar \\
& GHSV $=3000$ liters $/ \mathrm{H} . \mathrm{kgcata}$ \\
\hline Molecular Sieve & $20 \%$ of ethanol and $97 \%$ of water are removed to purge gas \\
\hline
\end{tabular}

Tab. 14. Assumptions adopted for the Aspen block used to model the Mixed Alcohols reactor 


\section{PROCESS CONFIGURATIONS AND OPERATING CONDITIONS}

\subsection{Summary of technologies adopted for the major subsystems}

Tab. 15 summarizes the technologies adopted for the major subsystems, as described in the previous chapters. The following paragraphs give a detailed description of the plant arrangement and the operating conditions calculated for each case.

\begin{tabular}{|c|c|c|c|c|c|c|c|c|}
\hline & & DMEa & DMEb & DMEc & FTa & FTb & FTc & MixOH \\
\hline \multirow{3}{*}{$\begin{array}{l}\text { Technology for } \\
\text { energy recovery } \\
\text { from BL }\end{array}$} & Entrained-Flow Gasifier & $\mathrm{X}$ & $\mathrm{X}$ & $\mathrm{X}$ & $\mathrm{X}$ & $\mathrm{X}$ & $\mathrm{X}$ & $\mathrm{X}$ \\
\hline & Quench & $\mathrm{X}$ & $\mathrm{X}$ & $\mathrm{X}$ & $\mathrm{X}$ & $x$ & $\mathrm{X}$ & $\mathrm{X}$ \\
\hline & Oxygen feed & $\mathrm{X}$ & $\mathrm{X}$ & $\mathrm{X}$ & $\mathrm{X}$ & $\mathrm{X}$ & $\mathrm{X}$ & $\mathrm{X}$ \\
\hline \multirow{5}{*}{$\begin{array}{l}\text { Technology for } \\
\text { energy recovery } \\
\text { from biomass }\end{array}$} & Fluidized Bed Gasifier & & $\bar{X}$ & $\bar{X}$ & $\mathrm{X}$ & $\bar{x}$ & $\mathrm{X}$ & $\bar{x}$ \\
\hline & Syngas Cooler & & $\mathrm{X}$ & $\mathrm{X}$ & $\mathrm{X}$ & $\mathrm{X}$ & & \\
\hline & Quench & & & & & & $\mathrm{X}$ & $\mathrm{X}$ \\
\hline & Oxygen feed & & $\mathrm{X}$ & $\mathrm{X}$ & $\mathrm{X}$ & $\mathrm{X}$ & $\mathrm{X}$ & $\mathrm{X}$ \\
\hline & Power Boilers & $\mathrm{X}$ & & & & & & \\
\hline \multirow{2}{*}{$\begin{array}{l}\text { Technology for Gas Clean } \\
\text { Up ahead of FSI }\end{array}$} & Rectisol & $\mathrm{X}$ & $\mathrm{X}$ & $\bar{x}$ & $\bar{X}$ & $\bar{x}$ & $\bar{x}$ & \\
\hline & Selexol & & & & & & & $\mathrm{X}$ \\
\hline \multirow{3}{*}{$\begin{array}{l}\text { Syngas treatment ahead } \\
\text { of Gas Turbine }\end{array}$} & Ceramic Filter & & $\bar{x}$ & $\bar{x}$ & $\bar{x}$ & $\bar{x}$ & & \\
\hline & Syngas Expander & & $X$ & $\mathrm{X}$ & $\mathrm{X}$ & $\mathrm{X}$ & & \\
\hline & Saturator & & & & & & $\mathrm{X}$ & $\mathrm{X}$ \\
\hline \multirow{5}{*}{$\begin{array}{l}\text { Technology for } \\
\text { Fuel Synthesis }\end{array}$} & Feed from BL gasifier & $\mathrm{X}$ & $\mathrm{X}$ & $\mathrm{X}$ & $\mathrm{X}$ & $\mathrm{X}$ & $\mathrm{X}$ & $\bar{X}$ \\
\hline & Feed from biomass gasifier & & & & & & $\mathrm{X}$ & $\mathrm{X}$ \\
\hline & Slurry Bed & $\mathrm{X}$ & $\mathrm{X}$ & $\mathrm{X}$ & $\mathrm{X}$ & $\mathrm{X}$ & $\mathrm{X}$ & \\
\hline & Fixed Bed & & & & & & & $\mathrm{X}$ \\
\hline & Unconverted Gas Recycle & $\mathrm{X}$ & $X$ & & & & & $\mathrm{X}$ \\
\hline \multirow{2}{*}{$\begin{array}{l}\text { Technology used to } \\
\text { meet mill steam demand }\end{array}$} & Power Boilers & $\bar{X}$ & & & & & & \\
\hline & Duct Burner ahead of HRSG & & $\mathrm{X}$ & $\mathrm{X}$ & $\mathrm{X}$ & & & $\mathrm{X}$ \\
\hline \multirow{4}{*}{$\begin{array}{l}\text { Technology for } \\
\text { Power Production }\end{array}$} & Backpressure Steam Turbine & $\bar{X}$ & $\mathrm{X}$ & $\mathrm{X}$ & $\mathrm{X}$ & & & $\mathrm{X}$ \\
\hline & Condensing Steam Turbine & & & & & $\mathrm{X}$ & $\mathrm{X}$ & \\
\hline & Medium-scale Gas Turbine & & $X$ & $\mathrm{X}$ & $X$ & & $\mathrm{X}$ & $\mathrm{X}$ \\
\hline & Large-scale Gas Turbine & & & & & $\mathrm{X}$ & & \\
\hline
\end{tabular}

Tab. 15. Technologies adopted for the major subsystems

\subsection{Input to Fuel Synthesis Island}

As shown in Tab. 15, in all cases the syngas generated in the black liquor gasifier is cooled, cleaned and then fed to the FSI. In schemes DMEa, DMEb, DMEc, FTa and FTb this syngas is the only input to the FSI. Instead, in schemes FTc and MixOH the FSI is fed by a mixture of the syngas generated by the BL gasifier and the syngas generated by the biomass gasifier.

\subsubsection{Fuel synthesis fed with syngas from BLG}

The process designs of cases DMEa, DMEb, DMEc, FTa and FTb are similar: the syngas generated by BL gasification is cooled and cleaned in the Rectisol system and then sent to fuel synthesis. Some of the mill steam demand is met by recovering waste heat from the biorefinery; the remainder is provided by the power island. We have considered two basic configurations:

In case DMEa, the mill steam demand is matched by burning hog fuel and purchased wood wastes in a boiler.

In the other cases (DMEb, DMEc, FTa, FTb), hog fuel and wood residuals feed a biomass gasifier that generates syngas that is burned in a gas turbine. The gas turbine exhaust gases raise steam in a heat recovery steam generator (HRSG) which feeds the steam turbine. The mill steam 
demand is matched by adjusting the fuel input to a duct burner placed between the gas turbine and the HRSG; the only exception is case FTb, where the steam generated in the HRSG is more than enough to feed the mill and so no duct burner is needed. Both the gas turbine combustor and the duct burner are fed with a mixture of biomass syngas and unconverted syngas from the FSI. The amount of purchased wood wastes fed to the biomass gasifier (in addition to hog fuel) must be such that the biomass syngas plus unconverted syngas from the FSI are enough to fully fire the gas turbine and provide the required input to the duct burner.

In all cases the high pressure steam generated in the biomass boilers (case DMEa) or the HRSG expands through a steam turbine prior to being sent to the mill. In case FTb, the steam in excess of the mill demand expands through the LP section of the steam turbine.

\subsubsection{Fuel synthesis fed with syngas from BLG and from biomass gasification}

In cases FTc and $\mathrm{MixOH}$ the syngas generated by $\mathrm{BL}$ gasification and by biomass gasification are mixed together. The mixture is cleaned and sent to the FSI. Ahead of mixing, the biomass syngas is quenched to remove tar, particulates and alkali to very low levels. The unconverted syngas exiting the fuel synthesis island is used to fuel the GT. If needed, some unconverted syngas is also burned in a duct burner to match the mill steam demand.

The amount of purchased wood wastes sent to the biomass gasifier (in addition to hog fuel) is set to a value that gives enough unconverted syngas to fully fire the gas turbine and to feed the duct burner.

\subsection{Design and basic features of major subsystems}

\subsubsection{BL gasification}

Concentrated black liquor with a solid content of $80 \%$ is gasified in an entrained-flow oxygen-blow reactor at 32 bar pressure and at a temperature of about $1000^{\circ} \mathrm{C}$. The black liquor is partially oxidized to produce a molten smelt of sodium and sulfur compounds, as well as a combustible gas consisting mainly of $\mathrm{CO}, \mathrm{CO}_{2}$ and $\mathrm{H}_{2}$; the gas also includes part of the sulfur from the black liquor in the form of $\mathrm{H}_{2} \mathrm{~S}$. The raw gas and the smelt droplets flow into the lower section of the gasifier vessel, where they are cooled by injection of the condensate coming from the downstream syngas cooler. The smelt dissolves in the quench liquid to form green liquor, which is sent to chemical recovery after being cooled by heating the condensate used for the quench. The smelt-free raw gas leaves the quench at $217^{\circ} \mathrm{C}$ and 35 bar and is subsequently cooled to about $120^{\circ} \mathrm{C}$ through a heat exchanger. The heat released by the syngas in the first sections of the heat exchanger generates MP and LP steam, while the heat released in the last section is used to heat feed water. Most of the water in the syngas condenses, thereby releasing most of the energy picked-up in the quench. Chemrec, the developer of the BL gasifier design modeled here, claims that the counter-current arrangement envisaged for the heat exchanger design to cool the syngas can remove alkali down to very low concentrations. 


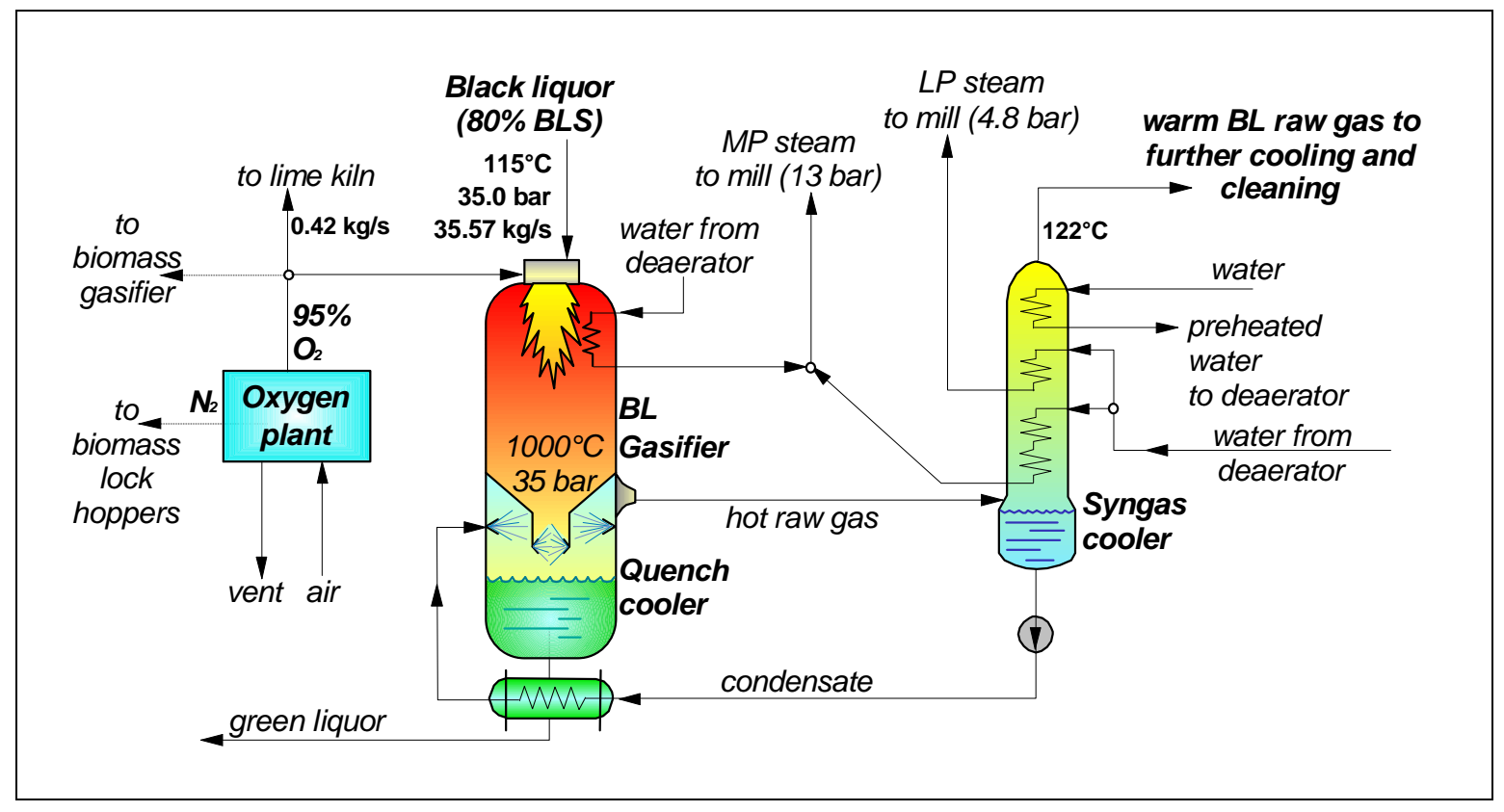

Fig. 5. Plant configuration for BL gasification

\subsubsection{Biomass Gasification}

Hog fuel and purchased wood wastes are chipped and dried from $50 \%$ to $20 \%$ moisture content using heat from the gas leaving the HRSG. The dried biomass is then pressurized in a lock-hopper system with inert gas and then fed to the fluidized-bed gasifier operating at 36 bar. $\mathrm{N}_{2}$ from the ASU is used as inert gas for the lock-hoppers. An intercooled compressor pressurizes the nitrogen made available by the ASU at atmospheric pressure up to 37.7 bar.

Steam at 38 bar generated in the fuel synthesis reactor (except for $\mathrm{MixOH}$, where steam is extracted from the steam turbine) is used to fluidize the bed. The gasifying agent is oxygen provided by the same ASU that supplies the BL gasifier. The syngas produced in the gasifier passes first through a cyclone to remove most of the solids, which are returned to the gasification vessel, and then in another reactor designed to crack the tar by means of a catalyst like nickel. The heat and mass balance of the gasifier have been calculated by assuming that the syngas composition at the cracker exit is at equilibrium except for methane and tar, for which we've imposed the concentration suggested by data found in the literature (as discussed earlier).

\subsubsection{Biomass gasification with syngas cooler}

In the configurations where the syngas generated in the biomass gasifier feeds the gas turbine, the gas exiting the cracker is cooled in a steam generator that feeds the same drum of the HRSG. The syngas at $495-420^{\circ} \mathrm{C}^{8}$ exiting the syngas cooler goes through a high-temperature candle filter and subsequently expands through a radial turbine to generate some electricity using the difference in pressure between the filter (approximately 34 bar) and the pressure assumed to be necessary for fuel injection into the gas turbine combustor (24 bar). Ahead of the gas turbine combustor, the syngas from biomass gasification is mixed with the unconverted syngas (from the

\footnotetext{
${ }^{8}$ The syngas temperature at the outlet of the syngas cooler is such that the temperature of the flow fed to the gas turbine is $375^{\circ} \mathrm{C}$, thereby avoiding tar condensation. The relatively large variation of the temperature at the outlet of the syngas cooler is due to the large variation, from one case to another, of the amount of relatively cold unconverted syngas added ahead of the gas turbine feed.
} 
FSI) not needed by the duct burner. To avoid tar deposition, the syngas temperature at the exit of the syngas cooler is set to a value that ensures a syngas temperature above $375^{\circ} \mathrm{C}$ along the whole syngas line, i.e. a temperature of at least $375^{\circ} \mathrm{C}$ after mixing with the unconverted syngas from the FSI.

The amount of wood residues fed to the gasifier is adjusted to generate the amount of syngas needed to fully fire the gas turbine (together with the available fraction of unconverted syngas). Fig. 6 illustrates the design of biomass gasification system with syngas cooler.

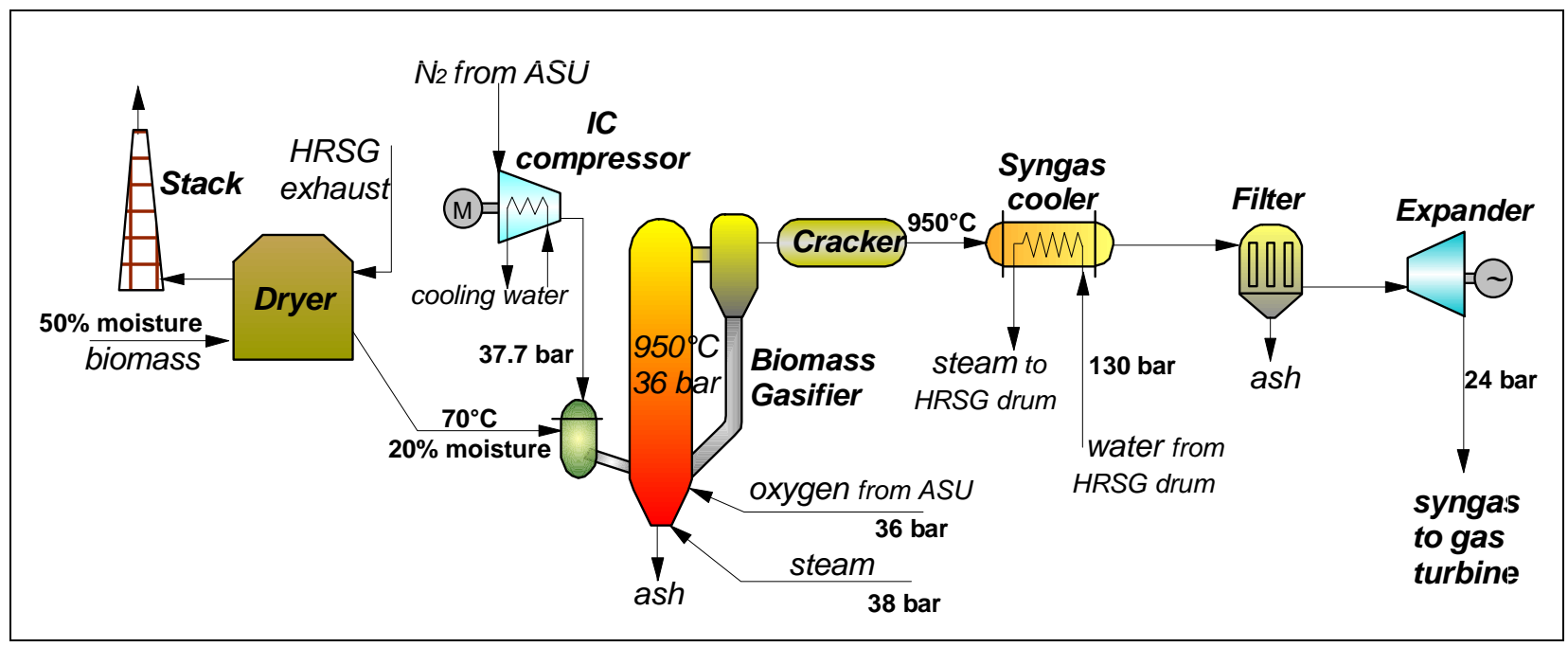

Fig. 6. Biomass gasification system with syngas cooler

\subsubsection{Biomass gasification with quench}

When the biomass syngas is sent to the FSI to produce liquid fuel the syngas exiting the cracker is quenched with water. The saturated syngas leaving the quench (at the saturated temperature of water at its outlet partial pressure, i.e. about $200^{\circ} \mathrm{C}$ ) goes through a boiler and a water heater that recover the large amounts of heat released by water vapour condensation. The flow of condensate at about $120^{\circ} \mathrm{C}$ exiting these heat exchangers is recycled and used as quench water. The cool biomass syngas is mixed with the BL syngas at about the same temperature (to minimize mixing losses), and the whole flow is sent to the gas clean-up system (Rectisol or Selexol).

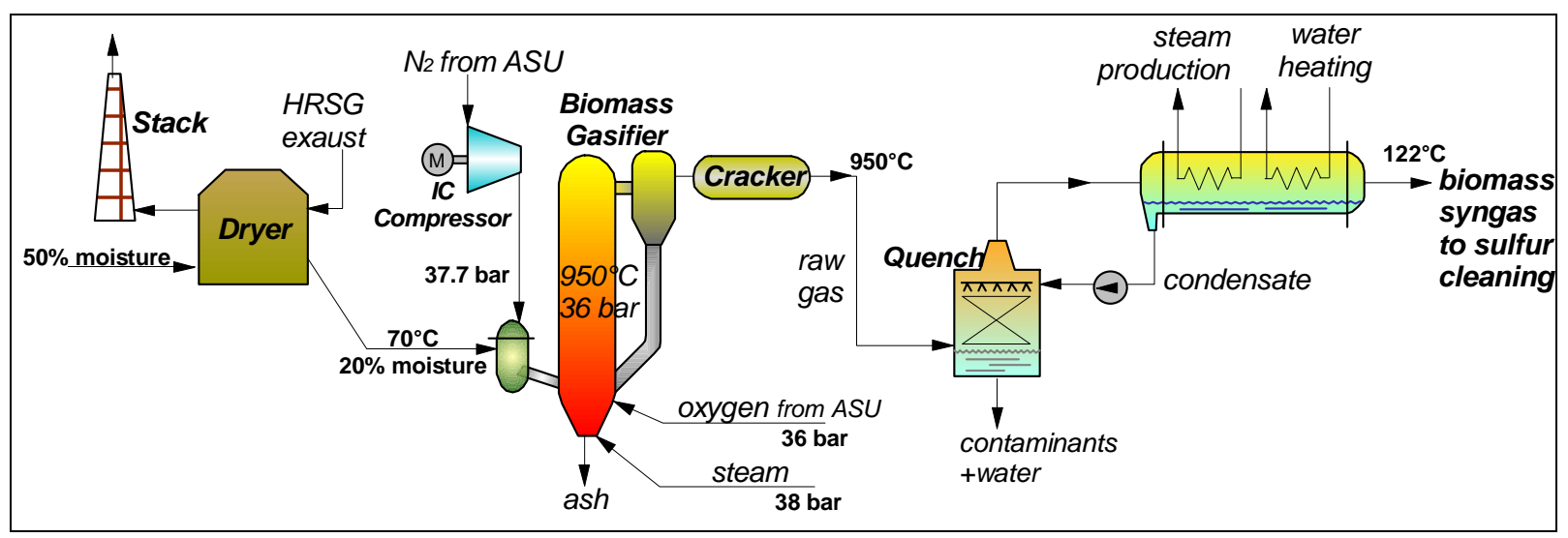

Fig. 7. Biomass gasification system with quench 


\subsubsection{Combined cycle}

The gas turbine is fed with unconverted syngas coming from the FSI and, in several cases, also with syngas generated in the biomass gasifier. Except for case DMEa, where there is no gas turbine, and case FTb, where we've considered a large scale turbine, the gas turbine is a medium-scale, $70 \mathrm{MW}$-class, heavy-duty machine.

The gas turbine exhaust goes through a single-pressure HRSG. The HP drum at 130 bar is integrated with the syngas cooler of the biomass gasifier (cases DMEb, DMEc, FTa and FTb) and the mixed alcohol reactor (case $\mathrm{MixOH}$ ): the drum provides saturated water and receives saturated steam from the syngas cooler and the $\mathrm{MixOH}$ reactor.

In the DME and FT cases the fuel synthesis reactor generates saturated steam at 38 bar from saturated water taken from the HRSG. Saturated steam is subsequently sent back to the HRSG for superheating, and eventually to the IP port of the steam turbine; some saturated steam is sent to the biomass gasifier for fluidization.

The steam generated in the HRSG, the syngas cooler and the FSI expands through a steam turbine. A bleed at 13 bar provides MP steam to the mill. In all cases except FTb and FTc, the steam turbine is backpressure and its discharge provides the LP steam required by the mill. In cases FTb and FTc the LP steam demand is met by bleeding just a fraction of the steam turbine flow; the remainder expands to a condenser at 0.074 bar.

When the turbine is backpressure and the steam flow is just the amount needed by the mill, the required steam flow is achieved by burning some unconverted syngas and/or biomass derived syngas in a duct burner ahead of the HRSG.

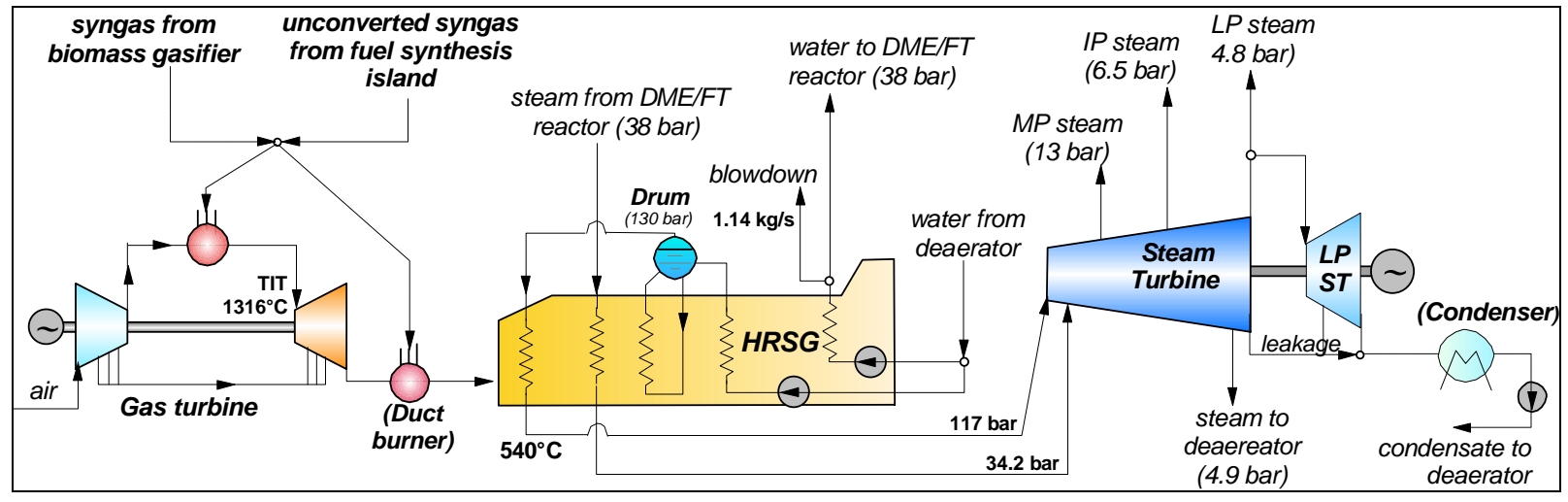

Fig. 8. Combined cycle general configuration

\subsubsection{Rectisol system}

\subsubsection{Total $\mathrm{H}_{2} \mathrm{~S}$ and $\mathrm{CO}_{2}$ removal}

The design adopted for the Rectisol system with total $\mathrm{H}_{2} \mathrm{~S}$ and $\mathrm{CO}_{2}$ removal is showed in Fig. 9. Cooled raw gas from BL gasification enters at the bottom of the acid gas absorber (C1) and it is scrubbed with methanol introduced at the top. The absorber consists of two columns, one on top of the other: part of the liquid collected at the bottom of the upper column is introduced at the top of the bottom column, while the gas exiting the bottom column feeds the upper column. The bottom column captures essentially all $\mathrm{H}_{2} \mathrm{~S}$, while the removal of $\mathrm{CO}_{2}$ is partial because its solubility into methanol is significantly lower than that of $\mathrm{H}_{2} \mathrm{~S}$. The rest of the $\mathrm{CO}_{2}$ is captured in the upper column, where its full absorption is favored by the low temperature of methanol. The low temperature is necessary also to reduce the volatility of the solvent so as to 
reduce the solvent losses in the product gas. As the $\mathrm{CO}_{2}$ absorption in polar solvents is a relatively highly exothermic process, the methanol solvent needs to be fed to the absorber column at a very low temperature $\left(-60^{\circ} \mathrm{C}\right)$ in order to maintain a low operating temperature in the column.

With this configuration, the methanol fed at the top of the upper column is nearly pure, while the methanol used to scrub $\mathrm{H}_{2} \mathrm{~S}$ in the lower column is rich in $\mathrm{CO}_{2}$. The liquid stream exiting at the bottom of the upper section is rich in $\mathrm{CO}_{2}$ with nearly no $\mathrm{H}_{2} \mathrm{~S}$, while the liquid collected at the bottom of the bottom section is rich in both acid gases $\mathrm{H}_{2} \mathrm{~S}$ and $\mathrm{CO}_{2}$.

In addition to $\mathrm{H}_{2} \mathrm{~S}$ and $\mathrm{CO}_{2}$, methanol may absorb significant fractions of possibly valuable gases. To avoid loosing such gases, our scheme includes two flash drums (D2 and D3) at an intermediate pressure ( 7.5 bar) between the Absorber and the Solvent Regenerator pressure: the less soluble gas (such as $\mathrm{CO}, \mathrm{H}_{2}, \mathrm{Ar}, .$. ) are re-transferred in the gas phase and recycled by compressing and mixing them with the raw syngas.

The process is composed of three other main blocks:

- $\mathrm{H}_{2} \mathrm{~S}$ Concentrator $(\mathrm{C} 2)$, where methanol rich in $\mathrm{H}_{2} \mathrm{~S}$ is concentrated at the bottom while $\mathrm{CO}_{2}$, the more volatile compound, is obtained almost pure at the top.

- $\mathrm{CO}_{2}$ Stripper (C3), where the methanol stream rich in $\mathrm{H}_{2} \mathrm{~S}$ is contacted with nitrogen to strip another fraction of the $\mathrm{CO}_{2}$ absorbed in the Acid Gas Absorber, which is transferred back to the gas phase; a mixture of $\mathrm{N}_{2}$ and $\mathrm{CO}_{2}$ is extracted at the top of the stripper.

- Solvent Regenerator (C4), where the liquid from the bottom of the $\mathrm{CO}_{2}$ Stripper, containing the $\mathrm{H}_{2} \mathrm{~S}$ absorbed in the Acid Gas Absorber and the remaining $\mathrm{CO}_{2}$ is regenerated in the regeneration column via indirect heating with steam. Following cooling at low temperature to condense any methanol in the gas phase, the mixture of $\mathrm{H}_{2} \mathrm{~S}$ and $\mathrm{CO}_{2}$ exiting the top of the column is routed to a Claus/SCOT unit.

The acid gas stream of $\mathrm{H}_{2} \mathrm{~S}$ and $\mathrm{CO}_{2}$ goes first through a regenerative heat exchanger and then to a Claus/SCOT plant where $\mathrm{H}_{2} \mathrm{~S}$ is converted to elemental sulfur. According to the literature, with Rectisol the sulfur content in the $\mathrm{CO}_{2}$ and tail gas flow is so low that they can be discharged into the atmosphere (or used in the process industry).

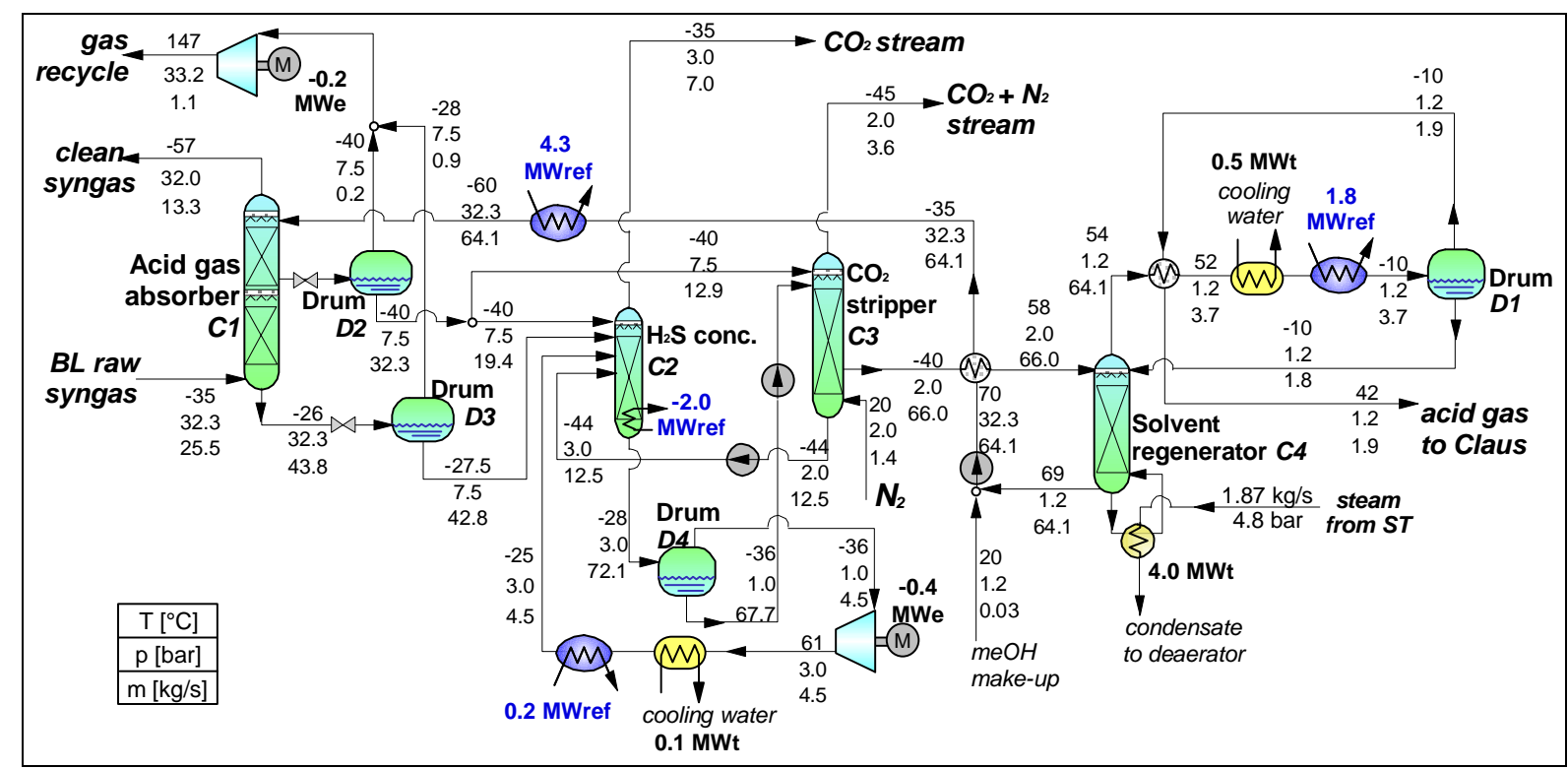

Fig. 9. Energy and mass balances for DMEa and DMEb cases of Rectisol model with $\mathrm{H}_{2} \mathrm{~S}$ and $\mathrm{CO}_{2}$ abatement. 


\subsubsection{2 $\mathrm{H}_{2} \mathrm{~S}$ removal}

The scheme developed for the removal of both $\mathrm{H}_{2} \mathrm{~S}$ and $\mathrm{CO}_{2}$ was modified and adapted to the case where no specific target is set on $\mathrm{CO}_{2}$ removal. In this case Absorber $(\mathrm{Cl})$ comprises only 1 column and the process scheme becomes the one shown in Fig. 10 and Fig. 11.

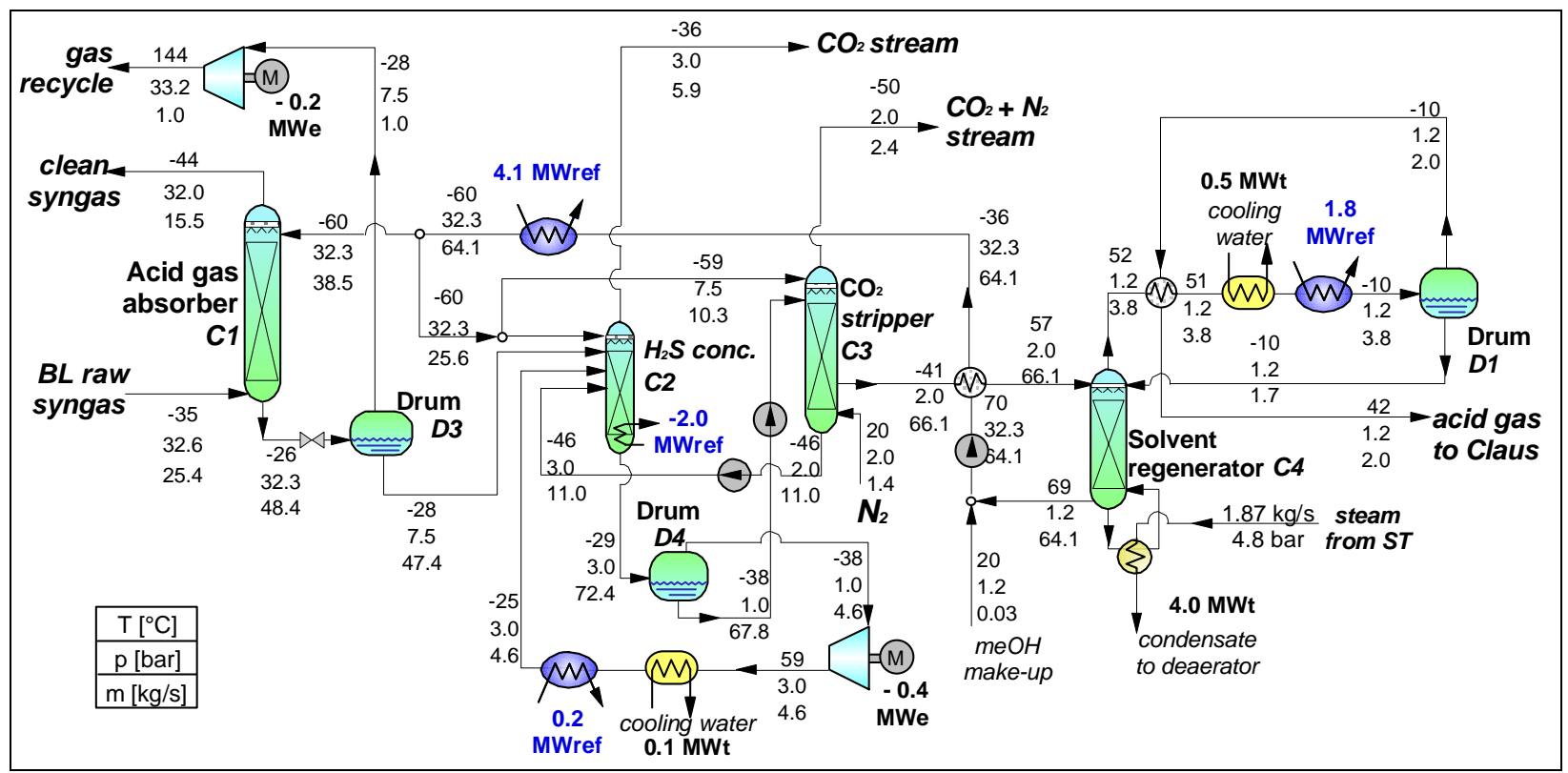

Fig. 10. Energy and mass balances of the Rectisol system adopted for cases DMEc, FTa and FTb, where $\mathrm{H}_{2} \mathrm{~S}$ is removed with no specific target on the removal of $\mathrm{CO}_{2}$.

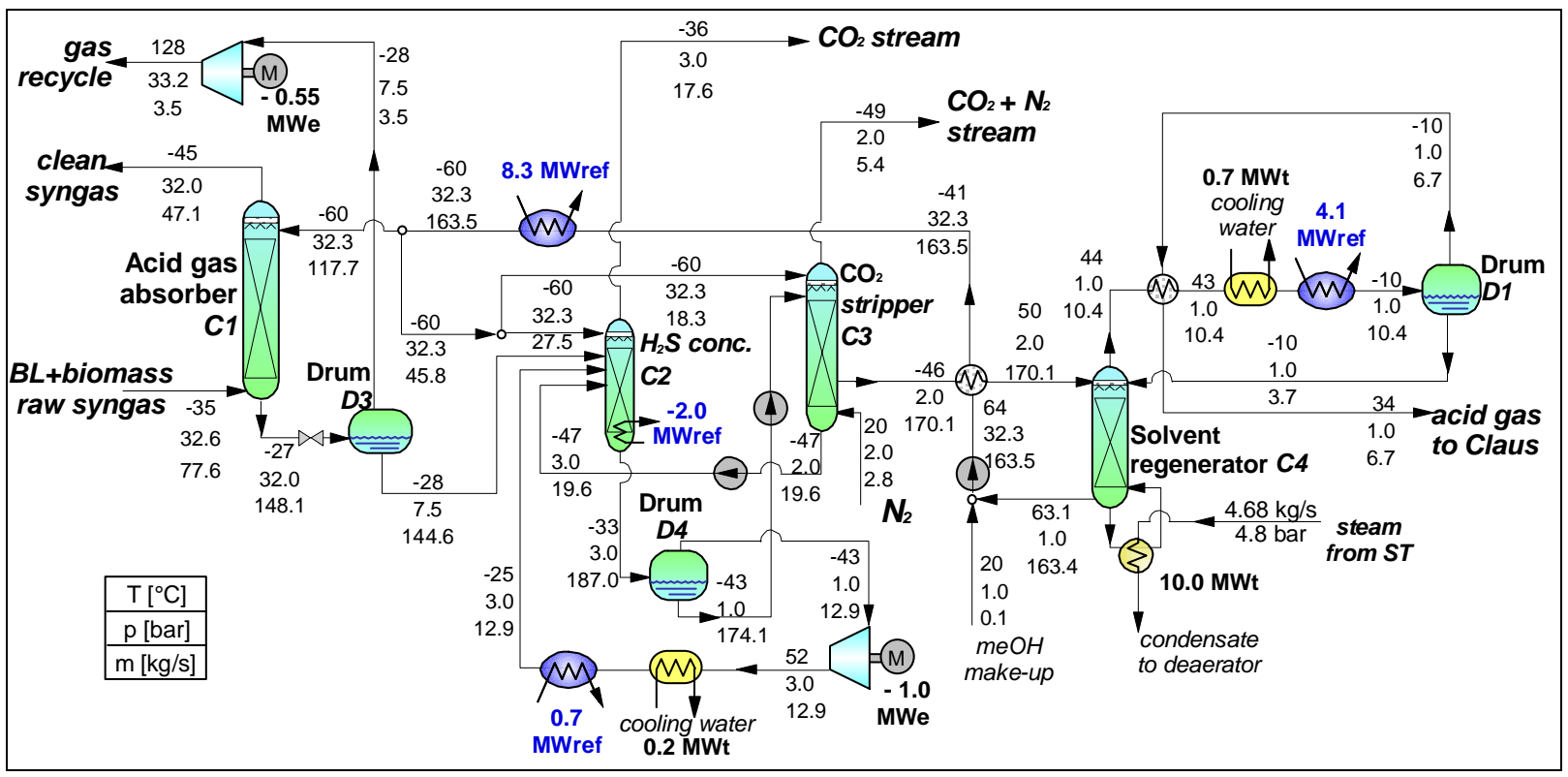

Fig. 11. Energy and mass balances of the Rectisol system adopted for case FTc, where $\mathrm{H}_{2} \mathrm{~S}$ is removed with no specific target on the removal of $\mathrm{CO}_{2}$. The syngas entering absorber $\mathrm{C} 1$ is a mixture of the syngas coming from the $B L$ and the biomass gasifier. 


\subsubsection{DME synthesis island}

The clean BL syngas at 66 bar is heated to $240^{\circ} \mathrm{C}$ using the product stream from the synthesis reactor and then fed to the DME reactor. To maintain isothermal synthesis conditions at $260^{\circ} \mathrm{C}$, steam is generated in boiler tubes immersed in the liquid reactor bed. In a single pass of gas through the DME reactor only a portion of $\mathrm{CO}$ and $\mathrm{H}_{2}$ is converted to DME.

The mixture of gases leaving the reactor passes to the product separation area, where DME with high purity $99.8 \%$ is separated from methanol, unconverted syngas, and water. A series of flash tanks separate most of unconverted synthesis gas, then the separation is achieved by cryogenic distillation, cooling the gasses and separating based on boiling points. DME, methanol, and water all have boiling points higher than those of syngas components, so they are cooled and condensed, and then separated from each other. In this project, three columns are applied. The first is used to separate $\mathrm{DME} / \mathrm{methanol} /$ water from $\mathrm{CO}_{2}$ and other light gases $(\mathrm{CO}$, $\mathrm{H}_{2}$, etc.). The second is used to separate DME from methanol/water. The last one separates water from methanol.

The methanol flow is heated to $250^{\circ} \mathrm{C}$, in a regenerative heat exchanger using steam, and then sent to an adiabatic reactor where DME is produced by methanol dehydration. A downstream flash tank separates the most volatile part of the product, including all DME produced, and this is sent to the second distillation column. The liquid fraction is recycled to the third distillation column.

Separating $\mathrm{CO}_{2}$ and DME is difficult due to similar boiling points. Getting the last DME out of $\mathrm{CO}_{2}$-laden gas is very difficult, and some small losses are tolerated.

The heat exchangers in the DME separation area are arranged in order to optimize heat integration by minimizing heat and refrigeration requirements. The net heat duty of the area is provided by steam from the power island.

The methanol separated out using the 2 nd column can be recycled to the synthesis reactor inlet. However, we chose instead to separately dehydrate the methanol to DME for several reasons, including increasing the partial pressures of reactants, eliminating the recycle pump and additional heat exchangers, and other factors.

About the use of the unconverted gas, we have considered two plant configurations:

1. most of the unconverted gas (97\%) from the separation area is returned, via compressor, to the synthesis reactor to generate additional DME (recycle configuration), the small remaining unconverted is sent to the power island (Fig. 12);

2. all the unconverted gas from the separation area goes to the power island (once-through configuration). In this case, the syngas passes only once through the synthesis reactor (Fig. 13). 


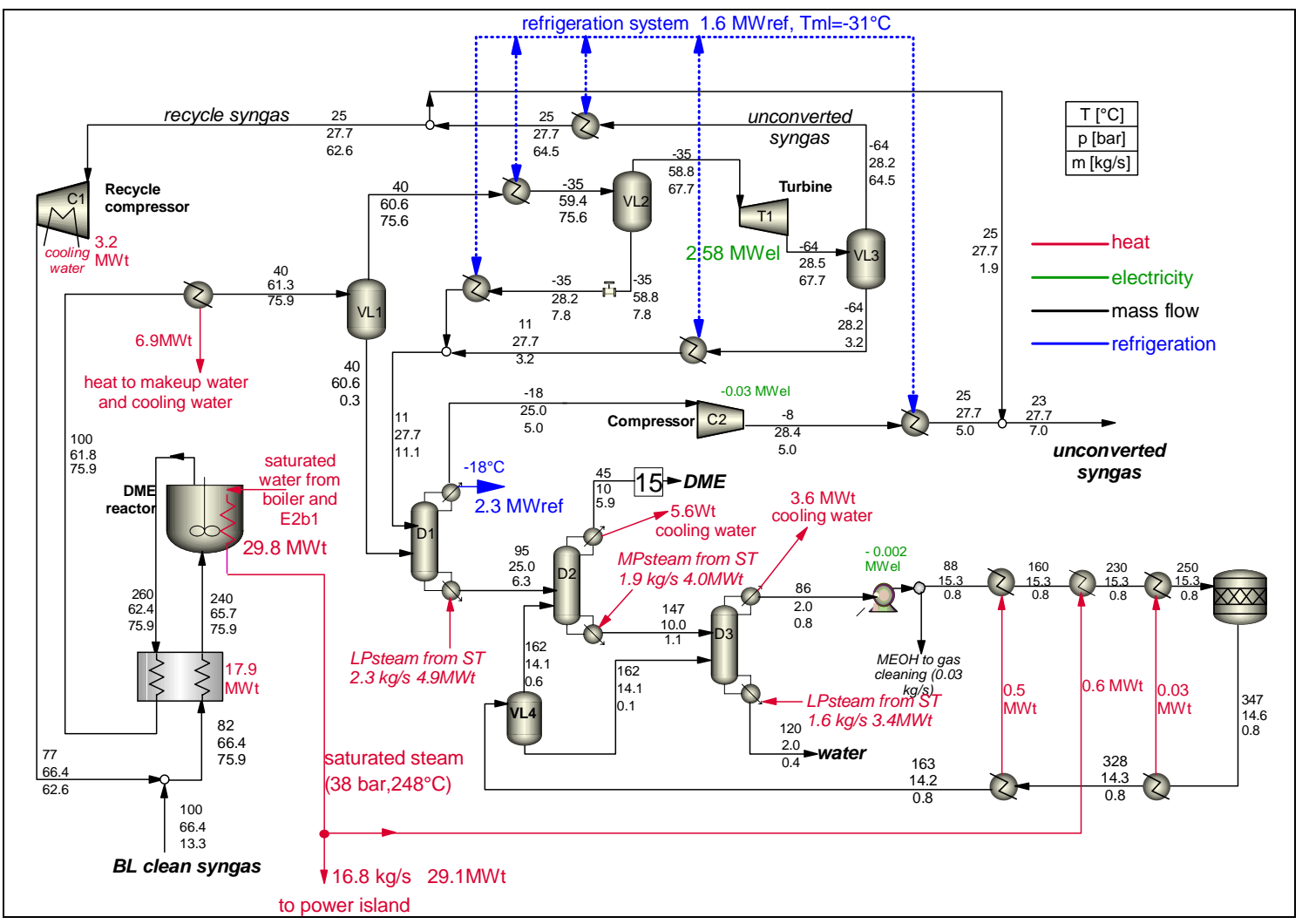

Fig. 12. Energy/mass balance of DME synthesis island with recycle (DMEa and DMEb)

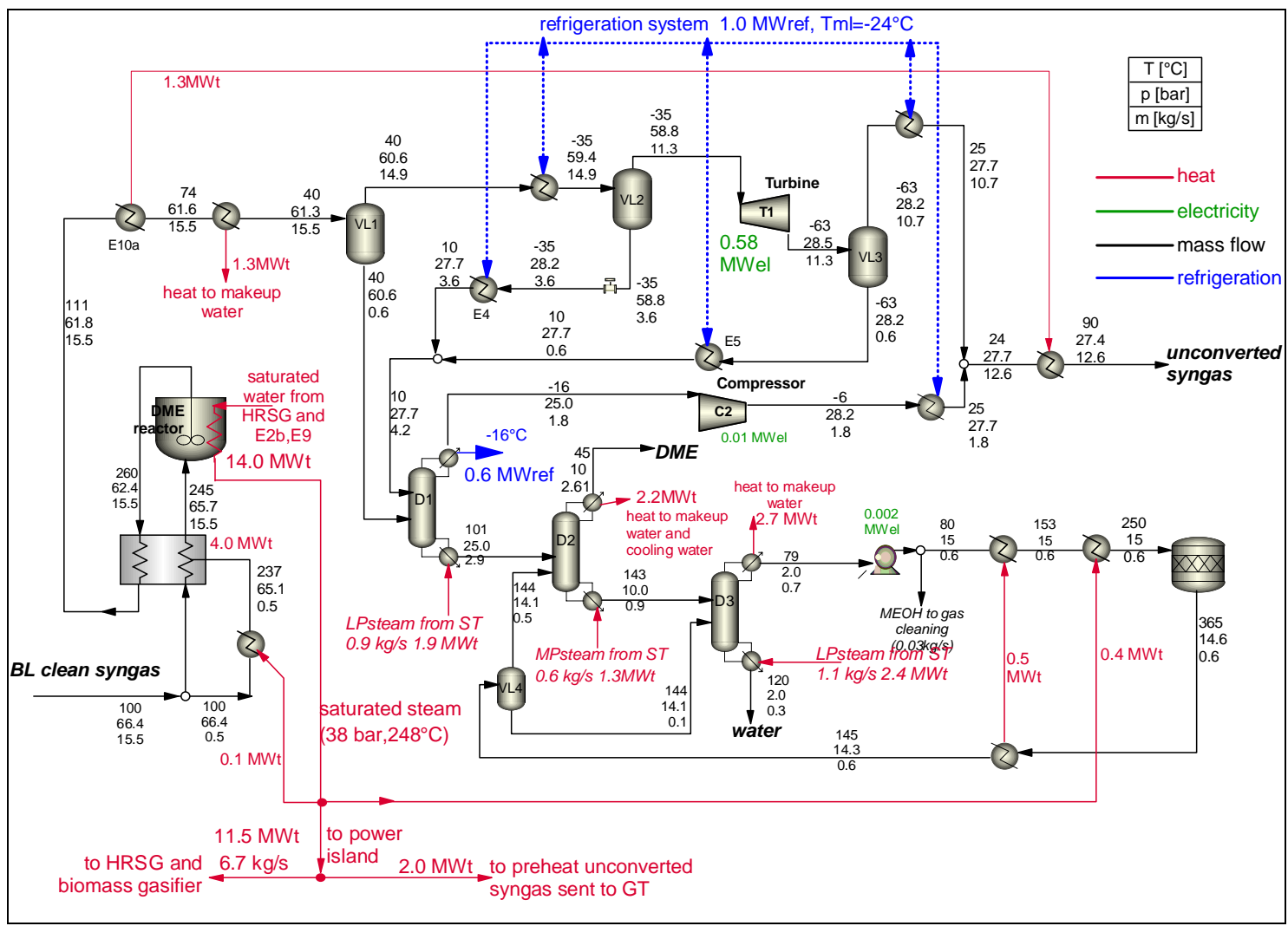

Fig. 13. Energy and mass balances of once-through DME synthesis island (DMEc case) 


\subsubsection{FT synthesis island}

The design configuration and main results of the FT synthesis island are illustrated in Fig. 14 and Fig. 15. The clean syngas is preheated and sent to the FT slurry-bed reactor using an ironbased catalyst. Two streams exit from the reactor at $260^{\circ} \mathrm{C}$ : a liquid reactor effluent stream, and a overhead vapor stream. The gas flow is used to preheat reactor inlet syngas to $245^{\circ} \mathrm{C}$ and heat purge gas or generate steam (depending on the case). These heat exchangers cool the stream to $38^{\circ} \mathrm{C}$, then a gas-liquid separator is used to recover more FT products from the mixture and to separate a waste water stream. The gas flow exiting this separator is unconverted syngas that is sent to the power island. In FT synthesis island, the unconverted gas recycle design is not considered, because the single pass conversion is already relatively high.

A mixture of distillate, naphtha, and wax from the reactor, together with the liquid hydrocarbons recovered in the gas-liquid separator, constitute the liquid final product of FT synthesis.

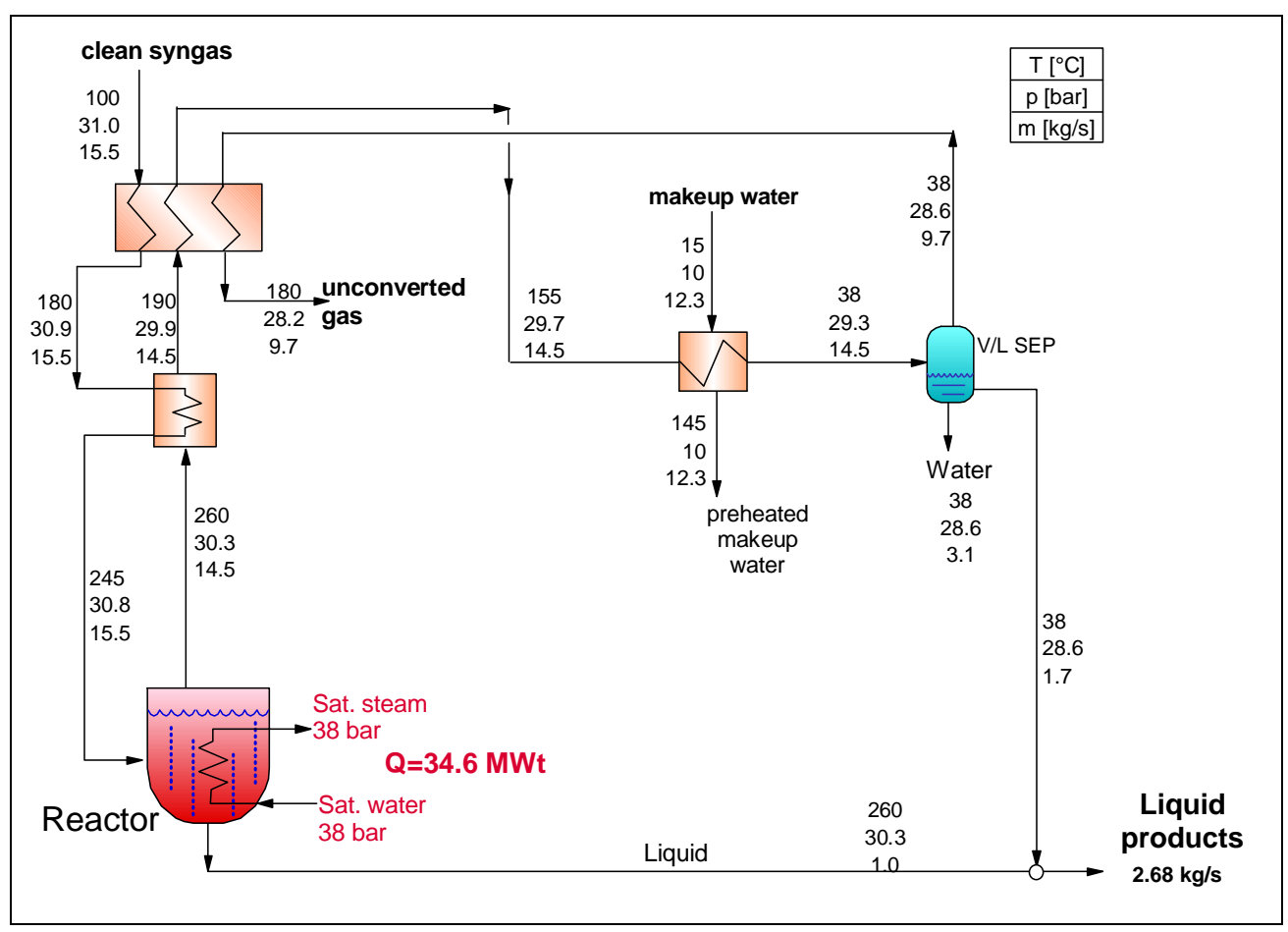

Fig. 14. Energy and mass balances of FT synthesis island for FTa and FTb cases (syngas from BL gasification) 


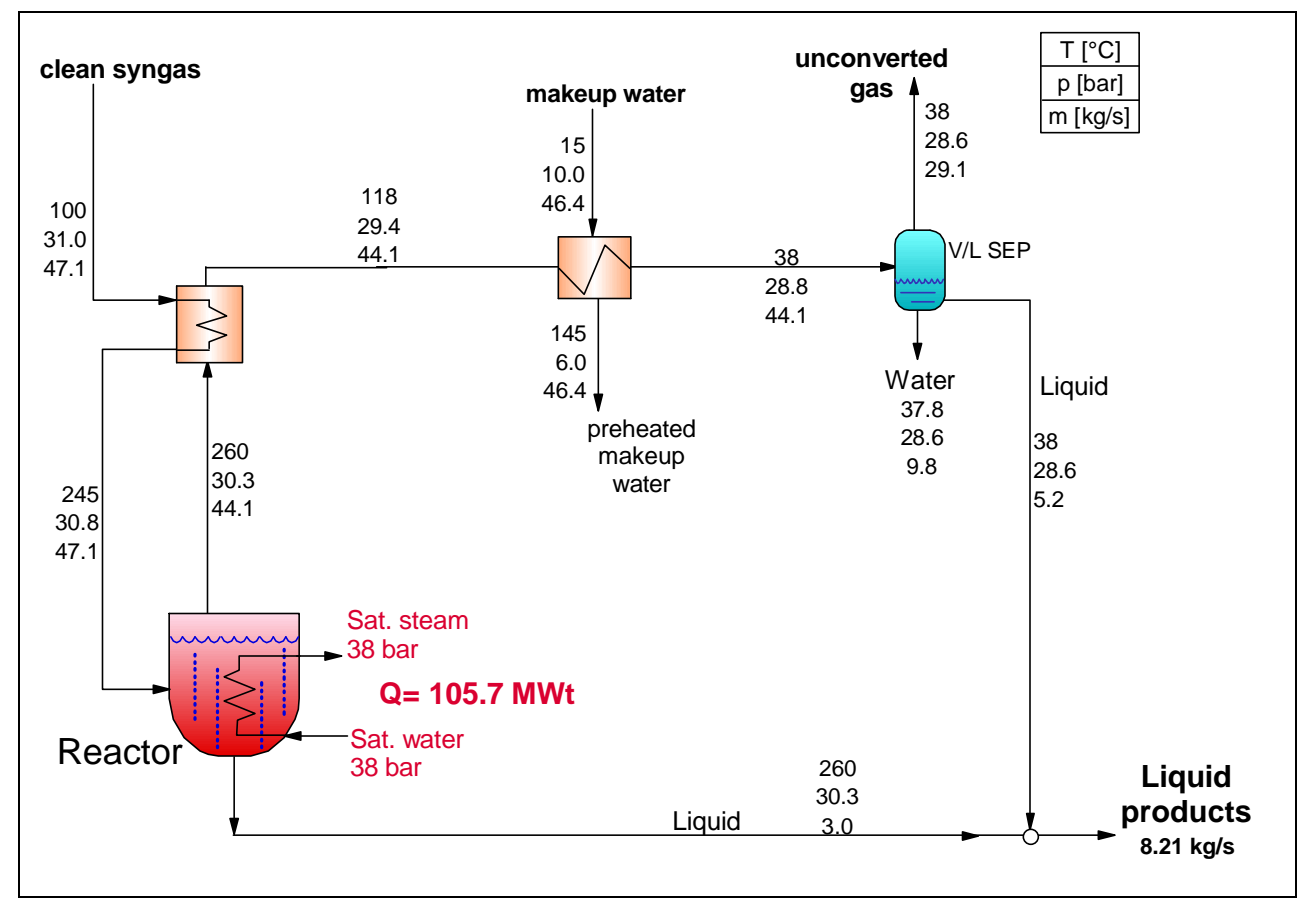

Fig. 15. Energy and mass balances of FT synthesis island for FTc cases (syngas from both BL and biomass gasification)

\subsubsection{Mixed alcohols synthesis island}

Fig. 16 show the design and the energy and mass balances of the Selexol system and mixed alcohols synthesis island.

The fresh clean syngas from the Selexol system is mixed with two recycle flows, then it is preheated to $330^{\circ} \mathrm{C}$ by cooling the outlet flow and is fed to the synthesis reactor. The heat released during reaction is used for HP steam raising, so as the reactor temperature is maintained at $350^{\circ} \mathrm{C}$. After reaction, the hot effluent is cooled first by the reactor inlet flow and then by cooling water to $36^{\circ} \mathrm{C}$. At this temperature the majority of alcohols condense, so the unconverted gas is separated from the liquid alcohols in a vapor/liquid separator. The gas stream is divided into two flows: part (76\% of the unconverted syngas) is compressed and recycled back to the synthesis reactor. The remaining gas is preheated, expanded to about 25 bar for power production, humidified and finally used to fuel the GT.

The liquid flow, after a pressure drop to 3.5 bar via a valve, goes to a distillation column where methanol and other gases are separated, recompressed to the reactor operating pressure and recycled to the synthesis reactor. The flow from the bottom of the distillation column containing higher alcohols (C2+ alcohols) goes to a molecular sieve, where water is separated from the liquid alcohols. The purge gas from the molecular sieve, composed of water with a small percentage of alcohols, is compressed and sent to the gas turbine to recover the energy content and also to increase the mass flow of the fuel so as to increase power production.

The mixture with $\mathrm{C} 2+$ alcohol is treated as the final product of this section. 


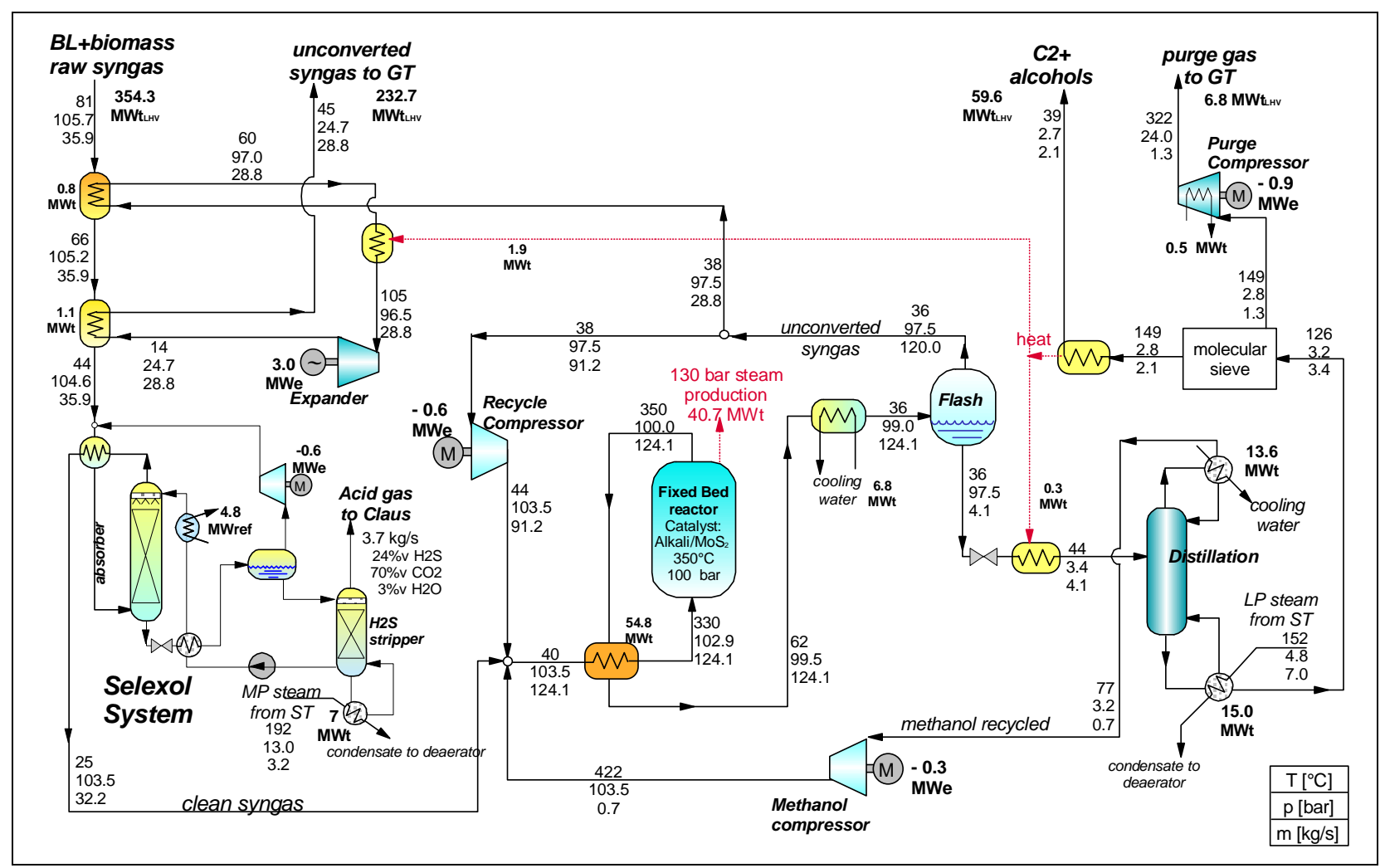

Fig. 16. Energy and mass balances of Selexol system and mixed alcohols synthesis island

\subsection{DME cases}

\subsubsection{DMEa case: BLG with DME recycle island}

In DMEa case (Fig. 18) the fuel synthesis island is designed to maximize the DME production: since in a single pass through the synthesis reactor only a portion of syngas is converted to the fuel, most of the unconverted syngas is recycled to the reactor to increase DME output. Because of the recycle of unconverted syngas, the Rectisol plant removes almost completely the $\mathrm{CO}_{2}$ in the BL syngas, in addition to sulfur compounds.

The mill process steam is provided by burning in a boiler the hog fuel, the purge unconverted syngas and additional wood residues. The only electricity produced is from a backpressure steam turbine through which steam is expanded before it goes to meet mill process demands.

\subsubsection{BL syngas cooling}

The $\mathrm{BL}$ is gasified and the syngas is quenched and cooled to $120^{\circ} \mathrm{C}$, as described in par. 5.3.1 BL gasification. Then the syngas has to be cooled down to about $-35^{\circ} \mathrm{C}$, before entering the absorption column of the Rectisol plant. Since the cold clean syngas must be fed to the fuel synthesis reactor at high temperature (around $200^{\circ} \mathrm{C}$ ), a regenerative heat exchanger is used to cool the raw syngas to about $120^{\circ} \mathrm{C}$ by heating to $100^{\circ} \mathrm{C}$ the clean syngas leaving the Rectisol process. The raw syngas is further cooled to $35^{\circ} \mathrm{C}$ through a water heater, in which make-up water is preheated, and then chilled to $-35^{\circ} \mathrm{C}$ by a refrigeration system.

The clean syngas at the Rectisol plant outlet is compressed to the pressure required by the DME reactor (about 65 bar) before entering the regenerative heat exchanger and then sent to the DME synthesis island (described in par. 5.3.5 DME synthesis island). This compression is 
carried out at low temperature, the Rectisol absorber exit temperature, so as to reduce compression power.

\subsubsection{Power boiler and steam cycle}

In DMEa, biomass is used in a boiler rather than being gasified. Hog fuel available as a by-product of the pulpwood feed to the mill (9\% of the pulpwood logs), together with the purge gas from the DME synthesis island, is burned in a boiler. Additional wood wastes are purchased in order to generate enough steam to meet the mill demand.

The power boiler generates steam at 87.2 bar and $480^{\circ} \mathrm{C}$. It also produces saturated water at 38 bar for the DME synthesis reactor cooling and superheats to $480^{\circ} \mathrm{C}$ the saturated steam coming back. These two steam flows expand through a back-pressure steam turbine with two main extractions. The first extraction at 13 bar provides the MP process steam for the mill and the second extraction at 6.5 bar supplies the IP steam to the SCOT unit. The balance of steam exhausts at 4.8 bar to provide the LP steam required by the mill. The

Fig. 17 shows the plant configuration for the biomass boiler and the steam cycle.

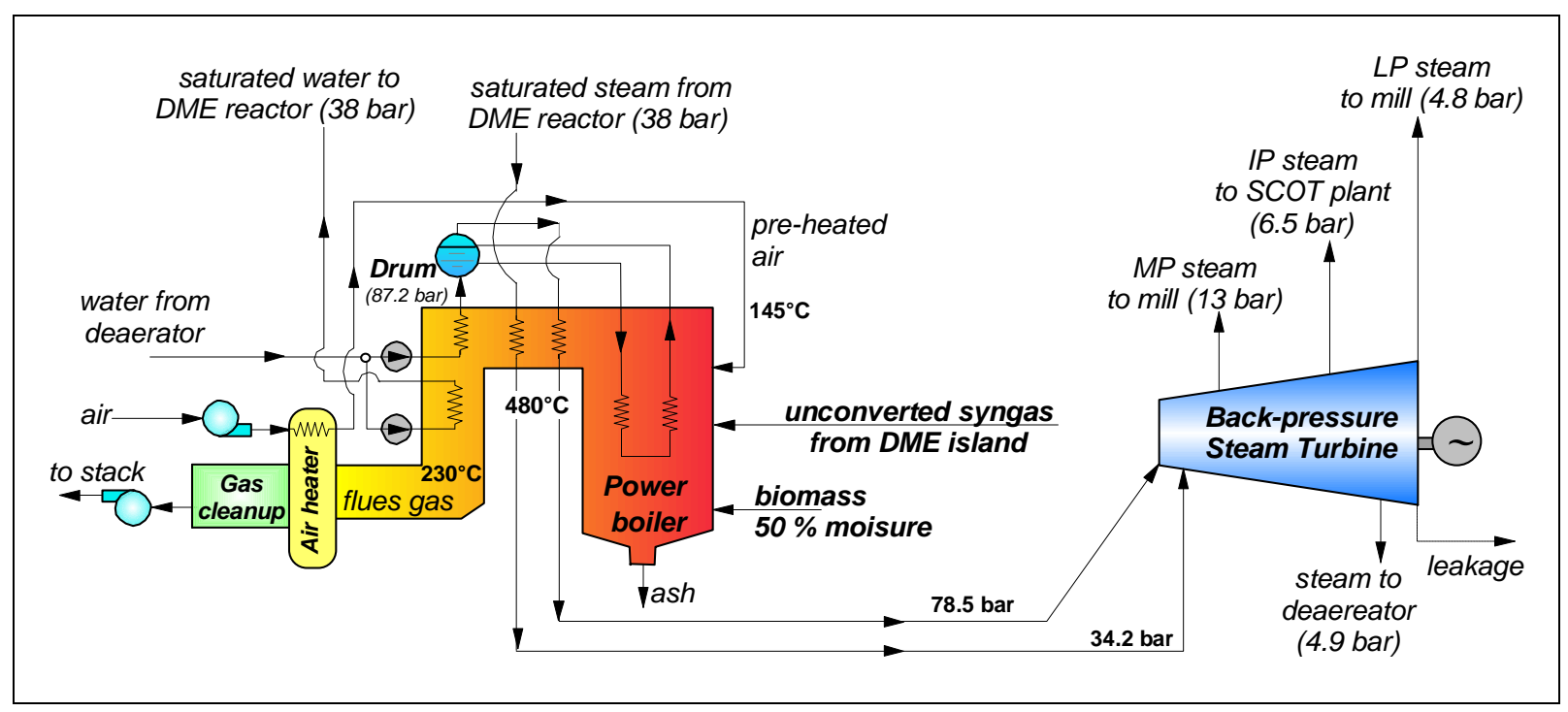

Fig. 17. Power island configuration for DMEa case

\subsubsection{DMEb case: BLG and BGCC with DME recycle}

In DMEb, as in DMEa, the syngas from black liquor gasification is cooled and cleaned in the Rectisol plant and sent to the DME synthesis island with unconverted gas recycle. This portion of the plant is identical to the one adopted for DMEa., The power island is different: the wood residuals are gasified, as described in par. 5.3.2.1 Biomass gasification with syngas cooler, and the produced syngas feeds a medium scale gas turbine (6FA). Part of the biomass syngas together with the unconverted syngas from the DME island, is sent to the duct burner. The steam generated in the HRSG by recovering heat from the gas turbine exhaust drives a back-pressure steam turbine and then is sent to the mill (Fig. 19).

The gas turbine enables more electricity production than in DMEa, and the combined cycle provides a significant amount of the power required by the mill, but the amount of purchased biomass increases compared to DMEa. 


\subsubsection{DMEc case: BLG and BGCC with DME once-through production}

In DMEc, the syngas from black liquor gasification is used for making DME, as in the two other DME cases, but the syngas is passed only once through the synthesis reactor instead of recycling the unconverted syngas. DME production is reduced as a result. The configuration of BL syngas cooling and cleaning is similar to the other DME cases, except for the lower $\mathrm{CO}_{2}$ removal requirement at the Rectisol plant: without the recycle loop in the synthesis island, total $\mathrm{CO}_{2}$ abatement is not necessary.

The power island configuration is essentially the same as DMEb: it includes a biomass gasifier and a downstream combined cycle with a medium scale gas turbine (Fig. 20).

Without recycle, the unconverted syngas mass flow to the power island is higher. Part of this syngas is used to feed the duct burner, so that the HRSG produces enough steam to meet the mill process demands, and the remainder is sent to the gas turbine combustor. Because a significant amount of unconverted syngas goes to the gas turbine, the amount of biomass syngas required to fully fire the gas turbine is reduced compared to DMEb.

\subsection{FT cases}

\subsubsection{FTa case: BLG with FT production and BGCC with medium GT}

As in the DME cases, the black liquor is gasified and cooled, then all sulfur and a large amount of $\mathrm{CO}_{2}$ are absorbed from the product syngas by a Rectisol system. Since all of our FT designs adopt a once-through synthesis configuration, total $\mathrm{CO}_{2}$ capture at the Rectisol island is not required.

The FT synthesis reactor operates at about 31 bar. Unlike for the DME cases, a syngas compressor is not necessary before the FT island. The chilled clean syngas at the Rectisol absorption column exit is used to cool down the raw syngas, so as to reduce the duty of the refrigeration system upstream of the Rectisol absorption column. Then the clean syngas is heated to $100^{\circ} \mathrm{C}$ by cooling the raw BL syngas, as in the DME cases, and sent to the FT synthesis island. The unconverted syngas after synthesis is sent to the power island: part to the duct burner and the remainder to the gas turbine (Fig. 21).

The power section configuration, including a biomass gasifier with syngas cooler and a combined cycle with back-pressure steam turbine, is very similar to the DMEb and DMEc cases.

\subsubsection{FTb case: BLG with FT production and BGCC with large GT}

The FTb plant configuration (Fig. 22) is similar to the FTa design with one major difference: the gas turbine adopted is a large scale one (7FA). As a consequence a larger amount of exhaust gas is available from the gas turbine for steam production in the HSRG, and no duct burner is needed because the steam raised is more then the mill requires. The excess steam is expanded in a condensing section of the steam turbine to generate additional electricity.

\subsubsection{FTc case: BLG and BG with FT production and CC with medium GT}

In the FTc case (Fig. 23) BL syngas and biomass syngas are both used for fuel production: the raw $\mathrm{BL}$ syngas at $122^{\circ} \mathrm{C}$ is mixed with the syngas from biomass gasification, with the design 
described in par. 5.3.2.2 Biomass gasification with quench, at the same temperature. The subsequent configuration of raw syngas cooling, cleaning in Rectisol plant and reheating is the same as in the other FT cases. Unlike the other FT cases, the gas turbine is fed only with unconverted syngas from the fuel synthesis island. It passes through a saturator, wherein it is humidified and pre-heated by mixing with water at $185^{\circ} \mathrm{C}$. The saturator recovers low temperature heat and also leads to increased power production from the gas turbine because of the increase of syngas mass flow. Moreover, the humidified gas also results in a lower flame temperature in the gas turbine combustor, thereby reducing thermal $\mathrm{NO}_{\mathrm{x}}$ emissions. In previous cases the syngas sent to the gas turbine doesn't pass through a saturator because the gas comes from a biomass gasification with syngas cooler; it already has a high temperature and a high water vapor content.

Using the biomass syngas to produce fuel, in addiction to BL syngas, enables production of a larger amount of FT liquid. Also, more heat for steam raising is available in the synthesis reactor, so a duct burner is not necessary to raise sufficient steam to meet mill process demands. In fact, there is an excess of steam produced, so a condensing section in the steam turbine is used to recover a larger amount of electricity.

\subsection{MixOH case: BLG and BG with mixed alcohols production and CC with medium GT}

The configuration of the MixOH plant (Fig. 24) is similar to the FTc case design. The mixture of BL syngas and syngas from biomass gasification with quench design is cooled by preheating makeup water and compressed in an intercooled compressor to about 106 bar, the assumed operating pressure of the synthesis reactor. Then the raw syngas goes thorough heat exchangers that cool the gas to about $45^{\circ} \mathrm{C}$ before entering the Selexol system where most of $\mathrm{H}_{2} \mathrm{~S}$ and part of $\mathrm{CO}_{2}$ are removed.

Following the Selexol acid gas removal system, the clean syngas is used as the feed for mixed alcohols synthesis. The unconverted syngas leaving the mixed alcohols synthesis island (described in 5.3.7 Mixed alcohols synthesis island) is humidified in a saturator, mixed with the purge gas from the alcohols separation area and burned in the gas turbine. Steam required by the mill and by the biorefinery plant (Selexol process, biomass gasifier, SCOT plant, alcohol distillation, etc.) is provided by the HRSG, integrated with the synthesis reactor steam generation. Since heat recovered from the gas turbine exhaust is not sufficient to raise all required process steam, additional syngas from biomass gasification is burned in a duct burner to increase steam generation. 


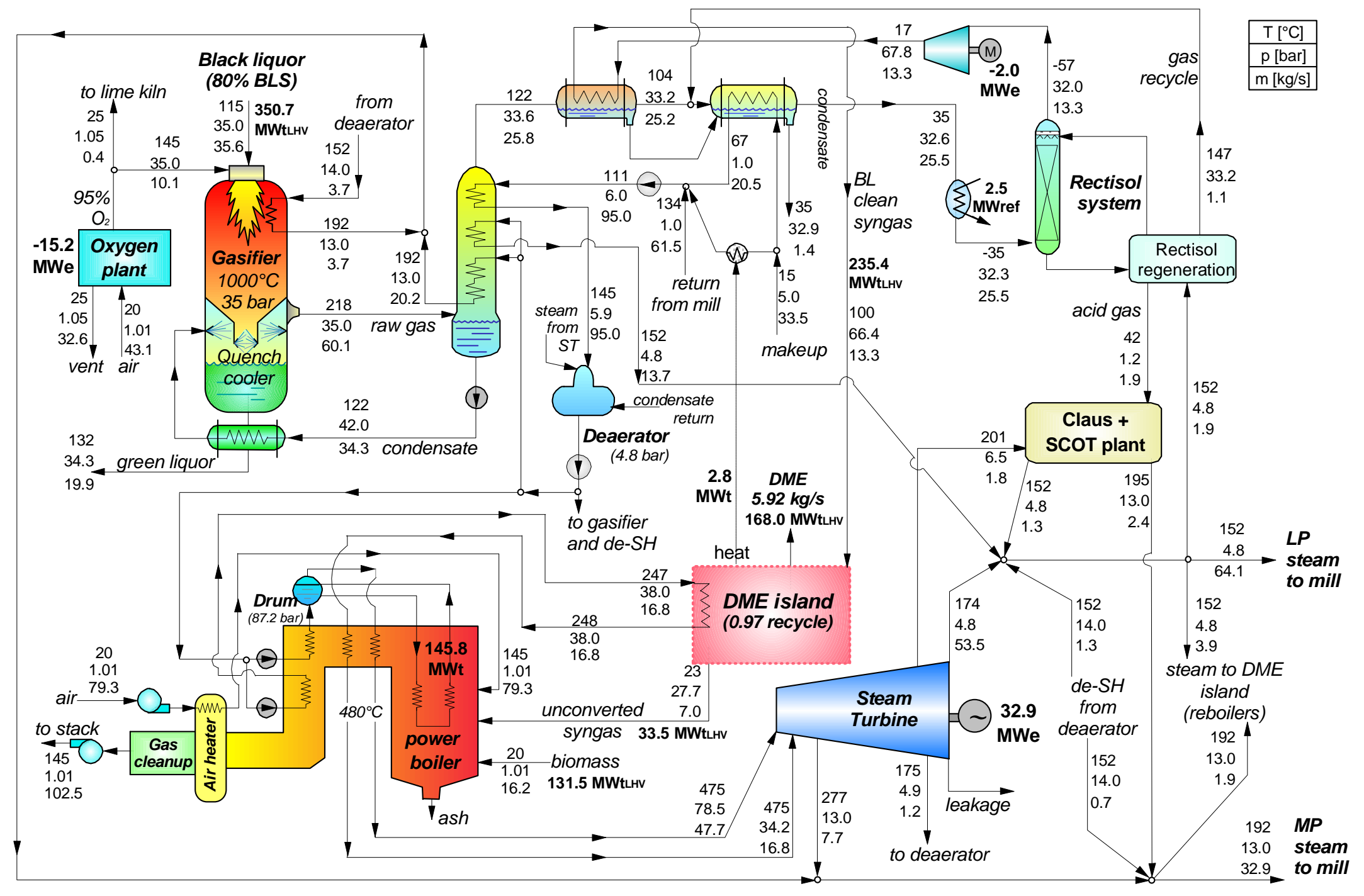

Fig. 18. Plant configuration and mass/energy balances for DMEa case 


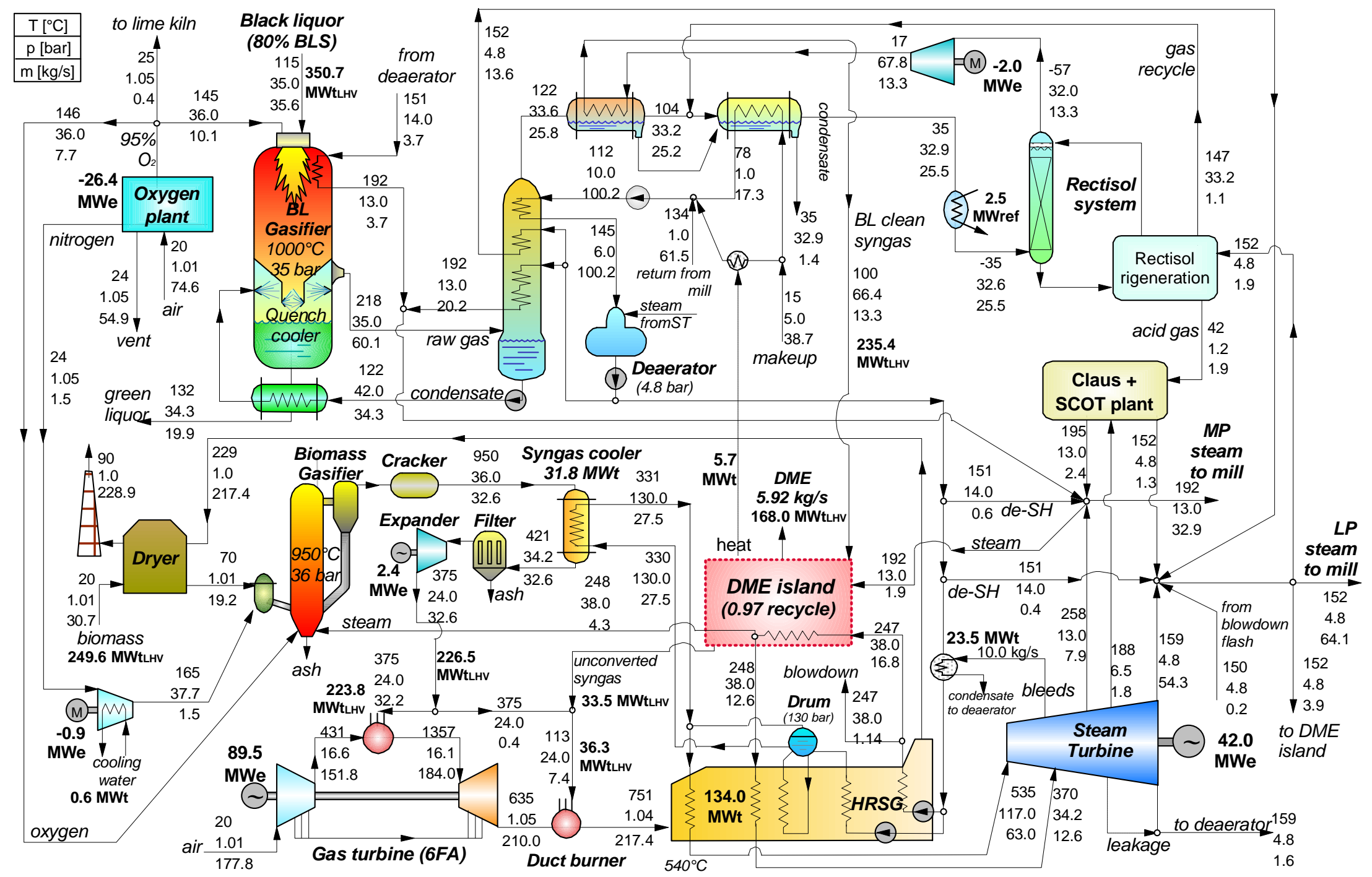

Fig. 19. Plant configuration and mass/energy balances for DMEb case 


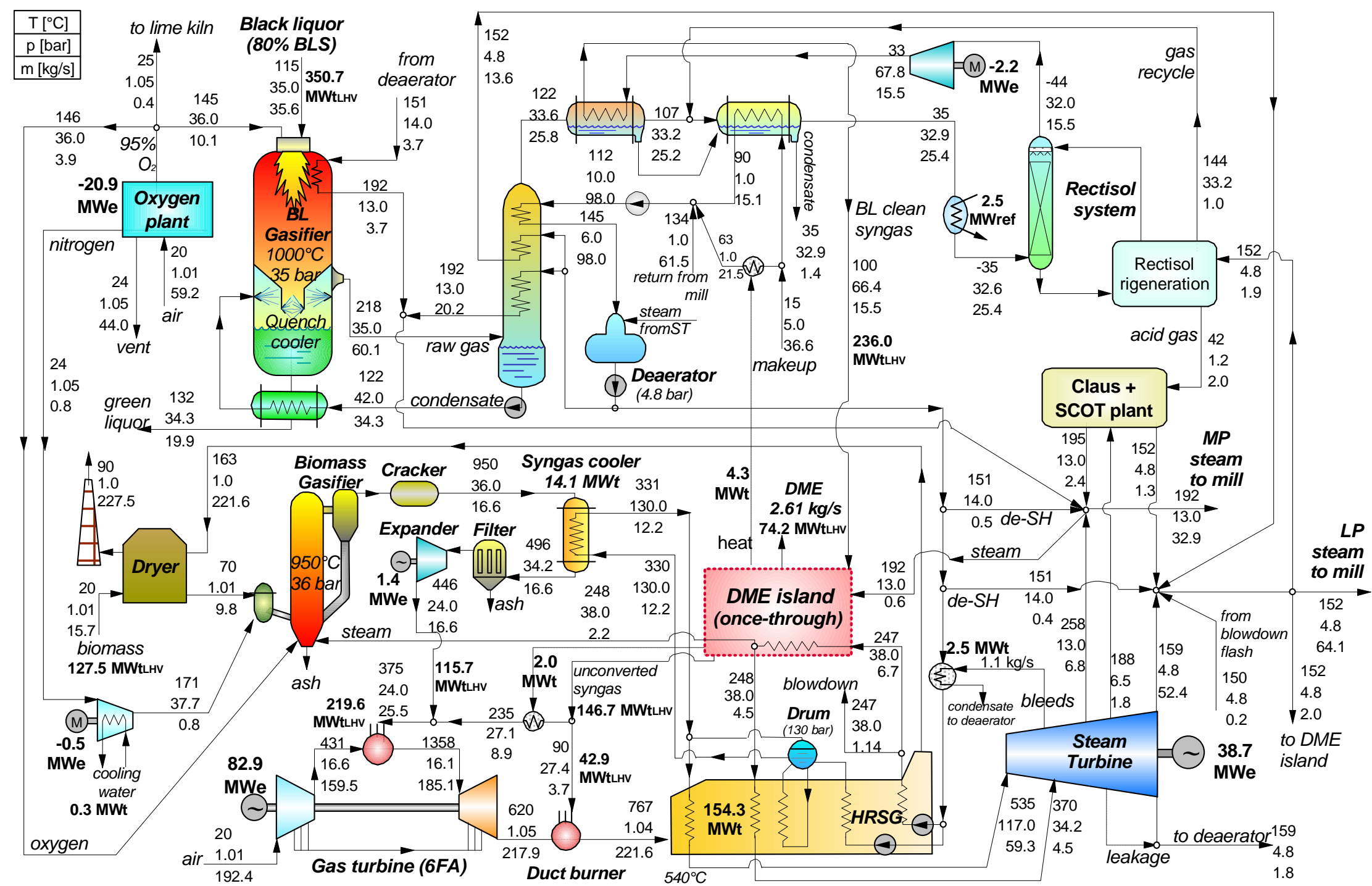

Fig. 20. Plant configuration and mass/energy balances for DMEc case 


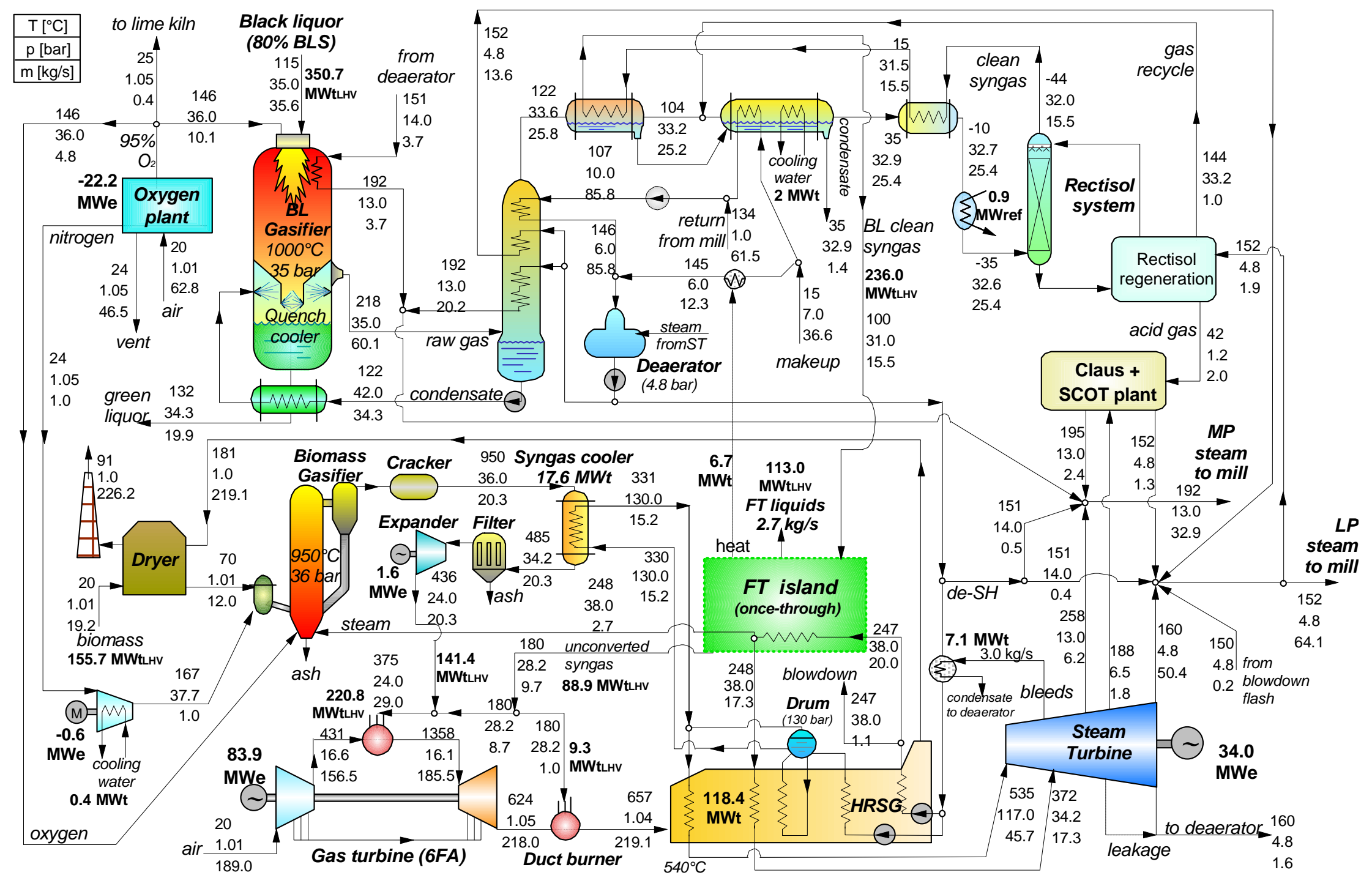

Fig. 21. Plant configuration and mass/energy balances for FTa case 


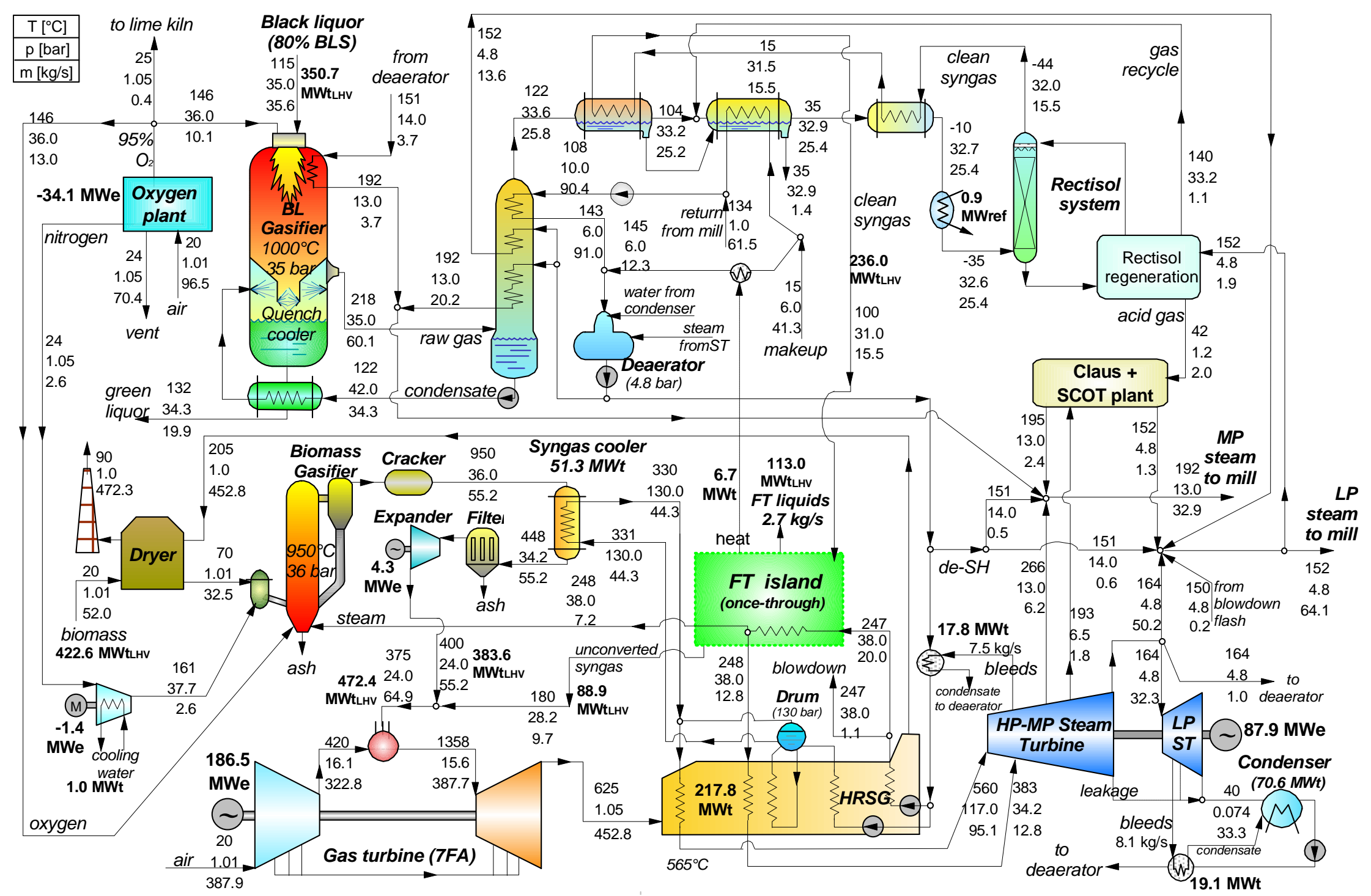

Fig. 22. Plant configuration and mass/energy balances for FTb case 


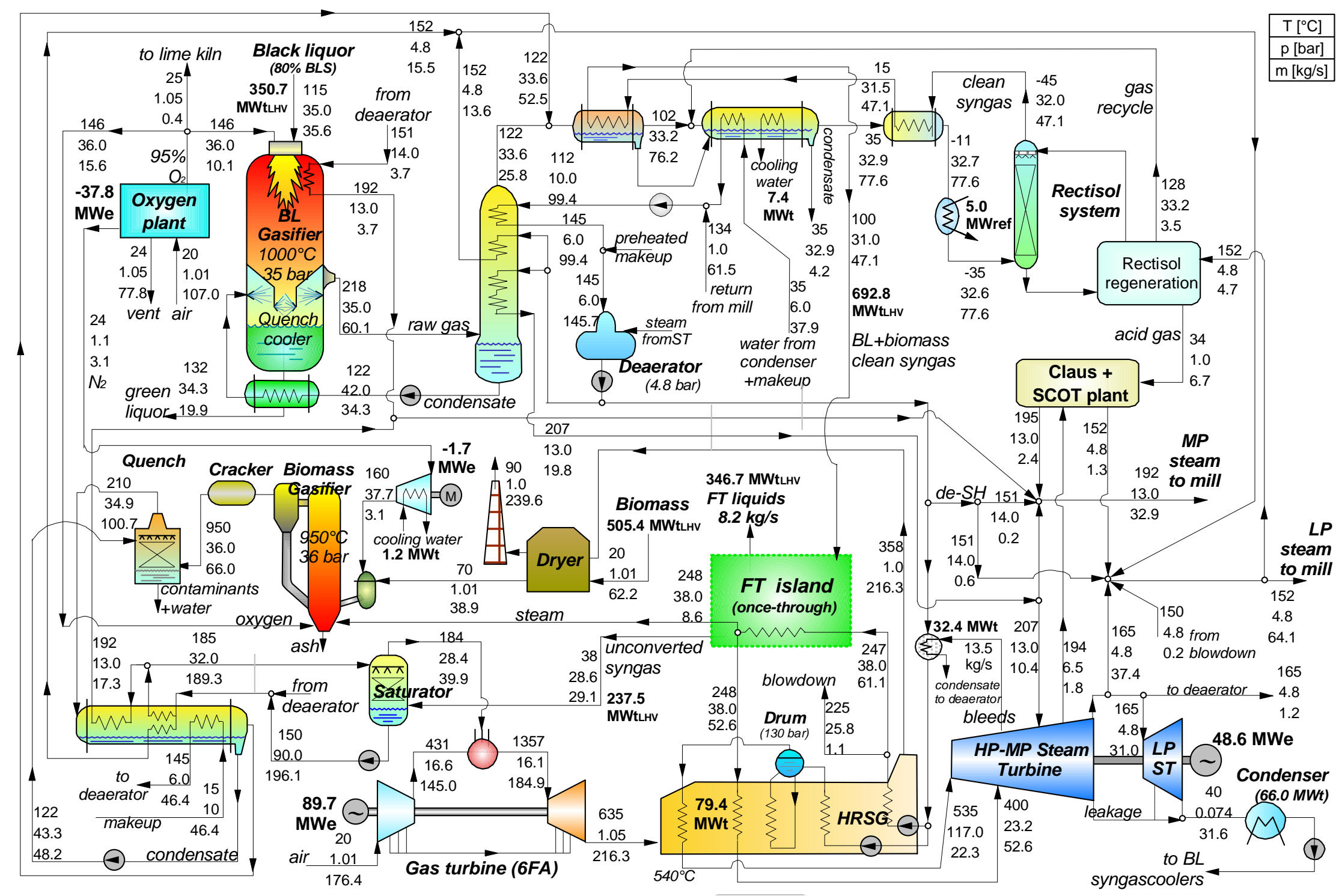

Fig. 23. Plant configuration and mass/energy balances for FTc case 


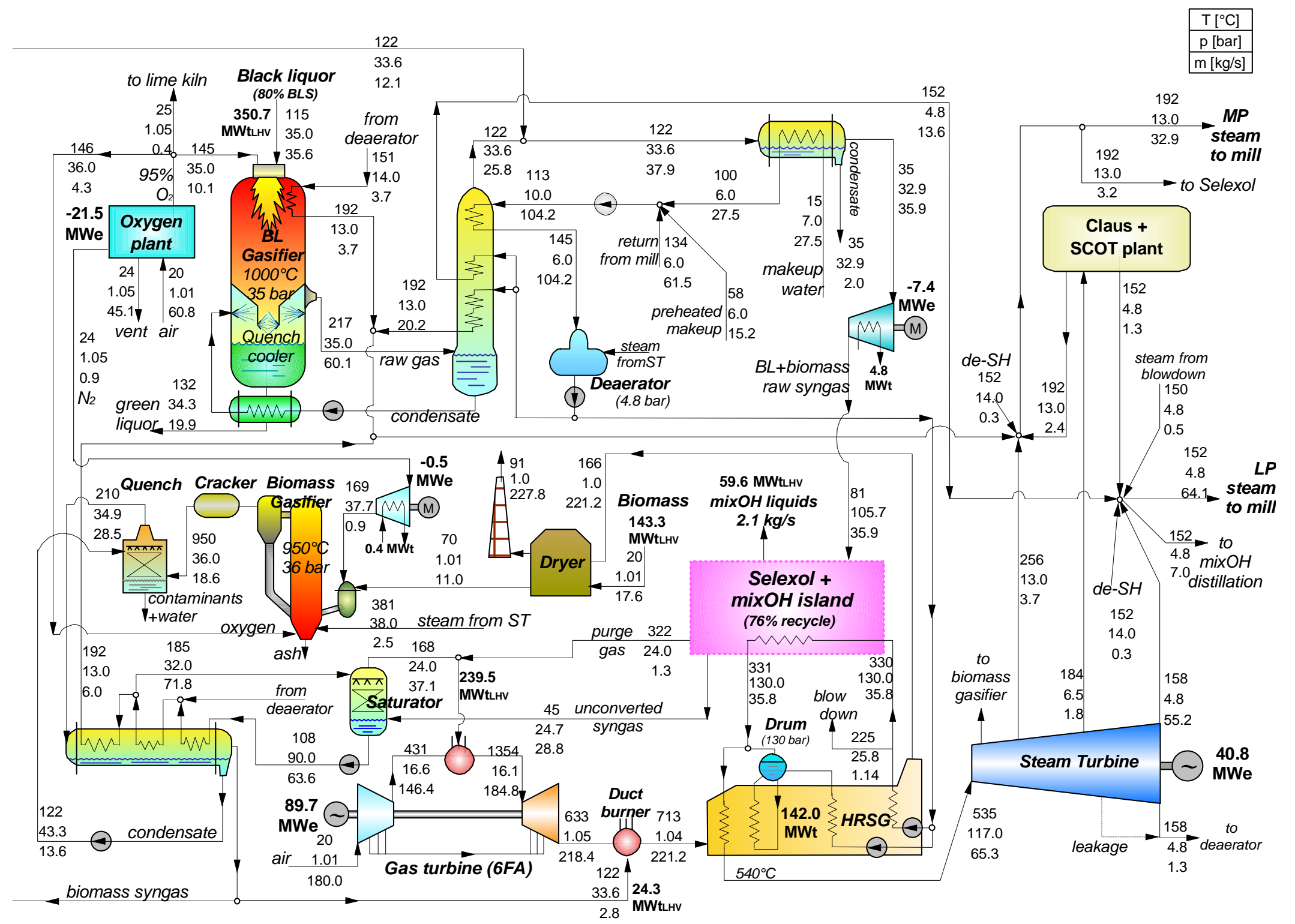

Fig. 24. Plant configuration and mass/energy balances for MixOH case 


\section{PROCESS SIMULATION RESULTS}

\subsection{Overall performances}

Tab. 16 to Tab. 18 and Fig. 25 show the energy balance and the overall performances predicted in our simulations. The tables and the figure report also the conventional Tomlinson boiler system described and calculated by Larson, Consonni and Katofsky [2003].

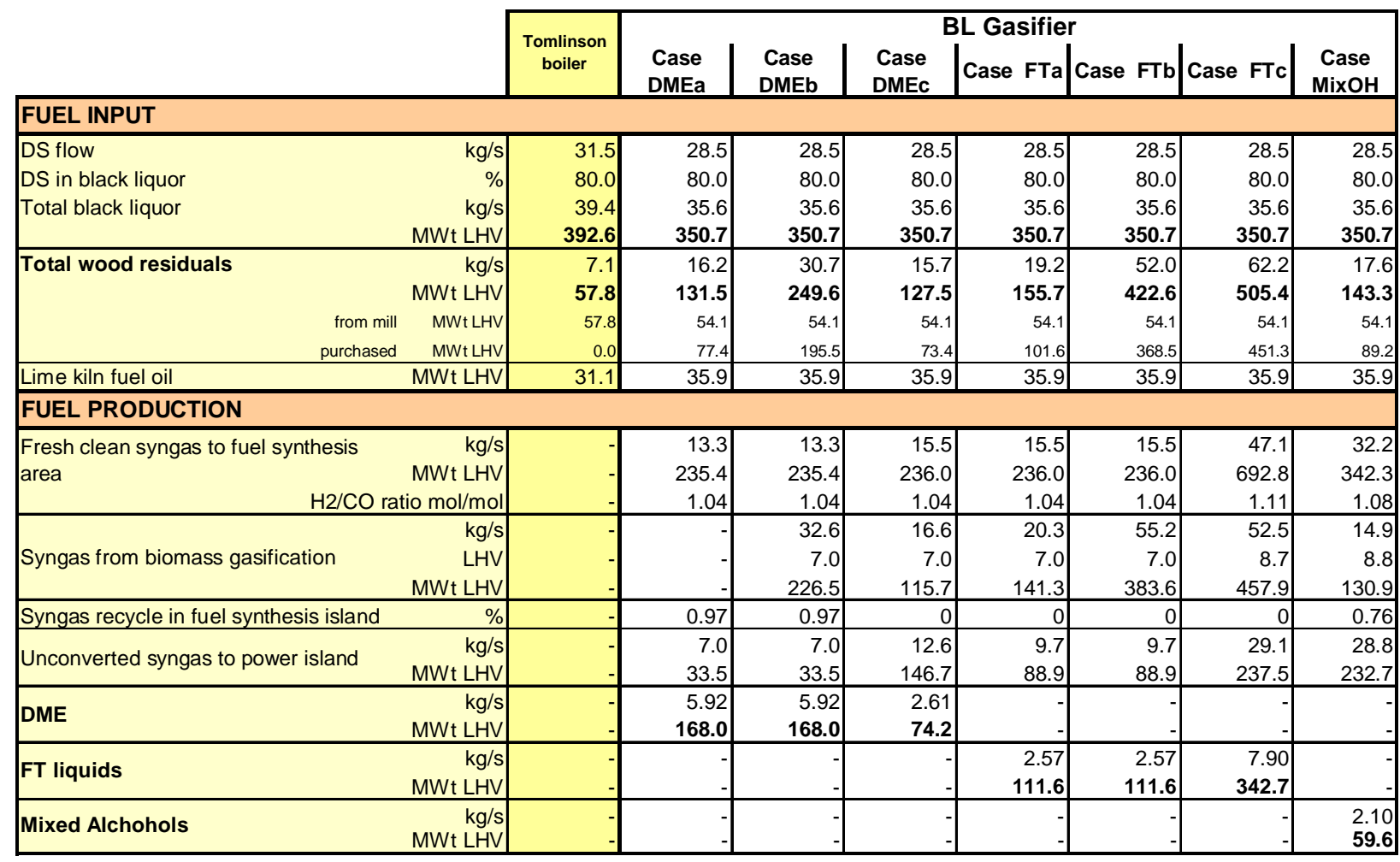

Tab. 16. Summary of performance estimates: mass and energy balances of fuel inputs and fuel productions 


\begin{tabular}{|c|c|c|c|c|c|c|c|c|c|}
\hline & & $\begin{array}{c}\text { Tomlinson } \\
\text { boiler }\end{array}$ & $\begin{array}{c}\text { Case } \\
\text { DMEa }\end{array}$ & $\begin{array}{c}\text { Case } \\
\text { DMEb }\end{array}$ & $\begin{array}{c}\text { Case } \\
\text { DMEc }\end{array}$ & $\begin{array}{l}\text { L Gasifie } \\
\text { Case FTa }\end{array}$ & Case FTb & Case FTc & $\begin{array}{c}\text { Case } \\
\text { MixOH }\end{array}$ \\
\hline \multicolumn{10}{|l|}{ REFRIGERATION DUTY } \\
\hline Rectisol/Selexol plant & MWref & & 6.8 & 6.8 & 6.6 & 5.0 & 5.0 & 16.0 & 4.8 \\
\hline DME island & MWref & & 3.9 & 3.9 & 1.7 & & & & \\
\hline \multicolumn{10}{|l|}{ STEAM } \\
\hline HP steam from power boiler ( 87.2 bar) & $\mathrm{kg} / \mathrm{s}$ & 125.56 & 47.7 & & & & & & \\
\hline HP steam from HRSG (130 bar) & $\mathrm{kg} / \mathrm{s}$ & & & 35.5 & 47.1 & 30.5 & 50.8 & 22.3 & 29.5 \\
\hline $\begin{array}{l}\text { HP steam from biomass syngas cooler } \\
(130 \text { bar) }\end{array}$ & $\begin{array}{r}\mathrm{kg} / \mathrm{s} \\
\mathrm{MWt}\end{array}$ & & & $\begin{array}{l}27.5 \\
31.8 \\
\end{array}$ & $\begin{array}{l}12.2 \\
14.1\end{array}$ & \begin{tabular}{l|}
15.2 \\
17.6
\end{tabular} & $\begin{array}{l}44.3 \\
51.3\end{array}$ & & \\
\hline $\begin{array}{l}\text { Steam from DME/FT reactor to power } \\
\text { island (38 bar) }\end{array}$ & $\begin{array}{r}\mathrm{kg} / \mathrm{s} \\
\mathrm{MWt}\end{array}$ & & $\begin{array}{l}16.8 \\
29.1\end{array}$ & $\begin{array}{l}16.8 \\
29.1 \\
\end{array}$ & $\begin{array}{r}6.7 \\
11.5 \\
\end{array}$ & $\begin{array}{l}20.0 \\
34.6 \\
\end{array}$ & $\begin{array}{l}20.0 \\
34.6 \\
\end{array}$ & $\begin{array}{r}61.1 \\
105.7 \\
\end{array}$ & \\
\hline $\begin{array}{l}\text { Steam from MixOH reactor to power } \\
\text { island (130 bar) }\end{array}$ & $\begin{array}{r}\mathrm{kg} / \mathrm{s} \\
\mathrm{MWt}\end{array}$ & & & & - & & & & $\begin{array}{l}35.8 \\
40.7 \\
\end{array}$ \\
\hline MP steam from Claus plant (13 bar) & $\begin{array}{r}\mathrm{kg} / \mathrm{s} \\
\mathrm{MWt}\end{array}$ & & $\begin{array}{l}2.4 \\
4.7 \\
\end{array}$ & \begin{tabular}{l|}
2.4 \\
4.7 \\
\end{tabular} & $\begin{array}{l}2.4 \\
4.7\end{array}$ & $\begin{array}{l}2.4 \\
4.7 \\
\end{array}$ & $\begin{array}{l}2.4 \\
4.7 \\
\end{array}$ & $\begin{array}{l}2.4 \\
4.7 \\
\end{array}$ & $\begin{array}{l}2.4 \\
4.7\end{array}$ \\
\hline LP steam from Claus plant (4.8 bar) & $\begin{array}{r}\mathrm{kg} / \mathrm{s} \\
\mathrm{MWt}\end{array}$ & & $\begin{array}{l}1.3 \\
2.7 \\
\end{array}$ & \begin{tabular}{l|}
1.3 \\
2.7 \\
\end{tabular} & $\begin{array}{l}1.3 \\
2.7\end{array}$ & \begin{tabular}{l|}
1.3 \\
2.7
\end{tabular} & $\begin{array}{l}1.3 \\
2.7 \\
\end{array}$ & $\begin{array}{l}1.3 \\
2.7 \\
\end{array}$ & $\begin{array}{l}1.3 \\
2.7\end{array}$ \\
\hline $\begin{array}{l}\text { MP steam to Selexol and to fuel } \\
\text { synthesis island (13 bar) }\end{array}$ & $\begin{array}{r}\mathrm{kg} / \mathrm{s} \\
\mathrm{MWt}\end{array}$ & & $\begin{array}{l}1.9 \\
4.0 \\
\end{array}$ & $\begin{array}{l}1.9 \\
4.0 \\
\end{array}$ & $\begin{array}{l}0.6 \\
1.3 \\
\end{array}$ & & & & $\begin{array}{l}3.2 \\
7.0 \\
\end{array}$ \\
\hline IP steam to SCOT plant (6.5 bar) & $\begin{array}{l}\mathrm{kg} / \mathrm{s} \\
\mathrm{MWt}\end{array}$ & & $\begin{array}{l}1.8 \\
3.6 \\
\end{array}$ & \begin{tabular}{l|}
1.8 \\
3.6 \\
\end{tabular} & $\begin{array}{l}1.8 \\
3.6\end{array}$ & $\begin{array}{l}1.8 \\
3.6 \\
\end{array}$ & $\begin{array}{l}1.8 \\
3.6 \\
\end{array}$ & $\begin{array}{l}1.8 \\
3.6 \\
\end{array}$ & $\begin{array}{l}1.8 \\
3.6\end{array}$ \\
\hline $\begin{array}{l}\text { LP steam to Rectisol and to fuel } \\
\text { synthesis island (4.8 bar) }\end{array}$ & $\begin{array}{r}\mathrm{kg} / \mathrm{s} \\
\mathrm{MWt}\end{array}$ & & $\begin{array}{r}5.8 \\
12.3 \\
\end{array}$ & $\begin{array}{r}5.8 \\
12.3 \\
\end{array}$ & $\begin{array}{l}3.9 \\
8.3\end{array}$ & $\begin{array}{l}1.9 \\
4.0 \\
\end{array}$ & $\begin{array}{l}1.9 \\
4.0 \\
\end{array}$ & $\begin{array}{r}4.7 \\
10.0 \\
\end{array}$ & $\begin{array}{r}7.0 \\
15.0\end{array}$ \\
\hline MP steam to mill (13 bar) & $\begin{array}{r}\mathrm{kg} / \mathrm{s} \\
\mathrm{MWt}\end{array}$ & $\begin{array}{l}35.15 \\
69.28 \\
\end{array}$ & $\begin{array}{l}32.9 \\
64.8 \\
\end{array}$ & $\begin{array}{l}32.9 \\
64.8 \\
\end{array}$ & $\begin{array}{l}32.9 \\
64.8\end{array}$ & $\begin{array}{l}32.9 \\
64.8 \\
\end{array}$ & $\begin{array}{l}32.9 \\
64.8 \\
\end{array}$ & $\begin{array}{l}32.9 \\
64.8 \\
\end{array}$ & $\begin{array}{l}32.9 \\
64.8\end{array}$ \\
\hline LP steam to mill ( $4.8 \mathrm{bar})$ & $\begin{array}{r}\mathrm{kg} / \mathrm{s} \\
\mathrm{MWt}\end{array}$ & $\begin{array}{r}67.60 \\
142.78\end{array}$ & $\begin{array}{r}64.1 \\
135.3\end{array}$ & $\begin{array}{r}64.1 \\
135.3\end{array}$ & $\begin{array}{r}64.1 \\
135.3\end{array}$ & $\begin{array}{r}64.1 \\
135.3\end{array}$ & $\begin{array}{r}64.1 \\
135.3\end{array}$ & \begin{tabular}{r|}
64.1 \\
135.3
\end{tabular} & $\begin{array}{r}64.1 \\
135.3\end{array}$ \\
\hline
\end{tabular}

Tab. 17. Summary of performance estimates: refrigeration duties and steam balance

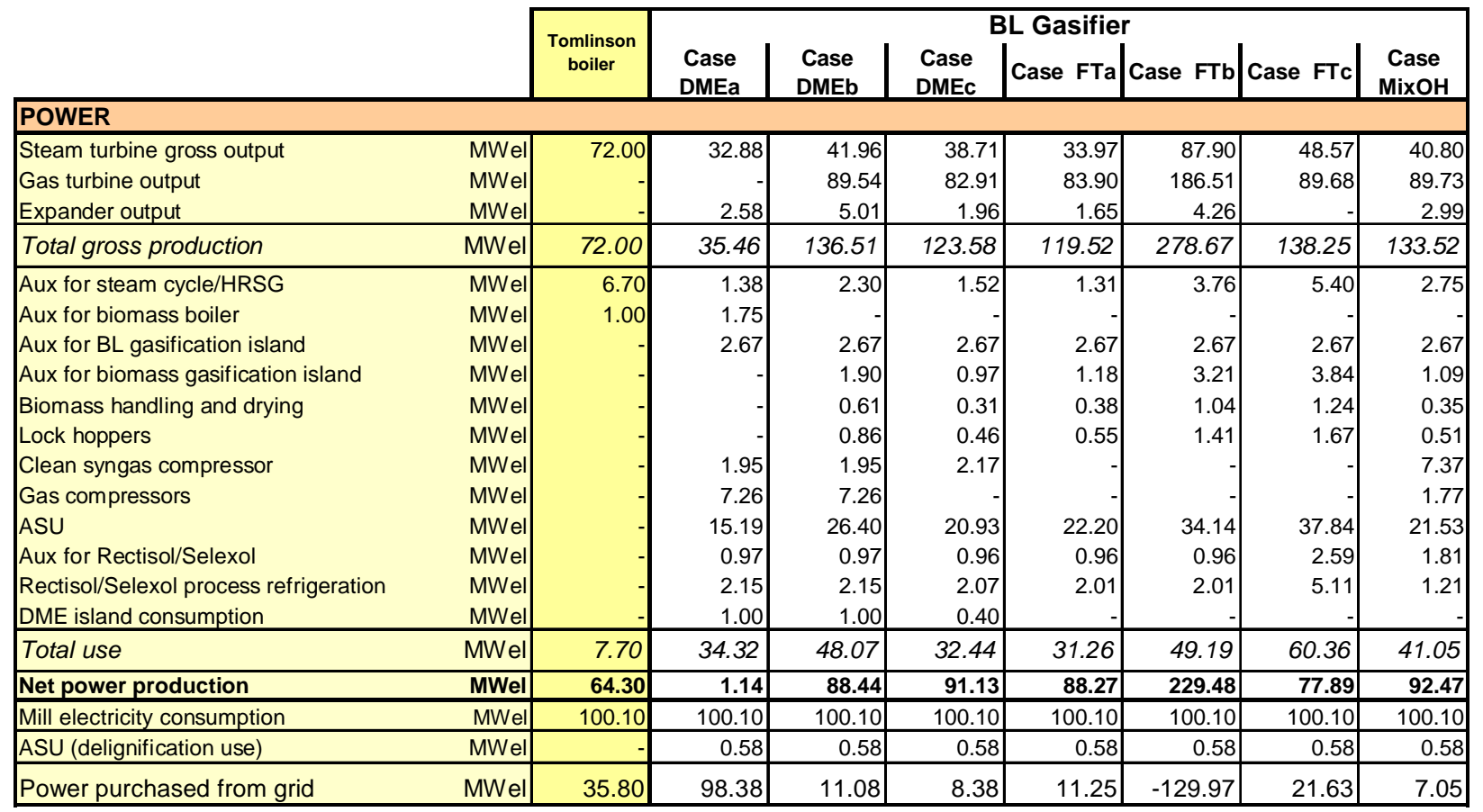

Tab. 18. Summary of performance estimates: electricity balance 


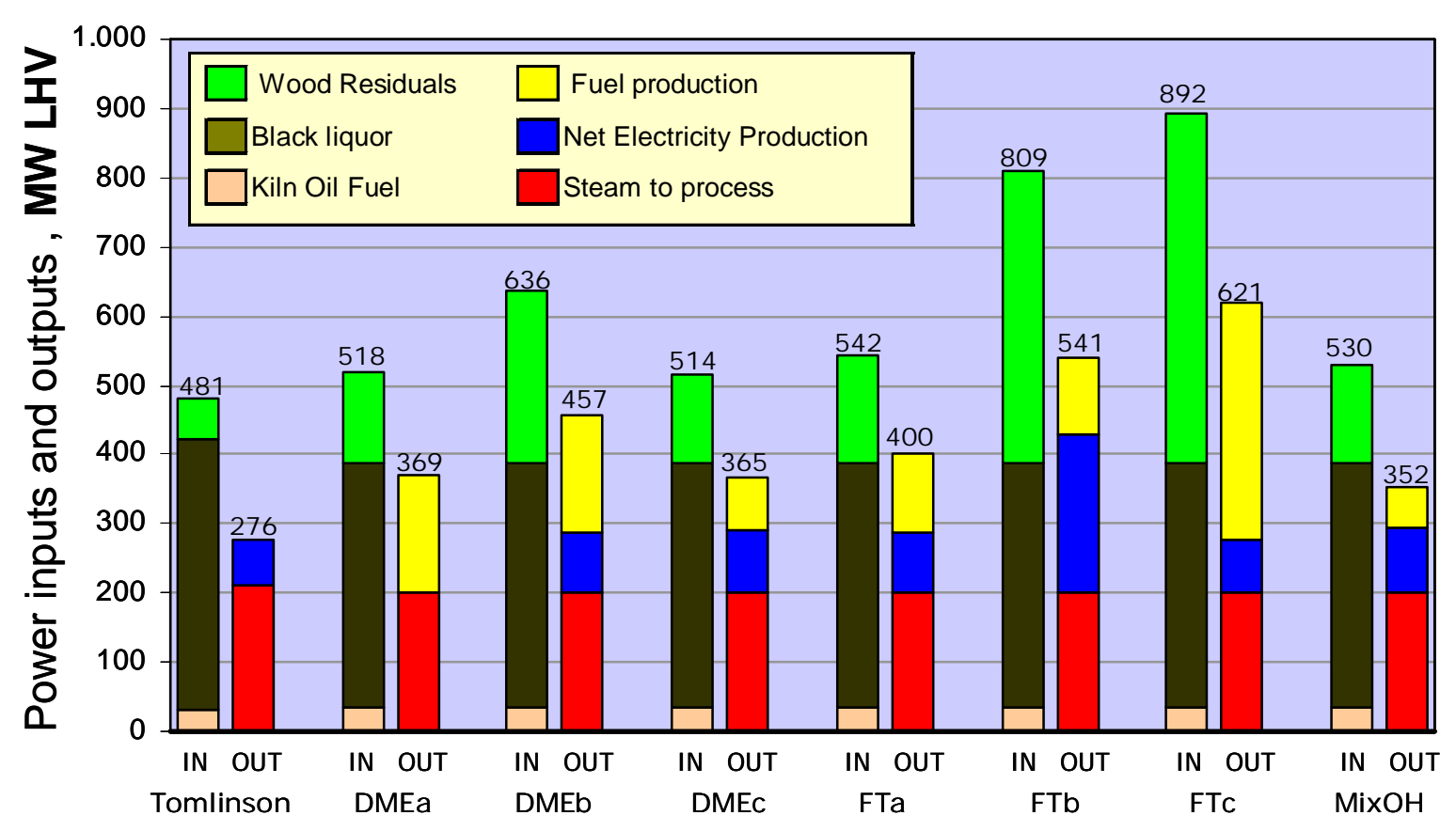

Fig. 25. Energy balance of biorefinery simulations and Tomlinson system

\subsection{Energy efficiencies}

Tab. 19 shows the value of various energy efficiency parameters for the biorefinery designs and of the Tomlinson system. ETA electricity is the ratio of net electricity production to total fuel inputs. ETA fuel is the ratio of exportable fuel to total fuel inputs. ETA heat is the ratio of process steam heat to total fuel inputs. ETA $1 s t$ is the efficiency with which primary energy is converted to useful outputs $\left(1^{\text {st }}\right.$ law thermodynamic efficiency), i.e. ETA electricity + ETA fuel + ETA heat.

ETA $1 s t$ is helpful to appreciate the energy balance of the biorefinery system; however, it is not an appropriate performance indicator because electricity, fuel and heat have quite different thermodynamic (and economic) relevance and their mere sum (the numerator of ETA 1st) does not account for their actual "value".

In an attempt to quantify the actual thermodynamic quality or "value" of the outputs generated by each plant, in the last row of Tab. 19 we've introduced ETA equivalent electricity total, defined as the ratio between the electricity that could be produced by converting all outputs to electricity and the primary energy input. This enables an "apples-to-apples" thermodynamic comparison among systems that produce no liquid fuel (e.g. Tomlinson system) and those that produce some fuel. Clean liquid fuels like DME and MixOH could generate electricity by a combined cycle (the most efficient technology now available) with an efficiency of $0.55 \mathrm{MWel} / \mathrm{MW}_{\mathrm{LHVfuel}}$. This is not the case for the raw FT fuel, which would require further upgrading; assuming that the raw FT liquid could be converted to light fuels with $91 \%$ efficiency, the overall electric efficiency achievable with FT raw products is 0.50 $\mathrm{MWel} / \mathrm{MW}_{\mathrm{LHVfuel}}$. The steam exported from the biorefinery could be fed to a steam turbine and expanded to the condenser pressure assumed here of 0.074 bar; this would generate $610 \mathrm{~kJ}_{\mathrm{el}}$ per $\mathrm{kg}$ of MP steam at $13 \mathrm{bar}, 510 \mathrm{~kJ}_{\mathrm{el}}$ per $\mathrm{kg}$ of LP steam 4.8 bar (these conversion factors account for an expansion efficiency equal to the one of the LP turbines considered in this study).

Fig. 26 shows the contribution of each output (heat, fuel and electricity) to ETA1st and to ETA equivalent electricity total. 
From the point of view of just the energy balance $\left(E T A I^{s t}\right)$ the three DME cases are about equivalent, FTa is the best case while FTb and MixOH stay behind (but still much better than Tomlinson). This ranking is misleading, because it doesn't account for the different "quality" of the three forms of energy generated by each plant. Energy quality is accounted for in the ETA equivalent electricity total parameter. The best option with this measure is FTb, which reaches ETA equivalent electricity total close to $42 \%$ thanks to the high electric efficiency of the large scale combined cycle. Instead, the worst biorefinery option is DMEa which, being without a combined cycle, suffers from no net electricity production. This situation indicates that generating electricity from black liquor and biomass is thermodynamically more efficient than generating fuels. Or, from a different point of view, that significant margins do exist to improve the thermodynamic efficiencies of the processes for the production of fuels via the thermochemical route.

The comparison between Tomlinson and DMEa shows that generating DME is thermodynamically more efficient than the conventional Tomlinson technology. On the other hand, the higher values of ETA equivalent electricity total of all other BLGF cases with respect to DMEa show that co-producing fuel and electricity is a more rational way of taking advantage of the black liquor resource and of the opportunity of heat integration with the mill.

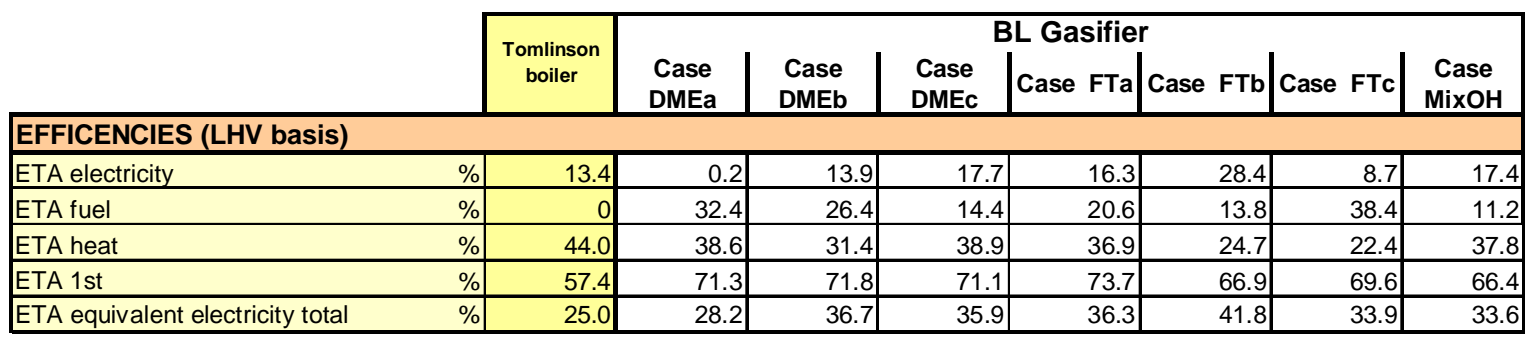

Tab. 19. Energy efficiencies:

ETA electricity = net electricity production / sum of all fuel energy inputs;

ETA fuel = liquid fuel energy / sum of all fuel energy inputs;

ETA heat $=$ process steam heat $/$ sum of all fuel energy inputs;

ETA 1st = ETA electricity + ETA fuel + ETA heat;

ETA electricity equivalent tot. $=$ (net electricity production $+K 1^{\star}$ liquid fuel energy $+K 2^{\star}$ MPsteam flow $+K 3^{\star}$ LPsteam flow) / sum of all fuel energy inputs;

where sum of all fuel energy inputs $=$ total residual wood $+\mathrm{BL}+$ lime kiln oil. For details on $K 1, K 2$ and $K 3$ see Tab. 20 and text. 


\begin{tabular}{|c|c|c|c|c|c|c|}
\hline & & DME & FT & MixOH & MPsteam & LPsteam \\
\hline $\mathrm{K} 1$ & MWel/MW fuellHV & 0.55 & 0.50 & 0.55 & - & - \\
\hline K2 & $\mathrm{kJel} / \mathrm{kg}$ steam & -- & -- & -- & 610 & \\
\hline K3 & kJel/kgsteam & - & - & - & - & 510 \\
\hline
\end{tabular}

Tab. 20. Coefficients of liquid fuels and steam conversions to electricity.

K1 = Electricity that could be produced by a combined cycle fed with the liquid fuel. The electrical efficiency of the CC is assumed $55 \%$ for DME and MixOH and $50 \%$ for FT raw liquid (thus assuming $91 \%$ of efficiency for the conversion from raw FT to light fuels).

K2 = Electricity that could be produced by MP (13 bar) steam expansion to 0.074 bar in steam turbine. Isentropic eff. $=0.81$; mechanical-electrical eff. $=0.98$. The resulting ratio between electricity and heat is $\mathbf{0 . 3 1}$.

K3 = Electricity that could be produced by LP (4.8 bar) steam expansion to 0.074 bar in steam turbine. Isentropic eff. $=0.84$; mechanical-electrical eff. $=0.98$. The resulting ratio between electricity and heat is $\mathbf{0 . 2 4}$.

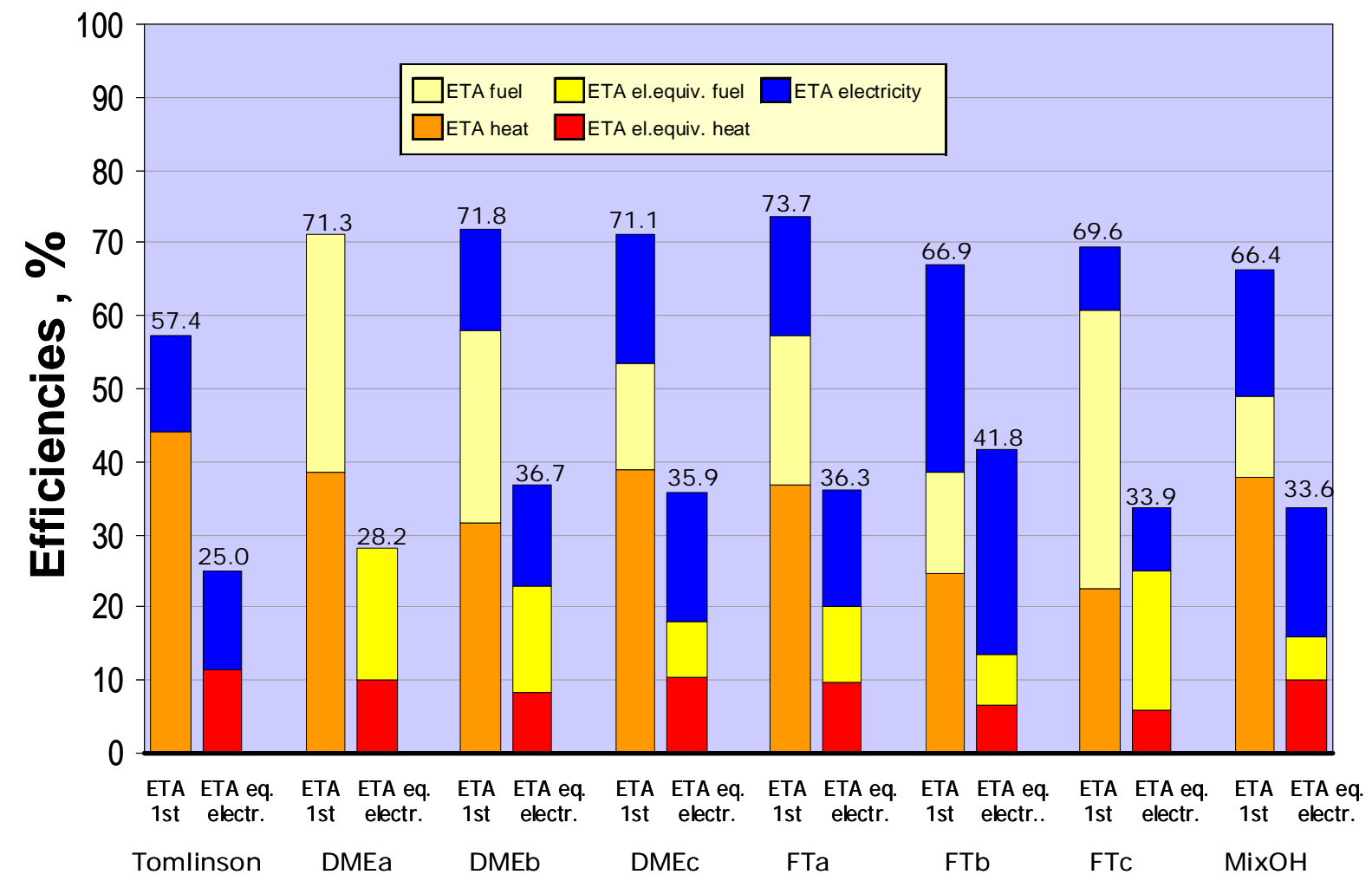

Fig. 26. Energy efficiencies and contribution of each output (steam heat, liquid fuel and electricity) to ETA1st and to ETA equivalent electricity total

\subsection{Biorefinery designs vs. conventional Tomlinson systems}

Fig. 27 shows the increment of energy inputs required by biorefineries and their additional electricity generation, both relative to the Tomlinson case. The production of liquid fuels is always an extra output with respect to the Tomlinson system.

The marginal biorefinery efficiencies reported in Tab. 21 show the effectiveness with which biorefinery designs utilize the extra fuel (compared to the Tomlinson case) to generate extra electricity (Marginal electrical efficiency) and to produce liquid fuels (Marginal fuel efficiency). 
The third column of Tab. 21 shows the Marginal equivalent electricity efficiency, i.e the ratio between the extra equivalent electricity generated by BLGF (numerator of ETA equivalent electricity total minus electricity generated in the Tomlinson case) divided by the extra-fuel consumption. From a thermodynamic perspective, this is the "fairest" measure of comparison. The very high values reached by this marginal efficiency indicate that BLGF is a way to compensate the inefficiencies of the reference Tomlison system. The larger the "marginal" system added to the reference mill, the lower the marginal gains, because the relevance of compensating the inefficiencies of the reference Tomlison decreases. This explains why the marginal efficiency of the largest plants (FTb and FTc) is relatively low.

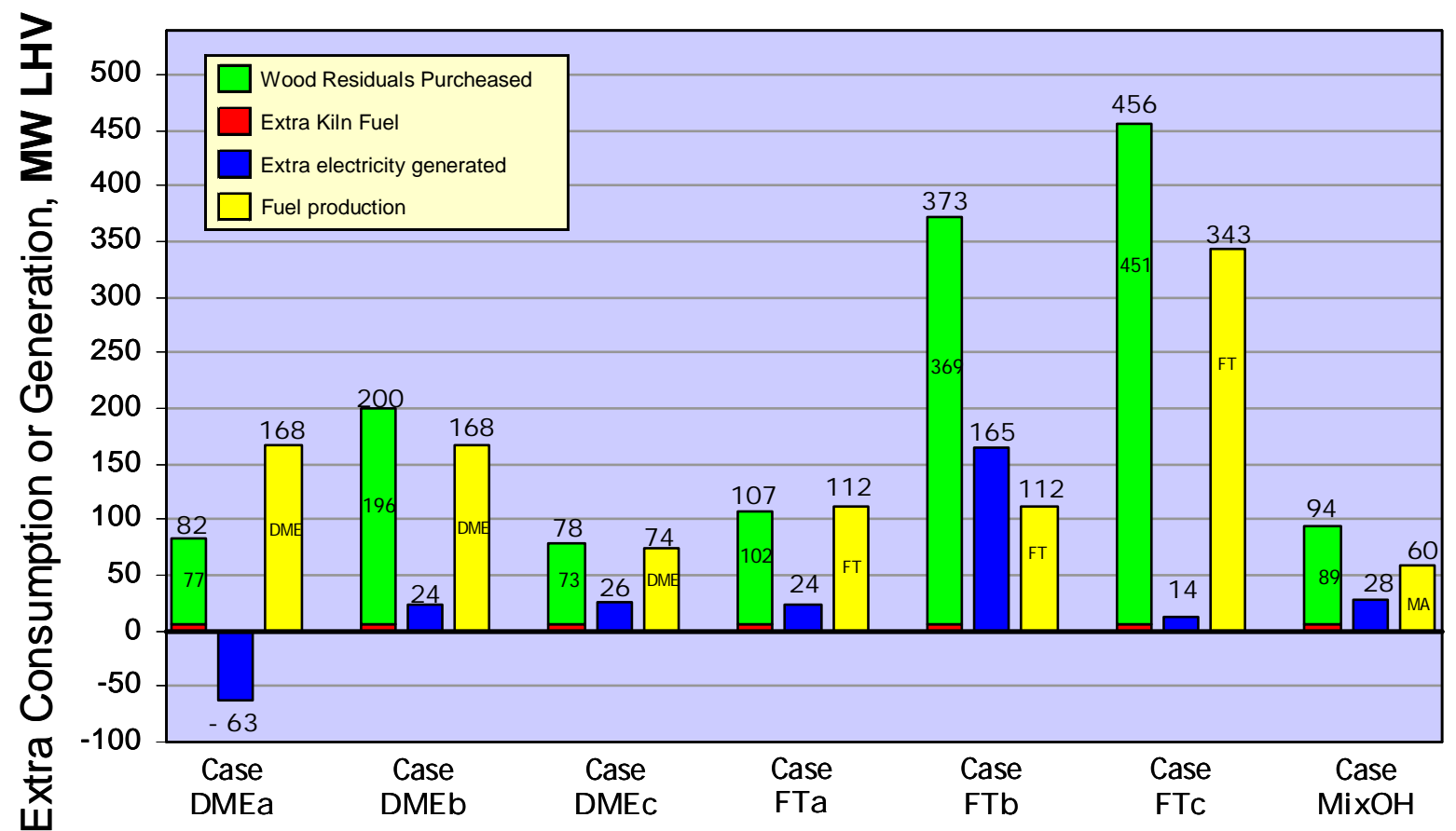

Fig. 27. Biorefinery energy inputs and outputs variations with respect to Tomlinson system 


\begin{tabular}{|l|c|c|c|}
\cline { 2 - 4 } \multicolumn{1}{c|}{} & $\begin{array}{c}\text { "Marginal” electric } \\
\text { efficiency \% }\end{array}$ & $\begin{array}{c}\text { "Marginal" fuel } \\
\text { production efficiency \% }\end{array}$ & $\begin{array}{c}\text { "Marginal” equivalent } \\
\text { electricity production } \\
\text { efficiency \% }\end{array}$ \\
\hline Case DMEa & -76.1 & 204.4 & 36.3 \\
\hline Case DMEb & 12.3 & 83.9 & 58.5 \\
\hline Case DMEc & 35.0 & 94.8 & 87.2 \\
\hline Case FTa & 23.1 & 104.8 & 75.4 \\
\hline Case FTb & 44.4 & 29.9 & 59.3 \\
\hline Case FTc & 3.1 & 75.1 & 40.7 \\
\hline Case MixOH & 30.6 & 63.4 & 65.4 \\
\hline
\end{tabular}

Tab. 21. Marginal efficiencies with respect to Tomlinson system.

Marginal electric efficiency = extra net electricity production / extra total fuel consumption Marginal fuel production efficiency = liquid fuel production / extra total fuel consumption

Marginal equivalent electricity efficiency $=($ extra net electricity production + liquid fuel

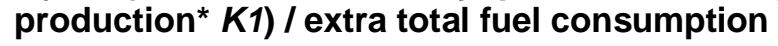

$K 1$ is the efficiency of liquid fuel conversion to electricity in a combined cycle, as described in Tab. 20. 


\section{REFERENCES}

Aden A., Spath P., Atherton B., 2005. "The Potential of Thermochemical Ethanol Via Mixed Alcohols Production", Milestone Completion Report, National Renewable Energy Laboratory (NREL), October 31

Bechtel, 1998. "Aspen Process Flowsheet Simulation Model of a Battelle Biomass-Based Gasification, Fischer-Tropsch Liquefaction and Combined-Cycle Power Plant", DE-AC2293PC91029-16, May, US Dept. of Energy, Pittsburgh, Pennsylvania.

Blackadder W.H., Lundberg H., Rensfelt E., and Waldheim L., 1994. "Heat and Power Production via Gasification in the Range $550 \mathrm{MWe,"} \mathrm{in} \mathrm{Advanced} \mathrm{In} \mathrm{Biomass}$ Thermochemical Conversion, A.V. Bridgwater (ed.), Balckie Academic \& Professional Press, London.

Brammer J.G. and Bridgwater A.V., 1999. "Drying technologies for an integrated gasifcation bio-energy plant", Renewable and Sustainable Energy Reviews, 3: 243-289

Bridgwater A.V., 1995. "The technical and economic feasibility of biomass gasi cation for power generation", Fuel 74(5):631-53.

Celik, F.E., Larson, E.D. and Williams, R.H. "Transportation fuels from coal with low $\mathrm{CO}_{2}$ emissions," paper presented at the 7th International Conference on Greenhouse Gas Control Technologies, Vancouver, BC, 5-9 September, 2004.

Consonni S. and Larson E.D., 1998. "Biomass-Gasifier/Aeroderivative Gas Turbine Combined Cycle: Part A - Techonologies and Performance Modeling, and Part B - Performance Calculations and Economic Assessment", J. of Engineering for Gas Turbines and Power, 118: 507-525.

Cummer K. and Brown R., 2002. "Ancillary equipment for biomass gasification”, Biomass and Bioenergy, 23: 113-128

Dayton D., 2002. "A Review of the Literature on Catalytic Biomass Tar Destruction", NREL/TP-510-32815, National Renewable Energy Laboratory (NREL), December

Devi L., Ptasinski K. and Janssen F., 2003. "A review of the primary measures for tar elimination in biomass gasification processes", Biomass and Bioenergy 24:125 - 140

Dry M.E., 2002. ’The Fischer-Tropsch process: 1950-2000”, Catalysis Today 71:227-241

Ekbom T., Lindblom M., Berglin N. and Ahlvik P., 2003. "Technical and Commercial Feasibility Study of Black Liquor Gasification with Methanol/DME Production as Motor Fuels for Automotive Uses - BLGMF"

Fox J.M. and Tam S.S., 1995. "Correlation of slurry reactor Fischer-Tropsch yield data", Topics in Catalysis, 2:285-300 
Graaf G.H., Winkelman J.G.M., and Stamhuis E.J., 1988. "Kinetics of three-phase methanol synthesis', Chemical Engineering Science, 43 (8), pp. 2161-2168.

Graaf G.H., and Beenackers A.A.C.M., 1996. "Comparison of two-phase and three-phase methanol synthesis processes', Chemical Engineering and Processing, 35, pp. 413-427.

Gunturu A.K., Kugler E.L., Cropley J.B. and Dadyburjor D.B., 1998. “A Kinetic Model for the Synthesis of High-Molecular-Weight Alcohols over a Sulfided Co-K-Mo/C Catalyst”, Ind. Eng. Chem. Res. 37: 2107-2115

Hamelinck C. Faaij A., den Uil H. and Boerrigter H., 2004. "Production of FT transportation fuels from biomass; technical options, process analysis and optimisation, and development potential", Energy 29:1743-1771

Larson E.D. and Tingjin R., 2003. "Synthetic fuel production by indirect coal liquefaction", Energy for Sustainable Development, Volume VII No. 4

Larson, E.D., Consonni, S., and Katofsky, R.E., 2003. "A Cost-Benefit Assessment of Biomass Gasification Power Generation in the Pulp and Paper Industry, Final Report" final report, Princeton Environmental Institute, Princeton, NJ, October.

Larson, E.D., Kreutz, T.G. and Consonni, S., 1999. "Combined Biomass and Black Liquor Gasifier/Gas Turbine Cogeneration at Pulp and Paper Mills," J. of Engineering for Gas Turbines and Power, 121: 394-400.

Lau F.S., Bowen D.A., Dihu R., Doong S., Hughes E.E., Remick, R., Slimane R., Turn S.Q., and Zabransky R., 2003. "Techno-Economic Analysis of Hydrogen Production by Gasification of Biomass", Gas Technology Institute (GTI), contract DE-FC36-01GO11089 for DOE, June

Lau F.S., Carty R.H., Onischak M., and Bain R.L., 1993. "Development of the IGT Renugas Process," Conference on Strategic Benefits of Biomass and Waste Fuels, Electric Power Research Institute, Washington, DC, 30 March - 1 April, 1993.

Liu Z., Li X., Close M.R., Kugler E.L., Peterson J.L., Dadyburjor D.B., 1997. Ind. Eng. Chem. Res., 36, 3085-3093

Milne T.A., Evans R.J. and Abatzoglou N., 1998. "Biomass gasifier "Tars": Their Nature, Formation and Conversion", NREL/TP-570-25357, National Renewable Energy Laboratory, November

Ng K.L., Chadwick D., and Toseland B.A., 1999. "Kinetics and modeling of dimethyl ether synthesis from synthesis gas', Chemical Engineering Science, 54, pp. 3587-3592. Contract DE-AC26-99FT40675 for US DOE by Research Triangle Institute, Research Triangle

Pan Y.G., Roca X., Velo E., Puigjaner L., 1999. "Removal of tar by secondary air injection in Iuidized bed gasification of residual biomass and coal", Fuel; 78:1703-9.

Ranke, G. and Weiss, H., "Separation of Gaseous Components from a Gaseous Mixture by Physical Scrubbing”, United States patent 4,324,567, 1982 
Riesenfeld F.C., Kohl, A., “Gas Purification”, II Edition, Gulf Publishing Company, 1974

Simell P., Kurkela, E., Stahlberg P. and Hepola, J., 1996. "Catalytic hot gas cleaning of gasification gas." Catalysis Today 27(1-2), 55-62.

Spath P.L., Dyton D.C., 2003. "Preliminary Screening - Technical and Economic Assessment of Synthesis Gas to Fuels and Chemicals with Emphasis on the Potential for BiomassDerived Syngas", NREL/TP-510-34929, National Renewable Energy Laboratory (NREL), December

SRI Consulting, 2002. "Dimethyl ether as alternate fuel", Report No. 245, June

The Rectisol ${ }^{\circledR}$ Process for Gas Purification, Lurgi Engineering Oel-Gas-Chemie, brochure available @ http://www.lurgi.com

Tijmensen M., Faaij A., Hamelinck C. and van Hardeveld M., 2002. "Exploration of the possibilities for production of Fischer Tropsch liquids and power via biomass gasification", Biomass and Bioenergy 23:129 - 152

U.S. Department of Energy, 1998. "Baseline Design/Economics for Advanced Fischer-Tropsch Technology, Final report", April 


\section{APPENDIX A: DME AND FT SYNTHESIS}

\section{A.1 DME synthesis}

\section{A.1.1 Kinetics equations}

Direct synthesis of DME from syngas involves two parallel steps, methanol synthesis and methanol dehydration. This process can be represented by following reactions:

$\mathrm{CO}+2 \mathrm{H}_{2} \Leftrightarrow \mathrm{CH}_{3} \mathrm{OH}$

$\mathrm{CO}_{2}+3 \mathrm{H}_{2} \Leftrightarrow \mathrm{CH}_{3} \mathrm{OH}+\mathrm{H} 2 \mathrm{O}$

$\mathrm{CO}+\mathrm{H}_{2} \mathrm{O} \Leftrightarrow \mathrm{H}_{2}+\mathrm{CO}_{2}$

$2 \mathrm{CH}_{3} \mathrm{OH} \Leftrightarrow \mathrm{CH}_{3} \mathrm{OCH}_{3}+\mathrm{H}_{2} \mathrm{O}$

$$
\begin{array}{rl}
\Delta \mathrm{H}^{0}{ }_{298} & =-94.084 \mathrm{~kJ} / \mathrm{mol} \\
\Delta \mathrm{H}^{0} & 298 \\
\Delta \mathrm{H}^{0} & =-52.814 \mathrm{~kJ} / \mathrm{mol} \\
\Delta \mathrm{H}^{0} & =-41.270 \mathrm{~kJ} / \mathrm{mol} \\
{ }_{298} & =-19.76 \mathrm{~kJ} / \mathrm{mol}
\end{array}
$$

The rates for reactions (A1), (A2) and (A3) use in our kinetic model, expressed in terms of partial fugacity, results:

$$
\begin{aligned}
r_{\mathrm{A} 1}=\frac{k_{\mathrm{A} 1} K_{\mathrm{CO}}\left(f_{\mathrm{CO}} f_{\mathrm{H}_{2}}^{3 / 2}-\frac{f_{\mathrm{MeOH}}}{f_{\mathrm{H}_{2}}^{1 / 2} K_{\mathrm{A1}}^{0}}\right)}{\left(1+K_{\mathrm{CO}} f_{\mathrm{CO}}+K_{\mathrm{CO}_{2}} f_{\mathrm{CO}_{2}}\right)\left(f_{\mathrm{H}_{2}}^{1 / 2}+\frac{K_{\mathrm{H}_{2} \mathrm{O}}}{K_{\mathrm{H}_{2}}^{1 / 2}} f_{\mathrm{H}_{2} \mathrm{O}}\right)} \\
r_{\mathrm{A} 2}=\frac{k_{\mathrm{A} 2} K_{\mathrm{CO}_{2}}\left(f_{\mathrm{CO}_{2}} f_{\mathrm{H}_{2}}^{3 / 2}-\frac{f_{\mathrm{H}_{2} \mathrm{O}} f_{\mathrm{MeOH}}}{f_{\mathrm{H}_{2}}^{3 / 2} K_{\mathrm{A} 2}^{0}}\right)}{\left(1+K_{\mathrm{CO}} f_{\mathrm{CO}}+K_{\mathrm{CO}_{2}} f_{\mathrm{CO}_{2}}\right)\left(f_{\mathrm{H}_{2}}^{1 / 2}+\frac{K_{\mathrm{H}_{2} \mathrm{O}}}{K_{\mathrm{H}_{2}}^{1 / 2}} f_{\mathrm{H}_{2} \mathrm{O}}\right)} \\
r_{\mathrm{A3}}=\frac{k_{\mathrm{A} 3} K_{\mathrm{CO}_{2}}\left(f_{\mathrm{CO}_{2}} f_{\mathrm{H}_{2}}-\frac{f_{\mathrm{H}_{2} \mathrm{O}} f_{\mathrm{CO}}}{K_{\mathrm{A} 3}^{0}}\right)}{\left(1+K_{\mathrm{CO}} f_{\mathrm{CO}}+K_{\mathrm{CO}_{2}} f_{\mathrm{CO}_{2}}\right)\left(f_{\mathrm{H}_{2}}^{1 / 2}+\frac{K_{\mathrm{H}_{2} \mathrm{O}}}{K_{\mathrm{H}_{2}}^{1 / 2}} f_{\mathrm{H}_{2} \mathrm{O}}\right)}
\end{aligned}
$$

where $f_{i}$ is component fugacity (bar), $r$ is reaction rate based on weight of catalyst (mol/s- $\mathrm{kg}_{\mathrm{cat}}$ ).

The temperature dependencies of rate parameters and adsorption coefficients can be expressed as

$$
K=A \exp \left(\frac{B}{R T}\right)
$$


where $R$ is ideal gas constant, $8.314 \mathrm{~J} / \mathrm{K}$-mol; $T$ is reaction temperature, $\mathrm{K} ; A, B$ are constants listed in Tab. A1 for liquid-phase methanol synthesis reactions.

\begin{tabular}{|l|l|l|}
\hline & \multicolumn{2}{|c|}{ Liquid Phase } \\
\hline Parameter & Constant A & Constant B \\
\hline$k_{A 1}$ & $2.12 \times 106$ & -98800 \\
\hline$k_{A 2}$ & $2.58 \times 1018$ & -220000 \\
\hline$k_{A 3}$ & $1.09 \times 101$ & -48300 \\
\hline$K_{C O}$ & $5.15 \times 10-11$ & 91500 \\
\hline$K_{C O_{2}}$ & $7.83 \times 10-5$ & 41000 \\
\hline$K_{H_{2} O} / \sqrt{K_{H_{2}}}$ & $2.30 \times 10-12$ & 114100 \\
\hline$K_{A 1}^{0}$ & $2.391 \times 10-13$ & 98388 \\
\hline$K_{A 2}^{0}$ & $1.068 \times 102$ & -39683 \\
\hline$K_{A 3}^{0}$ & $2.544 \times 10^{-11}$ & 58705 \\
\hline
\end{tabular}

Tab. A1. Parameters of Graaf methanol synthesis kinetic models ${ }^{9}$

For reaction (A4), in terms of liquid concentration, the left to right reaction rate is given by rA4, proposed by $\mathrm{Ng} 10$ :

$$
r_{A 4}=k_{A 4} K_{M e O H}^{2}\left[\frac{C_{M e O H}^{2}-\frac{C_{\mathrm{H}_{2} \mathrm{O}} C_{D M E}}{K_{A 4, A 3}}}{\left(1+2 \sqrt{K_{\mathrm{MeOH}} C_{\mathrm{MeOH}}}+K_{\mathrm{H}_{2} \mathrm{O}} C_{\mathrm{H}_{2} \mathrm{O}}\right)^{4}}\right]
$$

where $C_{i}$ is the concentration of component $i$, and the constants are as follows:

$$
\begin{aligned}
& k_{A 4}=3.7 \times 10^{10} \exp \left(-\frac{105000}{R T}\right) \\
& K_{\mathrm{MeOH}}=7.9 \times 10^{-4}
\end{aligned}
$$

${ }^{9}$ Graaf G.H., Winkelman J.G.M., and Stamhuis E.J., 1988. "Kinetics of three-phase methanol synthesis", Chemical Engineering Science, 43 (8), pp. 2161-2168; Graaf G.H., and Beenackers A.A.C.M., 1996. 'Comparison of two-phase and three-phase methanol synthesis processes", Chemical Engineering and Processing, 35, pp. 413427.

${ }^{10} \mathrm{Ng}$, K.L., Chadwick, D., and Toseland, B.A., 1999, "Kinetics and modeling of dimethyl ether synthesis from synthesis gas," Chemical Engineering Science, 54: 3587-3592. 
$K_{A 4, A 3}$ is the equilibrium constant expressed in terms of concentration. We have assumed the fix value $^{11}$ of 8.571 .

\section{A.1.2 $\underline{\text { Reactor model }}$}

Performance of the reactor is defined by the following material and energy balances:

$$
\begin{aligned}
& F_{i}^{i n}-F_{i}^{\text {out }}=k_{L} \alpha(i) V_{\text {comp }}\left(P_{G, i} / H_{i}-c_{L, i}\right) \\
& k_{L} \alpha(i) V_{\text {comp }}\left(P_{G, i} / H_{i}-c_{L, i}\right)=k_{s} \alpha_{s}\left(C_{G, i} / H_{i}-C_{L, i}\right) \\
& k_{s} \alpha_{s}\left(C_{G, i} / H_{i}-C_{L, i}\right)=\sum W_{\text {cata }} r_{i, j}
\end{aligned}
$$

If include the factors of mass transfer into reaction rates, the above model can be simplified as:

$$
F_{i}^{i n}-F_{i}^{o u t}=\sum W_{c a t a} r_{i, j}
$$

where $r_{i, j}$ stands for the reaction rates of component $\mathrm{i}$ in reaction $\mathrm{j}$. The total consumption/formation rates of components considered in the DME reaction are as follows:

$$
\begin{aligned}
& r_{M e O H}=r_{A 1}+r_{A 2}-2 r_{A 4} \\
& r_{C O}=-r_{A 1}+r_{A 3} \\
& r_{H_{2}}=-2 r_{A 1}-3 r_{A 2}-r_{A 3} \\
& r_{C O_{2}}=-r_{A 2}-r_{A 3} \\
& r_{H_{2} O}=r_{A 2}+r_{A 3}+r_{A 4} \\
& r_{D M E}=r_{A 4}
\end{aligned}
$$

in which $r_{A 1}, r_{A 2}, r_{A 3}$ and $r_{A 4}$ are defined by equations (A5), (A6), (A7), and (A8).

\section{A.1.3 Comparisons with experiment results}

In order to test this kinetic model, comparisons with experimental results were made. Experimental data are from Gogate and Lee ${ }^{12}$. The properties of the catalysts used in it that work are listed in Tab. A2. Tab. A3 shows the operating conditions considered. Tab. A4 shows a comparison of experimental results with predictions using our model for three different ratios of

${ }^{11}$ Seidel, A., 1990, "Calculating chemical reaction equilibrium for a homogeneous phase from the material balance of a batch reactor," Chemical Engineering Science, 45(9): 2970-2973.

12 Gogate, M.R., and Vijayaraghavan, P., 1992. "A single-stage, liquid-phase dimethyl ether synthesis process from syngas: thermodynamic analysis of the LPDME process system', Fuel Science and Technology International, 10

(3), pp. 281-311. 
the mass of methanol synthesis catalyst and dehydration catalyst: $1,0.5$, and 0 . The comparison is satisfactory.

\begin{tabular}{|c|c|c|}
\hline \multicolumn{3}{|c|}{ Methanol Synthesis Catalyst } \\
\hline Identification & \multicolumn{2}{|c|}{ EPJ-19 } \\
\hline Manufacturer & \multicolumn{2}{|c|}{ United Catalysts, Inc. } \\
\hline \multirow[t]{4}{*}{ Composition } & $\mathrm{CuO}$ & $55 \%$ \\
\hline & $\mathrm{ZnO}$ & $36 \%$ \\
\hline & $\mathrm{Al}_{2} \mathrm{O}_{3}$ & $8 \%$ \\
\hline & $\mathrm{SiO}_{2}$ & $1 \%$ \\
\hline Geometry & \multicolumn{2}{|c|}{$2.38 \mathrm{~mm}$ cylindrical extrudates } \\
\hline Length & \multicolumn{2}{|c|}{ Varying between 3 to $15 \mathrm{~mm}$} \\
\hline Specific Area & \multicolumn{2}{|c|}{$92 \mathrm{~m}^{2} / \mathrm{g}$} \\
\hline Pore Volume & \multicolumn{2}{|c|}{$0.43 \mathrm{~cm}^{3} / \mathrm{g}$} \\
\hline \multicolumn{3}{|c|}{ Methanol Dehydration Catalyst } \\
\hline Identification & \multicolumn{2}{|c|}{ Gamma-Alumina (AL-3916P) } \\
\hline Manufacturer & \multicolumn{2}{|c|}{ Harshaw-Filterol Partnership } \\
\hline Specific Area & \multicolumn{2}{|c|}{$198 \mathrm{~m}^{2} / \mathrm{g}$} \\
\hline Pore Volume & \multicolumn{2}{|c|}{$0.43 \mathrm{~cm}^{3} / \mathrm{g}$} \\
\hline Inert Liquid Medium & \multicolumn{2}{|c|}{ Witco-40 white mineral oil } \\
\hline Reactor & \multicolumn{2}{|c|}{ One-liter stirred autoclave by Autoclave Engineers, inc } \\
\hline
\end{tabular}

Tab. A2. Assumptions adopted for catalysts in DME synthesis model

\begin{tabular}{|l|r|}
\hline Temperature & $250^{\circ} \mathrm{C}$ \\
\hline Pressure & 70 bar \\
\hline Oil & $550 \mathrm{~mL}$ of Witco 40 oil \\
\hline Impeller speed & $1500 \mathrm{rpm}$ \\
\hline Feed flow rate & $1 \mathrm{SLPM}^{13}$ \\
\hline
\end{tabular}

Tab. A3. Co-production of methanol and DME operating conditions considered for comparison

\footnotetext{
${ }^{13}$ Standard Liters per Minute.
} 


\begin{tabular}{|c|c|c|c|c|c|c|c|c|}
\hline \multicolumn{9}{|c|}{ Co-production of Methanol and DME } \\
\hline \multicolumn{3}{|c|}{ Content } & Literature & Model & Literature & Model & Literature & Model \\
\hline \multirow{2}{*}{ Catalyst } & \multicolumn{2}{|c|}{ EPJ-19 (g) } & \multicolumn{2}{|c|}{15} & \multicolumn{2}{|c|}{15} & \multicolumn{2}{|c|}{15} \\
\hline & \multicolumn{2}{|c|}{$\begin{array}{c}\text { Gamma-Alumina to } \\
\text { EPJ-19 ratio }\end{array}$} & \multicolumn{2}{|l|}{0} & \multicolumn{2}{|c|}{0.5} & \multicolumn{2}{|l|}{1} \\
\hline \multirow{5}{*}{$\begin{array}{l}\text { Reactor } \\
\text { Feed Flow } \\
\text { Rate and } \\
\text { Mol } \\
\text { Fractions }\end{array}$} & Flow & $\mathrm{mol} / \mathrm{h}$ & 2.6787 & 2.6787 & 2.6787 & 2.6787 & 2.6786 & 2.6786 \\
\hline & $\mathrm{H} 2$ & \multirow{4}{*}{$\mathrm{mol} \%$} & 0.3815 & 0.3815 & 0.3696 & 0.3696 & 0.3616 & 0.3616 \\
\hline & $\mathrm{CO}$ & & 0.4564 & 0.4564 & 0.4727 & 0.4727 & 0.4836 & 0.4836 \\
\hline & $\mathrm{CH} 4$ & & 0.0860 & 0.0860 & 0.0826 & 0.0826 & 0.0790 & 0.0790 \\
\hline & $\mathrm{CO} 2$ & & 0.0762 & 0.0762 & 0.0752 & 0.0752 & 0.0757 & 0.0757 \\
\hline \multirow{8}{*}{$\begin{array}{l}\text { Reactor } \\
\text { Exit Flow } \\
\text { Rate and } \\
\text { Mol } \\
\text { Fractions }\end{array}$} & Flow & $\mathrm{mol} / \mathrm{h}$ & 2.1093 & 2.1413 & 1.9953 & 2.1290 & 1.9557 & 2.1172 \\
\hline & $\mathrm{H} 2$ & \multirow{7}{*}{$\mathrm{mol} \%$} & 0.2150 & 0.2252 & 0.1918 & 0.2219 & 0.1956 & 0.2214 \\
\hline & $\mathrm{CO}$ & & 0.4556 & 0.4465 & 0.4494 & 0.4506 & 0.4469 & 0.4502 \\
\hline & $\mathrm{CH} 4$ & & 0.1097 & 0.1076 & 0.1109 & 0.1038 & 0.1082 & 0.1001 \\
\hline & $\mathrm{CO} 2$ & & 0.0946 & 0.0941 & 0.1247 & 0.1097 & 0.1425 & 0.1248 \\
\hline & $\mathrm{MEOH}$ & & 0.1242 & 0.1255 & 0.1038 & 0.0959 & 0.0755 & 0.0695 \\
\hline & $\mathrm{H} 2 \mathrm{O}$ & & 0.0009 & 0.0011 & 0.0011 & 0.0016 & 0.0012 & 0.0025 \\
\hline & DME & & 0.0000 & 0.0000 & 0.0184 & 0.0166 & 0.0300 & 0.0315 \\
\hline GHSV & & & & 4545 & & 4545 & & 4545 \\
\hline \multirow{2}{*}{$\begin{array}{c}\text { Syngas } \\
\text { Conv. }\end{array}$} & Conv. & $\%$ & 31.0365 & 30.0922 & 34.6148 & 29.4633 & 34.6907 & 28.9465 \\
\hline & Error & & & $-3.0 \%$ & & $-14.9 \%$ & & $-16.6 \%$ \\
\hline \multirow{2}{*}{$\begin{array}{c}\text { Carbon } \\
\text { Conv. }\end{array}$} & Conv. & $\%$ & 18.3626 & 18.8336 & 19.1147 & 18.7288 & 17.6884 & 18.7360 \\
\hline & Error & & & $2.6 \%$ & & $-2.0 \%$ & & $5.9 \%$ \\
\hline \multirow{2}{*}{$\begin{array}{l}\text { MeOH } \\
\text { Yield }\end{array}$} & Yield & $\mathrm{mol} / \mathrm{h}$ & 0.2620 & 0.2687 & 0.2071 & 0.2041 & 0.1477 & 0.1472 \\
\hline & Error & & & $2.6 \%$ & & $-1.4 \%$ & & $-0.3 \%$ \\
\hline \multirow{2}{*}{ DME Yield } & Yield & $\mathrm{mol} / \mathrm{h}$ & 0.0000 & 0.0000 & 0.0367 & 0.0354 & 0.0587 & 0.0667 \\
\hline & Error & & & & & $-3.6 \%$ & & $13.7 \%$ \\
\hline
\end{tabular}

Tab. A4. Comparisons between results calculated with the model adopted and experimental data

\section{A.1.4 Sensitivity study of DME synthesis section}

The kinetic model enables us to simulate performance under different operating conditions. Reactor pressure and syngas recycle fraction were varied to see the performance impact (Tab. A5). 


\begin{tabular}{|l|r|}
\hline Reaction pressure & 35 bar -150 bar \\
\hline Unconverted gas recycle ratio & $0-0.97$ \\
\hline Reactor operation temperature & $260^{\circ} \mathrm{C}$ \\
\hline GSHV & 6000 liters/h.gcat \\
\hline CATAdme/CATAmeth & 0.3 \\
\hline Turbine outlet pressure & $28.5 \mathrm{bar}$ \\
\hline 1st distillator pressure & $25 \mathrm{bar}$ \\
\hline
\end{tabular}

Tab. A5. Assumptions and parameters investigated in sensitivity analysis of DME production

\section{A.1.4.1 Effect of reactor pressure variation}
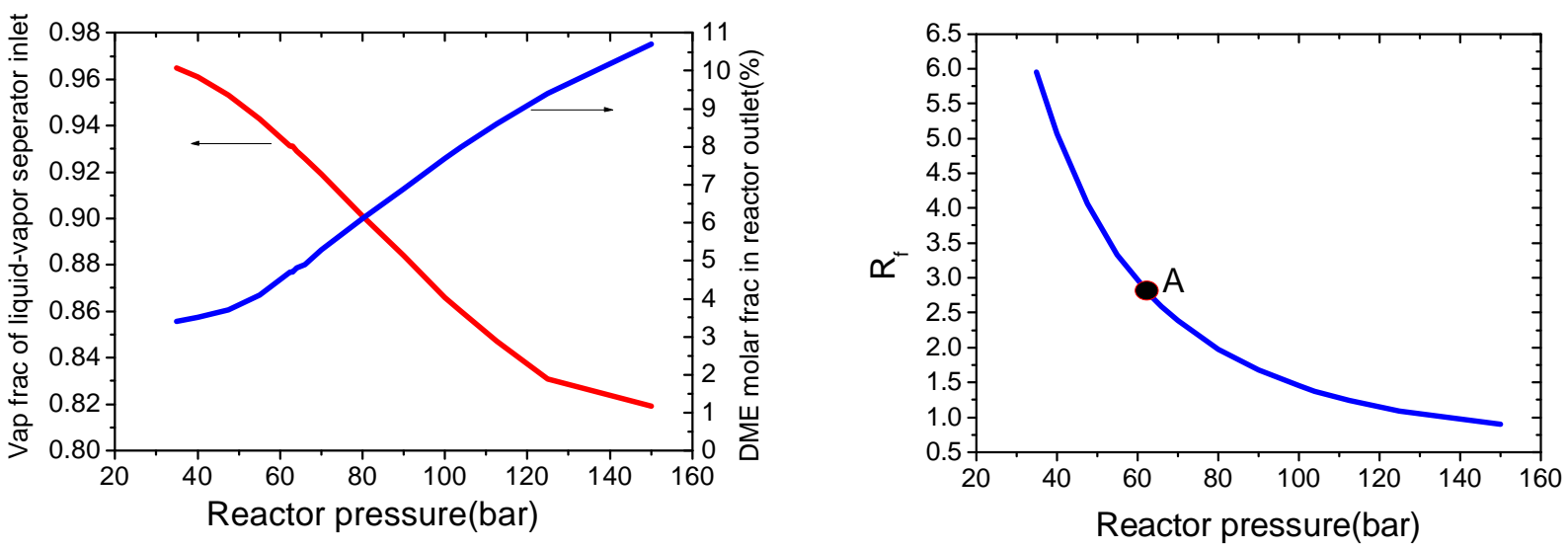

Fig. A1. Effect of reactor pressure variation on vapor fraction of products at $40^{\circ} \mathrm{C}$, on DME molar fraction in products and on unconverted recycled gas-to-fresh gas ratio (Rf). The unconverted recycle ratio is fixed at 0.97 . Point $A$ shows the pressure adopted in this study (62.5 bar).

With increasing reactor pressure, the vapor fraction at the reactor outlet decreases (Fig. A1, red curve), so less unconverted syngas is separated from the product mixture. Assuming that the fraction of unconverted gas recycled back to the reactor inlet is constant (in our case, 97\%), lower unconverted syngas mass flow means lower ratio $\mathrm{R}_{\mathrm{f}}$ between the mass flow of unconverted syngas recycled to the reactor inlet and the mass flow of fresh syngas; in turn, this implies that the composition of the syngas at the reactor inlet becomes closer to the composition of the fresh syngas.

The DME molar fraction in exiting reactor stream increases with increasing reactor pressures (Fig. A1). This is augmented by less inert gas dilution due to the decreased amount of unconverted syngas recycled. Both these effects give a DME yield increment. At the same time the mass flow at the reactor outlet decreases when the pressure increases because of a inlet reactor flow decrement.

The combined effects of these factors give a DME production increment with reaction pressure at pressures lower than 100 bar, while the DME production begins to decrease with reaction pressure at higher pressures. 

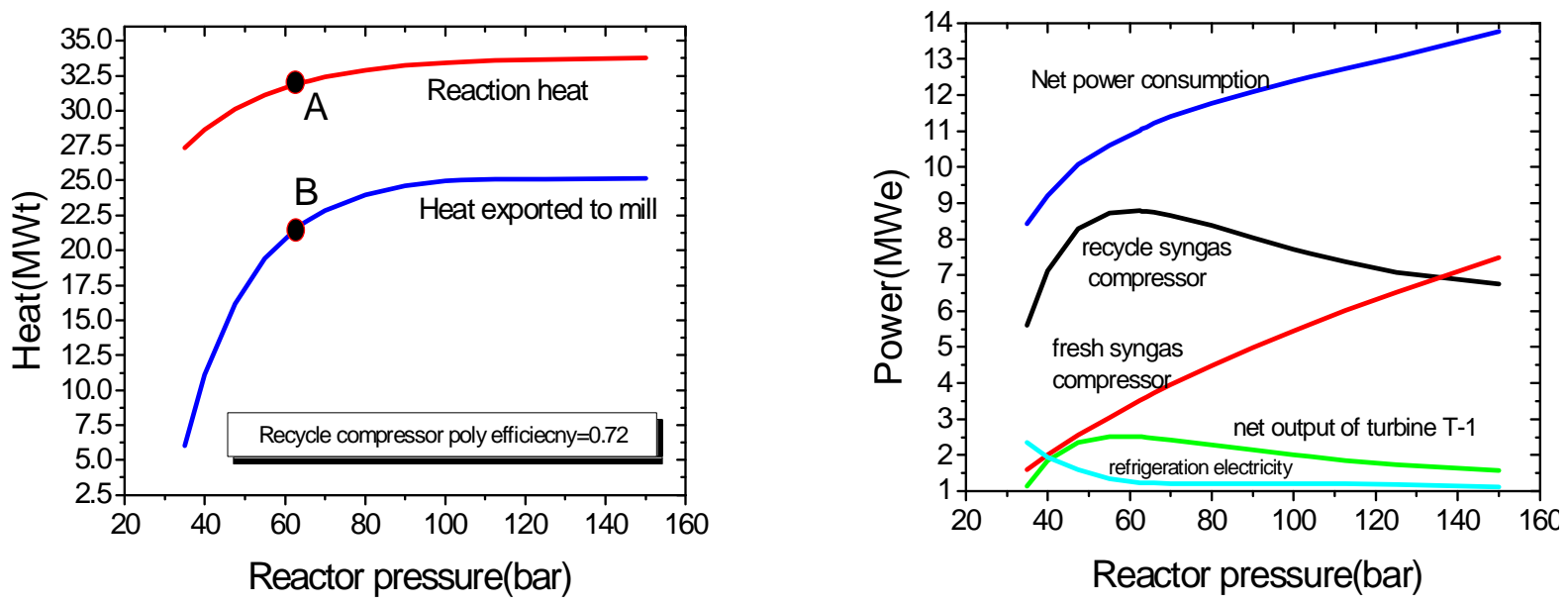

Fig. A2. Effect of reactor pressure variation on heat released in reaction, on heat exported to mill and on electricity consumed and generated by the DME synthesis island. The unconverted recycle ratio is fixed at 0.97 . Point $A$ and point $B$ show the pressure adopted in this study (62.5 bar).

With increasing pressure, the $\mathrm{CO}+\mathrm{H}_{2}$ molar fraction in the unconverted gas decreases, which reduces the heating value of the purge gas. At pressures higher than 100 bar, this decrement is minor.

Synthesis reactions are favored by higher reaction pressure, thus more reaction heat is produced as pressure increases (Fig. A2). Moreover, the steam usage in the DME synthesis section decreases with pressure, so that increasing amounts of export steam are available for other uses (e.g., export to the mill) as pressure increases (Fig. A2). But at pressures higher than 100 bar this increment becomes negligible.

The fresh syngas compressor power consumption increases with reaction pressure (Fig. A2, right). With syngas recycle, the recycle compressor pressure ratio increases with the reaction pressure but, at the same time, the flow of gas recycled back to the reactor decreases for a fixed unconverted gas recycle ratio. These two factors lead to an increase in power consumption of the recycle compressor when reactor pressure increases up to about $60 \mathrm{bar}$, and to a decrease at pressures higher then 60 bar. The total compressor power consumption (considering both the fresh feed and recycle compressors) increases continuously with increasing reaction pressure.

In summary, when reaction pressures are varied from 35bar-150bar:

- the maximum DME mass flow production can be achieved at around 100 bar,

- the DME yield variation is about $0.01 \mathrm{~kg} / \mathrm{s} / \mathrm{bar}$,

- at reaction pressures higher than 100 bar, the heat available for export from the synthesis reactor and the purge gas energy content changes very little,

- total compressor work increases steadily with increasing pressure.

From the results above, a suitable pressure range for the DME synthesis reactor is $60-80$ bar.

\section{A.1.4.2 Effect of unconverted gas recycle}

The recycle of a fraction of the unconverted gas to the reactor can be changed to increase the ratio of DME output to purge gas energy

The recycle ratio $(\mathrm{R})$ is defined as the portion of the unconverted gas recycled back to the reactor. 
By increasing $\mathrm{R}$, an increase of DME production is achieved. But at $\mathrm{R}$ higher than 0.97, this effect becomes very trivial. Moreover, a purge gas flow taken from the recycle loop is necessary to prevent an excessive built-up of inert gases. For these reasons, the recycle ratio selected in DMEa and DMEb cases is 0.97 .

The Fig. A3 shows the relation between $\mathrm{R}$ and $\mathrm{Rf}$, and the values adopted in this study (point A). The figures A4, A5 and A6 show the effects of Rf change.

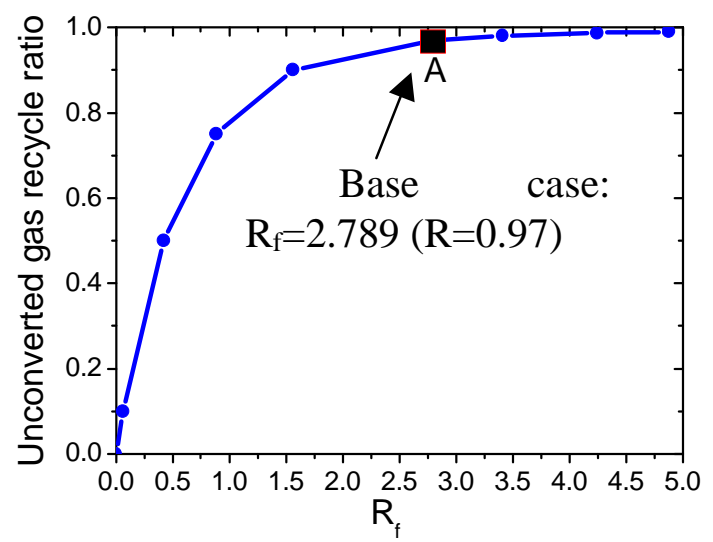

Fig. A3. The unconverted gas recycle ratio is the fraction of unconverted syngas recycled back to reactor. This value determines the unconverted recycled gas-to-fresh gas ratio (Rf). Point $A$ shows the value of $\mathrm{Rf}$ adopted in this study $(2.79$, given by a recycle ratio of 0.97$)$.
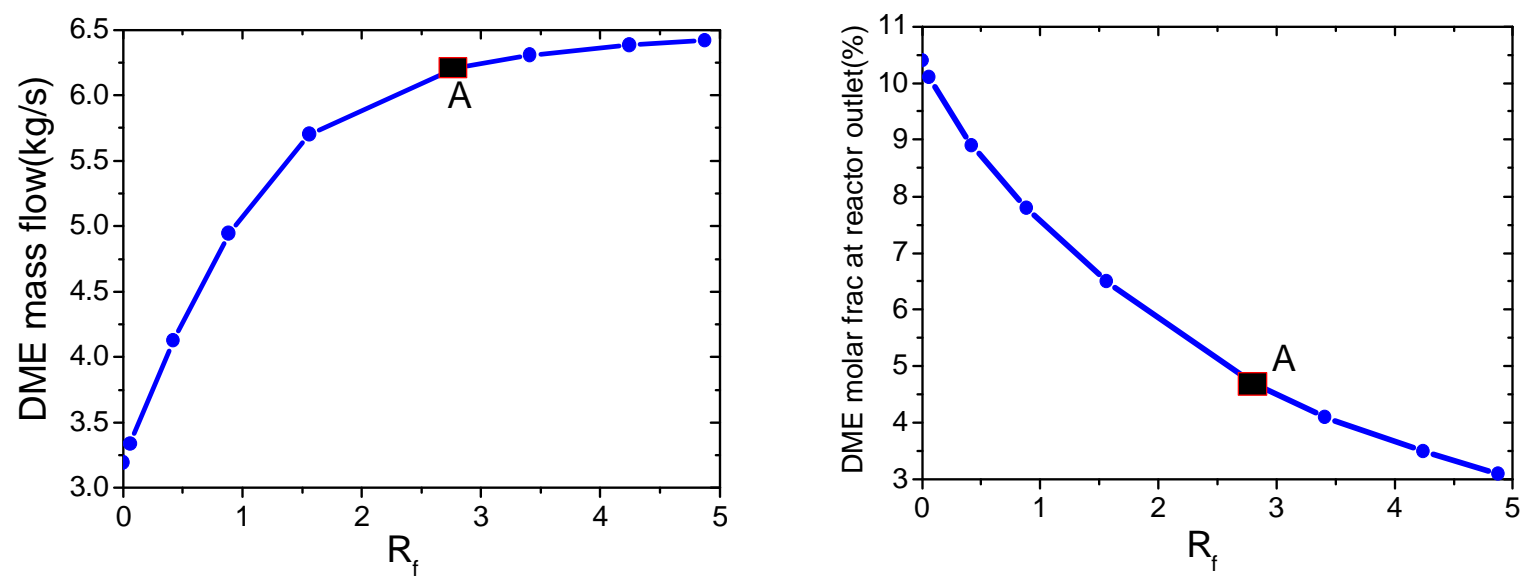

Fig. A4. Effect of unconverted recycled gas-to-fresh gas ratio (Rf) on DME production and on DME molar fraction at reactor outlet. The reactor pressure is fixed at 62.5 bar. Point A shows the value of $\mathrm{Rf}$ adopted in this study (2.79, given by a recycle ratio of 0.97$)$. 


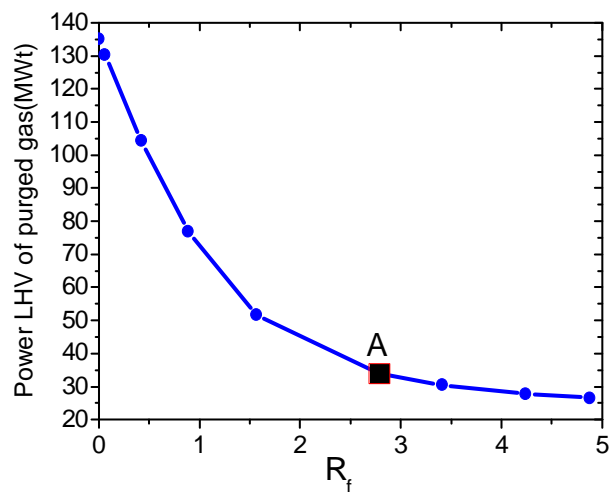

Fig. A5. Effect of unconverted recycled gas-to-fresh gas ratio (Rf) on purged gas energy content. The reactor pressure is fixed at $\mathbf{6 2 . 5}$ bar. Point A shows the values of Rf adopted in this study $(2.79$, given by a recycle ratio of 0.97$)$.
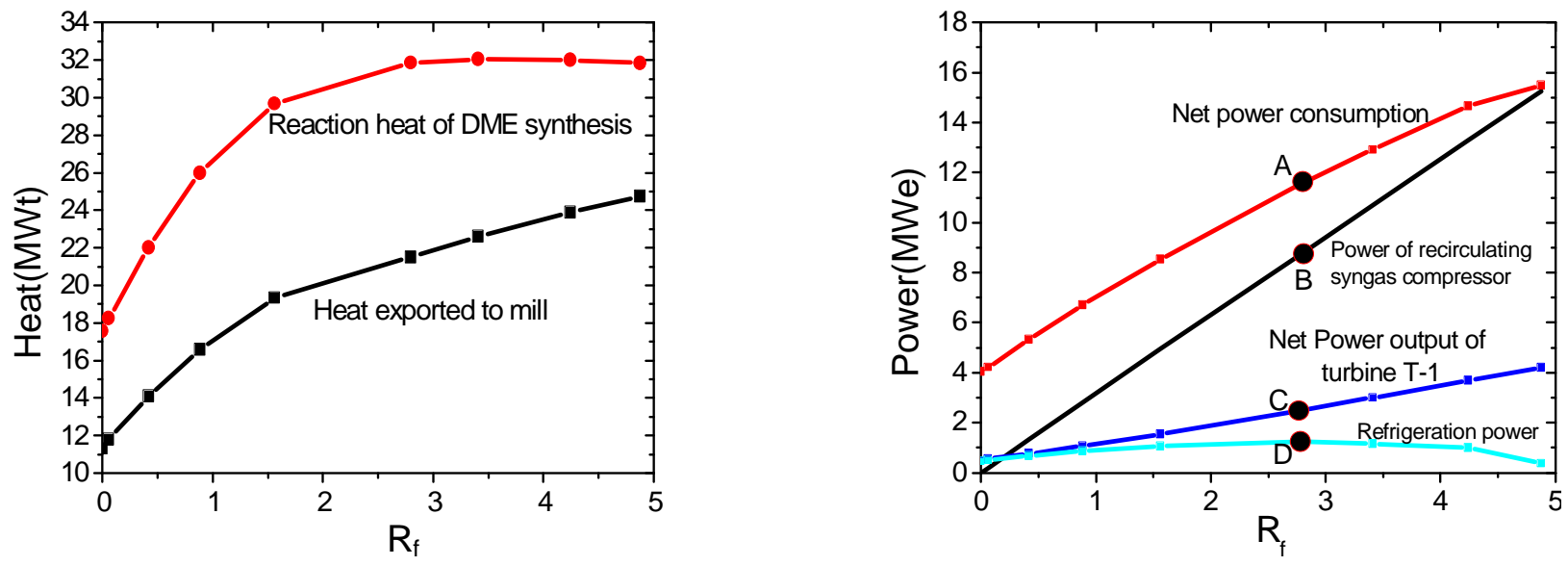

Fig. A6. Effect of unconverted recycled gas-to-fresh gas ratio (Rf) on heat released in reaction, on heat exported from the synthesis island for other uses (e.g., for the mill) and on electricity consumed and generated by the DME synthesis island. The reactor pressure is fixed at 62.5 bar. Points A, B, C, D show the value of $\mathrm{Rf}$ adopted in this study $(2.79$, given by a recycle ratio of 0.97$)$.

The power consumption of the recycle gas compressor increases almost linearly with increasing recycle ratio. Also the reaction heat increases when the recycle ratio increases, but at high recycle ratio the variation becomes small.

In summary, at recycle ratio higher then 0.97 :

- the DME yield increases only slowly,

- the purge gas energy content decreases, and

- heat export from, and power consumption in, the synthesis section increase.

From these results, the most suitable unconverted gas recycle ratio is about 0.97 . 


\section{A.2 FT synthesis}

\section{A.2.1 Kinetics equations}

The reactions considered in the FT reactor are:

$$
\begin{aligned}
& \mathrm{CO}+\mathrm{H}_{2} \mathrm{O} \Leftrightarrow \mathrm{CO}_{2}+\mathrm{H}_{2} \\
& \mathrm{CO}+3 \mathrm{H}_{2} \Leftrightarrow \mathrm{CH}_{4}+\mathrm{H}_{2} \mathrm{O} \\
& a_{1} \mathrm{CO}+\left(2 a_{1}+1\right) \mathrm{H}_{2} \Leftrightarrow \mathrm{C}_{a_{1}} \mathrm{H}_{2 a_{1}+2}+a_{1} \mathrm{H}_{2} \mathrm{O}\left(a_{1} \text { is between } 2 \text { to } 4\right) \\
& a_{2} \mathrm{CO}+\left(2 a_{2}+1\right) \mathrm{H}_{2} \Leftrightarrow \mathrm{C}_{a_{2}} \mathrm{H}_{2 a_{2}+2}+a_{2} \mathrm{H}_{2} \mathrm{O}\left(a_{2} \text { is between } 5 \text { to } 11\right) \\
& a_{3} \mathrm{CO}+\left(2 a_{3}+1\right) \mathrm{H}_{2} \Leftrightarrow \mathrm{C}_{a_{3}} \mathrm{H}_{2 a_{3}+2}+a_{3} \mathrm{H}_{2} \mathrm{O}\left(a_{3} \text { is between } 12 \text { to } 18\right) \\
& a_{4} \mathrm{CO}+\left(2 a_{4}+1\right) \mathrm{H}_{2} \Leftrightarrow \mathrm{C}_{a_{4}} \mathrm{H}_{2 a_{4}+2}+a_{4} \mathrm{H}_{2} \mathrm{O}\left(a_{4} \text { is } 19 \text { or above }\right) \\
& b_{1} \mathrm{CO}+2 b_{1} \mathrm{H}_{2} \Leftrightarrow \mathrm{C}_{b_{1}} \mathrm{H}_{2 b_{1}}+b_{1} \mathrm{H}_{2} \mathrm{O} \quad\left(b_{1} \text { is between } 2 \text { to } 4\right) \\
& b_{2} \mathrm{CO}+2 b_{2} \mathrm{H}_{2} \Leftrightarrow \mathrm{C}_{b_{2}} \mathrm{H}_{2 b_{2}}+b_{2} \mathrm{H}_{2} \mathrm{O} \quad\left(b_{2} \text { is between } 5 \text { to } 11\right) \\
& b_{3} \mathrm{CO}+2 b_{3} \mathrm{H}_{2} \Leftrightarrow \mathrm{C}_{b_{3}} \mathrm{H}_{2 b_{3}}+b_{3} \mathrm{H}_{2} \mathrm{O} \quad\left(b_{3} \text { is between } 12 \text { to } 18\right) \\
& b_{4} \mathrm{CO}+2 b_{4} \mathrm{H}_{2} \Leftrightarrow \mathrm{C}_{b_{4}} H_{2 b_{4}}+b_{4} \mathrm{H}_{2} \mathrm{O} \quad\left(b_{4} \text { is } 19 \text { or above }\right)
\end{aligned}
$$

The following are expressions used to determine reaction rates:

- methane

$$
R_{C H_{4}}=k_{H C 5} p_{H_{2}} \frac{\left(\frac{k_{H C 1} p_{c o}}{k_{H C 1} p_{c o}+k_{H C 5} p_{H_{2}}}\right)}{1+\left(\frac{k_{H C 1} p_{c o}}{k_{H C 1} p_{c o}+k_{H C 5} p_{H_{2}}}\right) \frac{1}{1-\alpha}}
$$

- $\mathrm{C}_{2}-\mathrm{C}_{4}$ (light gases)

$$
R_{C_{n} H_{2 n}}=\sum_{i=2}^{4}\left(\left(k_{H C 6} \frac{\left(\frac{k_{H C 1} p_{c o}}{k_{H C 1} p_{c o}+k_{H C 5} p_{H_{2}}}\right) \alpha^{n-1}}{1+\left(\frac{k_{H C 1} p_{c o}}{k_{H C 1} p_{c o}+k_{H C 5} p_{H_{2}}}\right) \frac{1}{1-\alpha}}\right) \times \frac{i}{n}\right)
$$

$n$ is a number between 2 to 4 .

If we define the fraction of olefins for $C_{2}-C_{4}$ as $f O_{2-4}$, the general reaction rate for paraffins is:

$$
R_{C_{n} H_{2 n+2}}=R_{C_{n} H_{2 n}}\left(1-f O_{2-4}\right) / f O_{2-4} .
$$

- $\mathrm{C}_{5}-\mathrm{C}_{11}$ (FT gasoline) 
Similarly, for $\mathrm{C}_{5}-\mathrm{C}_{11} \mathrm{FT}$ gasoline, the general reaction rate for olefins is:

$$
R_{C_{n} H_{2 n}}=\sum_{i=5}^{11}\left(\left(k_{H C 6} \frac{\left(\frac{k_{H C 1} p_{c o}}{k_{H C 1} p_{c o}+k_{H C 5} p_{H_{2}}}\right) \alpha^{n-1}}{1+\left(\frac{k_{H C 1} p_{c o}}{k_{H C 1} p_{c o}+k_{H C 5} p_{H_{2}}}\right) \frac{1}{1-\alpha}}\right) \times \frac{i}{n}\right)
$$

$n$ is a number between 5 to 11 .

If we define the fraction of olefins for $C_{5}-C_{11}$ as $f O_{5-11}$, the general reaction rate for paraffins is:

$$
R_{C_{n} H_{2 n+2}}=R_{C_{n} H_{2 n}}\left(1-f O_{5-11}\right) / f O_{5-11} .
$$

- $\quad \mathrm{C}_{12}-\mathrm{C}_{18}(\mathrm{FT}$ diesel)

$$
R_{C_{n} H_{2 n}}=\sum_{i=12}^{18}\left(\left(k_{H C 6} \frac{\left(\frac{k_{H C 1} p_{c o}}{k_{H C 1} p_{c o}+k_{H C 5} p_{H_{2}}}\right) \alpha^{n-1}}{1+\left(\frac{k_{H C 1} p_{c o}}{k_{H C 1} p_{c o}+k_{H C 5} p_{H_{2}}}\right) \frac{1}{1-\alpha}}\right) \times \frac{i}{n}\right)
$$

$n$ is a number between 12 to 18 .

Is we define the fraction of olefins for $C_{12}-C_{18}$ as $f O_{12-18}$, the general reaction rate for paraffins is:

$$
R_{C_{n} H_{2 n+2}}=R_{C_{n} H_{2 n}}\left(1-f O_{12-18}\right) / f O_{12-18} .
$$

- $\mathrm{C}_{19+}($ wax $)$

$$
R_{C_{n} H_{2 n}}=\sum_{i=19}^{100}\left(\left(k_{H C 6} \frac{\left(\frac{k_{H C 1} p_{c o}}{k_{H C 1} p_{c o}+k_{H C 5} p_{H_{2}}}\right) \alpha^{n-1}}{1+\left(\frac{k_{H C 1} p_{c o}}{k_{H C 1} p_{c o}+k_{H C 5} p_{H_{2}}}\right) \frac{1}{1-\alpha}}\right) \times \frac{i}{n}\right)
$$

$n$ is a number between 19 to 30 .

If we define the fraction of olefins for $C_{19}+$ as $f_{19+}$, the general reaction rate for paraffin is:

$$
R_{C_{n} H_{2 n+2}}=R_{C_{n} H_{2 n}}\left(1-f O_{19+}\right) / f O_{19+}
$$




\section{A.2.2 Reactor model}

The performance of the reactor is defined by the following material and energy balances: Gas phase:

$$
\begin{aligned}
& F_{i}^{\text {in }}-F_{i}^{\text {out }}=k_{L} \alpha(i) V_{\text {comp }}\left(P_{G, i} / H_{i}-c_{L, i}\right) \\
& k_{L} \alpha(i) V_{\text {comp }}\left(P_{G, i} / H_{i}-c_{L, i}\right)=k_{s} \alpha_{s}\left(C_{G, i} / H_{i}-C_{L, i}\right) \\
& k_{s} \alpha_{s}\left(C_{G, i} / H_{i}-C_{L, i}\right)=\sum W_{\text {cata }} r_{i, j}
\end{aligned}
$$

Accounting for the influence of mass transfer on reaction rates, the above model can be simplified as:

$$
F_{i}^{\text {in }}-F_{i}^{\text {out }}=\sum W_{\text {cata }} r_{i, j}
$$

$r_{i, j}$ stands for the reaction rates of component $i$ in reaction $j$.

The total consumption/formation rates of components considered in FT reaction $\left(\mathrm{CO}, \mathrm{CO}_{2}\right.$, $\mathrm{H}_{2} \mathrm{O}, \mathrm{H}_{2}$ and FT products) are defined as follows:

$$
\begin{aligned}
& r_{C O}=-r_{W G S}-r_{C H 4}-\sum_{i=1}^{4} a_{i} R_{C_{i} H_{2 i+2}}-\sum_{j=1}^{4} b_{j} R_{C_{j} H_{2 j}} \\
& r_{H_{2}}=r_{W G S}-3 r_{C H 4}-\sum_{i=1}^{4}\left(2 a_{i}+1\right) R_{C_{i} H_{2 i+2}}-\sum_{j=1}^{4} 2 b_{j} R_{C_{j} H_{2 j}} \\
& r_{\mathrm{CO}_{2}}=r_{W G S} \\
& r_{\mathrm{H}_{2} \mathrm{O}}=-r_{W G S}+r_{\mathrm{CH} 4}+\sum_{i=1}^{4} a_{i} R_{C_{i} H_{2 i+2}}+\sum_{j=1}^{4} b_{j} R_{C_{j} H_{2 j}}
\end{aligned}
$$




\section{APPENDIX B: KINETIC MODEL FOR MIXED ALCOHOL SYNTHESIS ${ }^{14}$}

\section{B.1 Model development and preliminary results}

\section{B.1.1 Introduction}

It has been known for many decades that mixtures of methanol and higher alcohols (i.e. long chain alcohols) could be used directly as fuel, as fuel additives for octane or cetane enhancement, or as oxygenate fuel additives for environmental reasons [1 - 4 and references therein]. In the '90s, the abrupt development of MTBE demand and the prognoses for a mid-term shortage of oil-derived isobutene has led to a renewed interest in the synthesis, particularly over methanol-modified synthesis catalysts which lead to the production of mainly methanol and isobutanol. The consecutive dehydration of isobutanol to isobutene, the precursor of MTBE along with methanol, is state of the art: in this way, a syngas route to MTBE would be accessible [3]. However to date the synthesis of higher alcohols, particularly of isobutanol, still suffers from poor selectivity, so that the synthesis of methanol and Fischer-Tropsch liquid fuels are preferably considered nowadays as a way of exploitation the huge reserves of natural gas located in remote areas, via syngas production (Gas-to-liquid, GTL).

Catalysts used for the production of higher alcohols from synthesis gas (mixtures of CO and $\mathrm{H} 2$ ) can be divided into four categories [2,5 and references therein]. The first one is based on a soluble Ru complex used as an homogeneous catalyst. The second one can be described as modified methanol catalysts (e.g. alkali-doped $\mathrm{ZnO} /$ chromia or $\mathrm{Cu}$-based catalysts). The third category of catalysts comprises mixed-metal Fischer-Tropsch catalysts (e.g. Co and $\mathrm{Fe}$ on a support). Finally, the last category includes alkali-promoted MoS2 catalysts.

Among the various catalysts, Mo-based systems are the catalysts of choice in the case of S-containing feed due to their high tolerance for sulfur compounds. They also show high activity in the water-gas shift reaction and high activity and selectivity for linear alcohols. The last characteristic is important in view of the fact that there are several possible reactions between $\mathrm{CO}$ and $\mathrm{H}_{2}$, that are thermodynamically competitive to the synthesis of higher alcohols. In particular, the formation of hydrocarbons ( $\alpha$-olefins and n-paraffins) from $\mathrm{CO}$ and $\mathrm{H}_{2}$ is thermodynamically favored with respect to the formation of higher alcohols (i.e. Keq of hydrocarbons are higher than Keq of alcohols) [1]. For this reason, for the higher alcohols synthesis, the usage of an highly selective catalysts is necessary to guide the process selectivity toward alcohols.

\section{B.1.2 Scope of the work}

The scope of this work is to build a Fortran code able to estimate, given a set of process conditions (temperature, pressure, feed composition), the rates of formation of the main products (i.e. methanol, ethanol, propanol, methane, carbon dioxide and water) involved in the higher alcohols synthesis over a Mo-based catalyst.

For this reason we first selected, based on literature indications, a set of rate expressions describing the kinetic behavior of the species involved in the mechanism of formation of the higher alcohols; based on such rate equations, we then constructed a Fortran code able to estimate directly the $\mathrm{CO}$ conversion and alcohols productivity given a set of process conditions.

${ }^{14}$ Authors: Prof. Enrico Tronconi, Prof. Luca Lietti, Eng. Zuzana Vallusova, Eng. Carlo Giorgio Visconti. Milano, July 2006 


\section{B.1.3 Development of the kinetic model}

In a paper recently published by Gunturu et al. [6] a C-supported, K-promoted Co-Mo sulfide catalyst (Mo-Co-K/C) was used to study the kinetics of the synthesis of methanol and higher alcohols from syngas. The content of Mo in the catalyst was $18 \mathrm{wt} \%$, the molar ratio of $\mathrm{K} / \mathrm{Mo}$ was equal to 1.3 and the ratio of $\mathrm{Co} / \mathrm{Mo}$ was 0.34 . The catalyst was tested in a gradientless Berty reactor, which was used as an internal recycle reactor. The kinetic runs were performed in the temperature range of $300-350^{\circ} \mathrm{C}$, at the total pressure of $40.8-68.1$ atm (400-1000 psig) with a $\mathrm{CO} / \mathrm{H}_{2}$ feed ratio ranging from 0.5 to 2 . All the experiments were performed at a fixed gas hourly space velocity (GHSV) of $9000 \mathrm{~L} / \mathrm{h} / \mathrm{kgcatalyst}$.

The article provides detailed experimental data for the whole set of higher alcohols synthesis kinetic runs. The results of the related kinetic study, including rate expressions and kinetic parameter estimates, are also published.

Accordingly, the kinetic model reported in [6] has been herein adopted as a starting point for the purposes of the present work. In the following we describe its structure, its implementation in a computer code, and its validation against data from other literature sources. below.

The adopted simplified reaction scheme for the synthesis of higher alcohols is shown

$$
\begin{aligned}
& \mathrm{CO}+2 \mathrm{H}_{2} \leftrightarrow \mathrm{CH}_{3} \mathrm{OH} \\
& \mathrm{CH}_{3} \mathrm{OH}+\mathrm{H}_{2} \rightarrow \mathrm{CH}_{4}+\mathrm{H}_{2} \mathrm{O} \\
& \mathrm{CH}_{3} \mathrm{OH}+\mathrm{CO}+2 \mathrm{H}_{2} \rightarrow \mathrm{C}_{2} \mathrm{H}_{5} \mathrm{OH}+\mathrm{H}_{2} \mathrm{O} \\
& \mathrm{C}_{2} \mathrm{H}_{5} \mathrm{OH}+\mathrm{CO}+2 \mathrm{H}_{2} \rightarrow \mathrm{C}_{3} \mathrm{H}_{7} \mathrm{OH}+\mathrm{H}_{2} \mathrm{O} \\
& \mathrm{CO}+\mathrm{H}_{2} \mathrm{O} \leftrightarrow \mathrm{CO}_{2}+\mathrm{H}_{2}
\end{aligned}
$$

In this lumped reaction scheme, the production of methanol from $\mathrm{CO}$ and $\mathrm{H}_{2}$, reaction (B1), is regarded as reversible, and limited by chemical equilibrium. Further, it is assumed that all the hydrocarbon products are produced from methanol and are composed exclusively by methane, reaction (B2). The formation of ethanol, reaction (B3), and the formation of propanol, reaction (B4), proceed by reaction of $\mathrm{CO} / \mathrm{H}_{2}$ with methanol and with ethanol, respectively, according to a consecutive scheme. The water-gas shift reaction, reaction (B5), which accounts for $\mathrm{CO}_{2}$ formation, is assumed to be always in thermodynamic equilibrium.

Alcohols of carbon number higher than three (C4+ alcohols) are formed in quantities small enough to be neglected for present purposes ( $\mathrm{C} 4+$ carbon selectivity < 4\% [7]). In addition, all the formed ethers (dimethyl ether, diethyl ether) and other oxygenates not explicitly identified as alcohols were lumped into the methane (hydrocarbon) fraction.

The equation for the calculation of the gross rate of formation of methanol published in [6] contained some mistakes, possibly due to misprints. So we corrected this equation into the following form:

$$
r_{C H 3 O H}^{\text {gross }}=\frac{A_{m} e^{-(E m / R)(1 / T-1 / T c p)}\left(\left[\frac{p_{c o}}{p_{c o}^{c p}}\right]\left[\frac{p_{H 2}}{p_{H 2}^{c p}}\right]^{2}-\frac{1}{K_{e q}}\left[\frac{p_{C H 3 O H}}{p_{C H 3 O H}^{c p}}\right]\right)}{\left(1+K_{1}\left[\frac{p_{c o}}{p_{c o}^{c p}}\right]+K_{2}\left[\frac{p_{H 2}}{p_{H 2}^{c p}}\right]+K_{3}\left[\frac{p_{C H 3 O H}}{p_{C H 3 O H}^{c p}}\right]\right)^{n m}}
$$

with 


$$
\begin{aligned}
& K_{e q}=K_{a} /\left(K_{z} K^{C P}\right) \\
& K^{C P}=\frac{p_{C H 3 O H}^{C P}}{p_{C O}^{C P}\left(p_{H 2}^{C P}\right)^{2}}
\end{aligned}
$$

where ri gross is the rate of formation of species $\mathrm{i}$ in $\mathrm{kmol} / \mathrm{h} / \mathrm{kgcat}$ and $\mathrm{p}$ are the partial pressures of the reactants measured in atm. Tcp is the temperature and pcp is the partial pressure of the center-point experiment $(\mathrm{Tcp}=598 \mathrm{~K}, \mathrm{pcp}=47.6 \mathrm{~atm}), \mathrm{Em}$ is activation energy for methanol formation, $\mathrm{R}$ is the ideal gas constant, the parameters $\mathrm{K} 1, \mathrm{~K} 2$ and $\mathrm{K} 3$ are adsorption coefficients, $\mathrm{Keq}$ is nondimensional equilibrium constant and $\mathrm{Ka}$ is equilibrium constant in $\mathrm{kPa}-2$. This experiment performed under $\mathrm{CP}$ conditions was replicated after every four runs made at different conditions. $\mathrm{KCP}$ is the nondimensionalizing term represented by the ratio of the partial pressures at the central point (equation B8).

The expressions used for the calculation of ethanol, propanol and methane gross rates of formation were used exactly as reported in [6]:

$$
\begin{gathered}
r_{C 2 H 5 O H}^{\text {gross }}=\frac{A_{e} e^{-(E e / R)(1 / T-1 / T c p)}\left[\frac{p_{C H 3 O H}}{p_{C H 3 O H}^{c p}}\right]}{\left(1+K_{e}\left[\frac{p_{C H 3 O H}}{p_{C H 3 O H}^{c p}}\right]\right)^{n_{e}}} \\
r_{C 3 H 7 O H}^{\text {gross }}=\frac{A_{p} e^{-(E p / R)(1 / T-1 / T c p)}\left[\frac{p_{C 2 H 5 O H}}{p_{C 2 H 5 O H}^{c p}}\right]}{\left(1+K_{p}\left[\frac{p_{C 2 H 5 O H}}{p_{C 2 H 5 O H}^{c p}}\right]\right)^{n_{p}}} \\
r_{H C}^{\text {gross }}=\frac{A_{h} e^{-(E h / R)(1 / T-1 / T c p)}\left[\frac{p_{C H 3 O H}}{p_{C H 3 O H}^{c p}}\right]}{\left(1+K_{h}\left[\frac{p_{C H 3 O H}}{p_{C H 3 O H}^{c p}}\right]\right)^{n_{h}}}
\end{gathered}
$$

The net rates (defined as the difference between the gross rates of species i) were obtained as follows:

$$
\begin{aligned}
& r_{\mathrm{CH} 3 \mathrm{OH}}^{\text {net }}=r_{\mathrm{CH} 3 \mathrm{OH}}^{\text {gross }}-r_{\mathrm{C} 2 \mathrm{H} 5 \mathrm{OH}}^{\text {gross }}-r_{\mathrm{HC}}^{\text {gross }} \\
& r_{\mathrm{C} 2 \mathrm{H} 5 \mathrm{OH}}^{\text {net }}=r_{\mathrm{C} 2 \mathrm{H} 5 \mathrm{OH}}^{\text {gross }}-r_{\mathrm{CH} 7 \mathrm{OH}}^{\text {gross }} \\
& r_{\mathrm{C} 3 \mathrm{H} 7 \mathrm{OH}}^{\text {net }}=r_{\mathrm{C} 3 \mathrm{H}}^{\text {gros }} \\
& r_{\mathrm{HC}}^{\text {net }}=r_{\mathrm{HC}}^{\text {gross }}
\end{aligned}
$$

Gunturu et al. used a fugacity correction factor $\mathrm{Kz}=0.3359$ estimated by nonlinear regression.

On the other hand a value of $\mathrm{Kz}$ for the reaction (B1) estimated from the literature [8] at a 
pressure of $54 \mathrm{~atm}$ and temperature of $598 \mathrm{~K}$ is 0.84 . So, in order to use a fugacity correction factor closer to chemical reality we decided to replace $\mathrm{Kz}$ of Gunturu with the new value 0.84.

Using this value of $\mathrm{Kz}$ and the parameter estimates from Gunturu's article, summarized in Table B1, we calculated gross and net rates of formation of methanol, ethanol, propanol and hydrocarbons for all the experimental runs reported in Gunturu's paper.

Table B1. Parameters published in [6] for Methanol, Ethanol, Propanol and Hydrocarbon Synthesis Model $^{\text {a }}$.

\begin{tabular}{llllll}
\hline $\mathrm{A}_{\mathrm{m}}=4.9047$ & $\mathrm{E}_{\mathrm{m}}=117.733$ & $\mathrm{~K}_{\mathrm{l}}=0.0696$ & $\mathrm{~K}_{2}=0.6400$ & $\mathrm{~K}_{3}=0.6940$ & $\mathrm{n}_{\mathrm{m}}=2$ \\
$\mathrm{~K}_{\mathrm{z}}=0.8359$ & & & & \\
$\mathrm{~A}_{\mathrm{e}}=1.5259$ & $\mathrm{E}_{\mathrm{e}}=24.986$ & $\mathrm{~K}_{\mathrm{e}}=0.7367$ & $\mathrm{n}_{\mathrm{e}}=1$ & \\
$\mathrm{~A}_{\mathrm{p}}=0.1101$ & $\mathrm{E}_{\mathrm{p}}=89.943$ & $\mathrm{~K}_{\mathrm{p}}=0.2502$ & $\mathrm{n}_{\mathrm{p}}=1$ & \\
$\mathrm{~A}_{\mathrm{h}}=4.6928$ & $\mathrm{E}_{\mathrm{h}}=95.416$ & $\mathrm{~K}_{\mathrm{h}}=1.2472$ & $\mathrm{n}_{\mathrm{h}}=1$ & \\
\hline
\end{tabular}

${ }^{\mathrm{a}} \mathrm{A}_{\mathrm{m}}, \mathrm{A}_{\mathrm{e}}, \mathrm{A}_{\mathrm{p}}, \mathrm{A}_{\mathrm{h}}\left[\mathrm{mol} / \mathrm{h} / \mathrm{kg}_{\mathrm{cat}}\right], \mathrm{E}_{\mathrm{m}}, \mathrm{E}_{\mathrm{e}}, \mathrm{E}_{\mathrm{p}}, \mathrm{E}_{\mathrm{h}}[\mathrm{kJ} / \mathrm{mol}]$, all other parameters are dimensionless.

A comparison of the calculated and experimental values of the net rates of formation of all the species cited in the Gunturu's article is reported in the parity plots of Figures B1 - B4.

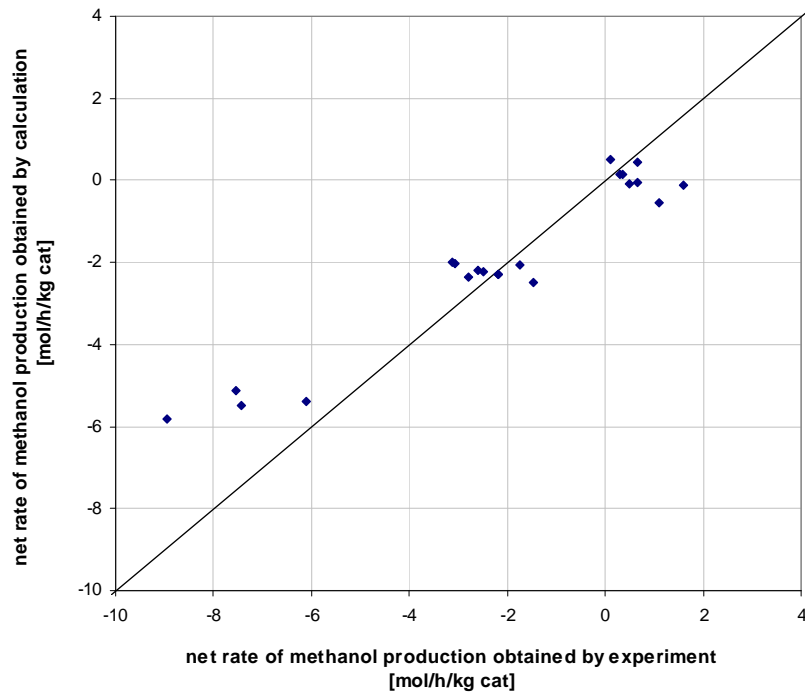

Figure B1. Parity plot for net rates of methanol production.

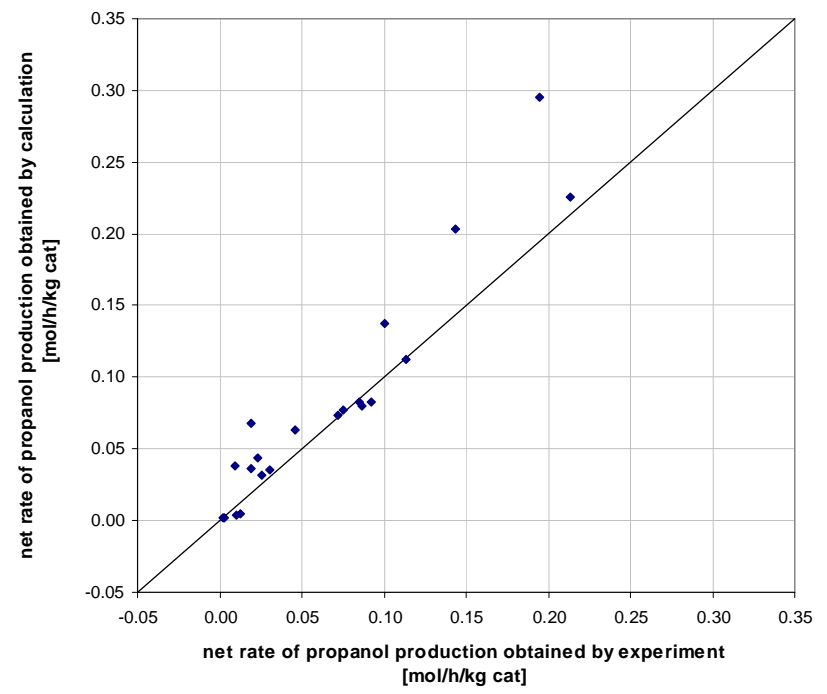

Figure B2. Parity plot for net rates of propanol production. 


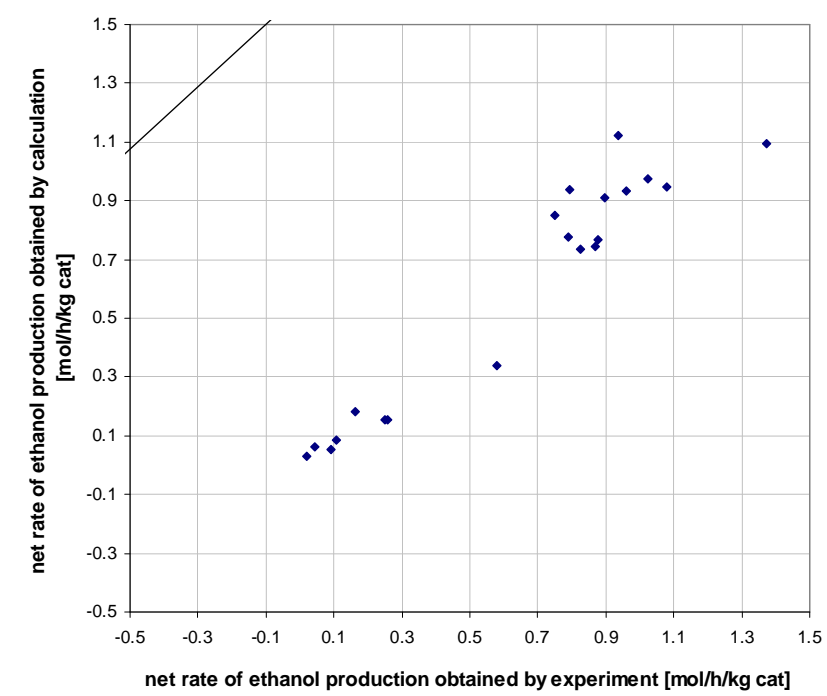

Figure B3. Parity plot for net rates of ethanol production.

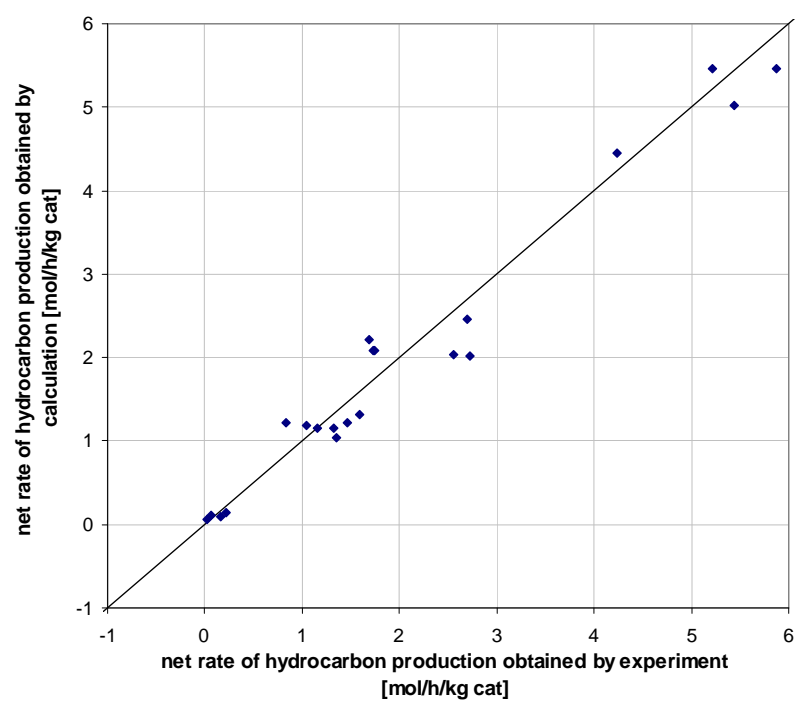

Figure B4. Parity plot for net rates of hydrocarbon production.

Figures B3 and B4 (parity plots for net rates of ethanol and hydrocarbon) are similar to the figures published in [6]. But in the case of figures B1 and B2 (plots for net rates of methanol and propanol) there results were somewhat at variance with those published in [6].

Hence a regression was performed using the experimental data of article [6] in order to obtain improved estimates of the parameters for methanol and propanol gross rates of formation.

We also implemented some additional changes concerning the parameter Ka used in these equations. In fact, in the article the values of the equilibrium constant $\mathrm{Ka}$ were given for the temperatures of 573,598 and $623 \mathrm{~K}$. We have replaced these values with the value of equilibrium constant Ka calculated as a function of temperature from equation B16 [8]. The new parameter estimates are shown in Table B2.

$$
K_{a}=0.99998 * \exp \left[21.225+9143.6 / T-7.492 * \ln T+4.076 E-3 * T-7.161 E-8 * T^{2}\right]
$$

Table B2. Revised parameter estimates for the Methanol and Propanol Synthesis Model ${ }^{\mathrm{a}}$.

\begin{tabular}{llllll}
\hline $\mathrm{A}_{\mathrm{m}}=7.3117$ & $\mathrm{E}_{\mathrm{m}}=143.472$ & $\mathrm{~K}_{1}=7.6393 \mathrm{E}-9$ & $\mathrm{~K}_{2}=0.6785$ & $\mathrm{~K}_{3}=0.9987$ & $\mathrm{n}_{\mathrm{m}}=3$ \\
$\mathrm{~K}_{\mathrm{z}}=0.8359$ & & & & & \\
$\mathrm{~A}_{\mathrm{p}}=0.1074$ & $\mathrm{E}_{\mathrm{p}}=89.3328$ & $\mathrm{~K}_{\mathrm{p}}=0.6086$ & $\mathrm{n}_{\mathrm{p}}=1$ & & \\
\hline
\end{tabular}

${ }^{\mathrm{a}} \mathrm{A}_{\mathrm{m}}, \mathrm{A}_{\mathrm{p}}\left[\mathrm{mol} / \mathrm{h} / \mathrm{kg}_{\mathrm{cat}}\right], \mathrm{E}_{\mathrm{m}}, \mathrm{E}_{\mathrm{p}}[\mathrm{kJ} / \mathrm{mol}]$, all other parameters are dimensionless.

Figures B5 and B6 show the parity plots for methanol and propanol obtained using the revised parameter estimates. 


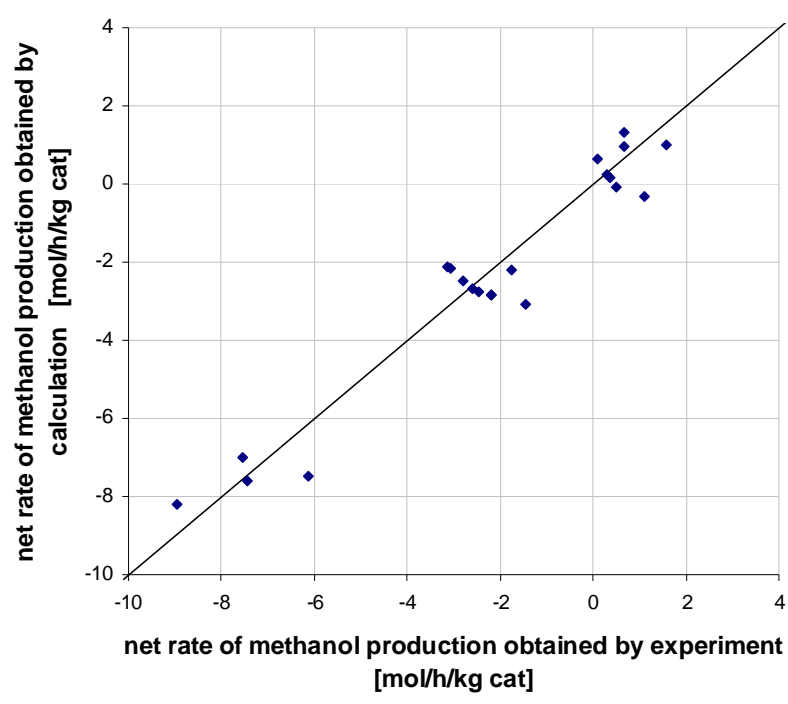

Figure B5. Comparison plot for net rates of methanol production: revised parameters in Table B2.

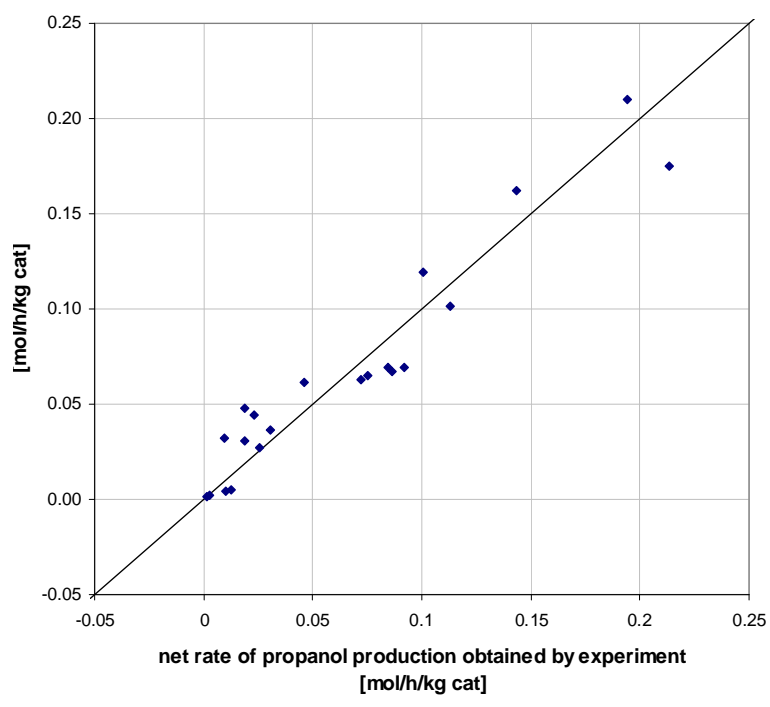

Figure B6. Comparison plot for net rates of propanol production: revised parameters in Table B2.

From these figures we can conclude that the new parameters allow a good fit of the experimental rate data from [6].

\section{B.1.4 Reactor simulation and validation of the kinetic model}

Once obtained "good" estimates of the kinetic parameters for methanol and higher alcohol synthesis, these were used to set up a Fortran program for simulation of the higher alcohols synthesis in ideal reactors. Both the options of perfectly-mixed reactor (CSTR) and plug-flow reactor (PFR) were considered.

The simulation program works with the following input data:

- Inlet flow rates of $\mathrm{CO}, \mathrm{H}_{2}, \mathrm{~N}_{2}$, methanol, ethanol, propanol and methane [kg/h]

- Temperature [K]

- Pressure [atm]

- Mass of catalyst $[\mathrm{kg}]$

- Type of reactor (CSTR or PFR).

The simulation program used the subroutine LSODI [9] to integrate numerically a system of ordinary differential equations (reactor model for PFR case, system (a)) and the subroutine BUNLSI [10] to solve a system of nonlinear algebraic equations (reactor model for CSTR case, system (b)).

System (a): 


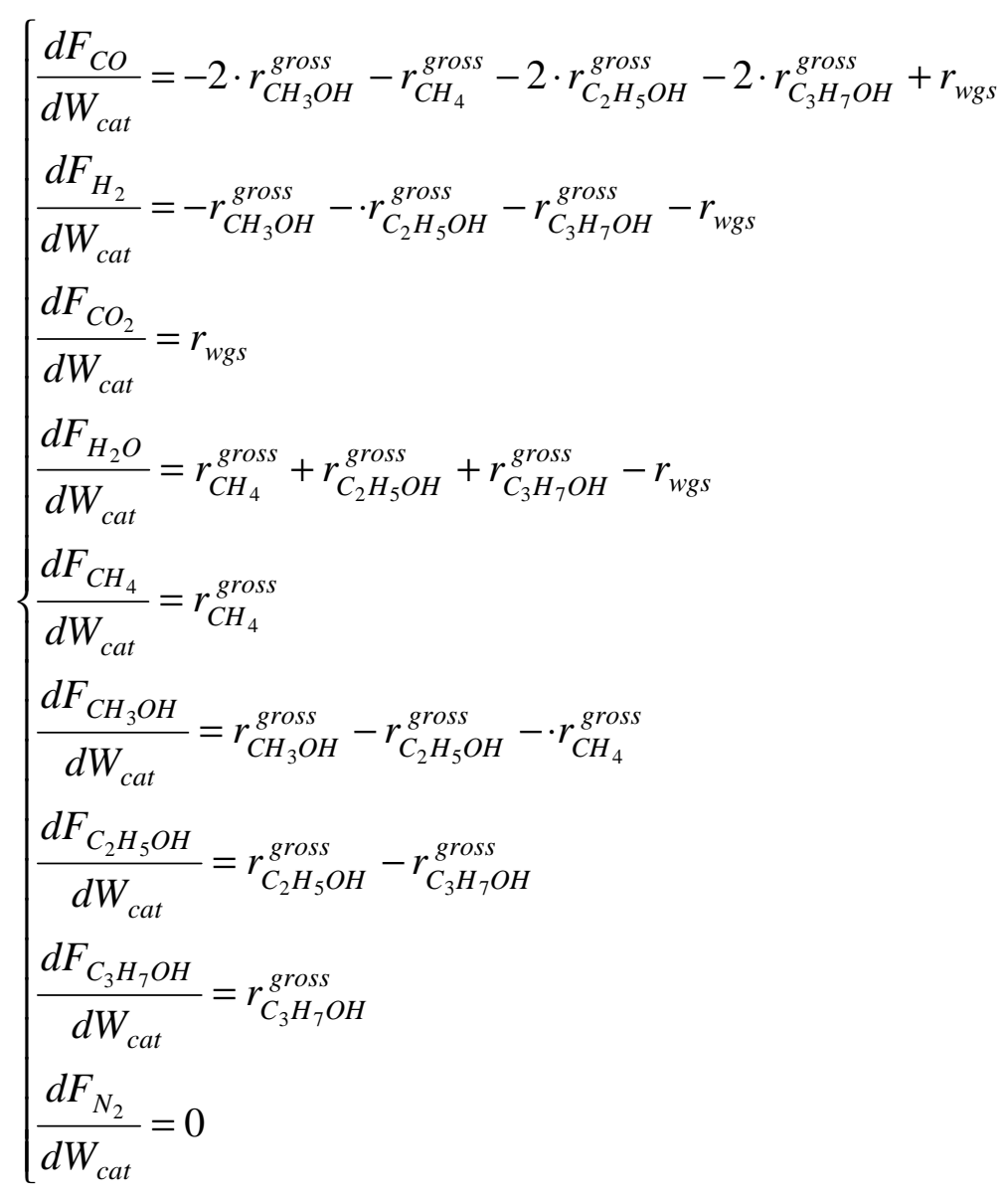

with initial conditions:

$$
\left\{\begin{array}{l}
F_{\mathrm{CO}}\left(\mathrm{W}_{\text {cat }}=0\right)=\mathrm{F}_{\mathrm{CO}}^{\mathrm{IN}} \\
F_{\mathrm{H}_{2}}\left(\mathrm{~W}_{\text {cat }}=0\right)=\mathrm{F}_{\mathrm{H}_{2}}^{\mathrm{IN}} \\
F_{\mathrm{CO}_{2}}\left(\mathrm{~W}_{\text {cat }}=0\right)=\mathrm{F}_{\mathrm{CO}_{2}} \\
F_{\mathrm{H}_{2} O}\left(\mathrm{~W}_{\text {cat }}=0\right)=\mathrm{F}_{\mathrm{H}_{2} O}^{\mathrm{IN}} \\
F_{\mathrm{CH}_{4}}\left(\mathrm{~W}_{\text {cat }}=0\right)=\mathrm{F}_{\mathrm{CH}_{4}}^{\mathrm{IN}} \\
F_{\mathrm{CH}_{3} O H}\left(\mathrm{~W}_{\text {cat }}=0\right)=\mathrm{F}_{\mathrm{C}_{3} O H}^{\mathrm{IN}} \\
F_{\mathrm{C}_{2} H_{5} O H}\left(\mathrm{~W}_{\text {cat }}=0\right)=\mathrm{F}_{\mathrm{C}_{2} H_{5} O H}^{\mathrm{IN}} \\
F_{\mathrm{C}_{3} H_{7} O H}\left(\mathrm{~W}_{\text {cat }}=0\right)=\mathrm{F}_{\mathrm{C}_{3} H_{7} O H}^{\mathrm{IN}} \\
F_{\mathrm{N}_{2}}\left(\mathrm{~W}_{\text {cat }}=0\right)=\mathrm{F}_{\mathrm{N}_{2}}^{\mathrm{IN}}
\end{array}\right.
$$

where $\mathrm{F}^{\mathrm{IN}}{ }_{\mathrm{i}}$ is the feed flow of the generic $\mathrm{i}$-species $[\mathrm{kmol} / \mathrm{h}]$ and $\mathrm{W}_{\text {cat }}$ the mass of catalyst $[\mathrm{kg}]$. 
System (b):

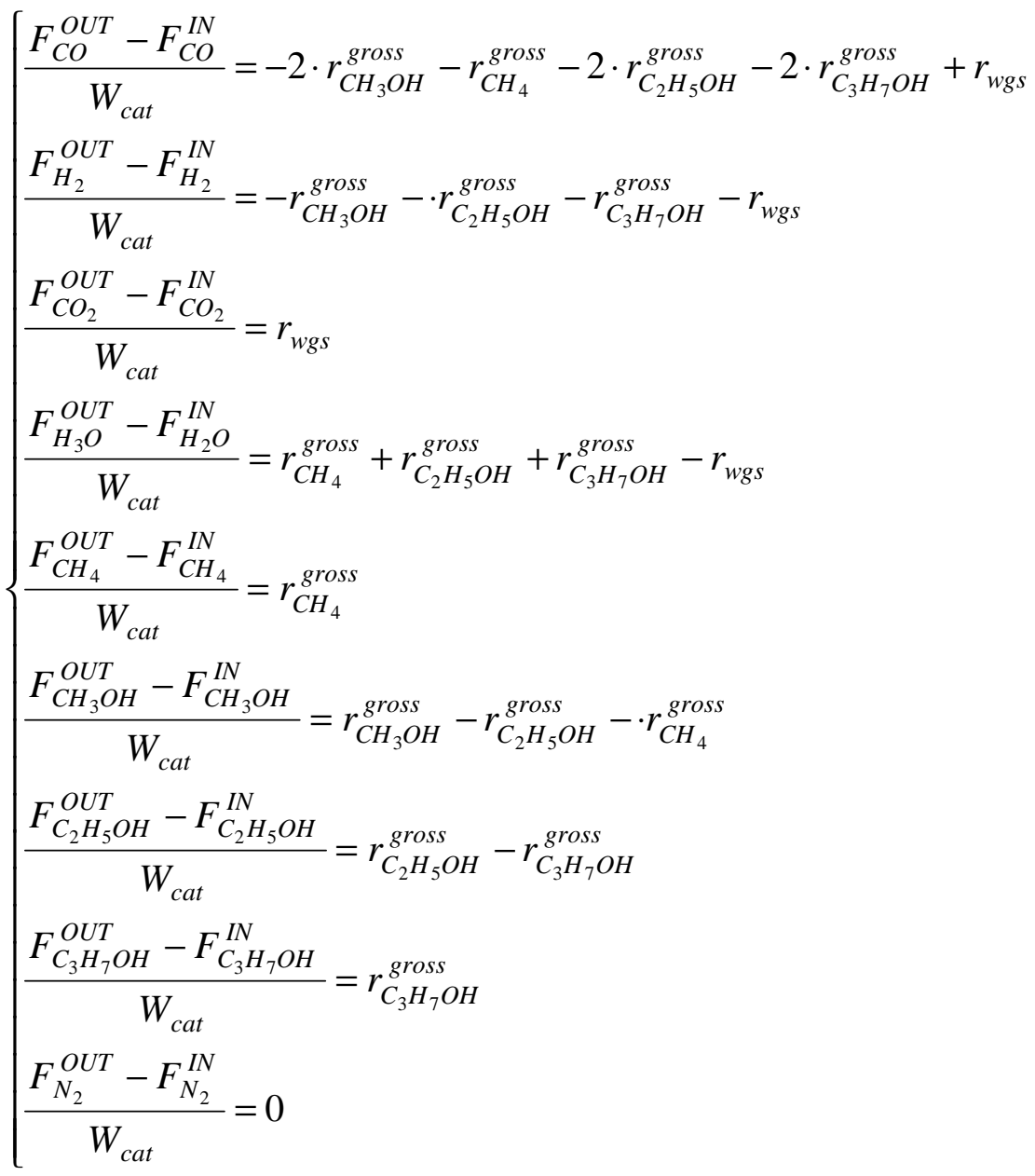

The Fortran code included the system of kinetic equations described above (eq.s B6, B9B11). In addition we inserted the water-gas shift reaction, with rate equation (17), into the model:

$$
r_{w g s}=k_{w g s}\left(p_{\mathrm{CO}} p_{\mathrm{H}_{2} \mathrm{O}}-1 / K_{w e q} p_{\mathrm{CO}_{2}} p_{\mathrm{H}_{2}}\right)
$$

The equilibrium constant for the water gas shift reaction was calculated as a function of temperature according to equation (B18) [11].

$$
K_{w e q}=1 / \exp \left[13.148-5639.5 / T-1.077 * \ln T-5.446 E-4 * T-1.1251 E-7 * T^{2}+49170 / T^{2}\right\rfloor
$$

The rate constant of water gas shift reaction kwgs was arbitrarily assumed to have the value $10000 \mathrm{kmol} / \mathrm{h} / \mathrm{kgcat} / \mathrm{atm} 2$. It was verified, that in both cases (PFR reactor and CSTR reactor) the water-gas shift reaction was essentially at equilibrium under these conditions.

Figure B7 compares the CO conversions calculated using the CSTR (open symbols) and PFR (solid symbols) models with the data of Gunturu [6]. The two experimental data reported in the figure were obtained under the same experimental conditions ( $\mathrm{T}=623 \mathrm{~K}, \mathrm{p}=54 \mathrm{~atm}$, GHSV $=9000 \mathrm{~L} / \mathrm{h} / \mathrm{kgcatalyst}, \mathrm{H} 2 / \mathrm{CO}$ ratio $=1 / 1$, mass of the catalyst $0.5 \mathrm{~g}$ ), with and without the 
addition of methanol in the feed flow (at a flow rate of $0.02 \mathrm{ml} / \mathrm{min}$ ). In both cases, from the parity plot in figure B7 it is clear that the experimental $\mathrm{CO}$ conversion is underestimated by the model. Notably, due to the very limited CO conversions no significant differences are apparent using either the CSTR or the PFR models.

We have attempt to improve the model fit of $\mathrm{CO}$ conversion by multiplying the gross rates by a constant factor equal to 1.5 (triangles) and 2 (circles), respectively.

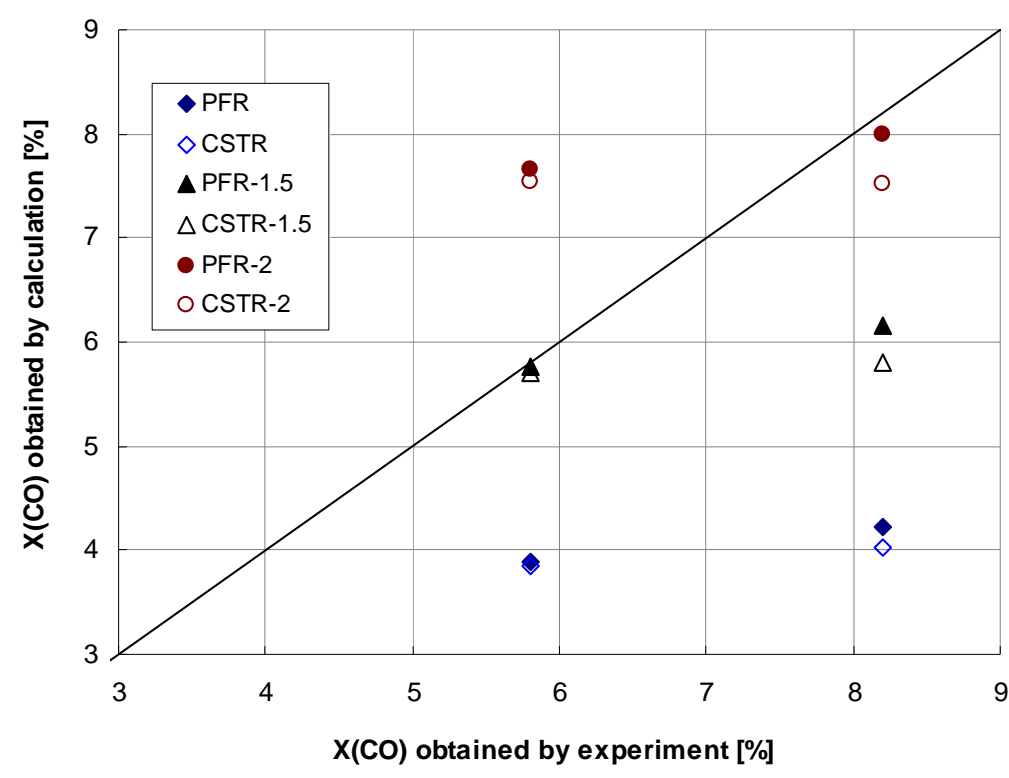

Figure B7. Parity plot for CO conversion - X(CO) of data form Gunturu using the gross rates without modification, the gross rates multiplied by the constant factor equal to 1.5 and 2 , respectively.

Multiplying all the gross rates by 1.5 the fit improved. However it is difficult to evaluate the goodness of our result using the data from Gunturu because only two CO conversion values (out of 21 runs) are available in the paper.

Due to this reason, in order to better verify the validity of our simulation results, we used data from two additional papers, i.e. Li et al. [12] and Yun Park et al. [13].

Li et al. [12] used in his work a series of carbon-supported molybdenum-based catalysts for higher alcohols synthesis from synthesis gas. One of these used catalysts was also a catalyst with the same content of Mo (18 wt. \%), the same ratios of K/Mo (1.3) and Co/Mo (0.34) and prepared in the same way as the catalyst used in [6] (except the way of sulfidation of the catalyst before the catalytic reaction, but also it was similar to Gunturu). Since Li et al. [12] work in the same Department of Gunturu (West Virginia University) it is likely that the same catalyst was used. However $\mathrm{Li}$ et al. tested the catalyst in a stainless-steel tubular reactor, the reaction temperature was varied from 200 to $400{ }^{\circ} \mathrm{C}$, the total pressure was $51 \mathrm{~atm}(750 \mathrm{psig}), \mathrm{CO} / \mathrm{H}_{2}$ ratio was 1/1, GHSV varied from 6 to $21.6 \mathrm{~m} 3 / \mathrm{h} / \mathrm{kg}$ of catalyst (from 267.7 to $963.7 \mathrm{~mol} / \mathrm{h} / \mathrm{kgcat}$ ) and the mass of the catalyst was $0.5 \mathrm{~g}$.

In Figure B8 the results of calculation of $\mathrm{CO}$ conversion for data from $\mathrm{Li}$ et al. [12] for a $\mathrm{PF}$ and a CST reactor model (solid and open symbols, respectively) are compared with the published experimental data. The model clearly underestimated the experimental data. For this reason, as previously done with the data of Gunturu, we multiplied the gross rates by a constant factor equal to 1.5 (figure B9) and 2 (figure B10), respectively. 

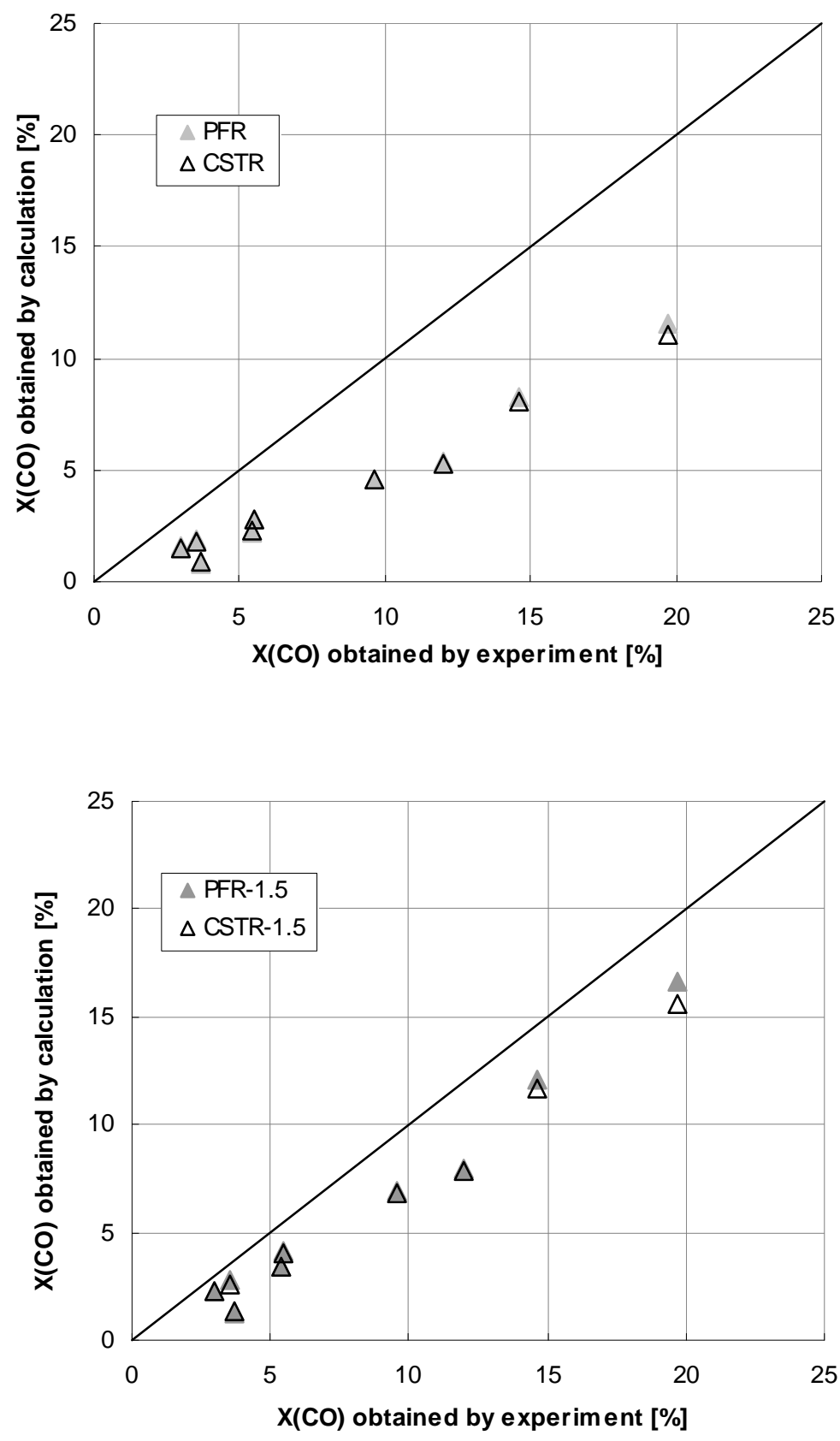

Figure B8. Parity plot for CO conversion - X(CO) calculated for PFR (solid points) and CSTR (open points) reactor on the basis of data from Li (Gunturu catalyst).

Figure B9. Parity plot for CO conversion - X(CO) of data from Li for Gunturu catalyst using the gross rates multiplied by the constant factor 1.5. 


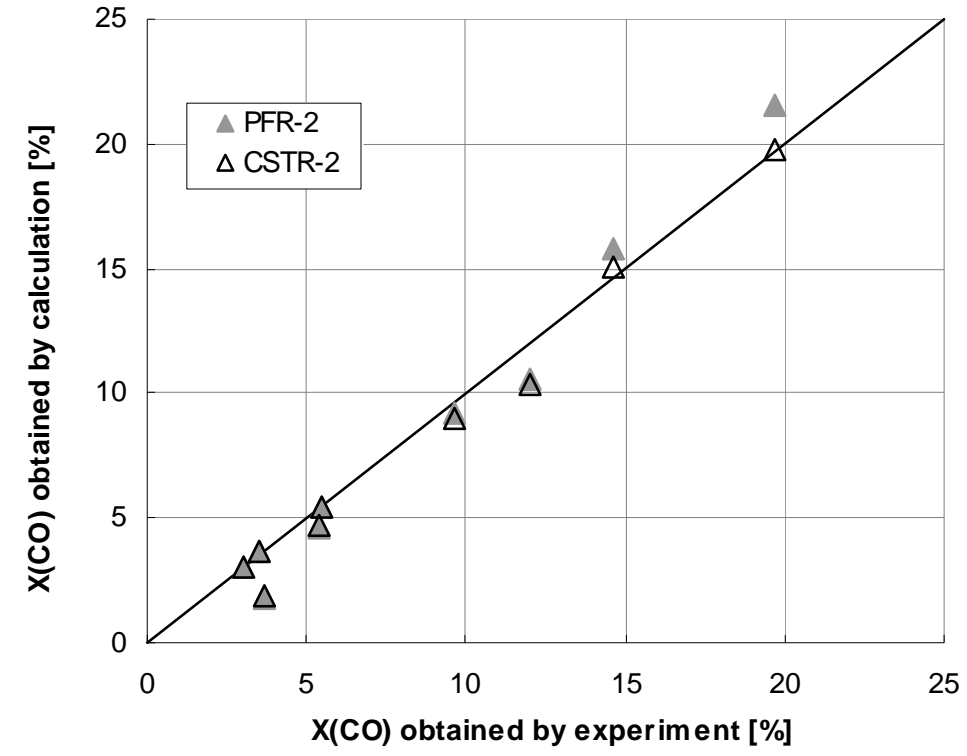

Figure B10. Parity plot for CO conversion - X(CO) of data from $\mathrm{Li}$ for Gunturu catalyst using the gross rates multiplied by the constant factor 2.

The best agreement between experimental and calculated data for both reactor models was obtained multiplying the gross rates by a constant factor equal to 2 (figure B10).

Yun Park et al. [13], on the contrary, used in their study a $\mathrm{K} / \mathrm{MoS}_{2}$ catalyst with a $\mathrm{K}_{2} \mathrm{CO}_{3}$ content of 17 wt. \%. The alcohol synthesis reaction was carried out in a tubular fixed-bed integral reactor.

The reaction temperature was varied in the range $250-350{ }^{\circ} \mathrm{C}$, the total pressure was varied from 15-90 atm, the space time $\mathrm{W} /(\mathrm{FCO}) 0$ or $\tau$ was varied between $4-22 \mathrm{gcat} * \mathrm{~h} / \mathrm{mol}(\mathrm{GHSV}=$ $250-45 \mathrm{~mol} / \mathrm{h} / \mathrm{kgcat}$ ), with the $\mathrm{H} 2 / \mathrm{CO}$ molar feed ratio ranging from 0.5 to 4 and with a catalyst mass of $1.0 \mathrm{~g}$.

In Figure B11 the calculated CO conversion for data from Yun Park [13] for PF and CST reactor models (solid and open symbols, respectively) are compared with the published experimental data. The experimental data, as for the Gunturu [6] and the Li [12] data, are clearly underestimated.

The results obtained by multiplying the gross rates by a factor of 1.5 or 2 are shown in figures B12 and B13, respectively. In this case the best fit was observed using a factor equals to 1.5; however, considering that Yun Park [13] used in his work a different catalyst with respect to Gunturu's and Li's catalyst, the results obtained by using the factor 2 appear also very reasonable. 

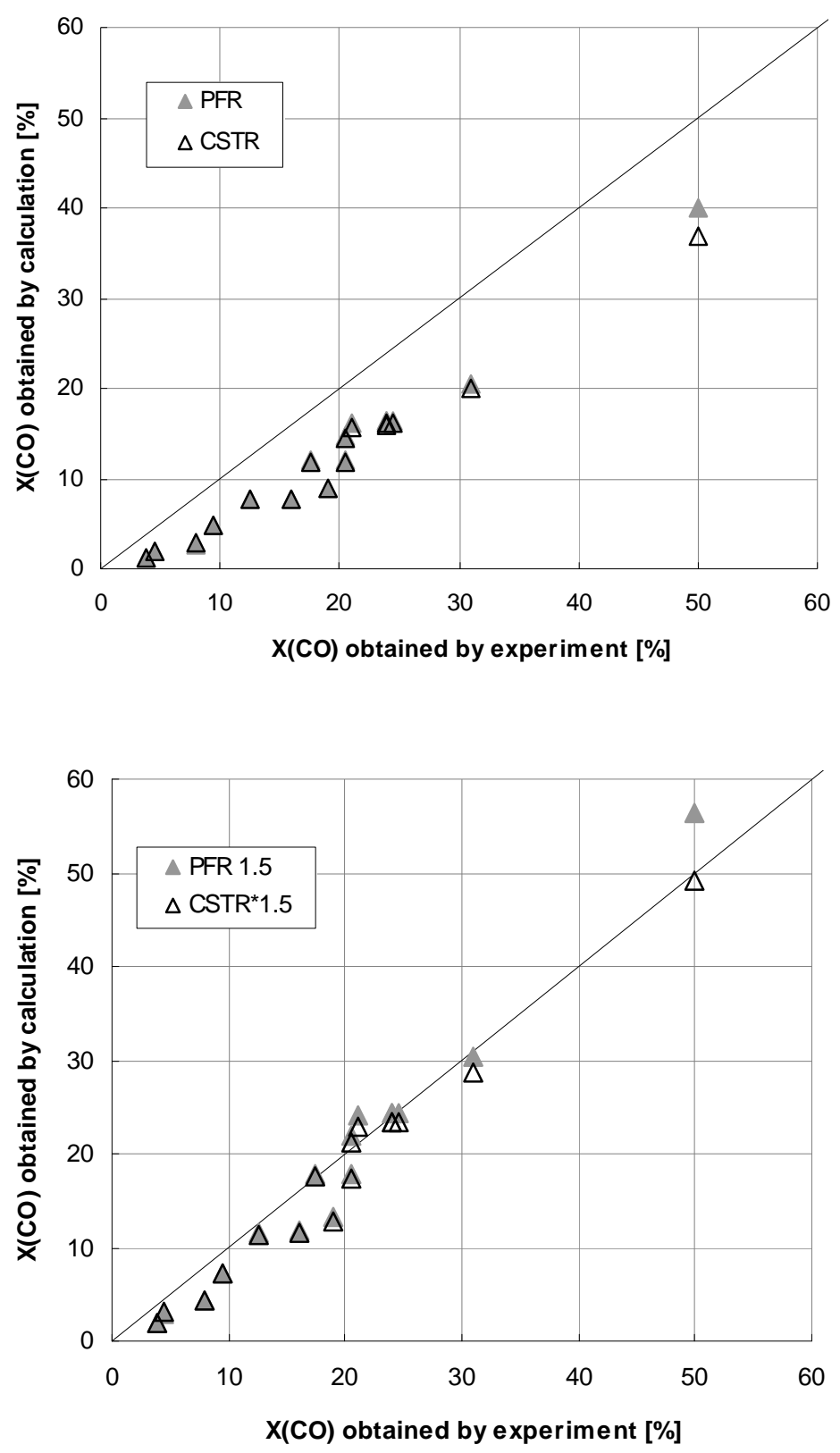

Figure B11. Parity plot for CO conversion - $X(C O)$ of data from Yun Park catalyst.
Figure B12. Parity plot for CO conversion - $X(\mathrm{CO})$ of data from Yun Park catalyst - the rates of every components multiplied by $\mathbf{1 . 5}$. 


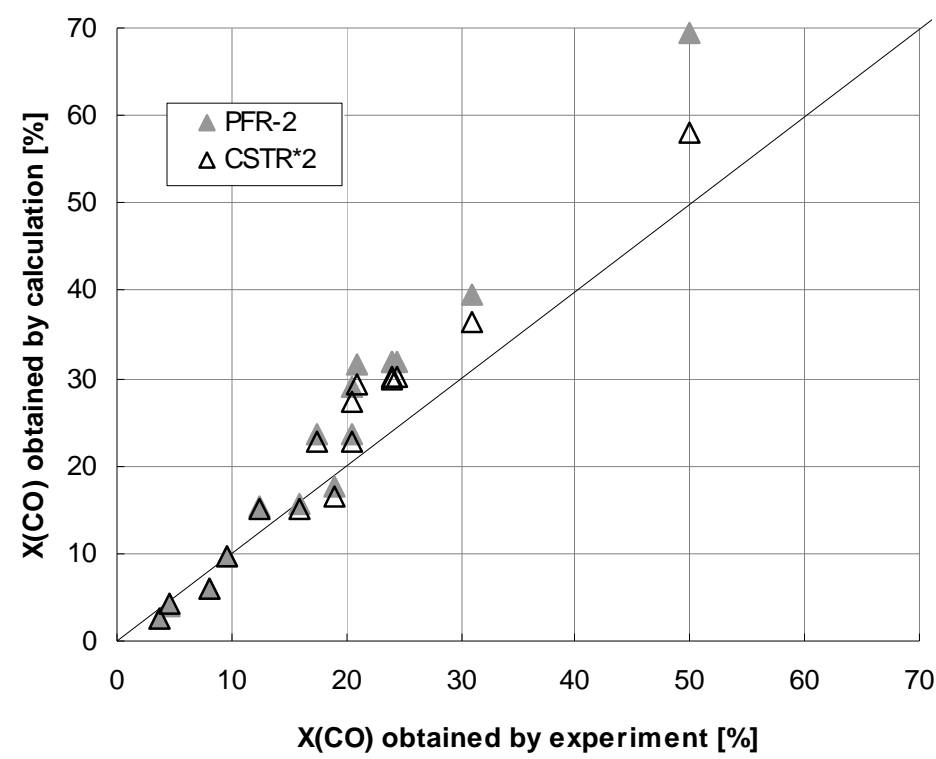

Figure B13. Parity plot for CO conversion - X(CO) of data from Yun Park catalyst- the rates of every components multiplied by 2.

As a conclusion, in the kinetic scheme the gross rates originally estimated from Gunturu's paper [6] have been multiplied by a factor equal to 2 . In particular, the pre-exponential factors in the rate constants (the parameters $\mathrm{Ai}$ ) of the gross rate equations have been multiplied by 2 .

These results are probably close to the best ones which is possible to obtain from the available data sets. In order to develop a more accurate kinetic model, a dedicated experimental work is required.

In any case, the final parameter estimates obtained from the available data for the methanol, ethanol, propanol and hydrocarbon formation rates are collected in table B3.

Table B3. Final parameter estimates for the Methanol, Ethanol, Propanol and Hydrocarbons Synthesis Model ${ }^{\mathrm{a}}$.

\begin{tabular}{llllll}
$\mathrm{A}_{\mathrm{m}}=14.6233$ & $\mathrm{E}_{\mathrm{m}}=143.472$ & $\mathrm{~K}_{\mathrm{l}}=7.6393 \mathrm{E}-9$ & $\mathrm{~K}_{2}=0.6785$ & $\mathrm{~K}_{3}=0.9987$ & $\mathrm{n}_{\mathrm{m}}=3$ \\
$\mathrm{~K}_{\mathrm{z}}=0.8359$ & & & & & \\
$\mathrm{~A}_{\mathrm{e}}=3.0518$ & $\mathrm{E}_{\mathrm{e}}=24.986$ & $\mathrm{~K}_{\mathrm{e}}=0.7367$ & $\mathrm{n}_{\mathrm{e}}=1$ & \\
$\mathrm{~A}_{\mathrm{p}}=0.2148$ & $\mathrm{E}_{\mathrm{p}}=89.3328$ & $\mathrm{~K}_{\mathrm{p}}=0.6086$ & $\mathrm{n}_{\mathrm{p}}=1$ & & \\
$\mathrm{~A}_{\mathrm{h}}=9.3856$ & $\mathrm{E}_{\mathrm{h}}=95.416$ & $\mathrm{~K}_{\mathrm{h}}=1.2472$ & $\mathrm{n}_{\mathrm{h}}=1$ & & \\
\hline
\end{tabular}

${ }^{\mathrm{a}} \mathrm{A}_{\mathrm{i}}\left[\mathrm{mol} / \mathrm{h} / \mathrm{kg}_{\mathrm{cat}}\right], \mathrm{E}_{\mathrm{i}}[\mathrm{kJ} / \mathrm{mol}]$, all other parameters are dimensionless.

\section{B.1.5 Simulation study of the effects of the operating variables}

In order to point out the effects of reaction conditions on both $\mathrm{CO}$ conversion and final product distribution we performed reactor simulations under the following conditions:

Temperature $=553-623 \mathrm{~K}$

Pressure $=30-160$ bar

$\mathrm{H}_{2} / \mathrm{CO}$ ratio $=1.2$

$\mathrm{GHSV}=155-51.7 \mathrm{~mol} / \mathrm{h} / \mathrm{kg}_{\text {cat }}$

The results of these calculations are shown in figures B14 and B15.

$\mathrm{CO}$ conversion increases with increasing temperature and pressure and with decreasing GHSV, as expected. 


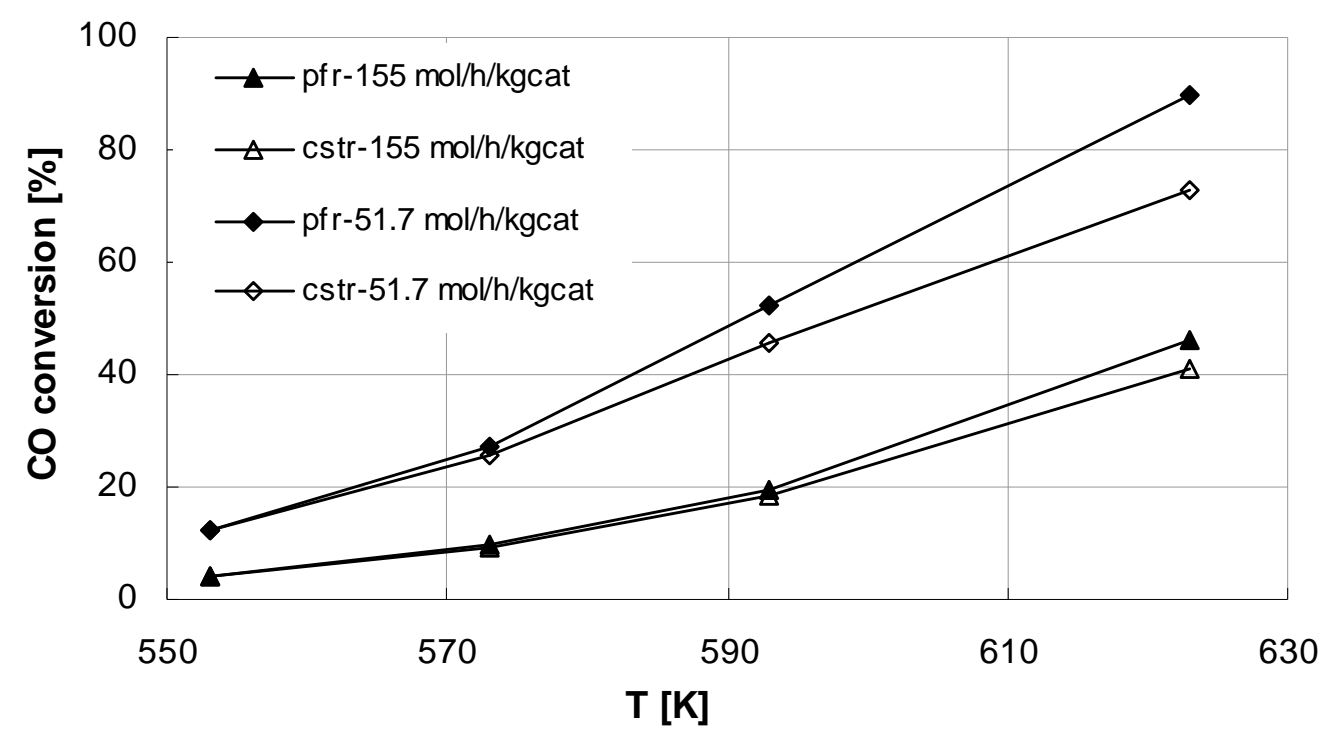

Figure B14. CO conversion, Xco, calculated for PFR (solid symbols) and CSTR (open symbols) reactor models at $134.7 \mathrm{~atm}, \mathrm{H}_{2} / \mathrm{CO}$ ratio $=1.2$ and $\mathrm{GHSV}$ equal to 155 and $51.7 \mathrm{~mol} / \mathrm{h} / \mathrm{kg}_{\text {cat }}$.

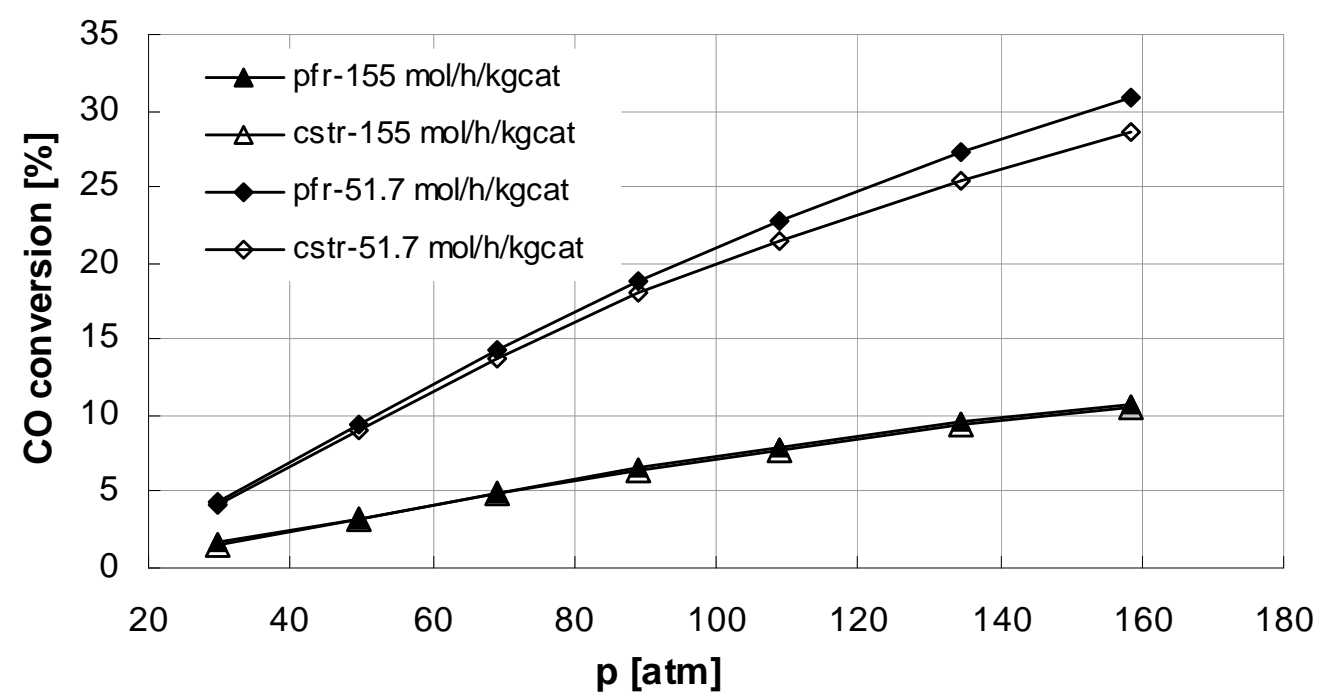

Figure B15. CO conversion, Xco, calculated for PFR (solid symbols) and CSTR (open symbols) reactor models at $573 \mathrm{~K}, \mathrm{H}_{2} / \mathrm{CO}$ ratio $=1.2$ and $\mathrm{GHSV}$ equal to 155 (triangles) and 51.7 (diamonds) $\mathrm{mol} / \mathrm{h} / \mathrm{kg}_{\text {cat }}$.

It is of interest to analyze the results in term of productivity of the various species upon changing temperature (see Figure B16) and pressure (see Figure B17) as well as space velocity. 

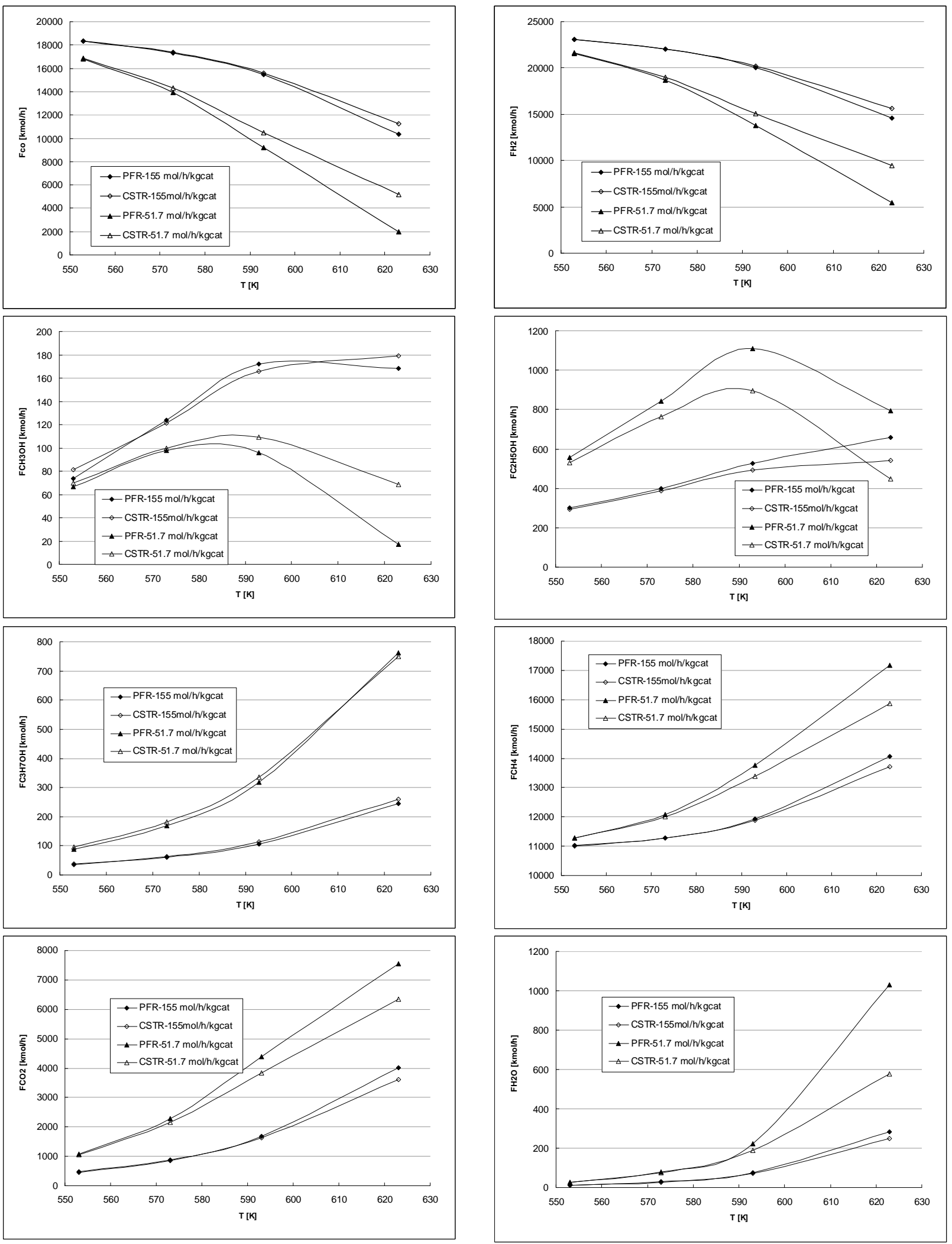

Figure B16. Outlet flow of CO, $\mathrm{H}_{2}, \mathrm{CH}_{3} \mathrm{OH}, \mathrm{C}_{2} \mathrm{H}_{5} \mathrm{OH}, \mathrm{C}_{3} \mathrm{H}_{7} \mathrm{OH}, \mathrm{CH}_{4}, \mathrm{CO}_{2}$ and $\mathrm{H}_{2} \mathrm{O}$ calculated for PF (solid symbols) and CST (open symbols) reactors with varying temperature at the following conditions: Pressure= $134.7 \mathrm{~atm}, \mathrm{H}_{2} / \mathrm{CO}$ ratio= 1.2 and $\mathrm{GHSV}=155$ (triangles) and 51.7 (diamonds) $\mathrm{mol} / \mathrm{h} / \mathrm{kg}_{\text {cat }}$. 

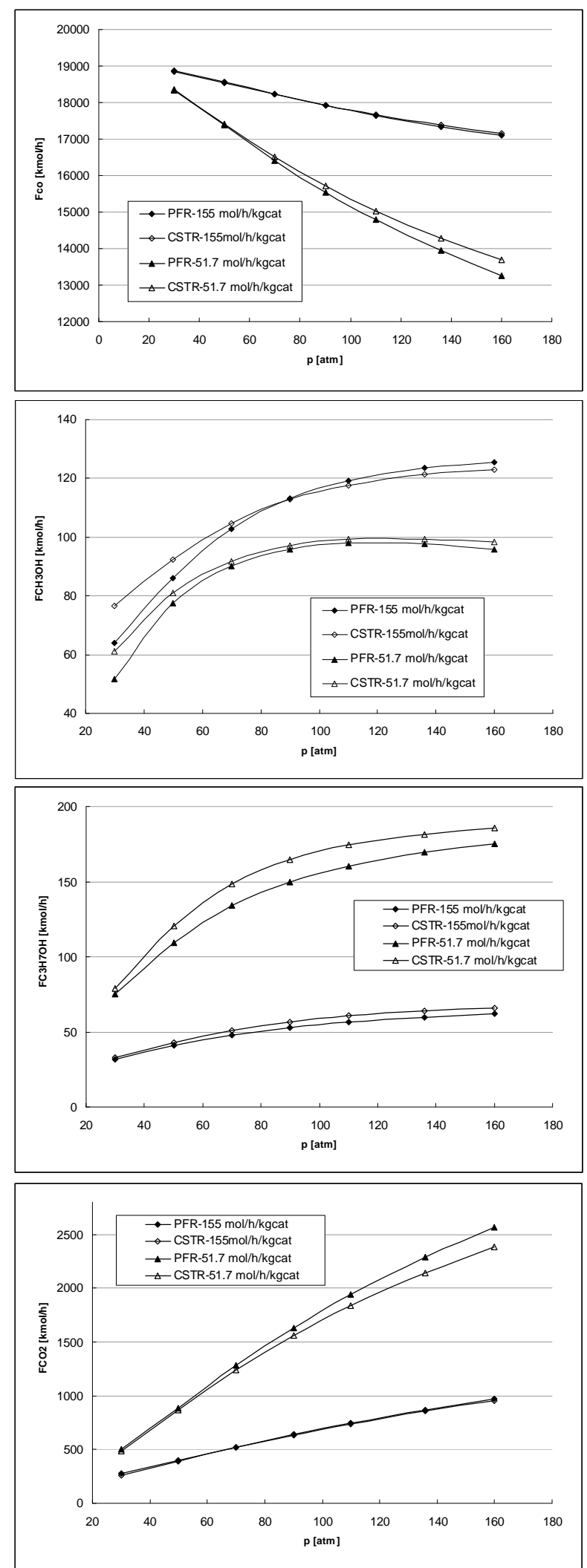
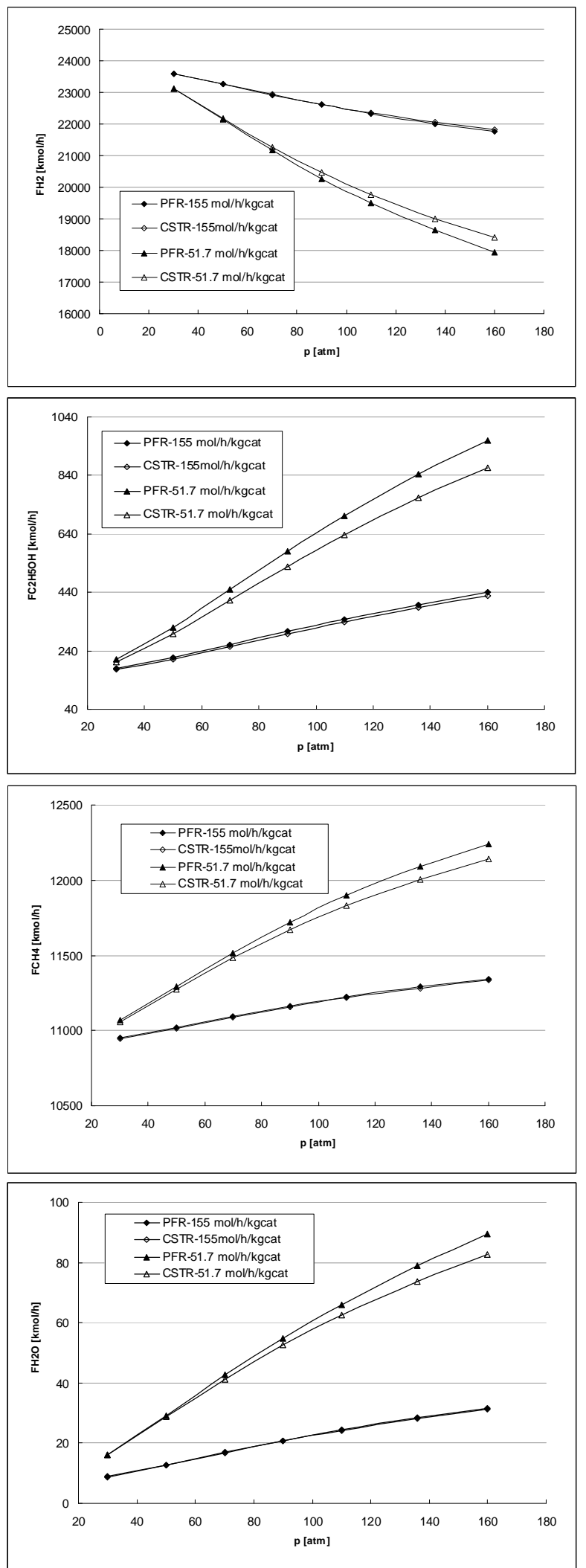

Figure B17. Outlet flow of $\mathrm{CO}, \mathrm{H}_{2}, \mathrm{CH}_{3} \mathrm{OH}, \mathrm{C}_{2} \mathrm{H}_{5} \mathrm{OH}, \mathrm{C}_{3} \mathrm{H}_{7} \mathrm{OH}, \mathrm{CH}_{4}, \mathrm{CO}_{2}$ and $\mathrm{H}_{2} \mathrm{O}$ calculated for PF (solid symbols) and CST (open symbols) reactors with varying pressure at the following conditions: Temperature $=573 \mathrm{~K}, \mathrm{H}_{2} / \mathrm{CO}$ ratio= 1.2 and $\mathrm{GHSV}=155$ (triangles) and 51.7 (diamonds) $\mathrm{mol} / \mathrm{h} / \mathrm{kg}_{\text {cat }}$. 
From Figure B16 it is clear that it is possible to increase the $\mathrm{CO}$ and the $\mathrm{H}_{2}$ conversion simply by increasing the temperature and decreasing the GHSV. In addition, from Figure B16 it is evident that, working at fixed temperature and decreasing the GHSV, it is possible to maximize the selectivity to $\mathrm{C} 2+$ alcohols. In the same manner, it is clear that increasing the temperature, at fixed GHSV, it is possible to maximize the $\mathrm{C}_{3} \mathrm{H}_{7} \mathrm{OH}$ selectivity.

These trends are typical of chemical systems in which there are consecutive reactions, i.e. reactions following the generic scheme:

$$
\text { A }->\mathrm{B}->\mathrm{C}
$$

In the case of the mixed alcohols synthesis, in particular, this generic scheme can be written as the sum of the two following reactions paths:

$$
\begin{aligned}
& \mathrm{CO}+\mathrm{H}_{2} \rightarrow \mathrm{CH}_{3} \mathrm{OH}->\mathrm{C}_{2} \mathrm{H}_{5} \mathrm{OH}->\mathrm{C}_{3} \mathrm{H}_{7} \mathrm{OH} \\
& \mathrm{CO}+\mathrm{H}_{2} \rightarrow \mathrm{CH}_{3} \mathrm{OH} \rightarrow \mathrm{CH}_{4}
\end{aligned}
$$

This means that methanol and ethanol are intermediates compounds in the higher alcohols synthesis reaction, so their outlet flows depend, as it is also clear from the balance equations (1213), from the rates of formation of methanol, ethanol and methane in the case of methanol and from both the rates of formation of ethanol and propanol in the case of ethanol.

So, the effect of the temperature on the net reaction rate of these components (i.e. the outlet flows of these compounds) is complex, deriving from the linear combination of more than one "Arrhenius-type" equations. This justifies the graphs reported in Figure B16, which show a maximum in the outlet flow of methanol and ethanol with respect to the temperature.

Concerning the effects of pressure, from Figure B17 it is clear that increasing pressure results in higher conversions of the reactants and, in the investigated range, also in higher alcohols selectivities.

This monotonic and limited effect of the pressure on the $\mathrm{CO}$ conversion and alcohols selectivity can be ascribed to the limited effect of the pressure on the kinetic laws of the reactions involved in the mixed alcohols synthesis and it evidences that the temperature and the GHSV are the two major parameters to vary in order to optimize both the $\mathrm{CO}$ conversion and the higher alcohols selectivity.

\section{B.1.6 Implementation of the kinetic model in a Fortran subroutine}

On the basis of the received template USRKIN.f, we have developed two different Fortran codes to be interfaced with the process simulator ASPEN. Such routines are able to evaluate the gross rates of formation of $\mathrm{CO}, \mathrm{H}_{2}, \mathrm{CH}_{3} \mathrm{OH}, \mathrm{C}_{2} \mathrm{H}_{5} \mathrm{OH}, \mathrm{C}_{3} \mathrm{H}_{7} \mathrm{OH}, \mathrm{CH}_{4}, \mathrm{H}_{2} \mathrm{O}$ and $\mathrm{CO}_{2}$ in a multitubolar plug flow reactor and in a continuous stirred tank reactor on the basis of the following parameters supplied by Aspen:

- Molar fraction of the inlet components

- Temperature $[\mathrm{K}]$

- Pressure [Pa]

- Mass of catalyst $[\mathrm{kg}]$

In the program we used the system of kinetic equation represented by eq.s 6, 9-11, with parameter estimates as in Table B3. In addition we inserted into the model the water-gas shift reaction, with rate equation (17). The equilibrium constant for the water gas shift reaction was calculated as a function of temperature according to equation (18) [11]. 


\section{B.1.7 Comparison between the results obtained using ASPEN and the Fortran program}

In order to check the subroutine developed and its correct interface with Aspen, we simulated the two PF and CST reactors for a set of conditions supplied by Xun Wang, i.e.:

Temperature $=573 \mathrm{~K}$

Pressure $=136$ bar

Feed flow rates $[\mathrm{kmol} / \mathrm{s}]$ :

\begin{tabular}{|l|r|}
\hline $\mathrm{H}_{2}$ & 6.5691 \\
$\mathrm{CO}$ & 5.3216 \\
$\mathrm{Ar}$ & 0.369 \\
$\mathrm{~N}_{2}$ & 1.1275 \\
$\mathrm{CO}_{2}$ & 0.0336 \\
$\mathrm{H}_{2} \mathrm{O}$ & 0.0012 \\
$\mathrm{CH}_{4}$ & 3.0101 \\
$\mathrm{METHANOL}$ & 0.03312359 \\
ETHANOL & 0.04081143 \\
PROPANOL & 0.00349779 \\
\hline
\end{tabular}

The obtained $\mathrm{CO}$ conversion data, as well as the calculated product distributions are reported in table B4. The same table also shows the results calculated by Xun Wang using Aspen.

Table B4. The product distribution calculated for PF reactor with Aspen and with the Fortran code, for the reaction condition reported above

\begin{tabular}{|l|c|c|}
\hline & $\begin{array}{c}\text { Aspen } \\
(\mathrm{kmol} / \mathrm{s})\end{array}$ & $\begin{array}{c}\text { Fortran } \\
(\mathrm{kmol} / \mathrm{s})\end{array}$ \\
\hline $\mathrm{CO}$ & 4.8099 & 4.8136 \\
$\mathrm{CO}_{2}$ & 0.2435 & 0.2428 \\
$\mathrm{H}_{2}$ & 6.0559 & 6.1102 \\
$\mathrm{Ar}$ & 0.369 & $1.6547^{*}$ \\
$\mathrm{~N}_{2}$ & 1.1275 & \\
$\mathrm{H}_{2} \mathrm{O}$ & 0.0079 & 0.0079 \\
$\mathrm{CH}_{3} \mathrm{OH}$ & 0.0344 & 0.0343 \\
$\mathrm{C}_{2} \mathrm{H}_{5} \mathrm{OH}$ & 0.1113 & 0.1113 \\
$\mathrm{C}_{3} \mathrm{H}_{7} \mathrm{OH}$ & 0.0167 & 0.0166 \\
$\mathrm{CH}_{4}$ & 3.1298 & 3.1369 \\
\hline $\mathrm{X}_{\mathrm{CO}}(\%)$ & 9.62 & 9.58 \\
\hline
\end{tabular}

$*$ In the FORTRAN code we used only one species representing all the inert gases together i.e., the lump of nitrogen and argon.

From the data reported in Table B4 it can be concluded that the two programs leads to essentially the same results.

We note that all calculations were performed for single-pass process (i.e., with no recycle). In the case of the presence of a recycle, large quantity of $\mathrm{CO}_{2}$ would be present in the feed. Although the literature sources we have worked with did not investigate the effect of $\mathrm{CO}_{2}$ 
content in the feed on the behaviour of the catalyst, it is likely that this compound affect the activity of the catalyst.

As matter of facts, the inhibiting effect of the presence of $\mathrm{CO}_{2}$ in the feed on the higher alcohol synthesis has been demonstrated for a $\mathrm{ZnCrO}+15 \% \mathrm{Cs} 2 \mathrm{O}$ catalyst [2]. In this case, the presence of $6 \% \mathrm{CO}_{2}$ in the feed depresses the yield of higher alcohols by a factor of three. Methanol formation is only marginally affected, however, so that the relative content of higher alcohol with respect to methanol is greatly reduced. It is also worth noticing that the presence of carbon dioxide in the feed causes greater amounts of water to be produced via the water gas shift reaction. The inhibiting effects of the $\mathrm{CO}_{2}$ were explained by assuming that water rather than $\mathrm{CO}_{2}$ inhibits the HAS reaction by competing for adsorption with the intermediate $\mathrm{C} 1$-species on the catalyst surface.

\section{B.1.8 Conclusions}

On the basis of a kinetic analysis reported in the literature for the synthesis of higher alcohols from $\mathrm{CO} / \mathrm{H}_{2}$ mixtures over a Mo-based catalyst [6], a Fortran subroutine to be integrated in Aspen able to estimate the rate of formation of the main products of the synthesis (i.e. methanol, ethanol, propanol, methane, carbon dioxide and water) was developed.

The ability of the lumped kinetic model to predict the $\mathrm{CO}$ conversion and the product distribution of the higher alcohol synthesis over Mo-based catalysts was validated against experimental data measured at different reaction conditions (type of reactor, catalyst, T, P, inlet flows, GHSV) obtained from various literature sources [6, 12, 13].

Finally, an analysis of the effect of temperature and pressure on the $\mathrm{CO}$ conversion and on the products distribution was performed. It was so verified that higher temperature and pressure and lower space velocities have a positive effect on the conversion of CO. The optimization of the process conditions, however, should be performed also on the basis of the products selectivities, that exhibit a complex trend with increasing temperature and pressure.

The lumped kinetic model has been implemented in a FORTRAN subroutine which has been successfully interfaced with the ASPEN process simulation program.

\section{B.2 Additional results and model validation}

\section{B.2.1 Introduction}

In our previous paragraphs of Appendix B we have discussed the results of a Fortran subroutine developed on the basis of a lumped kinetic analysis described in the literature [12] for the synthesis of higher alcohols from $\mathrm{CO} / \mathrm{H}_{2}$ mixtures over a Mo-based catalyst. The derived kinetics were able to estimate the rates of formation of the main products of the synthesis (i.e. methanol, ethanol, propanol, methane, carbon dioxide and water).

The ability of the lumped kinetic model to predict the $\mathrm{CO}$ conversion in the higher alcohol synthesis over Mo-based catalysts was validated against experimental data measured at different reaction conditions (type of reactor, catalyst, T, P, inlet flows, GHSV) obtained from various literature sources $[6,12,13]$. In our previous report we have shown that in order to obtain good fits of $\mathrm{CO}$ conversion the gross rates must be multiplied by a factor equal to 2 . In this way we were able to achieve a good fit of the experimental $\mathrm{CO}$ conversion data from three different sources $[6,12,13]$. 
However, in our previous report we did not fully analyze the products distribution. It is the goal of the present addendum to investigate whether the introduction of the above mentioned factor is suitable to simulate the product distribution as well.

\section{B.2.2 Validation of the kinetic model}

Figures B18 and B19 show the comparison of experimental data (points) published in [12] with the simulations obtained by multiplying the gross rates by a factor 1 ( 1 *PFR, i.e. without modifications) and a factor 2 ( $2 * \mathrm{PFR})$ (experimental conditions are reported in the figure captions). Upon comparison of figures B18 and B19 we can conclude that multiplication of the gross rates by a constant factor of 2 has a positive effect not only on the prediction of $\mathrm{CO}$ conversion (see paragraphs B.1) but also on the prediction of the product distribution of alcohols. Indeed the yields of mixed alcohols is better estimated, even though a worse fit of the selectivity to mixed alcohols and yields of $\mathrm{HC}$ is obtained if compared to the case of $1 * \mathrm{PFR}$.

In order to improve the prediction of the product distribution we have tried to change again the multiplication factor for gross rates of individual products. We have observed that the best fit of experimental data can be obtained using a multiplication factor of 2 for the gross rates of methanol, ethanol and propanol, and a multiplication factor of 1 for the gross rates of hydrocarbons $(2 *$ Alcohols, $1 * \mathrm{HC})$. The results obtained with these multiplication factors are shown in figure B20. In this case also for the mole fraction of individual alcohols we have observed a god fit of experimental data [12]. 

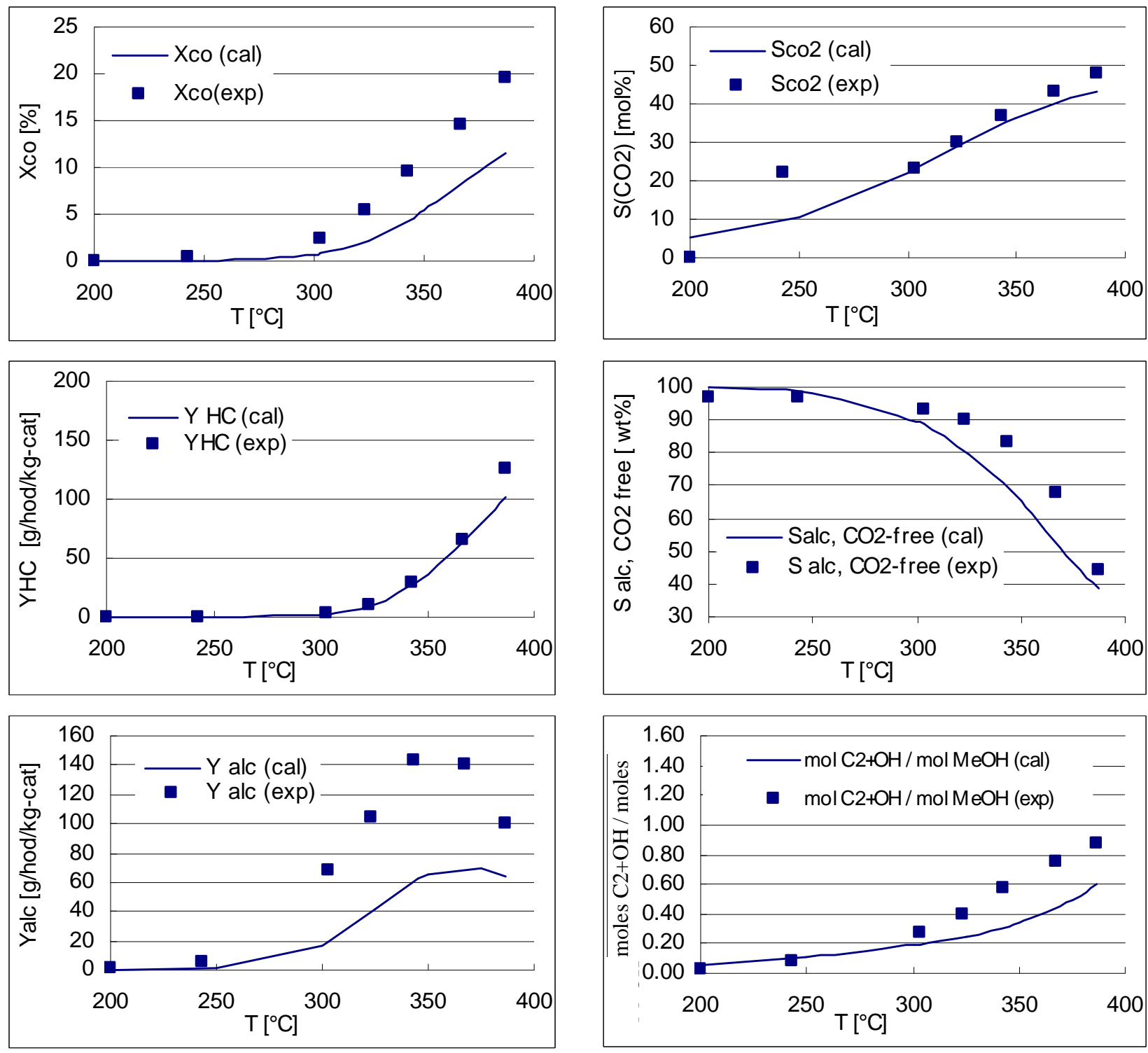

Figure B18. Comparison of experimental [12] and calculated data. Calculated data have been obtained for PF reactor using the gross rates of products without modifications (1*PFR). Experimental conditions: $51 \mathrm{~atm}, 0.5 \mathrm{~g}$ cat., $\mathrm{H} 2=\mathrm{CO}=25 \mathrm{ml} / \mathrm{min}(268 \mathrm{~mol} / \mathrm{h} / \mathrm{kg}$-cat.). The following parameters are reported: $X_{\mathrm{CO}}$, conversion of $\mathrm{CO} ; \mathrm{Y}_{\mathrm{HC}}$ and $\mathrm{Y}_{\text {alc }}$, space-time yelds of hydrocarbons and total alcohols $\left(\mathrm{CO}_{2}\right.$-free basis), respectively; and $\mathrm{C}_{2+} \mathrm{OH} / \mathrm{MeOH}$, molar ratio of higher alcohols to methanol. 

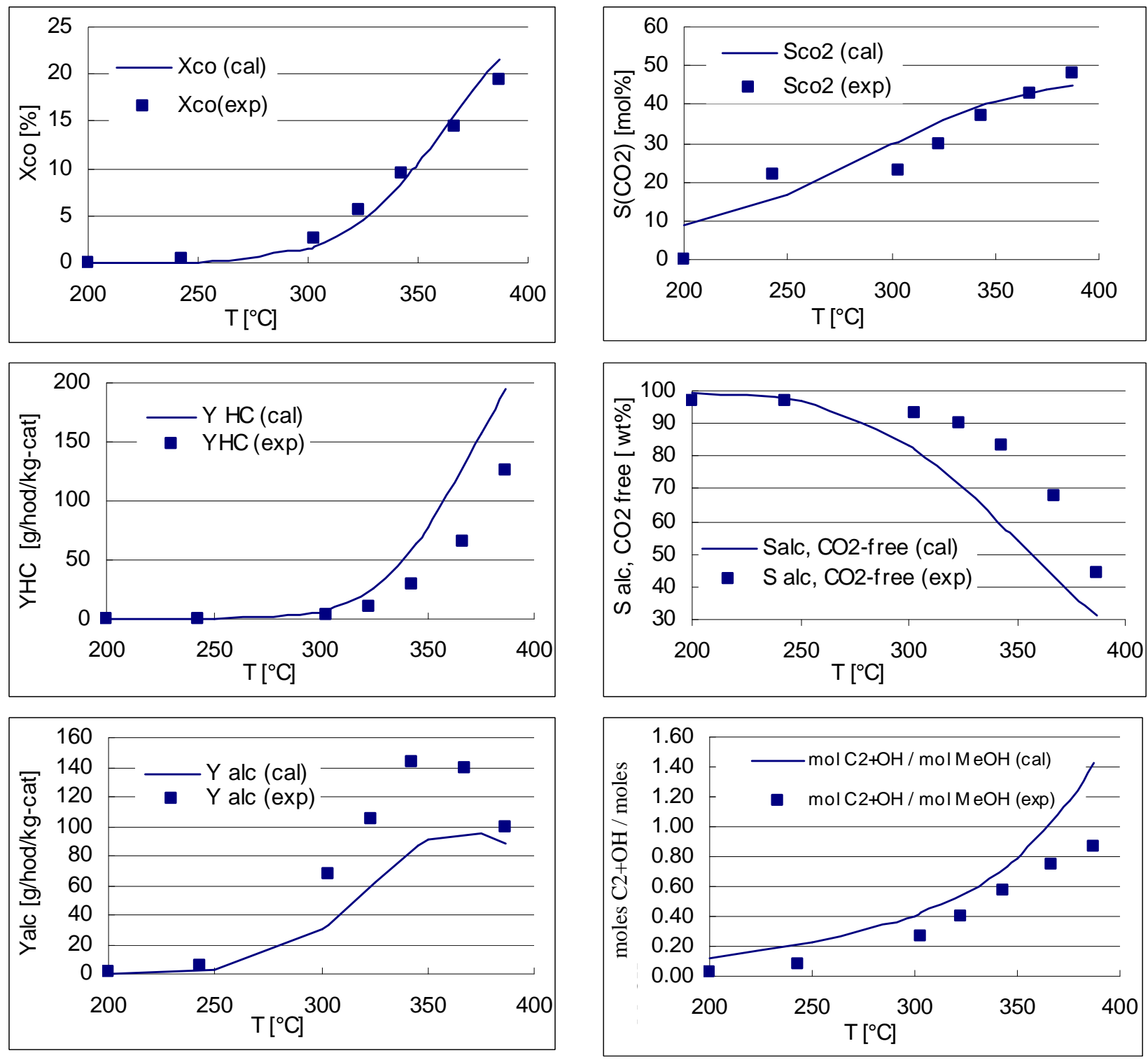

Figure B19. Comparison of experimental [12] and calculated data. Calculated data have been obtained for PF reactor using the constant factor of 2 for multiplication of the gross rates of all the species involved in the mechanism $\left(2^{\star} P F R\right)$. Experimental conditions: $51 \mathrm{~atm}, 0.5 \mathrm{~g}$ cat., $\mathrm{H} 2=\mathrm{CO}=25 \mathrm{ml} / \mathrm{min}(268 \mathrm{~mol} / \mathrm{h} / \mathrm{kg}$-cat $)$. Catalyst parameters are as defined in figure B18. 

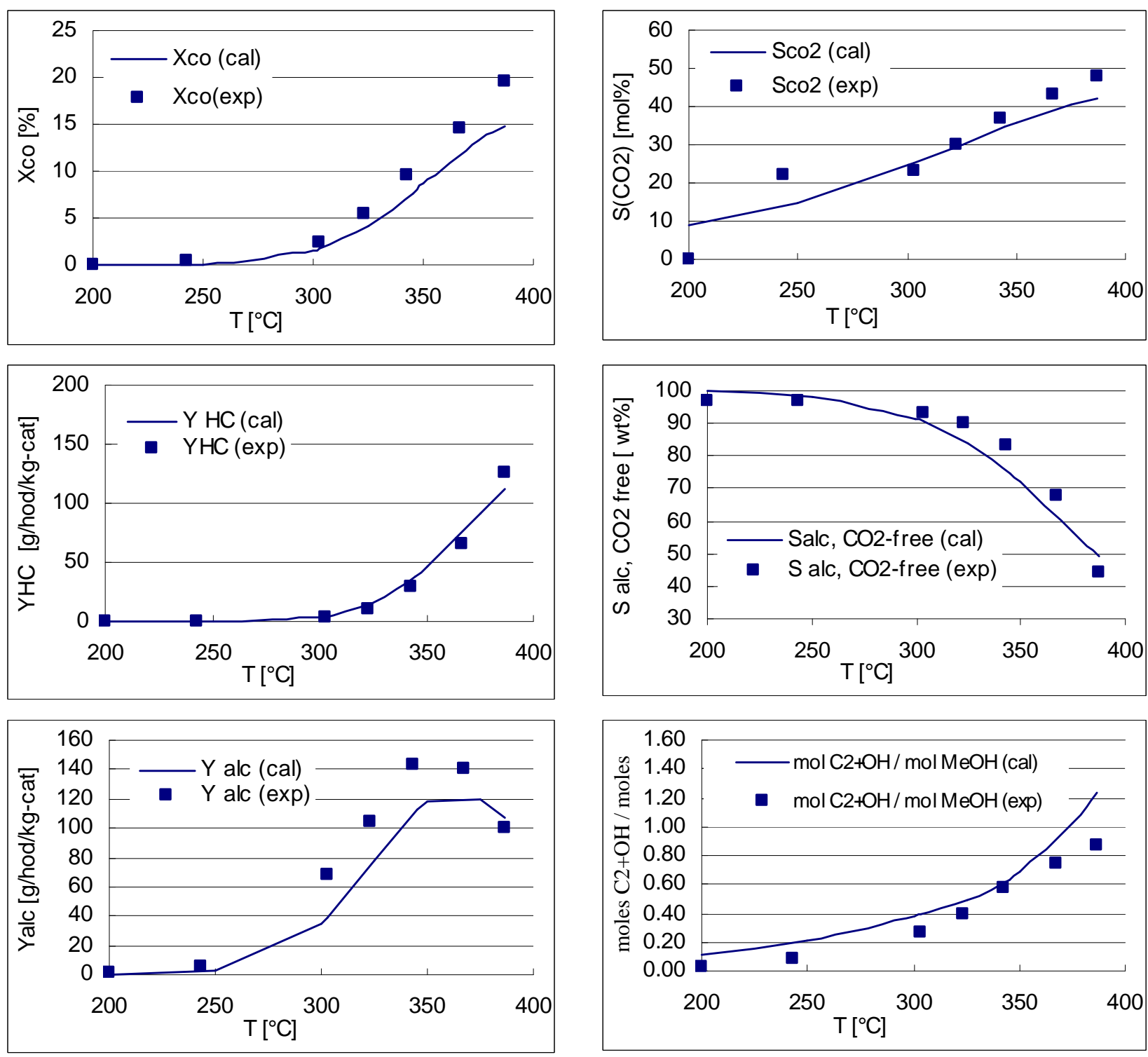

Figure B20. Comparison of experimental [12] and calculated data. Calculated data have been obtained for PF reactor using the constant factor of 2 for multiplication of the gross rates of all the alcohols and factor of 1 for gross rate of hydrocarbons $\left(2^{*} A / c o h o l s, 1^{\star} H C\right)$. Experimental conditions: $51 \mathrm{~atm}, 0.5 \mathrm{~g}$ cat., $\mathrm{H} 2=\mathrm{CO}=25 \mathrm{ml} / \mathrm{min}(268 \mathrm{~mol} / \mathrm{h} / \mathrm{kg}$-cat). Catalyst parameters are as defined in figure $B 18$.

Figures B21, B22 and B23 show the comparison between the experimental data (points) published in [13] and the calculated data (experimental conditions are reported in the figure captions). Calculated data have been obtained using the multiplication factors reported in the figure captions. In figures $\mathrm{B} 21-\mathrm{B} 23 \mathrm{XCO}$ is the $\mathrm{CO} \%$ conversion, $\mathrm{XCO}_{2}$ the $\mathrm{CO}_{2} \%$ yield, $\Sigma \mathrm{Xpi}$ the paraffins yield, $\Sigma$ Xai the mixed alcohols yield, defined as [13]:

$\mathrm{Xij}=$ (moles of $\mathrm{CO}$ consumed to produce $\mathrm{i}$ component group with carbon number $\mathrm{j}$ ) / (moles of $\mathrm{CO}$ fed to the reactor)

From the comparison the results obtained using $1 * \mathrm{PFR}$ and $2 * \mathrm{PFR}$ (figures B21 and B22, respectively) it is concluded that the model predictions obtained using 1 *PFR underestimates the $\mathrm{CO}$ conversion and the selectivity to $\mathrm{CO}_{2}$, while the prediction of selectivity to paraffins and alcohols for these experimental condition was quite good. On the other hand, when using the 
multiplication factor of 2 the $\mathrm{CO}$ conversion is overestimated along with the selectivity to alcohols, whereas the selectivity to $\mathrm{CO}_{2}$ (and hydrocarbons) are satisfactory.

Finally, we have also attempted in this case to improve the prediction of product distribution by multiplying the gross rate of methanol, ethanol and propanol by constant factor of 2 and that of hydrocarbons by a factor of $1(2 *$ Alcohols, $1 * \mathrm{HC})$. The results obtained in this case are shown in figure B23. The new set of multiplication factors was able to predict nicely the experimental data, but for the selectivity to total alcohols. Also the selectivity of the individual alcohols are not adequately fitted (results not shown).

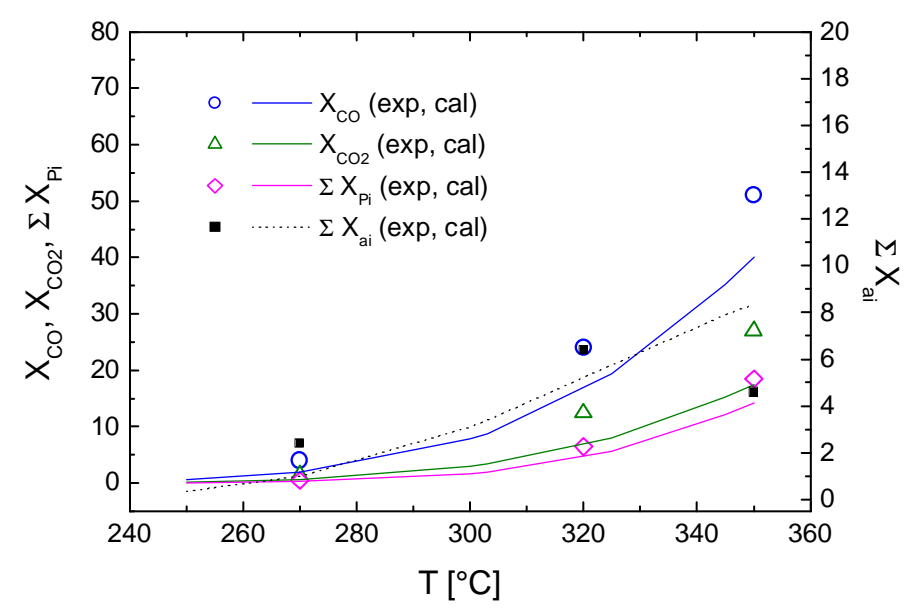

Figure B21. Comparison of experimental [13] and calculated data. Calculated data have been obtained for PF reactor using the gross rates of products without modifications (1*PFR). Experimental conditions: 90 atm, $1 \mathrm{~g}$ cat., $\mathrm{H} 2 / \mathrm{CO}=1.01 \quad(17.1$ g-cat $. \mathrm{h} / \mathrm{mol}$, $58.48 \mathrm{~mol} / \mathrm{h} / \mathrm{kg}$-cat).

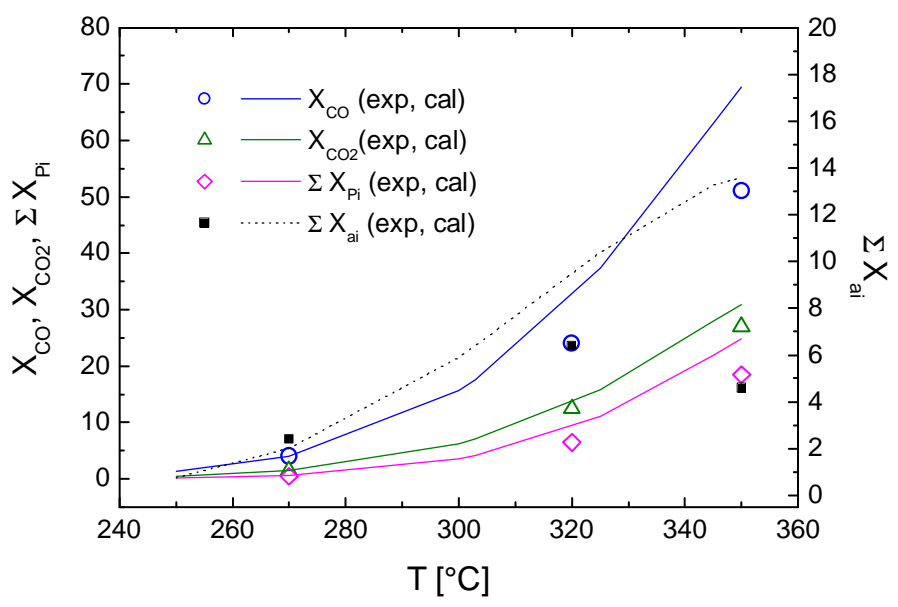

Figure B22. Comparison of experimental [13] and calculated data. Calculated data have been obtained for PF reactor using the constant factor of 2 for multiplication of the gross rates of all species involved in the mechanism $\left(2^{\star} P F R\right)$. Experimental conditions: same as figure B21. 


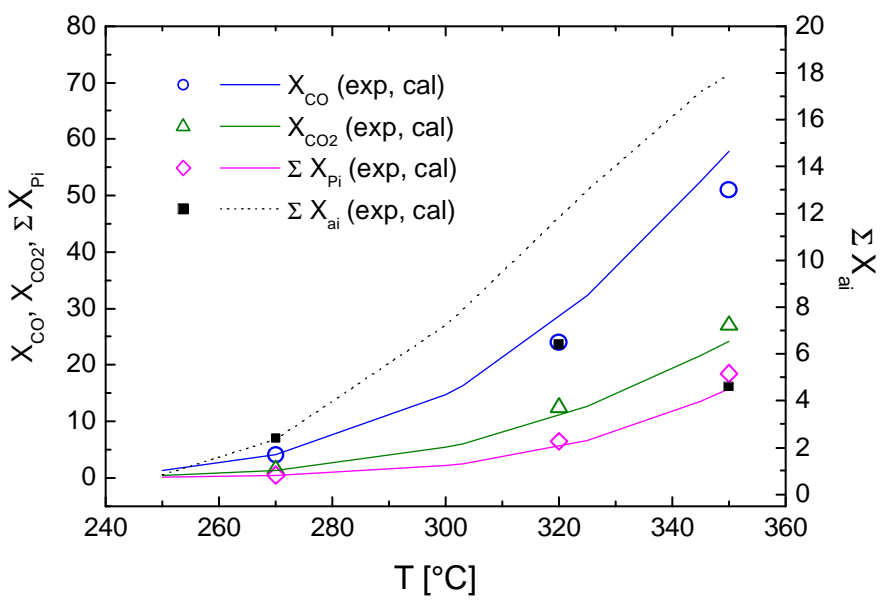

Figure B23. Comparison of experimental [13] and calculated data. Calculated data have been obtained for PF reactor using the constant factor of 2 for multiplication of the gross rates of all alcohols and factor of 1 for gross rate of hydrocarbons $\left(2^{\star} A l\right.$ cohols, $\left.1^{\star} H C\right)$. Experimental conditions: same as figure B21.

Figures B24 and B25 compare the results obtained upon calculating the CO conversion from the data of $\mathrm{Li}$ et al. [12] for PF and a CST reactor model (solid and open symbols, respectively) with the published experimental data. When multiplying the gross rates by a constant factor of 2 (figure B25) the model well simulates the experimental data. On the other hand, when multiplying by factor of 2 only the gross rates of alcohols (figure B24) the model clearly underestimated the experimental data. However, considering that different multiplying factors for alcohols and hydrocarbons allowed to improve the product distribution, these results appear reasonable.

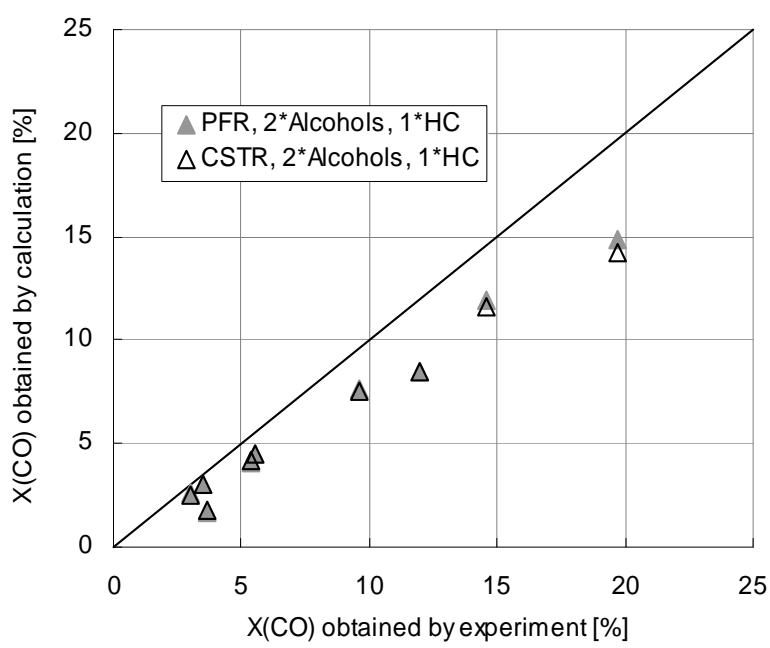

Figure B24. Parity plot for CO conversion $X(C O)$ calculated for PFR (solid points) and CSTR (open points) reactor using the gross rates multiplied by the constant factor 2 for alcohols and 1 for $\mathrm{HC}$ on the basis of data from [12].

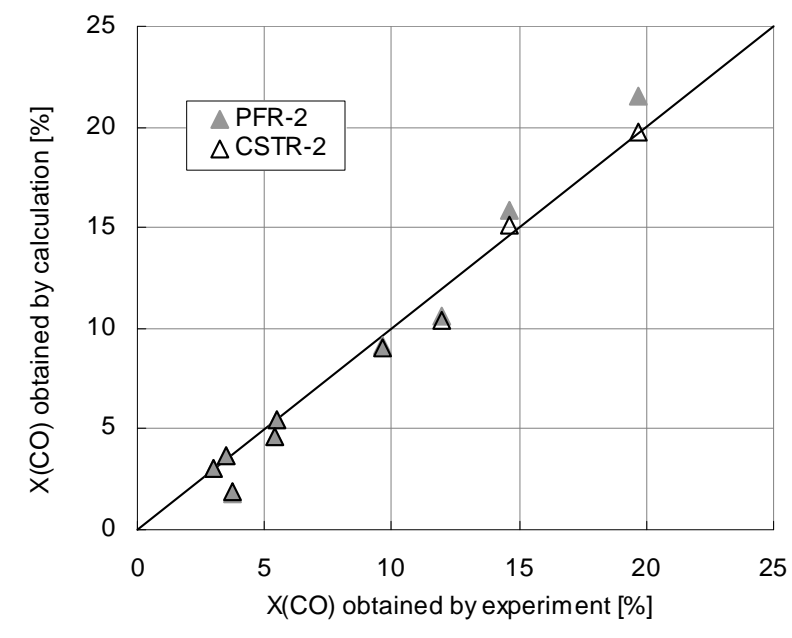

Figure B25. Parity plot for CO conversion X(CO) calculated for PFR (solid points) and CSTR (open points) reactor using the gross rates multiplied by the constant factor 2 on the basis of data from [12] (Figure B10).

Figures B26 and B27 compare the results obtained upon calculating the $\mathrm{CO}$ conversion from the data of Yun Park et al. [13] for PF and a CST reactor model (solid and open symbols, respectively) with the published experimental data. When multiplying the gross rates by a 
constant factor of 2 (figure B27) the model underestimates a few experimental data. Better fit was observed using multiplying factors equals to 2 for alcohols and to 1 for hydrocarbons (figure B26).

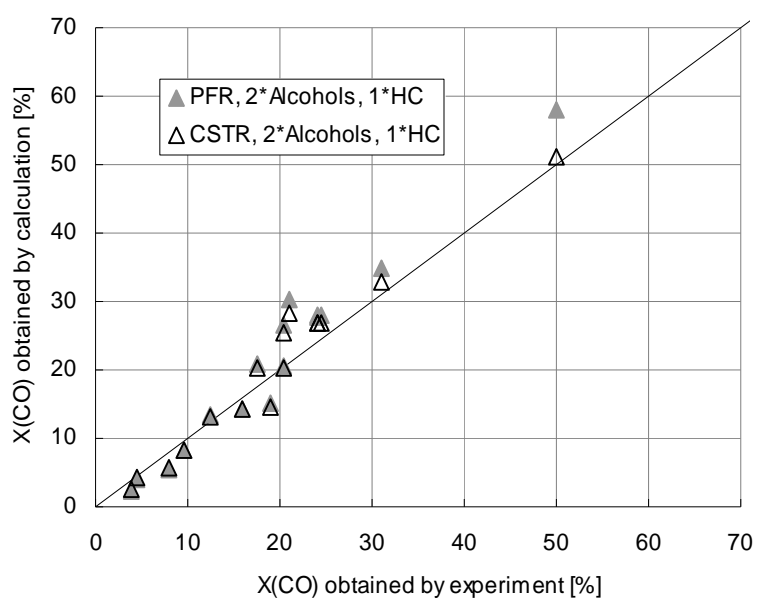

Figure B26. Parity plot for CO conversion $X(C O)$ calculated for PFR (solid points) and CSTR (open points) reactor using the gross rates multiplied by the constant factor 2 for alcohols and 1 for $\mathrm{HC}$ on the basis of data from [13].

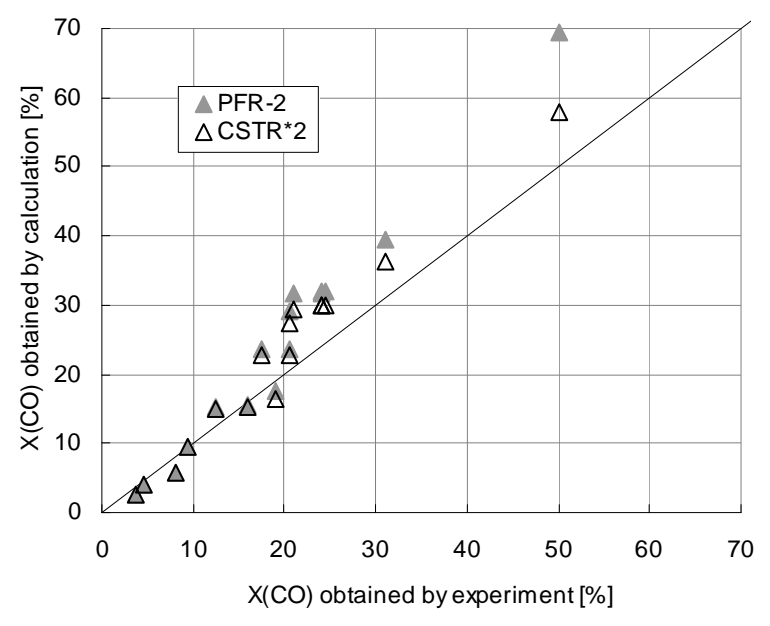

Figure B27. Parity plot for CO conversion $X(C O)$ calculated for PFR (solid points) and CSTR (open points) reactor using the gross rates multiplied by the constant factor 2 on the basis of data from [13] (Figure B13).

Finally, we have tried to simulate also the experimental conditions of Quarderer [14]: temperature $262^{\circ} \mathrm{C}$, total pressure 122 atm, GHSV 33,7 mol/h/kg-cat, $\mathrm{H}_{2} / \mathrm{CO}$ ratio 1:1. Our predictions together with the experimental data are published in table B5. Unfortunately, at these experimental conditions (very low temperature and GHSV) our sets of kinetic parameters is not able to fit correctly the experimental data (neither CO conversion, nor distribution of alcohols).

Table B5. Comparison of experimental data published in Quarderer [14] with data calculated using the $2^{\star}$ PFR and PFR,2*Alcohols, ${ }^{\star}{ }^{\star} \mathrm{HC}$, respectively.

\begin{tabular}{|l|r|r|r|}
\hline \multicolumn{1}{|c|}{ wt. \% } & $\begin{array}{c}\text { Experimental } \\
\text { data }\end{array}$ & 2*PFR & 2*Alcohols, 1*HC \\
\hline water & - & 0.80 & 0.67 \\
\hline methanol & 36 & 8.14 & 8.47 \\
\hline ethanol & 38 & 79.40 & 80.40 \\
\hline propanol & 13 & 11.66 & 10.46 \\
\hline butanol & 3 & - & - \\
\hline Xco, \% & 29 & 6.54 & 6.66 \\
\hline
\end{tabular}

Nevertheless in case of total carbon selectivities to mixed alcohols, on a carbon dioxide free basis, (Figures B28 and B29) when multiplying the gross rates of alcohols by constant factor of 2 and hydrocarbons by constant factor of 1, we have achieved good results. However for creating these plots we have fixed the $\mathrm{H}_{2} / \mathrm{CO}$ ratio (1.2) [14] and we have supposed that the 
authors used in these experiments a total pressure of 122 atm and a GVSH of 33,7 mol/h/ $/ \mathrm{kg}$-cat as in previous experiments.
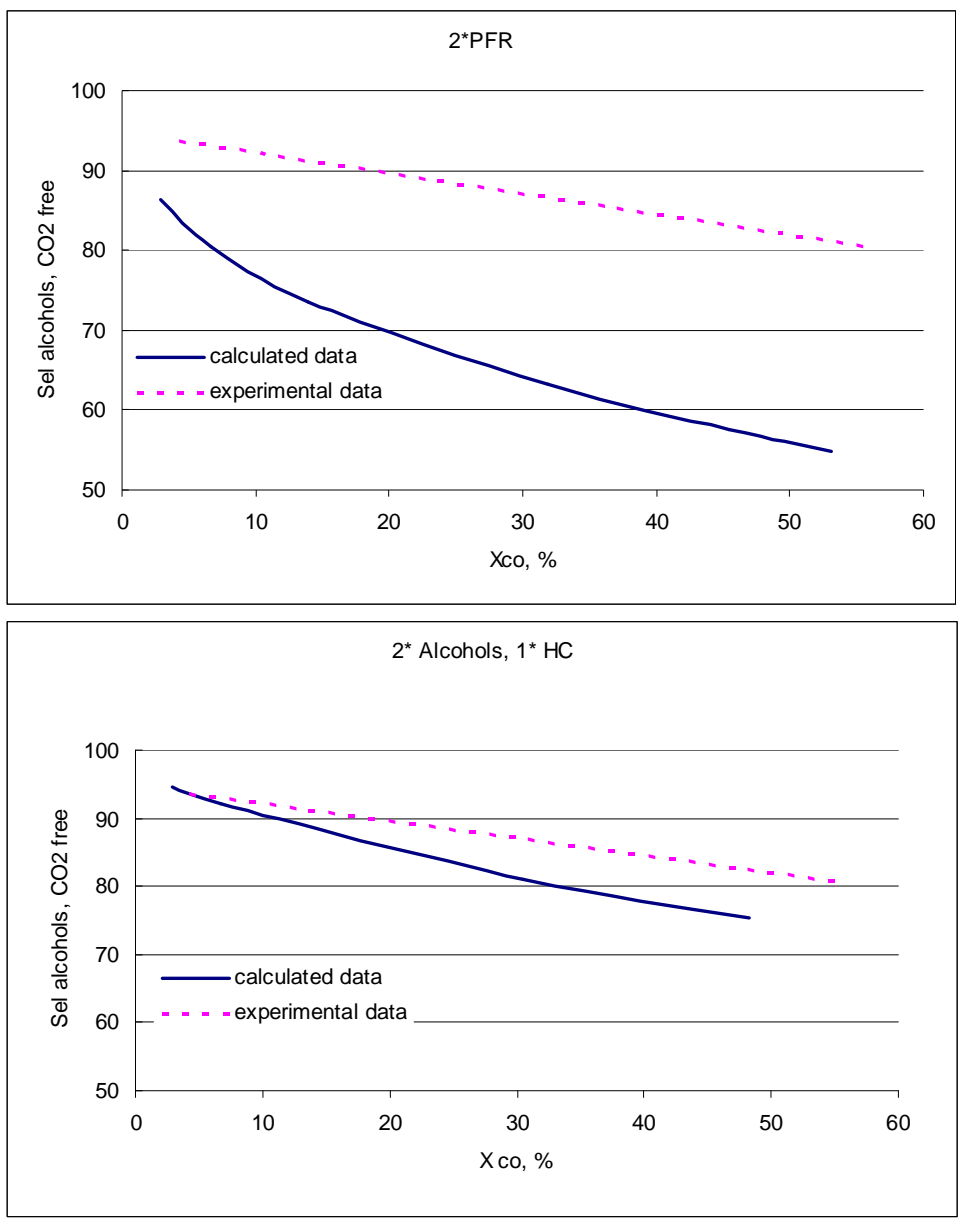

Figure B28. Carbon selectivity to mixed alcohols [\%], experimental data [14] and data calculated using a constant factor of 2.

Figure B29. Carbon selectivity to mixed alcohols [\%], experimental data [14] and data calculated using constant factor of 2 for alcohols rate of formation and 1 for $\mathrm{HC}$.

\section{B.2.3 Conclusions}

The ability of the lumped kinetic model to predict both the $\mathrm{CO}$ conversion and the product distribution of the higher alcohol synthesis over Mo-based catalysts was tested against experimental data measured at different reaction conditions (type of reactor, catalyst, $\mathrm{T}$, $\mathrm{P}$, inlet flows, GHSV) obtained from various literature sources [12, 13, 14].

Considering that all the three sources make use of different catalysts and experimental conditions, the best agreement between experimental and calculated data for PFR reactor models, for both the $\mathrm{CO}$ conversion and distribution of products, was obtained by multiplying the gross rates of individual alcohols by a constant factor equal to 2 and the gross rate of hydrocarbons by a constant factor of 1 . 


\section{B.3 Literature cited}

[1] G. Natta, U. Colombo, I. Pasquon, in Catalysis (P.H. Ammet, Ed.), Vol V., Charter 3, Reinhold, New York, 1957, p.131.

[2] P. Forzatti, E. Tronconi, I. Pasquon, Catal. Rev.-Sci.Eng., 33 (1\&2), 109-168 (1991).

[3] K.A.N. Verkerk, B. Jaeger, C.-H. Finkeldei, W. Keim, Appl. Catal. A: General, 186, 407431 (1999).

[4] R.G. Herman, Catal. Today, 55, 233-245 (2000).

[5] Z. Liu, X. Li, M.R. Close, E.L. Kugler, J.L. Peterson, D.B. Dadyburjor, Ind. Eng. Chem. Res., 36, 3085-3093 (1997).

[6] A.N. Gunturu, E.L. Kugler, J.B. Cropley, D.B. Dadyburjor, Ind. Eng. Chem. Res., 37, 2107-2115 (1998).

[7] A. Aden, P. Spath, B. Atherton, NREL Milestone Completion Report "The Potential of thermochemical Ethanol Via Mixed Alcohols Production", (2005).

[8] Ullmann's Encyclopedia of Industrial Chemistry, Fifth, Completely Revised Edition, Volume A16, B. Elvers, S. Hawkins, G. Schulz (Eds.), ISBN 3-527-20116-5 (VCH, Wienheim).

[9] J.F. Painter and A.C. Hindmarsh, Computing and mathematics research division, 1-316, Lawrence Livermore national laboratory, Livermore, 1987.

[10] G. Buzzi-Ferraris, E. Tronconi, "BUNLSI - A FORTRAN program for solution of systems of nonlinear algebraic equations", Comput. Chem. Eng. 10, 129-141 (1986).

[11] L. Bisset, Chem. Eng. (N.Y.) 84 (1997) no.21, 155.

[12] X. Li, L. Feng, Z. Liu, B. Zhong, D.B. Dadyburjor and E.L. Kugler, Ind. Eng. Chem. Res., 37, 3853-3863 (1998).

[13] T. Yun Park, I.S. Nam and Y. Gul Kim, Ind. Eng. Chem. Res., 36, 5246-5257 (1997).

[14] G.J. Quarderer, 78th Spring National AIChe Meeting, April 6-10, 1986, New Orleanse, Luisiana. 


\section{APPENDIX C: ANALYSIS AND SIMULATION OF A RECTISOL-BASED ACID GAS PURIFICATION PROCESS ${ }^{15}$}

\section{C.1 Background}

The study reported in this appendix analyses the performances of a commercially wellknown process for acid gas washing with the major scope of quantifying the utilities consumptions in relation with the raw gas produced within a specific plant for the gasification of the black liquor produced by the US Pulp \& Paper industry.

The process commercial name is Rectisol and its license is property of Lurgi Oel-GasChemie $\mathrm{GmbH}$ and Linde AG.

The analysis was performed via a detailed study on the thermodynamics bases for the Rectisol and the major Study outcome is an Aspen Plus simulation (Aspentech) (http://www.aspentech.com), a flexible tool able to provide basic information on a "Rectisollike" process performances when the operating variables and feed characteristics are varied.

The Rectisol process is particularly suitable to turn the gas produced by the gasification of coal or other carbon-based materials into a valuable gas composed essentially of $\mathrm{H}_{2}$ and $\mathrm{CO}$ in various ratios (so called syngas) by removing impurities such as $\mathrm{H}_{2} \mathrm{~S}, \mathrm{CO}_{2}, \mathrm{HCN}, \mathrm{NH}_{3}$, mercaptans, etc. which are the most frequent gasification by-products, depending of course on the gasifier feed.

Lurgi (Gas Generation and Purification Division) affirms [Ref. 5] that Rectisol is a technology that always requires a tailor-made design to the actual application: the design needs therefore to consider the upstream gasification technology, the downstream use of purified gas as well as the specifications for the offgases and the sulfur-rich gas streams.

Lurgi in fact claims that the design is certainly influenced by small "bugs" (e.g. trace contaminants in the raw gas) which might be present down to the ppb range. On the other hand, Lurgi confirms that even though, based on the previous statements, a non-proprietary simulation model such as an Aspen one, cannot provide detailed design information, it is useful to obtain general information on the main process components and the major process performances.

The present Study was conducted following this philosophy.

\section{C.1.1 The selected Rectisol process layout}

Several Rectisol process design configurations exist, in certain cases substantially different with each other, as the purified gas applications can be quite diverse.

In the present Study, the base-design was reproduced, following the original 1982 US Patent [Ref. 1] as this design definitely fits the needs for the black liquor gasification case and in addition the detailed description given in the Patent was a strong support to the comprehension of the process design.

Furthermore, the consistency of the results provided by the Aspen simulation could be verified against the information available in Literature [Refs. 2,3], most of all regarding the process utilities consumptions, as these information will be integrated in the Study on the Black Liquor Gasification Plant.

\footnotetext{
${ }^{15}$ Author: Eng.Vittorio Felli
} 


\section{C.2 “Rectisol-based" process design \& features}

\section{C.2.1 Process principles}

The process presented here was designed to treat a raw acid gas containing sulphur compounds $\left(\mathrm{H}_{2} \mathrm{~S} \& \mathrm{COS}\right)$ and carbon dioxide which need to be entirely removed from the gas phase using a physical scrubbing liquid (methanol), in order to produce a "clean" gas to further process units. The acid gases on the other hand are separated in at least two gas streams.

The process presented in this Study was designed trying inspiration from the layout described in [Ref. 1] US Patent 4,324,567 (April 13, 1982), assigned to Linde: "Separation of Gaseous Components from a Gaseous Mixture by Physical Scrubbing"; this patented process received the market name of Rectisol ${ }^{\circledR}$.

As already discussed in paragraph C.1, the results presented and the Aspen simulation itself is claimed to be representative of a "Rectisol-based" acid gas washing, and not of course of the Rectisol itself.

\section{C.2.2 Process duties}

Input stream:

The raw acid gas feed has the following characteristics (reference values):

- Flowrate: $\quad 90,000 \mathrm{Nm}^{3} / \mathrm{h}$

- $\mathrm{H}_{2} \mathrm{~S}$ content: $2 \%$ vol

- $\mathrm{CO}_{2}$ content: $20 \%$ vol

- COS: $\quad 0.02 \%$ vol

- Present gas species: $\mathrm{CH}_{4}, \mathrm{CO}, \mathrm{CO}_{2}, \mathrm{H}_{2} \mathrm{~S}, \mathrm{COS}, \mathrm{H}_{2}, \mathrm{NH}_{3}$, $\mathrm{Ar}$

Products \& duty specifications:

- Clean gas from the raw acid gas Absorber:

$\mathrm{H}_{2} \mathrm{~S}+\mathrm{COS}$ content: $<0.1 \mathrm{ppm}$ vol

$\mathrm{CO}_{2}$ content: $<1 \%$ vol

- $\mathrm{CO}_{2}$-concentrated gas:

$\mathrm{CO}_{2}$ content $>97 \%$ vol

$\mathrm{H}_{2} \mathrm{~S}+\mathrm{COS}$ content: none

- Tailgas:

$\mathrm{CO}_{2}$ content $50 \%$ vol

$\mathrm{H}_{2} \mathrm{~S}+\mathrm{COS}$ content:none

- Acid gas stream (feed to a sulphur recovery unit, e.g. Claus ${ }^{\circledR}$ ):

$\mathrm{H}_{2} \mathrm{~S}+\mathrm{COS}$ content: $>40 \%$ vol

$\mathrm{CO}_{2}$ remaining

Note that in the following description, " $\mathrm{H}_{2} \mathrm{~S}$ " will refer to both species $\mathrm{H}_{2} \mathrm{~S}$ and COS: this shortcut was adopted as only traces of COS are present in the feed gas. A further support to this simplification is given in paragraph C.4.

\section{C.2.3 Process bases}

The basic concepts for process design are underlined here below (refer to fig. C1). A more detailed description of the thermodynamics can be found in paragraph C.3. 
- The acid gas $\mathrm{CO}_{2}$ and $\mathrm{H}_{2} \mathrm{~S}$ are absorbed by a physical scrubbing liquid at high pressure without any chemical reaction, in order for the solvent to be easily regenerated via indirect heating at the Regenerator column (C4 in fig. C1). At the same time, the solvent must be not volatile at the Absorber operating conditions in order to reduce the solvent losses in the product gas: methanol at low temperatures $\left(<-20^{\circ} \mathrm{C}\right)$ presents these characteristics.

- As the $\mathrm{CO}_{2}$ absorption in polar solvents is a relatively highly exothermic process, the methanol solvent needs to be fed to the Absorber column ( $\mathrm{Cl}$ in fig. C1) at a low temperature (its value depends in turn on the operating pressure) in order also to maintain a low operating temperature in the column and consequently to reduce the volatility of the acid gas absorbed as much as possible. If the solvent feed temperature is not sufficiently low, the heat released by the absorbed $\mathrm{CO}_{2}$ would raise the liquid temperature up to the point at which any further gas absorption would be prevented.

- The $\mathrm{H}_{2} \mathrm{~S}$ is roughly five times more soluble in methanol than $\mathrm{CO}_{2}$ : this fact is used to separate the two absorbed acid gas. One single column might be used to separate a portion of the $\mathrm{CO}_{2}$ absorbed in the loaded solvent (methanol $+\mathrm{CO}_{2}+\mathrm{H}_{2} \mathrm{~S}$, stream ClD3) obtaining a pure $\mathrm{CO}_{2}$ stream; in effect the physical characteristics of the system require the use of stripping nitrogen in a further column in order to increase the $\mathrm{CO}_{2}$ volatility and to drastically reduce its content in the methanol liquid stream.

The process is composed of four main blocks (refer to fig. C1):

- The Acid Gas Absorber Cl: the raw gas enters the column at the bottom section and it is contacted with the scrubbing methanol introduced at the top of the column.

- The $\mathrm{H}_{2} \mathrm{~S}$ Concentrator $\mathrm{C2}$ : the methanol rich in the absorbed acid gas is concentrated in hydrogen sulphide as the carbon dioxide, the more volatile compound, is obtained almost pure at the top of the column.

- The $\mathrm{CO}_{2}$ Stripper $C 3$ : the methanol stream concentrated in $\mathrm{H}_{2} \mathrm{~S}$ is contacted with stripping nitrogen; another portion of the $\mathrm{CO}_{2}$ absorbed in the Acid Gas Absorber is transferred back to the gas phase, so that a gas mixture of $\mathrm{N}_{2}$ and $\mathrm{CO}_{2}$ is obtained at the top of the stripper.

- The Solvent Regenerator C4: the liquid bottom from the $\mathrm{CO}_{2}$ Stripper, containing the $\mathrm{H}_{2} \mathrm{~S}$ absorbed in the Acid Gas Absorber and the remaining $\mathrm{CO}_{2}$ is regenerated in the regeneration column via indirect heating with steam. Following a further cooling at low temperature to condensate the methanol present in the gas phase, the gas exiting the top of the column is composed of $\mathrm{H}_{2} \mathrm{~S}$ and $\mathrm{CO}_{2}$ and it can be routed to a Sulphur Recovery Unit (outside the scope of the present Study).

\section{C.2.4 Process description}

Refer to fig. C1. 


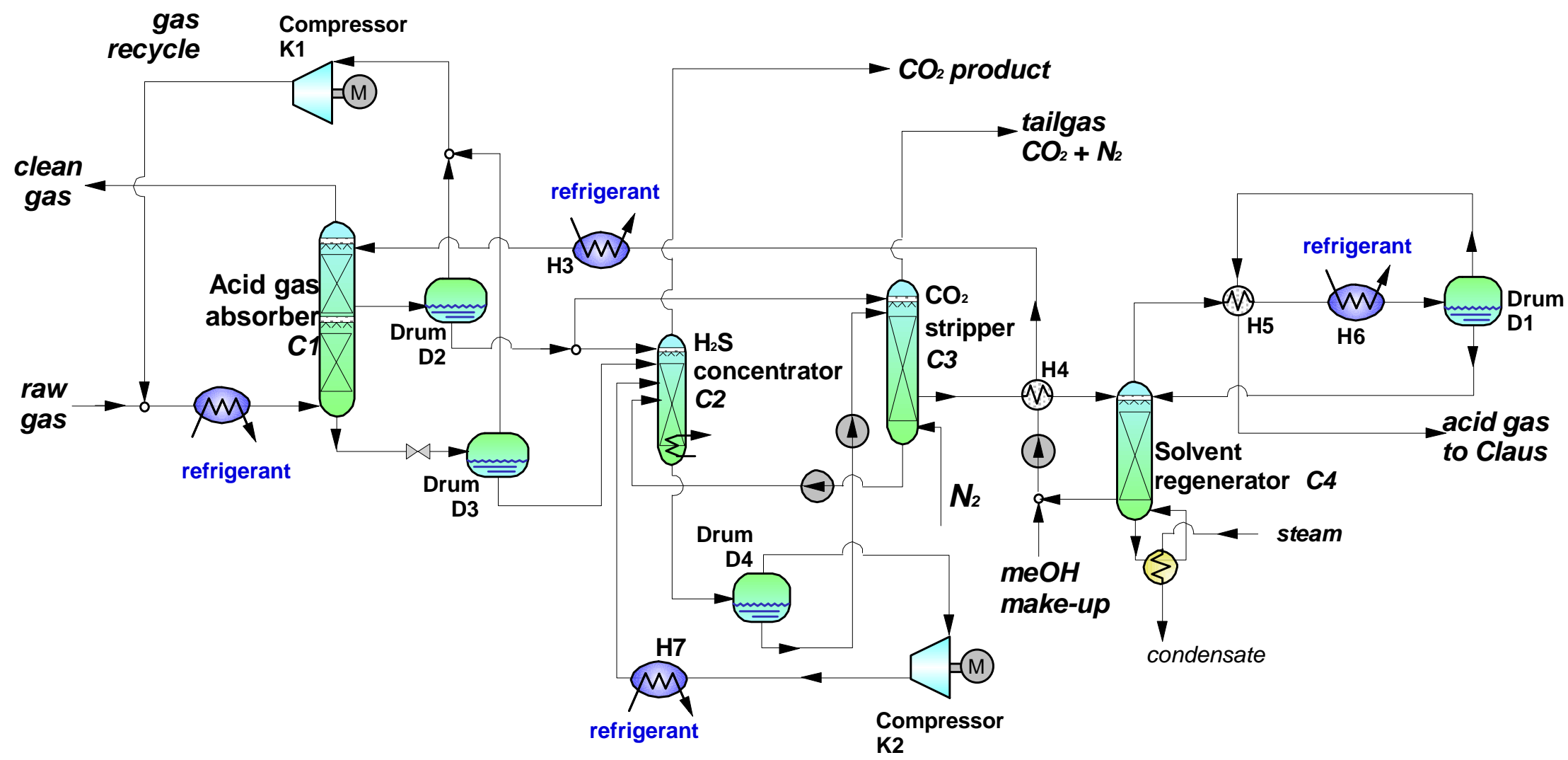

Figure $\mathrm{C} 1: \mathrm{H}_{2} \mathrm{~S}+\mathrm{CO}_{2}$ absorption

C. 4 


\section{C.2.4.1 The Acid Gas Absorber C1}

The pressure of the column was fixed at 32 bar based on the pressure of the raw feed gas (EXH1), which is an external input. This high pressure raw gas stream $E X H 1$ is pre-cooled in the exchanger $H 1$ by the lean gas stream $C 1 H 1$; it is then mixed with the recycle gas $K 1 M 2$ to be finally cooled in the exchanger $H_{2}$ before being introduced at the bottom stage of the absorber column $C 1$.

The absorber is composed of two columns, one on top of the other: part of the upper column bottom liquid is introduced at the top of the bottom column while the gas exiting the bottom column feeds the upper column.

- The bottom column is the $\mathrm{H}_{2} \mathrm{~S}$ Absorption Section where the H2S originally present in the raw gas is totally absorbed by the scrubbing methanol, while only part of the $\mathrm{CO}_{2}$ is absorbed, as this is less soluble than $\mathrm{H}_{2} \mathrm{~S}$ in methanol. Furthermore, as the $\mathrm{CO}_{2}$ absorption in polar solvents is an exothermic phenomenon, the portion of absorbed $\mathrm{CO}_{2}$ in the bottom section raises the liquid temperature in the column so that the driving force for the $\mathrm{CO}_{2}$ absorption itself sharply decreases and the $\mathrm{CO}_{2}$ remaining in the gas phase requires a further treatment in the upper section to be completely absorbed.

- In the upper section, the $\mathrm{CO}_{2}$ which left in the gas phase is completely absorbed by means of the top low-temperature pure methanol liquid stream $\mathrm{H} 3 \mathrm{Cl}$.

It is clear thereby that while pure methanol is fed at the top of the absorber $C 1$, methanol rich in $\mathrm{CO}_{2}$ is fed at the top of the $\mathrm{H}_{2} \mathrm{~S}$ absorber.

On the other hand, two liquid streams exit the absorber $C 1$ :

- C1D2: rich in $\mathrm{CO}_{2}$ while no $\mathrm{H}_{2} \mathrm{~S}$ is present

- C1D3: rich in both acid gases $\mathrm{H}_{2} \mathrm{~S}$ and $\mathrm{CO}_{2}$

Note that clearly other gases which are much less soluble in methanol with respect to $\mathrm{H}_{2} \mathrm{~S}$ and $\mathrm{CO}_{2}$ at the operating conditions might still be partially absorbed in the liquid phase and this could be a problem as they might be valuable products for purposes of the Process Designer. To solve this issue, two flash drums $D 2$ and $D 3$ at an intermediate pressure $(7.5$ bar) between the Absorber and the Solvent Regenerator pressure were introduced: the less soluble gas (such as $\left.\mathrm{CO}, \mathrm{H}_{2}, \mathrm{Ar}, \ldots\right)$ are re-transferred in the gas phase and they can be recycled to the column via the compressor $K 1$.

\section{C.2.4.2 The $\mathrm{H}_{2} \mathrm{~S}$ Concentrator $\mathrm{C} 2$}

This column is designed to enrich the down coming liquid in $\mathrm{H}_{2} \mathrm{~S}$ by a selective desorption of $\mathrm{CO}_{2}$, the less soluble component. Column $C 2$ is composed of two sections:

- The bottom section is the stripping column: both $\mathrm{H}_{2} \mathrm{~S}$-loaded streams $D 3 C 2$ from the absorber $\mathrm{Cl}$ and $\mathrm{P} 4 \mathrm{C} 2$ from the $\mathrm{CO}_{2}$ Stripper are fed to the column to let the gas being desorbed. The stripping gas is provided by the low pressure (1 bara) flash vaporization of the bottom $C 2$ residue $C 2 D 4$ in drum $D 4$ : the gas phase is re-compressed through compressor $K 1$, cooled in exchanger $H 7$ and introduced at $C 2$ bottom.

- The top section is the $\mathrm{H}_{2} \mathrm{~S}$ absorber that in fact is absorbed by the stream $S 1 C 2$, coming from the absorber $C 1$, which is rich in $\mathrm{CO}_{2}$ but does not contain any $\mathrm{H}_{2} \mathrm{~S}$.

Therefore, two streams exit the $\mathrm{H}_{2} \mathrm{~S}$ Concentrator $\mathrm{C} 2$ : 
- C2EX: gas stream exiting the top stage of the $\mathrm{H}_{2} \mathrm{~S}$ Concentrator, which is composed of $\mathrm{CO}_{2}\left(>97 \%\right.$ vol) and other gases, excluding $\mathrm{H}_{2} \mathrm{~S}$.

- P2C3: liquid stream containing both $\mathrm{CO}_{2}$ and $\mathrm{H}_{2} \mathrm{~S}$; a portion of these gaseous components was already released in the low pressure vessel $D 4$.

\section{C.2.4.3 The $\mathrm{CO}_{2}$ Stripper $\mathrm{C} 3$}

This column leads to a further extent the $\mathrm{CO}_{2}$ desorption from the acid gases rich solvent from column $C 2$ as it works at a lower pressure ( 2 bar) with respect to $C 2$ and stripping nitrogen is used in order to obtain a tailgas with no $\mathrm{H}_{2} \mathrm{~S}$ on top of the stripper. The Stripper $C 3$ is again composed of two sections:

- the bottom one is the stripping section: the stream $P 2 C 3$ is fed at the top (theoretic) plate while the stripping nitrogen is introduced at the bottom one. Both $\mathrm{CO}_{2}$ and $\mathrm{H}_{2} \mathrm{~S}$ are stripped from the liquid solvent.

- The gas leaving the bottom section is then scrubbed in the top one via the liquid stream $S 1 C 3$ which comes from the absorber $C 1$ and it is rich in $\mathrm{CO}_{2}$ but it does not contain any $\mathrm{H}_{2} \mathrm{~S}$. In the top $\mathrm{H}_{2} \mathrm{~S}$ scrubbing section, $\mathrm{H}_{2} \mathrm{~S}$ is completely absorbed in the liquid phase.

Three product streams exit the $\mathrm{CO}_{2}$ Stripper $\mathrm{C} 3$ :

- C3EX: tailgas composed of $\mathrm{CO}_{2}$ and nitrogen, roughly in the same ratio.

- $\mathrm{C} 3 \mathrm{H} 4$ : liquid stream containing the $\mathrm{CO}_{2}$ left in the solvent after the stripping columns and practically the whole $\mathrm{H}_{2} \mathrm{~S}$ which is absorbed in the Absorber $C 1$. This stream is routed to the Solvent Regenerator C4.

- C3P4: liquid stream to the bottom section of column $C 2$.

\section{C.2.4.4 The Solvent Regenerator C4}

The methanol solvent is fed to an intermediate plate of the atmospheric Regenerator C4 and the stripping heat is provided by the low pressure steam reboiler.

As methanol boiling temperature at atmospheric pressure is around $65^{\circ} \mathrm{C}$ and methanol is quite volatile at these operating conditions, the column top section is provided with a heat exchanger $H 6$, fed by a refrigerant, which cools down the vapors to a temperature low enough ($10^{\circ} \mathrm{C}$ ) that practically all the methanol is condensed and re-routed to the column $C 4$ as reflux.

$H 6$ is represented in fig. $\mathrm{C} 1$ as external to column $C 4$, but indeed it is quite common having it inside the very top section of the Regenerator, above the first plate.

This is a fundamental design item as it prevents high solvent losses.

\section{C.2.5 Key process data \& variables}

\section{C.2.5.1 $\mathrm{CO}_{2}$ heat of absorption in methanol.}

As already pointed out, the $\mathrm{CO}_{2}$ absorption in polar solvents is an exothermic phenomenon: if the heat released increases the scrubbing liquid temperature above a certain point, depending on the Absorber pressure, the absorption cannot take place and only a very small part of the column is effective.

Two process variables are strictly dependent on this phenomenon:

- the scrubbing methanol circulation rate to the Absorber Cl (and consequently, for a fixed gas rate fed to the column, the molar ratio liquid/gas);

- the scrubbing methanol feed temperature to Absorber C1. 
Both variables contribute to maintain a sufficiently low operating temperature inside the Absorber and consequently a good acid gas absorption level: the first variable, which must be above a minimum, provides a sufficiently high liquid heat capacity, while the second variable, which must be below a maximum, prevents any hot spot throughout the column.

This basic equations and models governing the effect of the previous variables are extensively presented in paragraph C.3, while figures C2-C3 show the effect of the methanol circulation rate on the clean product gas quality.

\section{C.2.5.2 Different $\mathrm{H}_{2} \mathrm{~S}$ and $\mathrm{CO}_{2}$ solubility in methanol}

This property guarantees the possibility of separating the two gases downstream of the Absorber, obtaining therefore two $\mathrm{CO}_{2}$ rich gas streams containing no $\mathrm{H}_{2} \mathrm{~S}$. The relative solubility of the two acid gases has a number of implications on the process design, mainly on the solvent flowrates selected for the various column of the layout of fig. $\mathrm{C} 1$ : as an example, the flow ratio between streams $C 1 D 2$ and $C 1 D 3$ is quite important for the Absorber design.

Refer again to paragraph C.3 for details.

\section{C.2.5.3 Methanol volatility}

Among other polar solvents, methanol is used in Rectisol process as it is relatively cheap and at the selected Absorber operating conditions it is not volatile: it is generally assumed that the solvent losses to the product gas are negligible.

\section{C.2.6 Aspen Plus Model}

The model here presented was simulated with the Aspen Plus Process Simulator; the Aspen Plus file, the heat and material balance together with the most useful concentration and temperature profiles for the various column are reported in paragraph C.4.

The simulation performed provides all the information on the "Rectisol-based" plant included in the scope of the present Study.

It is quite important though reminding here that the process simulation performed in the present Study and the Rectisol process available on the market share the same design principles but of course a large amount of information related to Rectisol are not available in the Literature as they are property of the Licensor. This implies that the model designed here must be taken as a first approximation of the industrial plant. This is particularly true for the secondary product streams such as the "Tailgas" or the " $\mathrm{CO}_{2}$ gas": in certain cases the Aspen Model cannot provide for these streams exactly the same characteristics that the Rectisol would provide and this is only because of the lack of proprietary information.

\section{C.2.7 Aspen Plus Model results and discussion}

The results of the Aspen Plus process simulation are reported in detail in paragraph C.4.

Here below, the overall results and performance parameters are presented in comparison with the published data, in order to confirm the reliability of the Model.

- Table C1: the Model and the original Patent [Ref. 1] are compared in terms of main streams characteristics

- Table C2: the Model and the original Patent [Ref. 1] are compared in terms of overall performance parameters

- Table C3: the Model utilities consumptions are compared to the data available in Literature. 


\begin{tabular}{|c|c|c|c|c|c|c|c|c|}
\hline & $\begin{array}{l}\text { raw gas to } \\
\text { Absorber }\end{array}$ & $\begin{array}{c}\text { lean scrubbing } \\
\text { MeOH to } \\
\text { Absorber }\end{array}$ & \begin{tabular}{|c|} 
solvent to \\
Absorber \\
bottom section
\end{tabular} & $\begin{array}{l}\text { clean gas } \\
\text { product }\end{array}$ & $\begin{array}{l}\mathrm{CO} 2 \text { gas } \\
\text { product }\end{array}$ & stripping N2 & Tailgas & $\begin{array}{l}\text { Claus gas (to } \\
\text { sulphur } \\
\text { recovery unit) }\end{array}$ \\
\hline \multicolumn{9}{|c|}{ Aspen Plus Model for present Study } \\
\hline Absorber pressure (bara) & 32 & & & & & & & \\
\hline Methanol top Absorber stage T $\left({ }^{\circ} \mathrm{C}\right)$ & -60 & & & & & & & \\
\hline \multicolumn{9}{|l|}{ FLOW } \\
\hline $\mathrm{Nm} 3 / \mathrm{h}$ & 91188 & & & 70338 & 12969 & 4035 & 8037 & 3954 \\
\hline $\mathrm{t} / \mathrm{h}$ & & 230 & 113 & & & & & \\
\hline $\mathrm{kmol} / \mathrm{s}$ & 1.13 & 2.00 & 0.90 & 0.87 & 0.161 & 0.05 & 0.10 & 0.05 \\
\hline \multicolumn{9}{|l|}{ COMPOSITION } \\
\hline $\mathrm{CO} 2(\mathrm{~mol} \%)$ & $20.95 \%$ & & & $0.45 \%$ & $97.95 \%$ & & $49.52 \%$ & $53.21 \%$ \\
\hline $\mathrm{H} 2 \mathrm{~S}+\mathrm{COS}(\mathrm{mol} \%$ / ppm vol) & $1.93 \%$ & & & 0.0007 & $0.18 \%$ & & $0.14 \%$ & $43.60 \%$ \\
\hline CO2/S-compounds (mol/mol) & 11 & & & & & & & \\
\hline $\mathrm{H} 2(\mathrm{~mol} \%)$ & $37.57 \%$ & & & $48.65 \%$ & & & & \\
\hline $\mathrm{CO}(\mathrm{mol} \%)$ & $36.09 \%$ & & & $46.63 \%$ & & & & \\
\hline $\operatorname{Ar}(\mathrm{ml} \%)$ & $1.01 \%$ & & & $1.23 \%$ & & & & \\
\hline $\mathrm{CH} 4(\mathrm{~mol} \%)$ & $2.06 \%$ & & & $2.54 \%$ & & & & \\
\hline $\mathrm{N} 2(\mathrm{~mol} \%)$ & $0.37 \%$ & & & $0.41 \%$ & & & $49.34 \%$ & \\
\hline $\mathrm{NH} 3(\mathrm{~mol} \%)$ & $0.01 \%$ & & & $0.00 \%$ & & & & \\
\hline Methanol (mol \%) & $0.00 \%$ & $99.995 \%$ & & $0.00 \%$ & $0.0955 \%$ & & $0.0563 \%$ & $1.6546 \%$ \\
\hline \multicolumn{9}{|c|}{ Rectisol Patent (Ref. 1) } \\
\hline Absorber pressure (bara) & 75 & & & & & & & \\
\hline Methanol top Absorber stage $\mathrm{T}\left({ }^{\circ} \mathrm{C}\right)$ & -50 & & & & & & & \\
\hline \multicolumn{9}{|l|}{ FLOW } \\
\hline $\mathrm{Nm} 3 / \mathrm{h}$ & 100000 & & & 72500 & 23300 & 3000 & 5650 & 1480 \\
\hline$t / h$ & & 100 & 45 & & & & & \\
\hline $\mathrm{kmol} / \mathrm{s}$ & 1.24 & 0.87 & 0.39 & 0.90 & 0.289 & 0.04 & 0.07 & 0.02 \\
\hline \multicolumn{9}{|l|}{ COMPOSITION } \\
\hline $\mathrm{CO} 2(\mathrm{~mol} \%)$ & $26.00 \%$ & & & none & $99.00 \%$ & & $47.75 \%$ & $57.43 \%$ \\
\hline H2S+COS (mol\% / ppm vol) & $0.63 \%$ & & & none & $0.00 \%$ & & $0.00 \%$ & $42.57 \%$ \\
\hline CO2/S-compounds (mol $/ \mathrm{mol})$ & 41 & & & & & & & \\
\hline $\mathrm{H} 2(\mathrm{~mol} \%)$ & $69.90 \%$ & & & $96.24 \%$ & & & & \\
\hline $\mathrm{CO}(\mathrm{mol} \%)$ & $1.70 \%$ & & & \multirow{3}{*}{$2.30 \%$} & & & & \\
\hline $\operatorname{Ar}(\mathrm{ml} \%)$ & & & & & & & & \\
\hline $\mathrm{CH} 4(\mathrm{~mol} \%)$ & & & & & & & & \\
\hline $\mathrm{N} 2(\mathrm{~mol} \%)$ & $1.18 \%$ & & & $1.61 \%$ & & & $53.10 \%$ & \\
\hline $\mathrm{NH3}(\mathrm{mol} \%)$ & $0.00 \%$ & & & & & & & \\
\hline Methanol (mol \%) & & $100.000 \%$ & & $0.00 \%$ & & & & \\
\hline
\end{tabular}

\section{Table C1}


scrubbing MeOH to Absorber (top stage)/MeOH to Absorber bottom section $(\mathrm{kg} / \mathbf{k g})$

lean $\mathrm{MeOH} / \mathrm{CO} 2$ flow in raw gas $(\mathrm{mol} / \mathrm{mol})$

lean $\mathrm{MeOH} / \mathrm{H} 2 \mathrm{~S}$ flow in raw gas $(\mathrm{mol} / \mathrm{mol})$ )

lean $\mathrm{MeOH} / \mathrm{raw}$ gas $(\mathrm{mol} / \mathrm{mol})$

$\mathrm{CO} 2$ in "pure" CO2 product / raw gas $\mathrm{CO} 2(\mathrm{~mol} / \mathrm{mol})$

$\mathrm{CO} 2$ in Tailgas / raw gas $\mathrm{CO} 2(\mathrm{~mol} / \mathrm{mol})$

CO2 in "Claus Gas" / raw gas $\mathrm{CO} 2(\mathrm{~mol} / \mathrm{mol})$

H2S in "Claus Gas" / raw gas H2S (mol/mol)

CO2/S-compounds (mol/mol) in "Claus Gas"

overall CO2/S-compounds concentration ratio

overall methanol losses (t/h)

\begin{tabular}{|c|c|}
\hline $\begin{array}{c}\text { Aspen Plus } \\
\text { Model for } \\
\text { present Study }\end{array}$ & $\begin{array}{c}\text { Rectisol Patent } \\
\text { (Ref. 1) }\end{array}$ \\
\hline 2.0 & 2.2 \\
\hline 8.4 & 2.7 \\
\hline 91.7 & 111.2 \\
\hline 1.8 & 0.7 \\
\hline 0.7 & 0.9 \\
\hline 0.2 & 0.1 \\
\hline 0.1 & 0.0 \\
\hline 1.0 & 1.0 \\
\hline 1.2 & 1.3 \\
\hline 8.9 & 30.6 \\
\hline 0.1 & not available \\
\hline
\end{tabular}

\section{Table C2}

\begin{tabular}{|c|c|c|c|}
\hline MODEL & $\begin{array}{c}\text { Aspen Plus } \\
\text { Simulation for } \\
\text { present Study }\end{array}$ & $\begin{array}{l}\text { Data published in } \\
\text { Ref. } 2\end{array}$ & $\begin{array}{c}\text { Data published in } \\
\text { Ref. } 3\end{array}$ \\
\hline Absorber pressure (bar) & 32 & 56 & 78 \\
\hline \multicolumn{4}{|l|}{ Raw acid gas to the Absorber } \\
\hline $\mathrm{CO} 2(\mathrm{kmol} / \mathrm{s})$ & 0.24 & 0.54 & 0.57 \\
\hline $\mathrm{H} 2 \mathrm{~S}(\mathrm{kmol} / \mathrm{s})$ & 0.02 & 0.02 & 0.004 \\
\hline $\mathrm{MeOH}$ circulation rate $(\mathrm{kmol} / \mathrm{s})$ & 2.00 & NA & NA \\
\hline \multicolumn{4}{|l|}{ CO2 product } \\
\hline Flow $(\mathrm{kmol} / \mathrm{s})$ & 0.16 & 0.52 & 0.36 \\
\hline $\mathrm{CO} 2(\mathrm{vol} \%)$ & $98 \%$ & $99 \%$ & $99 \%$ \\
\hline \multicolumn{4}{|l|}{ Claus gas from Regenerator } \\
\hline Flow $(\mathrm{kmol} / \mathrm{s})$ & 0.05 & 0.05 & 0.02 \\
\hline $\mathrm{CO} 2(\mathrm{vol} \%)$ & $53 \%$ & $42 \%$ & $68 \%$ \\
\hline $\mathrm{H} 2 \mathrm{~S}(\mathrm{vol} \%)$ & $44 \%$ & $47 \%$ & $27 \%$ \\
\hline Methanol make-up $(\mathrm{kg} / \mathrm{h})$ & 120 & 40 & 30 \\
\hline \multicolumn{4}{|l|}{ Refrigeration } \\
\hline Duty $(M W)$ & 7.41 & 4.20 & 2.00 \\
\hline H3 - major solvent refrigeration $(M W)$ & 4.34 & & \\
\hline Refrigerant temperature $\left({ }^{\circ} \mathrm{C}\right)$ & $<-60$ & -31 & -38 \\
\hline H2 feed gas cooler (MW) & 0.43 & & \\
\hline H6 regenerator top condenser $(M W)$ & 2.31 & & \\
\hline H7 Recycle gas cooler (MW) & 0.33 & & \\
\hline Cooling water @ regenerator top condenser (m3/h) & none & 133 & 300 \\
\hline Heating duty @ regenerator reboiler (MW) & 4.00 & 3.20 & 3.75 \\
\hline Shaft power @ methanol pumps (kW) & 421 & 1640 & 1100 \\
\hline
\end{tabular}

\section{Table C3}




\section{C.2.7.1 Discussion}

Tables C1 and C2 show a high reproducibility of the Patent data by the Model:

- the raw gas flow and the $\mathrm{CO}_{2} \& \mathrm{H}_{2} \mathrm{~S}$ compositions are very similar in the two cases in the different streams

- the distribution of the $\mathrm{CO}_{2}$ in the feed raw gas into the product streams and the Claus Gas (to Sulphur Recovery Unit) is reproduced quite consistently in the two cases

- the Claus Gas composition is very close in the two cases

- the overall $\mathrm{CO}_{2}$ concentration factor $\left[\left(\mathrm{CO}_{2} / \mathrm{S}\right.\right.$-compounds $\left.\mathrm{mol} / \mathrm{mol}\right)$ ratio between Claus Gas and the raw feed gas] has the same order of magnitude in the two cases

The two process layouts, although very similar, do present minor differences: the key ones are the Absorber pressure that in the Patent case is roughly 2.5 times as much the Model Absorber pressure. In addition, in the Patent case the Absorber column is provided of an interstage cooler which helps the absorption and which was not introduced in the Model layout.

The previous explain how the molar ratio methanol solvent/raw gas for the Model case is roughly 2 times as much the Patent value.

Table C3 compares the utilities consumption for the Aspen Model and the Rectisol typical plants data available in Literature.

The results have the same order of magnitude, which confirms again the Model consistency.

The heat duty to the Regenerator reboiler is higher in the Model case because the methanol circulation rate in the plant is higher, which in turn depends on the lower Absorber pressure in the Model case.

The previous considerations confirm that the main scope of the Present Study was achieved: the Model is a tool which allows a first evaluation of the Rectisol process performances in terms of lean gas characteristics, process key parameters and process utilities consumptions.

\section{C.2.7.2 Addenda}

1. It is clear from what previously explained that methanol circulation rate within the "Rectisolbased" plant has a very important effect on its utilities consumptions as they are mostly related to this key parameter.

It is important stressing the fact that the choice of the methanol circulation rate as per the Model results reported in paragraph C. 4 is not unique: a smaller value could have been selected respecting nevertheless the specifications on the product clean gas from the Absorber.

The choice of $2 \mathrm{kmol} / \mathrm{s}$ (methanol stream to the Absorber) guarantees though the best compromise between the utilities consumption values reported in Literature and the Aspen simulation results (although not perfect!) for all the process product streams, including the tailgas and the $\mathrm{CO}_{2}$ gas stream.

In this way, the utilities consumptions were slightly overestimated but the Aspen Model resulted being consistent.

The effects of methanol circulation rate on various process parameters are reported in figures $\mathrm{C} 3$ to $\mathrm{C6}$. 
2. Figures C7-C16 show the Aspen Model results in detail.

For each column or column section, the following variables are plot against the theoretic stages:

- temperature

- gas \& liquid molar flow

- $\mathrm{H}_{2} \mathrm{~S}$ and $\mathrm{CO}_{2}$ volume/molar concentration

Actually, it was thought that the previous figures, when compared to the explanations and the background given in paragraph C.3 could help to better understand the process basics.

Note that the numeration of the theoretic column stages always assigns the top column stage the number " 1 " (for each column section).

\section{C.2.8 Aspen Plus Model for the abatement of $\mathrm{H}_{2} \underline{\mathrm{S} \text { only }}$}

The Model prepared for the abatement of both acid gases $\mathrm{H}_{2} \mathrm{~S}$ and $\mathrm{CO}_{2}$ from the raw feed gas was modified and adapted to the case in which the specification on the $\mathrm{H}_{2} \mathrm{~S}$ in the clean product gas remains the same as in the previous model, while there is no target on the $\mathrm{CO}_{2}$.

In practice, the Absorber $\mathrm{Cl}$ (fig. C2) is composed of 1 column only (the upper one in the previous model is not required here) and the process scheme is adapted coherently.

As the process description is very similar to the one provided above, it is not reported here. The Aspen Plus process simulation was performed on two different acid gas feeds: one equal to the previous case fed, the other roughly 3 times as much in flow.

It is important to underline that:

- The simulated Rectisol-based process is able to achieve the desired separation even with this modified and unusual process layout.

- The utilities consumption are very close between the " $\mathrm{H}_{2} \mathrm{~S} \& \mathrm{CO}_{2}$ " and the " $\mathrm{H}_{2} \mathrm{~S}$-only" abatement cases at constant acid gas feed rate.

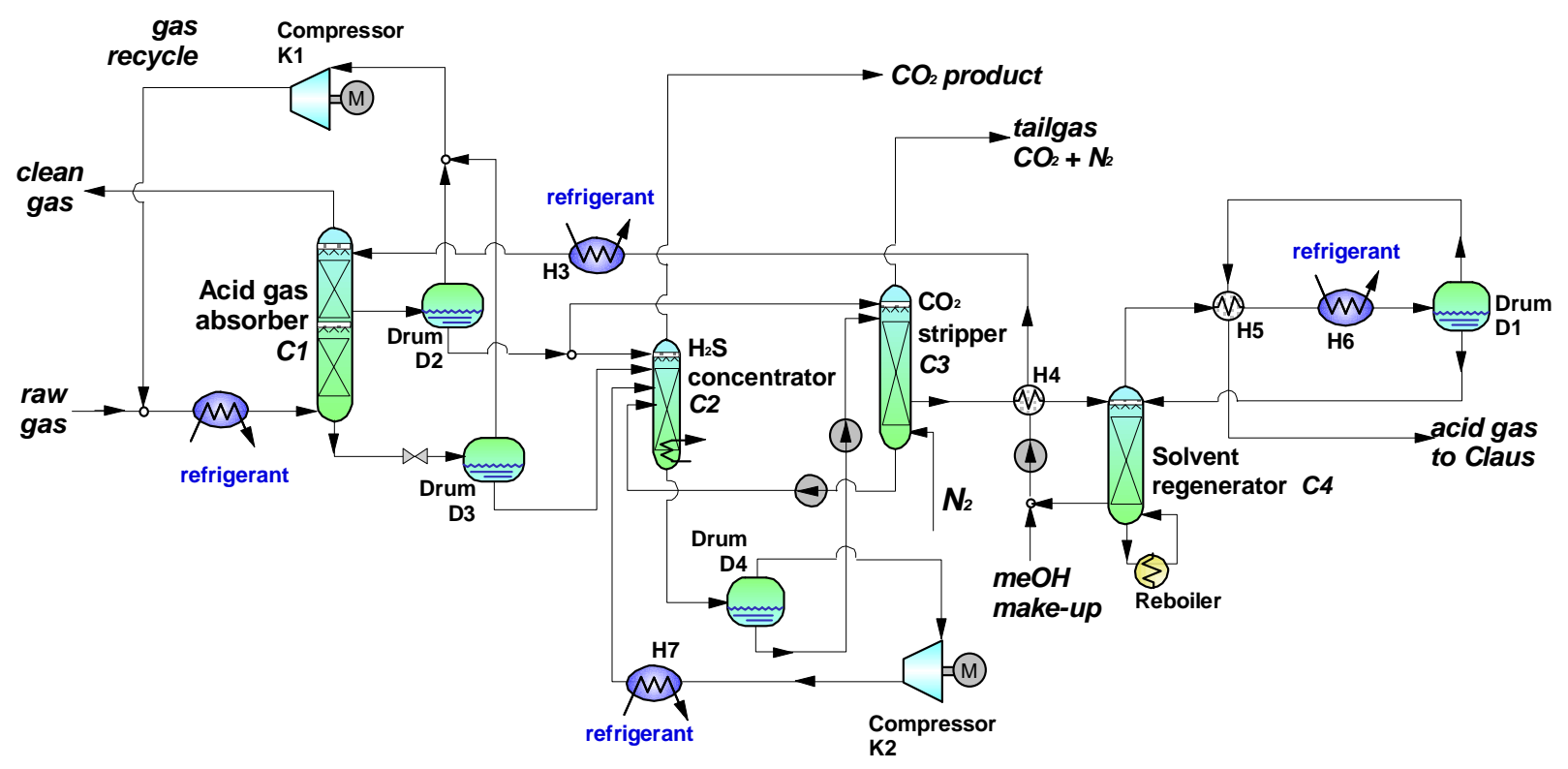

Figure $\mathrm{C2}$ : " $\mathrm{H}_{2} \mathrm{~S}$ only" absorption 


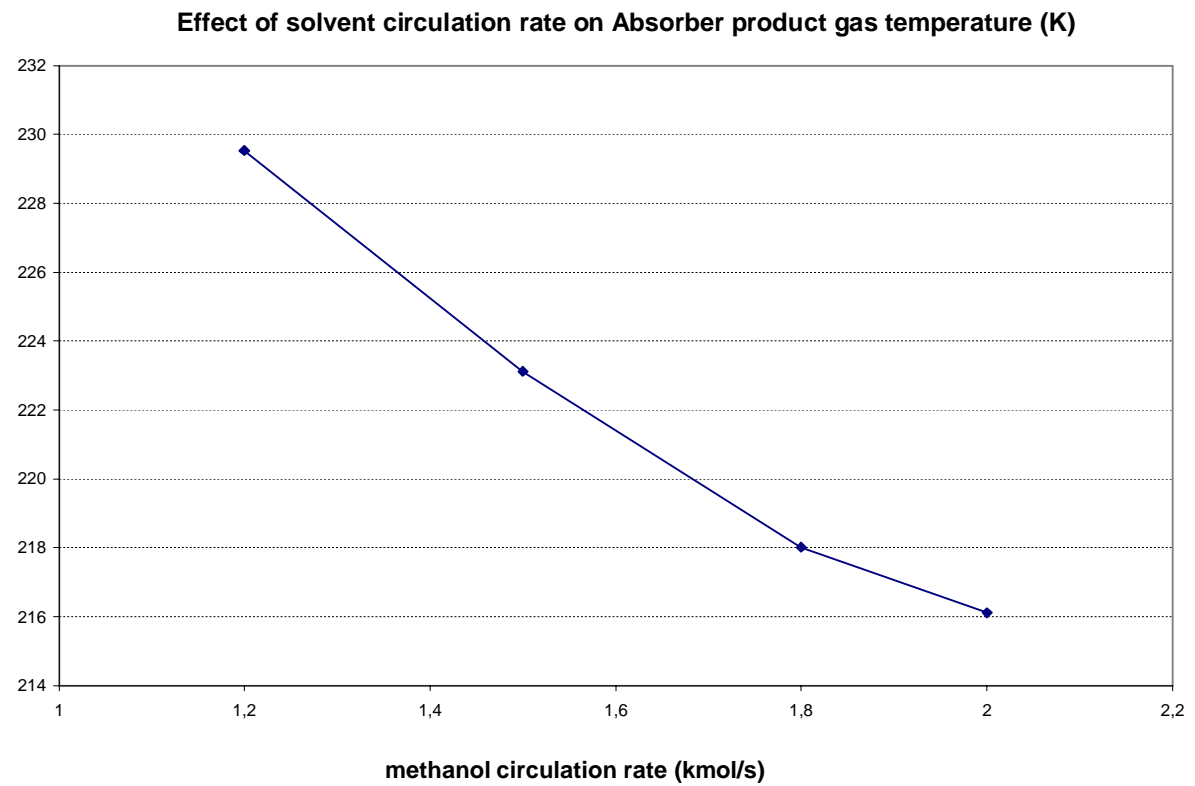

Effect of solvent circulation rate on $\mathrm{H} 2 \mathrm{~S}$ Absorber product gas concentration (ppm vol)

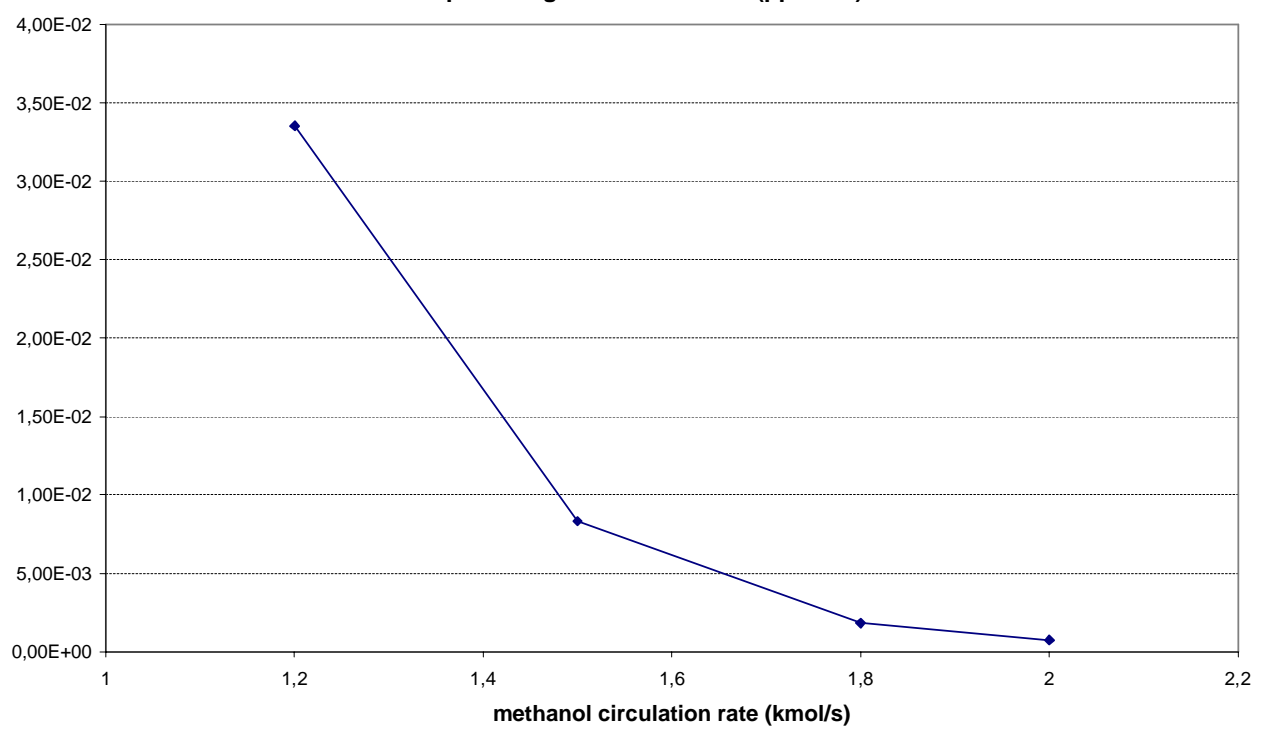

Figure C3: Effect of solvent circulation rate 
Effect of solvent circulation rate on $\mathrm{CO} 2$

Absorber product gas concentration (vol)

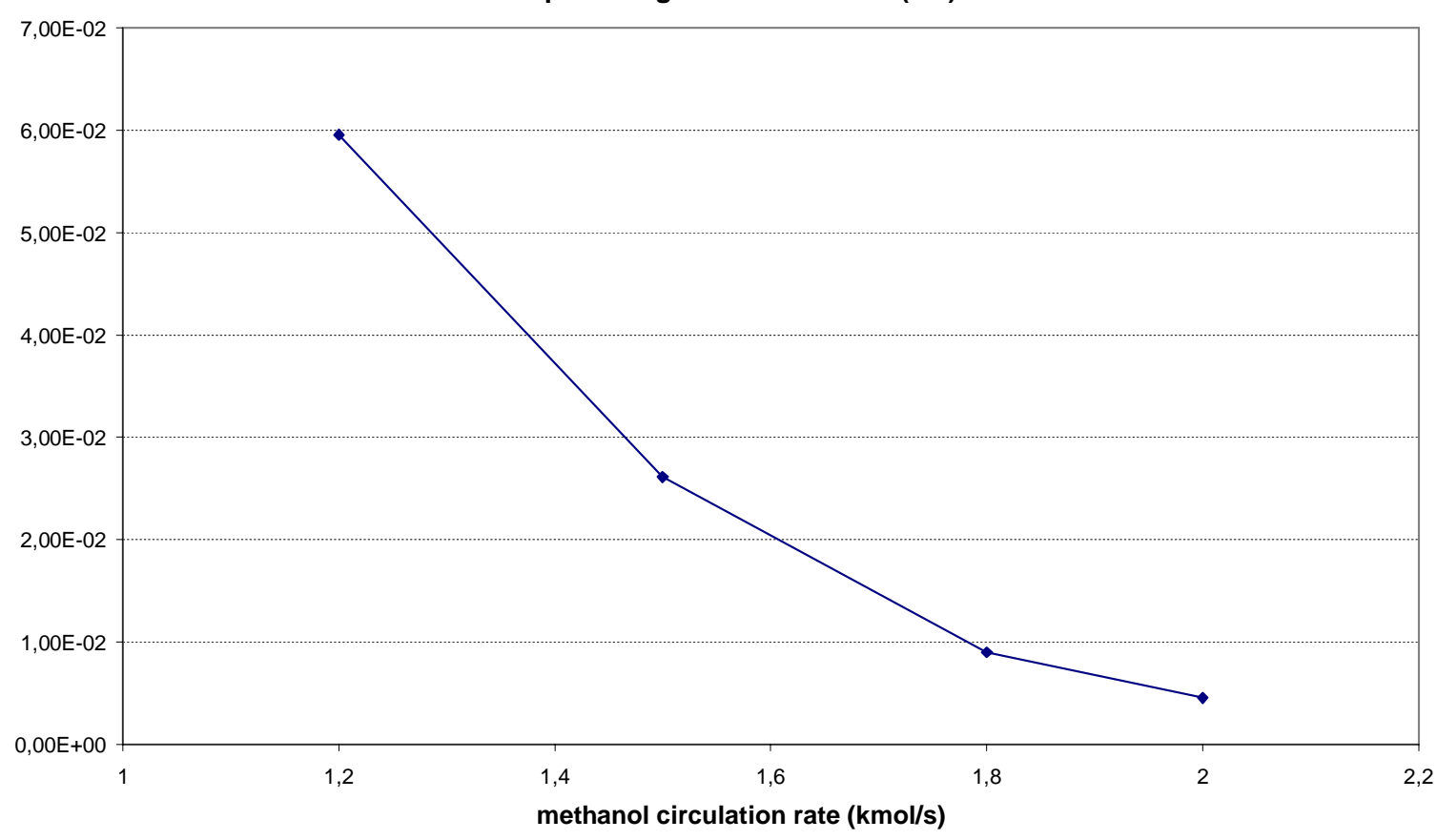

Effect of solvent circulation rate on $\mathrm{H} 2 \mathrm{~S}$ concentration (vol)

in $\mathrm{CO} 2$ stream from H2S Concentrator

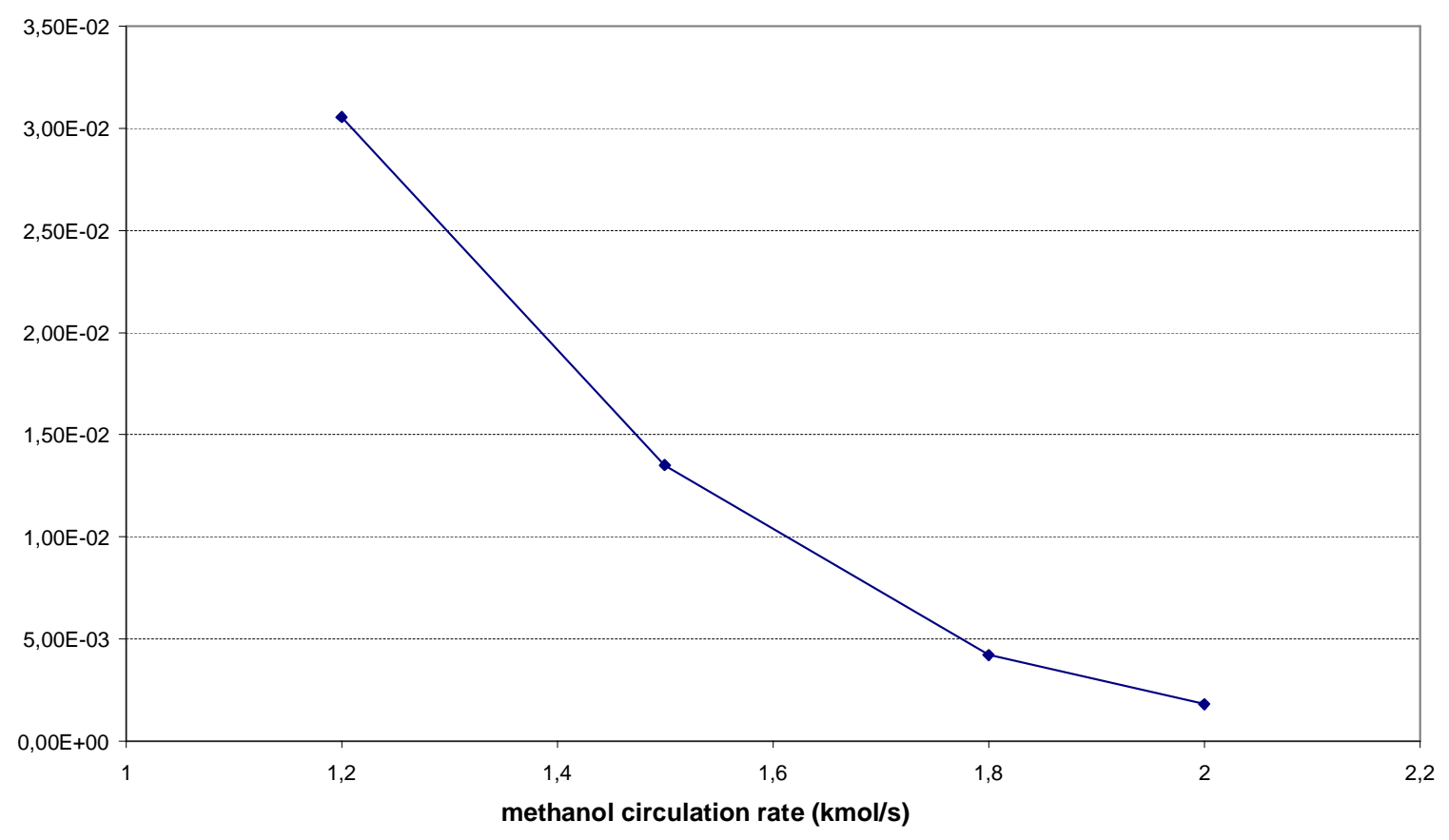

Figure C4: Effect of solvent circulation rate 
Effect of solvent circulation rate on $\mathrm{H} 2 \mathrm{~S}$ concentration (vol) in Tailgas

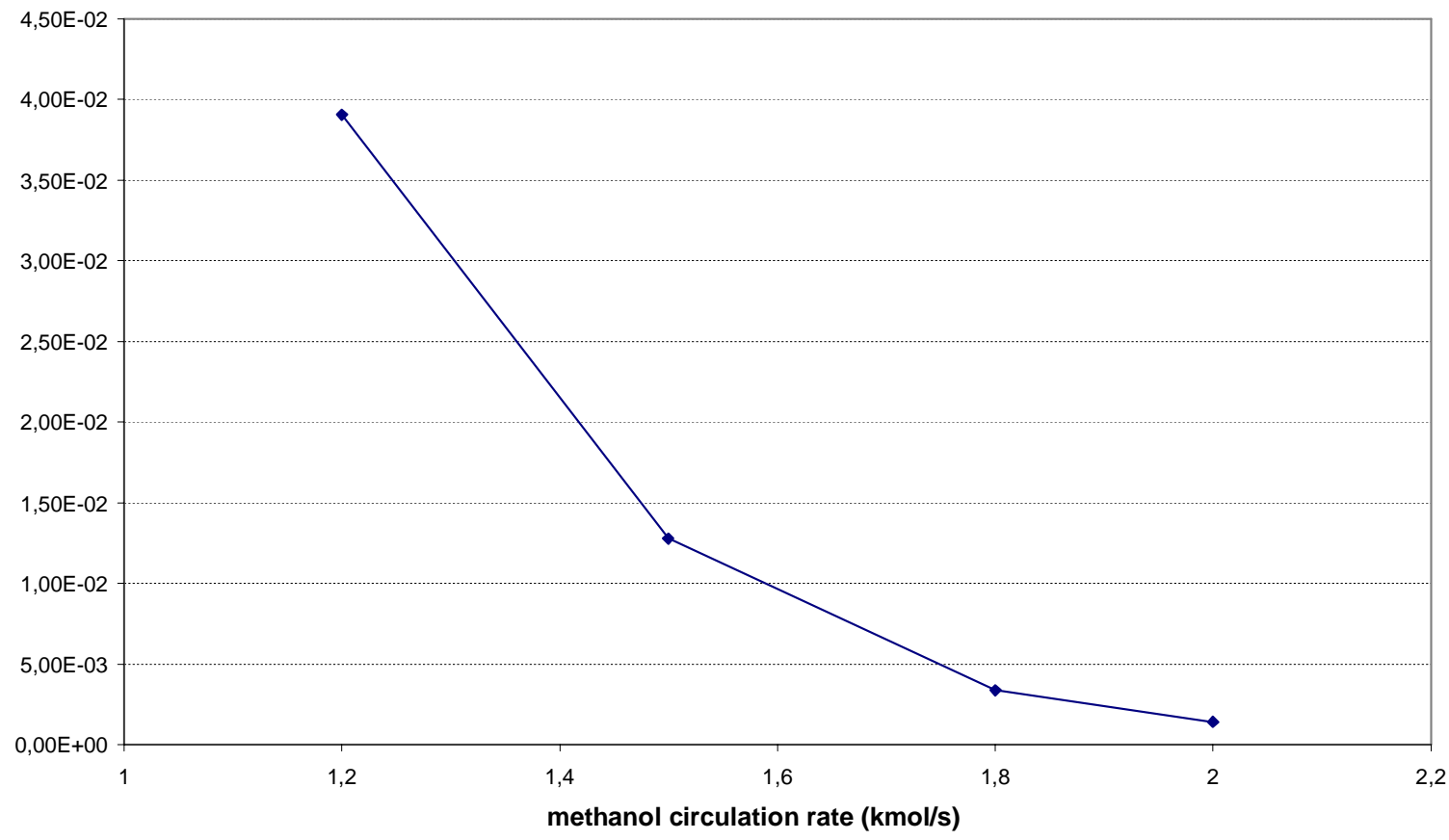

Effect of solvent circulation rate on $\mathrm{N} 2 / \mathrm{CO} 2$ concentration (vol) in Tailgas

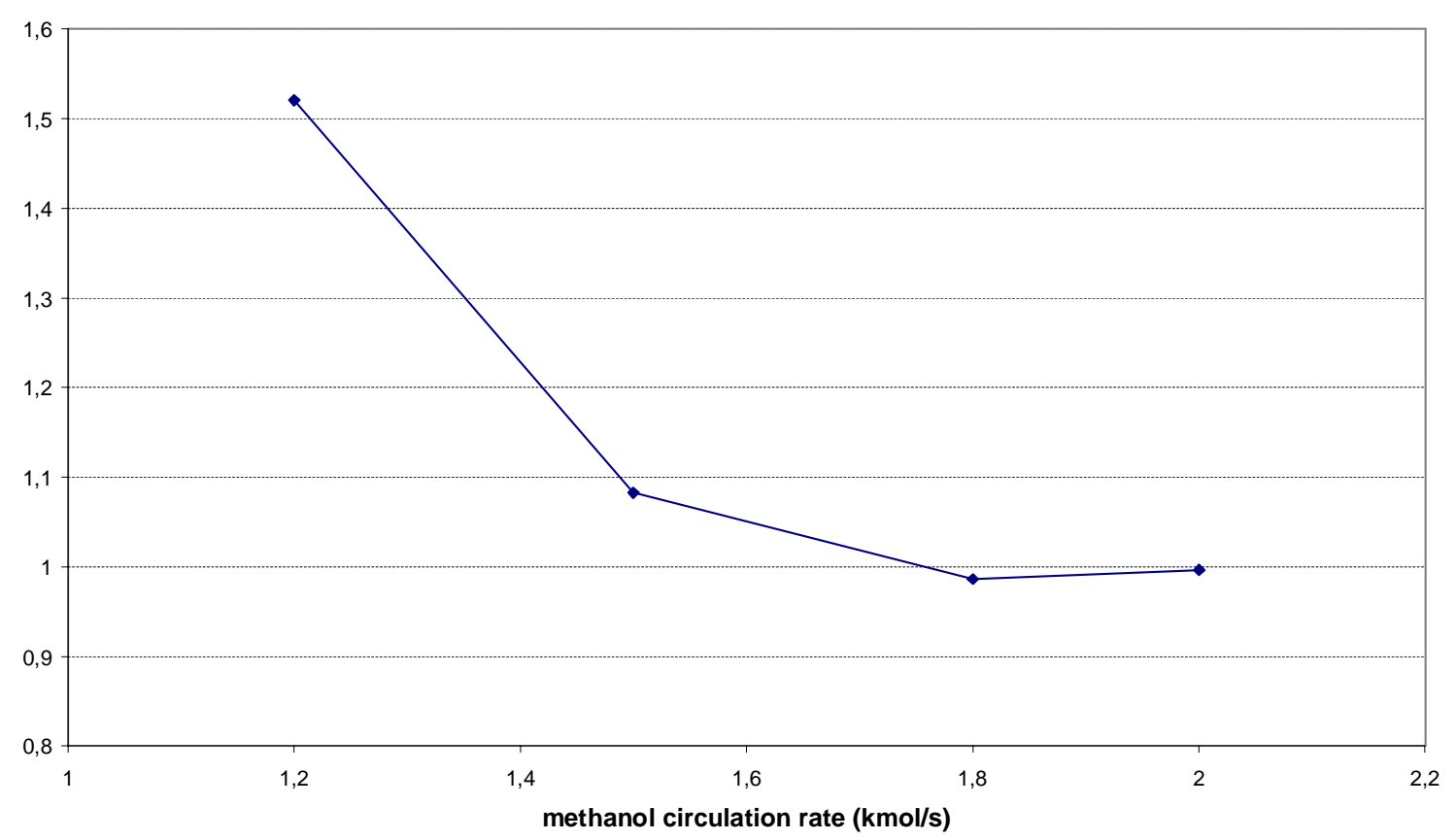

Figure C5: Effect of solvent circulation rate 


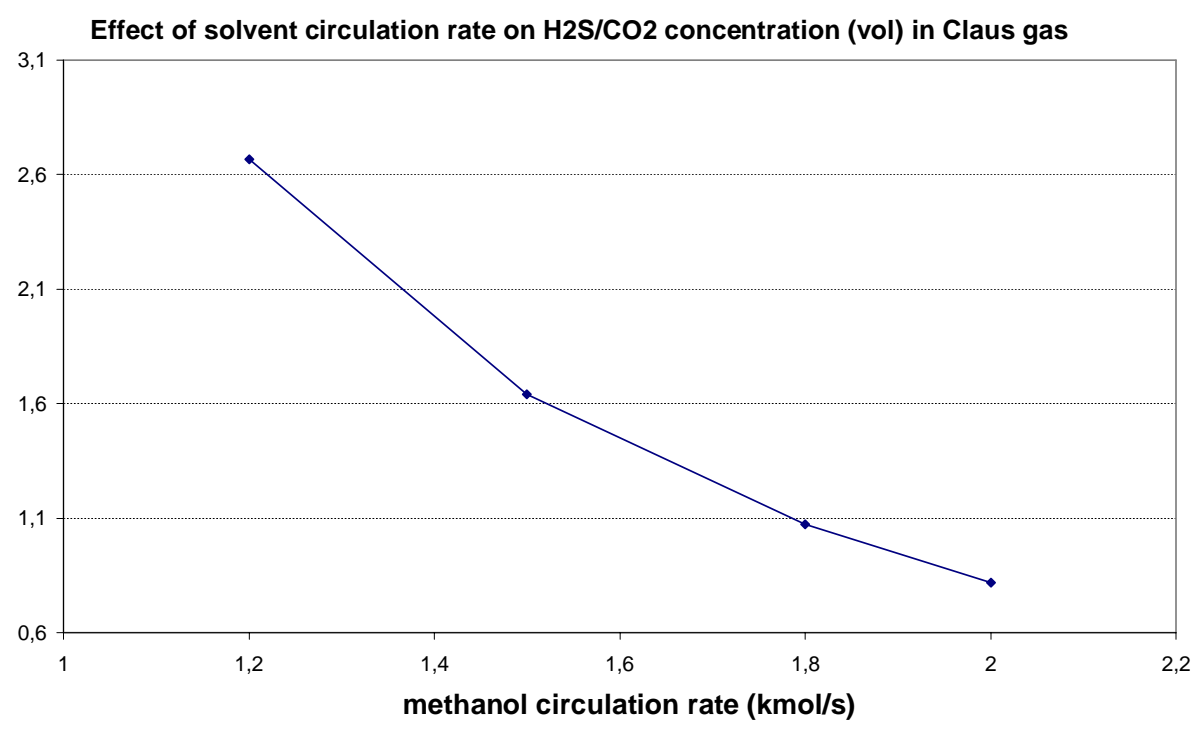

Figure C6: Effect of solvent circulation rate
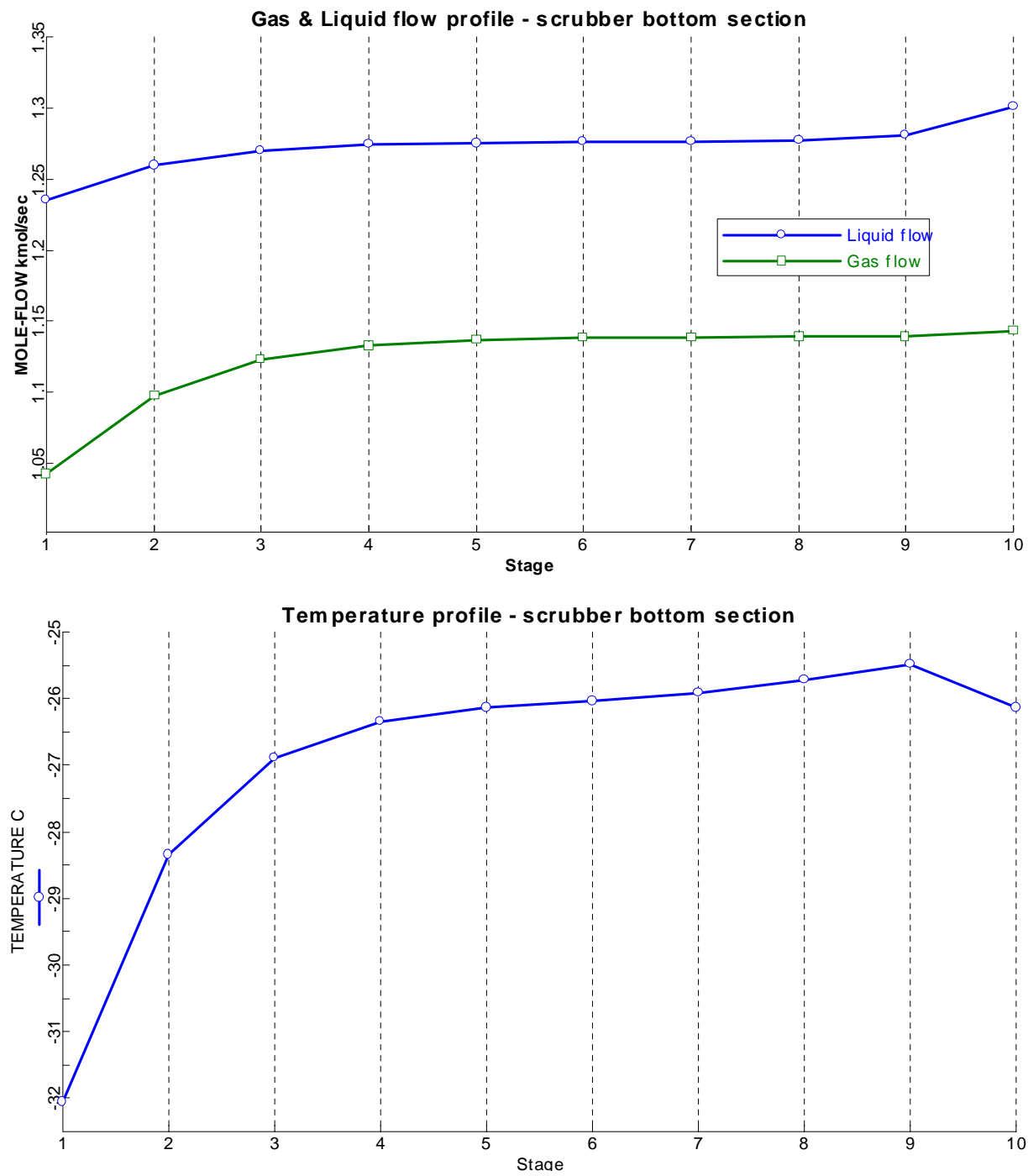

Figure C7: Aspen Model results 

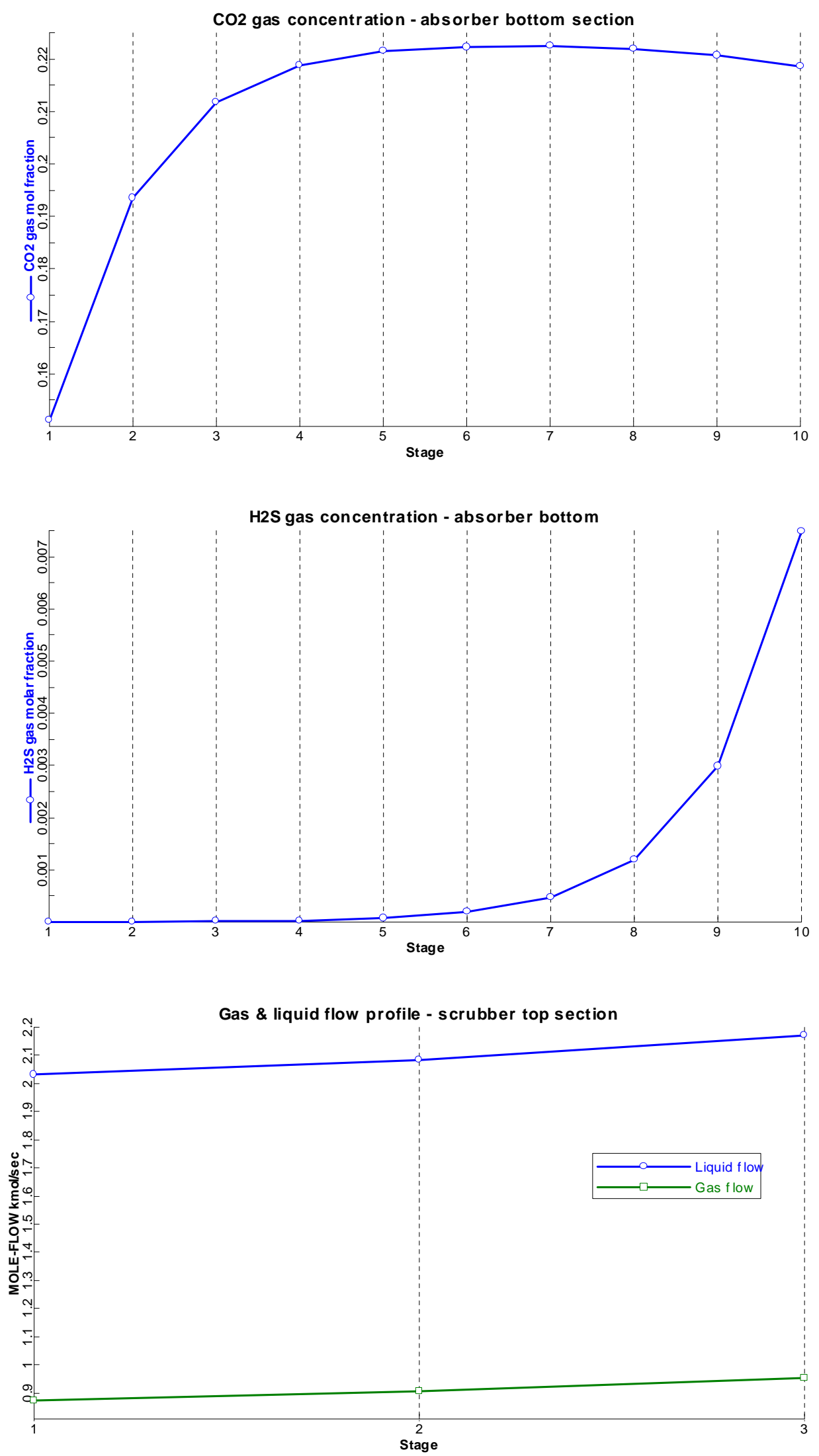

Figure C8: Aspen Model results

C. 16 

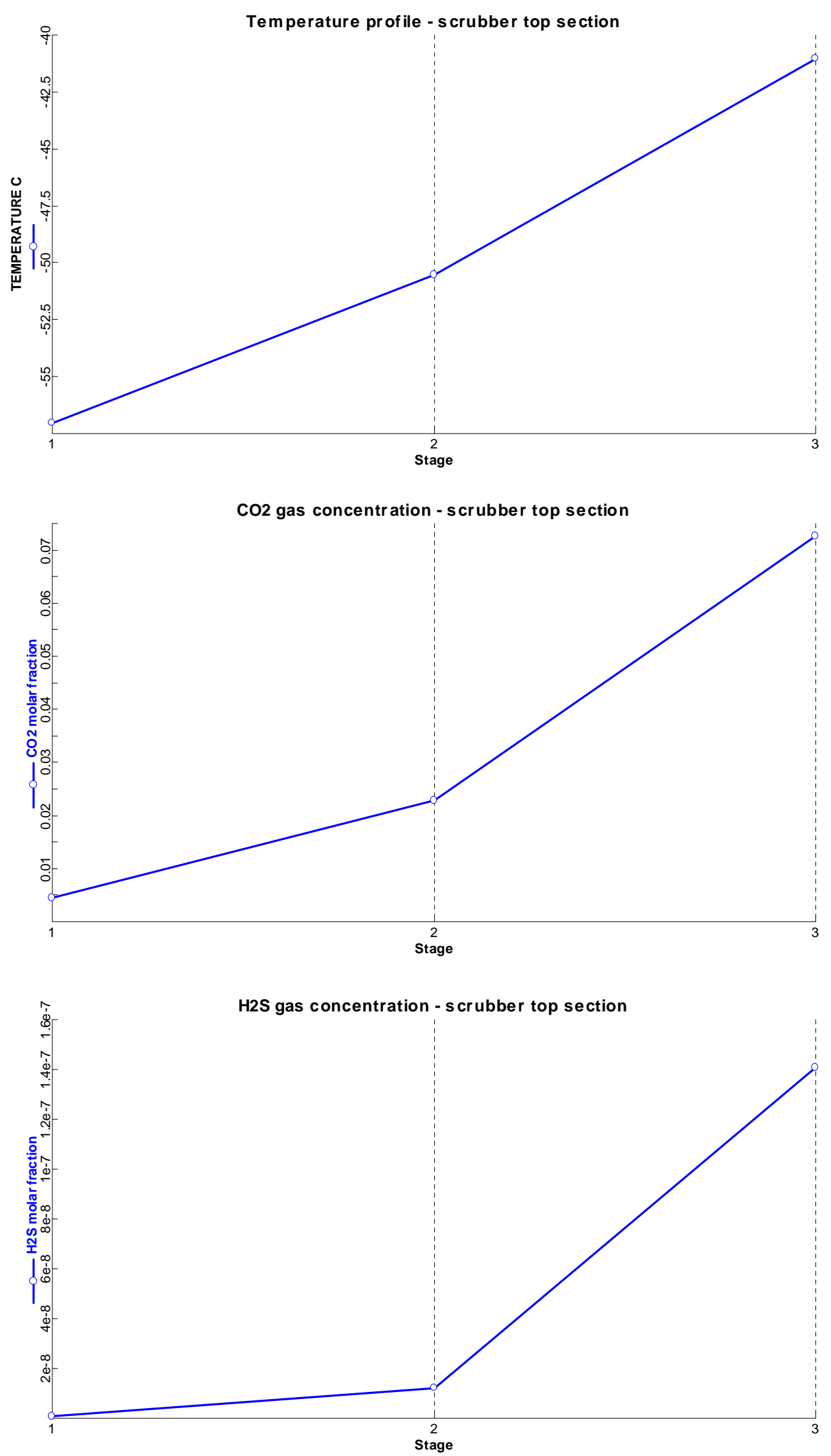

Figure C9: Aspen Model results 

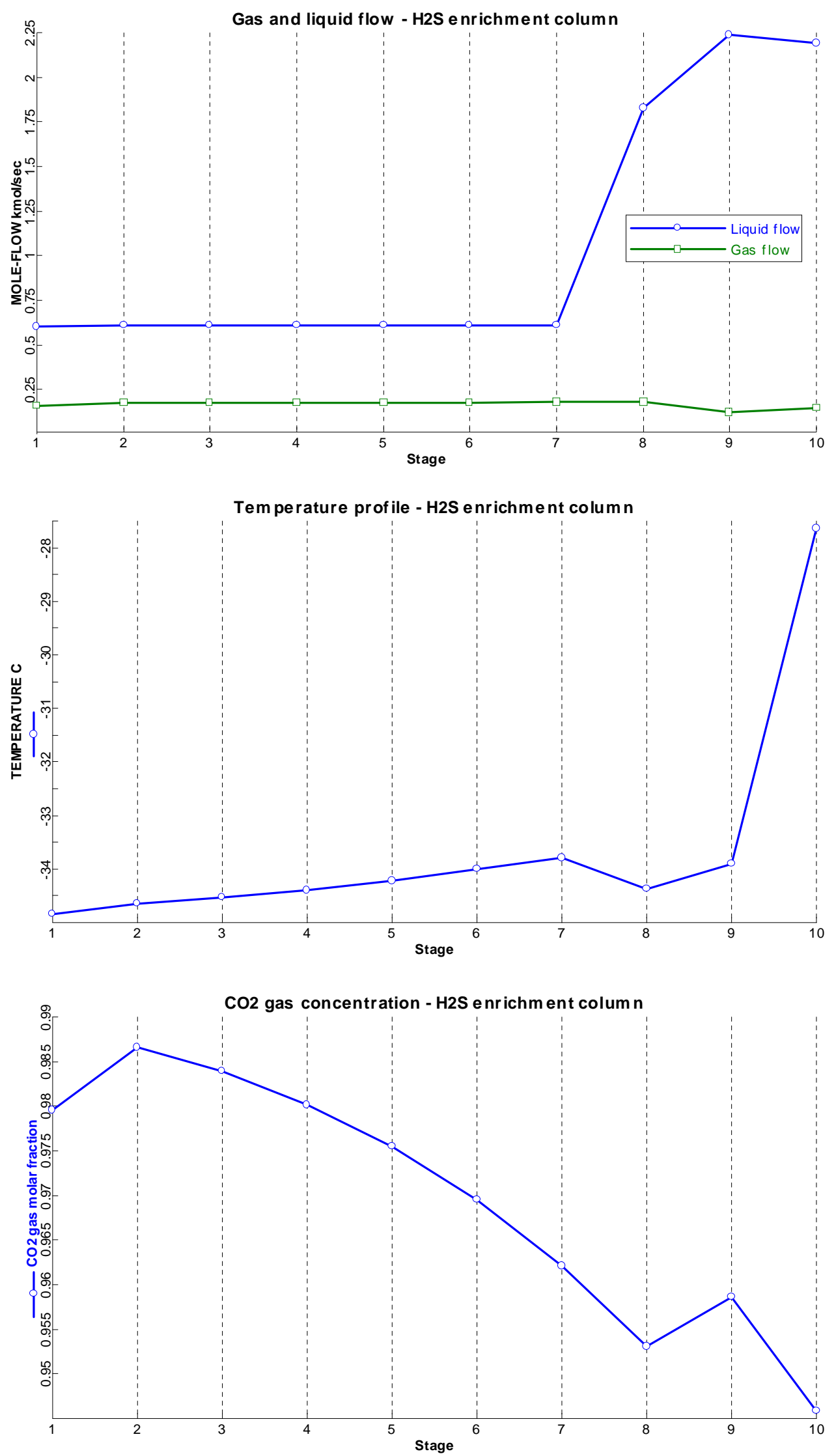

Figure C10: Aspen Model results

C. 18 

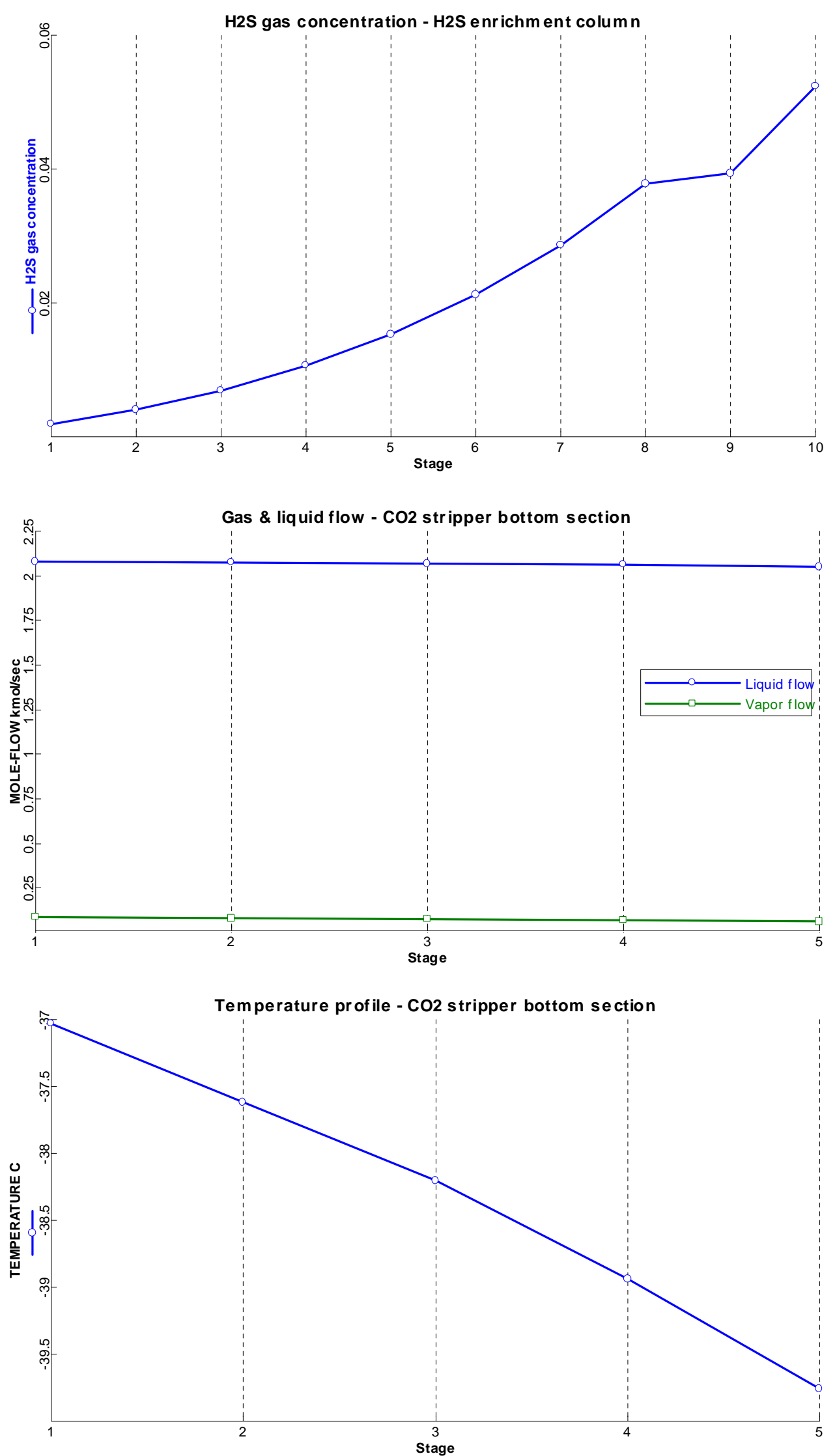

Figure C11: Aspen Model results

C.19 

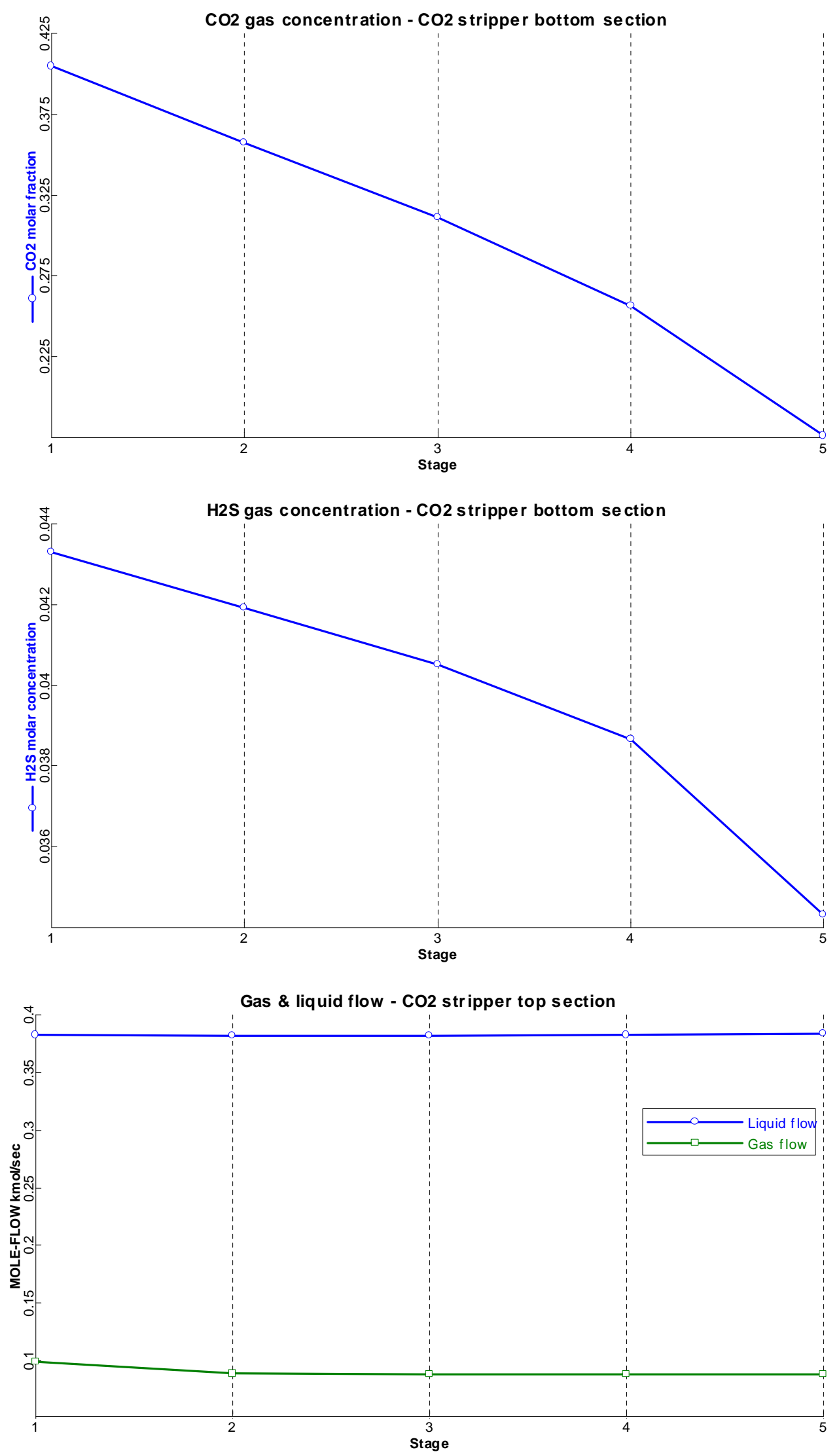

Figure C12: Aspen Model results 

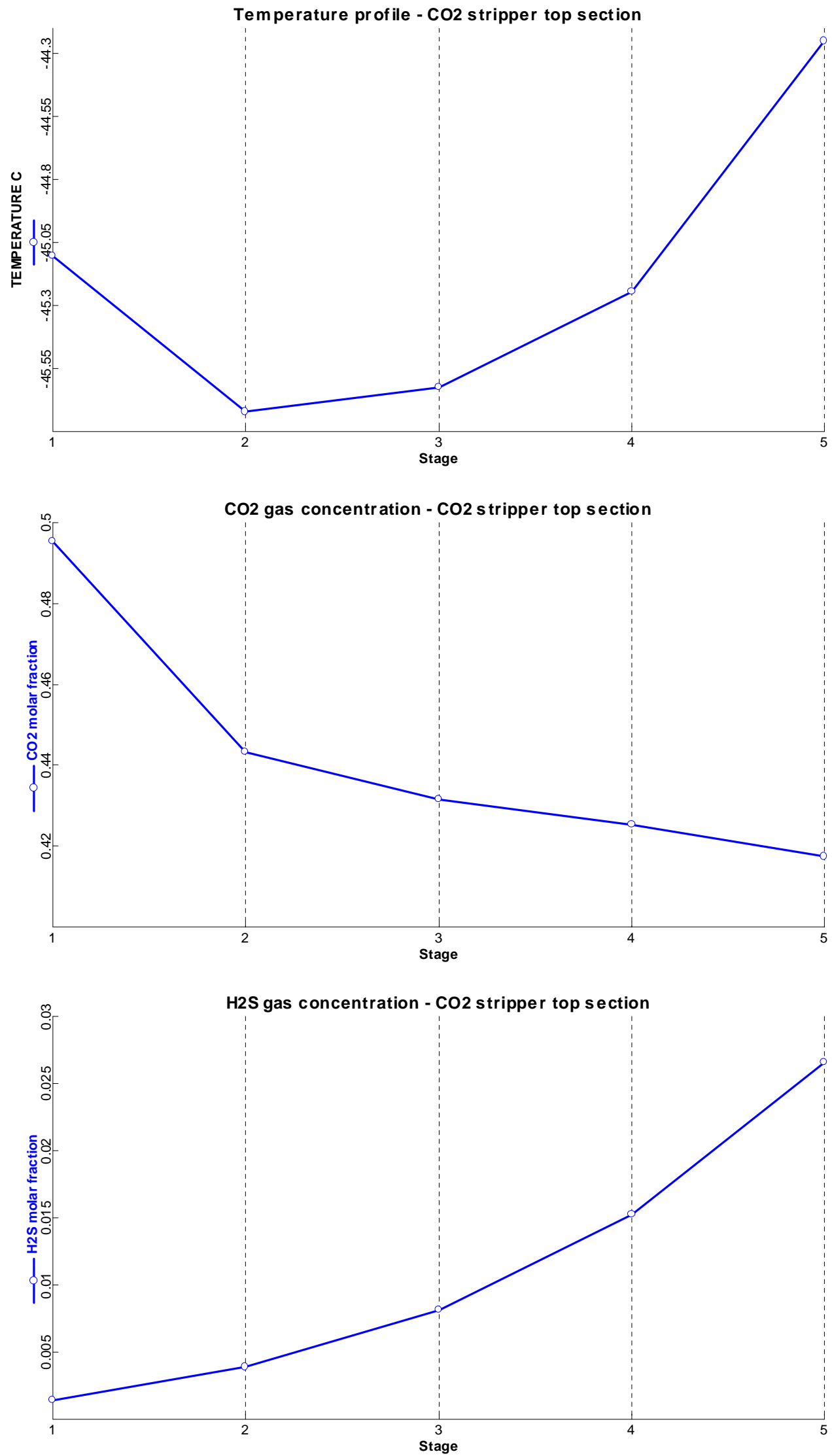

Figure C13: Aspen Model results 

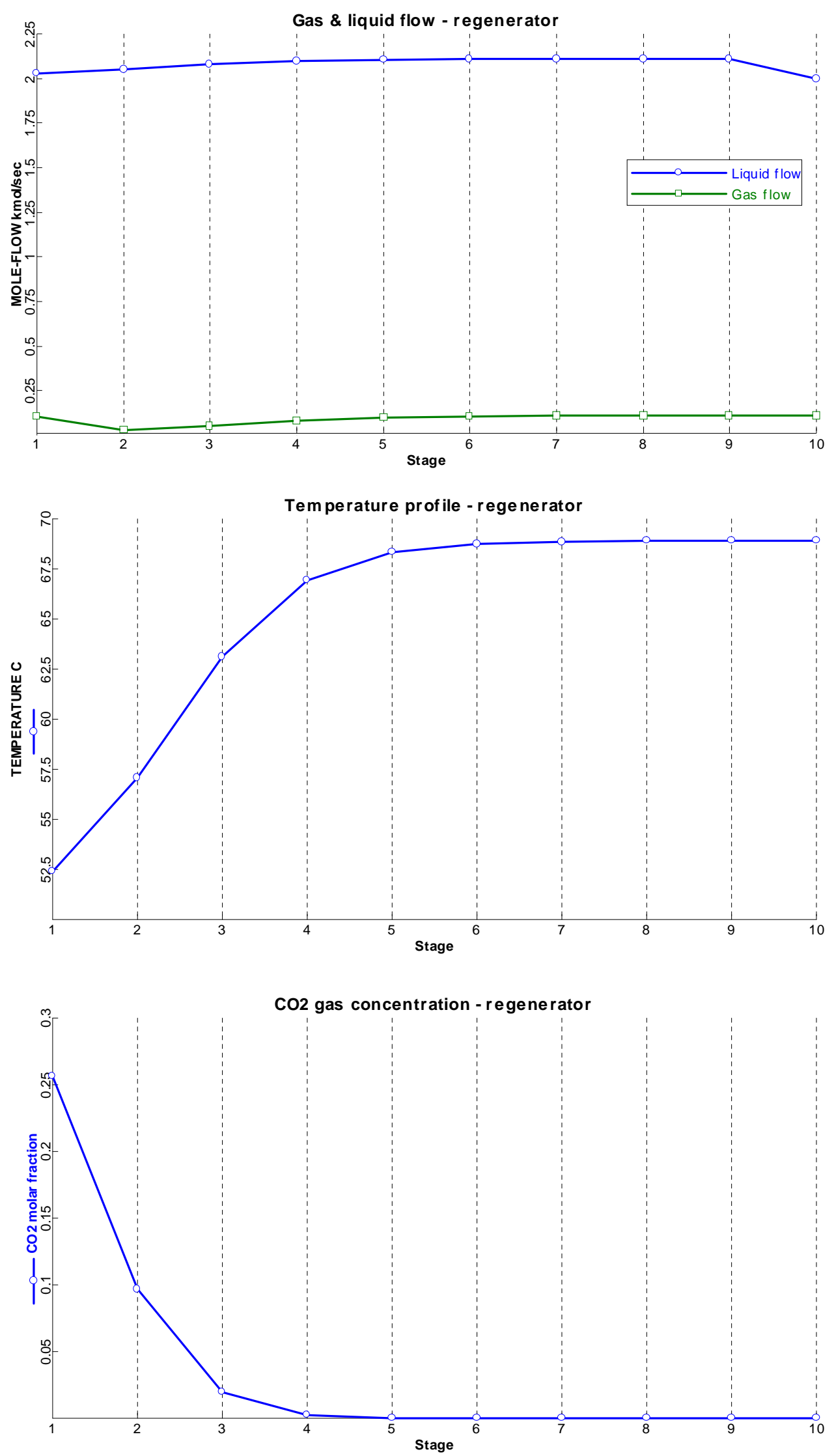

Figure C14: Aspen Model results 

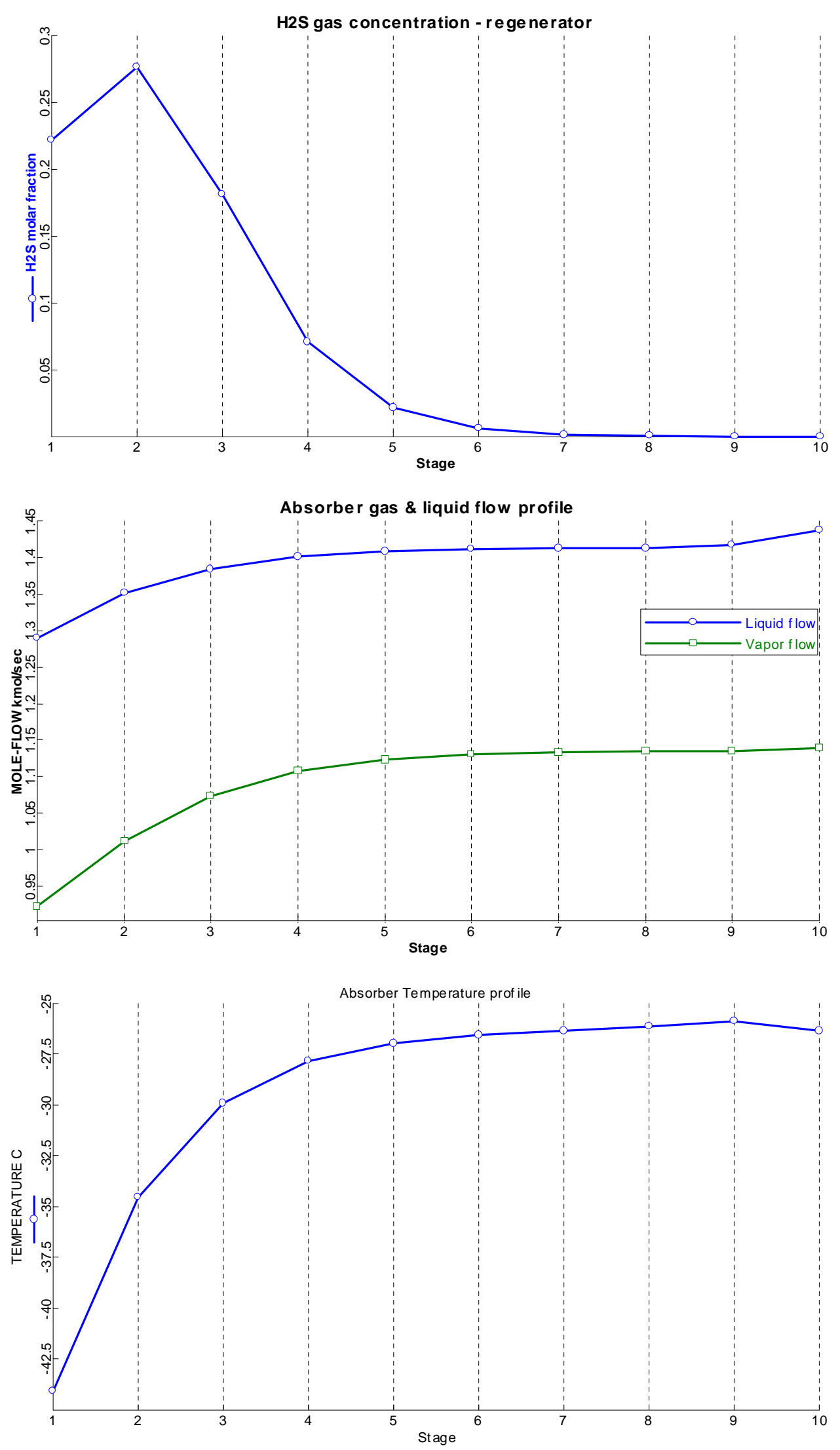

Figure C15: Aspen Model results 

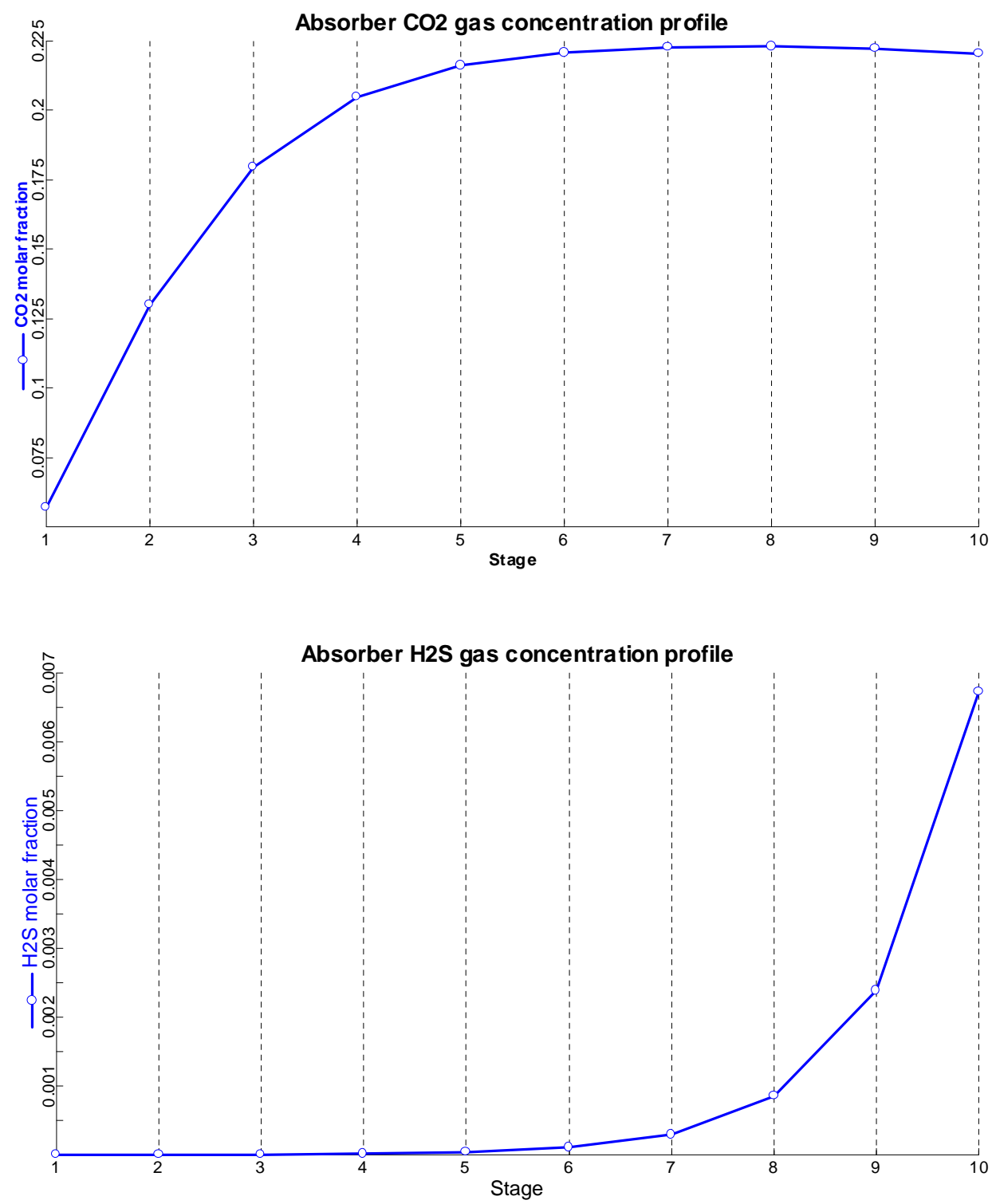

Figure C16: Aspen Model results

\section{C.3 Absorption column: model and thermodynamics}

Model and thermodynamics of an absorption column designed for an acid gas containing $\mathrm{CO}_{2}$ and $\mathrm{H}_{2} \mathrm{~S}$, using methanol at low temperatures as a solvent, with no chemical reaction involved.

The preliminary model presented in this chapter was prepared in order to provide a basic comprehension of the thermodynamic system for the highly exothermic absorption of a gas in a liquid, such as $\mathrm{CO}_{2}$ in methanol.

This was achieved through simple material and energy balance equations written at various sections (theoretic stages) throughout the absorption column.

Above all, the two following issues were analyzed:

- the influence of the high heat of absorption of $\mathrm{CO}_{2}$ in methanol on the scrubbing liquid temperature and consequently on the absorption kinetics 
- the effect of the scrubbing methanol flowrate on the methanol temperature, as a result of the variation of the total liquid flow heat capacity, and on the acid gas concentration in the gas product.

The results of the model are expected to highlight potential problems for a Process Simulation Software (Aspen Plus in the present Study) on the "Rectisol-based" process, at the same time suggesting starting realistic operating conditions for the simulation itself.

A simple thermodynamic model was coupled with basic heat and material balance equations and it was applied to each theoretic stage of an absorption column: the mathematic model was implemented on the Excel file ABSORBER.xls (reported in paragraph C.4). The excel file output provides the details for the product gas from the scrubbing column (temperature, composition, flowrate), the number of ideal stages required and the profiles for the temperature, the $\mathrm{H}_{2} \mathrm{~S}$ and $\mathrm{CO}_{2}$ gas and liquid concentration throughout the column.

\section{C.3.1 Nomenclature}

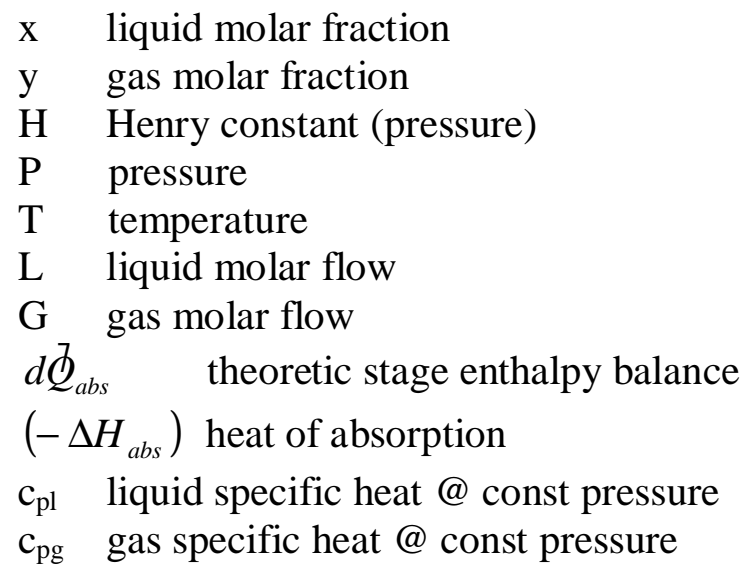

\section{C.3.2 Acid gas solubility}

$\mathrm{CO}_{2}$ and $\mathrm{H}_{2} \mathrm{~S}$ are both soluble in methanol, even though the solubility of $\mathrm{H}_{2} \mathrm{~S}$ is higher than the $\mathrm{CO}_{2}$ one: roughly 5 times as much. The following table $\mathrm{C} 4$ [Ref. 3] reports the equilibrium solubility of $\mathrm{H}_{2} \mathrm{~S}$ and $\mathrm{CO}_{2}$ in methanol at two different temperatures when the acid gas partial pressure is equal to $1 \mathrm{~atm}$ :

\begin{tabular}{|c|c|c|c|}
\hline temperature $\left({ }^{\circ} \mathrm{C}\right)$ & \multicolumn{2}{|c|}{ solubility (vol/vol) } & selectivity H2S/CO2 \\
\hline & $\mathrm{H} 2 \mathrm{~S}$ & $\mathrm{CO} 2$ & \\
\hline-10 & 41 & 8 & 5.1 \\
\hline-20 & 92 & 15 & 6.1 \\
\hline
\end{tabular}

Table C4

\section{C.3.3 Heat of absorption of $\mathrm{CO}_{2}$ in methanol $(-\Delta \mathrm{H}$ abs $)$}

It is hard finding this experimental data in Literature, as the system $\mathrm{CO}_{2} /$ methanol (physical absorption, no reaction) is quite specific to the Rectisol process, and consequently very few experimental data have been published.

It is well known though that the $\mathrm{CO}_{2}$ absorption in polar solvents is a quite exothermic process: 
- $\mathrm{CO}_{2}$ is commonly absorbed in water following the reaction: $\mathrm{CO}_{2}+\mathrm{H}_{2} \mathrm{O}=\mathrm{H}_{2} \mathrm{CO}_{3}$ and developing roughly $5830 \mathrm{kcal} / \mathrm{kmol}$ of absorbed $\mathrm{CO}_{2}$

- $\mathrm{CO}_{2}$ is commonly absorbed in alkaline basics following the reaction (e.g.): $\mathrm{CO}_{2}+\mathrm{H}_{2} \mathrm{O}+$ $\mathrm{NaCO}_{2}=2 \mathrm{NaHCO}_{3}$ and developing roughly $4930 \mathrm{kcal} / \mathrm{kmol}$ of absorbed $\mathrm{CO}_{2}$

- $\mathrm{CO}_{2}$ is commonly absorbed in aqueous solutions containing ethanol-amines, following again a highly exothermic reaction.

Therefore, in order to obtain a first approximation value, an Aspen Plus simulation based on the thermodynamic model presented in paragraph C.4 was used.

The process model is the following fig. C17:

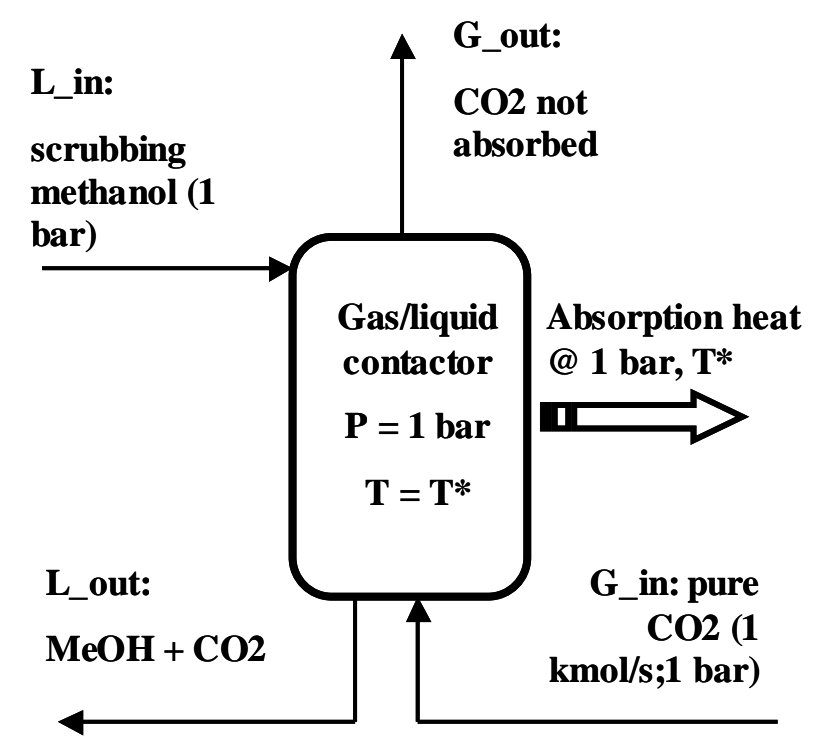

Figure C17: Model used to obtain the $\mathrm{CO}_{2}$ absorption heat through an Aspen Plus simulation

- $1 \mathrm{kmol} / \mathrm{s}$ G_in gas stream composed of $100 \% \mathrm{CO}_{2}$ at conditions of 1 bar and a temperature $\mathrm{T}^{*}$ enters a gas/liquid contactor maintained at constant pressure $(1 \mathrm{bar})$ and temperature $\mathrm{T}^{*}$

- the gas is contacted with a continuous liquid stream L_in of pure methanol at 1 bar and a temperature $\mathrm{T}^{*}$; the flowrate is not an input

- the system calculates the methanol flowrate $L \_$in required to entirely absorb $G$ _in into the liquid phase, so that the output stream $\mathrm{G}_{-}$out (the gas exiting the contactor) is zero, while the inlet $\mathrm{CO}_{2}$ is completely absorbed in the output liquid stream L_out

- the system at the same time calculates the heat power which must be withdrawn from the system in order to maintain a constant temperature $\mathrm{T}^{*}$ in the contactor: this value is the actual heat of absorption of $\mathrm{CO}_{2}$ in methanol at atmospheric $\mathrm{CO}_{2}$ partial pressure and a temperature equal to $\mathrm{T}^{*}$.

The results of the Aspen Plus simulation are reported in table C5. 


\begin{tabular}{|c|c|c|c|c|}
\hline $\begin{array}{c}\text { INPUT } \\
\mathrm{T}\left({ }^{\circ} \mathrm{C}\right)\end{array}$ & $\begin{array}{c}\text { INPUT } \\
\text { G_in }(\mathrm{kmol} / \mathrm{s})\end{array}$ & $\begin{array}{c}\text { OUTPUT } \\
\mathrm{L} \_ \text {in }(\mathrm{kmol} / \mathrm{s})\end{array}$ & $\begin{array}{c}\text { OUTPUT } \\
-\Delta \mathrm{H}(\mathrm{kcal} / \mathrm{kmol})\end{array}$ & $\begin{array}{c}\text { CALCULATED } \\
\text { solubility (vol } \\
\mathrm{CO} 2 / \mathrm{vol} \mathrm{MeOH})\end{array}$ \\
\hline-35 & 1 & 35 & 4024 & 14 \\
\hline-60 & 1 & 25 & 4914 & 19 \\
\hline
\end{tabular}

Table C5

The results for $(-\Delta \mathrm{H}$ abs) are clearly of the same order of magnitude with respect to the ones published in Literature for similar systems and the calculated solubility values for $\mathrm{CO}_{2}$ are very close to the values reported in table $\mathrm{C} 4$.

In conclusion, as the absorption column in the ABSORBER.xls model is foreseen to be working in a temperature range between $-35^{\circ} \mathrm{C}$ and $-70{ }^{\circ} \mathrm{C}$, we assumed an average value for $(-$ $\Delta \mathrm{H}$ abs)_CO $\mathrm{O}_{2} / \mathrm{MeOH}=4500 \mathrm{kcal} / \mathrm{kmol}$.

Note also that the partial pressure of $\mathrm{CO}_{2}$ in the ABSORBER.xls absorption column ranges between 6 and 0.5 bar: the pressure effect on $(-\Delta H$ abs $)$ can definitely be neglected at this level of approximation.

\section{C.3.4 Thermodynamic model}

For the gas/liquid equilibrium, we took into account the ideal Henry law, even though this is expected to be completely reliable only at pressures close to the atmospheric:

\section{Equation 1- Henry law}

$$
y P=H(P, T) x
$$

The Henry constant $\mathrm{H}(\mathrm{P}, \mathrm{T})$ was expressed at 1 bar as a function of the temperature using an Aspen Plus simulation quite similar to the one represented in fig. C17. The values obtained were interpolated obtaining the relationships in (2) \& (3) and they were verified using experimental data published in Literature [Ref. 3].

\section{Equation 2}

$H(1 b a r, T)_{-} H_{2} S / M e O H=0.039 T^{2}+0.5679 T+22.188$

$\mathrm{T}$ is expressed in ${ }^{\circ} \mathrm{C}$.

\section{Equation 3}

$\mathrm{H}(\mathrm{lbar}, \mathrm{T})_{-} \mathrm{CO}_{2} / \mathrm{MeOH}=0.0116 T^{2}+1.9985 T+87.941$

$\mathrm{T}$ is expressed in ${ }^{\circ} \mathrm{C}$.

\section{C.3.5 Heat and material balance equations in the absorption column}

The heat and material balance equations referred to each column theoretic stage (considered as an adiabatic system) are reported here below (refer to fig. C18).

The basic assumptions behind the equations (4-10) are the followings:

- on the liquid side, methanol does not vaporize

- on the gas side, only $\mathrm{H}_{2} \mathrm{~S}$ and $\mathrm{CO}_{2}$ are possibly transferred into the liquid phase

- the contribution of $\mathrm{H}_{2} \mathrm{~S}$ absorption to the liquid and gas enthalpy changes can be neglected with respect to the $\mathrm{CO}_{2}$ contribution 


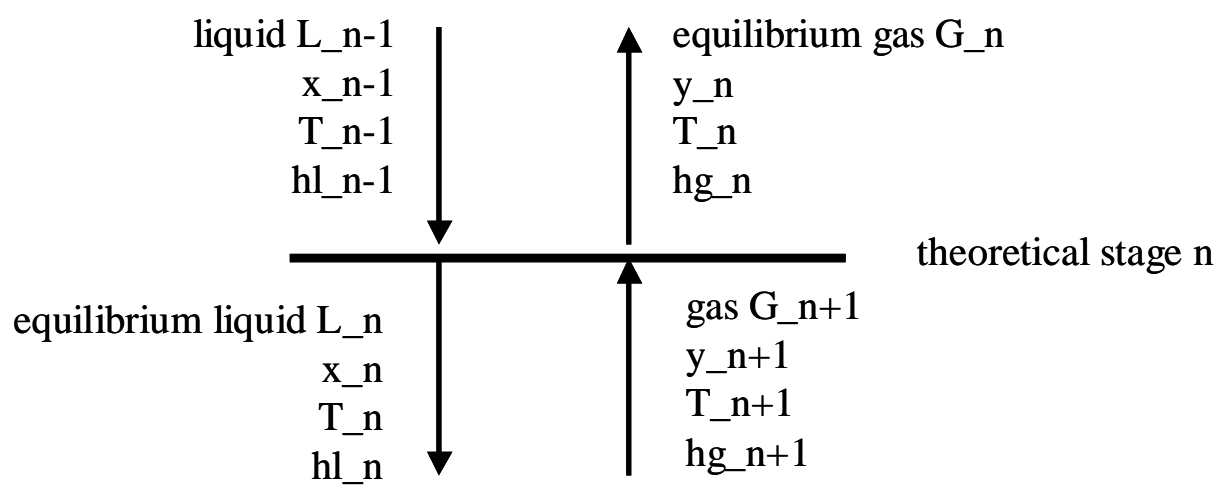

Figure C18: Theoretic stage in the absorption column

Considering a cross section in the absorber with an infinitive thickness, the enthalpy and mass balances can be written in differential terms as follows:

\section{Equation 4 Mass balance}

$d(G y)+d(L x)=0$

\section{Equation 5 Enthalpy balance}

$d\left(G h_{g}\right)+d\left(L h_{l}\right)=d \oint_{a b s}$

\section{Equation 6}

$d \oint_{a b s}=\left(-\Delta H_{a b s}\right) d(L x)$

\section{Equation 7}

$G c_{p g} d T_{g}+d G c_{p g} T_{g}+L c_{p l} d T_{l}+d L c_{p l} T_{l}=\left(-\Delta H_{a b s}\right) d(L x)$

Considering the previous equations applied to each theoretic stage:

\section{Equation 8}

$y_{n+1} G_{n+1}+x_{n-1} L_{n-1}=y_{n} G_{n}+L_{n} x_{n}$

\section{Equation 9}

$y_{n} P=H\left(P, T_{n}\right) x_{n}$

\section{Equation 10}

$T_{n-1}=\frac{c_{p g}\left(\left(G_{n+1}\left(T_{n}-T_{n+1}\right)+T_{n+1}\left(G_{n}-G_{n+1}\right)\right)+L_{n-1} c_{p l} T_{n}-\left(-\Delta H_{a b s}\right)\left(x_{n} L_{n}-x_{n-1} L_{n-1}\right)\right.}{c_{p l}\left(G_{n}-G_{n+1}+L_{n-1}\right)}$

This implies that the temperature, concentration, gas and liquid flow profiles can be calculated throughout the absorber starting, for example, from the bottom theoretic stage and calculating the various "upwards" unknowns, stage by stage, using eqs. 8-10. 
The calculation procedure can be verified in the ABSORBER.xls file described in the next paragraph.

\section{C.3.6 ABSORBER.xls user interface}

As the "bottom column calculation approach" was adopted, the process inputs required to ABSORBER.xls are the followings:

- absorber pressure (pressure drops throughout the column neglected)

- feed gas molar composition

- feed gas temperature

- feed gas molar flow

- product liquid temperature

- feed liquid molar composition

- duty specification for the $\mathrm{H}_{2} \mathrm{~S}$ and $\mathrm{CO}_{2}$ composition in the product gas

At this point, the ABSORBER.xls calculates the minimum liquid product flow at the column bottom section, the actual liquid product (with a factor of 120\%) and its composition and it proceeds "upwards" through the column providing the following outputs, for each theoretic stage:

- gas and liquid composition

- liquid and gas molar flow

- temperature

- number of theoretic stage required to achieve the separation of the duty specification

Please note that ABSORBER.xls is not "self-adjusting" and it requires of course a proper tuning of the input parameters and a proper verification of the system thermodynamics.

\section{C.3.7 Results and discussion}

A calculation example for the absorber column is reported in this paragraph: in this case the absorption column is designed for the complete abatement of $\mathrm{H}_{2} \mathrm{~S}$ only.

The feed gas properties and the column pressure were fixed in the Core Study: the main results are summarized here below:

- the theoretic stages required for the separation are usually $<10$

- the temperature profile is always roughly constant in the first 3,4 bottom absorber theoretic stages, while it steeply decreases moving upwards in the absorber

- the $\mathrm{CO}_{2}$ gas concentration decreases continuously moving upwards in the absorber, but the concentration drops much less rapidly than in the case of $\mathrm{H}_{2} \mathrm{~S}$, which is entirely absorbed in the first 2,3 bottom absorber stages

- provided a pure methanol scrubbing liquid on top of the column, its required temperature, in order to achieve the specified separation, is considerably lower than the feed gas temperature: in the reported example the liquid is heated from $-70^{\circ} \mathrm{C}$ (absorber top) to $20^{\circ} \mathrm{C}$ (absorber bottom).

- the liquid/gas molar ratio is always around 2

- the liquid temperature might generate a "hot spot" due to the $\mathrm{CO}_{2}$ absorption because either its feed temperature is not low enough or the scrubbing liquid flowrate is not high enough.

The reported results, which do vary consistently when the inlet conditions are changed, lead to the following considerations: 
- the $\mathrm{CO}_{2}$ absorption in methanol is highly exothermic and if the system is not over designed using a much larger liquid flow than what is calculated by the material balance, the feed scrubbing methanol is considerably heated when it flows downwards through the absorber.

- This implies that the feed methanol stream must be cold enough to maintain the temperature in the absorber low enough to allow for the $\mathrm{CO}_{2}$ absorption (which is much less soluble than $\mathrm{H}_{2} \mathrm{~S}$ ) and to avoid any methanol vaporization.

- In effect, at the absorber bottom section, where the majority of $\mathrm{CO}_{2}$ is absorbed, the temperature does not rapidly decrease because of the large absorption heat released: this has in turn an effect on the $\mathrm{CO}_{2}$ absorption rate.

- If at a certain stage the temperature reaches a "hot spot" the $\mathrm{CO}_{2}$ absorption is prevented.

- The results are consistent with the information available in Literature, mostly in the original Patent [Ref. 1].

\begin{tabular}{|c|c|c|c|c|c|c|c|c|}
\hline & C1 & C2 & C3 & C4 & C5 & $T \min ,{ }^{\circ} \mathrm{C}$ & $T, r e f$ & $\begin{array}{c}c p g, \mathrm{~kJ} / \mathrm{kmol} \\
\mathrm{K}\end{array}$ \\
\hline $\mathrm{CO}$ & $2,91 \mathrm{E}+04$ & $8,77 \mathrm{E}+03$ & $3,09 \mathrm{E}+03$ & $8,46 \mathrm{E}+03$ & $1,54 \mathrm{E}+03$ & -23 & 230 & 29,1 \\
\hline $\mathrm{CO} 2$ & $2,94 \mathrm{E}+04$ & $3,45 \mathrm{E}+04$ & $1,43 \mathrm{E}+03$ & $2,64 \mathrm{E}+04$ & $5,88 \mathrm{E}+02$ & -213 & 230 & 33,5 \\
\hline $\mathrm{H} 2$ & $2,76 \mathrm{E}+04$ & $9,56 \mathrm{E}+03$ & $2,47 \mathrm{E}+03$ & $3,76 \mathrm{E}+03$ & $5,68 \mathrm{E}+02$ & -213 & 230 & 28,3 \\
\hline \multicolumn{9}{|c|}{ 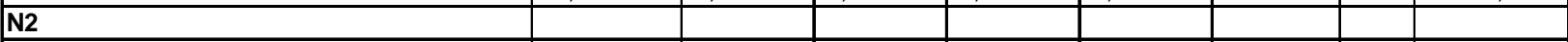 } \\
\hline & & & & & & & & \\
\hline CO2 latent heat of vaporization & $\mathrm{kcal} / \mathrm{kmol}$ & 3052 & & & & & & \\
\hline $\mathrm{cp}$ _liquid $\mathrm{CO} 2 @-23^{\circ} \mathrm{C}$ & $\mathrm{kcal} / \mathrm{kmolK}$ & 21 & & & & & & \\
\hline CO2 heat of solution in MeOH (-DELTA_h) & $\mathrm{kcal} / \mathrm{kmol}$ & 4500 & & & & & & \\
\hline cp_liquid MeOH (cons const) & $\mathrm{kcal} / \mathrm{kmolK}$ & 17,6 & & & & & & \\
\hline & & & & & & & & \\
\hline source: Perry & & & & & & & & \\
\hline
\end{tabular}

Table C6: Physical constants of ABSORBER.xls file 


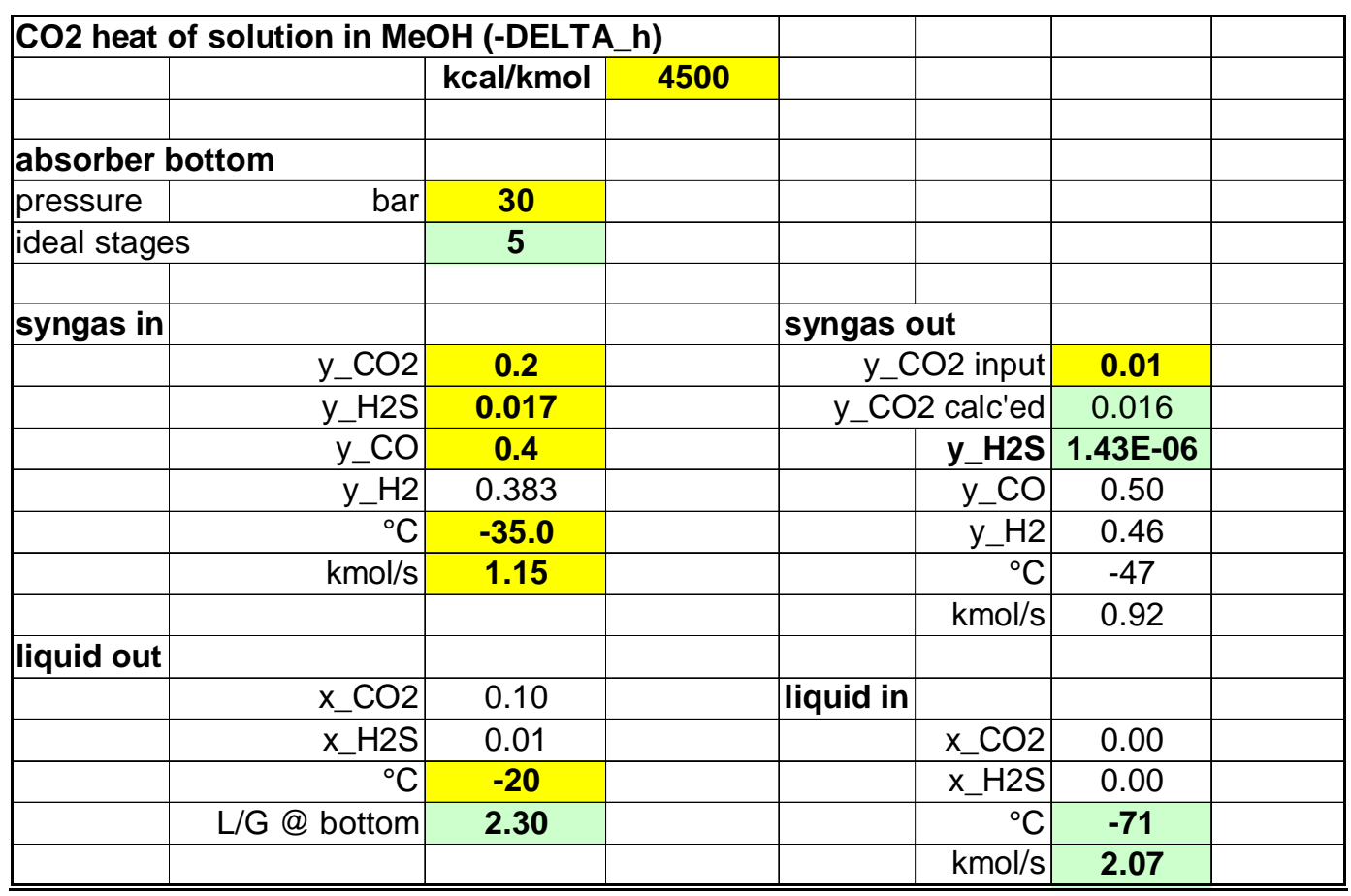

\section{Legend user input \\ output}

Table C7: Input and output data of ABSORBER.xls file

\begin{tabular}{|c|c|c|}
\hline input data to absorption columns & & \\
\hline column const pressure & bar & 30 \\
\hline $\mathrm{T} @$ bottom C1 & ${ }^{\circ} \mathrm{C}$ & -20 \\
\hline T syngas @ C1 inlet & ${ }^{\circ} \mathrm{C}$ & -35 \\
\hline y_CO2@ syngas to RCTBOL unit & & 0.2 \\
\hline y_H2S@ syngas to RCTBOL unit & & 0.017 \\
\hline y_CO@ syngas to ECTSOL unit & & 0.4 \\
\hline y_H2@syngas to BCTSOL unit & & 0.366 \\
\hline syngas flowrate to BCTSOL unit & $\mathrm{kmol} / \mathrm{s}$ & 1.15 \\
\hline $\mathrm{x}$ CO2 2 to top stage & & 0.00 \\
\hline $\mathrm{x}$ H2S to top stage & & 0.00 \\
\hline x_C02 (equilibrium with $\mathrm{C0} 2 @$ syngas inlet) & & 0.114 \\
\hline x_H2S (equilibrium with $\mathrm{H} 2 \mathrm{~S}$ @ syngas inlet) & & 0.041 \\
\hline y_CO2@ column exit (user design) & & 0.010 \\
\hline y_H2S@ column exit (user design) & & 0.000 \\
\hline$(\mathrm{L} / \mathrm{G})^{2}$ based on $\mathrm{CO} 2$ & & 1.67 \\
\hline$(\mathrm{L} / \mathrm{G})^{2}$ based on $\mathrm{H} 2 \mathrm{~S}$ & & 0.41 \\
\hline$(\mathrm{L} / \mathrm{G})$ & 1.2 & 2.00 \\
\hline $\mathrm{x}$ CO2 $@$ liquid from absorber & & 0.10 \\
\hline x_H2S@liquid from absorber & & 0.01 \\
\hline (a) C1 bottom & $\mathrm{kmol} / \mathrm{s}$ & 2.30 \\
\hline initial CO flowrate & $\mathrm{kmol} / \mathrm{s}$ & 0.46 \\
\hline initial $\mathrm{H} 2$ flowrate & $\mathrm{kmol} / \mathrm{s}$ & 0.42 \\
\hline hert gas & $\mathrm{kmol} / \mathrm{s}$ & 0.90 \\
\hline CO2 heat of solution (-ELTAh) & $\mathrm{dal} / \mathrm{kmol}$ & 500 \\
\hline
\end{tabular}

Table C8: Input to ABSORBER.xIs file 


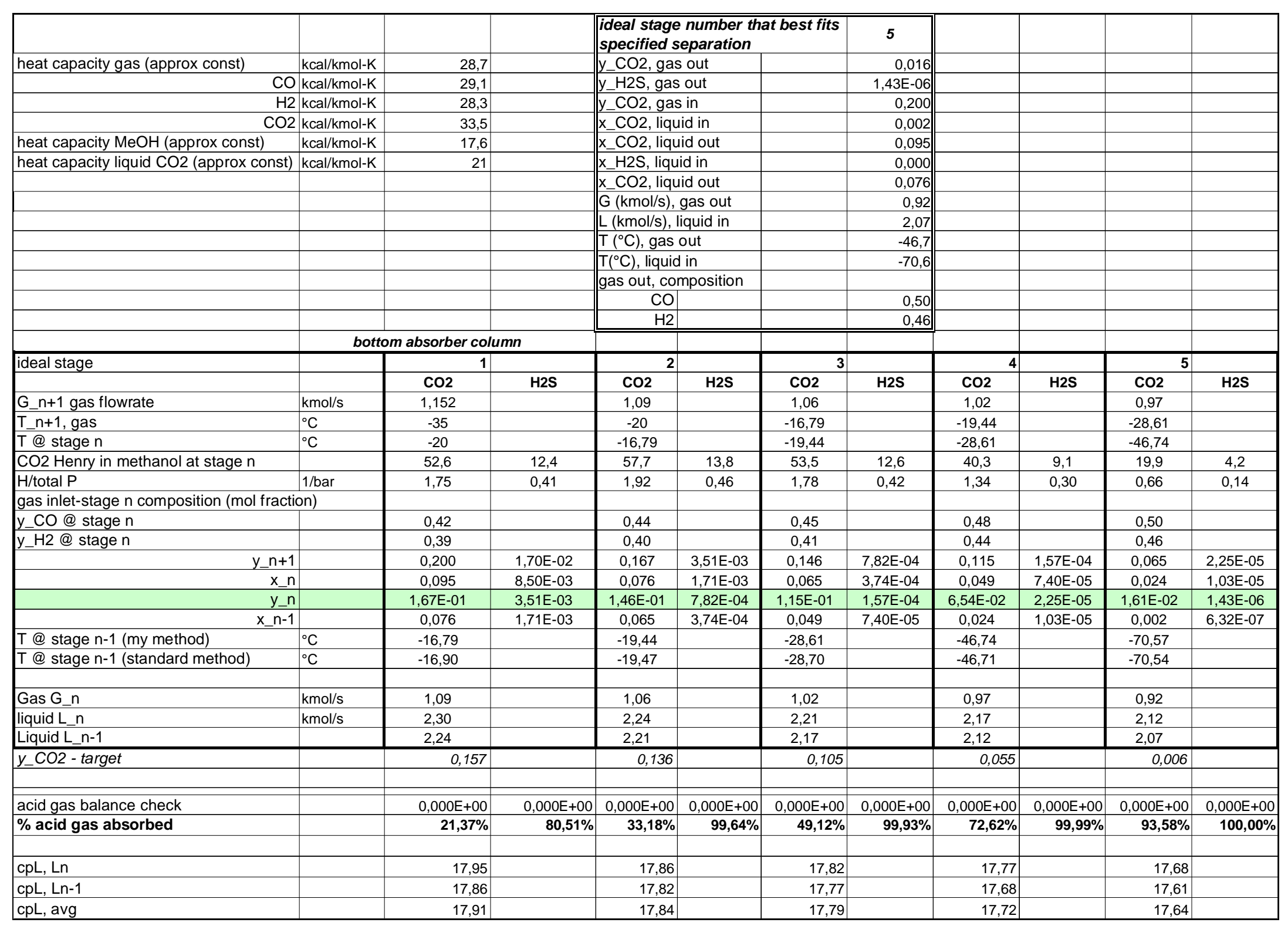

Table C9: Absorber model in the ABSORBER.xls file 


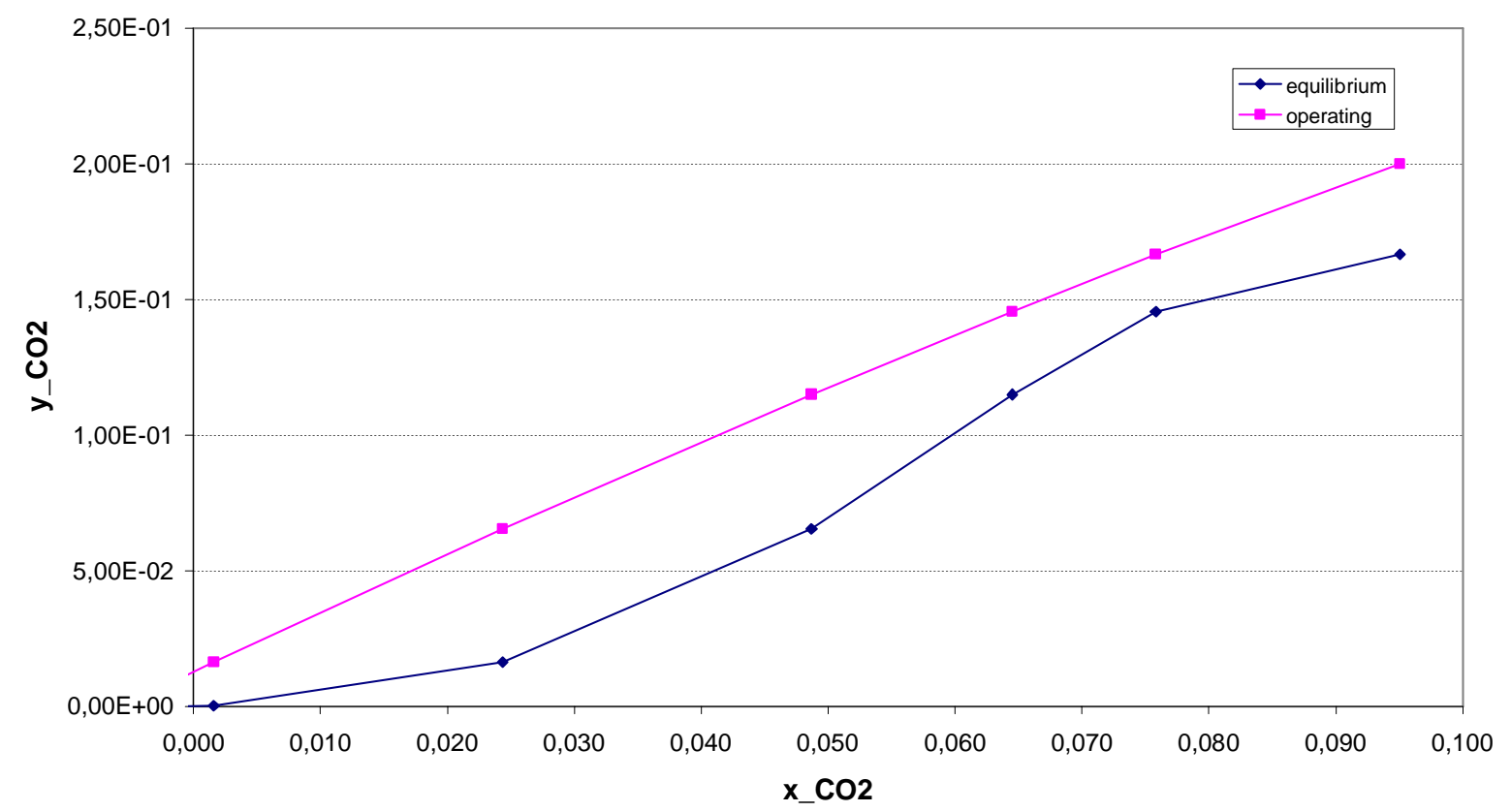

Fig. C19: Equilibrium \& operation curves

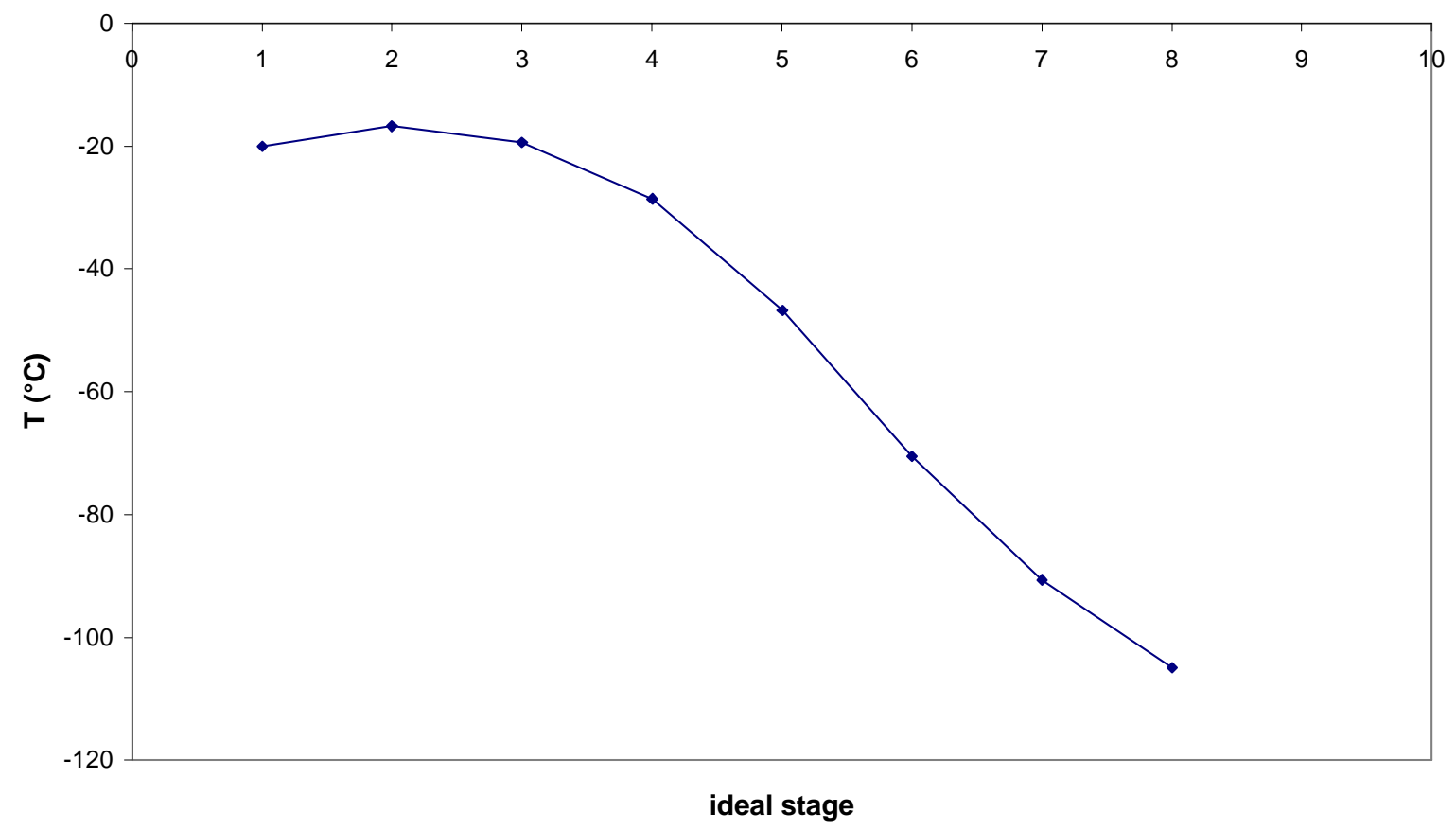

Fig. C20: Temperature profile in the absorption column 


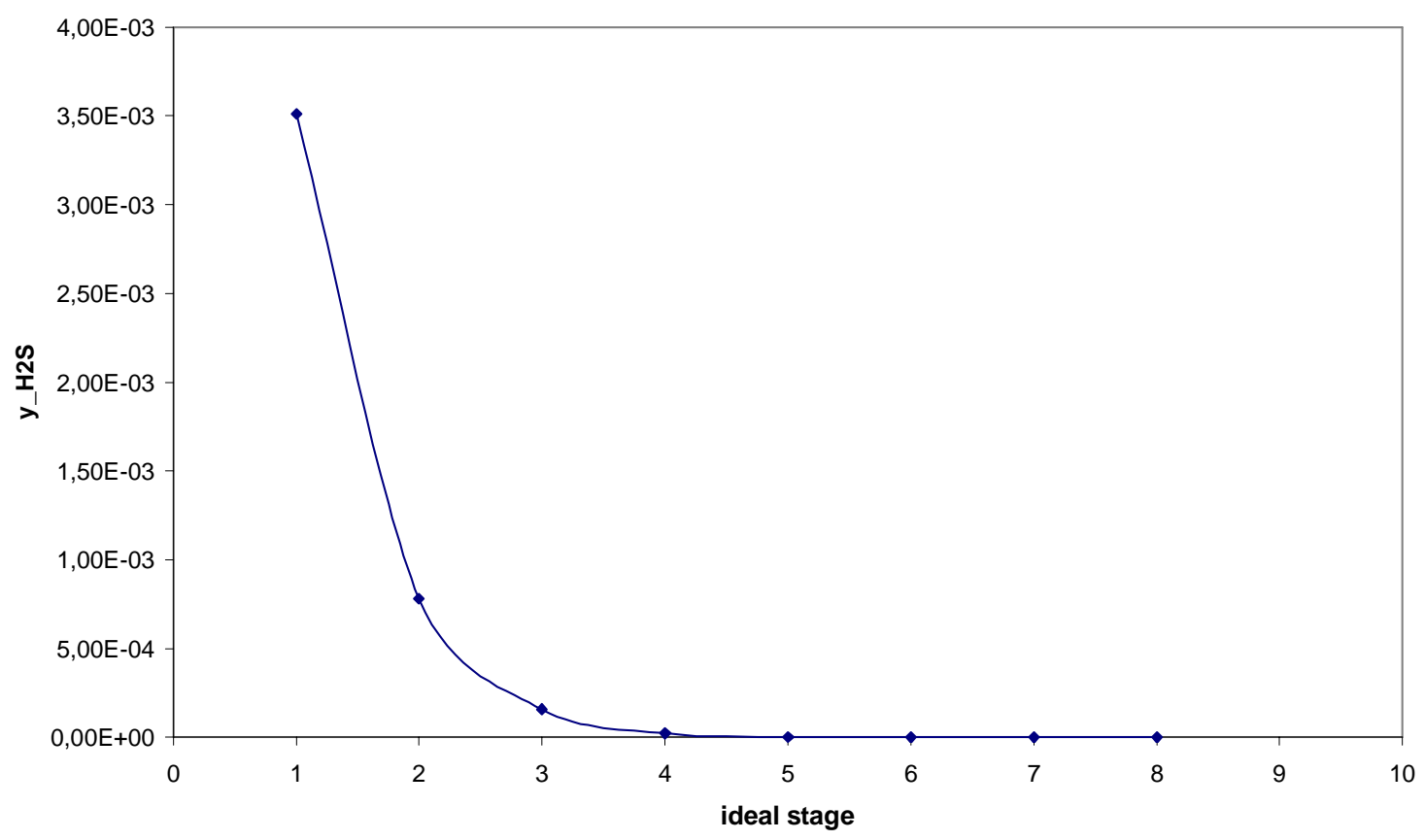

Fig. $\mathrm{C21}: \mathrm{H}_{2} \mathrm{~S}$ gas concentration profile in the absorption column

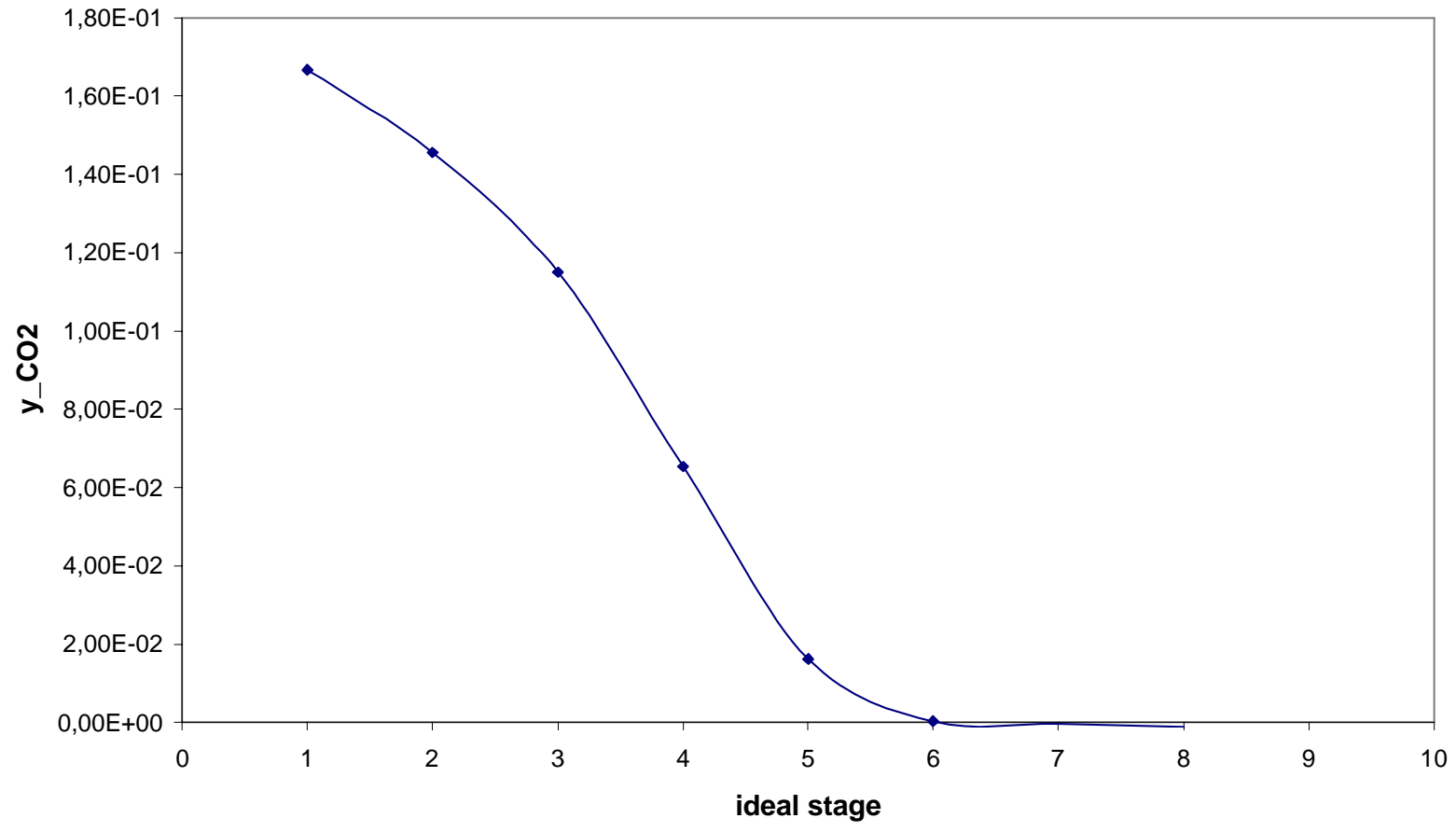

Fig. C22: $\mathrm{CO}_{2}$ gas concentration profile in the absorption column 


\section{C.4 Aspen Plus thermodynamic model}

The Aspen Plus Helpdesk provides a specific advice for the thermodynamic models that fit the acid gas absorption by a methanol solvent and a clear reference is made to the Rectisol process.

The list is reported here below:

- PRWS

- RKSWS

- PRMHV2

- PSRK

- SR-POLAR

The Aspen Support Service experts (email: AES.Support@aspentech.com) suggested that PSRK does not have adjustable parameters because it is based on the UNIFAC equation of state and it might not give the best results. The other listed models, though, require binary parameters (methanol/acid gas): Aspen Plus is not provided with data for the system methanol/COS and on the other hand these parameters were not available.

Actually, the only thermodynamic model which can process the COS without any external intervention is the SR-POLAR one.

It was decided therefore to use the PSRK model and to remove the COS from the raw gas feed stream (its composition is $0.02 \%$ vol) and replacing the flow of this component by a molarequivalent amount of $\mathrm{H}_{2} \mathrm{~S}$. This was done in the hypothesis that the binary parameters of the systems $\mathrm{MeOH} / \mathrm{COS}$ and $\mathrm{MeOH} / \mathrm{H}_{2} \mathrm{~S}$ are quite similar.

This hypothesis could not be verified directly as we lacked of the parameters, but the following sensitivity analysis was performed:

- a sample raw gas streams quite similar to the Aspen Model one in term of composition and properties was fed to a single stage absorber: in one case though the raw gas stream contained $1 \%$ vol of $\mathrm{H}_{2} \mathrm{~S}$, on the other case $1 \%$ vol of COS. An Aspen Plus simulation calculated the methanol flow (@ the raw gas T and P) required to absorb $99 \%$ of the molar flow of the raw S-containing gas $\left(\mathrm{H}_{2} \mathrm{~S}\right.$ or $\left.\mathrm{COS}\right)$.

- All the thermodynamic model listed here above were used, but as we anticipated only the SR-POLAR one performed the calculations for the COS case.

- The results reported in Table $\mathrm{C} 10$ show that:

1. for the $\mathrm{H}_{2} \mathrm{~S}$ case, the $\mathrm{MeOH}$ required flowrate and the absorption heat data are of the same order of magnitude for the different models, even though the PSRK and PRWS ones provide the largest estimation for the methanol flow and a relatively small heat of absorption;

2. The SR-POLAR model, which allows comparing the MeOH/COS and $\mathrm{MeOH} / \mathrm{H} 2 \mathrm{~S}$ performances, shows the same value for the heat and two equal order of magnitude values for the required methanol flow.

Based on the previous considerations and on the fact that the COS concentration is roughly $1 \% \mathrm{~mol} / \mathrm{mol}$ of the $\mathrm{H}_{2} \mathrm{~S}$ one, the error due to replacing the COS flow by a molar-correspondent flow of $\mathrm{H}_{2} \mathrm{~S}$ was considered negligible to the degree of approximation of the results provided in the present Study. 


\begin{tabular}{|c|c|c|c|c|}
\hline \multicolumn{5}{|c|}{ H2S CAPTURE } \\
\hline & RAWGAS & MODEL USED & $\begin{array}{l}\text { METHANOL FLOW } \\
\text { REQUIRED TO } \\
\text { CAPTURE 99\% OF } \\
\text { THE INCOMING H2S } \\
\text { GAS FLOW }\end{array}$ & HEAT released \\
\hline & VAPOR & & $\mathrm{kmol} / \mathrm{s}$ & $M W$ \\
\hline Mole Flow $\mathrm{kmol} / \mathrm{sec}$ & & RKSWS & 3 & 4.9 \\
\hline METHANOL & 0 & PRMHV2 & 1.47 & 8.9 \\
\hline NITROGEN & 0.07 & $P R W S$ & 8.55 & 4.7 \\
\hline COS & 0 & PSRK & 8.55 & 4.7 \\
\hline $\mathrm{H} 2 \mathrm{~S}$ & 0.01 & $S R P O L A R$ & 4.81 & 3.6 \\
\hline $\mathrm{CO}$ & 0.35 & & & \\
\hline $\mathrm{CO} 2$ & 0.20 & & & \\
\hline $\mathrm{CH} 4$ & 0.02 & & & \\
\hline $\mathrm{H} 2$ & 0.35 & & & \\
\hline Total Flow $\mathrm{kmol} / \mathrm{sec}$ & 1.00 & & & \\
\hline Temperature $\mathrm{K}$ & 238.15 & & & \\
\hline Pressure $\mathrm{N} / \mathrm{sqm}$ & $3.20 \mathrm{E}+06$ & & & \\
\hline \multicolumn{5}{|c|}{ COS CAPTURE } \\
\hline & RAWGAS & MODEL USED & $\begin{array}{l}\text { METHANOL FLOW } \\
\text { REQUIRED TO } \\
\text { CAPTURE 99\% OF } \\
\text { THE INCOMING COS } \\
\text { GAS FLOW }\end{array}$ & HEAT released \\
\hline & VAPOR & & $\mathrm{kmol} / \mathrm{s}$ & $M W$ \\
\hline Mole Flow $\mathrm{kmol} / \mathrm{sec}$ & & SRPOLAR & 8.68 & 3.6 \\
\hline METHANOL & 0 & & & \\
\hline NITROGEN & 0.07 & & & \\
\hline COS & 0.01 & & & \\
\hline $\mathrm{H} 2 \mathrm{~S}$ & 0 & & & \\
\hline $\mathrm{CO}$ & 0.35 & & & \\
\hline $\mathrm{CO} 2$ & 0.20 & & & \\
\hline $\mathrm{CH} 4$ & 0.02 & & & \\
\hline $\mathrm{H} 2$ & 0.35 & & & \\
\hline Total Flow $\mathrm{kmol} / \mathrm{sec}$ & 1.00 & & & \\
\hline Total Flow $\mathrm{kg} / \mathrm{sec}$ & 21.93 & & & \\
\hline Total Flow cum/sec & 0.58 & & & \\
\hline Temperature $\mathrm{K}$ & 238.15 & & & \\
\hline Pressure N/sqm & $3.20 \mathrm{E}+06$ & & & \\
\hline
\end{tabular}

Table C10

\section{C.5 References}

[Ref. 1]: "Separation of Gaseous Components from a Gaseous Mixture by Physical Scrubbing", Ranke, G.; Weiss, H., United States patent 4,324,567, 1982

[Ref. 2]: Gas Processes 2004, Hydrocarbon Processing®

[Ref. 3]: Gas Purification, II Edition, Riesenfeld, F.C.; Kohl, A., Gulf Publishing Company, 1974.

[Ref. 4]: The Rectisol® Process for Gas Purification, Lurgi Engineering Oel-Gas-Chemie, brochure available @ http://www.lurgi.com (in attachment to the present Study).

[Ref. 5]: Dr. Ulrich Koss, Ulrich_Koss@lurgi.de, Private Communication, 2005. 


\section{A Cost-Benefit Assessment of Gasification-Based Biorefining in the Kraft Pulp and Paper Industry}

\section{Volume 3: \\ Fuel Chain and National Cost-Benefit Analysis}

FINAL REPORT

Under contract DE-FG26-04NT42260 with the U.S. Department of Energy and with cost-sharing by the American Forest and Paper Association

21 December 2006

Eric D. Larson

Princeton Environmental Institute

Princeton University

Princeton, NJ

elarson@princeton.edu

Stefano Consonni

Department of Energy Engineering

Politecnico di Milano

Milan, Italy

stefano.consonni@polimi.it

Ryan E. Katofsky and Matthew Campbell

Navigant Consulting, Inc.

Burlington, MA

rkatofsky@navigantconsulting.com

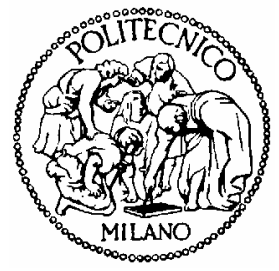

macampbell@navigantconsulting.com

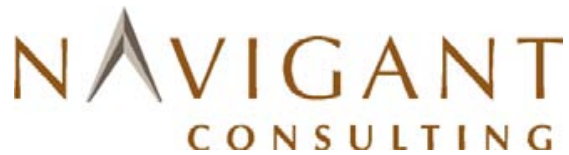

Kristiina Iisa and W. James Frederick, Jr.

Institute of Paper Science and Technology

School of Chemical and Biomolecular Engineering

Georgia Institute of Technology

Atlanta, GA

Kristiina.Iisa@ipst.gatech.edu

Jim.Frederick@ipst.gatech.edu 
"Navigant" is a service mark of Navigant International, Inc. Navigant Consulting, Inc. (NCI) is not affiliated, associated, or in any way connected with Navigant International, Inc. and NCI's use of "Navigant" is made under license from Navigant International, Inc. 


\section{TABLE OF CONTENTS}

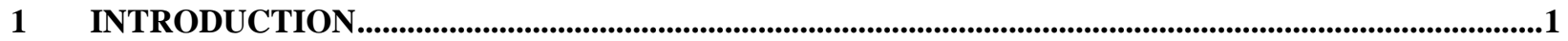

2 EMISSIONS FACTORS FOR STATIONARY SOURCES ...........................................................................1

3 EMISSIONS FACTORS FOR BIOFUEL FUEL CHAIN ELEMENTS .......................................................4

4 EMISSIONS FACTORS FOR CONVENTIONAL FUEL CHAINS ....................................................13

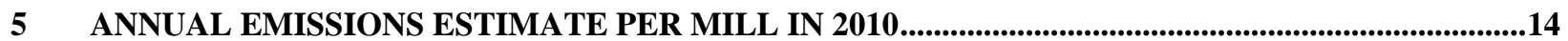

6 RESULTS FROM THE MARKET PENETRATION ANALYSIS ..........................................................18

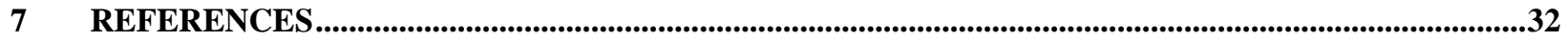




\section{List of Tables in Volume 3}

Table 1. Unit emission factors assumed for the New Tomlinson case (lb/MMBtu fuel input - HHV)

Table 2. Unit emission factors assumed for the Mill-Scale High-Temperature BLGCC case (lb/MMBtu fuel input HHV) .2

Table 3. Unit emission factors assumed for the DMEa case (lb/MMBtu fuel input - HHV)......................................2

Table 4. Unit emission factors assumed for the DMEb case (lb/MMBtu fuel input - HHV) ......................................

Table 5. Unit emission factors assumed for the DMEc case (lb/MMBtu fuel input - HHV)........................................

Table 6. Unit emission factors assumed for the FTa case (lb/MMBtu fuel input - HHV) ...........................................

Table 7. Unit emission factors assumed for the FTb case (lb/MMBtu fuel input - HHV)...........................................

Table 8. Unit emission factors assumed for the FTc case (lb/MMBtu fuel input - HHV) ...........................................

Table 9. Unit emission factors assumed for the mixed alcohols (MA) case (lb/MMBtu fuel input - HHV)................4

Table 10: Total average U.S. grid emissions (including non-fossil fuel sources) assumed in estimating grid offsets. 4

Table 11. Emissions and energy use ${ }^{a}$ from biomass collection and transport (75-miles one-way) ............................5

Table 12. Emissions and energy use $\mathrm{s}^{\mathrm{a}}$ from DME transportation and distribution .......................................................

Table 13. Emissions and energy use $\mathrm{a}^{\mathrm{a}}$ from FT Gasoline transportation and distribution ..........................................6

Table 14. Emissions and energy use ${ }^{\mathrm{a}}$ from FT Diesel transportation and distribution .............................................

Table 15. Emissions and energy use ${ }^{\mathrm{a}}$ from mixed alcohol transportation and distribution .......................................

Table 16. Emissions and energy use ${ }^{a}$ from FT Crude transportation and distribution...............................................

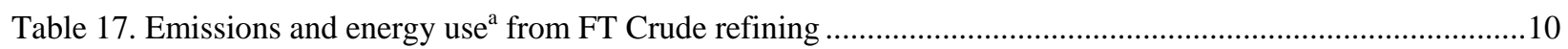

Table 18. Energy consumption and emissions assumptions for DME in light-duty vehicles (CIDI Engines) ${ }^{\mathrm{a}}$............10

Table 19. Energy consumption and emissions assumptions for FT fuels blended with conventional fuels in light-duty vehicles (FT gasoline in gasoline engines and FT diesel in CIDI engines) ${ }^{\mathrm{a}}$..

Table 20. Energy consumption and emissions assumptions for FT fuels in light-duty vehicles (FT gasoline in gasoline engines and FT diesel in CIDI engines). ${ }^{\mathrm{a}}$.

Table 21. Energy consumption and emissions assumptions for mixed alcohol use in light-duty vehicles (low-level blend with gasoline and Flexible-Fuel Vehicle ["E-85"]) $)^{\mathrm{a}}$

Table 22. Energy consumption ${ }^{\mathrm{a}}$ and emissions for the gasoline fuel chain .........................................................13

Table 23. Energy consumption ${ }^{a}$ and emissions for the low-sulfur diesel fuel chain ................................................13

Table 24: Summary of Biorefinery market penetration scenarios developed in this study........................................18 


\section{List of Figures in Volume 3}

Figure 1: Well-to-wheels analysis framework for pulp and paper biorefineries...................................................

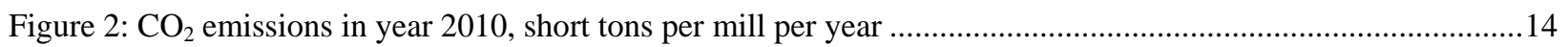

Figure 3: $\mathrm{SO}_{2}$ emissions in year 2010, short tons per mill per year.................................................................15

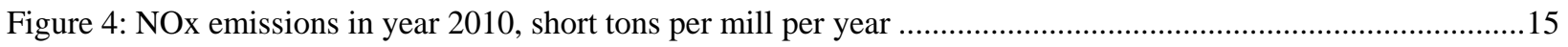

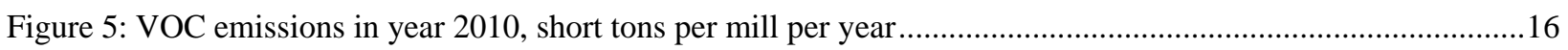

Figure 6: CO Emissions in year 2010, short tons per mill per year ..................................................................... 16

Figure 7: PM10 Emissions in year 2010, short tons per mill per year ..................................................................17

Figure 8: TRS Emissions in year 2010, short tons per mill per year ................................................................. 17

Figure 9: Market penetration estimates used to assess energy and environmental impacts of biorefinery

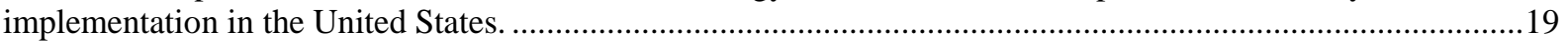

Figure 10: Net fossil fuel energy savings - HHV (Aggressive market penetration scenario)....................................19

Figure 11: Net fossil fuel energy savings - HHV (Base market penetration scenario) .............................................20

Figure 12: Net fossil fuel energy savings - HHV (Low market penetration scenario) .............................................20

Figure 13: Net $\mathrm{CO}_{2}$ emissions reductions (with credit for biomass $\mathrm{CO}_{2}$ ) (Aggressive market penetration scenario)..21

Figure 14: $\mathrm{Net}^{\mathrm{CO}_{2}}$ emissions reductions (with credit for biomass $\mathrm{CO}_{2}$ ) (Base market penetration scenario) ...........21

Figure 15: $\mathrm{Net}_{\mathrm{CO}_{2}}$ emissions reductions (with credit for biomass $\left.\mathrm{CO}_{2}\right)($ Low market penetration scenario) .............22

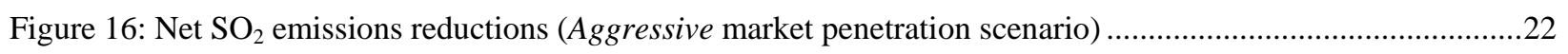

Figure 17: $\mathrm{Net}^{\mathrm{SO}_{2}}$ emissions reductions (Base market penetration scenario) ........................................................23

Figure 18: $\mathrm{Net}_{\mathrm{SO}_{2}}$ emissions reductions (Low market penetration scenario) ......................................................23

Figure 19: Net NOx emissions reductions (Aggressive market penetration scenario) ...............................................24

Figure 20: Net NOx emissions reductions (Base market penetration scenario)........................................................24

Figure 21: Net NOx emissions reductions (Low market penetration scenario) ......................................................25

Figure 22: Net VOC emissions reductions (Aggressive market penetration scenario) .............................................25

Figure 23: Net VOC emissions reductions (Base market penetration scenario) .......................................................26

Figure 24: Net VOC emissions reductions (Low market penetration scenario) ............................................................26

Figure 25: Net CO emissions reductions (Aggressive market penetration scenario) ................................................27

Figure 26: Net CO emissions reductions (Base market penetration scenario) .........................................................27

Figure 27: Net CO emissions reductions (Low market penetration scenario).........................................................28

Figure 28: Net PM10 emissions reductions (Aggressive market penetration scenario) ............................................28

Figure 29: PM10 emissions reductions (Base market penetration scenario) ……..............................................29

Figure 30: PM10 emissions reductions (Low market penetration scenario) ...........................................................29

Figure 31: Net VOC emissions reductions comparing low-level and high-level blends of mixed alcohols and FT

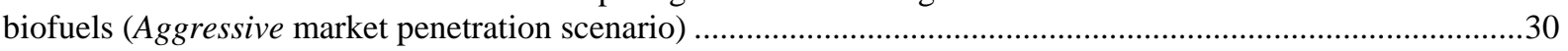

Figure 32: Net CO emissions reductions comparing low-level and high-level blends of mixed alcohols and FT biofuels (Aggressive market penetration scenario) . 


\section{Introduction}

This volume contains the detailed assumptions for the well-to-wheels (WTW) analysis and provides complete results of the national impacts analysis for all three market penetration scenarios. Figure 1 illustrates the components modeled in the WTW analysis. This volume is primarily a data volume. The reader is referred back to Volume 1 for a more complete discussion of the WTW approach and a description of the market penetration scenarios.

Note that the analysis, based on the assumptions presented here, is not intended to serve as a complete lifecycle analysis of biorefinery emissions. Rather the estimates provide indicative results of the potential impacts of biorefinery options relative to "business as usual" in the pulp and paper industry.

\section{The Forest Biorefinery Fuel Chain}

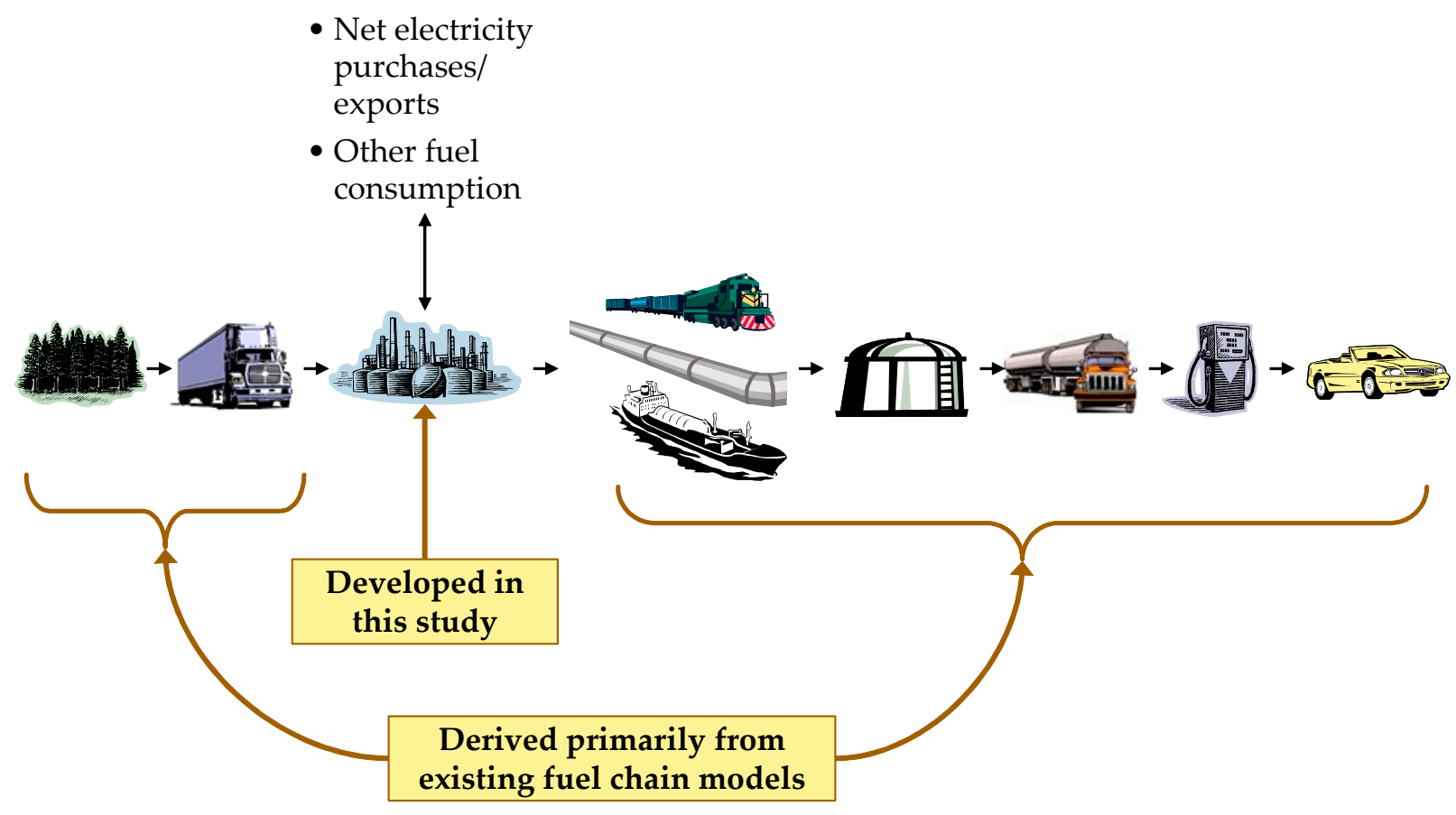

Figure 1: Well-to-wheels analysis framework for pulp and paper biorefineries

\section{Emissions Factors for Stationary Sources}

Table 1 through Table 9 show the emissions factors used for the point sources at the reference pulp and paper mill, expressed on a common basis for each of the configurations. All values are based on the higher heating value of the fuel. The primary energy represents the energy contained in the fuel consumed in the indicated step, e.g., black liquor in the case of the Tomlinson boilers and syngas in the case of the gas turbines. In the case of the gas turbine 
systems and the duct burners, the primary energy is a mixture of biomass syngas, unconverted syngas from biofuels synthesis, and natural gas (BLGCC configuration only), depending on the configuration. For this reason, $\mathrm{CO}_{2}$ and $\mathrm{SO}_{2}$ emissions rates differ among different cases. All other emissions are assumed to be the same. For the lime kiln, emissions are based on the use of \#6 fuel oil. Because of the reactions taking place inside a lime kiln, emissions of criteria pollutants from burning \#6 oil are not substantially different from emissions using natural gas. The $\mathrm{CO}_{2}$ emissions shown in Table 1 through Table 9 include $\mathrm{CO}_{2}$ from biomass. This $\mathrm{CO}_{2}$ is netted out in the fuel chain analysis, as described in Volume 1.

Emissions factor estimates for mill related sources are based on the following references:

- Lime kiln and Tomlinson boiler: [1, 2, 3, 4, 5, 6, 7]

- Bark boiler: [8]

- Gas turbine: $[9,10,11,12,13,14,15,16]$

- Duct burner: [17], assuming similar criteria pollutant emissions as for natural gas combustion.

Table 10 shows grid power emissions for 2010-2035 in five-year increments. Emissions in the intervening years are consistent with the trends indicated by the years shown.

Table 1. Unit emission factors assumed for the New Tomlinson case (Ib/MMBtu fuel input - HHV)

\begin{tabular}{|l|r|r|r|}
\hline & Lime kiln & Bark boiler & Tomlinson \\
\hline VOC & 0.0043 & 0.0130 & 0.0134 \\
\hline CO & 0.0285 & 0.6000 & 0.0940 \\
\hline NOx & 0.2857 & 0.2200 & 0.1544 \\
\hline PM10 & 0.0150 & 0.0540 & 0.0477 \\
\hline SOx & 0.0286 & 0.0698 & 0.0215 \\
\hline CO2 & 172 & 213 & 205 \\
\hline TRS & 0.0086 & 0.0000 & 0.0034 \\
\hline
\end{tabular}

Table 2. Unit emission factors assumed for the Mill-Scale High-Temperature BLGCC case (Ib/MMBtu fuel input - HHV)

\begin{tabular}{|l|r|r|r|r|}
\hline & Lime kiln & Bark boiler & GT & Duct burner \\
\hline VOC & 0.0043 & 0.0130 & 0.0021 & 0.0054 \\
\hline CO & 0.0285 & 0.6000 & 0.0330 & 0.0818 \\
\hline NOx & 0.2857 & 0.2200 & 0.0897 & 0.0974 \\
\hline PM10 & 0.0150 & 0.0540 & 0.0066 & 0.0074 \\
\hline SOx & 0.0286 & 0.0698 & 0.0000 & 0.0004 \\
\hline CO2 & 172 & 213 & 221 & 169 \\
\hline TRS & 0.0086 & 0.0000 & 0.0000 & 0.0000 \\
\hline
\end{tabular}

Table 3. Unit emission factors assumed for the DMEa case (Ib/MMBtu fuel input - HHV)

\begin{tabular}{|l|r|r|}
\hline & Lime kiln & Bark boiler \\
\hline VOC & 0.0043 & 0.0130 \\
\hline CO & 0.0285 & 0.6000 \\
\hline NOx & 0.2857 & 0.2200 \\
\hline PM10 & 0.0150 & 0.0540 \\
\hline SOx & 0.0286 & 0.1141 \\
\hline CO2 & 172 & 265 \\
\hline TRS & 0.0086 & 0.0000 \\
\hline
\end{tabular}


Note: in DMEa, the bark boiler also burns unconverted syngas. Aside from impacts on $\mathrm{CO}_{2}$ and $\mathrm{SO}_{2}$, no other benefits are assumed from the co-firing of clean syngas.

Table 4. Unit emission factors assumed for the DMEb case (Ib/MMBtu fuel input - HHV)

\begin{tabular}{|l|r|r|r|}
\hline & Lime kiln & GT & Duct burner \\
\hline VOC & 0.0043 & 0.0021 & 0.0054 \\
\hline CO & 0.0285 & 0.0330 & 0.0818 \\
\hline NOx & 0.2857 & 0.0897 & 0.0974 \\
\hline PM10 & 0.0150 & 0.0066 & 0.0074 \\
\hline SOx & 0.0286 & 0.1599 & 0.0000 \\
\hline CO2 & 172 & 245 & 474 \\
\hline TRS & 0.0086 & 0.0000 & 0.0000 \\
\hline
\end{tabular}

Table 5. Unit emission factors assumed for the DMEc case (Ib/MMBtu fuel input - HHV)

\begin{tabular}{|l|r|r|r|}
\hline & Lime kiln & GT & Duct burner \\
\hline VOC & 0.0043 & 0.0021 & 0.0054 \\
\hline CO & 0.0285 & 0.0330 & 0.0818 \\
\hline NOx & 0.2857 & 0.0897 & 0.0974 \\
\hline PM10 & 0.0150 & 0.0066 & 0.0074 \\
\hline SOx & 0.0286 & 0.0895 & 0.0000 \\
\hline CO2 & 172 & 240 & 237 \\
\hline TRS & 0.0086 & 0.0000 & 0.0000 \\
\hline
\end{tabular}

Table 6. Unit emission factors assumed for the FTa case (Ib/MMBtu fuel input - HHV)

\begin{tabular}{|l|r|r|r|}
\hline & Lime kiln & GT & Duct burner \\
\hline VOC & 0.0043 & 0.0021 & 0.0054 \\
\hline CO & 0.0285 & 0.0330 & 0.0818 \\
\hline NOx & 0.2857 & 0.0897 & 0.0974 \\
\hline PM10 & 0.0150 & 0.0066 & 0.0074 \\
\hline SOx & 0.0286 & 0.1069 & 0.0956 \\
\hline CO2 & 172 & 272 & 325 \\
\hline TRS & 0.0086 & 0.0000 & 0.0000 \\
\hline
\end{tabular}

Table 7. Unit emission factors assumed for the FTb case (Ib/MMBtu fuel input - HHV)

\begin{tabular}{|l|r|r|}
\hline & Lime kiln & GT \\
\hline VOC & 0.0043 & 0.0021 \\
\hline CO & 0.0285 & 0.0330 \\
\hline NOx & 0.2857 & 0.0897 \\
\hline PM10 & 0.0150 & 0.0066 \\
\hline SOx & 0.0286 & 0.1319 \\
\hline CO2 & 172 & 259 \\
\hline TRS & 0.0086 & 0.0000 \\
\hline
\end{tabular}


Table 8. Unit emission factors assumed for the FTc case (Ib/MMBtu fuel input - HHV)

\begin{tabular}{|l|r|r|}
\hline & Lime kiln & GT \\
\hline VOC & 0.0043 & 0.0021 \\
\hline CO & 0.0285 & 0.0330 \\
\hline NOx & 0.2857 & 0.0897 \\
\hline PM10 & 0.0150 & 0.0066 \\
\hline SOx & 0.0286 & 0.0000 \\
\hline CO2 & 172 & 322 \\
\hline TRS & 0.0086 & 0.0000 \\
\hline
\end{tabular}

Table 9. Unit emission factors assumed for the mixed alcohols (MA) case (Ib/MMBtu fuel input HHV).

\begin{tabular}{|l|r|r|r|}
\hline & Lime kiln & GT & Duct Burner \\
\hline VOC & 0.0043 & 0.0021 & 0.0021 \\
\hline CO & 0.0285 & 0.0330 & 0.0330 \\
\hline NOx & 0.2857 & 0.0897 & 0.0897 \\
\hline PM10 & 0.0150 & 0.0066 & 0.0066 \\
\hline SOx & 0.0286 & 0.0000 & 0.1667 \\
\hline CO2 & 172 & 303 & 259 \\
\hline TRS & 0.0086 & 0 & 0 \\
\hline
\end{tabular}

Table 10: Total average U.S. grid emissions (including non-fossil fuel sources) assumed in estimating grid offsets. ${ }^{a}$

\begin{tabular}{|l|r|r|r|r|r|r|}
\hline Ib/MWh & $\mathbf{2 0 1 0}$ & $\mathbf{2 0 1 5}$ & $\mathbf{2 0 2 0}$ & $\mathbf{2 0 2 5}$ & $\mathbf{2 0 3 0}$ & $\mathbf{2 0 3 5}$ \\
\hline VOC & 0.024 & 0.021 & 0.018 & 0.015 & 0.013 & 0.011 \\
\hline CO & 0.234 & 0.200 & 0.172 & 0.147 & 0.126 & 0.108 \\
\hline NOx & 1.125 & 0.938 & 0.886 & 0.848 & 0.703 & 0.584 \\
\hline PM10 & 0.326 & 0.279 & 0.239 & 0.205 & 0.175 & 0.150 \\
\hline SOx & 2.836 & 2.069 & 1.684 & 1.492 & 1.127 & 0.851 \\
\hline CO2 & 1,340 & 1,312 & 1,303 & 1,321 & 1,318 & 1,316 \\
\hline
\end{tabular}

(a) power plants only. Our WTW analysis did not include emissions from fuel supply to the power plants, and can thus be viewed as conservative in terms of the emissions benefits from displaced grid power.

References: [18, 19, 20, 21]. Estimates for 2031-2035 were extrapolated from the EIA forecast [19], which only goes to 2030.

\section{Emissions Factors for Biofuel Fuel Chain Elements}

The following tables summarize the assumptions used for the elements of the biorefinery fuel chains other than the biorefinery itself. They are all based on version 1.7 of the GREET model [22]. For the vehicle end-use, adjustments to fossil energy consumption are based on the fraction of renewable fuel. For example in Table 19, fossil energy use by the vehicle is adjusted to reflect the blend of conventional fuels and FT biofuels. The values further reflect relative energy content of the different fuels, since blends are expressed on a volume basis. Similarly, $\mathrm{CO}_{2}$ emissions are adjusted based on the relative carbon contents of the different fuels in the blends. 
Table 11. Emissions and energy use ${ }^{a}$ from biomass collection and transport (75-miles one-way)

\begin{tabular}{|l|l|r|r|r|}
\hline & & Collection & Transportation & Total \\
\hline Total energy input & Btu/dry ton & 296,885 & 535,817 & 832,703 \\
\hline Fossil Fuels & Btu/dry ton & 291,701 & 534,341 & 826,042 \\
\hline VOC & g/dry ton & 17 & 17 & 34 \\
\hline CO & g/dry ton & 84 & 75 & 158 \\
\hline NOx & g/dry ton & 163 & 221 & 384 \\
\hline PM10 & g/dry ton & 19 & 7 & 26 \\
\hline SOx & g/dry ton & 14 & 14 & 28 \\
\hline CH4 & g/dry ton & 27 & 47 & 74 \\
\hline CO2 & g/dry ton & 23,293 & 41,882 & 65,175 \\
\hline & & & & \\
\hline Petroleum & Btu/dry ton & 241,655 & 491,697 & 733,352 \\
\hline
\end{tabular}

(a) As reported in the GREET model, energy use is reported here on an LHV basis.

Table 12. Emissions and energy use ${ }^{a}$ from DME transportation and distribution

\begin{tabular}{|c|c|c|c|c|c|}
\hline & & Barge & Pipeline & Rail & Truck \\
\hline Length of haul & miles (one-way) & & & 250 & 50 \\
\hline \multicolumn{6}{|c|}{ Energy consumption and emissions by transport mode } \\
\hline & & Barge & Pipeline & Rail & Truck \\
\hline Energy Consumption & Btu/MMBtu & - & - & 4,398 & 6,108 \\
\hline Fossil Energy Consumption & Btu/MMBtu & - & - & 4,386 & 6,091 \\
\hline VOC & g/MMBtu & - & - & 0.30 & 0.20 \\
\hline $\mathrm{CO}$ & g/MMBtu & - & - & 0.84 & 0.85 \\
\hline NOx & g/MMBtu & - & - & 5.79 & 2.52 \\
\hline PM10 & g/MMBtu & - & - & 0.16 & 0.08 \\
\hline SOx & g/MMBtu & - & - & 0.11 & 0.16 \\
\hline $\mathrm{CH} 4$ & g/MMBtu & - & - & 0.40 & 0.54 \\
\hline $\mathrm{CO} 2$ & g/MMBtu & - & - & 342.90 & 477.40 \\
\hline Petroleum & Btu/MMBtu & - & - & 4,036 & 5,605 \\
\hline \multicolumn{6}{|c|}{ Shares by transport mode (shares need not sum to $100 \%$ ) } \\
\hline & & Barge & Pipeline & Rail & Truck \\
\hline Transportation & $\%$ & $0 \%$ & $0 \%$ & $100 \%$ & $0 \%$ \\
\hline Distribution & $\%$ & $0 \%$ & $0 \%$ & $0 \%$ & $100 \%$ \\
\hline \multicolumn{6}{|c|}{ Energy consumption and emissions in transportation and distribution } \\
\hline & & Transportation & Distribution & Total & \\
\hline Energy Consumption & Btu/MMBtu & 4,398 & 6,108 & 10,506 & \\
\hline Fossil Energy Consumption & Btu/MMBtu & 4,386 & 6,091 & 10,477 & \\
\hline VOC & g/MMBtu & 0.30 & 0.20 & 0.50 & \\
\hline $\mathrm{CO}$ & g/MMBtu & 0.84 & 0.85 & 1.69 & \\
\hline NOx & g/MMBtu & 5.79 & 2.52 & 8.31 & \\
\hline PM10 & g/MMBtu & 0.16 & 0.08 & 0.24 & \\
\hline SOx & g/MMBtu & 0.11 & 0.16 & 0.27 & \\
\hline $\mathrm{CH} 4$ & g/MMBtu & 0.40 & 0.54 & 0.94 & \\
\hline $\mathrm{CO} 2$ & g/MMBtu & 342.90 & 477.40 & 820.31 & \\
\hline Petroleum & Btu/MMBtu & 4,036 & 5,605 & 9,641 & \\
\hline
\end{tabular}

(a) As reported in the GREET model, energy use is reported here on an LHV basis. 
Table 13. Emissions and energy use ${ }^{a}$ from FT Gasoline transportation and distribution

\begin{tabular}{|c|c|c|c|c|c|}
\hline & & Barge & Pipeline & Rail & Truck \\
\hline Length of haul & miles (one-way) & 520 & 400 & 800 & 30 \\
\hline \multicolumn{6}{|c|}{ Energy consumption and emissions by transport mode } \\
\hline & & Barge & Pipeline & Rail & Truck \\
\hline Energy Consumption & Btu/MMBtu & 10,844 & 3,244 & 9,356 & 1,949 \\
\hline Fossil Energy Consumption & Btu/MMBtu & 10,822 & 3,185 & 9,330 & 1,943 \\
\hline VOC & g/MMBtu & 0.46 & 0.11 & 0.65 & 0.06 \\
\hline $\mathrm{CO}$ & g/MMBtu & 1.26 & 0.57 & 1.78 & 0.27 \\
\hline NOx & g/MMBtu & 10.67 & 2.42 & 12.31 & 0.81 \\
\hline PM10 & g/MMBtu & 0.30 & 0.10 & 0.34 & 0.03 \\
\hline SOx & g/MMBtu & 2.82 & 0.50 & 0.23 & 0.05 \\
\hline $\mathrm{CH} 4$ & g/MMBtu & 0.97 & 0.47 & 0.85 & 0.17 \\
\hline $\mathrm{CO} 2$ & g/MMBtu & 919.58 & 252.48 & 729.41 & 152.33 \\
\hline Petroleum & Btu/MMBtu & $10,311.29$ & $2,015.61$ & 8,586 & 1,788 \\
\hline & & & & & \\
\hline \multicolumn{6}{|c|}{ Shares by transport mode (shares need not sum to $100 \%$ ) } \\
\hline & & Barge & Pipeline & Rail & Truck \\
\hline Transportation & $\%$ & $4 \%$ & $73 \%$ & $7 \%$ & $0 \%$ \\
\hline Distribution & $\%$ & $0 \%$ & $0 \%$ & $0 \%$ & $100 \%$ \\
\hline \multicolumn{6}{|c|}{ Energy consumption and emissions in transportation and distribution } \\
\hline & & Transportation & Distribution & Total & \\
\hline Energy Consumption & Btu/MMBtu & 3,457 & 1,949 & 5,406 & \\
\hline Fossil Energy Consumption & Btu/MMBtu & 3,411 & 1,943 & 5,355 & \\
\hline VOC & g/MMBtu & 0.15 & 0.06 & 0.21 & \\
\hline $\mathrm{CO}$ & g/MMBtu & 0.59 & 0.27 & 0.86 & \\
\hline NOx & g/MMBtu & 3.06 & 0.81 & 3.86 & \\
\hline PM10 & g/MMBtu & 0.11 & 0.03 & 0.13 & \\
\hline SOx & g/MMBtu & 0.49 & 0.05 & 0.54 & \\
\hline $\mathrm{CH} 4$ & g/MMBtu & 0.44 & 0.17 & 0.61 & \\
\hline $\mathrm{CO} 2$ & g/MMBtu & 272.15 & 152.33 & 424.48 & \\
\hline Petroleum & Btu/MMBtu & 2,485 & 1,788 & 4,273 & \\
\hline
\end{tabular}

(a) As reported in the GREET model, energy use is reported here on an LHV basis. 
Table 14. Emissions and energy use ${ }^{\mathrm{a}}$ from FT Diesel transportation and distribution

\begin{tabular}{|c|c|c|c|c|c|}
\hline & & Barge & Pipeline & Rail & Truck \\
\hline Length of haul & miles (one-way) & 520 & 400 & 800 & 30 \\
\hline \multicolumn{6}{|c|}{ Energy consumption and emissions by transport mode } \\
\hline & & Barge & Pipeline & Rail & Truck \\
\hline Energy Consumption & Btu/MMBtu & 10,894 & 3,259 & 11,486 & 2,392 \\
\hline Fossil Energy Comsumption & Btu/MMBtu & 10,873 & 3,200 & 11,470 & 2,389 \\
\hline VOC & g/MMBtu & 0.47 & 0.11 & 0.67 & 0.07 \\
\hline $\mathrm{CO}$ & g/MMBtu & 1.27 & 0.57 & 1.85 & 0.28 \\
\hline NOx & g/MMBtu & 10.72 & 2.44 & 12.47 & 0.83 \\
\hline PM10 & g/MMBtu & 0.30 & 0.10 & 0.37 & 0.03 \\
\hline SOx & g/MMBtu & 2.84 & 0.50 & 0.24 & 0.05 \\
\hline $\mathrm{CH} 4$ & g/MMBtu & 0.97 & 0.47 & 1.21 & 0.25 \\
\hline $\mathrm{CO} 2$ & g/MMBtu & 923.85 & 253.65 & 779.37 & 162.74 \\
\hline Petroleum & Btu/MMBtu & $10,359.14$ & $2,024.96$ & 4,313 & 898 \\
\hline \multicolumn{6}{|c|}{ Shares by transport mode (shares need not sum to $100 \%$ ) } \\
\hline & & Barge & Pipeline & Rail & Truck \\
\hline Transportation & $\%$ & $6 \%$ & $75 \%$ & $7 \%$ & $0 \%$ \\
\hline Distribution & $\%$ & $0 \%$ & $0 \%$ & $0 \%$ & $100 \%$ \\
\hline \multicolumn{6}{|c|}{ Energy consumption and emissions in transportation and distribution } \\
\hline & & Transportation & Distribution & Total & \\
\hline Energy Consumption & Btu/MMBtu & 3,902 & 2,392 & 6,295 & \\
\hline Fossil Energy Consumption & Btu/MMBtu & 3,855 & 2,389 & 6,244 & \\
\hline VOC & g/MMBtu & 0.16 & 0.07 & 0.23 & \\
\hline $\mathrm{CO}$ & g/MMBtu & 0.63 & 0.28 & 0.92 & \\
\hline NOx & g/MMBtu & 3.34 & 0.83 & 4.17 & \\
\hline PM10 & g/MMBtu & 0.12 & 0.03 & 0.15 & \\
\hline SOx & g/MMBtu & 0.56 & 0.05 & 0.61 & \\
\hline $\mathrm{CH} 4$ & g/MMBtu & 0.50 & 0.25 & 0.74 & \\
\hline $\mathrm{CO} 2$ & g/MMBtu & 300.23 & 162.74 & 462.96 & \\
\hline Petroleum & Btu/MMBtu & 2,442 & 898 & 3,340 & \\
\hline
\end{tabular}

(a) As reported in the GREET model, energy use is reported here on an LHV basis. 
Table 15. Emissions and energy use ${ }^{a}$ from mixed alcohol transportation and distribution

\begin{tabular}{|c|c|c|c|c|c|}
\hline & & Barge & Pipeline & Rail & Truck \\
\hline Length of haul & miles (one-way) & & & 250 & 50 \\
\hline \multicolumn{6}{|c|}{ Energy consumption and emissions by transport mode } \\
\hline & & Barge & Pipeline & Rail & Truck \\
\hline Energy Consumption & Btu/MMBtu & - & - & 4,713 & 5,236 \\
\hline Fossil Energy Consumption & Btu/MMBtu & - & - & 4,700 & 5,222 \\
\hline VOC & g/MMBtu & - & - & 0.33 & 0.17 \\
\hline $\mathrm{CO}$ & g/MMBtu & - & - & 0.90 & 0.73 \\
\hline NOx & g/MMBtu & - & - & 6.20 & 2.16 \\
\hline PM10 & g/MMBtu & - & - & 0.17 & 0.07 \\
\hline SOx & g/MMBtu & - & - & 0.12 & 0.14 \\
\hline $\mathrm{CH} 4$ & g/MMBtu & - & - & 0.43 & 0.46 \\
\hline $\mathrm{CO} 2$ & g/MMBtu & - & - & 367.46 & 409.27 \\
\hline Petroleum & Btu/MMBtu & - & - & 4,325 & 4,805 \\
\hline & & & & & \\
\hline \multicolumn{6}{|c|}{ Shares by transport mode (shares need not sum to $100 \%$ ) } \\
\hline & & Barge & Pipeline & Rail & Truck \\
\hline Transportation & $\%$ & $0 \%$ & $0 \%$ & $100 \%$ & $0 \%$ \\
\hline Distribution & $\%$ & $0 \%$ & $0 \%$ & $0 \%$ & $100 \%$ \\
\hline \multicolumn{6}{|c|}{ Energy consumption and emissions in transportation and distribution } \\
\hline & & Transportation & Distribution & Total & \\
\hline Energy Consumption & Btu/MMBtu & 4,713 & 5,236 & 9,949 & \\
\hline Fossil Energy Consumption & Btu/MMBtu & 4,700 & 5,222 & 9,922 & \\
\hline VOC & g/MMBtu & 0.33 & 0.17 & 0.49 & \\
\hline $\mathrm{CO}$ & g/MMBtu & 0.90 & 0.73 & 1.63 & \\
\hline NOx & g/MMBtu & 6.20 & 2.16 & 8.36 & \\
\hline PM10 & g/MMBtu & 0.17 & 0.07 & 0.24 & \\
\hline SOx & g/MMBtu & 0.12 & 0.14 & 0.26 & \\
\hline $\mathrm{CH} 4$ & g/MMBtu & 0.43 & 0.46 & 0.89 & \\
\hline $\mathrm{CO} 2$ & g/MMBtu & 367.46 & 409.27 & 776.73 & \\
\hline Petroleum & Btu/MMBtu & 4,325 & 4,805 & 9,130 & \\
\hline
\end{tabular}

(a) As reported in the GREET model, energy use is reported here on an LHV basis. 
Table 16. Emissions and energy use ${ }^{\mathrm{a}}$ from FT Crude transportation and distribution

\begin{tabular}{|c|c|c|c|c|c|}
\hline & & Barge & Pipeline & Rail & Truck \\
\hline Length of haul & miles (one-way) & & & 100 & 0 \\
\hline \multicolumn{6}{|c|}{ Energy consumption and emissions by transport mode } \\
\hline & & Barge & Pipeline & Rail & Truck \\
\hline Energy Consumption & Btu/MMBtu & - & - & 1,190 & - \\
\hline Fossil Energy Consumption & Btu/MMBtu & - & - & 1,187 & - \\
\hline VOC & g/MMBtu & - & - & 0.08 & - \\
\hline $\mathrm{CO}$ & g/MMBtu & - & - & 0.23 & - \\
\hline NOx & g/MMBtu & - & - & 1.57 & - \\
\hline PM10 & g/MMBtu & - & - & 0.04 & - \\
\hline SOx & g/MMBtu & - & - & 0.03 & - \\
\hline $\mathrm{CH} 4$ & g/MMBtu & - & - & 0.11 & - \\
\hline $\mathrm{CO} 2$ & g/MMBtu & - & - & 92.81 & - \\
\hline Petroleum & Btu/MMBtu & - & - & 1,092 & - \\
\hline & & & & & \\
\hline \multicolumn{6}{|c|}{ Shares by transport mode (shares need not sum to $100 \%$ ) } \\
\hline & & Barge & Pipeline & Rail & Truck \\
\hline Transportation & $\%$ & $0 \%$ & $0 \%$ & $100 \%$ & $0 \%$ \\
\hline Distribution & $\%$ & $0 \%$ & $0 \%$ & $0 \%$ & $0 \%$ \\
\hline \multicolumn{6}{|c|}{ Energy consumption and emissions in transportation and distribution } \\
\hline & & Transportation & Distribution & Total & \\
\hline Energy Consumption & Btu/MMBtu & 1,190 & - & 1,190 & \\
\hline Fossil Energy Consumption & Btu/MMBtu & 1,187 & - & 1,187 & \\
\hline VOC & g/MMBtu & 0.08 & - & 0.08 & \\
\hline $\mathrm{CO}$ & g/MMBtu & 0.23 & - & 0.23 & \\
\hline NOx & g/MMBtu & 1.57 & - & 1.57 & \\
\hline PM10 & g/MMBtu & 0.04 & - & 0.04 & \\
\hline SOx & g/MMBtu & 0.03 & - & 0.03 & \\
\hline $\mathrm{CH} 4$ & g/MMBtu & 0.11 & - & 0.11 & \\
\hline $\mathrm{CO} 2$ & g/MMBtu & 92.81 & - & 92.81 & \\
\hline Petroleum & Btu/MMBtu & 1,092 & - & 1,092 & \\
\hline
\end{tabular}

(a) As reported in the GREET model, energy use is reported here on an LHV basis. 
Table 17. Emissions and energy use ${ }^{a}$ from FT Crude refining

\begin{tabular}{|c|c|c|c|c|}
\hline \multicolumn{5}{|c|}{ FT Gasoline } \\
\hline Energy Efficiency & $86 \%$ & Refining & $\begin{array}{c}\text { Non-Combustion } \\
\text { Emissions }\end{array}$ & Total \\
\hline Total energy & Btu/MMBtu & 180,956 & & 180,956 \\
\hline Fossil fuels & Btu/MMBtu & 178,621 & & 178,621 \\
\hline Petroleum & Btu/MMBtu & 88,740 & & 88,740 \\
\hline \multicolumn{5}{|c|}{ Total emissions: grams/mmBtu of fuel throughput } \\
\hline VOC & g/MMBtu & 0.92 & 2.31 & 3.226 \\
\hline $\mathrm{CO}$ & g/MMBtu & 3.78 & 1.15 & 4.930 \\
\hline NOx & g/MMBtu & 14.67 & 1.36 & 16.030 \\
\hline PM10 & g/MMBtu & 6.37 & 0.32 & 6.690 \\
\hline sox & g/MMBtu & 10.11 & 4.41 & 14.519 \\
\hline $\mathrm{CH} 4$ & g/MMBtu & 14.78 & 0.00 & 14.783 \\
\hline $\mathrm{CO} 2$ & g/MMBtu & $12,205.57$ & $1,172.00$ & 13,378 \\
\hline \multicolumn{5}{|c|}{ FT Diesel } \\
\hline & & Refining & $\begin{array}{c}\text { Non-Combustion } \\
\text { Emissions }\end{array}$ & Total \\
\hline Energy Efficiency & $89 \%$ & & & \\
\hline Total energy & Btu/MMBtu & 137,387 & & 137,387 \\
\hline Fossil fuels & Btu/MMBtu & 135,615 & & 135,615 \\
\hline Petroleum & Btu/MMBtu & 67,374 & & 67,374 \\
\hline \multicolumn{5}{|c|}{ Total emissions: grams/mmBtu of fuel throughput } \\
\hline VOC & g/MMBtu & 0.70 & 2.23 & 2.927 \\
\hline $\mathrm{CO}$ & g/MMBtu & 2.87 & 1.12 & 3.982 \\
\hline NOx & g/MMBtu & 11.14 & 1.32 & 12.453 \\
\hline PM10 & g/MMBtu & 4.84 & 0.31 & 5.145 \\
\hline SOx & g/MMBtu & 7.67 & 4.26 & 11.937 \\
\hline $\mathrm{CH} 4$ & g/MMBtu & 11.22 & - & 11.223 \\
\hline $\mathrm{CO} 2$ & g/MMBtu & $9,266.83$ & 920.86 & 10,188 \\
\hline \multicolumn{5}{|c|}{ Assumed Yield of FT Diesel vs. Gasoline - Energy Basis } \\
\hline FTD & $62 \%$ & & & \\
\hline FTG & $38 \%$ & & & \\
\hline
\end{tabular}

(a) As reported in the GREET model, energy use is reported here on an LHV basis. We assume the same refining requirements as for conventional gasoline and conventional diesel. See Volume 1 for additional details.

Table 18. Energy consumption and emissions assumptions for DME in light-duty vehicles (CIDI Engines) ${ }^{a}$

$\begin{array}{llr}\text { DME in CIDI engines } & & \\ \text { Energy Consumption Ratio to Conventional Fuel (c) } & 1.21 \\ \text { Energy Consumption } & \text { Btu/mile } & 3,405.1 \\ \text { Fossil Energy Cons. } & \text { Btu/mile } & 0.0 \\ \text { VOC } & \text { grams/mile } & 0.044 \\ \text { CO } & \text { grams/mile } & 0.269 \\ \text { NOx } & \text { grams/mile } & 0.106 \\ \text { PM10 } & \text { grams } / \text { mile } & 0.021 \\ \text { SOx } & \text { grams } / \text { mile } & 0.000 \\ \text { CH4 } & \text { grams } / \text { mile } & 0.005 \\ \text { CO2 } & \text { grams } / \text { mile } & 238.1\end{array}$
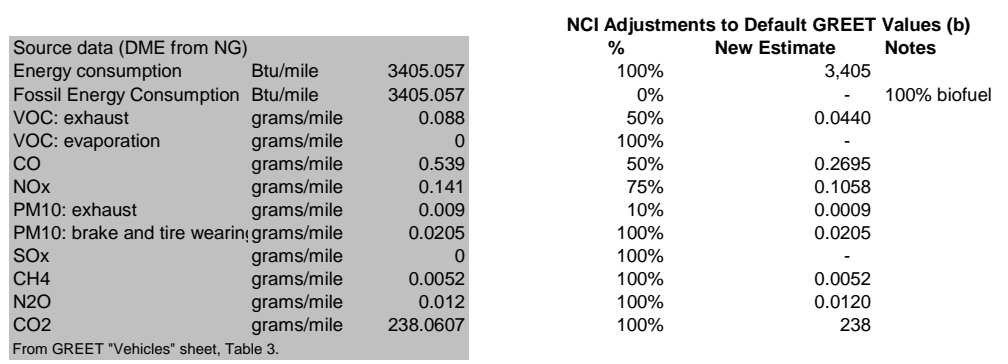

(a) As reported in the GREET model, energy use is reported here on an LHV basis..

(b) Adjustments to VOC, CO, NOx and PM10 emissions are based on [23].

(c) This ratio is the total energy used in the conventional fuel chain (well to wheels) relative to the amount of biofuel used by the vehicle. It is used to calculate the emissions displaced in the conventional fuel chain per unit of biofuel produced. 
Table 19. Energy consumption and emissions assumptions for FT fuels blended with conventional fuels in light-duty vehicles (FT gasoline in gasoline engines and FT diesel in CIDI engines) ${ }^{a}$

$\begin{array}{llr}\text { FT gasoline blend in gasoline engines } & \\ \text { Energy Consumption Ratio to Conventional Fuel (c) } & 1.24 \\ \text { Energy Consumption } & \text { Btu/mile } & 4,630.9 \\ \text { Fossil Energy Cons. } & \text { Btu/mile } & 4,106.7 \\ \text { VOC } & \text { grams/mile } & 0.180 \\ \text { CO } & \text { grams/mile } & 3.745 \\ \text { NOx } & \text { grams/mile } & 0.141 \\ \text { PM10 } & \text { grams/mile } & 0.029 \\ \text { SOx } & \text { grams/mile } & 0.006 \\ \text { CH4 } & \text { grams/mile } & 0.015 \\ \text { CO2 } & \text { grams/mile } & 342.9\end{array}$
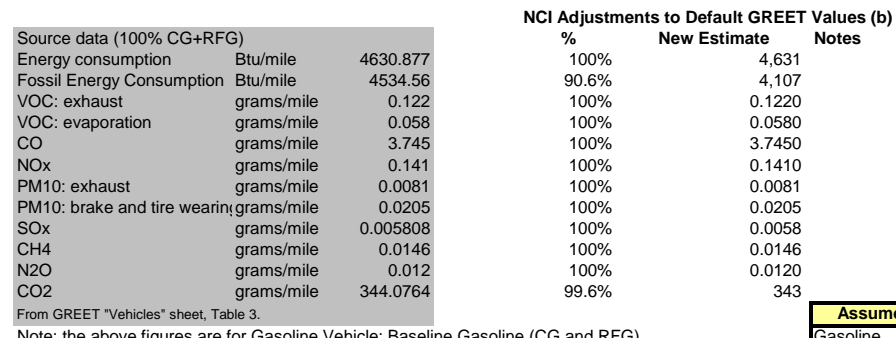

$\begin{array}{llr}\text { FT diesel blend in CIDI engines } & \\ \text { Energy Consumption Ratio to Conventional Fuel (c) } & 1.21 \\ \text { Energy Consumption } & \text { Btu/mile } & 3,405.1 \\ \text { Fossil Energy Cons. } & \text { Btu/mile } & 3,078.4 \\ \text { VOC } & \text { grams/mile } & 0.088 \\ \text { CO } & \text { grams/mile } & 0.539 \\ \text { NOx } & \text { grams/mile } & 0.141 \\ \text { PM10 } & \text { grams/mile } & 0.030 \\ \text { SOx } & \text { grams } / \text { mile } & 0.002 \\ \text { CH4 } & \text { grams } / \text { mile } & 0.003 \\ \text { CO2 } & \text { grams } / \text { mile } & 268.3\end{array}$

\begin{tabular}{|c|c|c|}
\hline \multicolumn{3}{|l|}{ Source data ( $100 \%$ LSD) } \\
\hline Energy consumption & Btu/mile & $3,405.06$ \\
\hline Fossil Energy Consumption & Btu/mile & $3,405.06$ \\
\hline VOC: exhaust & grams/mile & 0.088 \\
\hline VOC: evaporation & grams/mile & \\
\hline $\mathrm{CO}$ & grams $/$ mile & 0.54 \\
\hline NOx & grams/mile & 0.14 \\
\hline PM10: exhaust & grams/mile & 0.009 \\
\hline PM10: brake and tire wearin & ụgrams/mile & 0.021 \\
\hline sox & grams/mile & 0.002 \\
\hline $\mathrm{CH} 4$ & grams $/$ mile & 0.003 \\
\hline $\mathrm{N} 2 \mathrm{O}$ & grams/mile & 0.012 \\
\hline $\mathrm{CO} 2$ & grams $/$ mile & 269.238 \\
\hline
\end{tabular}

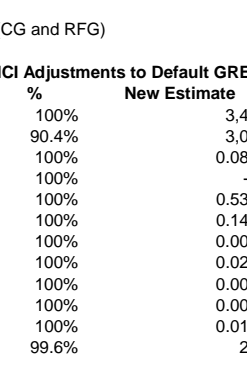

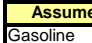

GT Gasoline

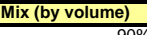

Values (b)

Notes

3,078

0.5390

0.0090

0.0205

0.0019

268

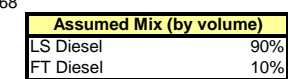

(a) As reported in the GREET model, energy use is reported here on an LHV basis.

(b) No adjustments made to emissions for low-level blends other than carbon and fossil fuel content.

(c) This ratio is the total energy used in the conventional fuel chain (well to wheels) relative to the amount of biofuel used by the vehicle. It is used to calculate the emissions displaced in the conventional fuel chain per unit of biofuel produced.

Table 20. Energy consumption and emissions assumptions for FT fuels in light-duty vehicles (FT gasoline in gasoline engines and FT diesel in CIDI engines). ${ }^{a}$

\begin{tabular}{llr}
\multicolumn{2}{l}{ FT gasoline in gasoline engines } & \\
Energy Consumption Ratio to Conventional Fuel (c) & 1.24 \\
Energy Consumption & Btu/mile & $4,630.9$ \\
Fossil Energy Cons. & Btu/mile & 0.0 \\
VOC & grams/mile & 0.180 \\
CO & grams/mile & 3.745 \\
NOx & grams/mile & 0.141 \\
PM10 & grams/mile & 0.029 \\
SOx & grams $/$ mile & 0.000 \\
CH4 & grams $/$ mile & 0.015 \\
CO2 & grams $/$ mile & 332.0
\end{tabular}

\begin{tabular}{|c|c|c|}
\hline \multicolumn{3}{|c|}{ FT diesel in CIDI engines } \\
\hline Energy Consumption & to Conventional Fuel (c) & 1.21 \\
\hline Energy Consumption & Btu/mile & $3,405.1$ \\
\hline Fossil Energy Cons. & Btu/mile & 0.0 \\
\hline VOC & grams/mile & 0.070 \\
\hline $\mathrm{CO}$ & grams/mile & 0.350 \\
\hline NOx & grams $/$ mile & 0.134 \\
\hline PM10 & grams $/$ mile & 0.027 \\
\hline sox & grams/mile & 0.000 \\
\hline $\mathrm{CH}_{4}$ & grams/mile & 0.003 \\
\hline $\mathrm{CO} 2$ & grams/mile & 259.8 \\
\hline
\end{tabular}
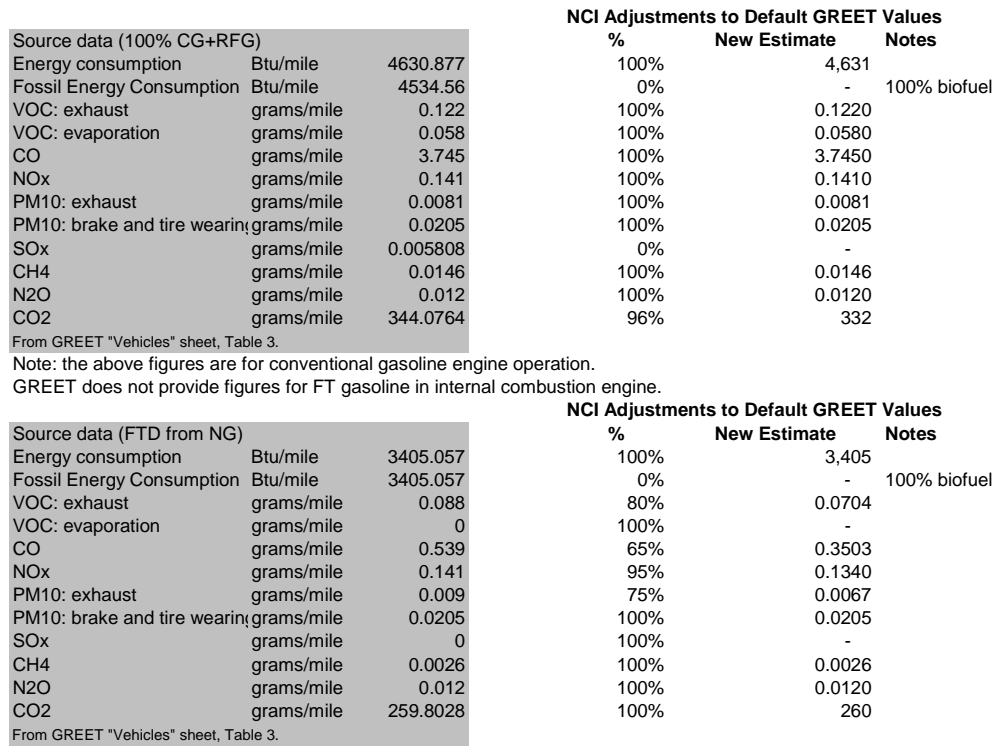

(a) As reported in the GREET model, energy use is reported here on an LHV basis..

(b) Adjustments to VOC, CO, NOx and PM10 emissions are based on [24].

(c) This ratio is the total energy used in the conventional fuel chain (well to wheels) relative to the amount of biofuel used by the vehicle. It is used to calculate the emissions displaced in the conventional fuel chain per unit of biofuel produced. 
Table 21. Energy consumption and emissions assumptions for mixed alcohol use in light-duty vehicles (low-level blend with gasoline and Flexible-Fuel Vehicle ["E-85"])

$\begin{array}{llr}\text { MA Case: Gasoline Vehicle - low-level blend with gasoline } & \\ \text { Energy Consumption Ratio to Conventional Fuel (c) } & 1.24 \\ \text { Energy Consumption } & \text { Btu/mile } & 4,630.9 \\ \text { Fossil Energy Cons. } & \text { Btu/mile } & 4,232.7 \\ \text { VOC } & \text { grams/mile } & 0.180 \\ \text { CO } & \text { grams } / \text { mile } & 3.74 \\ \text { NOx } & \text { grams } / \text { mile } & 0.141 \\ \text { PM10 } & \text { grams } / \text { mile } & 0.029 \\ \text { SOx } & \text { grams } / \text { mile } & 0.005 \\ \text { CH4 } & \text { grams } / \text { mile } & 0.015 \\ \text { CO2 } & \text { grams } / \text { mile } & 355.5\end{array}$

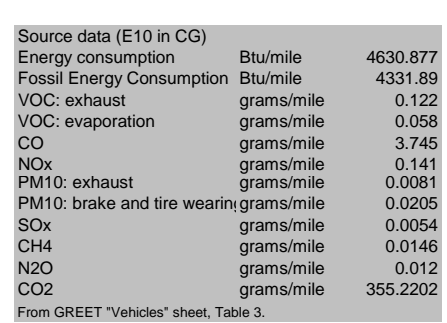

$\mathrm{NCl}$ Adjustments to Default GREET Values (b)

$\%$ New Estimate No

$\begin{array}{rr}100 \% & 4,631 \\ 98 \% & 4,233 \\ 100 \% & 0.1220\end{array}$

$100 \%-0.1220$

$100 \% \quad-3.0580$

$100 \%$

$100 \%-0.0205$

$100 \% \quad 0.0054$

$\begin{array}{lr}100 \% & 0.0146 \\ 100 \% & 0.0120\end{array}$

$100 \% \quad 355$

\begin{tabular}{|c|c|}
\hline NCl Adjustm & is to Default GREET \\
\hline$\%$ & New Estimate \\
\hline $100 \%$ & 4,410 \\
\hline $81 \%$ & 938 \\
\hline $100 \%$ & 0.1220 \\
\hline $100 \%$ & 0.0493 \\
\hline $100 \%$ & 3.7450 \\
\hline $100 \%$ & 0.1410 \\
\hline $100 \%$ & 0.0081 \\
\hline $100 \%$ & 0.0205 \\
\hline $100 \%$ & 0.0018 \\
\hline $100 \%$ & 0.0146 \\
\hline $100 \%$ & 0.0120 \\
\hline $101 \%$ & 334 \\
\hline
\end{tabular}

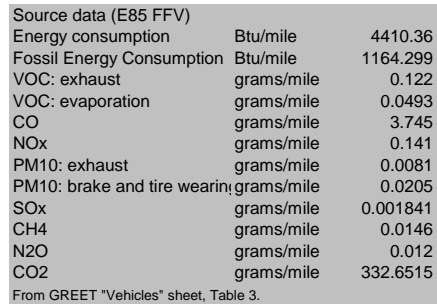

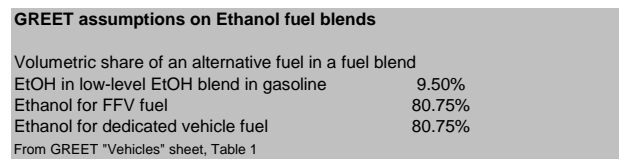

(a) As reported in the GREET model, energy use is reported here on an LHV basis.

(b) No adjustments made to emissions other than carbon and fossil fuel content.

(c) This ratio is the total energy used in the conventional fuel chain (well to wheels) relative to the amount of biofuel used by the vehicle. It is used to calculate the emissions displaced in the conventional fuel chain per unit of biofuel produced. 


\section{Emissions Factors for Conventional Fuel Chains}

These factors are all taken from the GREET model.

Table 22. Energy consumption ${ }^{\mathrm{a}}$ and emissions for the gasoline fuel chain

\begin{tabular}{|c|c|c|c|c|}
\hline $\begin{array}{l}\text { Gasoline Ve } \\
\text { (Btu/mile or }\end{array}$ & $\begin{array}{l}\text { Baseline G } \\
\text { s/mile) }\end{array}$ & ine (CG & RFG) & \\
\hline & Feedstock & Fuel & Vehicle Oper & Total \\
\hline Total Energy & 177.34 & 942.32 & $4,630.88$ & $5,750.53$ \\
\hline Fossil Fuels & 170.71 & 929.85 & $4,534.56$ & $5,635.12$ \\
\hline Petroleum & 56.25 & 444.69 & $4,534.56$ & $5,035.50$ \\
\hline $\mathrm{CO} 2$ & 17.71 & 70.14 & 344.08 & 431.93 \\
\hline $\mathrm{CH} 4$ & 0.42 & 0.08 & 0.01 & 0.52 \\
\hline $\mathrm{N} 2 \mathrm{O}$ & 0.00 & 0.01 & 0.01 & 0.02 \\
\hline GHGs & 27.52 & 73.87 & 347.96 & 449.36 \\
\hline VOC & 0.02 & 0.11 & 0.18 & 0.31 \\
\hline CO: Total & 0.03 & 0.03 & 3.74 & 3.8 \\
\hline NOx: Total & 0.09 & 0.11 & 0.14 & 0.3 \\
\hline PM10: Total & 0.01 & 0.04 & 0.03 & 0.07 \\
\hline SOx: Total & 0.04 & 0.08 & 0.01 & 0.12 \\
\hline
\end{tabular}

(a) As reported in the GREET model, energy use is reported here on an LHV basis.

Table 23. Energy consumption ${ }^{\mathrm{a}}$ and emissions for the low-sulfur diesel fuel chain CIDI Vehicle: LS Diesel

(Btu/mile or grams/mile)

\begin{tabular}{l|rrr|r} 
& Feedstock & Fuel & Vehicle Oper & Total \\
\hline Total Energy & 130.30 & 586.94 & $3,405.06$ & $4,122.29$ \\
Fossil Fuels & 125.43 & 579.45 & $3,405.06$ & $4,109.94$ \\
Petroleum & 41.33 & 294.58 & $3,405.06$ & $3,740.96$ \\
CO2 & 13.01 & 43.61 & 269.238 & 325.86 \\
CH4 & 0.31 & 0.05 & 0.003 & 0.36 \\
N2O & 0.00 & 0.00 & 0.012 & 0.01 \\
GHGs & 20.22 & 44.93 & 272.850 & 338.00 \\
VOC: Total & 0.01 & 0.02 & 0.088 & 0.11 \\
CO: Total & 0.02 & 0.02 & 0.539 & 0.58 \\
NOx: Total & 0.07 & 0.07 & 0.141 & 0.28 \\
PM10: Total & 0.01 & 0.02 & 0.030 & 0.06 \\
SOx: Total & 0.03 & 0.05 & 0.002 & 0.08 \\
VOC: Urban & 0.00 & 0.01 & 0.055 & 0.07 \\
CO: Urban & 0.00 & 0.01 & 0.335 & 0.35 \\
NOx: Urban & 0.00 & 0.03 & 0.088 & 0.12 \\
PM10: Urban & 0.00 & 0.00 & 0.018 & 0.02 \\
SOx: Urban & 0.00 & 0.02 & 0.001 & 0.03
\end{tabular}

(a) As reported in the GREET model, energy use is reported here on an LHV basis. 


\section{Annual Emissions Estimate per Mill in 2010}

Figure 2 through Figure 8 provide the results of the WTW analysis for the year 2010. They provide details of the emissions from the different biorefinery cases, the associated offsets and the net emissions. The difference between the net emissions of the Tomlinson case and the net emissions of the biorefinery cases is the improvement resulting from deployment of biorefinery technology. These were presented in Volume 1. Here we provide the details behind the results shown in Volume 1.

Figure 2 includes within the "mill" category the $\mathrm{CO}_{2}$ emissions from biomass . It is then taken as a credit in the "offset" column as "Biomass $\mathrm{CO}_{2}$ ". In Figure 8, only combustion sources of TRS are shown. Other existing sources of TRS emissions are not included in the analysis, as they are assumed to be the same in all cases, and were therefore not quantified here.

Figure 2: $\mathrm{CO}_{2}$ emissions in year 2010, short tons per mill per year

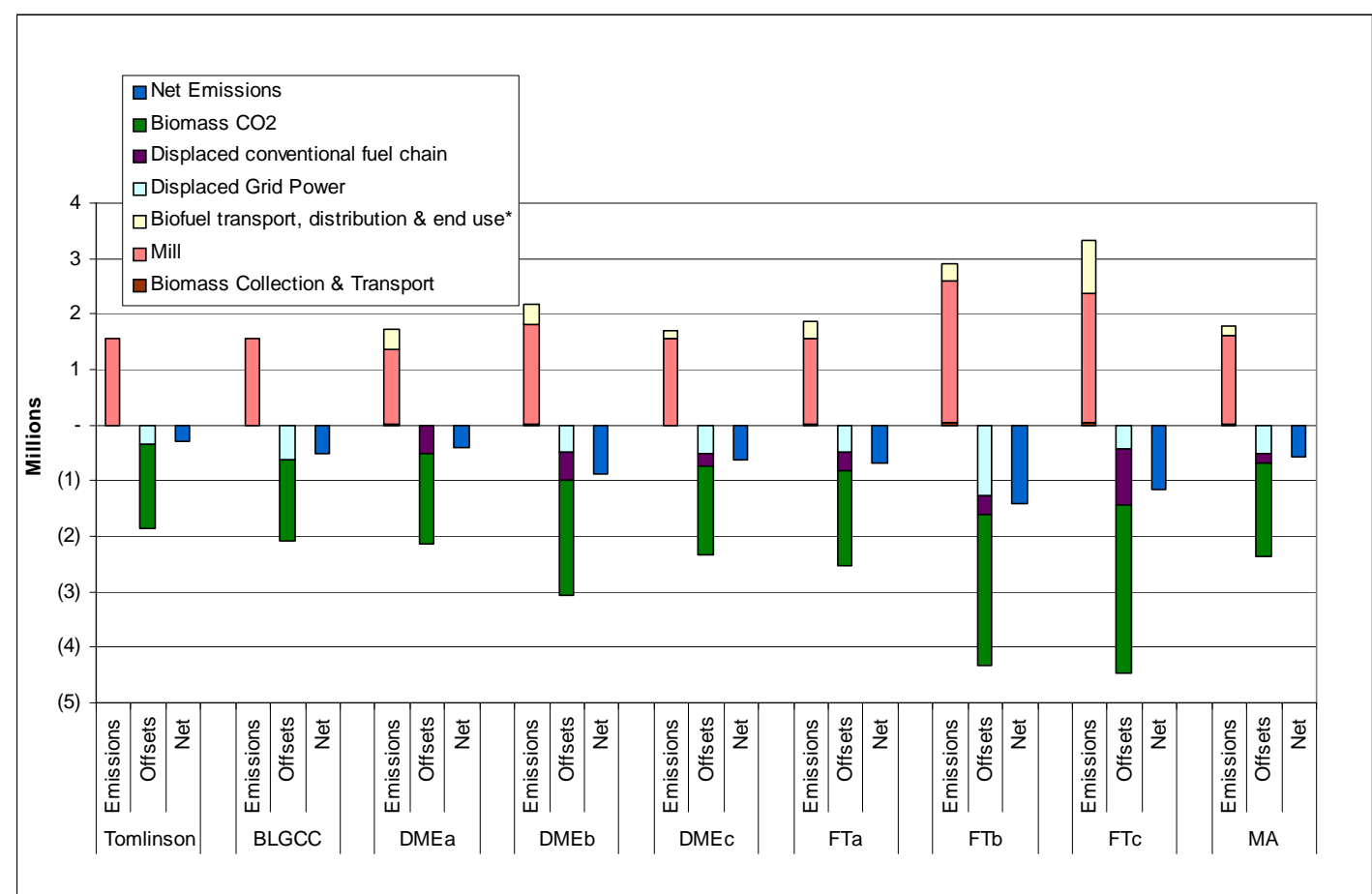

* Transportation of the crude FT product to the oil refinery included in FT cases.

Note: excludes any emissions from land use changes and biomass growth that are not related to harvesting and transportation. Note on vehicle end use: FT cases assume FT gasoline blend in gasoline engines and FT diesel blend in CIDI engines. MA case assumes low-level blend with gasoline. 
Figure 3: $\mathrm{SO}_{2}$ emissions in year 2010, short tons per mill per year

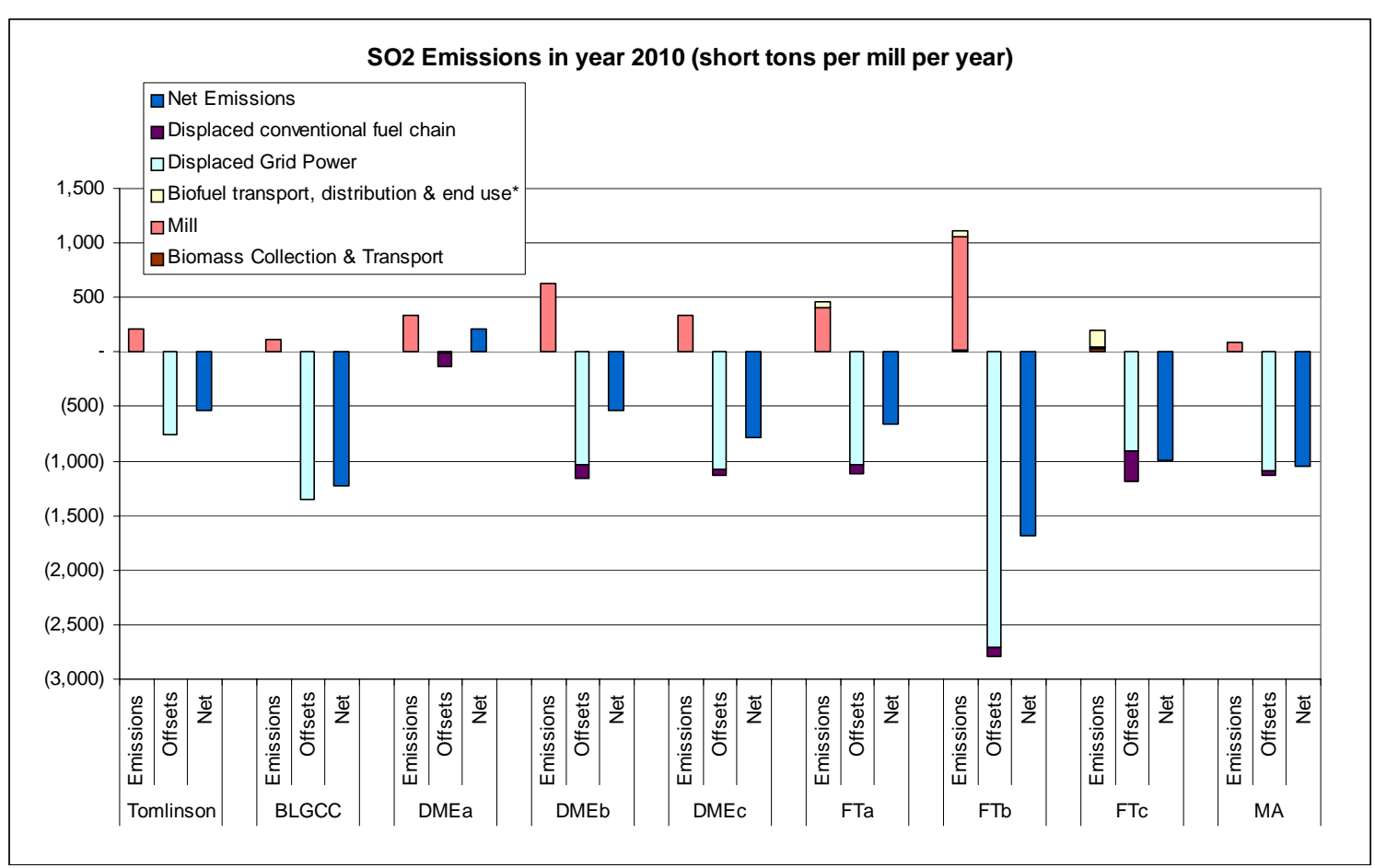

* Transportation of the crude FT product to the oil refinery included in FT cases.

Note: excludes any emissions from land use changes and biomass growth that are not related to harvesting and transportation. Note on vehicle end use: FT cases assume FT gasoline blend in gasoline engines and FT diesel blend in CIDI engines. MA case assumes low-level blend with gasoline.

Figure 4: NOx emissions in year 2010, short tons per mill per year

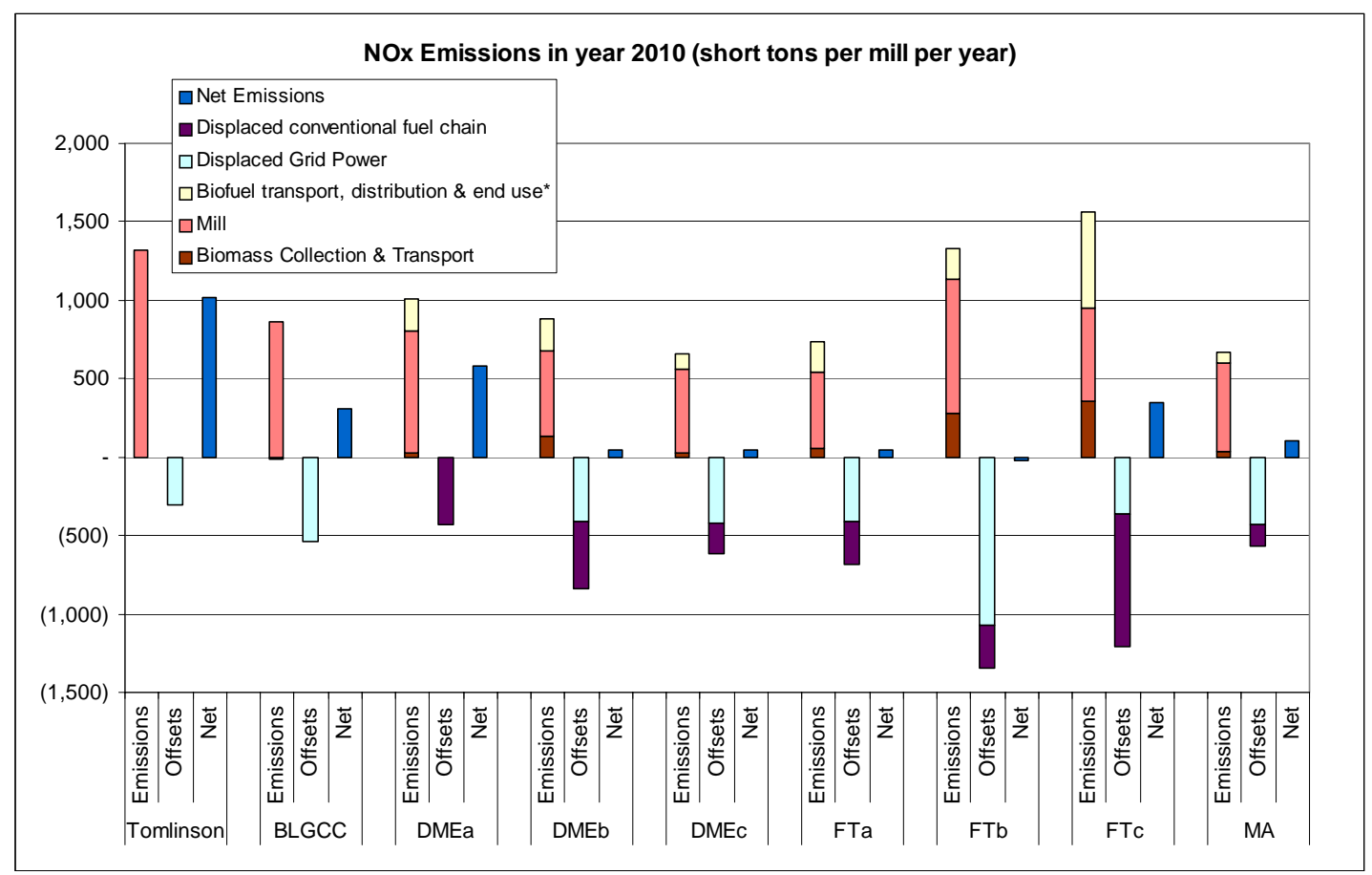

* Transportation of the crude FT product to the oil refinery included in FT cases.

Note: excludes any emissions from land use changes and biomass growth that are not related to harvesting and transportation. Note on vehicle end use: FT cases assume FT gasoline blend in gasoline engines and FT diesel blend in CIDI engines. MA case assumes low-level blend with gasoline. 
Figure 5: VOC emissions in year 2010, short tons per mill per year

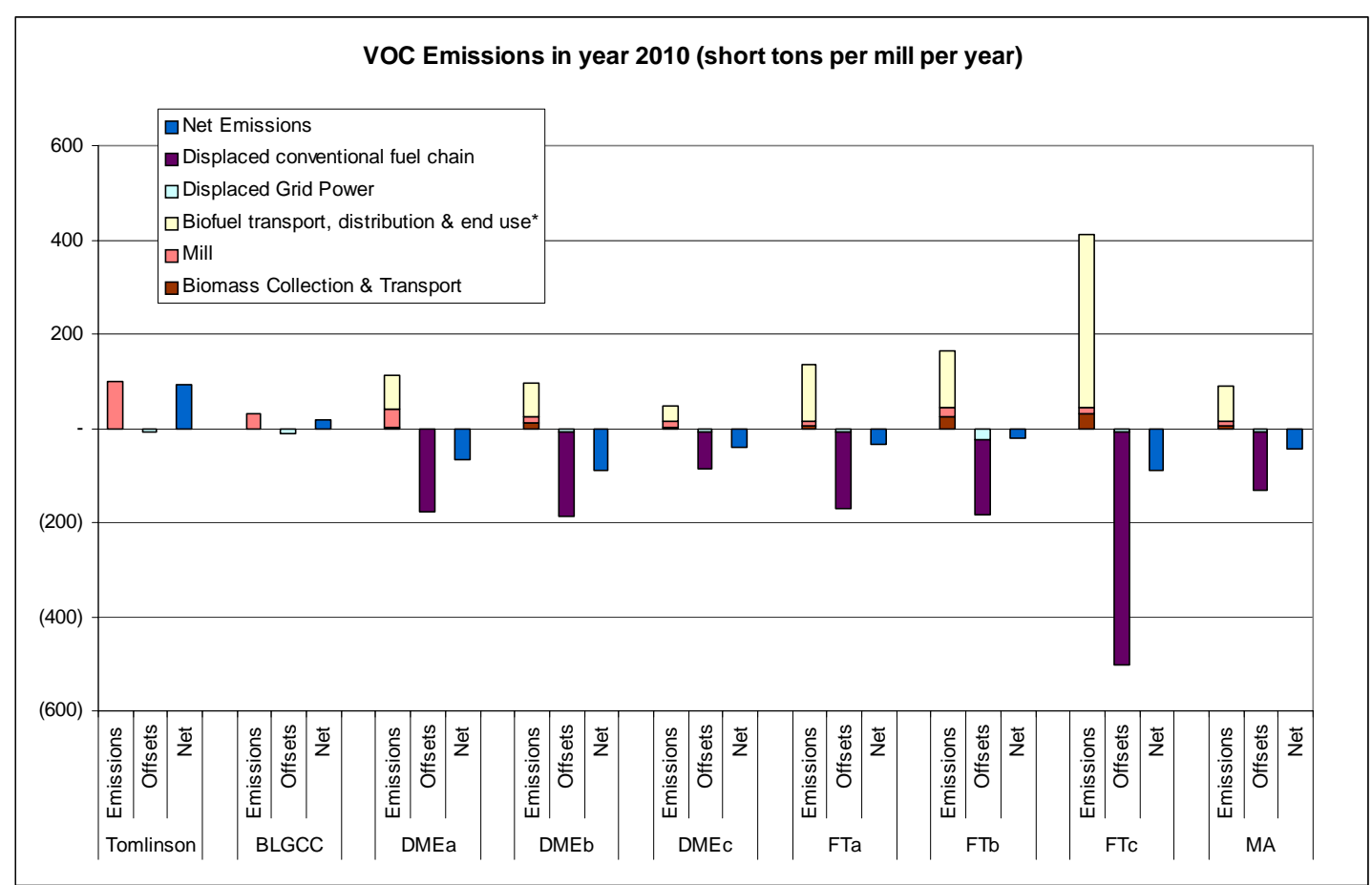

* Transportation of the crude FT product to the oil refinery included in FT cases.

Note: excludes any emissions from land use changes and biomass growth that are not related to harvesting and transportation. Note on vehicle end use: FT cases assume FT gasoline blend in gasoline engines and FT diesel blend in CIDI engines. MA case assumes low-level blend with gasoline.

Figure 6: CO Emissions in year 2010, short tons per mill per year

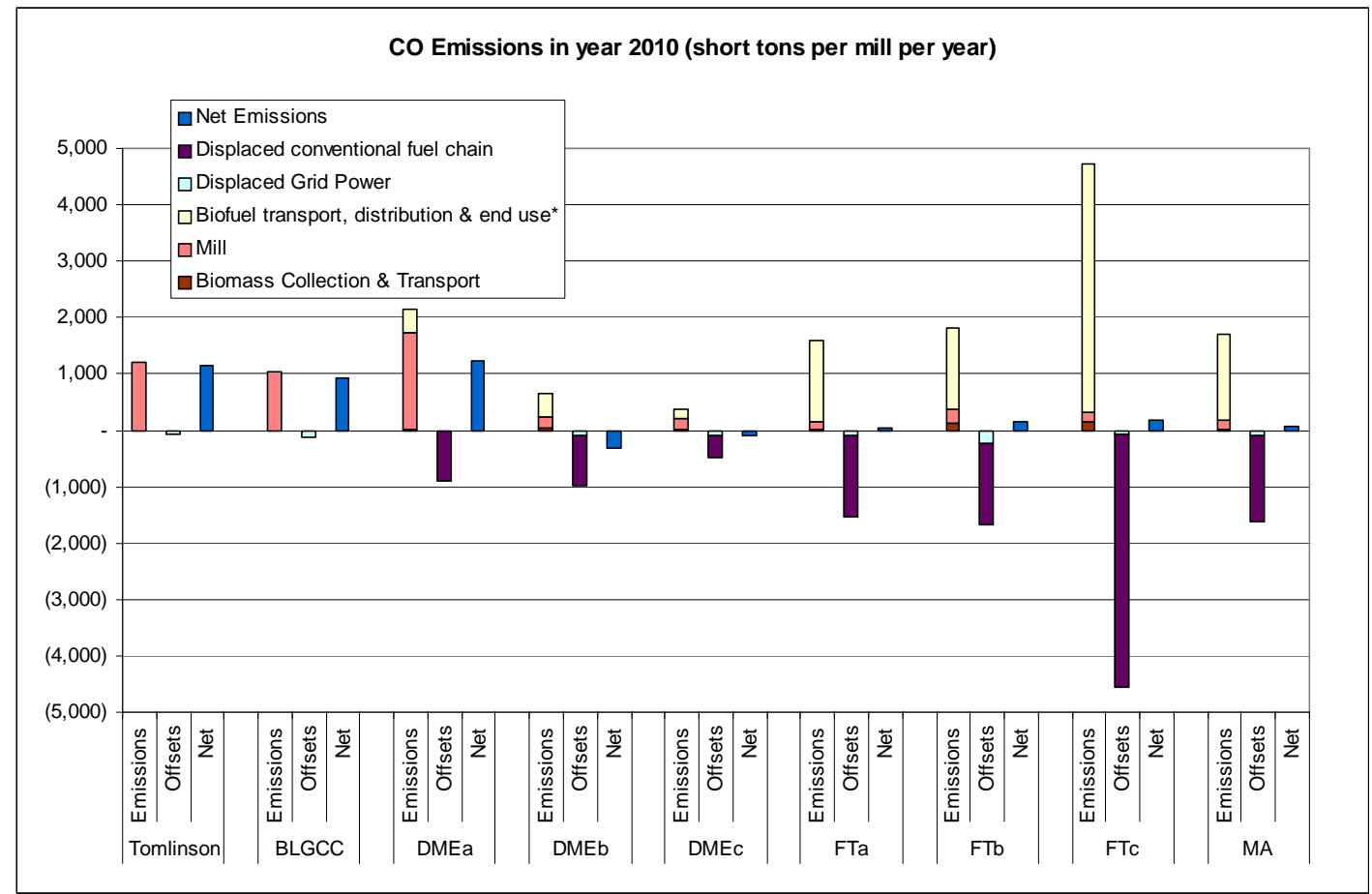

* Transportation of the crude FT product to the oil refinery included in FT cases.

Note: excludes any emissions from land use changes and biomass growth that are not related to harvesting and transportation. Note on vehicle end use: FT cases assume FT gasoline blend in gasoline engines and FT diesel blend in CIDI engines. MA case assumes low-level blend with gasoline. 
Figure 7: PM10 Emissions in year 2010, short tons per mill per year

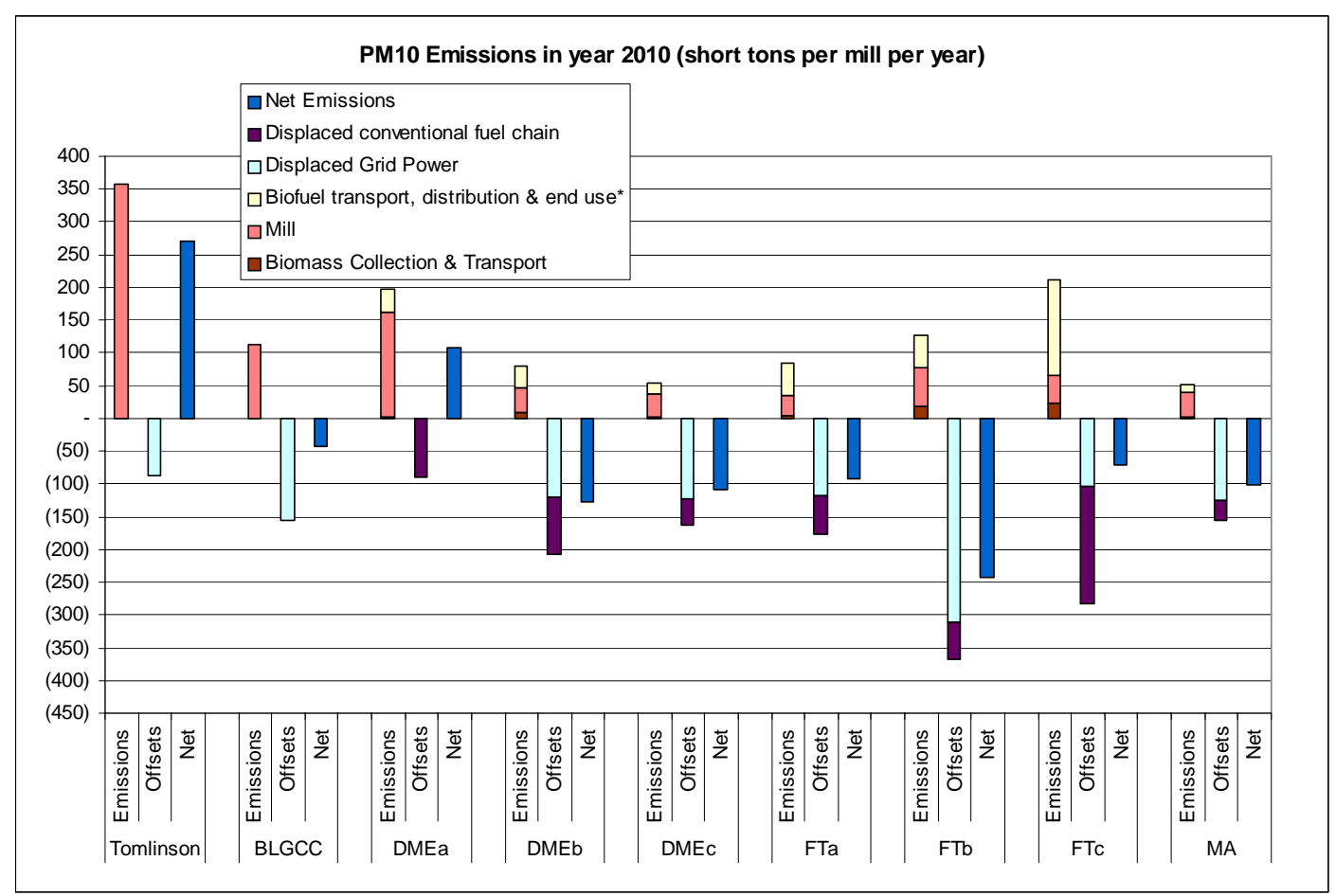

* Transportation of the crude FT product to the oil refinery included in FT cases.

Note: excludes any emissions from land use changes and biomass growth that are not related to harvesting and transportation. Note on vehicle end use: FT cases assume FT gasoline blend in gasoline engines and FT diesel blend in CIDI engines. MA case assumes low-level blend with gasoline.

Figure 8: TRS Emissions in year 2010, short tons per mill per year

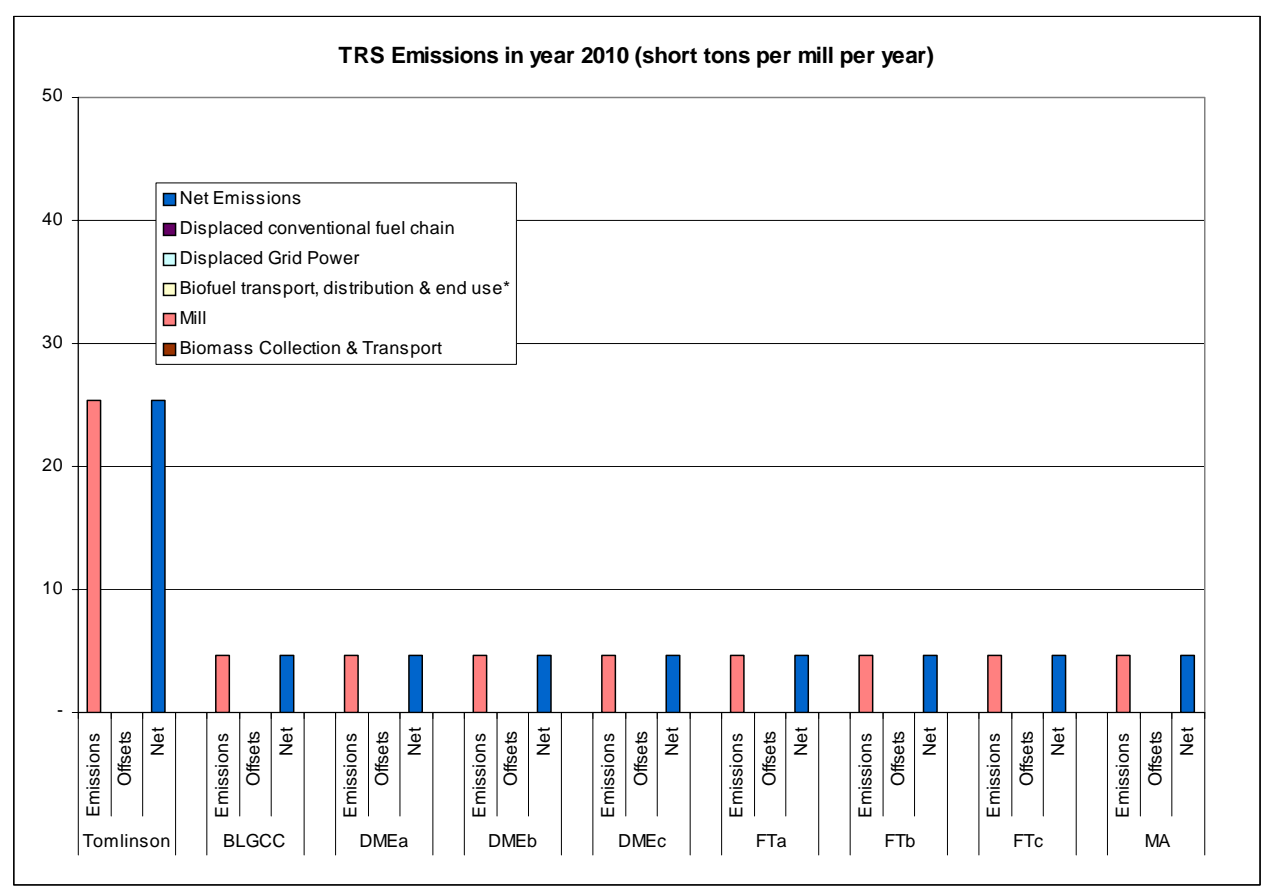

* Transportation of the crude FT product to the oil refinery included in FT cases.

Note: excludes any emissions from land use changes and biomass growth that are not related to harvesting and transportation. Note on vehicle end use: FT cases assume FT gasoline blend in gasoline engines and FT diesel blend in CIDI engines. MA case assumes low-level blend with gasoline.

TRS emissions are for combustion sources only. 


\section{Results from the Market Penetration Analysis}

National energy and emissions impacts were estimated under three separate market penetration scenarios. Table 24 summarizes the basic inputs to the three scenarios and Figure 9 shows the results, expressed in terms of total black liquor capacity and the number of reference mills this would represent. The reader is referred to Volume 1 for additional details on these scenarios, which were developed based on [25, 26, 27]. Figure 10 through Figure 30 summarize the results of the energy and emissions impacts for all the biorefinery cases and market penetration scenarios. These impact estimates assume that mixed alcohols and FT biofuels are used in lowlevel blends with their conventional counterparts, specifically, a 10\% blend of mixed alcohols with gasoline and a $10 \%$ blend of FT diesel with low-sulfur diesel. Impacts with high-level blends are described in Section 6.1.

Table 24: Summary of Biorefinery market penetration scenarios developed in this study.

\begin{tabular}{|c|c|c|c|}
\hline & $\begin{array}{c}\text { Low } \\
\text { Scenario }\end{array}$ & $\begin{array}{c}\text { Base } \\
\text { Scenario }\end{array}$ & Aggressive Scenario \\
\hline Technical Market Potential $^{\mathrm{a}}$ & \multicolumn{3}{|c|}{$\begin{array}{l}\text { - } 180 \text { operable recovery boilers } \\
\text { - } \quad \text { Combined capacity of } \sim 472 \text { million lbs/day dry solids ( } \sim 86 \text { million } \mathrm{t} / \mathrm{yr} \text { ) }\end{array}$} \\
\hline Ultimate Adoption Rate & \multicolumn{3}{|c|}{ - $90 \%$ of the technical market potential } \\
\hline Industry Growth & \multicolumn{3}{|c|}{$\begin{array}{l}\text { - } 1.27 \% \text { per year, based on total black liquor capacity, estimated from data } \\
\text { provided in [28] }\end{array}$} \\
\hline Basis & \multicolumn{2}{|c|}{$\begin{array}{l}\text { - Traditional market penetration "S" } \\
\text { curve for capital intensive, facility- } \\
\text { level investments }\end{array}$} & $\begin{array}{l}\text { - Aggressive penetration curve assuming } \\
\text { that normal rules of market penetration } \\
\text { may not apply due to the age of the } \\
\text { Tomlinson boiler fleet and other market } \\
\text { drivers (see main text for discussion) }\end{array}$ \\
\hline Saturation Time (years) ${ }^{b}$ & 30 & 20 & 10 \\
\hline $\begin{array}{l}\text { Age of "New" boilers when } \\
\text { replacement with BLGCC is } \\
\text { considered }\end{array}$ & 35 & 30 & 30 \\
\hline $\begin{array}{l}\text { Age of "Rebuilt" boilers } \\
\text { when replacement with } \\
\text { BLGCC is considered }\end{array}$ & 15 & 10 & 10 \\
\hline
\end{tabular}

(a) The Black Liquor Recovery Boiler Committee (BLRBC) of the American Forest and Paper Association maintains a database of individual recovery boilers with information on capacity, location, age, rebuild year (if any), and in some cases, the nature of the rebuild. This database can be used to calculate the average boiler size, average boiler age when a rebuild occurred ( 20 years), and to identify which boilers will be ready for replacement in any given future year. Because additional industry consolidation and mill closures are expected, and few if any new mills are likely to be built, the analysis is based on total capacity rather than number of mills.

(b) Defined as the time required to go from $10 \%$ penetration to $90 \%$ penetration. 
Figure 9: Market penetration estimates used to assess energy and environmental impacts of biorefinery implementation in the United States.

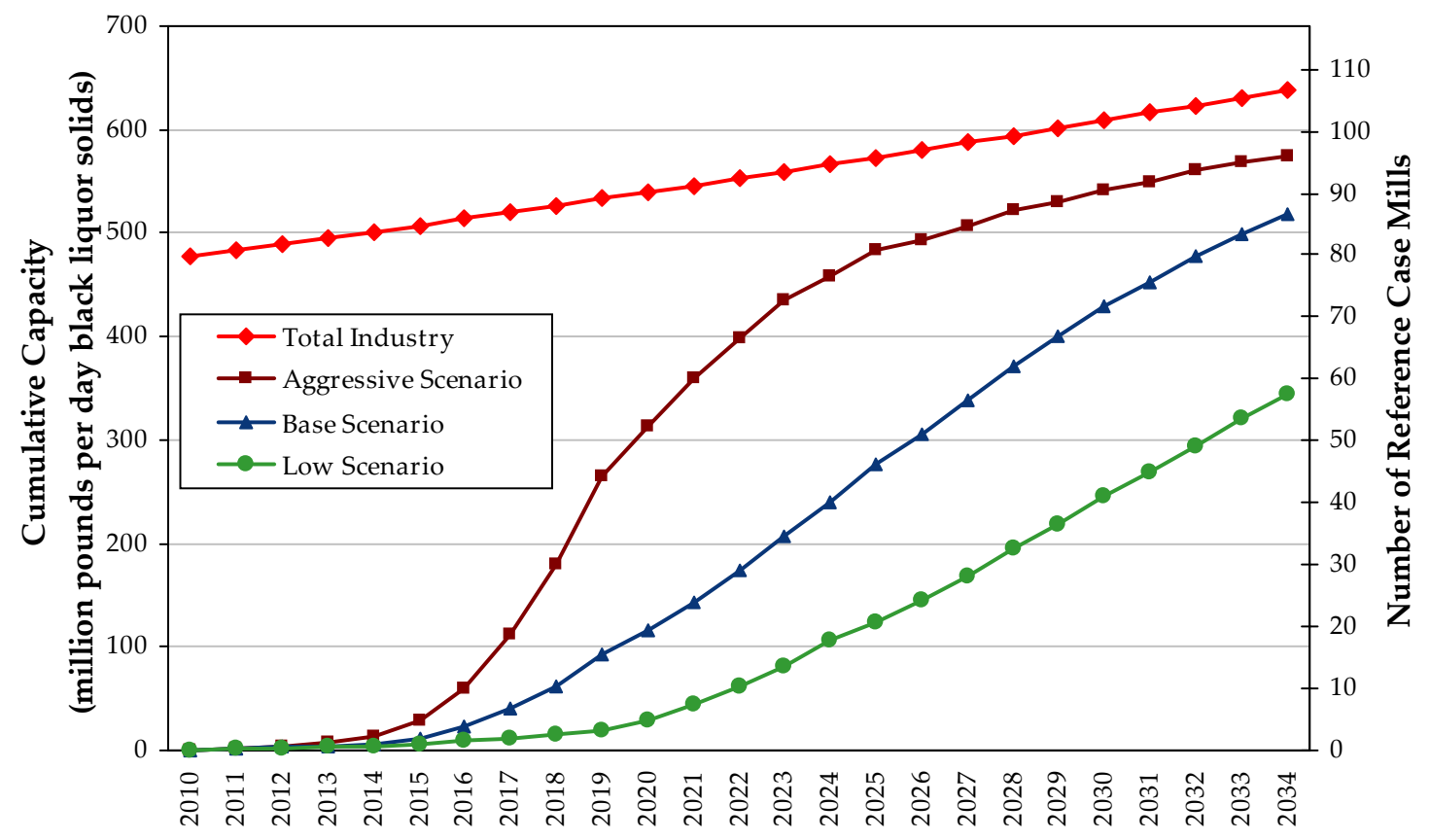

Figure 10: Net fossil fuel energy savings - HHV (Aggressive market penetration scenario)

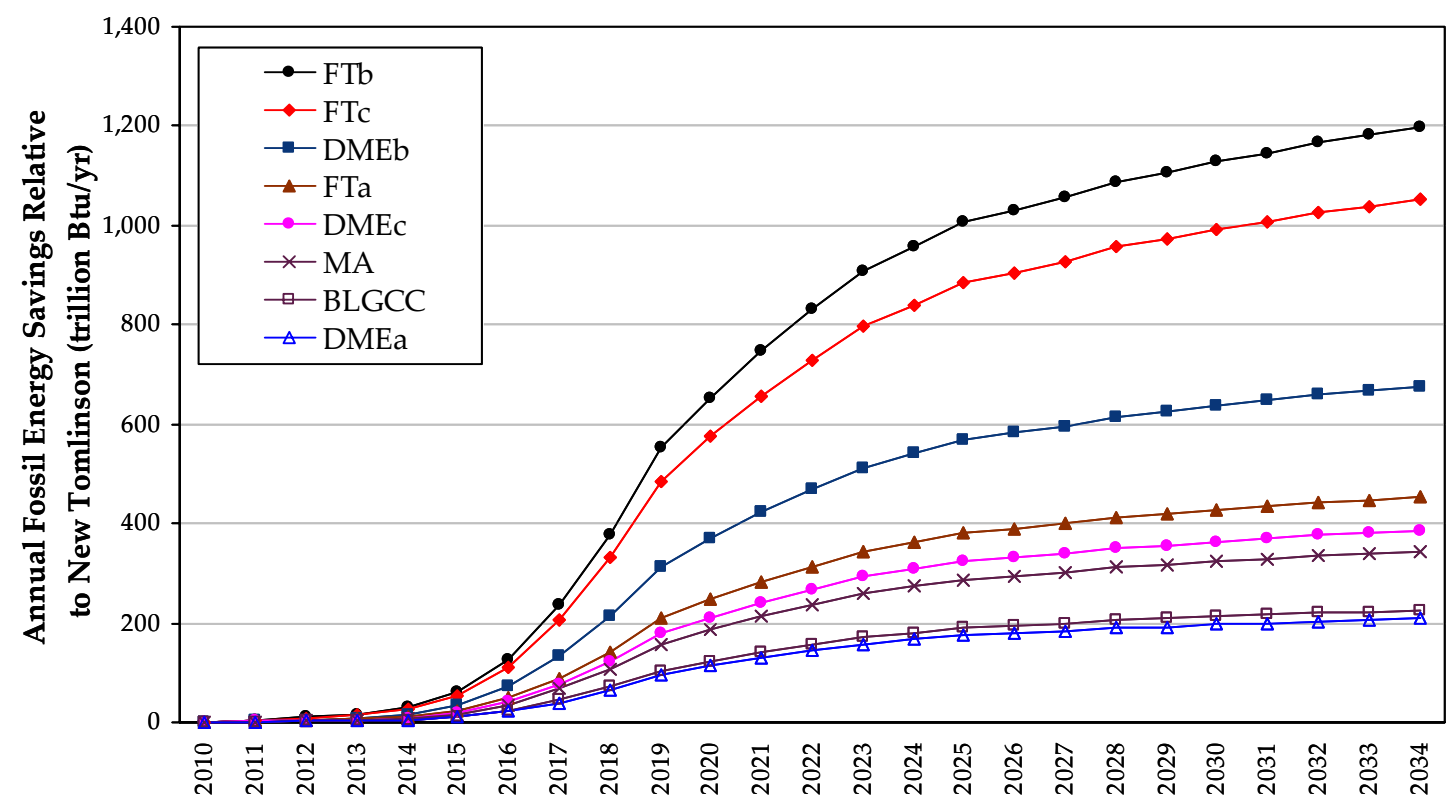

Note: Transportation of the crude FT product to the oil refinery included in FT cases.

Note on vehicle end use: FT cases assume FT gasoline blend in gasoline engines and FT diesel blend in CIDI engines. MA case assumes low-level blend with gasoline. 
Figure 11: Net fossil fuel energy savings - HHV (Base market penetration scenario)

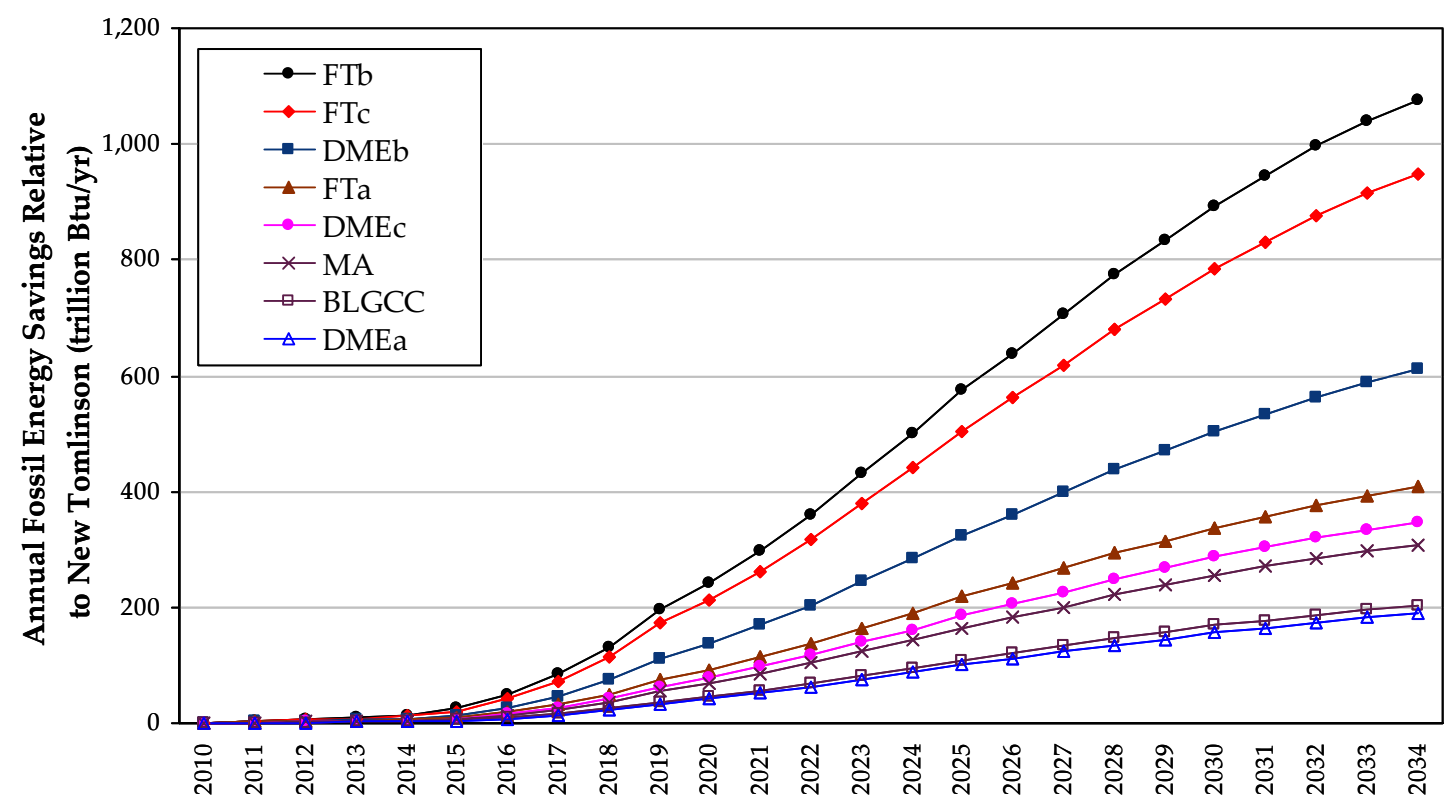

Note: Transportation of the crude FT product to the oil refinery included in FT cases.

Note on vehicle end use: FT cases assume FT gasoline blend in gasoline engines and FT diesel blend in CIDI engines. MA case assumes low-level blend with gasoline.

Figure 12: Net fossil fuel energy savings - HHV (Low market penetration scenario)

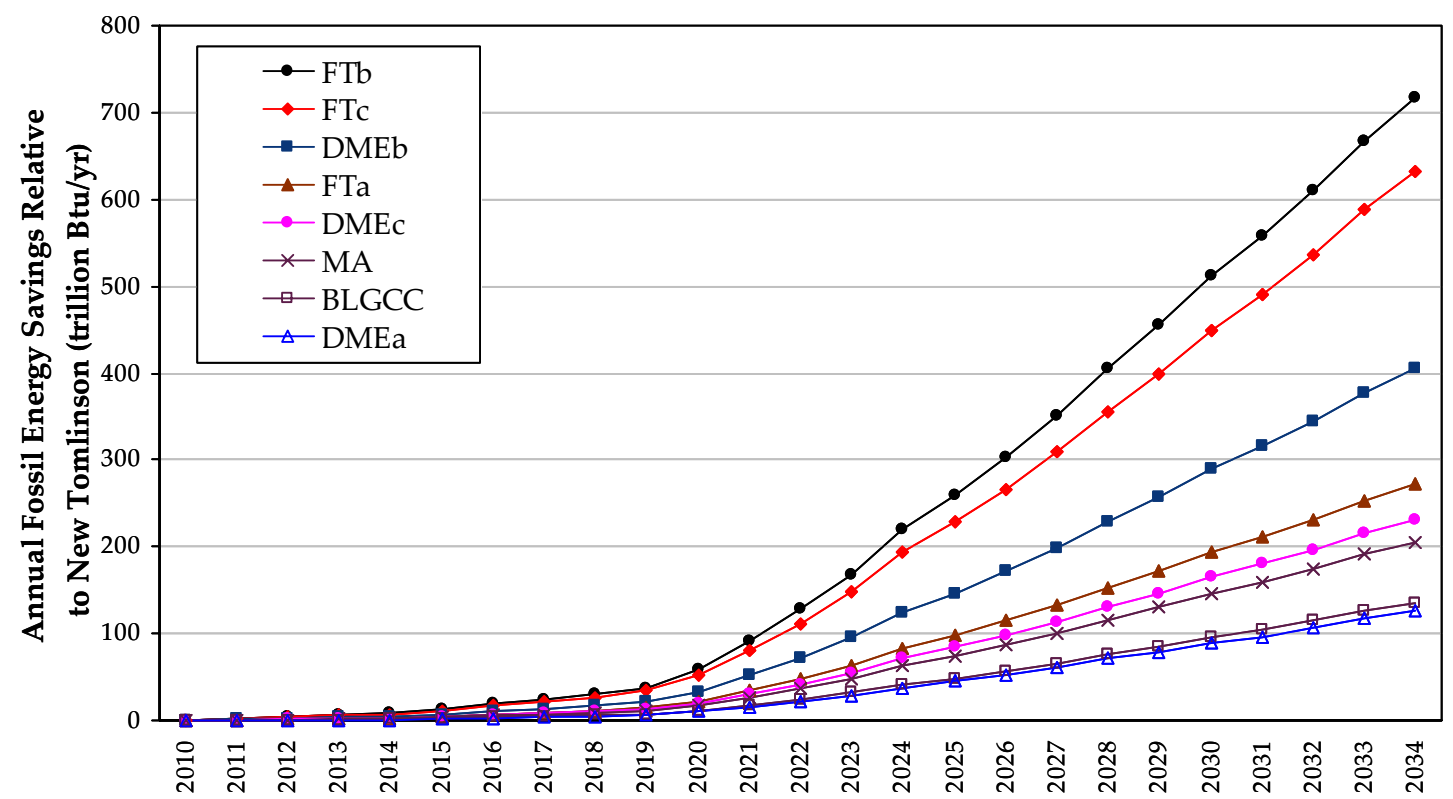

Note: Transportation of the crude FT product to the oil refinery included in FT cases.

Note on vehicle end use: FT cases assume FT gasoline blend in gasoline engines and FT diesel blend in CIDI engines. MA case assumes low-level blend with gasoline. 
Figure 13: $\mathrm{Net}_{\mathrm{CO}_{2}}$ emissions reductions (with credit for biomass $\left.\mathrm{CO}_{2}\right)($ Aggressive market penetration scenario)

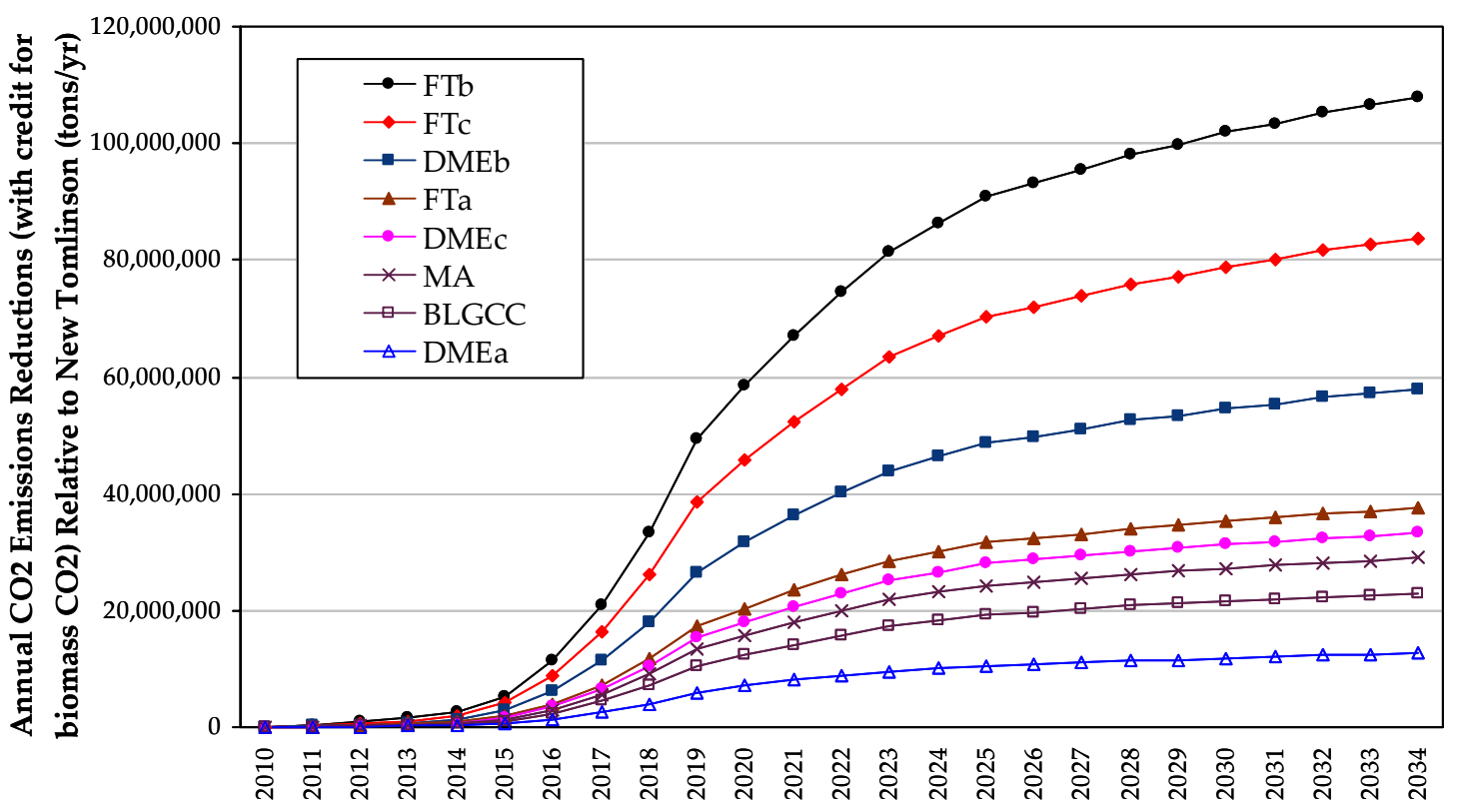

Transportation of the crude FT product to the oil refinery included in FT cases.

Note: excludes any emissions from land use changes and biomass growth that are not related to harvesting and transportation. Note on vehicle end use: FT cases assume FT gasoline blend in gasoline engines and FT diesel blend in CIDI engines. MA case assumes low-level blend with gasoline.

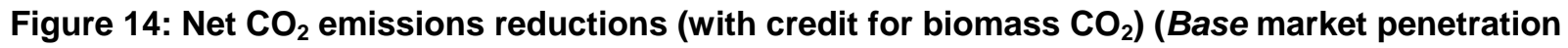
scenario)

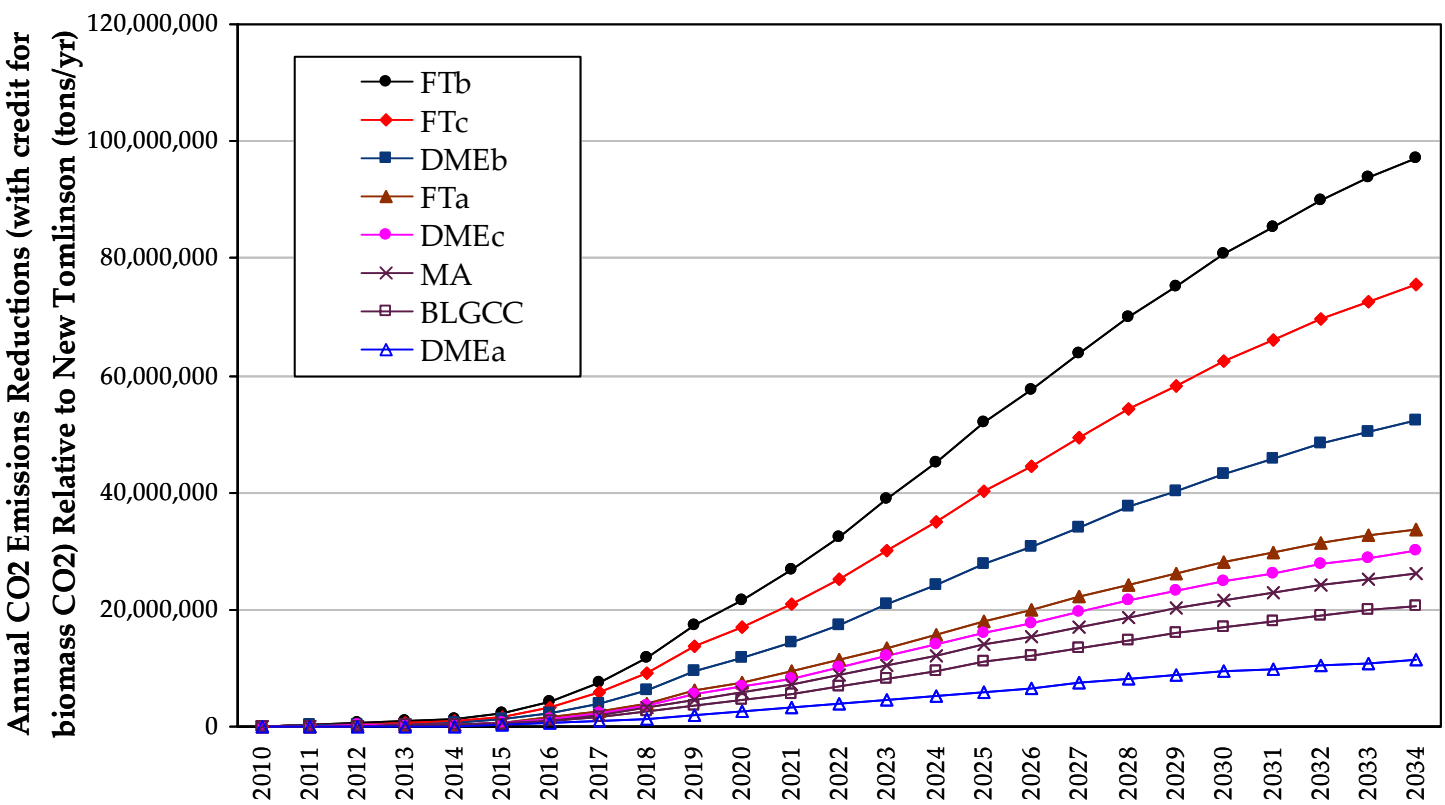

Transportation of the crude FT product to the oil refinery included in FT cases.

Note: excludes any emissions from land use changes and biomass growth that are not related to harvesting and transportation. Note on vehicle end use: FT cases assume FT gasoline blend in gasoline engines and FT diesel blend in CIDI engines. MA case assumes low-level blend with gasoline. 
Figure 15: Net $\mathrm{CO}_{2}$ emissions reductions (with credit for biomass $\left.\mathrm{CO}_{2}\right)($ Low market penetration scenario)

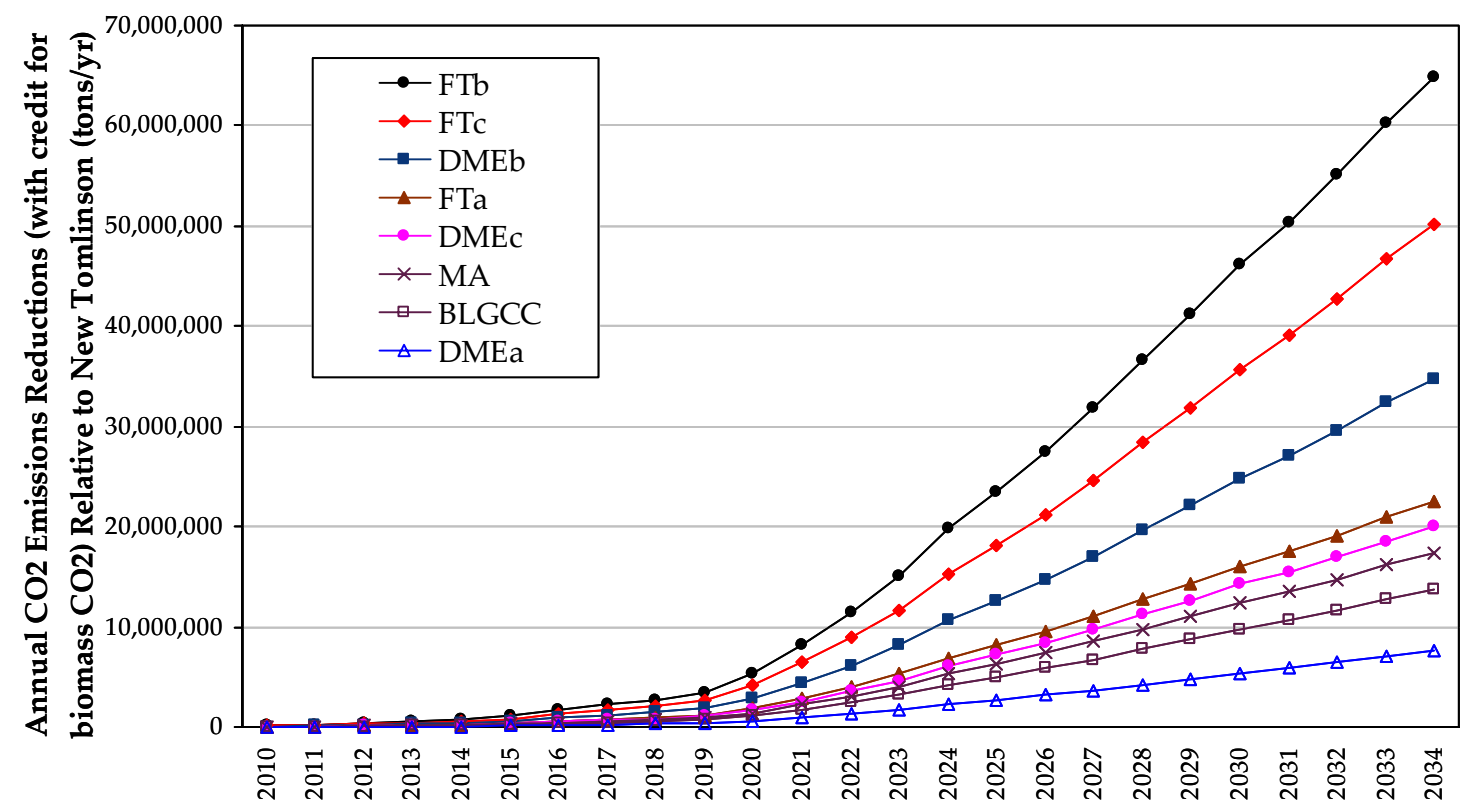

Transportation of the crude FT product to the oil refinery included in FT cases.

Note: excludes any emissions from land use changes and biomass growth that are not related to harvesting and transportation. Note on vehicle end use: FT cases assume FT gasoline blend in gasoline engines and FT diesel blend in CIDI engines. MA case assumes low-level blend with gasoline.

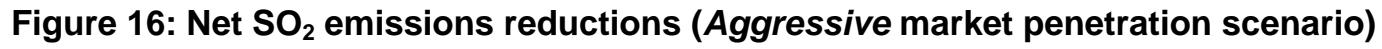

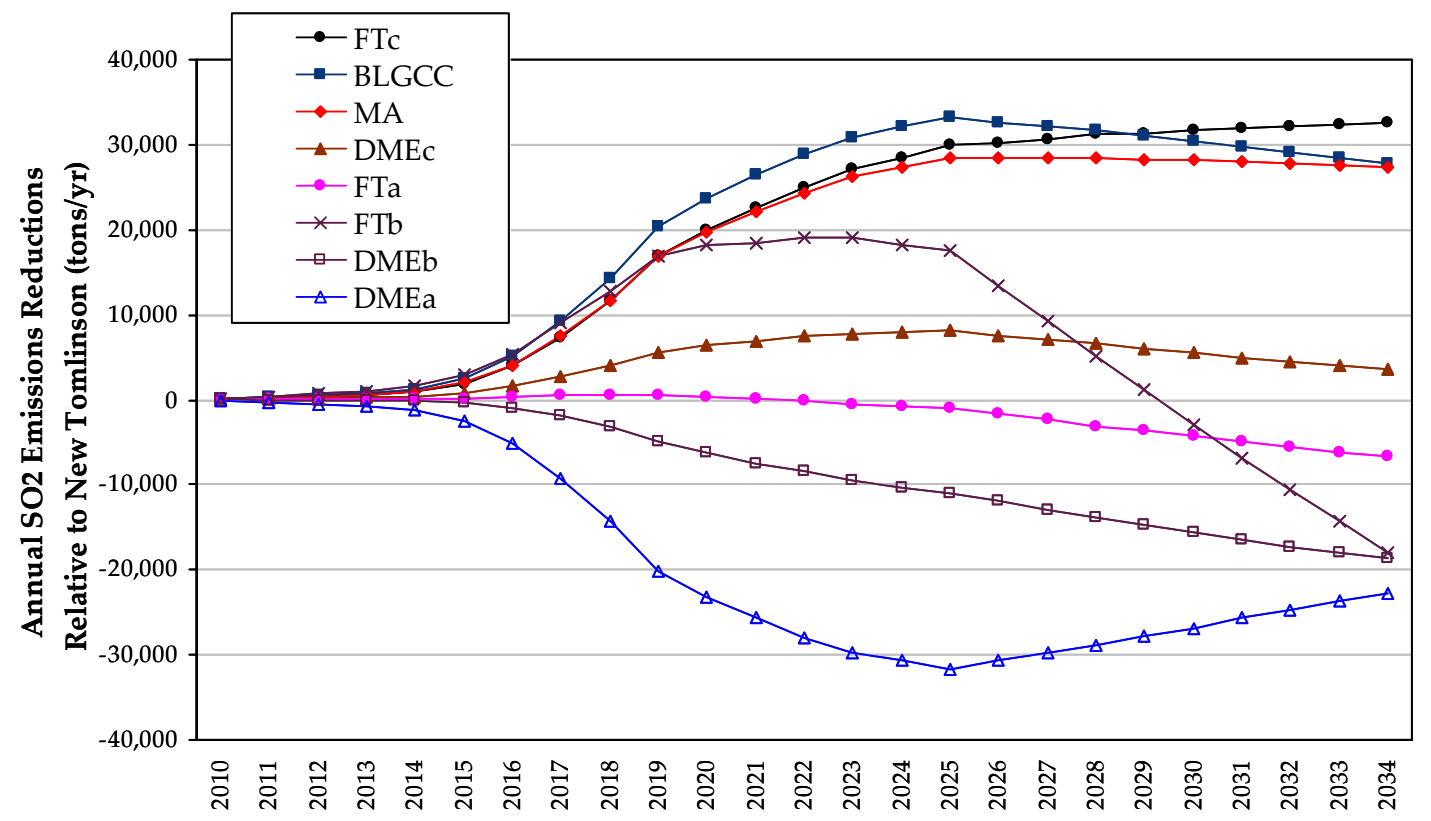

Transportation of the crude FT product to the oil refinery included in FT cases.

Note on vehicle end use: FT cases assume FT gasoline blend in gasoline engines and FT diesel blend in CIDI engines. MA case assumes low-level blend with gasoline. 
Figure 17: $\mathrm{Net}_{\mathrm{SO}_{2}}$ emissions reductions (Base market penetration scenario)

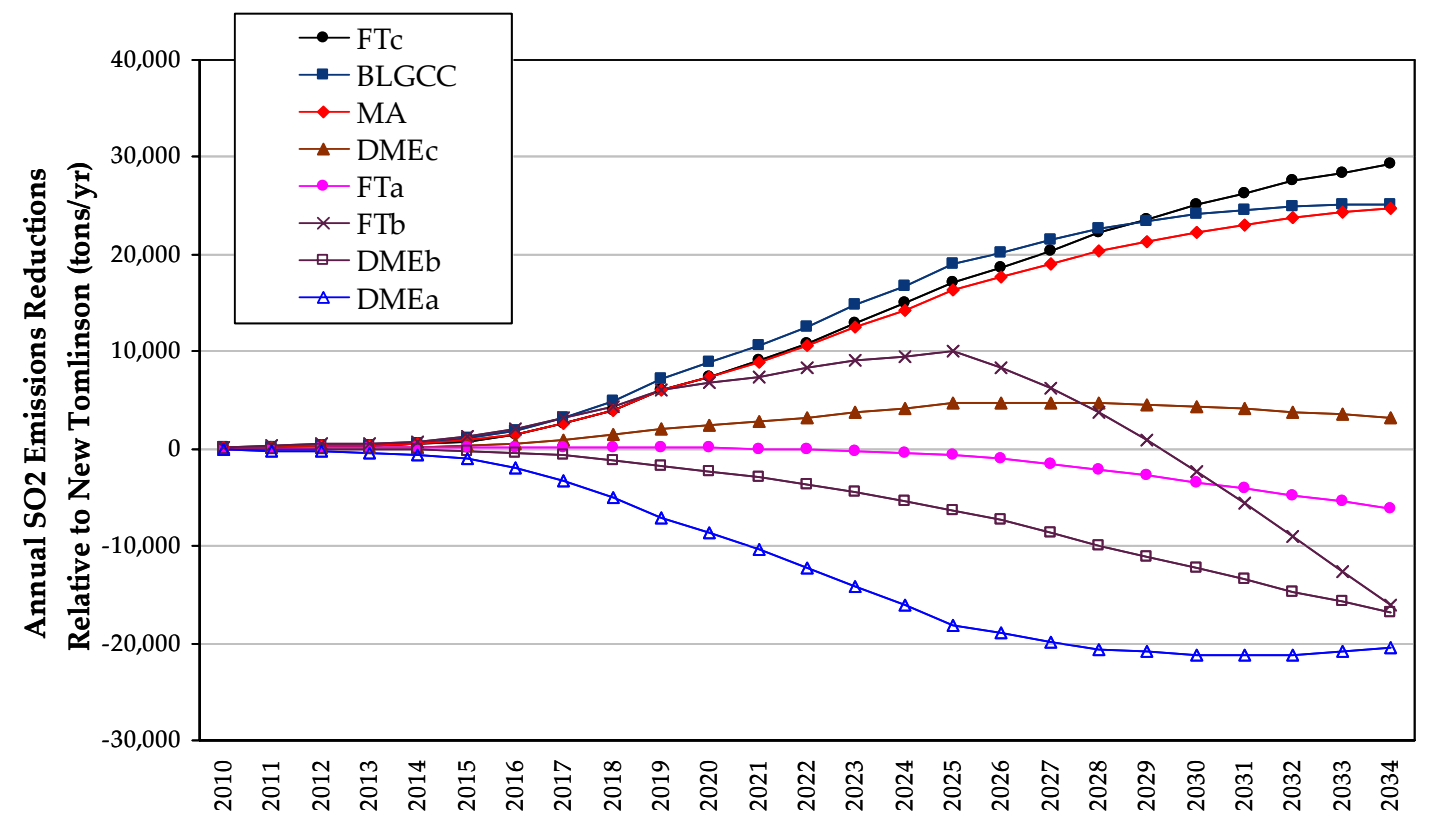

Transportation of the crude FT product to the oil refinery included in FT cases.

Note on vehicle end use: FT cases assume FT gasoline blend in gasoline engines and FT diesel blend in CIDI engines. MA case assumes low-level blend with gasoline.

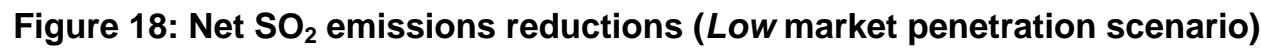

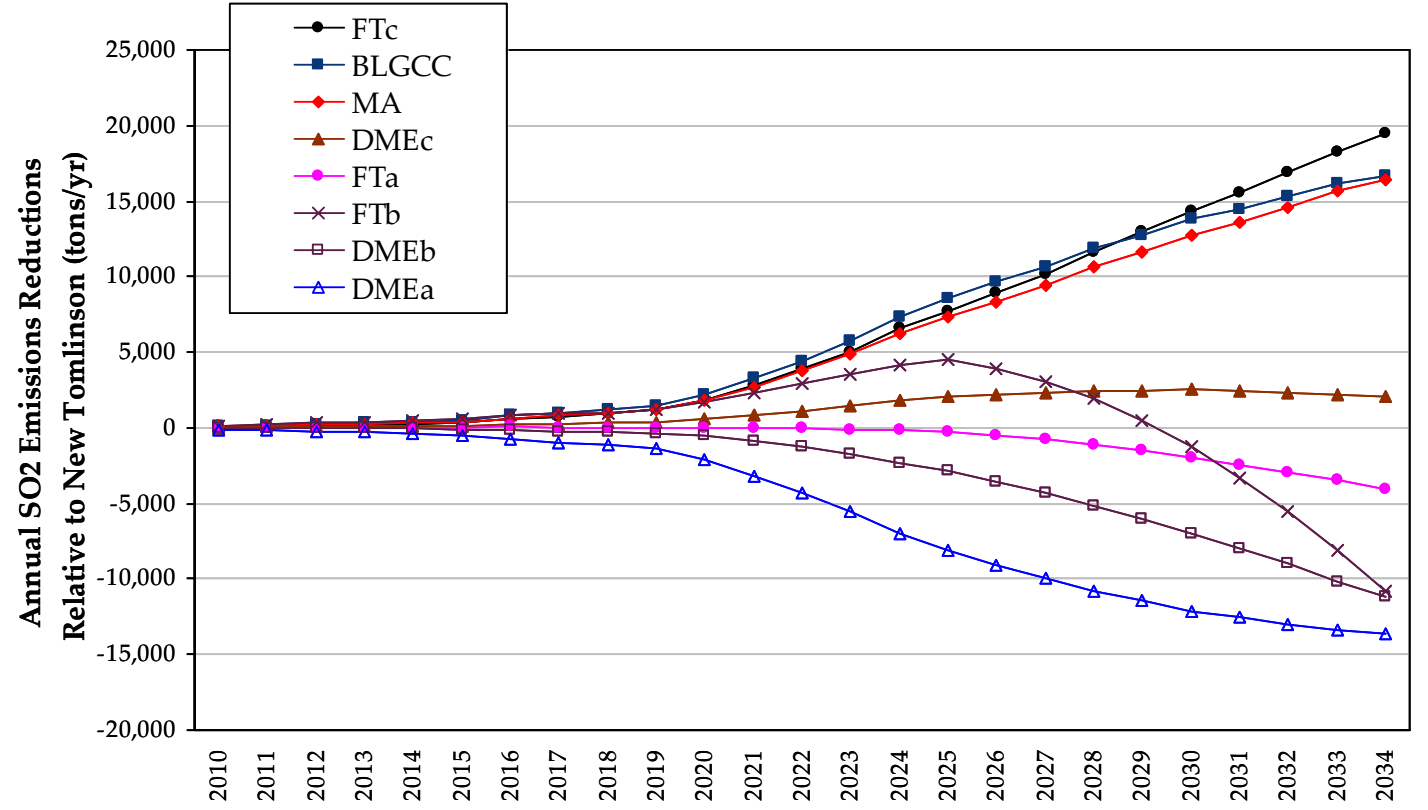

Transportation of the crude FT product to the oil refinery included in FT cases.

Note on vehicle end use: FT cases assume FT gasoline blend in gasoline engines and FT diesel blend in CIDI engines. MA case assumes low-level blend with gasoline. 
Figure 19: Net NOx emissions reductions (Aggressive market penetration scenario)

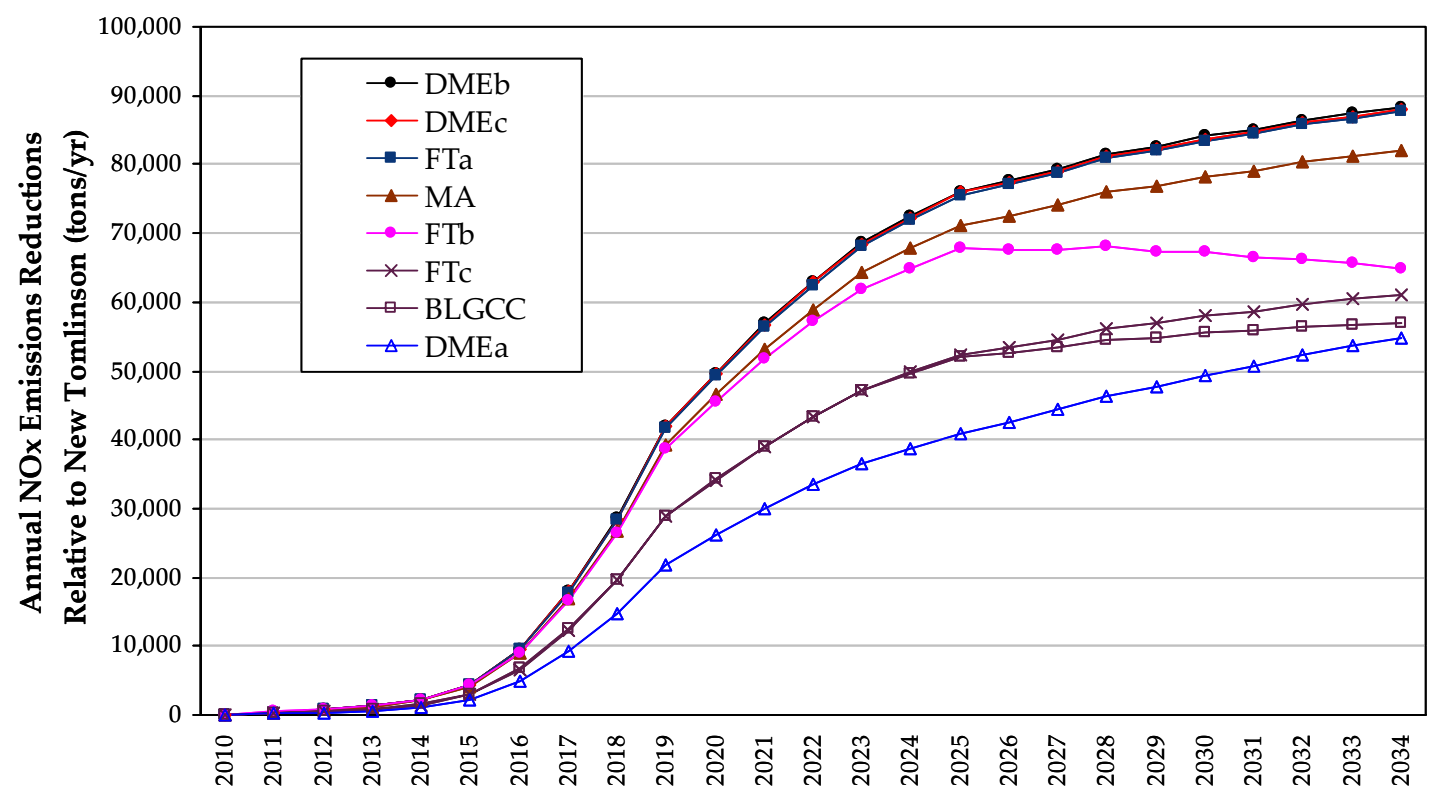

Transportation of the crude FT product to the oil refinery included in FT cases.

Note on vehicle end use: FT cases assume FT gasoline blend in gasoline engines and FT diesel blend in CIDI engines. MA case assumes low-level blend with gasoline.

Figure 20: Net NOx emissions reductions (Base market penetration scenario)

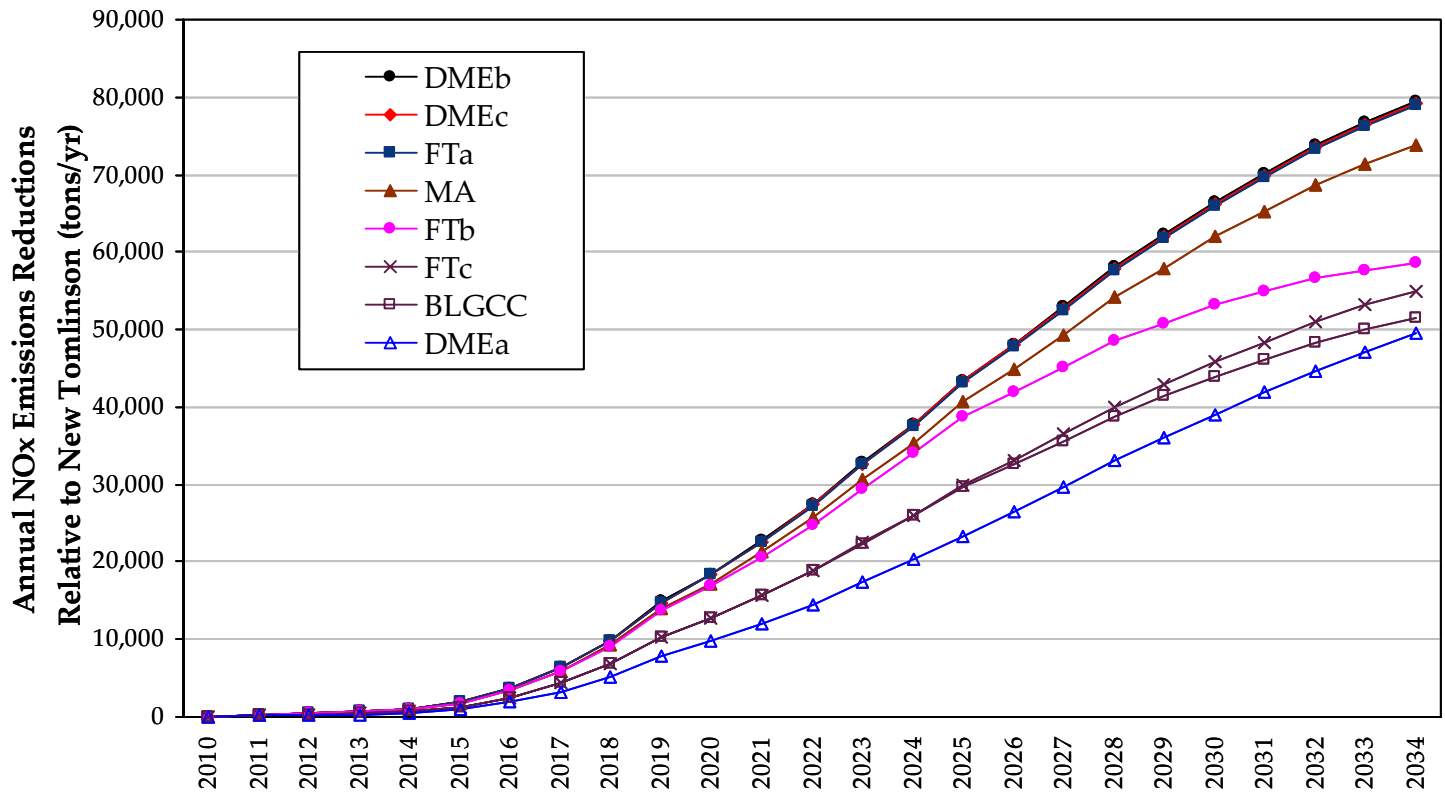

Transportation of the crude FT product to the oil refinery included in FT cases.

Note on vehicle end use: FT cases assume FT gasoline blend in gasoline engines and FT diesel blend in CIDI engines. MA case assumes low-level blend with gasoline. 
Figure 21: Net NOx emissions reductions (Low market penetration scenario)

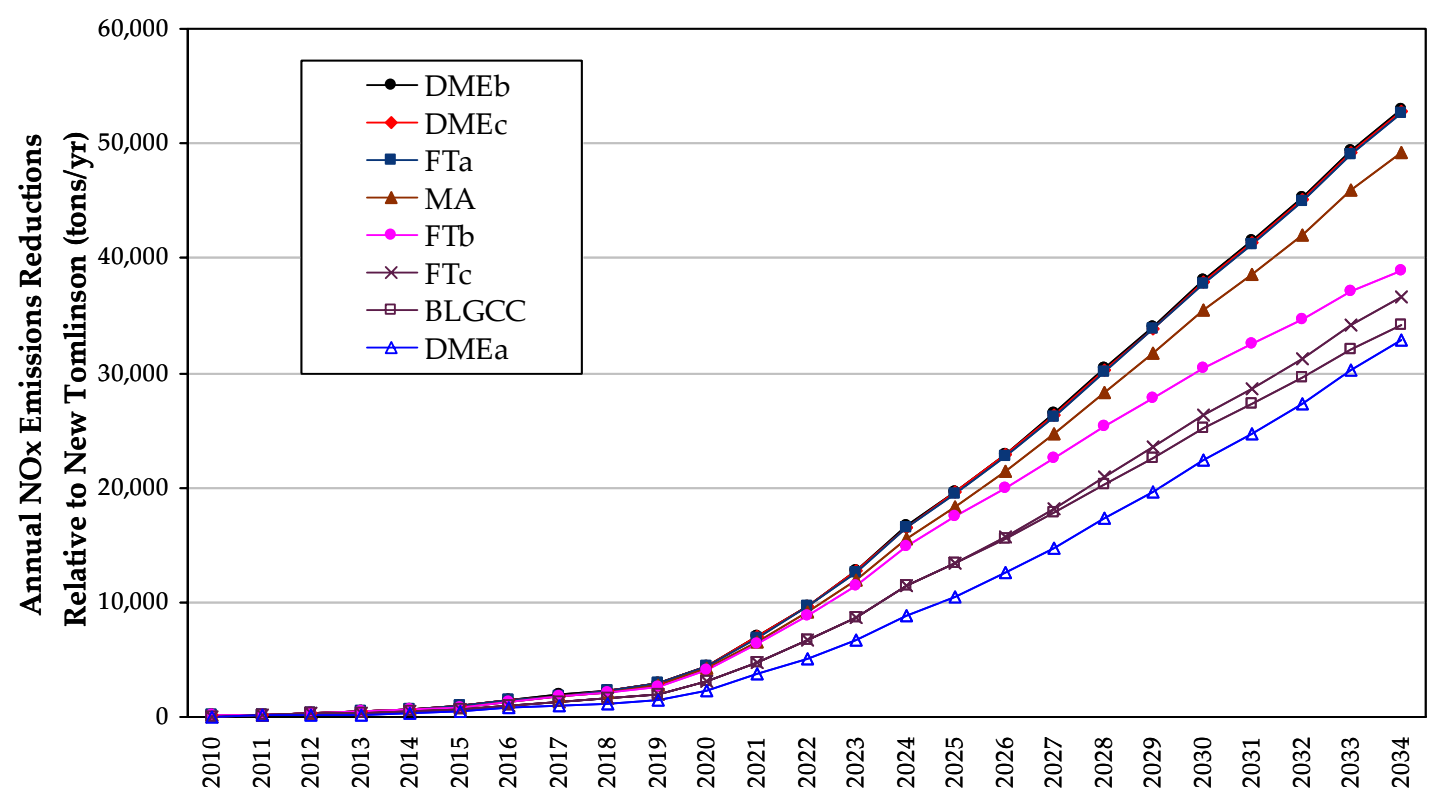

Transportation of the crude FT product to the oil refinery included in FT cases.

Note on vehicle end use: FT cases assume FT gasoline blend in gasoline engines and FT diesel blend in CIDI engines. MA case assumes low-level blend with gasoline.

Figure 22: Net VOC emissions reductions (Aggressive market penetration scenario)

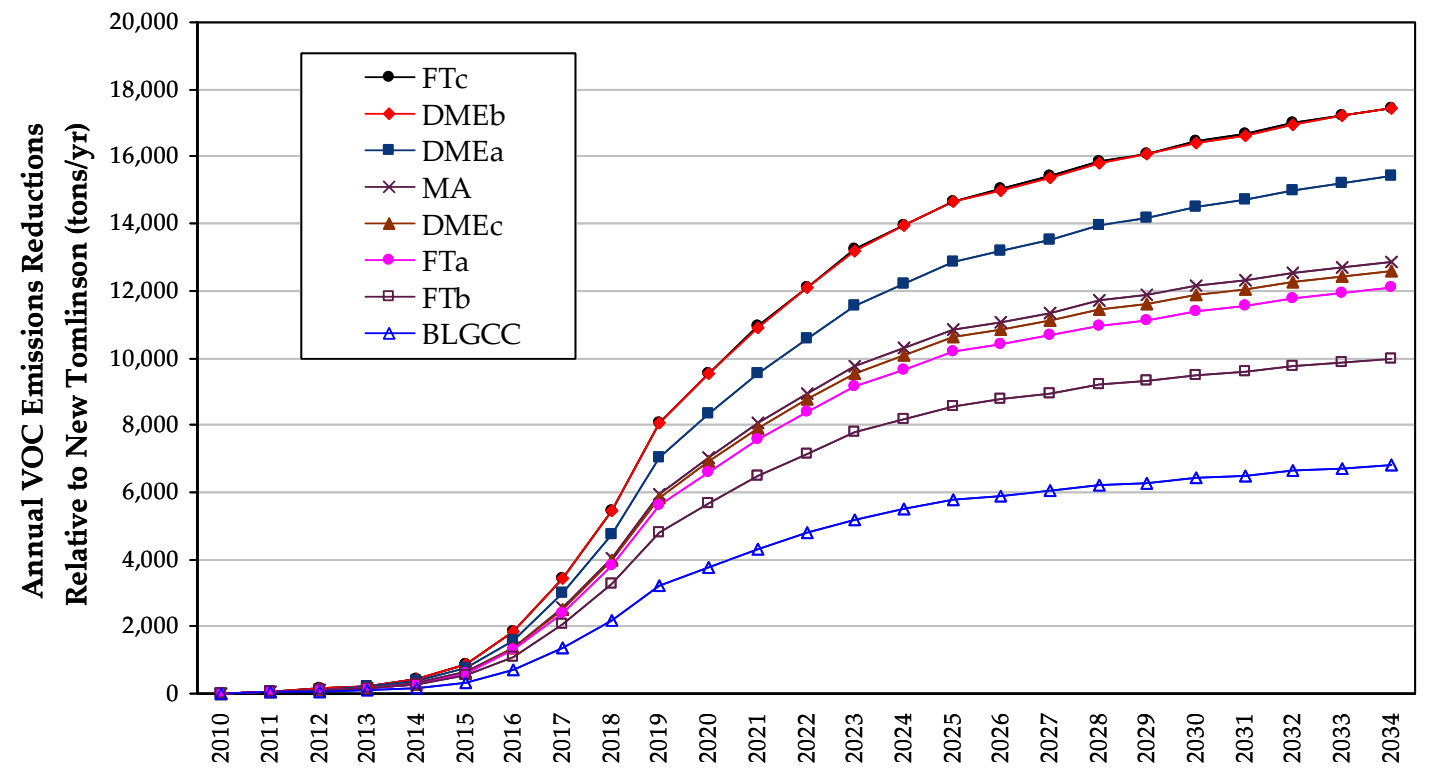

Transportation of the crude FT product to the oil refinery included in FT cases.

Note on vehicle end use: FT cases assume FT gasoline blend in gasoline engines and FT diesel blend in CIDI engines. MA case assumes low-level blend with gasoline. 
Figure 23: Net VOC emissions reductions (Base market penetration scenario)

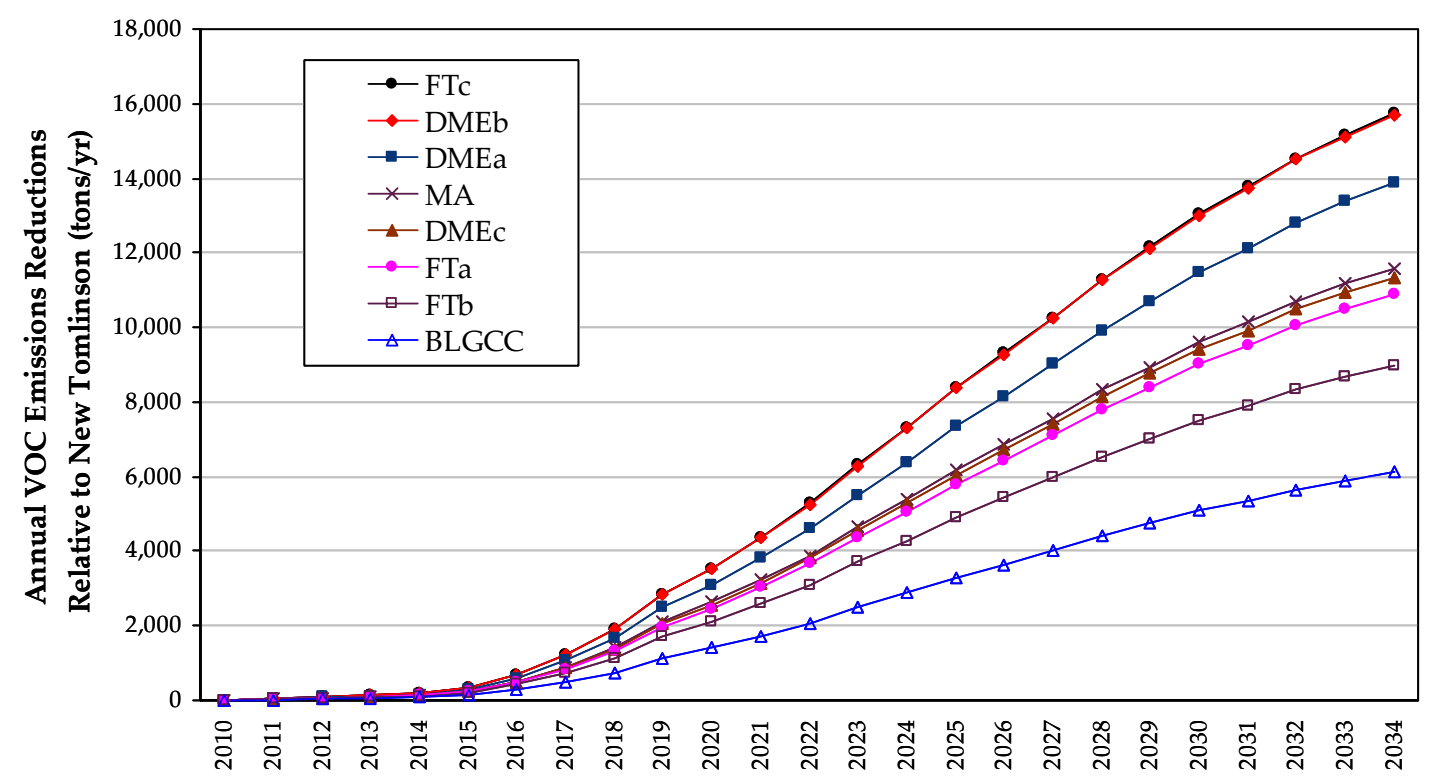

Transportation of the crude FT product to the oil refinery included in FT cases.

Note on vehicle end use: FT cases assume FT gasoline blend in gasoline engines and FT diesel blend in CIDI engines. MA case assumes low-level blend with gasoline.

Figure 24: Net VOC emissions reductions (Low market penetration scenario)

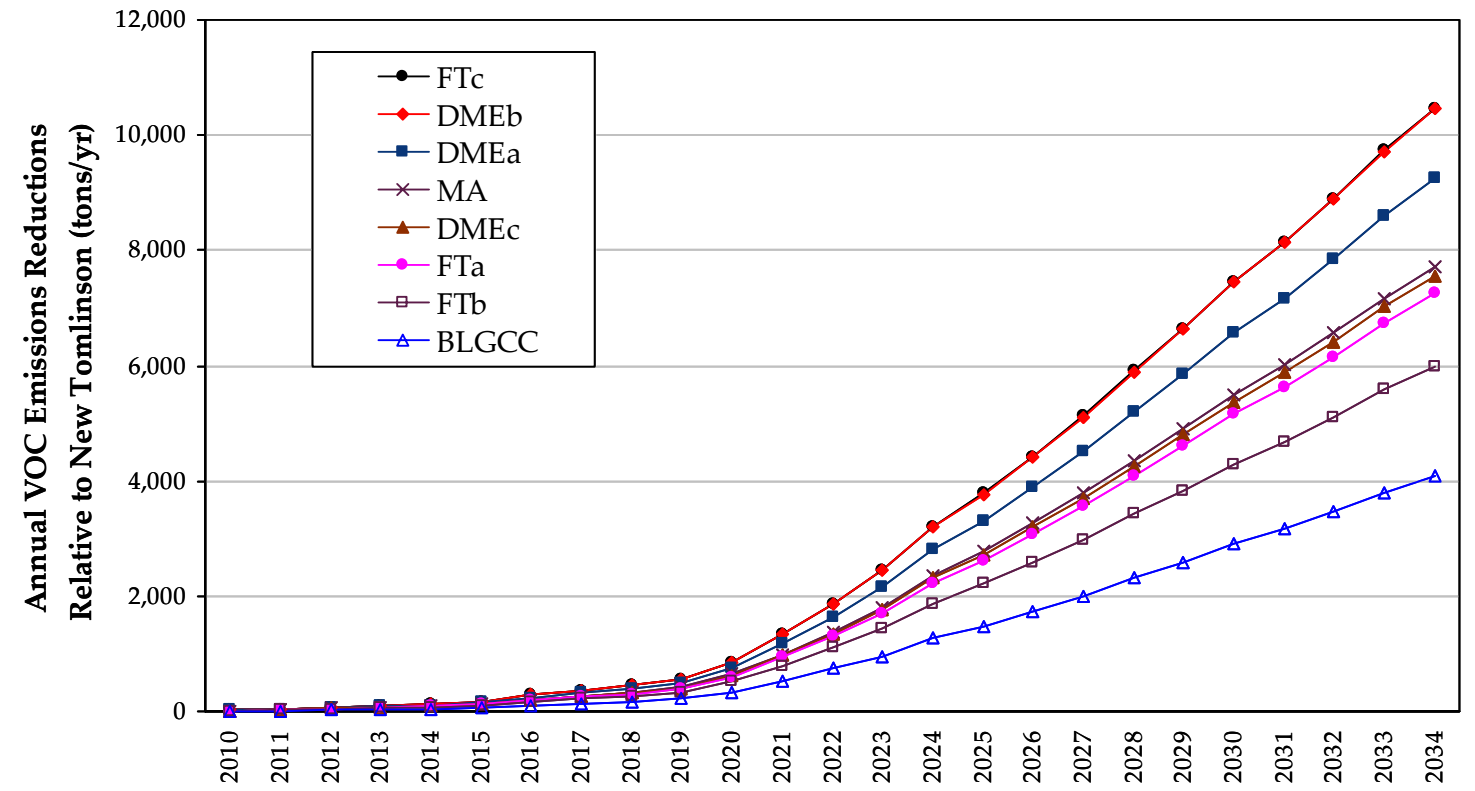

Transportation of the crude FT product to the oil refinery included in FT cases.

Note on vehicle end use: FT cases assume FT gasoline blend in gasoline engines and FT diesel blend in CIDI engines. MA case assumes low-level blend with gasoline. 
Figure 25: Net CO emissions reductions (Aggressive market penetration scenario)

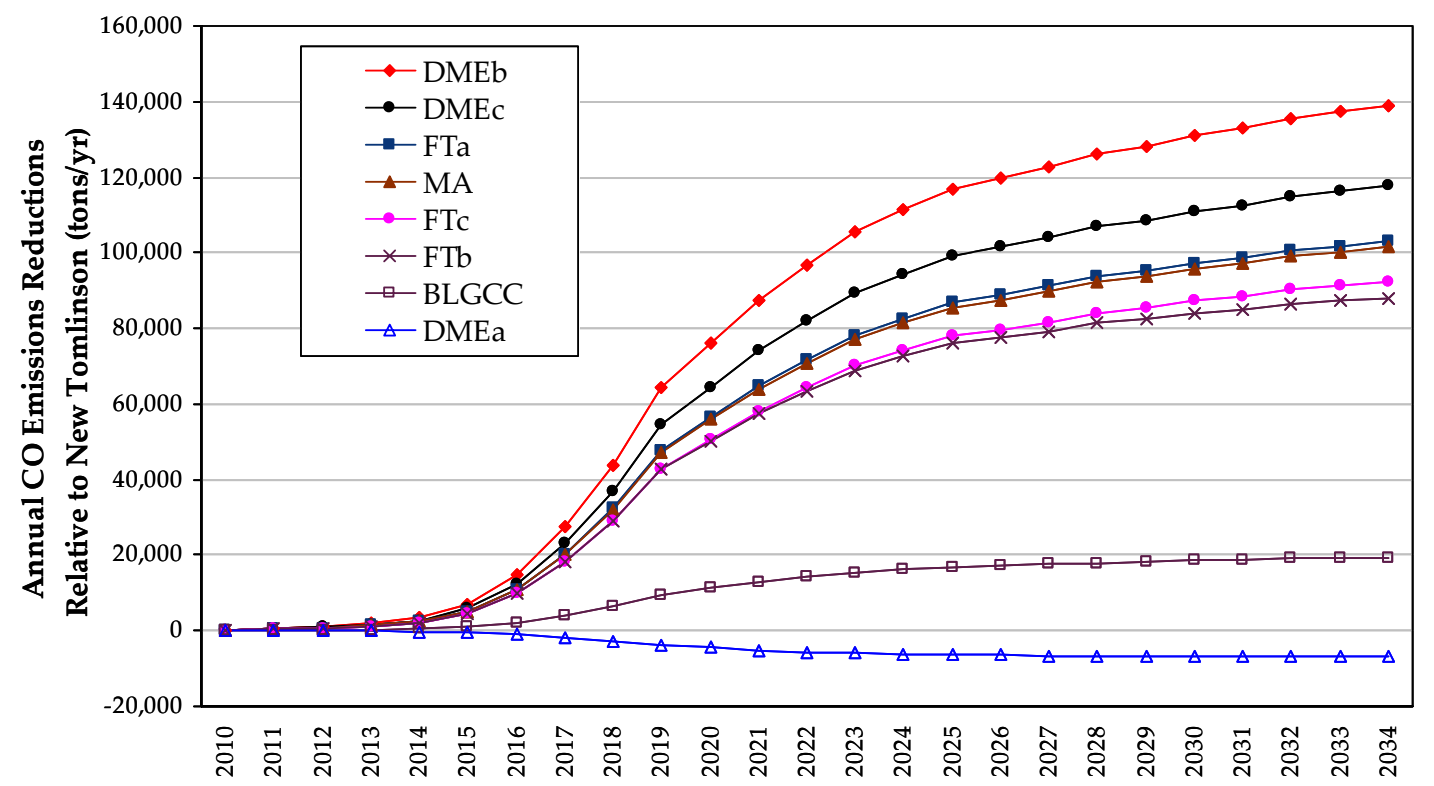

Transportation of the crude FT product to the oil refinery included in FT cases.

Note on vehicle end use: FT cases assume FT gasoline blend in gasoline engines and FT diesel blend in CIDI engines. MA case assumes low-level blend with gasoline.

Figure 26: Net CO emissions reductions (Base market penetration scenario)

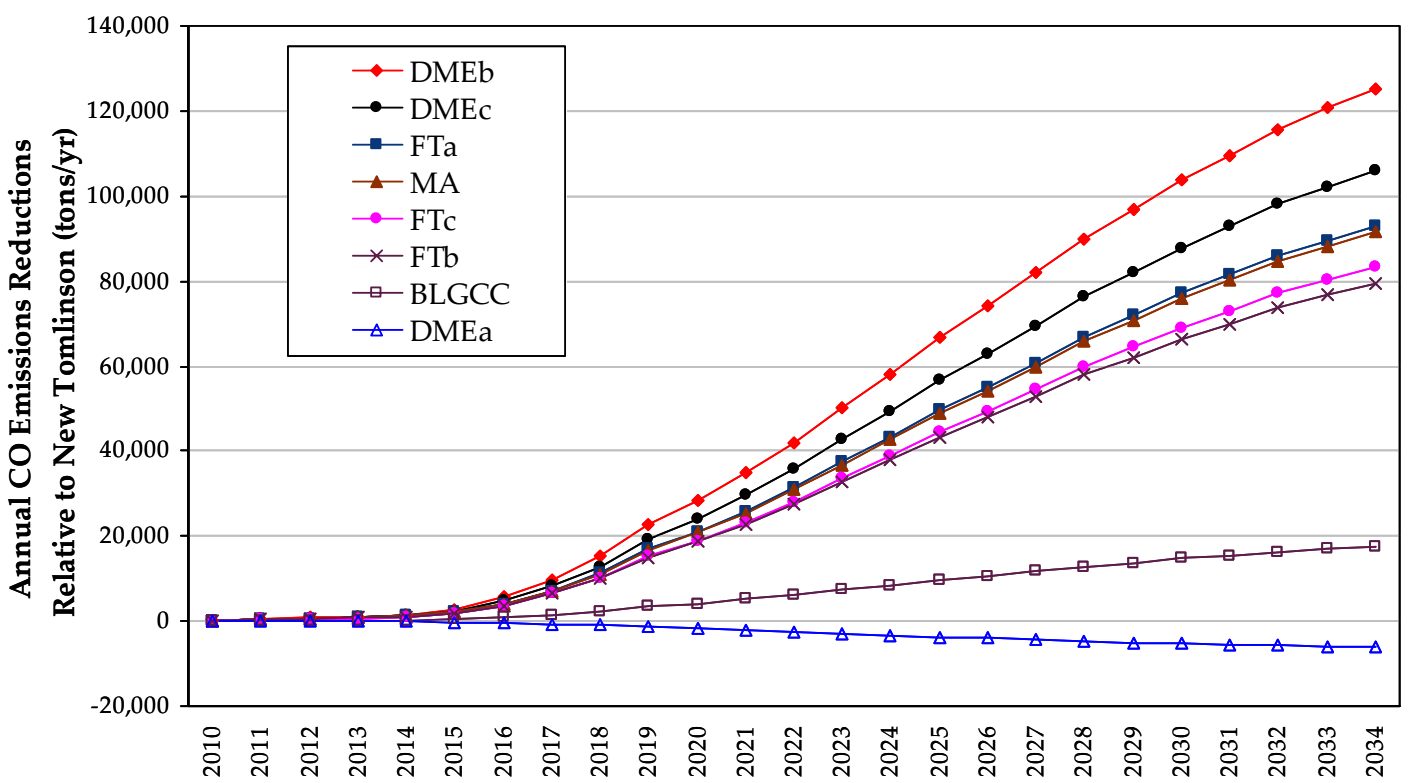

Transportation of the crude FT product to the oil refinery included in FT cases.

Note on vehicle end use: FT cases assume FT gasoline blend in gasoline engines and FT diesel blend in CIDI engines. MA case assumes low-level blend with gasoline. 
Figure 27: Net CO emissions reductions (Low market penetration scenario)

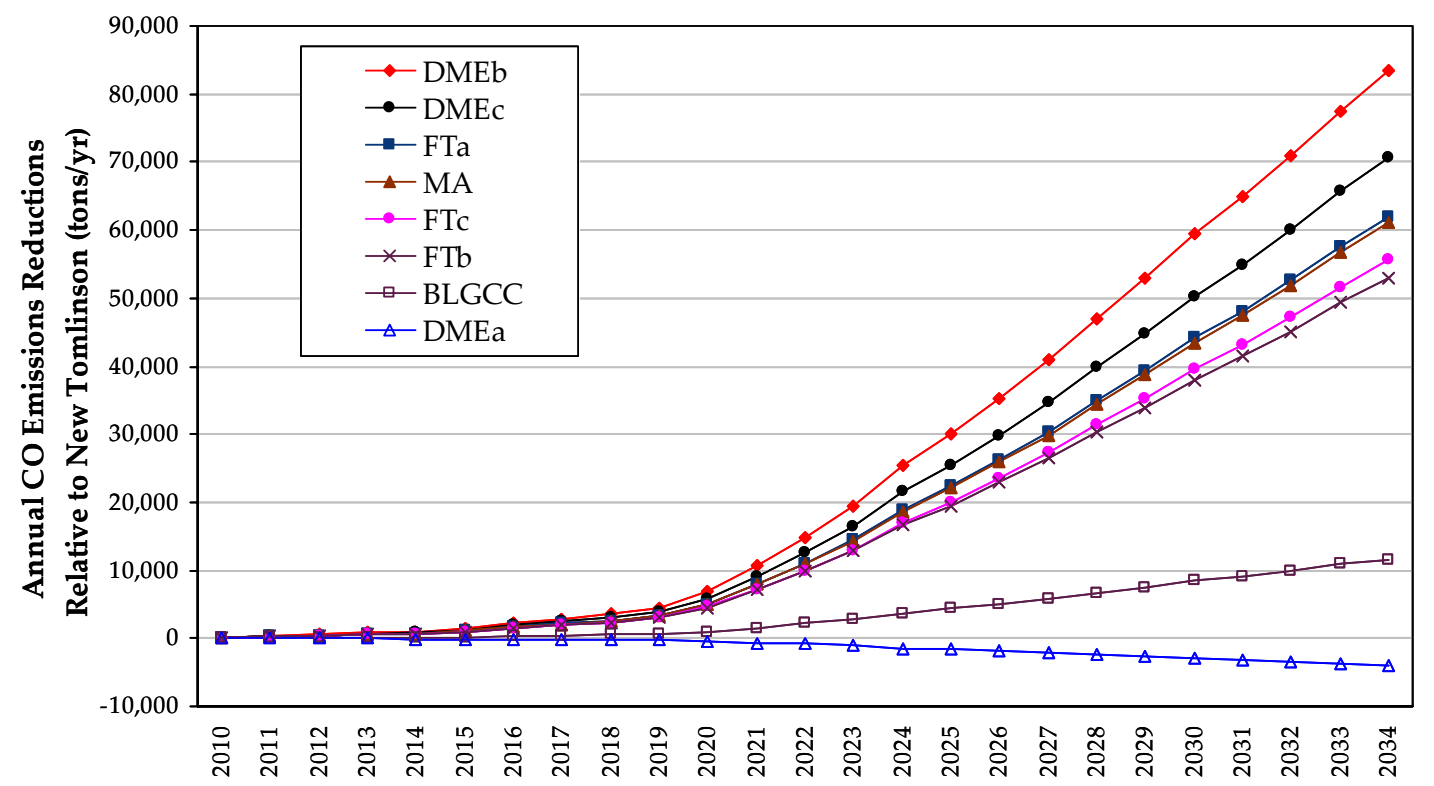

Transportation of the crude FT product to the oil refinery included in FT cases.

Note on vehicle end use: FT cases assume FT gasoline blend in gasoline engines and FT diesel blend in CIDI engines. MA case assumes low-level blend with gasoline.

Figure 28: Net PM10 emissions reductions (Aggressive market penetration scenario)

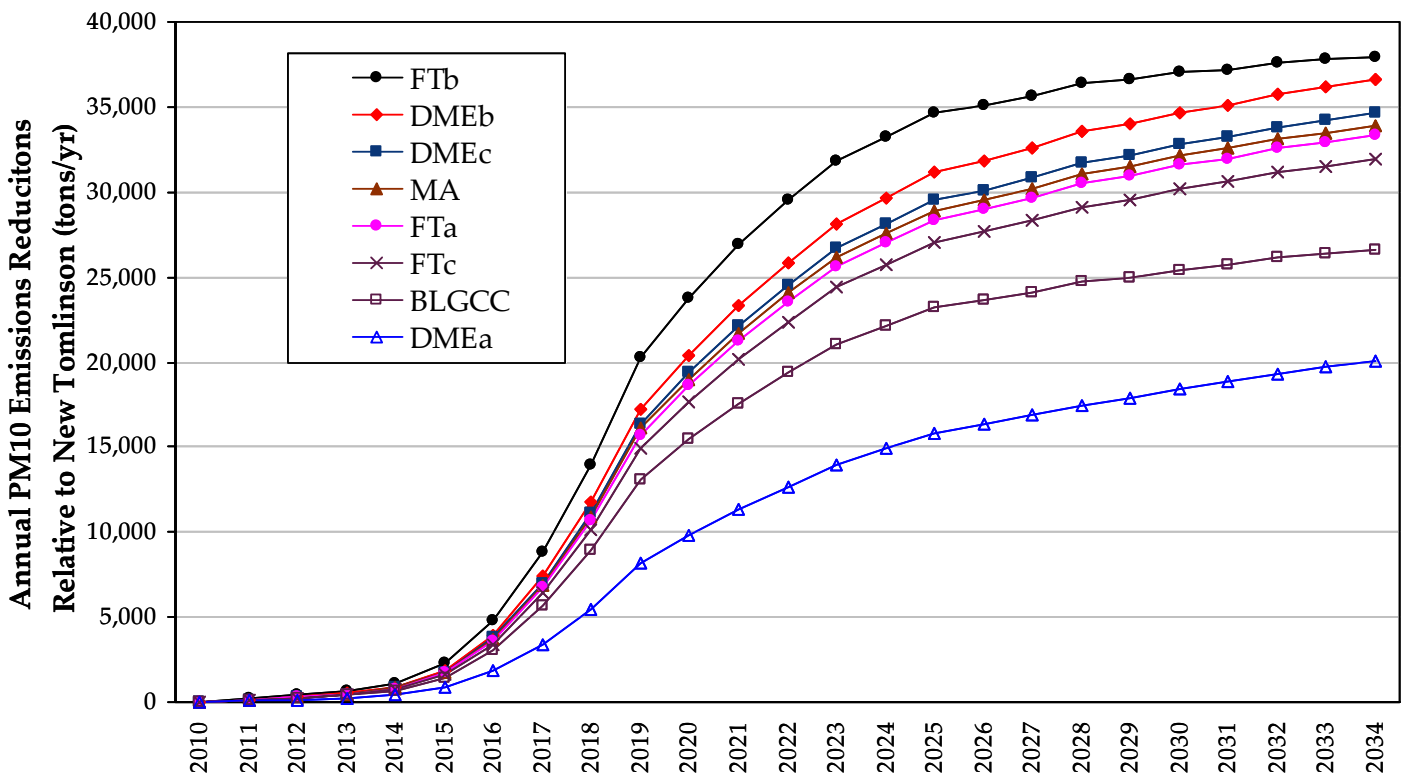

Transportation of the crude FT product to the oil refinery included in FT cases.

Note on vehicle end use: FT cases assume FT gasoline blend in gasoline engines and FT diesel blend in CIDI engines. MA case assumes low-level blend with gasoline. 
Figure 29: PM10 emissions reductions (Base market penetration scenario)

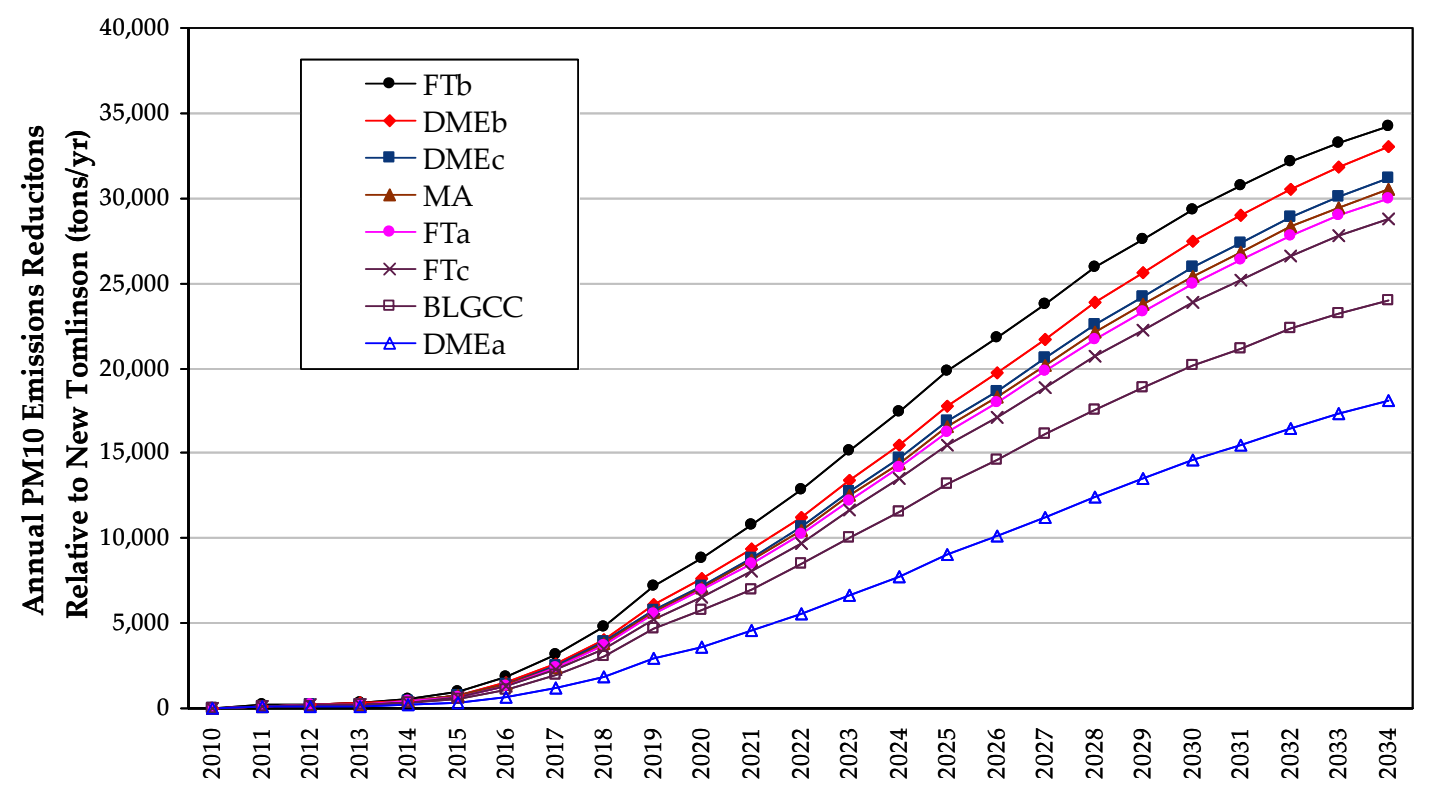

Transportation of the crude FT product to the oil refinery included in FT cases.

Note on vehicle end use: FT cases assume FT gasoline blend in gasoline engines and FT diesel blend in CIDI engines. MA case assumes low-level blend with gasoline.

Figure 30: PM10 emissions reductions (Low market penetration scenario)

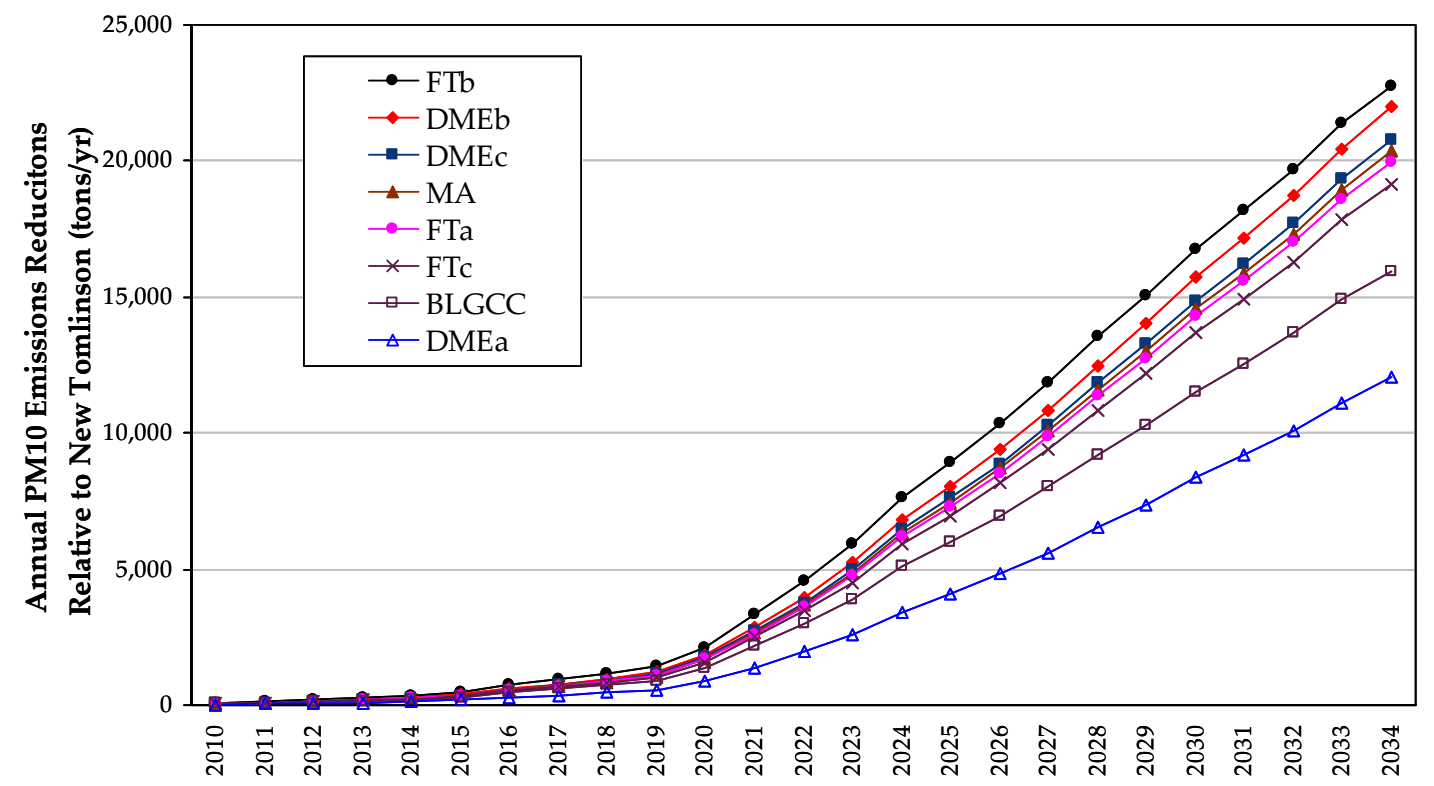

Transportation of the crude FT product to the oil refinery included in FT cases.

Note on vehicle end use: FT cases assume FT gasoline blend in gasoline engines and FT diesel blend in CIDI engines. MA case assumes low-level blend with gasoline. 


\subsection{High Level/Low Level Blend Comparison}

The preceding national impacts estimates assumed that mixed alcohols and FT biofuels were used in low-level blends with their conventional counterparts, specifically, a $10 \%$ blend of mixed alcohols with gasoline and a $10 \%$ blend of FT diesel with low-sulfur diesel. However, with some relatively minor engine and vehicle modifications (more so for alcohol fuels than FT fuels) these fuels can also be used in either high-level blends or as neat (100\%) biofuels. If used in this manner, certain tailpipe emissions are expected to decrease. However, data are either limited or non-existent regarding light-duty vehicle performance. As discussed in Volume 1, based on a review of the literature, we made estimates of the reductions in certain tailpipe emissions when vehicles are optimized for biofuels usage. Our assumptions in this regard are summarized in Table 20 and Table 21. The major impacts are expected to be:

- VOC emissions: tailpipe VOCs may be further reduced when neat FT diesel is used instead of low-sulfur diesel. Also, evaporative VOC emissions should be lower when mixed alcohols are used in a flex fuel vehicle compared to gasoline vehicles.

- CO emissions: CO may be reduced when neat FT diesel is used instead of low-sulfur diesel.

- There would be modest reductions in $\mathrm{SO}_{2}$ and possibly $\mathrm{NO}_{\mathrm{x}}$, but these are expected to be minimal.

For the VOC and CO cases, the differences between the low-blend and high blend cases are given in Figure 31 and Figure 32. Only the Aggressive market penetration scenario is shown.

Figure 31: Net VOC emissions reductions comparing low-level and high-level blends of mixed alcohols and FT biofuels (Aggressive market penetration scenario)

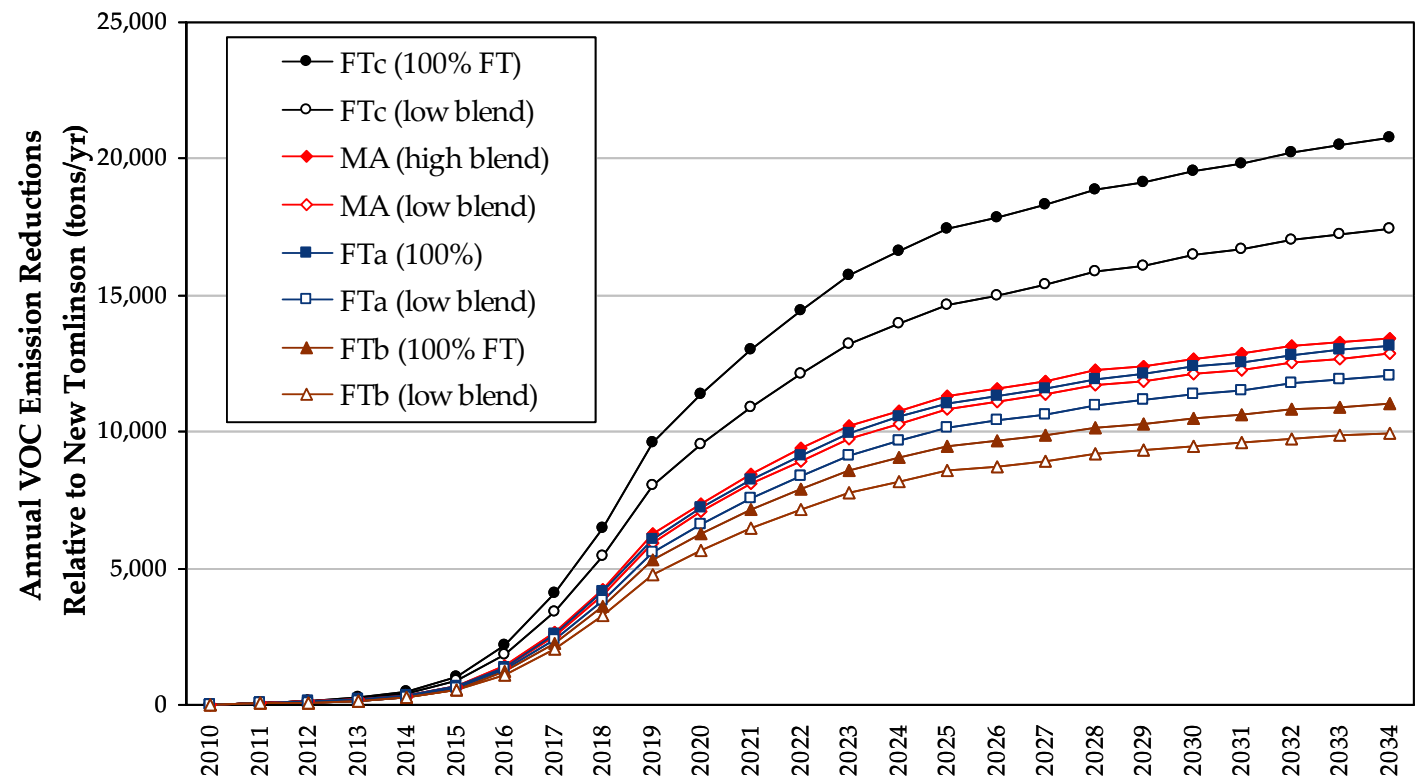

Transportation of the crude FT product to the oil refinery included in FT cases.

Note: excludes any emissions from land use changes and biomass growth that are not related to harvesting and transportation.

Note on vehicle end use: FT cases assume FT gasoline used in SI engines and FT diesel in CIDI engines. "Low Blend" cases

assumes $10 \%$ blend with conventional fuels, "high blend" assumes $85 \%$ blend of mixed alcohols with conventional gasoline. 
Figure 32: Net CO emissions reductions comparing low-level and high-level blends of mixed alcohols and FT biofuels (Aggressive market penetration scenario)

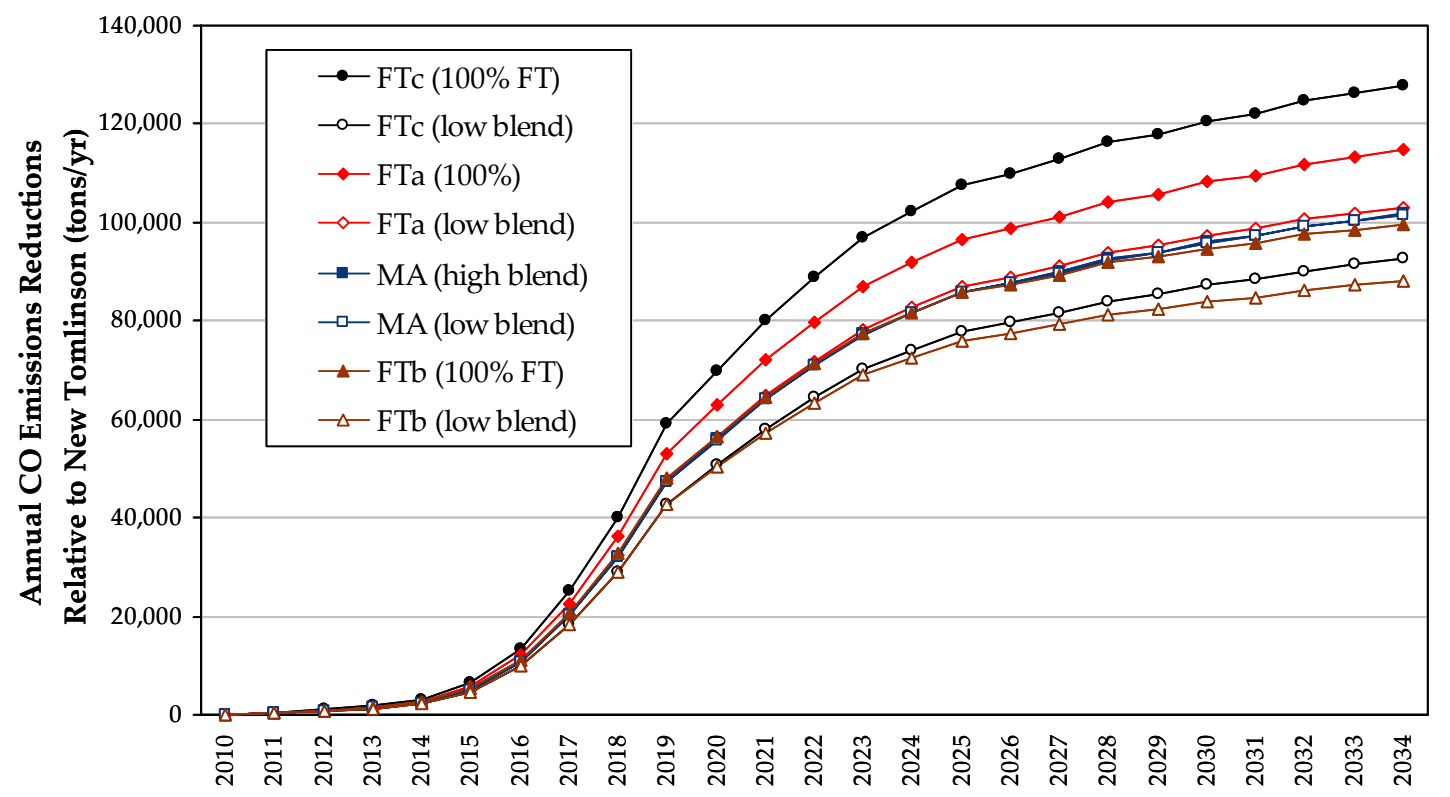

Transportation of the crude FT product to the oil refinery included in FT cases.

Note: excludes any emissions from land use changes and biomass growth that are not related to harvesting and transportation.

Note on vehicle end use: FT cases assume FT gasoline used in SI engines and FT diesel in CIDI engines. "Low Blend" cases

assumes $10 \%$ blend with conventional fuels, "high blend" assumes $85 \%$ blend of mixed alcohols with conventional gasoline. 


\section{References}

1. National Council for Air and Stream Improvement, Inc., "An Analysis of Kraft Recovery Furnace NOx Emissions and Related Parameters." Technical Bulletin No. 636. New York, NY: National Council of the Paper Industry for Air and Stream Improvement, Inc., July 1992.

2. National Council for Air and Stream Improvement, Inc., "Calculation Tools for Estimating Greenhouse Gas Emissions from Pulp and Paper Mills. Version 1.0," Research Triangle Park, NC: National Council for Air and Stream Improvement, Inc., December, 2002.

3. National Council for Air and Stream Improvement, Inc., "Compilation of Speciated Reduced Sulfur Compound and Total Reduced Sulfur Emissions Data for Kraft Mill Sources," Technical Bulletin No. 849.

Research Triangle Park, NC: National Council for Air and Stream Improvement, Inc., August 2002.

4. National Council for Air and Stream Improvement, Inc., "Performance of EPA Stack Sampling Methods for PM10, PM2.5 and Condensible Particulate Matter on Sources Equipped With Electrostatic Precipitators," Technical Bulletin No. 852, Research Triangle Park, NC: National Council for Air and Stream Improvement, Inc., September, 2002.

5. National Council for Air and Stream Improvement, Inc., "Table: Summary of 'Air Toxic' Emissions from NDCE Kraft Recovery Furnaces," Personal facsimile communication from John Pinkerton, December, 2002.

6. National Council for Air and Stream Improvement, Inc., "Sulfur Dioxide and Nitrogen Oxides Emissions from Pulp And Paper Mills In 2000,” NCASI Special Report No. 02-06, December 2002.

7. National Council for Air and Stream Improvement, Inc., "Factors Affecting NOx Emissions from Lime Kilns," Technical Bulletin No. 855, Research Triangle Park, NC: National Council for Air and Stream Improvement, Inc., January 2003.

8. Environmental Protection Agency, AP-42, Compilation of Air Pollutant Emission Factors. Section 1.6: External Combustion Sources, Wood Residue Combustion in Boilers. Research Triangle Park, NC: U.S. Environmental Protection Agency, March 2002.

9. Gasification Technologies Council, "Gasification Offers Significant Environmental and Economic Benefits," accessed at http://www.gasification.org, 16 June 2003.

10. Orr, D. and Maxwell, D., "A Comparison of Gasification and Incineration of Hazardous Wastes: Final Report,” DCN 99.803931.02. Austin, TX: Radian International, LLC, March 2000.

11. Ratafia-Brown, J.A., Manfredo, L.M., Hoffmann, J.W., and Massood, R. (Science Applications International Inc.) and Gary J. Stiegel (U.S. DOE/National Energy Technology Laboratory), "An Environmental Assessment of IGCC Power Systems,” presented at 19th Annual Pittsburgh Coal Conf., September 2002.

12. Simbeck, D, "Future of U.S. Coal-Fired Power Generation: Band-Aids or Corrective Surgery," presented at the Gasification Technologies Conference, San Francisco, October 2002.

13. Simbeck, D., "Process Screening Analysis of Alternative Gas Treating and Sulfur Recovery for Gasification," presented at the Nineteenth Annual Pittsburgh Coal Conf., September 2002.

14. Teco Energy, "Polk Power Station IGCC”, DOE/NARUC Clean Coal Technology Forum, 8 December 2002.

15. Ubis, T., Bressan, L. and O'Keefe, L., "The 800 MW PIEMSA IGCC Project," presented at the Gasification Technologies Conference, San Francisco, October 2000.

16. Environmental Protection Agency, AP-42, Compilation of Air Pollutant Emission Factors. Section 3.1: Stationary Gas Turbines. Research Triangle Park, NC: U.S. Environmental Protection Agency, April 2000.

17. Environmental Protection Agency, AP-42, Compilation of Air Pollutant Emission Factors. Section 1.4: External Combustion Sources, Natural Gas Combustion. Research Triangle Park, NC: U.S. Environmental Protection Agency, July 1998. 
18. Energy Information Administration, Annual Energy Outlook 2005 with Projections to 2030. DOE/EIA-0383 (2005). Washington, DC: U.S. Dept. of Energy, January, 2005.

19. Energy Information Administration, Annual Energy Outlook 2006, with Projections to 2030, DOE/EIA0383(2006), U.S. Department of Energy, February 2006.

20. Environmental Protection Agency (EPA). Inventory of U.S. Greenhouse Gas Emissions and Sinks: 19902003. EPA 430-R-05-003. Washington, DC: U.S. Environmental Protection Agency, April, 2005.

21. Environmental Protection Agency (EPA), National Emissions Inventory Trends Report, updated July 18, 2005. See also the NEI Air Pollutant Emissions Trends Data at www.epa.gov/ttn/chief/trends.

22. Argonne National Laboratory, "Greenhouse Gases, Regulated Emissions, and Energy Use in Transportation (GREET) Model, version 1.7 (beta), released January 18, 2006.

23. Oguma, M. and Goto, S. "Evaluation of Medium Duty DME Truck Performances - Field Test Results and Trace Level Emissions Measurement." Presented at the 2nd International DME Conference (DME2), London, UK, May 15-17, 2006.

24. Delucchi, Mark, Institute for Transportation Studies, UC Davis, A Lifecycle Emissions Model (LEM): Lifecycle Emissions from Transportation Fuels, Motor Vehicle, Transportation Modes, Electricity Use, Heating and Cooking Fuels, and Materials, Documentation of methods and data, UCD-ITS-RR-03-17, Main Report, December, 2003

25. Gilshannon, S.T. and Brown, D.R., Review of Methods for Forecasting the Market Penetration of New Technologies, Pacific Northwest National Laboratory, December 1996.

26. Fisher, J.C. and Pry, R.H., "A Simple Substitution Model of Technological Change," Technological Forecasting and Social Change, 3:75-88, 1971.

27. Homer, G. Air Liquide, personal communication, 31 January 2006.

28. American Forest \& Paper Association, personal communication from Elizabeth Davies, 22 May 2006. 


\section{A Cost-Benefit Assessment of Gasification-Based Biorefining in the Kraft Pulp and Paper Industry}

\section{Volume 4 \\ Preliminary Biorefinery Analysis with Low- Temperature Black Liquor Gasification}

FINAL REPORT

Under contract DE-FG26-04NT42260 with the U.S. Department of Energy and with cost-sharing by the American Forest and Paper Association

21 December 2006

Eric D. Larson

Princeton Environmental Institute

Princeton University

Princeton University

Princeton, NJ

elarson@princeton.edu

Stefano Consonni

Department of Energy Engineering

Politecnico di Milano

Milan, Italy

stefano.consonni@polimi.it

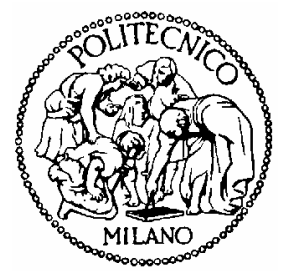

Ryan E. Katofsky

Navigant Consulting, Inc.

Burlington, MA

rkatofsky@navigantconsulting.com

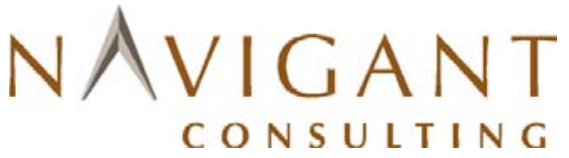

Kristiina Iisa, W. James Frederick, Jr., Charles

Courchene, Farminder Anand, and Matthew Realff

Institute of Paper Science and Technology

School of Chemical and Biomolecular Engineering

Georgia Institute of Technology

Atlanta, GA

CON S U L T I N G

kristiina.iisa@ipst.gatech.edu

jim.frederick@ipst.gatech.edu

Georgia|ns\}甜施 of́techno[og]y 


\section{Table of Contents}

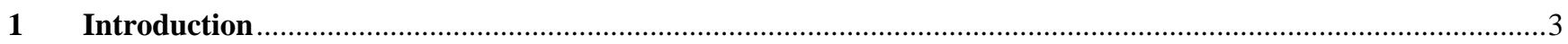

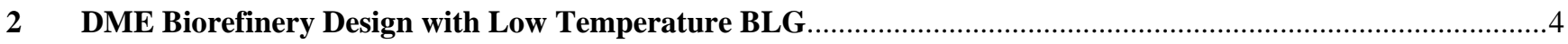

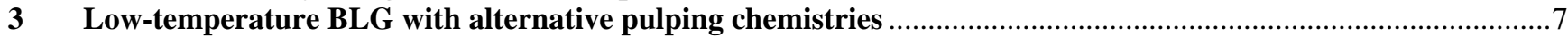

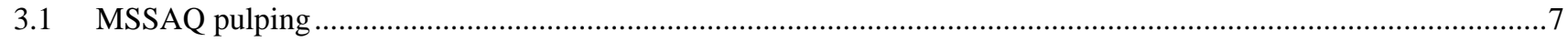

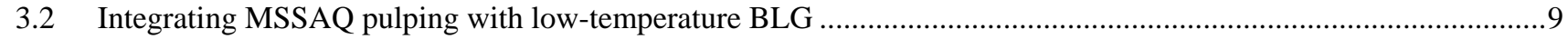

3.3 Some preliminary economics of MSSAQ pulping with LTBLG ..........................................................13

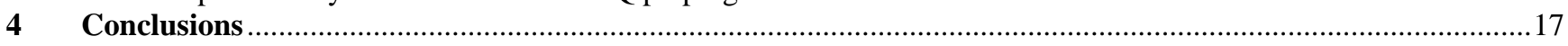

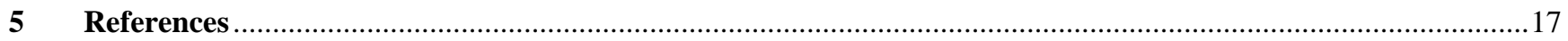

Note: "Navigant is a service mark of Navigant International, Inc. Navigant Consulting, Inc. (NCI) is not affiliated, associated, or in any way connected with Navigant International, Inc., and NCI's use of "Navigant” is made under license from Navigant International, Inc. 


\section{Introduction}

A number of concepts for black liquor gasification have been proposed in the past [1]. Our previous assessment of black liquor gasification combined cycle (BLGCC) systems [2] included detailed analysis of two different black liquor gasifier (BLG) designs, one (Chemrec design) operating at high temperature and pressure with the condensed phase leaving the gasifier as a molten liquid and one (MTCI design) operating at lower temperature and pressure, with the condensed phase leaving the gasifier as a solid.

A key objective in the current biorefinery assessment was to understand the relative costs/benefits of liquid fuels production vis-à-vis BLGCC electricity production. Accordingly, considering the limited resources available for our project, we made a tentative decision early in the project to focus the biorefinery analysis around a single black liquor gasifier design rather than carrying out parallel designs with two gasifiers, as we did in our BLGCC work. The BLGCC work showed more favorable performance and economics for BLGCC systems designed around the high-temperature BLG (HTBLG) design, so this one was selected for the detailed kraft pulp mill biorefinery designs described in Volume 1.

However, because there was still considerable interest in the low-temperature BLG (LTBLG) design at the Department of Energy and in the pulp and paper industry, we pursued a preliminary analysis to evaluate the LTBLG in a biorefinery application to determine whether the more favorable performance and cost for the HTBLG in the BLGCC analysis would persist in biorefinery applications. This preliminary analysis, which is described in Section 2 of this volume, confirmed that the HTBLG would likely give better results than the LTBLG in the biorefinery applications we were examining in our study.

This finding prompted discussion among project participants about what types of applications at pulp/paper mills would allow the unique features of the LTBLG technology to be best exploited. The unique features include the high hydrogen content of the synthesis gas and the nearly complete segregation of sulfur (to the gas phase) and sodium (to the condensed phase) that occurs due to the intrinsic thermodynamics of the LTBLG process.

One possibility is that applications involving the synthesis of products with a high hydrogen content, e.g., ammonia or pure hydrogen, might favor the LTBLG over the HTBLG because of the much higher $\mathrm{H}_{2}$ :CO ratio that characterizes LTBLG product gas $\left(\mathrm{H}_{2}\right.$ : $\mathrm{CO}$ of 2.6 versus 1.1 on a molar basis in our BLGCC study [2]). There is some merit to this line of reasoning. However, relatively inexpensive commercial water-gas shift (WGS) reactors can be used to increase the $\mathrm{H}_{2}$ :CO ratio of a synthesis gas to arbitrarily high values via the nearly-autothermal ${ }^{1}$ WGS reaction, $\mathrm{CO}+\mathrm{H}_{2} \mathrm{O} \leftarrow \rightarrow \mathrm{H}_{2}+\mathrm{CO}_{2}$. Thus, the cost and energy efficiency penalties of including a WGS system in a HTBLG application (to obtain a high hydrogen content syngas) are relatively minor, and there would appear to be little or no inherent advantage to be gained by the LTBLG technology because of its unique high-hydrogen content syngas production.

In contrast, there may be unique opportunities at a pulp mill to take advantage of the nearly complete segregation of sulfur and sodium that characterizes the LTBLG. Interestingly, this feature was one of the major factors contributing to the relatively unfavorable financial performance we predicted for the LTBLG in the BLGCC application at a pulp/paper mill using the kraft pulping process. The chemical

\footnotetext{
${ }^{1}$ The WGS reaction is only slightly exothermic $(-41 \mathrm{~kJ} / \mathrm{mol})$.
} 
segregation leads to a requirement that considerable additional causticizing capacity be installed at a kraft mill to enable the regeneration of the pulping liquor. If the concept of direct causticizing proves to be commercially viable, whereby the necessary pulping chemicals are largely regenerated directly by hydrolysis of the gasifier condensed phase [3], this might allow this limitation to be overcome at a kraft pulp mill. However, work on direct causticizing is still at the stage of laboratory investigations, and the most recent results from the Georgia Institute of Technology [4] suggest that direct causticizing may not work at conditions of low-temperature gasification. This finding led us to assess alternative pulping strategies (non-kraft processes) that might be able to achieve higher pulp yields using different pulping chemistries that take advantage of having separate streams of sulfur and sodium in the chemical recovery area. Section 3 in this Volume identifies some alternative pulping options and describes analysis aimed at better understanding the commercial implications of implementing the most promising of these. First we discuss analysis of a biorefinery application with the LTBLG using the same polysulfide pulping strategy as used for our biorefinery analyses in Volume 1.

\section{DME Biorefinery Design with Low Temperature BLG}

The DME biorefinery design we selected for a preliminary analysis with the LTBLG at a kraft mill with polysulfide pulping uses a process configuration that parallels the DMEa configuration in the analysis in Volume 1. In DMEa, syngas from the HTBLG is processed through the synthesis reactor, with most of the unconverted syngas recycled to the synthesis reactor to maximize liquid DME production (Figure 1). The resulting deficit in steam production is made up by burning hog fuel and some purchased residues in boilers, the steam from which is expanded through a back-pressure steam turbine before being delivered to the pulp/paper mill. The electricity generated by the turbine is sufficient only to meet all (or most) of the biorefinery's parasitic electricity demand. The pulp/paper mill's electricity needs would in this case need to be met by purchasing power from the grid.

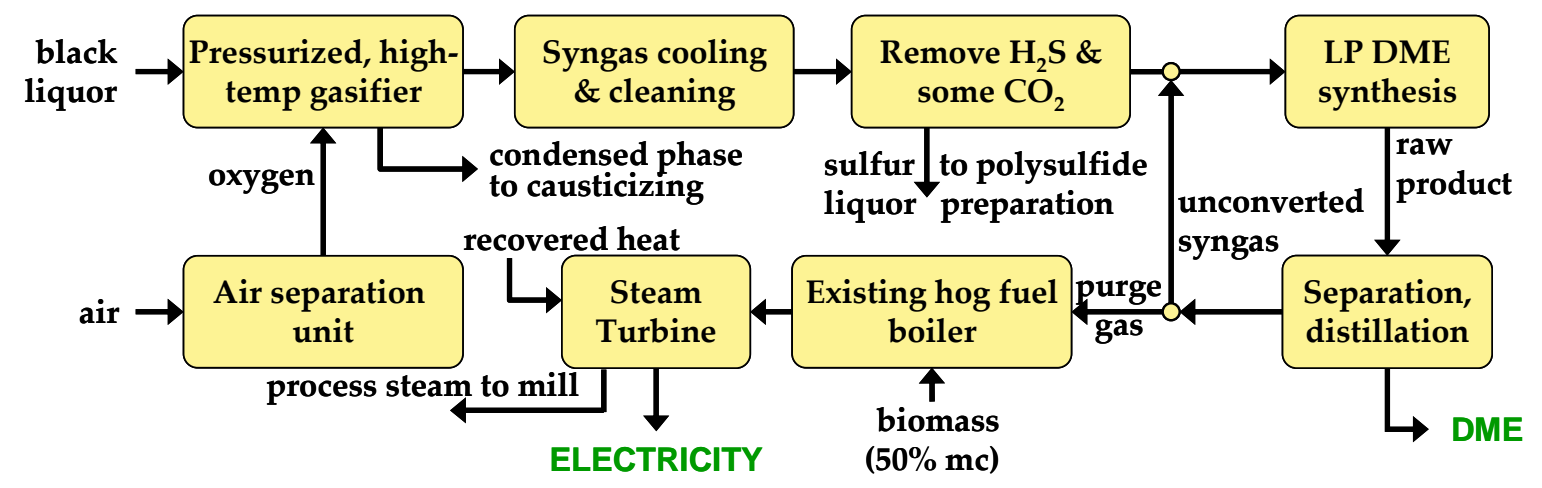

Figure 1. Schematic of biorefinery DMEa with high-temperature BLG. Most of the syngas that is not converted to DME in a single pass through the synthesis reactor is recycled to increase DME production. Steam is generated for pulp/paper mill needs by burning hog fuel and some purchased residues. The back pressure steam turbine generates some electricity.

To assist in developing heat and mass balances for the LTBLG case, we undertook some detailed process design and simulation. These simulations were not as comprehensive and detailed as our HTBLG simulations, but they are sufficiently detailed that one can be confident drawing conclusions regarding a comparison between the HTBLG and LTBLG in this application.

The LTBLG is an indirectly-heated fluidized bed that operates at near-atmospheric pressure. The heat needed for the endothermic gasification reactions is delivered to the gasifier through heat exchange tubes immersed in the fluidized bed and by fluidizing steam. Pulse combustors provide heat input by 
burning part of the syngas generated by the gasifier. The fluidizing steam is superheated to $540^{\circ} \mathrm{C}$ before injection. At the moderate temperature maintained in the reactor $\left(\sim 600^{\circ} \mathrm{C}\right)$, the condensedphase material is a dry solid.

For the LTBLG analysis, we ran our Aspen Plus model of the DME synthesis/purification area using as input the clean syngas produced by the LTBLG system. We used the syngas composition (Table 1) and mass flow developed in our BLGCC study, except that we assumed that all $\mathrm{CO}_{2}$ would be removed upstream of the synthesis reactor, as required for the synthesis step. The detailed Aspen simulation results for the synthesis/purification area are shown in Figure 2. We combined these results with spreadsheet estimates (based on the LTBLG performance calculated in our BLGCC study) of the impact on mill process steam production of integrating the upstream (syngas production) with downstream (synthesis/purification island).

Table 1. Composition of clean syngas in the BLGCC power/recovery system simulations.

\begin{tabular}{|l|c|c|}
\cline { 2 - 3 } \multicolumn{1}{c|}{} & LTBLG & HTBLG \\
\hline Composition (vol\%) & & \\
$\mathrm{Ar}$ & 0.00 & 0.66 \\
$\mathrm{CH}_{4}$ & 3.49 & 1.44 \\
$\mathrm{CO}$ & 23.74 & 26.09 \\
$\mathrm{CO}_{2}$ & 10.50 & 11.27 \\
$\mathrm{COS}_{\mathrm{H}}$ & 0.01 & 0.05 \\
$\mathrm{H}_{2} \mathrm{O}$ & 61.91 & 27.51 \\
$\mathrm{~N}_{2}$ & 0.34 & 32.73 \\
\hline
\end{tabular}

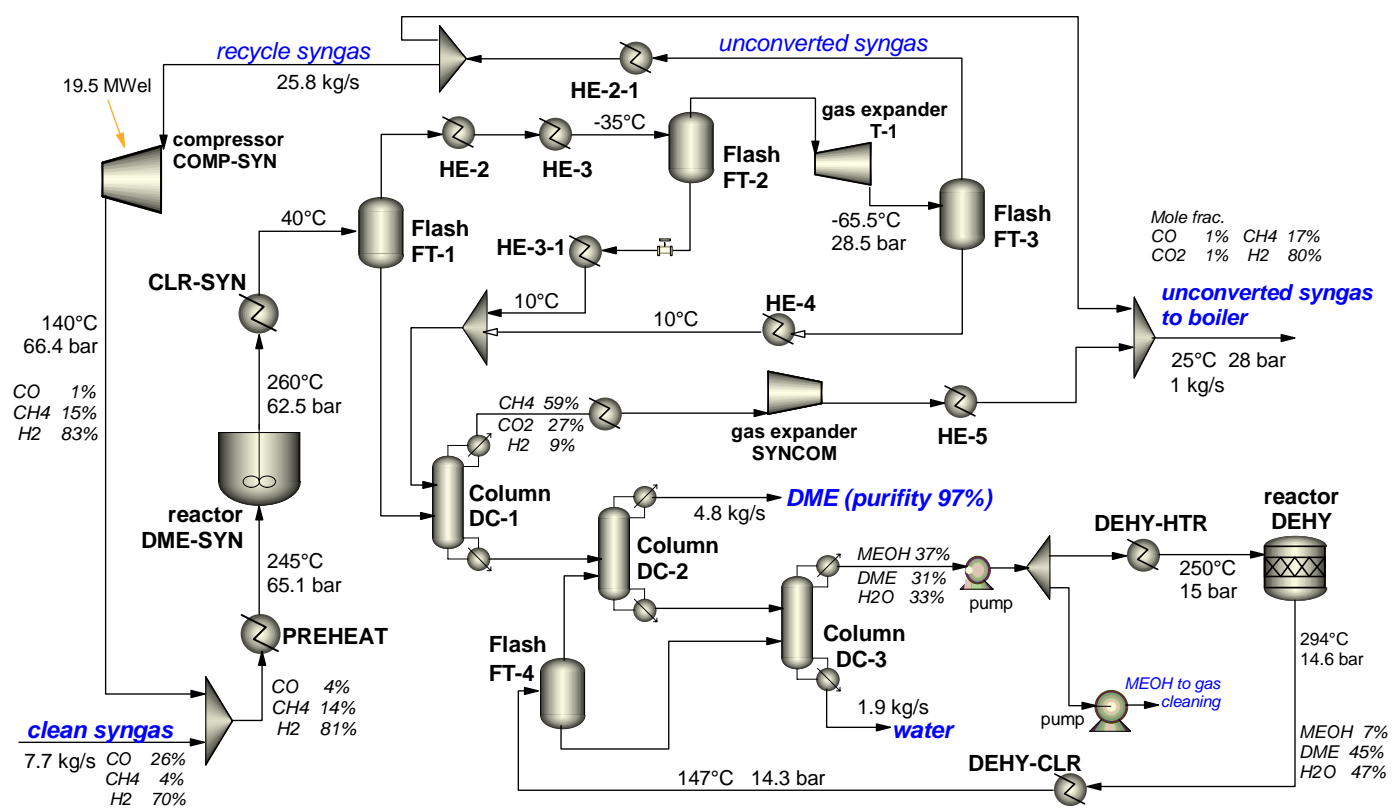

Figure 2. Aspen Plus simulation results for DME synthesis and purification based on syngas from low-temperature BLG (preliminary). 
The overall performance results for the LTBLG refinery are shown in Table 2, alongside our results (from Volume 1) for the HTBLG refinery. An important difference shown in the table is in the $\mathrm{H}_{2}$ : $\mathrm{CO}$ ratio of the syngas sent for synthesis. In the LTBLG case this ratio is much higher than in the HTBLG case due to the nature of the steam reforming reactions that occur in the LTBLG. The high $\mathrm{H}_{2}$ :CO ratio means that there is an excess of $\mathrm{H}_{2}$ for DME production (the stoichiometric $\mathrm{H}_{2}$ :CO ratio is 1.0 for DME: $3 \mathrm{CO}+3 \mathrm{H}_{2} \leftarrow \rightarrow \mathrm{C}_{2} \mathrm{H}_{6} \mathrm{O}+\mathrm{CO}_{2}$ ), such that a considerable amount of $\mathrm{H}_{2}$ cannot be converted to DME. This results in about $18 \%$ less DME being produced in the LTBLG case compared to the HTBLG case.

Table 2. Comparison of heat and mass balances for a DME biorefinery using a high-temperature BLG (HTBLG) and one using a low-temperature BLG (LTBLG).

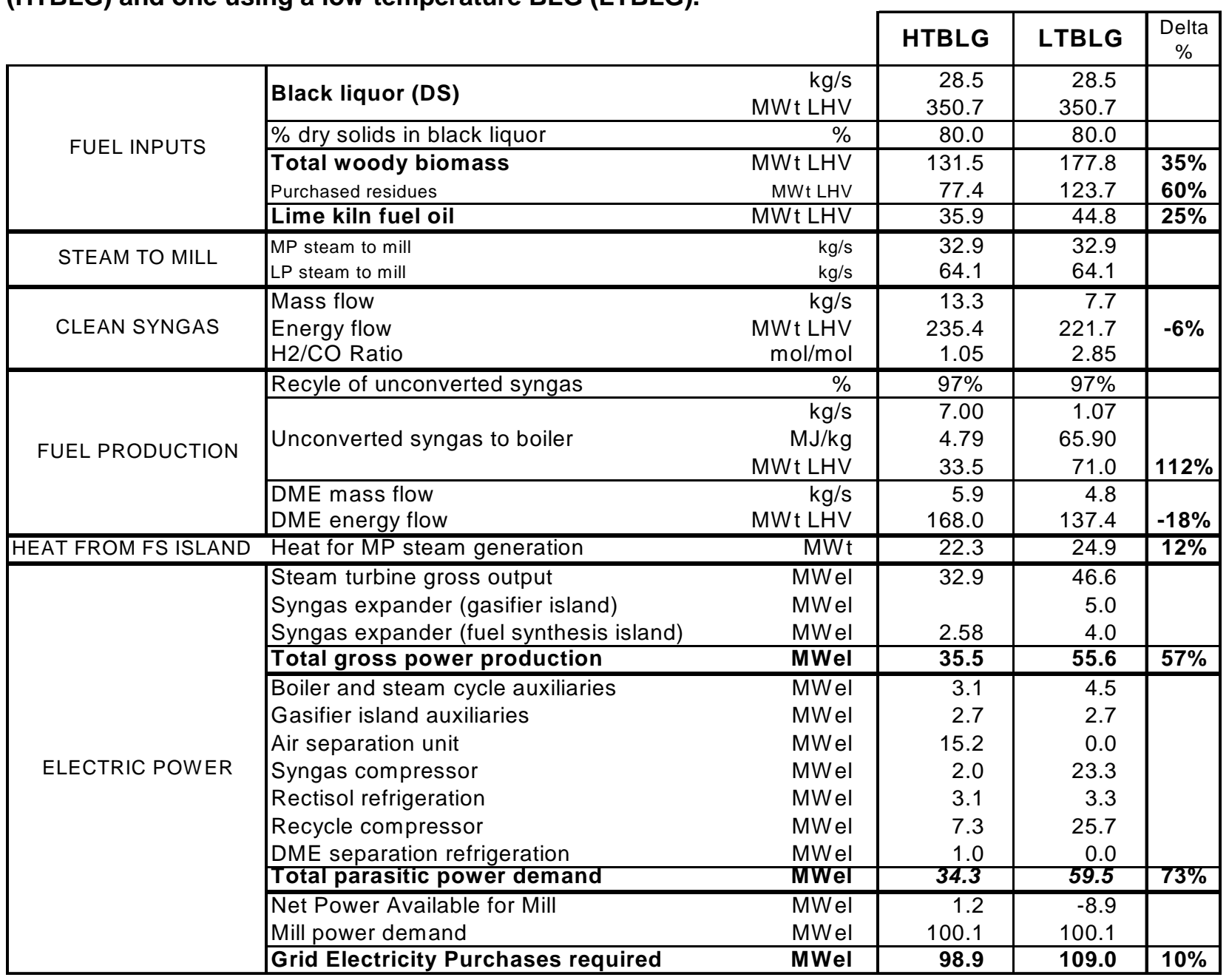

The excess of $\mathrm{H}_{2}$ also results in a much higher flow of unconverted syngas to the power boiler (more than double the HTBLG case), where process steam is generated from it. This might lead one to expect that the need for purchased residues (to meet process steam demands) might be lower. However, the LTBLG case actually requires more purchased woody residues as boiler fuel than the HTBLG case. This is due to the reduced heat recovery from the gasification island that is possible in the LTBLG case, as well as the steam requirements for the gasifier. The reduced heat recovery is due to a number of factors, including the lower temperature of the syngas leaving the gasifier (which enables less high- 
grade heat to be recovered from syngas cooling) and rejection of all heat in the syngas below $250^{\circ} \mathrm{C}$ (to avoid tar condensation problems).

The larger consumption of fuel (unconverted syngas and wood residues) in the power boiler results in $64 \%$ more back-pressure steam turbine power production in the LTBLG case than in the HTBLG case. However, the greater power production is almost entirely offset by the higher power demand in the LTBLG case for compressing the clean syngas to synthesis reactor pressure and for running the recycle compressor in the downstream area. There is little potential for pressurizing the operation of the LTBLG (which would reduce or eliminate the need for downstream syngas compression) because the unique pulse-combustor-tube bundle heat transfer system does not lend itself to doing so.

In summary, based on the preliminary calculations we have carried out, it appears that the LTBLG in a DME pulpmill biorefinery configuration would produce 15-20\% less DME than in a HTBLG biorefinery, with both requiring some purchases of electricity to meet parasitic electricity demands and thus not having any power available to help offset pulpmill electricity needs. Moreover, the LTBLG configuration would require the purchase of about double the wood residues that would need to be purchased with the HTBLG, and fuel oil purchases for the lime kiln would be some $25 \%$ higher. When these overall energy performance figures are taken into consideration, together with the likely higher capital investment required for a LTBLG biorefinery - a conclusion based on the comparison of LTBLG and HTBLG capital cost estimates developed for the BLGCC study - a pulpmill biorefinery based on LTBLG does not appear likely to show better financial performance for applications being targeted in the present work than one based on a HTBLG.

\section{Low-temperature BLG with alternative pulping chemistries}

The separation of sulfur and sodium during black liquor gasification enables the recovery of pulping

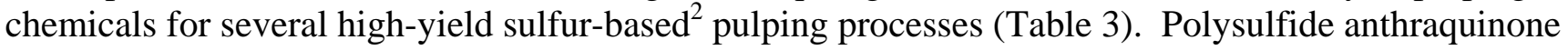
(PSAQ) pulping, which was the assumed pulping chemistry used in our biorefinery analysis reported in Volume 1, requires approximately $60 \%$ of sulfur to leave the gasifier in the gas phase. This chemistry gives a two to four percentage point increase in yield of pulp from the digester. Alkaline sulfite pulping processes can increase pulp yields substantially more than PSAQ pulping, but these chemistries require a higher degree of sulfur-sodium separation in the recovery area - levels of separation achievable only with the LTBLG technology. Specific pulping chemistries in this category include alkaline sulfite anthraquinone (ASAQ) and mini-sulfide sulfite anthraquinone (MSSAQ). Neither of these processes are commercially employed today primarily because there are no cost-effective means for recovering the pulping liquor with the Tomlinson recovery process.

\subsection{MSSAQ pulping}

We have chosen MSSAQ pulping for further analysis for several reasons: (i) MSSAQ pulping gives the highest pulp yield increases (up to 10 percentage points), (ii) MSSAQ pulping can completely eliminate the need for causticizing and the associated lime kiln, and (iii) the high degree of sulfursodium segregation required in the recovery process for MSSAQ makes it an especially good choice for integrating with a recovery system based on the LTBLG technology.

\footnotetext{
${ }^{2}$ We have chosen to limit the analysis here to sulfur-based processes because these processes can be implemented now, without major changes in the pulp mill.
} 
Among the pulping options shown in Table 3, MSSAQ offers the greatest yield enhancement potential, but the level of yield improvement that can be achieved with bleached grades of pulp/paper is modest. The benefit of MSSAQ is best exploited in the production of unbleached grades of pulp (characterized by high kappa numbers), e.g., for linerboard manufacture. This limits somewhat the market potential for application of MSSAQ pulping, but unbleached pulp grades account for about 38\% of total pulp production in the United States, so the potential market is not small.

Our detailed analysis here focuses on a reference mill utilizing MSSAQ pulping to make unbleached linerboard (LB). (This is a different product than the freesheet paper that we considered for our reference mill in the HTBLG analysis reported in Volume 1.) A typical yield increase with MSSAQ pulping for this LB application (with kappa numbers of 90 to 100) is ten percentage points. For our analysis, we assume a pulping yield of $67 \%$ for MSSAQ pulping and 57\% for conventional kraft cooking for unbleached linerboard. (For comparison, the digester yield at our reference freesheet mill [2] was $46.2 \%$.)

Table 3. Summary of some sulfur-based pulping options.

\begin{tabular}{|c|c|c|c|c|}
\hline & Kraft & PSAQ & MSSAQ & ASAQ \\
\hline Applicability & $\begin{array}{l}\text { Soft or hardwood; } \\
\text { unbleached or } \\
\text { bleached products }\end{array}$ & $\begin{array}{l}\text { Variant of kraft } \\
\text { pulping. Same } \\
\text { applicability. }\end{array}$ & $\begin{array}{l}\text { Limited to unbleached } \\
\text { grades (kappa \# } \geq 50 \text { ) }\end{array}$ & $\begin{array}{l}\text { Soft or hardwood; } \\
\text { unbleached or bleached } \\
\text { products }\end{array}$ \\
\hline $\begin{array}{l}\text { Pulping } \\
\text { chemicals }^{\mathrm{a}}\end{array}$ & $\mathrm{NaOH}+\mathrm{Na}_{2} \mathrm{~S}$ & $\mathrm{NaOH}+\mathrm{Na}_{2} \mathrm{~S}_{\mathrm{x}}+\mathrm{AQ}$ & $\mathrm{Na}_{2} \mathrm{SO}_{3}+\mathrm{Na}_{2} \mathrm{~S}+\mathrm{AQ}$ & $\mathrm{NaOH}+\mathrm{Na}_{2} \mathrm{SO}_{3}+\mathrm{AQ}$ \\
\hline Rate & $\begin{array}{l}\text { Fastest delignification } \\
\text { rate }\end{array}$ & $\begin{array}{l}\text { Similar to or slightly } \\
\text { slower than kraft (due } \\
\text { to lower sulfidity). }\end{array}$ & $\begin{array}{l}\text { Slower than kraft, but } \\
\text { faster than ASAQ. } \\
\text { Differences are small at } \\
\text { high kappa \#. }\end{array}$ & $\begin{array}{l}\text { Somewhat slower than } \\
\text { MSSAQ; needs longer } \\
\text { time and higher } \\
\text { temperature than kraft. }\end{array}$ \\
\hline Pulp yield & $\begin{array}{l}\text { Lowest yield: } \sim 56 \% \text { at } \\
\text { kappa } 100 \text { and } \sim 45 \% \\
\text { at kappa } 30 .\end{array}$ & $\begin{array}{l}2 \text { to } 4 \text { percentage } \\
\text { points higher than } \\
\text { kraft. }\end{array}$ & $\begin{array}{l}8 \text { to } 10 \text { percentage } \\
\text { points higher than kraft } \\
\text { at high kappa \#. Lower } \\
\text { gain at lower kappa \#. }\end{array}$ & $\begin{array}{l}3 \text { to } 7 \text { percentage points } \\
\text { higher than kraft, } \\
\text { depending on kappa \#. }\end{array}$ \\
\hline Brightness & Low brightness & Same as kraft. & $\begin{array}{l}10 \text { to } 20 \text { points higher } \\
\text { than kraft. }\end{array}$ & $\begin{array}{l}10 \text { to } 20 \text { points higher } \\
\text { than kraft. }\end{array}$ \\
\hline Strength & Highest tear strength & $\begin{array}{l}\text { Somewhat lower tear } \\
\text { than kraft, other } \\
\text { properties similar. }\end{array}$ & $\begin{array}{l}\text { Refining }{ }^{\mathrm{b}} 25-30 \% \text { less } \\
\text { than kraft; } \\
\text { similar/slightly higher } \\
\text { strength than kraft, } \\
\text { except lower tear. }\end{array}$ & $\begin{array}{l}\text { Less refining }{ }^{\mathrm{b}} \text { than kraft; } \\
\text { Similar/slightly higher } \\
\text { strength than kraft, } \\
\text { except lower tear. }\end{array}$ \\
\hline $\begin{array}{l}\text { Sulfur needs } \\
\text { for pulping }\end{array}$ & $\begin{array}{l}100 \% \text { of } \mathrm{S} \text { needed as } \\
\mathrm{Na}_{2} \mathrm{~S} .\end{array}$ & $\begin{array}{l}60 \% \text { of } \mathrm{S} \text { needed as } \\
\text { elemental sulfur to } \\
\text { mix with } 40 \% \text { of } \mathrm{S} \text { in } \\
\mathrm{Na}_{2} \mathrm{~S} \text { to form PS. }\end{array}$ & $\begin{array}{l}10-15 \% \text { of } \mathrm{S} \text { needed as } \\
\mathrm{Na}_{2} \mathrm{~S} \text { and } 85-90 \% \text { as } \\
\mathrm{Na}_{2} \mathrm{SO}_{3} . \mathrm{Na}_{2} \mathrm{SO}_{3} \text { can be } \\
\text { made from } \mathrm{H}_{2} \mathrm{~S} \text {. }\end{array}$ & $\begin{array}{l}100 \% \text { of } \mathrm{S} \text { needed as } \\
\mathrm{Na}_{2} \mathrm{SO}_{3} \text {, which can be } \\
\text { made from } \mathrm{H}_{2} \mathrm{~S} \text {. }\end{array}$ \\
\hline $\begin{array}{l}\text { Best } \\
\text { recovery } \\
\text { system }\end{array}$ & Tomlinson & HTBLG & LTBLG & LTBGL \\
\hline $\begin{array}{l}\text { Causticizing } \\
\text { demand with } \\
\text { BLG }\end{array}$ & $\begin{array}{l}\text { Small } \uparrow \text { with HTBLG } \\
\text { Large } \uparrow \text { with LTBLG }\end{array}$ & Small increase & Causticizing eliminated & Increase \\
\hline
\end{tabular}

(a) $\mathrm{AQ}=$ anthraquinone.

(b) Refining is a physico-mechanical process to increase the surface area available for inter-fiber bonding by defibrillation of fibers. It increases the strength properties of the fibers. Less refining means less electrical energy required.

(c) $\mathrm{H}_{2} \mathrm{~S} \rightarrow \mathrm{SO}_{2} \rightarrow \mathrm{Na}_{2} \mathrm{SO}_{3}$

The assumptions for MSSAQ pulping conditions are compared against kraft pulping conditions in Table 4 and the estimated black liquor elemental composition that would result with the MSSAQ option is given in Table 5. Because of the high pulping yield and the high alkali charge the MSSAQ black liquor has a high inorganic content and a relatively low heating value compared to black liquor 
produced at a kraft pulp mill. The heating value per unit mass is only about $75 \%$ of that for a conventional kraft mill. Moreover, as a consequence of the much higher pulp yield, the total energy content of the black liquor available at the recovery area of the mill is reduced by about one-third compared to the black liquor available at an unbleached LB mill using kraft pulping.

Table 4. Pulping conditions for MSSAQ and reference kraft cook for linerboard quality pulping with kappa numbers of 90-100. Data based on [5] and [6].

\begin{tabular}{|c|c|c|}
\hline Pulping & Kraft & MSSAQ \\
\hline Pulp yield & $57 \%$ & $67 \%$ \\
\hline \multicolumn{3}{|c|}{ Liquor inorganic composition ( $\mathrm{Na}_{2} \mathrm{O}$ equivalent basis) } \\
\hline $\mathrm{Na}_{2} \mathrm{SO}_{3}$ & - & $83 \%$ \\
\hline $\mathrm{Na}_{2} \mathrm{~S}$ & $21 \%$ & $7 \%$ \\
\hline $\mathrm{Na}_{2} \mathrm{CO}_{3}$ & $15 \%$ & $10 \%$ \\
\hline $\mathrm{NaOH}$ & $61 \%$ & - \\
\hline $\begin{array}{l}\text { Total alkali charge, } \\
\mathrm{kg} \mathrm{Na} \mathrm{O}_{2} \mathrm{O} / \mathrm{kg} \text { oven-dry wood }\end{array}$ & 0.176 & 0.22 \\
\hline Anthraquinone charge & - & $0.1 \%$ of oven-dry wood mass \\
\hline Liquor-to-wood ratio & 4 & 4 \\
\hline Max. temperature & $160^{\circ} \mathrm{C}$ & $160^{\circ} \mathrm{C}$ \\
\hline $\mathrm{H}_{\text {factor }}{ }^{\mathrm{a}}$ & 700 & 700 \\
\hline
\end{tabular}

(a) The $\mathrm{H}$ factor is the integral of the temperature-dependent delignification rate over the digestion period. A high $\mathrm{H}$ factor means a high temperature and/or long time indicating a high steam demand.

Table 5. Liquor elemental composition and higher heating value (HHV) for MSSAQ and for reference kraft cook for linerboard quality pulping with kappa numbers of 90-100.

\begin{tabular}{|l|c|c|}
\hline \multirow{2}{*}{} & \multicolumn{2}{|c|}{ Weight Percent } \\
\cline { 2 - 3 } & Kraft & MSSAQ \\
\hline $\mathrm{C}$ & $37.0 \%$ & $27.5 \%$ \\
\hline $\mathrm{H}$ & $4.2 \%$ & $2.8 \%$ \\
\hline $\mathrm{O}$ & $33.3 \%$ & $33.4 \%$ \\
\hline $\mathrm{Na}$ & $20.3 \%$ & $21.0 \%$ \\
\hline $\mathrm{S}$ & $3.1 \%$ & $13.2 \%$ \\
\hline $\mathrm{K}$ & $1.9 \%$ & $2.0 \%$ \\
\hline $\mathrm{Cl}$ & $0.2 \%$ & $0.2 \%$ \\
\hline $\mathrm{HHV}, \mathrm{kJ} / \mathrm{kg} \mathrm{BLS}$ & 14,700 & 10,600 \\
\hline
\end{tabular}

The conversion of an unbleached kraft linerboard mill to MSSAQ pulping may create significant operating cost savings for the mill. Increasing the pulp yield from $57 \%$ to $67 \%$ decreases wood consumption by $15 \%$ for the same level of pulp production. Another large source of savings is the complete elimination of the lime cycle and the associated savings in fuel cost. The anthraquinone would represent an important added operating cost. For pulp production of 1,580 short tons of oven dry pulp/day (the same level of unbleached pulp produced in our reference mill described in Volume 1) the estimated cost of these items is shown in Table 6 for an unbleached LB mill using either kraft or MSSAQ pulping. The capital investment and other operating cost changes that might be needed to achieve the indicated net savings of about $\$ 11$ million per year are discussed in Section 3.3.

\subsection{Integrating MSSAQ pulping with low-temperature BLG}

A simplified process diagram for LTBLG-based liquor recovery at a mill using the MSSAQ pulping process is shown in Figure 3. The black liquor is reformed in steam in a LBLG, after which the gas is cooled and cleaned of contaminants. Most of the sulfur in the black liquor (>90\%) appears as $\mathrm{H}_{2} \mathrm{~S}$ in the clean syngas. The $\mathrm{H}_{2} \mathrm{~S}$ is recovered using a conventional acid gas removal technology (e.g., 
Rectisol or Selexol). This $\mathrm{H}_{2} \mathrm{~S}$ is then oxidized to $\mathrm{SO}_{2}$, which in turn is absorbed into a sodium-rich green liquor stream (constituted by dissolving in water the condensed phase from the gasifier). This produces a white liquor stream to which anthraquinone is added before the liquor is recirculated to the digester.

Table 6. Estimate for major operating cost changes (\$ per year) after converting a mill making 1,580 oven-dry short tons of unbleached linerboard pulp per day from Kraft to MSSAQ pulping.

\begin{tabular}{|l|r|rr|rr|}
\hline & Kraft & MSSAQ & \multicolumn{2}{|c|}{ Cost savings } \\
\hline Pulpwood purchases & $\$ 60,616,267$ & $\$ 51,569,063$ & & 9,047,204 \\
\hline Anthraquinone & $\$$ & $\$ 2,813,000$ & $\$$ & $(2,813,000)$ \\
\hline Lime kiln fuel (\#6 oil) & $\$ 4,697,185$ & $\$$ & - & $\$$ & $4,697,185$ \\
\hline Net change & & & $\$ 10,931,389$ \\
\hline
\end{tabular}

Assumptions: pulpwood @ \$57.33 per dry short ton; AQ @ \$3.65/kg; lime kiln fuel @ \$5/MMBtu; 8,330 equivalent full-load operating hours/year.

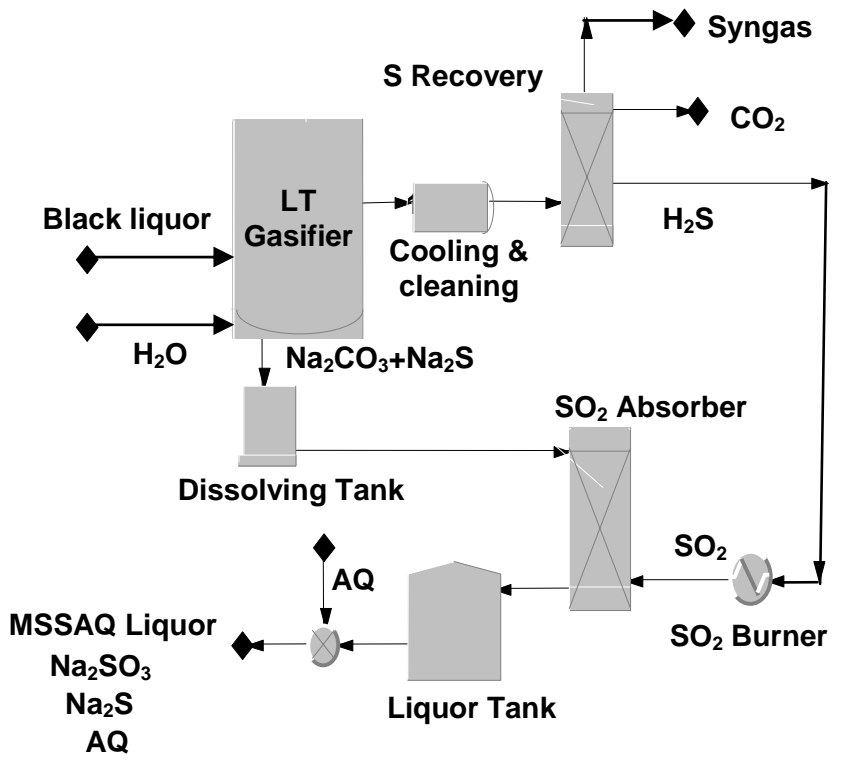

Figure 3. Schematic diagram of liquor recovery for MSSAQ pulping.

To gain some understanding of how this type of system might perform, we have carried out calculations to estimate on a preliminary basis the energy and mass balances for a LTBLG with input of MSSAQ black liquor generated at a kraft linerboard mill producing 1,580 short dry tons per day of unbleached pulp from the digester. We have limited our detailed modeling to the gasification island, without simulating the whole integrated system comprising a gas clean-up island and further downstream syngas processing (e.g., power and/or liquid fuel production) at the same level of detail. Because the LTBLG is the most complicated element of the system from an energy balance perspective, it is the most critical area to model in detail for an assessment aimed at giving a preliminary indication of the potential of LTBLG in MSSAQ mill applications.

Our calculations use the black liquor properties for MSSAQ (Table 5) as inputs to the LTBLG model we developed in our BLGCC study [2]. We have made the same assumptions regarding carbon 
conversion, tars and $\mathrm{Na}_{2} \mathrm{~S}$ as in our BLGCC study (Table 7). Our assumption of carbon conversion is high relative to what actually has been demonstrated to date. In particular, we assume $97 \%$ of the carbon input as black liquor is converted to light gases and 1.5\% is converted to tars, for a total carbon conversion of $98.5 \%$. (The remaining 1.5\% carbon input leaves with the bed solids.) This level of overall carbon conversion using the low-temperature gasification technology has not yet been demonstrated at commercially-relevant scales. DeCarrera $[7,8]$ reports that measured carbon conversion to light gases plus tars at the pilot-scale low-temperature gasifier installed at a pulp mill in Big Island, Virginia, ranged from $60 \%$ to $80 \%$, with the conversion to tars estimated to account for one-third to one-half of the converted carbon based on carbon balance closure. Measurements reported by researchers from the Institute of Paper Science and Technology for the Big Island gasifier [9] showed the following carbon distribution of carbon input with the black liquor: $65 \%$ to light gases, $23 \%$ to bed solids, $4.5 \%$ in heavy tars, and 6\% missing. Analysis suggests that the missing fraction was light tars. Thus, these measurements appear to be generally consistent with those reported by DeCarrera.

Using our modeling assumptions, Table 8 reports the calculated raw syngas composition at the gasifier exit.

Table 7. Assumptions adopted to evaluate the syngas composition and the heat/mass balances of the low temperature black liquor gasifier operating with black liquor from MSSAQ pulping.

\begin{tabular}{|ll|}
\hline Pressure & $2.7 \mathrm{bar}(25 \mathrm{psig})$ \\
\hline Temperature & $600^{\circ} \mathrm{C}\left(1112^{\circ} \mathrm{F}\right)$ \\
\hline Gasification steam & $0.25 \mathrm{~kg} / \mathrm{kg} \mathrm{BLS}$ \\
\hline Heat loss to environment & $1 \%$ of $\mathrm{BL} \mathrm{HHV}$ \\
\hline Carbon conversion & $98.5 \%$ of total $\mathrm{C}$ in $\mathrm{BL}$ \\
\hline Tar production & $1.5 \%$ of total $\mathrm{C}$ in $\mathrm{BL}$ \\
\hline $\mathrm{Na}_{2} \mathrm{~S}$ production & $7.8 \%$ of total $\mathrm{S}$ in $\mathrm{BL}$ \\
\hline $\begin{array}{l}\text { All other products (gas and condensed phases) assumed to be a } \\
\text { mixture at equilibrium. }\end{array}$ \\
\hline
\end{tabular}

Table 8: Calculated molar composition of syngas at the gasifier exit.

\begin{tabular}{|c|c|c|c|c|c|c|}
\hline $\mathbf{H}_{\mathbf{2}}$ & $\mathbf{C H}_{\mathbf{4}}$ & $\mathbf{H}_{\mathbf{2}} \mathbf{O}$ & $\mathbf{C O}$ & $\mathbf{C O}_{\mathbf{2}}$ & $\mathbf{H}_{\mathbf{2}} \mathbf{S}$ & $\mathbf{C O S}$ \\
\hline $30.5 \%$ & $9.3 \%$ & $26.7 \%$ & $8.1 \%$ & $18.2 \%$ & $7.0 \%$ & $0.1 \%$ \\
\hline
\end{tabular}

As part of the gasifier island calculations, we also estimate the mass and energy balances for cooling of the raw syngas (from $600^{\circ} \mathrm{C}$ to $250^{\circ} \mathrm{C}$ ) in a steam boiler, followed by scrubbing and cooling to $40^{\circ} \mathrm{C}$ to remove remaining alkali, tar and most of the water vapor. The cooled, dry syngas is then ready to be fed to the sulfur recovery unit (SRU), which would remove essentially all the $\mathrm{H}_{2} \mathrm{~S}$ in the syngas and some portion of the $\mathrm{CO}_{2}$. The technology used in the SRU would be selected to achieve concentrations of $\mathrm{H}_{2} \mathrm{~S}$ and $\mathrm{CO}_{2}$ required by the downstream processing equipment. Commercially-established SRU options include Rectisol ${ }^{\circledR}$ and Selexol ${ }^{\circledR}$ systems (which were used in the simulation work reported in Volume 1).

Figure 4 shows the results of our mass/energy balance simulation. The available black liquor from the MSSAQ pulping represents a gasifier energy feed rate of $204 \mathrm{MW}_{\mathrm{HHV}}$. This energy input to the 
gasifier, together with heat supplied via the pulse-combustor, and heat carried in the fluidization steam, produce the following energy outputs:

- Chemical and thermal energy in the syngas leaving the gasifier at $600^{\circ} \mathrm{C}$. Part of the thermal energy $\left(13 \mathrm{MW}_{\mathrm{t}}\right)$ is recovered as steam in the boiler that cools the syngas to $250^{\circ} \mathrm{C}$, but the majority of it is lost in the scrubber used to remove tar and to cool the gas to a temperature suitable for feeding to the compressor needed to pressurize the syngas for the SRU.

- Thermal energy in the solids discharged by the gasifier. We assume that $5 \mathrm{MW}_{\mathrm{t}}$ of this energy would be recoverable by cooling the green liquor to $250^{\circ} \mathrm{C}$.

- Chemical energy in the removed tar, in the $\mathrm{H}_{2} \mathrm{~S}$, and in the sulfides in the condensed phase leaving the gasifier.

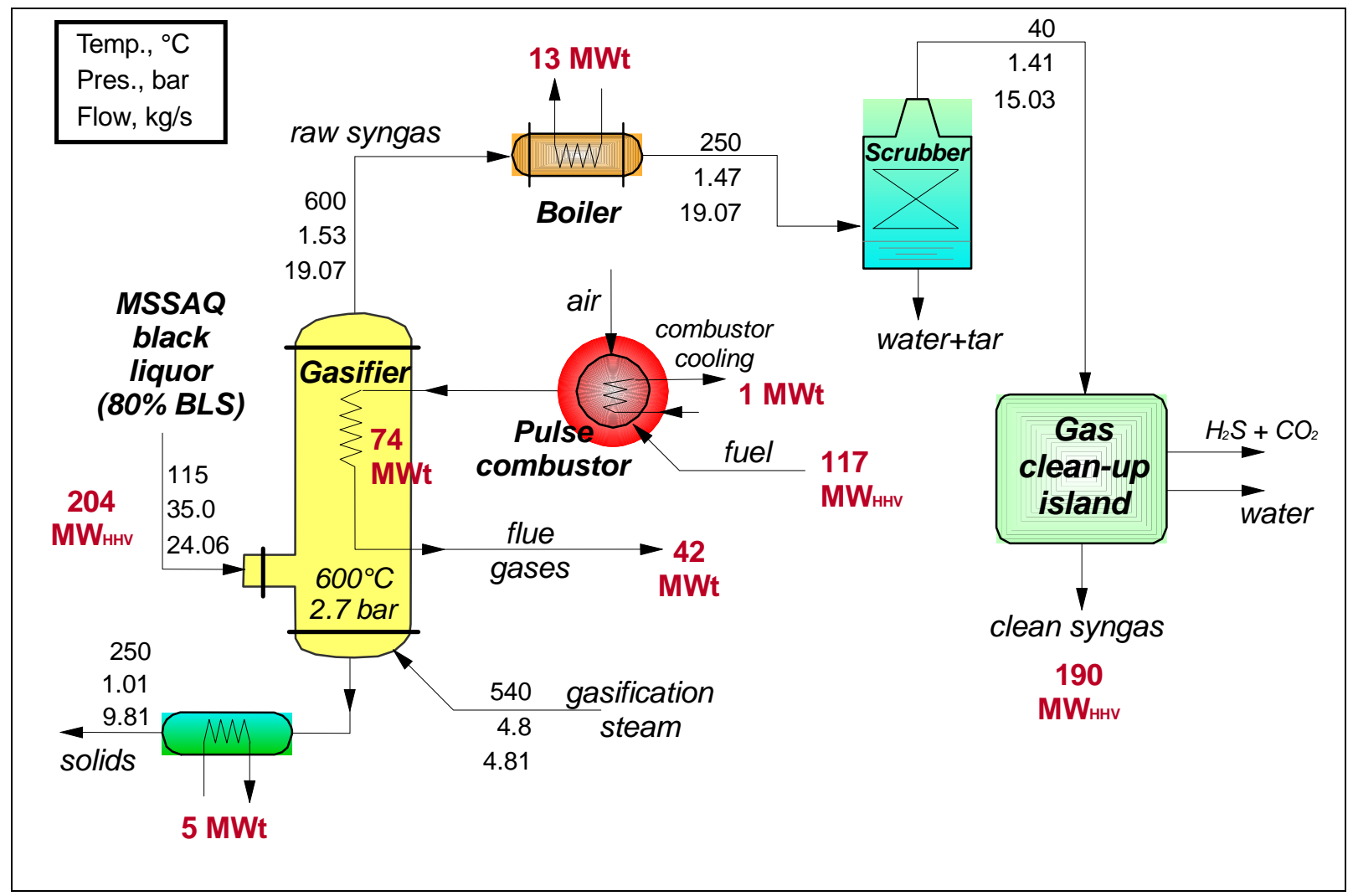

Figure 4. Heat and mass balance of the low temperature gasifier serving a plant producing 1580 short tons/day of pulp by the MSSAQ pulping.

The chemical energy remaining in the clean, cooled syngas is $190 \mathrm{MW}_{\mathrm{HHV}}$. A significant amount of this (117 $\mathrm{MW}_{\mathrm{HHV}}$ ) is needed for the pulse combustor, leaving $73 \mathrm{MW}_{\mathrm{HHV}}$ available for further downstream processing, e.g. into electricity or liquid fuels. The ratio between the energy that must be supplied by the pulse combustors and the heating value of the input black liquor is much higher than with a conventional kraft black liquor because of the different properties of the MSSAQ black liquor, namely higher inert content and reduced heating value. Only about $35 \%$ of the heating value of the 
black liquor is transferred to heating value in the final syngas, corresponding to a cold-gas efficiency of $35 \% .^{3}$

One of the most striking numbers in Figure 4 is the amount of chemical energy contained in the MSSAQ black liquor: $204 \mathrm{MW}_{\mathrm{HHV}}$. For comparison, our estimate of the chemical energy in the black liquor at an unbleached kraft linerboard mill is $261 \mathrm{MW}_{\mathrm{HHV}}{ }^{4}$ The low rate of black liquor energy input contributes significantly to a low net syngas production rate: $73 \mathrm{MW}_{\mathrm{HHV}}$, which can be compared with an estimated $194 \mathrm{MW}_{\mathrm{HHV}}$ of clean syngas that could be produced at an unbleached kraft linerboard mill using a high-temperature BLG recovery system. ${ }^{5}$

\subsection{Some preliminary economics of MSSAQ pulping with LTBLG}

The relatively modest amount of net clean syngas per unit of pulp that can be produced with the LTBLG/MSSAQ system makes the attractiveness of further processing the syngas (into liquid fuel and/or electricity) uncertain (due to scale economies of synthesis and refining). The following highlevel economic analysis attempts to resolve some of this uncertainty.

Consider the conversion of an existing unbleached linerboard mill from conventional kraft pulping with Tomlinson power/recovery system to MSSAQ pulping with LTBLG power/recovery. We assume the rate of production of unbleached pulp is 1,580 short dry tons/day, the same rate as for the reference kraft uncoated freesheet pulp/paper mill we used as the basis for our analysis in Volume 1. For preliminary calculations, we will assume that the linerboard mill, both before and after conversion to MSSAQ, has the same process steam and electricity demands as the freesheet mill, namely:

- process steam demand of $212 \mathrm{MW}, 2 / 3$ of which is low-pressure (5 bar) and $1 / 3$ of which is medium-pressure (13 bar) steam. (In reality, a linerboard mill with best available technology will have about 19\% lower total process steam demand than a freesheet mill with best available technology [10]. However, the steam demand for a linerboard mill using MSSAQ pulping will be approximately the same as one with the same output using kraft pulping. ${ }^{6}$ )

- process electricity demand of $100 \mathrm{MW}$. (In reality, a linerboard mill with best available technology will have about 8\% lower electricity demand than a corresponding freesheet mill [10].)

With these assumptions and the energy balance depicted in Figure 4, we can estimate the amount of electricity that can be generated by the LTBLG system and the amount of purchased residues needed (to augment available hog fuel) to produce the requisite amount of process steam. Table 9 shows our

\footnotetext{
${ }^{3}$ This can be compared with the high-temperature BLG application with conventional kraft black liquor. In that case about $2 / 3$ of the black liquor heating value ends up in the clean syngas, or a cold gas efficiency of about $67 \%$.

${ }^{4}$ The following are our estimates of black liquor flow rates at different types of pulp/paper mills:

Bleached kraft freesheet mill (from Table 5 in [2]): 6 million lbs/day BLS and $13.9 \mathrm{MJ} / \mathrm{kg}_{\mathrm{BLS}}=>438 \mathrm{MW}_{\mathrm{HHV}}$ Unbleached kraft linerboard mill (our estimate): 3.39 million lbs/day BLS and $14.7 \mathrm{MJ} / \mathrm{kg}_{\mathrm{BLS}}=>261 \mathrm{MW}_{\mathrm{HHV}}$ Unbleached MSSAQ linerboard mill (our estimate): 3.66 million lbs/day BLS and $10.6 \mathrm{MJ} / \mathrm{kg}_{\mathrm{BLS}}=>204 \mathrm{MW} \mathrm{HHV}_{\mathrm{HV}}$

${ }^{5}$ Estimated from BLGCC analysis [2] as follows. In that analysis, the high-temperature BLG system produced $291 \mathrm{MW}_{\mathrm{HHV}}$ of clean syngas at a bleached freesheet pulp/paper mill having the same rate of unbleached pulp production from the digester as in this LTBLG analysis (1,580 bone dry short tons per day) - see Table A6 in [2]. The black liquor flow in that case was $391 \mathrm{MW}_{\mathrm{HHV}}$ (with PSAQ pulping). Thus, we estimate that syngas flow at the kraft linerboard mill is $291 *(261 / 391)=194 \mathrm{MW}_{\mathrm{HHV}}$.

${ }^{6}$ This estimate is based on 15\% lower steam demand for the MSSAQ mill in the wood handling and digester areas (due to lower wood input) and 8\% higher steam demand in the evaporator area (due to a higher black liquor inorganic solids flow with MSSAQ compared to kraft pulping) [10].
} 
estimate of steam that can be produced from three sources: combustion of the clean syngas in a boiler, recovery of heat by syngas cooling and by cooling of the pulse combustor flue gases, and by combustion of hog fuel in a boiler. The amount of hog fuel is assumed to be $9 \%$ of the dry mass of pulpwood received at the mill (as in our analysis in Volume 1). The high digester yield with MSSAQ pulping reduces the amount of pulpwood needed to achieve the same pulp production rate as with conventional kraft pulping, leading to less hog fuel availability as well. The steam production amounts to $136 \mathrm{MW}_{\mathrm{th}}$, or $2 / 3$ of the process steam needs of the mill (Table 9 ).

Table 9. Estimated steam production from clean syngas, hog fuel, and LTBLG heat sources.

\begin{tabular}{|c|c|c|}
\hline LTBLG steam production & Available $\mathrm{MW}_{\mathrm{HHV}}$ & Approximate Steam MW \\
\hline Syngas (converted to steam @ 90\% HHV efficiency) & 73 & 65.7 \\
\hline Pulse combustor flue gas ( $84 \%$ heat exchanger efficiency) & 42 & 35.4 \\
\hline Hog fuel (converted to steam @ 90\% HHV efficiency) & 24.5 & 22.0 \\
\hline Syngas cooling & 13 & 13 \\
\hline Total steam before use of purchased residues & & 136.2 \\
\hline
\end{tabular}

Since $212 \mathrm{MW}_{\text {th }}$ of process steam are needed, the additional steam is generated by burning purchased residues in a boiler. To estimate the amount of purchased residues needed, we first estimate the amount of electricity that will be generated when $212 \mathrm{MW}_{\text {th }}$ of process steam are produced. This then enables an estimate of the amount of required purchased residues. Table 10 details our calculation of electricity generation. We assume that steam is generated at $78.5 \mathrm{bar}, 475^{\circ} \mathrm{C}$ and expanded through the existing back-pressure steam turbine at the mill. Two-thirds of the steam is expanded to 5 bar and onethird of the steam is expanded to 13 bar. The gross electricity generation is $48 \mathrm{MW}$. The net electricity production (after accounting for an estimated $5 \mathrm{MW}$ of parasitic electricity demand by the LTBLG system) is $43 \mathrm{MW}_{\mathrm{e}}$.

Table 10. Estimate of electricity generation with LTBLG system using existing back-pressure steam turbine.

\begin{tabular}{|l|r|}
\hline Total process steam required, MW & 212 \\
Delta-h of LP steam, MJ/kg & 2.115 \\
Approximate total process steam flow (assuming all LP), $\mathrm{kg} / \mathrm{s}$ & 100.2 \\
Enthalpy of steam for expansion (from78.5 bar, $475 \mathrm{C}$ ), MJ/kg & 3.339 \\
Enthalpy of LP steam (5 bar), assuming isentropic expansion, MJ/kg & 2.678 \\
Enthalpy of MP steam (13 bar), assuming isentropic expansion, MJ/kg & 2.864 \\
Delta-h for LP steam (isentropic), MJ/kg & 0.661 \\
Delta-h for MP steam (isentropic), MJ/kg & 0.475 \\
Fraction of total steam that is LP & 0.667 \\
Fraction of total steam that is MP & 0.333 \\
Average delta-h for steam expansion in steam turbine, MJ/kg & 0.599 \\
Assumed steam turbine efficiency & $80 \%$ \\
\hline Gross electricity generated, MW & $\mathbf{4 8 . 0}$ \\
LTBLG parasitic electricity load, MW & 5.0 \\
\hline Net electricity available for process use at the linerboard mill, MW & $\mathbf{4 3 . 0}$ \\
\hline
\end{tabular}

A simple energy balance around the steam turbine (Figure 5) enables an estimate of $124 \mathrm{MW}_{\text {th }}$ of steam required to be generated using purchased residues. Assuming a biomass boiler efficiency of $90 \%$, this corresponds to $138 \mathrm{MW}_{\mathrm{HHV}}$ of purchased biomass residues. 


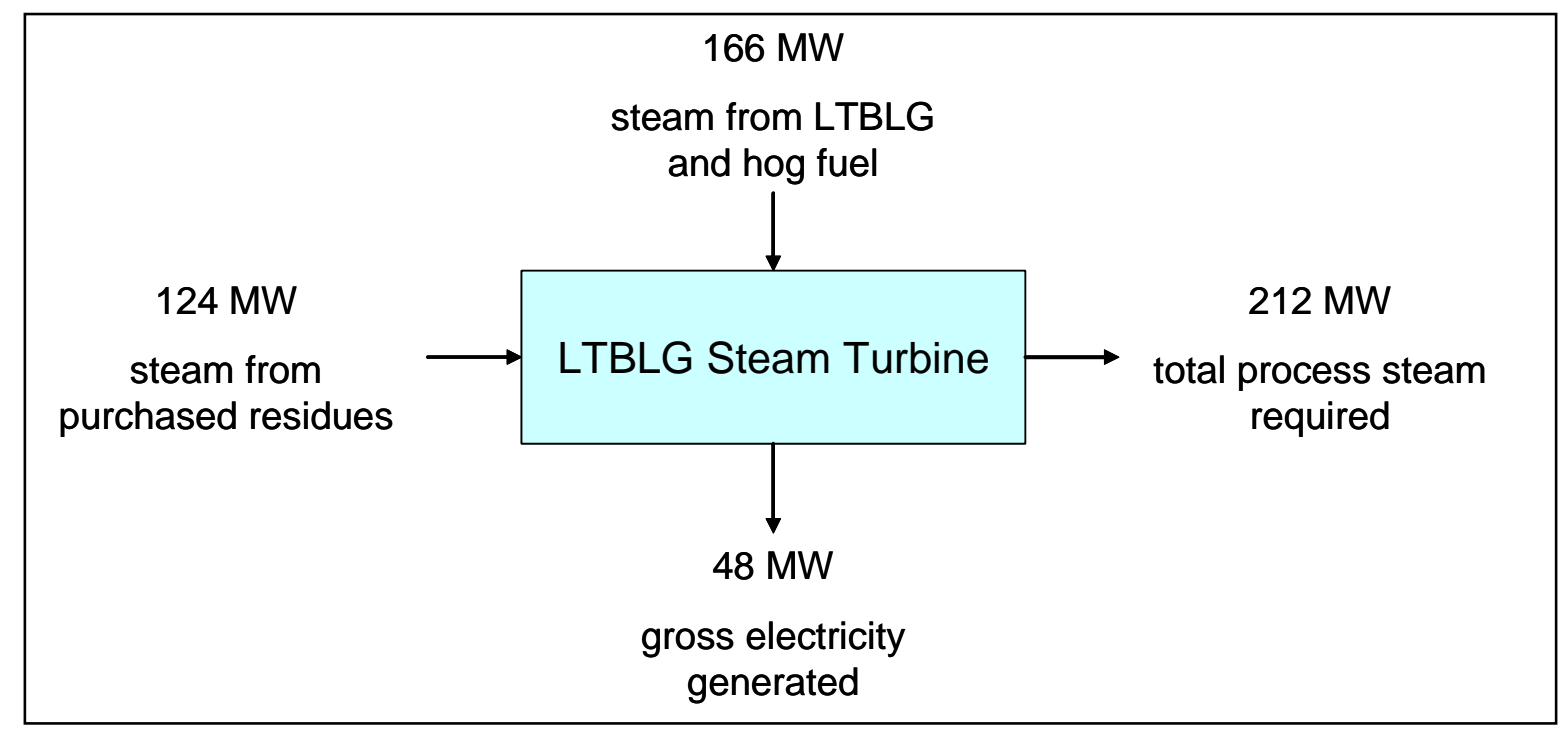

Figure 5. Approximate energy balance for LTBLG steam turbine island.

From the above approximate energy balance, we are able to estimate the main annual operating costs for the MSSAQ/LTBLG process relative to a Kraft/Tomlinson alternative (Table 11, which is an expanded version of Table 6). Our estimate of the electricity generation with a new Tomlinson system at an unbleached kraft linerboard, 38.4 $\mathrm{MW}_{\mathrm{e}}$, is calculated by linearly scaling (with black liquor energy flow rate ${ }^{7}$ ) our estimate in Volume 1 of the electricity generation for a Tomlinson system at a bleached kraft freesheet mill $\left(64 \mathrm{MW}_{\mathrm{e}}\right)$.

Table 11 shows an estimated net annual savings of about \$6.6 million after converting the unbleached linerboard mill from kraft/Tomlinson to MSSAQ/LTBLG. This includes consideration of the operating and maintenance (O\&M) costs for the LTBLG and Tomlinson systems. These annual O\&M costs are estimated as $4 \%$ of the overnight installed capital cost of the recovery system in each case. Our net annual savings are lower than those estimated by Naithani, et al. [6] for a kraft-to-MSSAQ conversion.

Table 11. Estimate of major operating costs (\$ per year) when converting a mill making 1,580 oven-dry short tons of pulp per day from Kraft/Tomlinson to MSSAQ/LTBLG.

\begin{tabular}{|c|c|c|c|}
\hline & Kraft & MSSAQ & Cost savings w/MSSAQ \\
\hline Pulpwood purchases & $\$ 60,616,267$ & $\$ 51,569,063$ & $9,047,204$ \\
\hline Anthraquinone & $\$$ & $\$ 2,813,000$ & $(2,813,000)$ \\
\hline Lime kiln fuel (\#6 oil) & $\$ \quad 4,697,185$ & $\$$ & $4,697,185$ \\
\hline Electricity purchases & $\$ 27,411,425$ & $\$ 25,351,254$ & $2,060,171$ \\
\hline Purchased residues & - & $\$ 3,911,855$ & $(3,911,855)$ \\
\hline Recovery area O\&M & $\$ 3,796,129$ & $\$ 6,260,606$ & $(2,464,477)$ \\
\hline Total savings / year & & & $6,615,229$ \\
\hline
\end{tabular}

Assumptions: pulpwood @ \$57.33 per dry short ton; AQ @ \$3.65/kg; lime kiln fuel @ \$5/MMBtu; electricity purchases@ 5 c/kWh; purchased residues @ \$1.53/MMBtu; 8,330 equivalent full-load operating hours per year. See text for discussion of recovery area O\&M costs.

${ }^{7}$ Black liquor energy flow rates are $438 \mathrm{MW}_{\mathrm{HHV}}$ for the kraft freesheet mill [2] and an estimated $261 \mathrm{MW}_{\mathrm{HHV}}$ for the kraft linerboard mill, with the same unbleached pulp production rate in both cases. 
Naithani, et al [6] estimated net operating cost savings of 30\% (from 142 to 110 \$/oven dry ton pulp). For a mill producing 1580 oven dry short tons per day, this translates to a savings of \$17 million, which is substantially higher than our estimated \$6.6 million. The difference between our estimate and that of Naithani, et al. is probably explained by the following factors:

- Naithani, et al. assumes a 20 percentage point yield increase when converting from kraft to MSSAQ pulping (from 50\% to 70\%), compared to our more conservative 10 percentage points.

- Naithani, et al. assumes a cost for anthraquinone that is approximately half of what we assume.

- Naithani, et al. assumes a value for avoided lime kiln fuel use that is approximately double what we assume.

- Naithani, et al. does not include recovery area O\&M costs in their study.

Table 12 details our estimate of the \$156 million installed capital cost estimate for the LTBLG system. The estimate is based on the capital cost for the LTBLG system in a BLGCC configuration [2] serving a mill with the same pulp production rate as assumed here (1,580 short dry tons/day). The original cost estimate for the LT-BLGCC system includes $\mathrm{H}_{2} \mathrm{~S}$ recovery equipment similar to that which would be needed for sulfur capture and conversion to $\mathrm{SO}_{2}$ with the LTBLG/MSSAQ system. We have adjusted the original LT-BLGCC cost estimate to account for the following:

- We have removed the cost for the gas turbine combined cycle, since in our LTBLG/ MSSAQ concept, electricity is generated using the steam turbine pre-existing at the mill.

- No syngas compressor and no syngas expander would be used in the LTBLG/MSSAQ concept (as is present in the LT-BLGCC system), since syngas pressurization is not part of our design.

- No lime kiln is required with the LTBLG/MSSAQ concept. In the prior LT-BLGCC analysis, additional lime kiln capacity was included in the cost estimate. This cost is removed.

- The black liquor flow with our LTBLG/MSSAQ concept is an estimated $204 \mathrm{MW}_{\mathrm{HHV}}$, compared to $391 \mathrm{MW}_{\mathrm{HHV}}$ for the LT-BLGCC system. We have scaled the cost estimate (after the three above adjustments), using a 0.7 scaling exponent.

- We have escalated the cost from 2002\$ (used in the BLGCC analysis) to 2005\$.

- We have included the cost for some additional biomass boiler capacity. Consistent with our BLGCC analysis [2], we assume that the existing hog fuel/biomass boiler capacity available for use at the existing mill is $40 \%$ larger than the capacity required to handle the hog fuel generated at the kraft/Tomlinson linerboard mill. We have estimated that the existing boiler capacity is $40 \mathrm{MW}_{\mathrm{HHV}}$. Since the required capacity for the LTBLG/MSSAQ system is 162 $\mathrm{MW}_{\mathrm{HHV}}$ [24.5 MW of hog fuel (Table 9) and 137.6 MW of purchased residues (noted in text above)], the new biomass boiler capacity required is $122 \mathrm{MW}_{\mathrm{HHV}}$. One of our biorefinery cases in Volume 1 (DMEa) included an installed capital cost of $\$ 50.736$ million for a biomass boiler with capacity of $50.5 \mathrm{MW}_{\mathrm{LHV}}$ (corresponding to $62.2 \mathrm{MW}_{\mathrm{HHV}}$ ). We scaled this $\$ 50.7$ million by $(122 / 62.2)^{0.7}$ to arrive at the estimate for the cost of additional biomass boiler capacity needed with the LTBLG/MSSAQ system.

We also estimate the cost for a new Tomlinson boiler at the unbleached kraft linerboard mill. We begin with the estimate in Volume 1 for a Tomlinson boiler at our reference kraft freesheet mill (\$136.15 million), and scale this (using 0.7 exponent) by the relative black liquor energy flows for these two types of mills. For the freesheet mill, the black liquor flow is $438 \mathrm{MW}_{\mathrm{HHV}}$ [2]. Our estimate for the kraft linerboard mill is $261 \mathrm{MW}_{\mathrm{HHV}}$. Thus, the capital investment for the Tomlinson system at the linerboard mill is $136.15 *(261 / 438)^{0.7}=\$ 95$ million. 
Thus, there is an incremental investment of about $\$ 62$ million required for the LTBLG/MSSAQ system in place of a new Tomlinson system, when the existing Tomlinson system reaches the end of its life. The annual operating cost savings of \$6.6 million (Table 11) yields a 25-year IRR of about 10\% on the incremental capital investment (assuming equity:debt = 100:0 and ignoring taxes).

Table 12. Estimate of overnight installed capital cost for LTBLG system (million \$).

\begin{tabular}{|l|r|}
\hline (a) Low-temperature BLGCC system from [2], 2002\$ & 252.51 \\
(b) Remove cost of combined cycle -- 36\% of (a) & 162.48 \\
(c) Remove cost of syngas compressor and expander & 148.25 \\
(d) Remove cost of additional lime kiln capacity included in (a) & 106.15 \\
(e) Scale to MSSAQ black liquor flow (0.7 scale exponent) & 69.55 \\
(f) Escalate to 2005\$ & 77.79 \\
(g) Add cost of new biomass boiler capacity (122 MW & 156.32 \\
\multicolumn{1}{|c|}{ Estimated overnight installed cost, million $\mathbf{2 0 0 5 \$}$} & $\mathbf{1 5 6 . 3 2}$ \\
\hline
\end{tabular}

Notes (corresponding to row lettering):

(a) This is "TIC BEFORE ADJUSTMENTS" found in Table 12 of [2].

(b) From Table 12 of [2], the combined cycle accounts for $36 \%$ of direct costs. We assumed this holds for installed costs as well.

(c) The LT BLGCC system in [2] includes an 18.7 MW syngas compressor and a 5 MW syngas expander. These are not required for the

LTBLG/MSSAQ system. We assume an average cost for these of $\$ 600$ per $\mathrm{kW}$.

(d) The figure in row (a) includes $\$ 42.1$ million for new lime kiln capacity (see note (d) of Table 12 in [2]). This \$42.1 million is removed since no lime kiln capacity is required with the MSSAQ process.

(f) We escalate from $2002 \$$ to $2005 \$$ using a factor of 1.1185

(g) We add the cost for new biomass boiler capacity, as described in the text.

\section{Conclusions}

Based on the preliminary analysis presented here, it appears likely that the low-temperature black liquor gasification technology designed into biorefineries similar to those evaluated in Volume 1 would yield lower energy efficiencies and less attractive financial performance than we found with the hightemperature black liquor gasifier. Financial performance for application of the LTBLG may be better if unique features of the technology can be exploited. Our preliminary analysis of one such option - the LTBLG used in the recovery cycle at a pulp mill adopting the MSSAQ pulping process - indicates potentially viable financial performance, but more detailed analysis is required to gain a more accurate estimate than we have presented here of the financial performance and to better understand how it might be improved.

\section{References}

1. Consonni, S., Larson, E.D., Kreutz, T.G. and Berglin, N., "Black Liquor Gasifier/Gas Turbine Cogeneration,” J. of Engineering for Gas Turbines and Power, 120: 442-449, 1998.

2. Larson, E.D., Consonni, S., and Katofsky, R.E., “A Cost-Benefit Assessment of Biomass Gasification Power Generation in the Pulp and Paper Industry,” final report, Princeton Environmental Institute, Princeton, NJ, 8 October 2003. (Downloadable from www.princeton.edu/ energy).

3. Nohlgren, I., “Non-Conventional Causticization Technology: A Review,” Nordic Pulp \& Paper Journal, 19(4): 470480, 2004.

4. Sinquefield, S.A., “In-Situ Causticizing for Black liquor Gasification,” Phase 2 Topical Report, Feb. 1, 2004 - Oct. 31, 2005, U.S. DOE Award \#DE-FC26-00NT41492.

5. Teder, A., Olm, L., Wilkén, T., "Process of Making Cellulose Pulp with a Sulphite Cooking Liquor Containing Sulphide and a Quinone or Hydroquinone Compound,” US Patent \#4,786,365, 22 November 1988. 
6. Naithani, V., Lindstrom, M., Kirkman, A., Jameel, H., “Alkaline Sulfite Pulping and its Integration with the RTI Absorption Technology,” presented at the 2005 TAPPI Engineering, Pulping, and Environmental Conference, Session 67, Philadelphia, PA, 28-31 August 2005.

7. DeCarrera, R., “Quarterly Technical Progress Report 20, Demonstration of Black Liquor Gasification at Big Island,” Report 40850R20 to U.S. Department of Energy from Georgia Pacific Corp., January 2006.

8. DeCarrera, R., “Quarterly Technical Progress Report 22, Demonstration of Black Liquor Gasification at Big Island,” Report 40850R22 to U.S. Department of Energy from Georgia Pacific Corp., July 2006.

9 . Iisa, K., Whitty, K., Sinquefield, S., Rubiano, C., Buchanan, M., Frederick, J., "Measurement of Tars Produced During Low-Temperature Black Liquor Gasification,” Paper 32-2 presented at 2006 TAPPI Engineering, Pulping and Environmental Conference, Atlanta, GA, 5-8 November 2006.

10. Jacobs Engineering Group, Inc. and IPST at Georgia Institute of Technology, "Pulp and Paper Industry Energy Bandwidth Study,” Report for AIChE, Project Number 16CX8700, August 2006. 